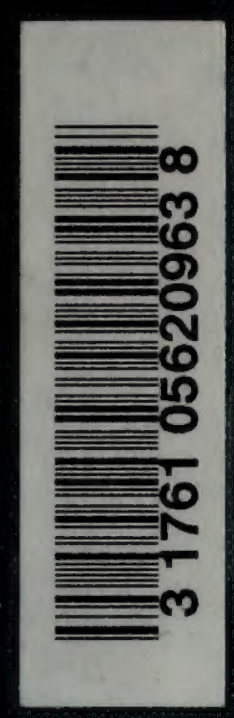







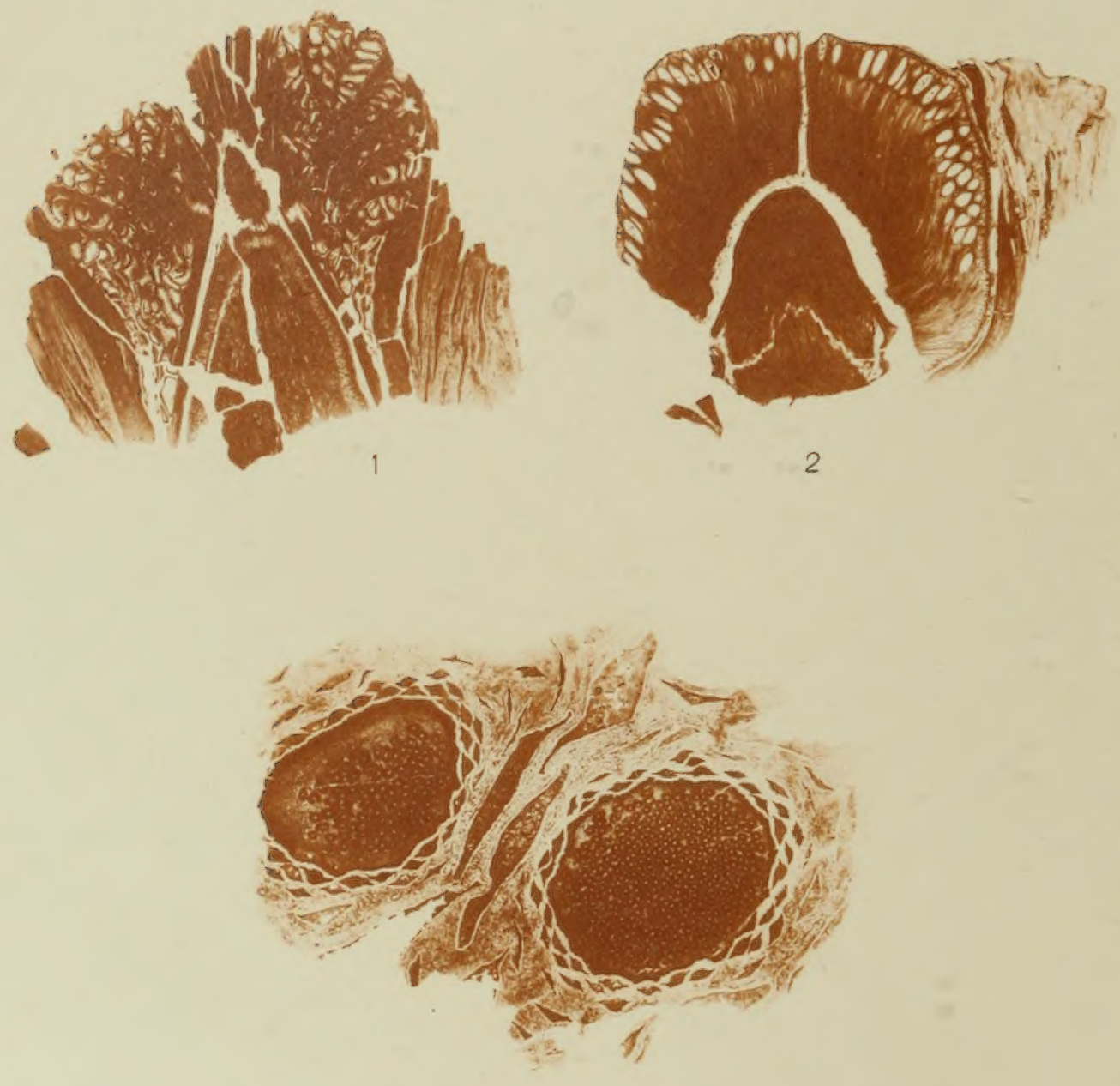

3

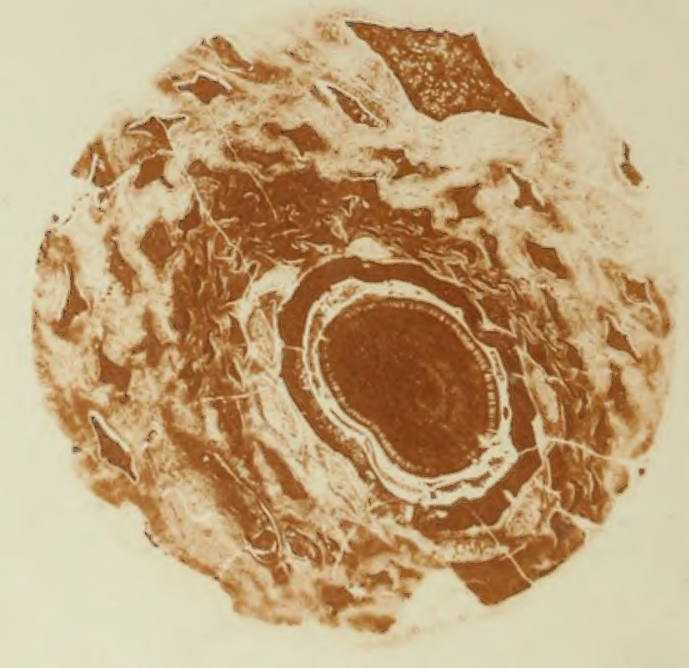

4

LONGITUDINAL AND TRANSVERSE SECTIONS OF BISPORANGIATE STROBILI AND OVULATE CONES OF CYCADEOIDEA IN NATURAL SIZE AND COLOR. 


\title{
AMERICAN FOSSIL CYCADS
}

BY

\author{
G. R. WIELAND
}

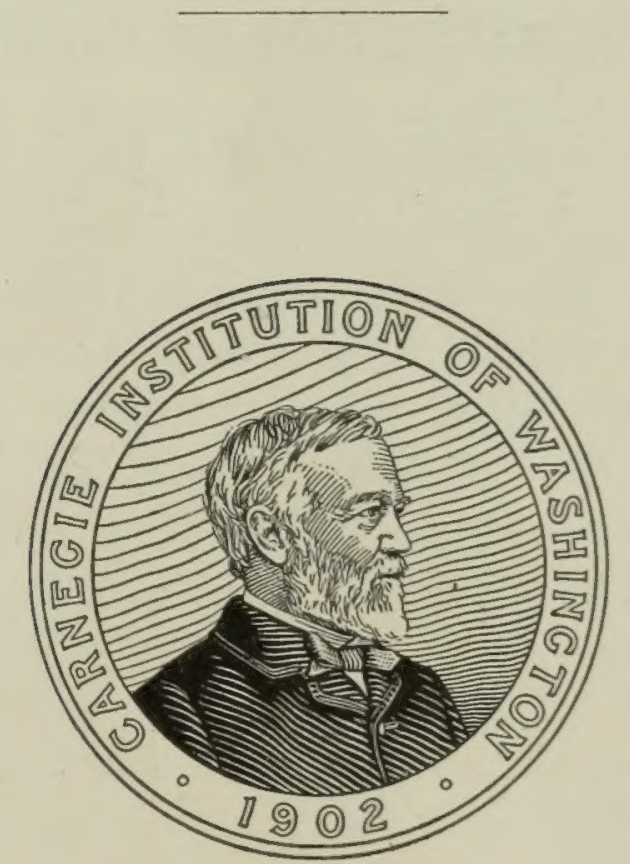

$\frac{8.169}{1.4194}$

PUBLISHED BY THE

CARNEGIE INSTITUTION OF WASHINGTON

AUGUST, $: 906$ 
CARNEGIE INSTITUTION OF WASHINGTON

PUbliCATION NO. 34 .

FROM THE PRESS OF THE WILKENS SHEIRY PRINTING CO.

WASHINGTON, D. C. 


\section{PREFATORY NOTE.}

The investigations here recorded were begun in the fieid in 1898 . During the summer of that year, while collecting Testudinata in the "Bad Lands" of the Cheyenne River and Dinosauria in the nearby Rim of the Eastern Black Hills, I had many opportunities for visiting and carefully examining the famous Black Hawk cycad locality, to which my attention had been previously directed by Professor Marsh, when the season's work was planned. It was, too, during the fall of 1898 that, as is more fully related in the fourth chapter, I had the good fortune to discover, well to the north of the old Black Hawk locality and to the east of Piedmont, the fossil cycad bearing the most perfectly silicified prefoliate fronds of any yet obtained. Soon after this discovery, furthermore, Professor Lester F. Ward, whom I then met for the first time, revisited the Piedmont-Black Hawk region. Thus I found myself in touch with the two men of all others in this country most interested in the fossil cycads-the one primarily in securing a great and representative collection, the other in making these peculiarly interesting and problematic forms accessible to the further study so urgently required; and I returned to New Haven with the fixed intention of attempting a complete elaboration of the structure of the Mesozoic cycads as soon as might prove feasible. The necessity for the proposed series of thin sections was fully appreciated by Professor Marsh, and it was particularly pleasing to me that he was able to take part in the discovery of the staminate disk and foliage which was made shortly thereafter.

The subsequent course of these studies is of lesser moment in this connection. As I have made all of the sections and most of the photographs and photomicrographs, it is evident that the labor involved has been arduous, however replete with interest. With respect to the mode of presentation of relationships in the two closing chapters, it may be said that the form adopted appeared the most practical in the present status of laboratory study of the existing cycads, and field and laboratory study of the fossil cycads. I am keenly aware that the conclusions reached therein can be at the best but tentative ones, and that, above all, the paleontologic record must be laboriously scanned afield for many years before mere hypothesis can be thrust aside for the clear and established truth. But it can not be doubted that it is fully possible to accomplish a final and satisfactory solution of the still largely obscure and hidden phases of homoplasy and parallelism involved in the origin of cycadaceous plants, the fuller knowledge of which is so centrally fundamental to an empiric conception of gymnosperm and perhaps even angiosperm evolution.

In taking up the study of the cycads at the point of relative urgency, and following the initial macroscopic descriptions by Ward, it has not been thought either necessary, or in any sense a convenient method, to attempt to deal, in this volume, with any of the minor questions of classification and nomenclature. Time 
and resources permitting, it is next in order to take up the investigation of genera and species from the structural point of view; for now that the more obvious boundaries and botanical aspects of the group have been determined, the logical order of subsequent study of the cycads clearly is to determine the taxonomy and coördinate such labor with field exploration. Amongst special features promising much further biologic interest the cycad seeds may well be mentioned. So far as the present work is concerned, however, it is felt that if any portion of it is to endure, it must more likely be the plates, in so far as they are not destined to be supplanted, in the course of time, by the photographs of larger, better cut, and handsomer sections.

Amongst those who, subsequent to Professor Marsh, have furthered these investigations, I desire to mention the following: To the late Professor C. E. Beecher, and to Mr. J. F. Malone, of New Haven, and especially to Professor Charles S. Hastings, I am much indebted for help in and explanation of the methods of photomicrography. The opportunity to secure various of the habitus illustrations, which have added much to the value of the ninth chapter, is due to Mr. Ferdinand Mangold, of Tarrytown, New York; while Mr. George C. Pope, of Brooklyn, New York, furnished from his conservatory the photographic text figures 8 and 9. Much has been added by the skill and painstaking attention to detail given by Mr. G. S. Barkentin to the brush drawings and to the ink work on the text figures, as chiefly done by him. To Professor Ikeno, the discoverer of antherozoids in the cycads, students of botany will be particularly grateful for having made the journey to the Ryûgeji Temple gardens, resulting in the unique plate-figure facing page $2 \mathrm{I}$. The permission of Professor Thomas H. Macbride, of the State University of Iowa, to section the splendid bisporangiate strobilus illustrated on the frontispiece, and plates XXXIV and $x x x v$, was especially considerate, the more so as coming at a time when the old prejudices against cutting certain trunks still lingered in places. To the courtesy of the late Professor Wilbur C. Knight of the State University of Wyoming at Laramie, I am similarly indebted for much material illustrating the genus Cycadella, although time has not yet permitted an adequate examination of all these specimens.

I wish especially to express my gratitude to Professor Lester F. Ward, not only for important material for study, but for many valuable suggestions and favors extending over the past eight years, and for taking the great trouble to read the proof of most of the chapters.

Above all I desire to here record my deep obligation to Professor Othniel Charles Marsh: With a keen and unerring appreciation of scientific values he furthered the field explorations which finally resulted in the great cycad collections now in the Yale Museum, and with an equally great and kindly interest, devotedly extending to life's last hour, he encouraged their laboratory study.

To the Carnegie Institution, and to the constant and laborious care of its officials, Science is indebted for the assemblage of these results in the costly and elegant form in which they are illustrated and presented in this volume.

G. R. WIELAND. 


\section{CONTENTS.}

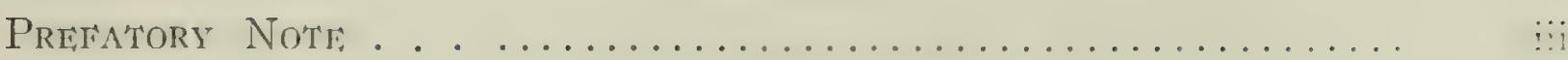

INTRODUCTORY (pages 3-48).

Chapter I.—Discoveries and Coliections.............. 5

American localities and types...................... 5 -11

Maryland . . . . . . . .

Isolated or little known localities................ 6-7

Discovery of cycads in the Black Hills............. 7 -10

Cycad localities of central Wyoming................ ro

California ............................. Io

Occurrence and distribution of North American fossil cycads

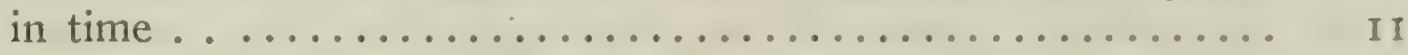

European cycads, discovery of various historic types.......... 12-16

Cycads of India .............................. 6 - 8

Old World Types of Cycadeoidex, the horizons in which they occur, and the museums in which they are located............. I8-20

Chapter II.-Preservation and External Characters......... 2I-44

Varying conditions of fossilization and resulting trunk forms...... 2I-29

Local conditions of preservation .................... 23-25

Rare occurrence of conditions requisite for mineralization of

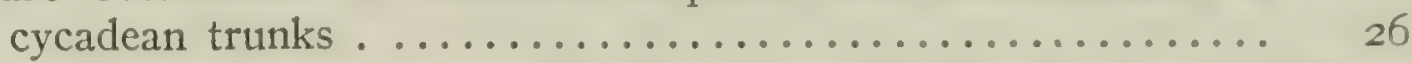

Trunk forms due to compression during or after fossilization... 26-29

Trunk types . ............................... 29-4t

Low growing unbranched trunks.................... 3 $1-33$

Short columnar trunks ..................... 33

Columnar trunks distinctly more than one meter high....... 33-36

Branching trunks . ............................ 36

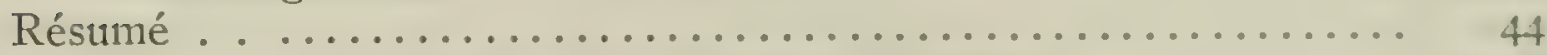

Chapter III.-On the Methods of Section Cutting.......... 45-48

VEGETATIVE FEATURES (pages 49-104).

Chapter IV.-Trunk Structure $\ldots \ldots \ldots \ldots \ldots \ldots \ldots \ldots \ldots \ldots \ldots \ldots \ldots \ldots \ldots$

Armor ..................................... $5^{I-66}$

Ramentum ................................. $5^{1-55}$

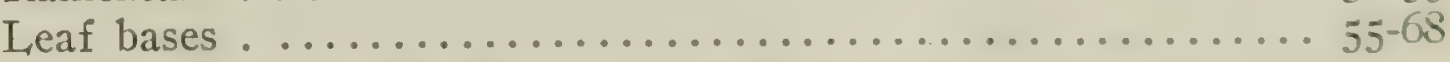

Outer features and arrangement .............. 55-59

Leaf-base bundle grouping .................. 59-64

Leaf-base bundle structure ................... $66_{4}-66_{0}$

Cortex ................................ $66-64$

General features . ........................... 66

Cortex of trunk $393 \ldots \ldots \ldots \ldots \ldots \ldots \ldots \ldots \ldots \ldots \ldots \ldots \ldots \ldots$

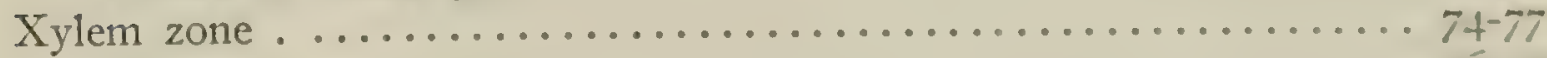

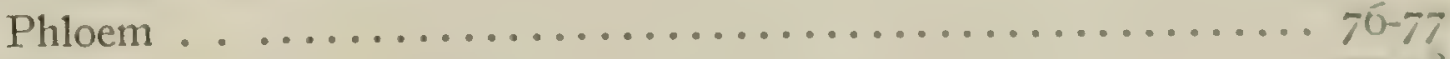

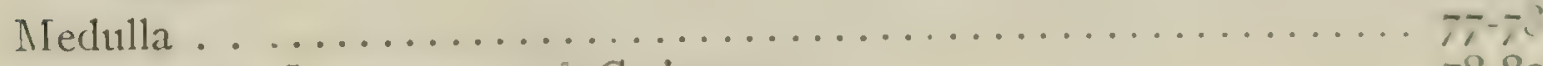

Cycadeoidea Jemeyana and $C$. ingens.................... 


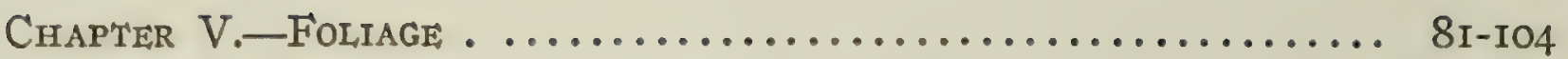

Historical . ............................. 8I-82

Foliage of Cycadeoidea ingens (type) $\ldots \ldots \ldots \ldots \ldots \ldots \ldots . \quad 83-94$

Prefoliation ............................... 86-87

Form and structure of fronds and pinnules.......... 87-94

Preservation of microscopic features ............ 9I-92

Comparison with existing cycads ............... 93

On Yale cycad No. 208 (a cotype of Cycadeoidea ingens) and its

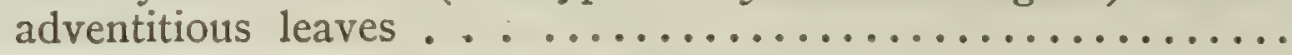

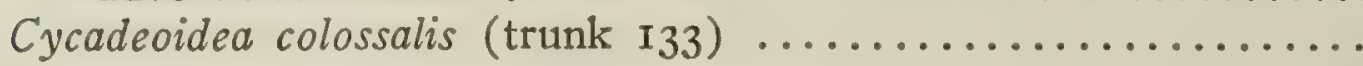

94-97

Cycadeoidea colossalis (trunks 2 and Io)................ 99-100

Cycadella ramentosa ........................... I00-102

Remarks on general characters of cycadeoidean foliage........ IOO-IO2

REPRODUCTIVE STRUCTURES (pages I05-186).

C.hapter VI.-Ovulate Cones . ................... IO

Historical . . .......................... I07-108

Ovulate cone of Cycadeoidea Wielandi................. I08-I26

General features . ...................... IO9-II2

Peduncle and its bundle supply................. II3-II4

Evidence of presence of hypogynous disks............ II4-II5

Bracts . ............................. II5-116

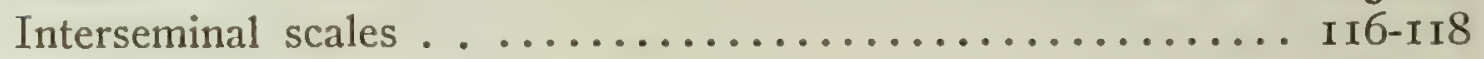

Seed pedicels $\ldots \ldots \ldots \ldots \ldots \ldots \ldots \ldots \ldots \ldots \ldots \ldots \ldots \ldots \ldots \ldots \ldots \ldots \ldots \ldots$ II 8 -I 20

Seeds . . ......................... 120-126

Embryos and pre-embryonal structures............ 124-126

Cone-bearing habitus of various trunks $\ldots \ldots \ldots \ldots \ldots \ldots \ldots \ldots$ I26-I 30

Bisexuality . ............................ I30-I 3 I

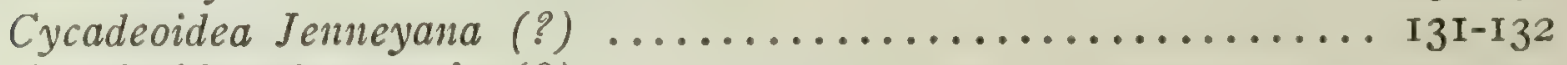

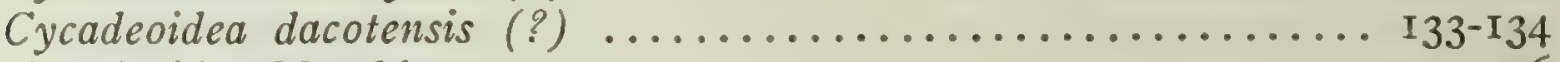

Cycadeoidea Marshiana . .......................... 135-136

Résumé ............................... I37

Citapter VII.-Bisporangiate Axes ................. I39-167

Historical . ........................... I39-143

Organization of the bisporangiate strobilus of the Cycadeoidex

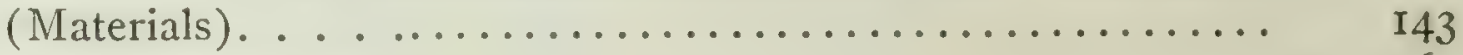

Cycadeoidea dacotensis ....................... I44-I62

Peduncle . ............................ I46

Bracts . ...................... I $46-147$

Ovulate cone ....................... I47-I49

Staminate disk ........................ I49-162

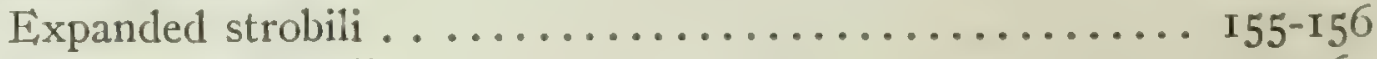

Histological details .................... I $57-162$

Synangia .................... 15 5 . 159

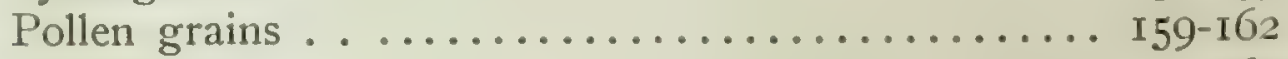

Cycadeoidea heliochorea ........................ I62

Cycadeoidea ingens and C. Jenneyana................. I62-163

Cycadeoidea Paynei........................... 163-164

Résumé ............................... I6 $65^{-1} 6_{7}$ 
Chapter Vili.-Young Fructitications

Cycadcoidea sp. (sections 4 IO and $4 \mathrm{II}$ )

I $69-186$

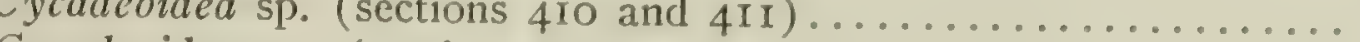

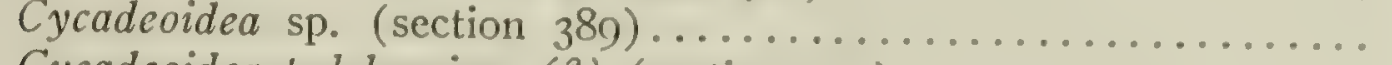

Cycadcoidea pulcherrima (?) (section 409$) \ldots \ldots \ldots \ldots \ldots \ldots \ldots$

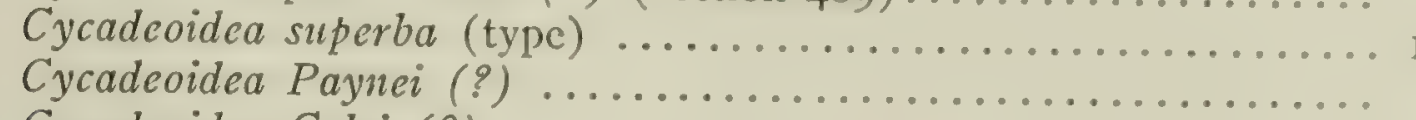

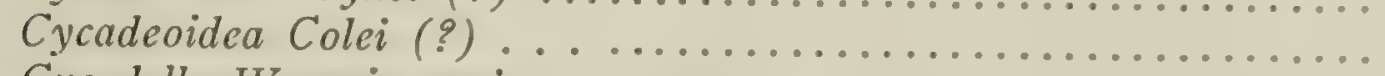

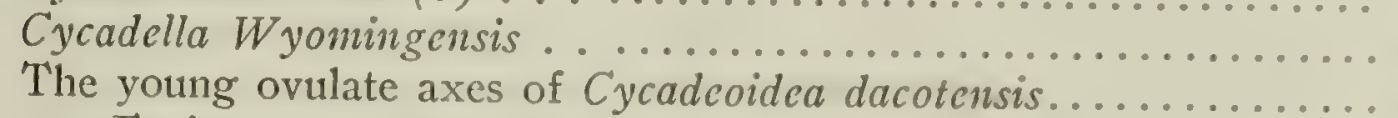

Fruits IX, VI and VIII.

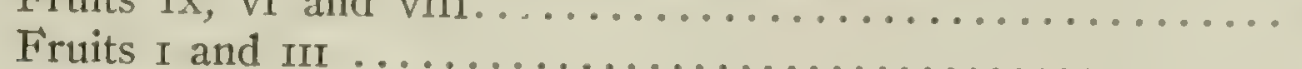

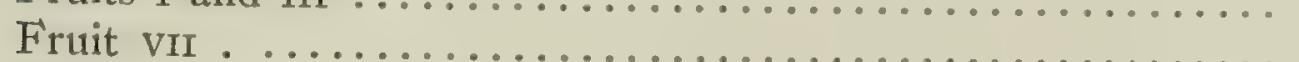

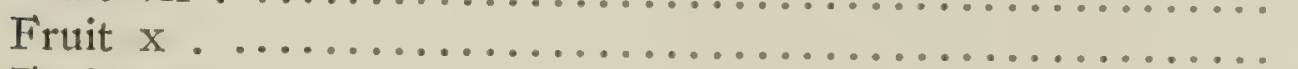

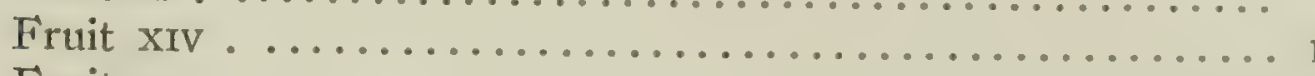

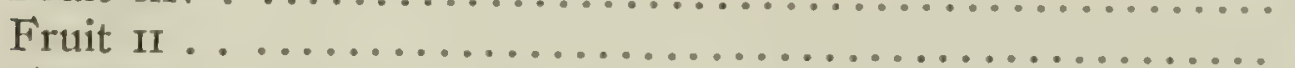

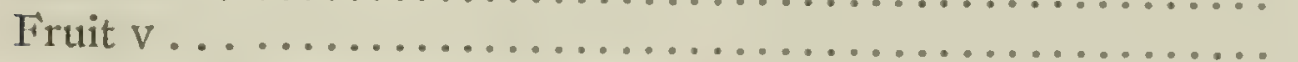

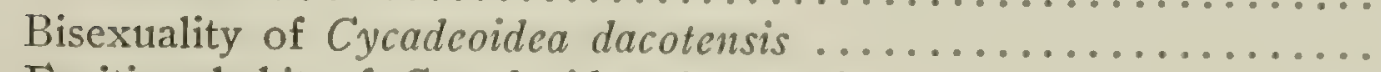

Fruiting habit of Cycadeoidea dacotensis....................... I84

The pulcherrima stage of trunk growth.................... 184

RELATIONSHIPS (pages 187-246).

Chapter IX.-Existing and Fossil, Cycads Compared.......... 189-238

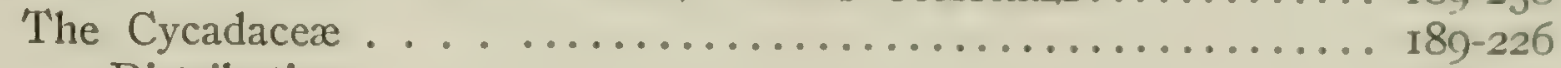

Distribution ....................... 189-19n

Zamia ...................................... IgI

Zamia floridana ........................ 192-195

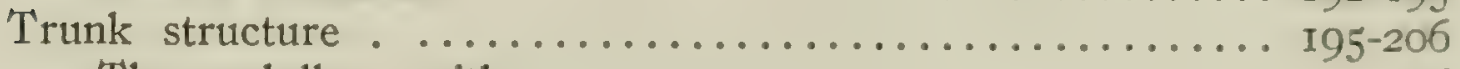

The medulla or pith................... I95-196

The vascular zone .................... 196-200

The cortex........................... 201-204

The armor . .............................. 205

The root

The leaves ................................... 209-213

Résumé of vegetative characters of the Cycadaceæ....... 2 I3

Fructification ......................... $213-226$

Microsporophylls .............................. 215

Fertilization . .................... 216

Megasporophylls ....................... 217

Ovules .......................... 217-219

Bundle system of seed ................. 219-222

Structure of megaspore bundle supply........... 222-224

Structure and significance of the axis of the cones..... 224-226

Fruits ................................ 226

Summary of relationships of the cycadeoidean to existing Cycads. . 225-238

Comparison of vegetative characters.............. 227-228

Comparison of reproductive characters............. 228-234

Tabular comparison of ovulate and staminate cones...... 235

Systematic position of the Cycadeoidex................ 236-23 8 
Chapter X.-Fern Ancestry and Angiosperm Analogies........ 239-246

The fern cycad relation summarized................. 239-24I

Sporophyte reduction correlated with elimination of separate prothallial stages and evolution of seed-bearing quasi-ferns.

Ultra-relationship of the cycadalean gymnosperms (or the cycadeoid

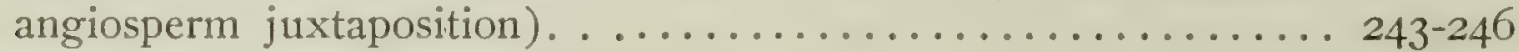

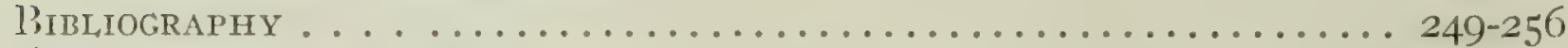

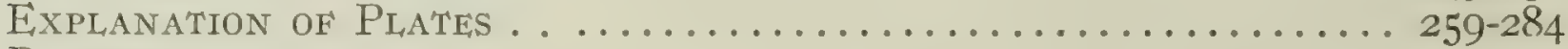

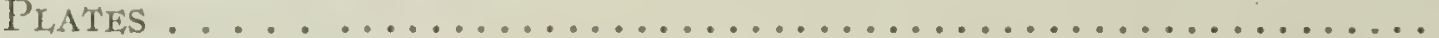

List of TEXT Figures . .......................... 285-285

INDEX . . . . . . . . . . . . . . . . . . . . . . . . 289-295

ADDENDA I.T CORRIGENDA ....................... 296 


\section{AMERICAN FOSSIL CYCADS.}

STRUCTURE.

BY G. R. WIELAND. 



\section{INTRODUCTORY.}




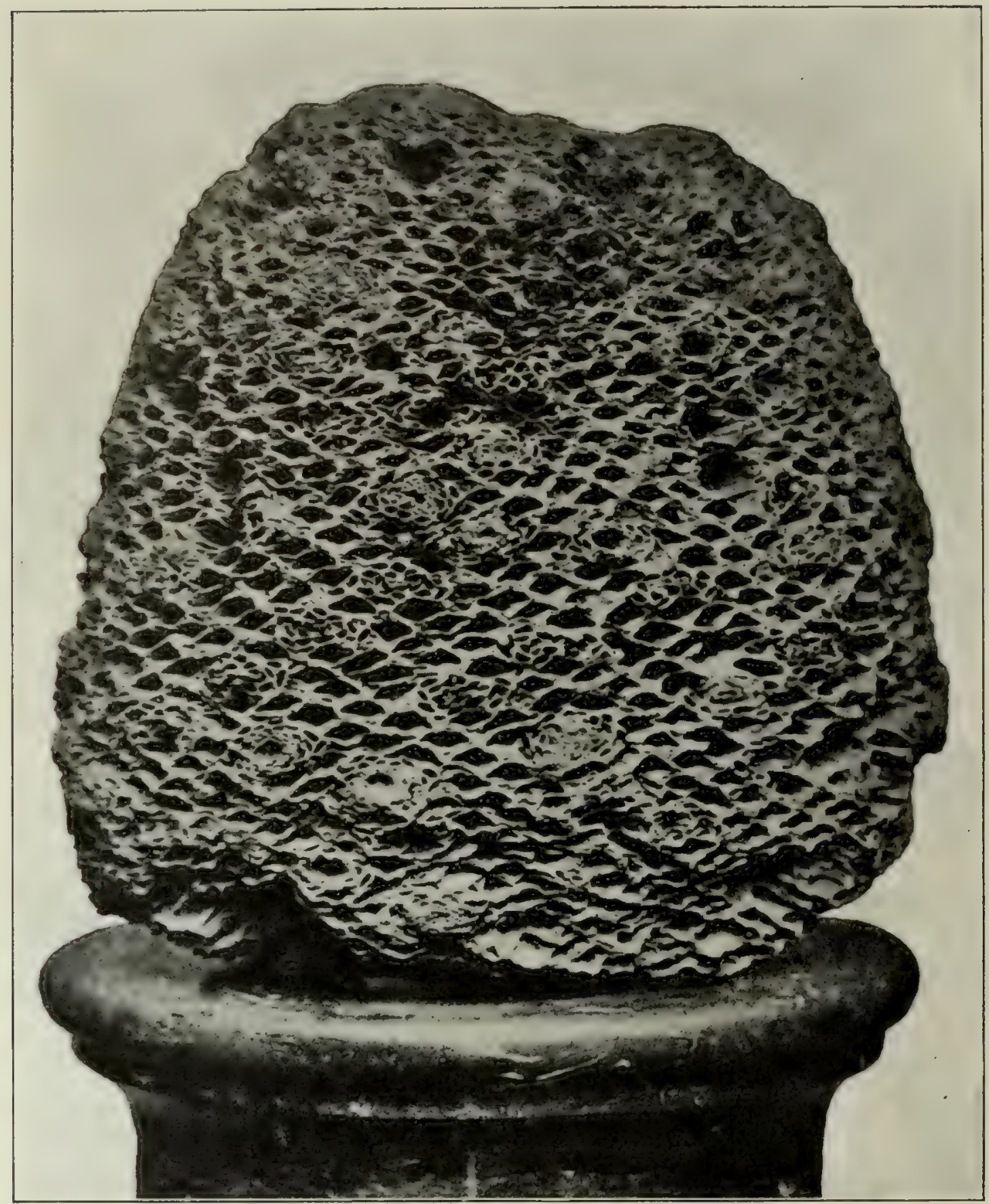

Fig. 1.-Cycadeoidea marylandica. The earliest described American fossil cycad.

Discovered about 1860, by Philip Tyson in the iron ore beds of the Potomac Formation of Maryland between Baltimore and Washington. From an original daguerreotype first sent to Sir William Dawson and afterwards by him to William Carruthers, but only recently published as Plate LXXXII, U. S. Geological Survey Monograph XLVIII. Reproduced through the courtesy of the officers of the Geological Survey.

This splendid and historically important specimen formerly belonged to the Maryland Academy of Science, and is now in the collection of Johns Hopkins University. It is shown about onefourth natural size. At the time of fossilization it was about to enter upon a period of fruit growth. Nearly thirty young fruits are marked in the present view by the groups of bract scars interpolated between the old leaf-bases, and thus obscuring the early spirally symmetric order of these latter organs of the armor. 


\section{CHAPTER 1 .}

\section{DISCOVERIES AND COLLECTIONS.}

The silicified trunks of cycads are among the most durable of fossils. Able to resist erosive action indefinitely, and usually occurring in considerable number at the few points where found at all, the unusual outlines of these rare fossils have probably never failed to arrest the attention of the lettered and the unlettered alike, from the remotest antiquity. It is, in fact, quite reasonable to suppose that in anciently settled and populous countries not a few of these fossil plants, so invaluable to science, have been sequestered and lost-perhaps gathered into cities long since destroyed. The instance of Cycadeoidea etrusca, which was placed on a tomb in the Necropolis at Marzabotto by the Etruscans more than four thousand years ago, and recently refound and described by Capellini \& Solms (22)* is well known. Certainly many important specimens have been carried away and lost to view. It is a very suggestive fact that nearly all of the trunks procured from the "Iron Ore Belt" of the Potomac Formation between Baltimore and Washington had been kept by miners and others about their homes, in some instances for quite a hundred years (I 72$)$. But the conditions requisite for silicification must have seldom occurred in geological time, for although the cosmopolitan development of cycadaceous plants in the middle Mesozoic is well attested by a great abundance of leaves in all plant-bearing strata of late Jurassic or Lower Cretaceous age, wherever found on the globe, the number of silicified cycadean trunks known is so limited as to necessitate their being ranked as among the rarest of fossils. Indeed, few good examples have been as yet found beyond the limits of western Europe and southern North America, though they are yet to be expected from all the other continents. The record of fossil cycad discovery and collection is hence in every way an interesting one and may well be dealt with at some length, together with mention of the museums in which the types and important material may be found.

\section{AMERICAN LOCALITIES AND TYPES.}

MARYLAND.

The first cycadean trunks from America to receive scientific mention were noticed by Philip Tyson (I68) in I860, he having discovered them the previous year in the iron ore beds of the Potomac Formation of Maryland. The original trunks found by Tyson, perhaps ten in number, were all obtained between Baltimore and Washington. Although much discussed at the time, these trunks did not at once receive scientific description, and for twenty-five years remained quite forgotten. A

* The numbers in parentheses refer to the bibliography at the end of this volume. 
number of photographs had, however, been sent by 'Tyson to various geologists in this country and in Europe. Two specimens of Cycadeoidea marylandica belonging to the original series are now in the Yale collection, having been presented by Tyson to Professor Marsh in 1867.

Not until r889, however, were several of the original Tyson specimens belonging to the museum of the Maryland Academy of Natural Science described on the basis of their macroscopic features and fully illustrated by Fontaine (54). Further details concerning what is known of the locality and collection of these trunks are given by Ward (I72, I74). But no further trunks were obtained from Maryland for thirty-three years. Then, in I893, Mr. Arthur Bibbins, of the Woman's College of Baltimore, obtained from various people of the countryside between Baltimore and Washington no less than sixty specimens, which had been unsuspectedly sequestered from time to time during the preceding hundred years. This valuable collection is now in the museum of the Woman's College of Baltimore. The people who had kept these trunks, with a careless or a semisuperstitious interest, had variously regarded them as "beehives," "wasps' nests," "corals," "mushrooms," "beefmaw stones" (referring to the reticulum of the ruminant stomach), and barnacles, thus curiously recalling the Italian "barnacles" of Monti (see infra). The decayed summits of the somewhat crushed cycadean trunks of the Purbeck beds of the Isle of Portland-I shall mention here, by way of diversion-are called "crows' nests" by the English quarrymen; and the magnificent branching specimens from the Black Hills, described in the present volume, were called by the ranchmen "cacti," from the small groups of "melon cactus" which grow here and there on the hillsides hard by where these beautiful fossil trunks weathered out. Being too heavy to be readily removed, many good specimens were broken through idle curiosity, and various important branching trunks were scattered, lost, or destroyed.

The investigation of the several collections from the Maryland locality, so far as macroscopic features can suffice, has been mainly made by Prof. Lester F. Ward. The types established by him are distributed as follows:

Cycadeoidea marylandica (Fontaine), Johns Hopkins University, Baltimore.

C. Uhleri, Museum of the Maryland Academy of Natural Sciences, Baltimore.

C. Tysoniana, C. McGeeana, C. Fontaineana, C. Goucheriana, and C. Bibbinsi (all Ward's species, I74), are, with various cotypes, in the museum of the Woman's College of Baltimore. These types are numbered I472, I47 I, I467, I479, and I427, respectively.

\section{ISOLATED OR LITTLE-KNOWN LOCALITIES.}

The finding of "a trunk of a cycad" in the Trias of North Carolina, by Emmons, in I857, as figured in his American Geology (45), scarcely deserves to rank as the first discovery of cycads in America. This type or a similar impression of a trunk was found in the museum of Williams College several years since, and later figured by Ward ( 178 ); but the original locality is now lost.

During the thirty years following the discovery of fossil cycads in Maryland only four specimens were obtained from other widely separated and isolated North American localities. 'They are as follows: 
Cycadeoidea abequidensis Dawson (36), an impression from the Trias of Gallas Point, Prince Edward Island, now in the museum of McGill University, Montreal. Cycadeoidea munita Cragin (34), from sonthern Kansas (probably from the Dakota formation), in the collection of Colorado College.

Cycadeoidea (Zamiostrobus) mirabilis Lesquerenx (77), from near Golden, Colorado, in the United States National Museum at Washington. The horizon of C. mirabilis is uncertain.

Cycadeoidea nigra Ward (I78), an exceedingly handsome and well-preserved trunk from a railway cut in the vicinity of Boulder, Colorado, assigned with some degree of uncertainty to strata of Jurassic age. Although found some fifteen years ago, this trunk was not described until r9oo. It bears a striking resemblance to the Italian C. Rammeriana of Capellini \& Solms, and to C. Uhleri of the Potomac Formation of Maryland.

\section{DISCOVERY OF CYCADS IN THE BLACK HILLS.}

Scientific attention was not directed to the most important of all the American cycad horizons, namely, the Mesozoic Rim of the Black Hills of South Dakota and Wyoming, until r893. Although various trunks had been noted at Black Hawk by miners on their way to Deadwood in 1878 , when the Hills were first opened for settlement, and later at Minnekahta, no careful collection at or study of either of these localities was made previous to 1893 - a year important alike for the discovery of many trunks in Maryland, as mentioned above, and for the first description of cycads from the Black Hills region. In February, I893, six silicified trunks were received at the United States National Museum from Minnekahta, on the southern side of the Black Hills, by Prof. Lester F. Ward, these having been forwarded by a local collector. 'They include the handsome types described by Ward five years later as Cycadeoidea colossalis, C. Paynei, C. pulchervina, and C. Colei (175).

With the exception of a fragmentary trunk picked up at the famous Black Hawk locality on the eastern side of the Hills in 1878 , a portion of which was secured by the writer twenty years later and is now in the Yale Museum, these six National Museum specimens were, then, the first of the marvelous trunks from the Black Hills Rim to reach a place of safety.

Later in the summer of I 893, after the collection of the abuve-mentioned trunks, the Minnekalita locality was visited by Prof. Thomas H. Macbride, of the State University of Iowa, who made a collection of twenty trunks. These are now in the museum of the State University of Iowa at Iowa City, and constitute one of the very handsomest cycad collections in the world. Gne of these trunks, of superb beauty and in full fruit, Professor Macbride described and figured in the American Geologist for October, I893, as the type of Cycadeoidea (Bennetites) aircolensis. This constitutes the first scientific description or printed reference to the occurrence of silicified cycads in the Black Hills. Prof. Lester F. Ward had, however, also visited the Minnekahta locality in the antumn of 1893 , securing among vai:ous other specimens the especially handsome trunk which he later described as Cyardeoidea minnekahtensis (I75). 
These various facts coming to the knowledge of Prof. O. C. Marsh, of Yale University, that famous scientist and collector-once a pupil of Goeppert-promptly made every effort to secure extensive collections from the Black Hills; and such was his success that there are now in the Yale Museum, including the collections subsequently made by the writer, more than seven hundred of these cycads from the Black Hills alone. This immense collection, with various additional specimens from elsewhere, is the most important in the world. In fact, it is doubtful if there now are in all other museums put together so many well-preserved trunks as are included in the Yale collection. Many of these trunks are figured and described macroscopically by Ward in the Nineteenth Annual Report of the United States Geological Survey (I76), and in the American Journal of Science for November, I 900 (179). Most are from Minnekahta and Black Hawk, South Dakota, the two localities which have yielded the most and the best-preserved fossil cycads known to science. In addition to the cycads already recorded from these two localities the writer should mention a collection of twenty specimens secured by him at Minnekahta for the American Museum of Natural History, New York, in the autumn of I900 and spring of I90I.* During the same year the writer also secured for the Yale collection, besides various other specimens, the remainder of the branches completing the fine branching trunks shown on plates VII and $\mathrm{x}$, as described in Chapter II of the present volume.

Cycads of the same species or genera and exhibiting the same characteristic features of preservation as those from the main Minnekahta and Black Hawk localities occur scatteringly at several other points of the "Rim," both east and west of the Black Hills. It is thus evident that this picturesque mountain knot mantled by the Permian, so strikingly like the Harzgebirge to the north of the Alps, is girdled by the cycad-bearing horizon in which the Minnekahta and Black Hawk trunks occur. Also, the writer found in a lower horizon on the western side of the Hills, several miles south of Inyan Kara Mountain, a few specimens of Ward's genus Cycadella. Numerous bones of large sauropodous dinosaurs accompanied these specimens, and beyond doubt their horizon agrees with that of the cycads of the Freezeout Hills, Wyoming, presently to be mentioned. Yale cycad 737, the type of Ward's Cycadella (Cycadeoidea) utopiensis. (I79), is evidently from the same horizon and general locality as these Inyan Kara Mountain specimens. This lower cycad horizon likewise girdles the Black Hills, with the exception of a small southeastern segment, and appears extensively in a similar position and development in the "Rims" of the Big Horn and other Rocky Mountain ranges.

* These specimens are of considerable interest as including an unusual proportion of trunks bearing very well preserved crowns of emergent young leaves, there being no less than six such among the twenty trunks represented. The trunks were obtained chiefly from the eastern limits of the main Minnekahta "cycad patch," and are not so dark in color as the specimens from larther west. Yale specimen No. 782 , also secured by the writer from the same general locality as the American Museum cycads, and of the same general appearance, bears a similar crown of young leaves. It is quite evident that this series represents trunks derived from the same forest source at some vernal period of the year and silicified under similar conditions. 
Thus far the fossil cycads from the Black Hills Rim have been assigned, on the basis of their macroscopic characters only, to twenty-nine species referred by Ward to the genus Cycadeoider of Buckland. The localities of the Black Hills types are indicated in the subjoined table:

Occurrence of Black Hills Cycad Types.

\begin{tabular}{|c|c|c|c|c|c|c|c|}
\hline Species. & $\begin{array}{c}\text { (1) } \\
\text { Min- } \\
\text { nekalita, } \\
\text { South } \\
\text { Dakota. }\end{array}$ & $\begin{array}{c}\text { (2) } \\
\text { Falls of } \\
\text { the } \\
\text { Cheyenne, } \\
\text { South } \\
\text { Dakota. }\end{array}$ & $\begin{array}{c}\text { (3) } \\
\text { Black } \\
\text { Hawk, } \\
\text { South } \\
\text { Dakota. }\end{array}$ & $\begin{array}{l}\text { (4) } \\
\text { Sturgis, } \\
\text { South } \\
\text { Dakota. }\end{array}$ & $\begin{array}{c}\text { (5) } \\
\text { Min. } \\
\text { nesela, } \\
\text { South } \\
\text { Dakota. }\end{array}$ & $\mid \begin{array}{c}\text { (6) } \\
9 \text { miles } \\
\text { northrwest } \\
\text { of } \\
\text { Sundance, } \\
\text { Wyomiag. }\end{array}$ & $\begin{array}{c}(7) \\
\text { Inyan } \\
\text { Kara } \\
\text { Mourtain } \\
\text { region, } \\
\text { wyoming. }\end{array}$ \\
\hline 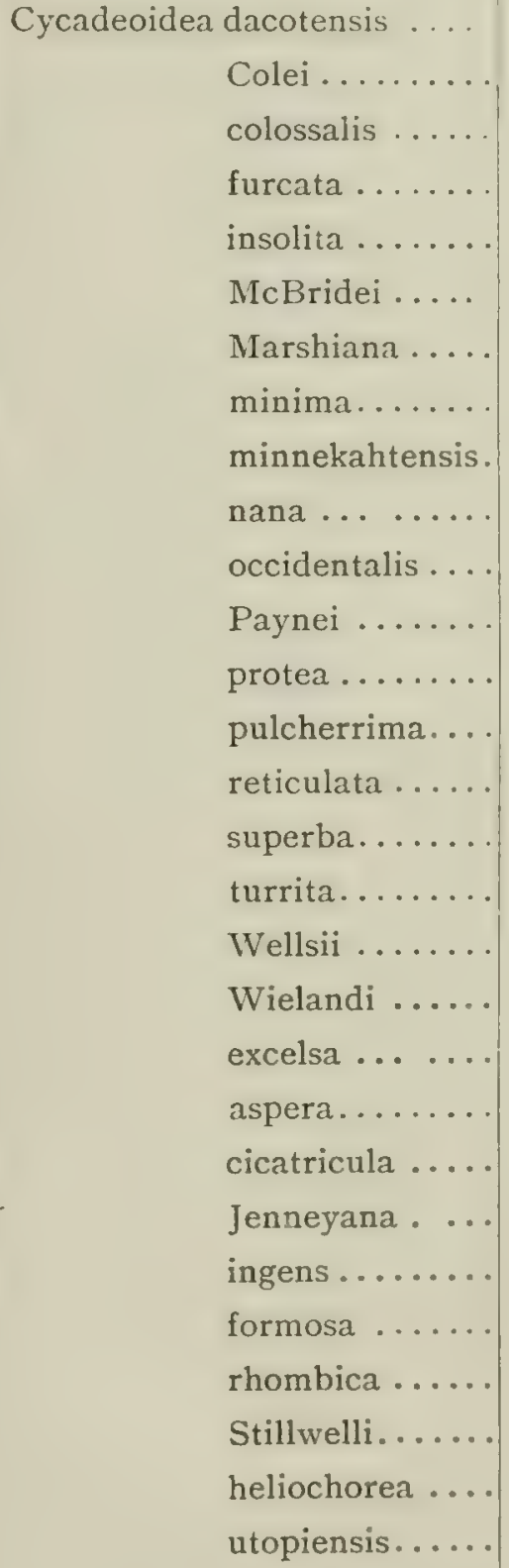 & $\begin{array}{l}\mathrm{x} \\
\mathrm{x} \\
\mathrm{x} \\
\mathrm{x} \\
\mathrm{x} \\
\mathrm{x} \\
\mathrm{x} \\
\mathrm{x} \\
\mathrm{x} \\
\mathrm{x} \\
\mathrm{x} \\
\mathrm{x} \\
\mathrm{x} \\
\mathrm{x} \\
\mathrm{x} \\
\mathrm{x} \\
\mathrm{x} \\
\mathrm{x} \\
\mathrm{x} \\
\ldots \\
\ldots \\
\ldots \\
\ldots \\
\ldots \\
\ldots \\
\ldots \\
\ldots \\
\ldots \\
\ldots \\
\ldots \\
\ldots \\
\\
\end{array}$ & 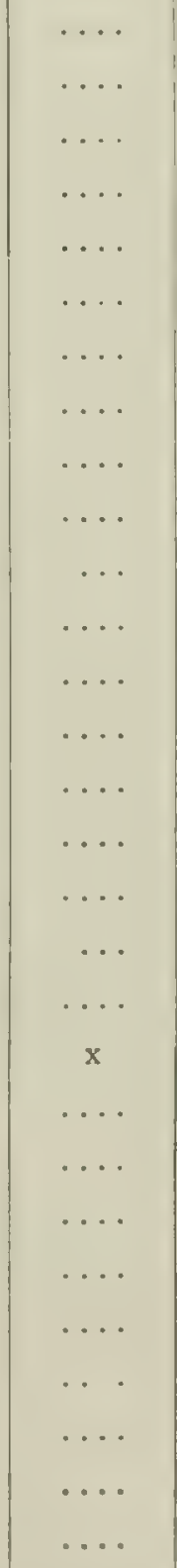 & 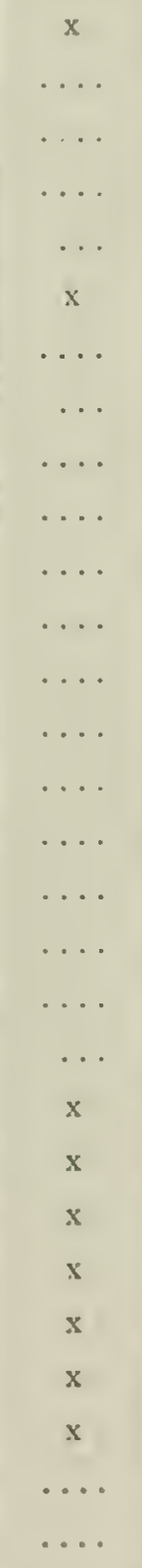 & 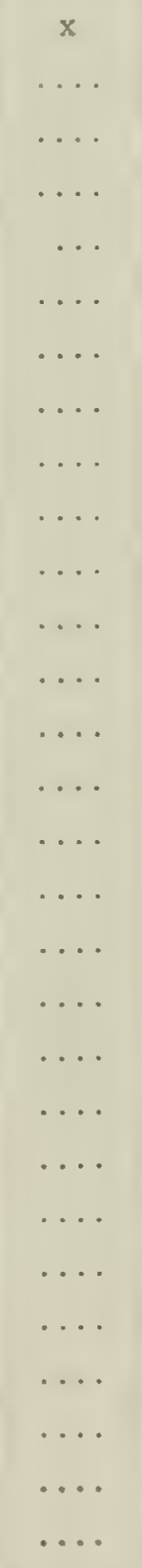 & 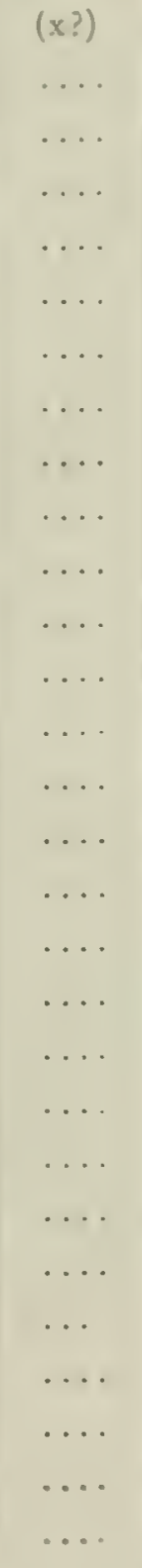 & $\begin{array}{l}(\mathrm{x} ?) \\
\ldots \\
\ldots \\
\ldots \\
\ldots \\
\ldots \\
\ldots \\
\ldots \\
\ldots \\
\ldots \\
\ldots \\
\ldots \\
\ldots \\
\ldots \\
\ldots \\
\ldots \\
\ldots \\
\ldots \\
\ldots \\
\ldots \\
\ldots \\
\ldots \\
\ldots \\
\ldots \\
\ldots \\
\ldots \\
\ldots \\
\ldots \\
\ldots \\
\ldots \\
\ldots \\
\\
\ldots \\
\\
\ldots \\
\\
\ldots \\
\\
\ldots \\
\\
\ldots \\
\end{array}$ & $\begin{array}{l}\ldots \\
\ldots \\
\ldots \\
\ldots \\
\ldots \\
\ldots \\
\ldots \\
\ldots \\
\ldots \\
\ldots \\
\ldots \\
\ldots \\
\ldots \\
\ldots \\
\ldots \\
\ldots \\
\ldots \\
\ldots \\
\ldots \\
\ldots \\
\ldots \\
\ldots \\
\ldots \\
\ldots \\
\ldots \\
\ldots \\
\ldots \\
\ldots \\
\\
\ldots \\
\\
\ldots \\
\\
\ldots \\
\\
\ldots \\
\\
\ldots \\
\\
\ldots \\
\\
\ldots \\
\end{array}$ \\
\hline
\end{tabular}

Of the Black Hills types, Cycadeoidea dacotensis Macbride and C. McBridei Ward are in the museum of the State University of Iowa, at Iowa City. Those in the United States National Museum at Washington are: Cycadcoidea colossalis, minnekahtensis, pulcherrima, Colei, Paynei, Jenneyrna, excelsa, and occidentalis (all Ward's species). 
The types of the remaining species are in the Yale Museum, New Haven, as follows : Cycadeoidea ingens, Stillwelli, rhombica, aspera, cicatricula, formosa, heliochorea, utopiensis, furcata, insolita, Marshiana, minima, nana, protea, reticulata, turrita, superba, Wellsii, and Wielandi (all Ward's species). The nuseum numbers of these twenty-nine ascribed types are to be found in Professor Ward's papers (I75, I76, I79). It should be noted that these Black Hills species are seldom based on a single specimen, and that they are at present represented by nearly $\mathrm{I}, \mathrm{ooo}$ more or less complete trunks, as included in the collections of the Yale University Museum, the United States National Museum, the museum of the State University of Iowa, and the American Museum of Natural History.*

THE CYCAD LOCALITIES OF CENTRAL WYOMING.

The third of the greater American cycad localities is that of the Freezeout Hills of Carbon County, Wyoming. Its discovery and Upper Jurassic age were first announced in August, I898, by Prof. O. C. Marsh (90). The fine series of silicified trunks thus far yielded by this locality gives it about the relative stratigraphic value and importance of the cycad horizons of Maryland, if we except the additional interest due to the fact that its equivalence to the lower of the two cycad beds of the Black Hills has been positively determined.

Professor Ward, who has made a careful examination, based principally on the macroscopic characters of the large collections from the Freezeout Hills, assigns all the specimens to his new genus Cycadella, and refers them to twenty species. Of these twenty species the types of two, namely, Cycadella Beecheriana and Reediu, belong to the Yale Museum. The remainder belong to the museum of the University of Wyoming, at Laramie, and the U. S. National Museum. The entire list of Wyoming species appears on the following page.

Although silicified cycad trunks are positively known to occur in the Atlantosaurus horizon in the southern "Rim" of the Big Horn Mountains, the writer was not fortunate enough to find any examples when he visited that region in August, 1902. He had been previously informed by the late Professor Wilbur F. Knight that he himself had seen one fine specimen from the Southern Big Horns. As was subsequently learned, this fossil came from the Big Horn Rim, about 6 miles south of Houk post-office, and its finder, a sheep-herder, who tenaciously withheld it, was finally relieved of its care by unknown parties.

\section{CALIFORNIA.}

The most recently discovered American locality yielding silicified cycad trunks is in the Grapevine Valley, Colusa County, California, 6 miles west of Sites, on the road to Stony Ford, at Prior's ranch. Here a trunk of much the same size and general features as Cycadeoidea marylandica was secured in September, I90o, and added

* One fine trunk from Minnekahta, in the southern Black Hills, was presented some time in I894 by Professor Macbride to William Carruthers, and is in the British Museum at South Kensington. 
to the cycad collection of the United States National Museum. The specimen is well silicified and bears various young fruits. The horizon from which it was eroded out is supposed to be either the Lower Chico or the Horsetown beds of the Lower Cretaceous, and hence a little more recent than or else of much the same age as the upper of the two Black Hills cycad horizons.*

OCCURRENCE AND DISTRIBUTION OF NORTH AMERICAN FOSSIL CYCADS IN TIME.

With the addition of the twenty species included in the new genus Cycadella of Ward, the assigned number of North American silicified cycadeoidean trunk species now numbers sixty. These are given in the following list, arranged according to geological horizons:

(I) Upper Jurassic, Wealden, or Lower Cretaceous of the Black Hills of South Dakota and Wyoming: Cycadeoidea aspera, cicatricula, Colei, colossalis, dacotensis, excelsa, formosa, furcata, heliochorea, ingens, insolita, Jenneyana, McBridei, Marshiana, minnekahtensis, nana, occidentalis, Paynei, prolea, pulcherrima, reticulata, rhombica, Stillwelli, superba, turrita, IVellsii, Vielandi.

(2) Upper Jurassic of central Wyoming and the Black Hills (about I 50 feet below No. I preceding, in heavy shales of the Atiantosaurus beds of Marsh, or Morrison Formation, as used in recent reports of the United States Geological Survey): Cycadella Beecheriana, carbonensis, cirrata, compressa, concinna, contracta, crepidaria, exogena, fermginea, jejuna, jurassica, gelida, gravis, Knightii, Knowltoniana, nodosa, ramentosa, Reedii, utopiensis, vermucosa, wyomingensis (all Ward's species). All except C. utopiensis are from the Freezeout Hills, Carbon County, Wyoming.

(3) Potomac Formation of Maryland (iron ore beds between Baltimore and Washington): Cycadeoidea marylandica (Fontaine), Tysoniana, Fontaineana, McGeeana, Uhleri, Bibbinsi, and Goucheriana (last six species TWard).

(4) Jurassic of Colorado (near Boulder): Cycadeoidea nigra Ward.

(5) Pre-Laramie (?), near Golden, Colorado: Cycadeoidea (Zamiostrobus) mirabilis (Lesquereux).

(6) Dakota formation (?), southern Kansas: Cycadeoidea marita Cragin.

(7) Upper Trias, North Carolina; locality unknown: Cycadeoidea Emmonsi (Fontaine).

(8) Trias of Prince Edward Island: Cycadeoidea abequidensis Dawson.

(9) Trias of York, Pennsylvania: Cycadeomyelon yorkense Fontaine.

(Io) Trunk from Lower Chico or Horsetornn beds (=Dakota Cretaceous or older), Grapevine Valley, Colusa County, California.

\footnotetext{
* See Monogr. U. S. Geol. Surv., vol. xLvir, p. 276.
} 


\section{EUROPEAN CYCADS.}

DISCOVERY OF THE DIFFERENT TYPES.

No study of American forms or enumeration of horizons and localities can be satisfactory without some similar consideration of European forms. As will further appear in this volume, and as was first definitely pointed out by the present writer (I99), there is an exceedingly close agreement between the cycads of North America and of Europe. Indeed, many of the American species are so entirely analogous to European forms in appearance and features of preservation, structure, and fructification, that as knowledge of the subject increases not a few of the former may prove identical with the latter, or be better held as merely subspecies of earlier described European cycads. The reverse, I strongly suspect, may also prove true in several instances. Compare, for instance, the Italian Cycadeoidea Masseiana Capellini \& Solms with Cycadeoidea nigra Ward from Colorado (I78, plate LVII, and I78, plate Lxvin, respectively), and both with the very similar and earlier proposed species C. Uhleri from Maryland (I74). In any case the close agreement already observed is a fact of much importance in all considerations of plant distribution in the Mesozoic, although it can not as yet be accepted as final evidence of the wholly synchronous existence of these highly specialized forms on both continents. Such being the fact, a brief catalogue of European forms and an account of Cycad discoveries in Europe is at once a matter of convenience and of importance to students, although it is of course beyond the scope of the present purely biologic study to attempt any extended comparison of species considered simply as such, this being necessarily deferred to a future time. It is only intended at present to give prominence to discoveries of distinct historic interest or of fundamental importance in the development of our knowledge of the distribution and structure of the Cycadeoider.

ITALY.-Historically speaking, the cycads of Italy may well receive mention before those of any other country; for a peculiar interest clusters especially around Cycadeoidea etrusca. Placed with vases and other objects of superstitious reverence on one of the sepulchral chambers of the ancient Necropolis at Marzabotto by the Etruscans more than four thousand years ago, this fine trunk was refound in 1867 and later described by Capellini \& Solms (22). It will also be remembered as the first trunk which afforded any clue to the probable position of the male inflorescence in the Cycadeoideæ, one of its fructifications having afforded quite distinct pollen grains scattered through the imperfectly conserved tissues surrounding a young laterally borne ovulate inflorescence. This specimen is now in the geological museum at Bologna.

Again, in 1753 an Italian named Monti described a small cycadean trunk as a congeries of barnacles, naming it Lapideorm balanomm congeries insignis! Although the original specimen has been unfortunately lost, Capellini, on the basis of Monti's excellent figure, happily redescribed it a few years since as Cycadeoidea Montiana (22). Furthermore, during the past seventy-five years the types on which are based a dozen additional species of silicified Cycadeoidean trunks have been secured from the "scaly clays," as enumerated below. 
Galicia.-The third oldest European cycad is the type of Cycadeoidea (Ranmeria) Reichenbachiana (Göppert) Capellini \& Solms. This is a very large trunk found at Lednice, near Wieliczka, in Galicia, winich, after being figured by Knorr in I755, was later described by Walch in his well-known work (I69a). It is conserved in the Royal Geological Museum at Dresden, and for a long time remained the largest of known fossil cycads, but is now far exceeded in this respect by certain Yale and United States National Museum specimens. An excellent figure of this trunk is given by Ward ( 176 , plate $L I X)$, who has recently further added an extended account of its interesting history and its macroscopic features (I80). As Professor Ward has very justly observed, there can be no question that its microscopic structure is conserved and would richly reward study. It evidently bears numerous ovulate cones, and staminate disks are either present in young stages of growth or were matured just previous to fossilization. Resemblance to the larger of the southern Black Hills specimens is from every point of view very close indeed.

FRANCE. - In France cycadean trunk discovery has extended over the past century, although, as in Italy, exact investigation of the material has been confined to the last dozen years.

The type of Cycadeoidea micromyela, discovered at Tournay-sur-Odon, Calvados, about 1837 , probably belongs to strata of the Middle Lias. It was described in I869 by Morière; but not until recently was it made the subject of a very complete microscopic examination by Lignier (84). Being a trunk that had evidently been macerated before silicification, and with structure quite well preserved but not differentiated, Professor Lignier successfully resorted to staining the thin sections with vesuvine by a method of his own, described several years since (79). The fine results obtained are hence of more than ordinary interest.

A far more notable specimen, however, is the superbly preserved ovulate cone, Cycadeoidea (Bennettites) Morierei (Sap. et Mar., I88I). This was found in 1865 by Morière in the Oxfordian of Vaches-Noire by the cliffs of Villers-sur-Mer, Calvados, Normandy; but not until nearly thirty years later was it made the subject of a thorough microscopic investigation by Lignier (82). The fossilizing material is iron carbonate, and the tissue differentiation is of rare beauty. The writer has been happy to secure from Professor Lignier for the Yale Musen six representative thin sections cut from the original type in exchange for sections cut from Black Hills cycads.

In this connection may be mentioned the English specimens from the Yorkshire coast now in the Paris Museum. As becomes evicient from the present studies, these fine fossil casts of isolated Williamsonia fruits, figured and described by Saporta in I89I ( 125 ), constitute a highly important series. Many of these now prove to be so closely related to some of the Black Hills forms that they constitute well nigh as important a fund of knowledge concerning the distribution of the Mesozoic cycadales as they might if their trunks as well had been preserved. Thus we cleurly see that the fortunate knowledge we at last possess concerning the exact microscopic structure of so many silicified and ferrized cycadean forms in varions stages 
of fructification enables us to interpret with precision a long series of fossil casts and imprints, which must in the absence of such knowledge have remained wholly problematical.. (See plates XLVI and XLVII.)

ENGLAND.-English horizons, more distinctly perhaps than in the case of those of any other European country, have mainly afforded the types upon which our earlier knowledge of the Cycadeoider has rested. The first cycadean trunks from England to receive mention were those obtained from the Wealden sandstones of the Tilgate Forest by Mantell, and described by him in I822 as fragments of stems "composed of a cylindrical imbricated axis, marked with intermpted longitudinal stria, and a cortical layer covered externally with rhomboidal markings." * I have italicized Mantell's statement, for this description of the outside appearance of these fossils is exact, however wide of the mark his supposition that they might be ferns, palms, or even Euphorbiaceæ. Their true nature was, however, soon discerned by Presl, who in 1825 placed them in their proper position with, as Carruthers says, "remarkable discrimination." They are structureless casts of pith, cortical surfaces, and leaf bases, said to be of two types. Bucklandia anomala (Stokes \& Webb) is the type of Presl's genus, and the other species referred to it are doubtful. Bucklandia was supposed by Carruthers (24) to represent forms allied to the living Cycas, on the ground that there was some evidence of a zonal distribution of the leaf bases which might be accounted for, as in Cycas, by the successional appearance of foliage leaves, scale leaves, and carpels, all borne on the same trunk. Should the types, however, ultimately prove to be related to those upon which the genus Cycadeoidea is founded, as may well be the fact, the latter name might have to be abandoned.

The second series of English trunks brought to light were the far more striking forms from the Oölite quarries of the Isle of Portland, mentioned under the generic name of Cycadeoidea by Buckland, in 1827 (I6), and more fully described by him in 1828 ( 17 ). To these specimens belongs the distinction of having been the first to receive a fairly adequate scientific description. Concerning their classification, Professor Ward says :

"I may remark that Buckland, in studying for the first time the fossil trunks from the Purbeck beds of the Portland quarries, called to his assistance the great contemporary botanist, Robert Brown, whom he expressly credits with the suggestion that the differences between the fossil and living forms are sufficient to establish a new family, distinct from the existing family of Cycader, and to which the name Cycadeoidere was given. The generic name Cycadeoidea was also employed at the same time, but it afterwards transpired that this was not approved by Robert Brown, who only proposed the family name. Brown must therefore be credited with the name Cycadeoidece, and Buckland with Cycadeoidea. The wisdom of Brown's suggestion has been abundantly vindicated by the subsequent study of these forms, and the more their internal anatomy is made known, especially the nature of their inflorescence and fructification, the clearer it becomes that all fossil cycadean vegetation from beds below the Tertiary represented a group distinct from the recent Cycadacer." (I 74).

* Mantell, Geology of Sussex, The Fossils of the South Downs, ipp. 42, 43. 
As yet, however, nothing was positively known as to the true nature of the inflorescence of any of the fossil cycadean trunks; nor was any such knowledge gained for the next thirty years. The earlier of the specimens from the Isle of Wight, now the most important European cycad locality known, received but brief notice. That by Robert Brown should be cited. In 185 I he exhibited before the Linnean Society of London a series of recent and fossil cycads, among them a trunk from the Isle of Wight, which he called Cycadiles Saxbyanus. Regarding this he said (Proceedings of I85I, p. I 30 ):

"All the specimens of Cycadites hitherto found in the Isle of Wight agree in having an elliptical outline, unaccompanied by any inequality in the woody ellipsis, and also having a bud in the axilla of each leaf; in these respects differing from the Cyradiles of the Isle of Portland, and from all the recent species of the Cycadere with which we are acquainted, which have a circular outline and scattered buds."

It is thus plain that in their general anatomy and vegetative characters no great and fundamental difference from living forms had at this time been recognized in any of these fossils, if we except their copious development of fern-like ramentum, so unlike the cycads of to-day. In short, the peculiar character of fructification in the Cycadeoidex, so all-important to our conceptions of plant evolution, had not as yet been discovered, and was scarcely even suspected before the discoveries of Williamson and Carruthers in I868. On June 4 of that year Professor Williamson read his noteworthy contribution on Zamia gigas (202). The specimens he described were the result of thirty years of collecting by various persons, including himself and his father, who had discovered the Hawkser locality on the Yorkshire coast in I832. These fossils were obtained from the "lower sandstone" of Phillips, as exposed in the débris along the cliffs of Hawkser and Runswick, and consisted in the closely associated imprints of leaves and casts of trunks, and of fruits of new and at that time highly problematical character. On the basis of these, Williamson prepared a restoration which at once became the subject of coutroversy, and remained such for thirty years, until the discovery by the writer of the fructification and foliage of the Black Hills trunks set at rest the doubts concerning it. Professor Williamson's interpretations, while in part erroneous, are of extraordinary interest; and the fact that his figures and restorations are in nowise fanciful, but constitute a contribution of great intrinsic value, must be again referred to later in this volume.

On June I8, I868, two weeks after the amnouncement of the discoreries of Williamson, William Carruthers read his highly important menoir on the fossil cycadean stems from the secondary rocks of Britain (24). In this are described some of the beautiful silicified trunks from the Lower Greensand of Luccomb Chine, in the Isle of Wight. On these Carruthers found wonderfully preserved, bractsurrounded, ovulate strobili interspspersed laterally between the persistent leaf bases. These fructifications he studied in thin sections, the first prepared from fossil cycads. The more important details in their entirely unique structures were clearly described, and the new genus and species Pennetties Gibsonianus was proposed. It became obvious that a lively hope for the discovery of further material might be entertained, and that this must be of the highest botanical interest when 
found. With the work of Williamson and Carruthers the exact investigation of the Cycadeoidex may be said to have been fairly begun.

Since the time of Carruthers various details have been added to our knowledge of the trunk structure and ovulate fructification of the Isle of Wight genus Bennettites. In particular, Solms-Laubach, in his restudy of the type material, gave a much clearer account of the structure of the ovulate strobilus, and discovered its dicotyledonous embryos ( $156, \mathrm{I} 57$ ).

Much additional interest has also been lent to the Isle of Portland as a cycad locality by the discovery, about I895, of Cycadeoidea gigantea described by Seward (I44). This fine silicified trunk is one of the largest and tallest complete specimens known, its height being $\mathrm{I} . \mathrm{I} 8$ meters and greatest diameter $4 \mathrm{I} \mathrm{cm}$. It is now on exhibition in the fossil plant gallery of the British Museum.

\section{OTHER EUROPEAN CYCAD LOCALITIES.}

In addition to the European localities already mentioned there are few others requiring mention in any other than a wholly complete list. Various trunks have been reported from Germany, also Belgium, Poland, and Russia. Eichwald, as early as I86o, figured several supposed cycadean and other trunks from the cupriferous sandstones of the Carboniferous terrane of the Altai in the department of Orenburg (44, plate XVII, fig. 2, etc.), and further material from this region may prove of great interest.

\section{CYCADS OF INDIA.}

The occurrence in the Gondwana system of various cycadean trunks associated with Williamsonia fruits and a plenitude of cycadaceous leaves is of the greatest interest as indicating that the dominating feature of the Indian Jurassic was a highly developed cycad flora closely related to and probably contemporaneous with that of Europe and America. The great extent of this Jurassic cycad flora of India was first made known by Oldham \& Morris in 1863 (I05), although, as these authors state (p. I4), several earlier references to the occurrence of cycads in India had been made.

In addition to figuring and describing a large number of fronds, Oldham \& Morris mention a considerable number of "silicified trunks of cycads," many of which were said to be well preserved, as shown by microscopic examination. This reference, as well as that in their introduction (105, p. 5), to "large quantities of other silicified stems, chiefly exogenous, in the upper group of the Rajmahal series (Bengal)" is, however, rather vague. They also mention a number of smaller trunks from Amrapara, Puchwara Pass, which were associated with Paleozamia (=Ptilophyllum) leaves. Some of these are figured and they, as well as the types, are again mentioned with reference to Oldham \& Morris' figures by Feistmantel (48), who suggests very reasonably that they may possibly be related to the Wealden genus Bucklandia. The interesting observation is added that on the same slab with one of the trunks there is an "involucrum" of Williamsonia gigas. Thus we 
have here, in close association, cycad trunks of rather slender labit with Pliloploy?lum leaves and Williamsonia fruits. 'The ne.t reference to Indian cycad trunks, so far as I know, is by Seward, who figures preliminarily a cycad trunk from India with its principal structural details indicated. This specimen has Plilophyllum cutchense leaves attached (I49).

Before leaving the subject of Indian cycads it may be well worth while to mention several occurrences of associated leaves and fruits. The genus Ptilophyllum is more common than any other in the flora of Kach and of the Rajmahal Hills, and in both is found accompanying typical Williamsonia fruits, as shown in the
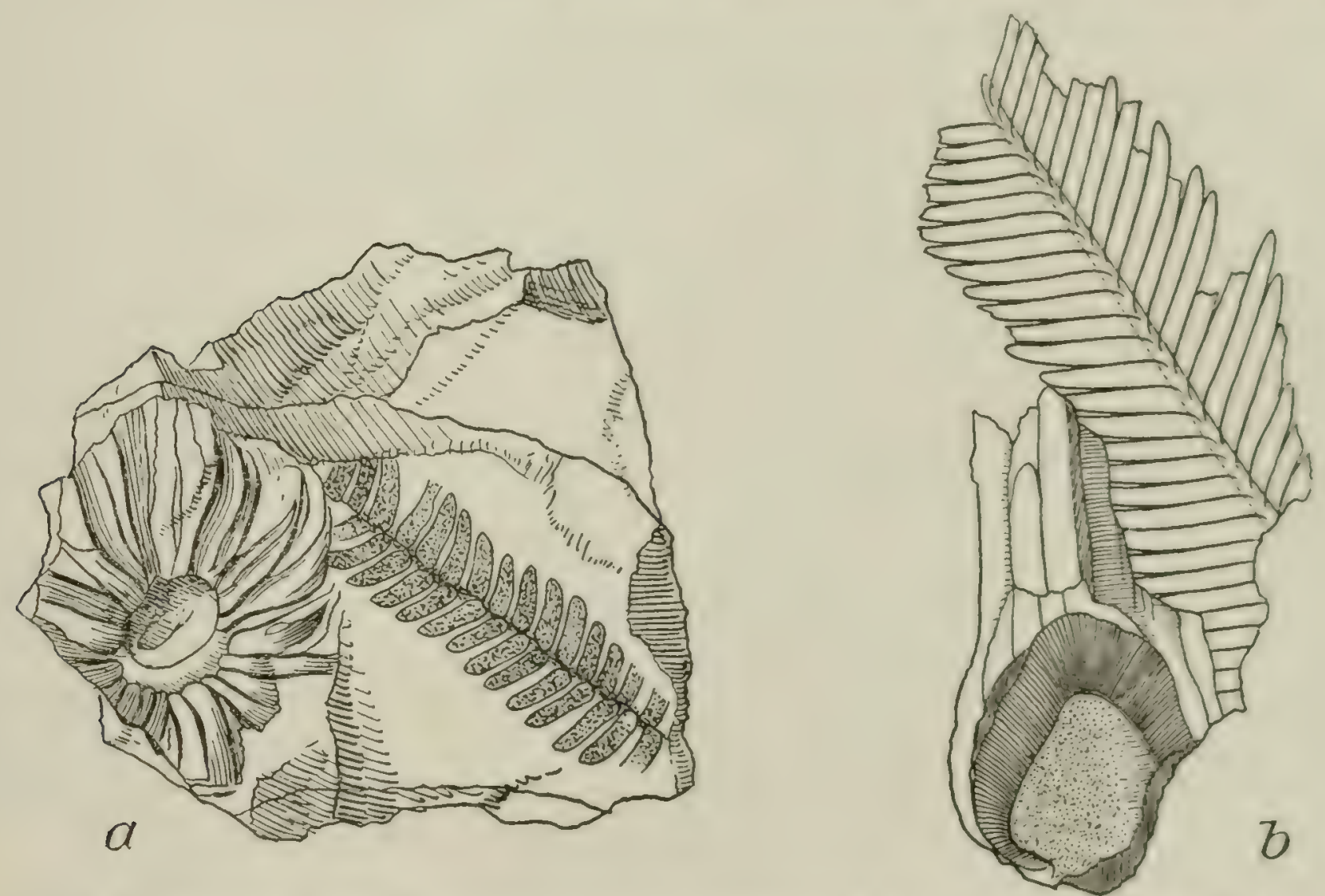

Fig. 2.-Cycadeoidean strobili and associated fronds from the Jurassic of India, $\times \frac{5}{5}$. After Feistmantel.

(a) Williamsonia Blanfordi F'stm. Strobilus and Pilophyllum cutchense frond on same slab from the Oolite of Kukurbit, Kach or Curch. (47, Plate XII, figure 6.)

(b) Ptilophyllum acutifolium Morr. Williamsonia-like strobilus and frond on same slab from the Black Shale, Jabalpur Group. Sher River. (51, Plate VII, figure 6.)

subjoined text-figure 2. In his Jurassic Flora of Kach (47), Feismantel figures three different slabs, each bearing the fruit Williamsonia Blanfordi, accompanied by characteristic portions of Ptilophyllum culchense fronds; though, for reasons not clear, no mention is made of the latter fact in the description $(47, \mathrm{p} .42)$, reference being made solely to the fruits. Similarly, in various European localitiss there is the corresponding association without actual organic connection of the fronds called Cycadites pecten, or Williamsonia pecten and pectinoides, with the small fruits named Williansonia Leckenbyi. Moreover, no one has yet pointed oni a single indubitable generic difference between the Indian and European forms just mentioned, so that their nomenclature is a moot point despite their consequent great interest and importance from every point of view. Evidently in such a case 
as the present wholly valuable inferences may be made only from associated stems, leaves, and fruits, if preceded by exact field work in all the important localitiesthe prime necessity in all cases, and the fountain head whence alone our knowledge of extinct floræ may derive that completeness which is of final and intrinsic value. We need not, however, go beyond the present group to show that important inferences may be drawn from associated stems, leaves, and fruits, if the evidence at hand is simply presented or considered with care. However loath botanists were for many years to accept as fairly correct the restoration of Williamsonia gigas, it must now be admitted that here is an instance in which association led to correct inference. That much may be done in the case of dissociated parts of the more highly organized plants, towards learning which are portions of one and the same plant, if careful work is done in the field by competent workers, is a fact to bear in mind. For, each additional pre-Tertiary plant we learn to know by stem, leaves, and fruit has, biologically speaking, an immense value.

Having mentioned the principal cycad localities known, it may not be amiss to point out very briefly how great is the additional field concerning which we as yet know nothing, and from which it is to be hoped that valuable supplementary material may yet be obtained. In central North America, which has yielded the most and the best-silicified trunks, scarcely a third of the Rocky Mountain slope has been adequately explored, perhaps not a fifth. But as a large reward of initial exploration the barrier islands of Antarctica have already yielded cycad and other floræ, paralleling the extinct plant life of Greenland and of like marvelous interest. Concerning the western slopes of the Andes we know exceedingly little, some Jurassic plants having been reported from Patagonia. Of the slopes of the great mountain chains of Asia we know nothing. And of the countless fossil plants of which science has to learn from Africa, Australia, and the great wastes facing the Arctic Ocean, but few or no tidings have yet come. Truly, paleobotany is yet young, and its most successful votary must yet be the field-worker and the explorer.

\section{OLD-WORLD TYPES OF CYCADEOIDEAE, THE HORIZONS IN WHICH THEY OCCUR, AND THE MUSEUMS IN WHICH THEY ARE LOCATED.}

In the following general list of Old World cycads it is the purpose rather to give only those forms which are either very well known and structurally important, or that have especial value in studying the general character of evolution in the group. Such genera as Draccena Withamia, Becklesia, Dichopteris, with little or no structure preserved and of doubtful cycadean affinity, are mostly omitted.

Scaly Clays of Italy. Types, with Date of Discovery. (From Capellini.)

I745. Cycadeoidea Montiana Capellini \& Solms. Lapideorum balanorum, congeries insignis, Monti. Rio della Cavaliera, Bolognese. Figured by Monti (I753). The type has been lost.

1825. C. intermedia Ranzani. Fiume Reno, Bolognese. Museo geologico di Bologna.

1849. C. Scarabelli Meneghini. Fiume Sauterno, Imolese. Musei d'Imola e Pisa.

1850. C. Pirazzoliana Massalongo. Torrente Correchio, Imolese. Museo geologico di Bologna.

1852. C. Bianconiana Massalongo. Torrente Samoggia, Bolognese. Museo geologico di Bologna.

1859. C. veroncnsis Massalongo. Veronese? Museo civico di Verona. 
1869. C. Capelliniana Solms. Fiume Idice, Bolognese. Iruseo geologica di Bologna.

1870. C. Cocchiana Caruel. Torrente Marnia in Valdarn !. Musen di Firenze.

1874 and 1875. C. Capelliniana Solms. Two additional specimens, both from Torrente Fresinaro preso Scandiano. S. ta Ruffina coll. Ferretti.

I875. C. MTaraniana Scarabelli. Castel S. Pietro. Museo civico d'Imola.

1875. C. (Cycader) imolensis Capellini \& Solms. Fiume Santerno?, Imolese. Iruseid'Imola e Bologna.

1878. C. etrusca Capellini \& Solms. Necropoli etrusca di Marzabotto. Museo geologico di Bologna.

I879. C. Ferrettianc Capellini \& Solms. Monte Babbio, Reggiano. Museo geologico di Bologna.

1879. C. Capelliniana Solms. One specimen from Paullo nel Reggiana, one specimen from Vallestra. Reggiano. Both in Musei di Reggio Emilia e Bologna.

I889. C. Maraniana Scarabelli. A second specimen from torrente Correchio, Imolese. Museid'Imola e Bologna.

I889. C. Masseiana Capellini, Ozzano, Bolognese. Museo geologico di Bologna.

Upper Cretaceous.

Cycadeoidca (Cycadiles) Schachti Coemans. Hainaut, Gault of Louvière, Belgium.-Mem. Conn. des Savants Etrangers de l'Acad, Roy. de Belgique, vol. xxxin, No. 3, p. 7; pl. Irr, figs. 1, 2, 5 .

Fittonia (or Bucklandia?) squamata Carr. Bonchurch, Isle of Wight, England. Type in Museum of Practical Geology, Jermyn street, London.

\section{Lower Cretaceous.}

Cycadeoidea (Mantellia) inclusa Carr (24). Potton-Sands, Bedfordshire, England. Types in collection of $\mathrm{Wm}$. Reed, York, in 1870.

Cycadeoidea Yatesii Morris and Carr (23). Potton-Sands, Bedfordshire, England. Type in Royal Agricultural College, Cirencester, England.-Geol. Mag., vol. Ix, p. I99, pl. IX.

Cycadcoidea forata (Sap.) Solms. Gault of Cauville, near Havre, France.-Saporta. P1. Jurass., rol. Ir. p. 297; pl. cxxiv, figs. r, 2.

\section{Lower GreEnsand.}

Bennettites Gibsoniamus Carr (24). Luccomb Chine, Isle of Wight, England. Type in British Museum. Bennettites maximus Carr (24). Shanklin, Isle of Wight, England. Type in IIuseum of Practical Geology, Jermyn street, London.

\section{WEALDEN.}

Bucklandia anomala Presl. Cuckfield, Sussex. Type in British Museum.

Bucklandia Mlantellii Carruthers. Cuckfield, Sussex. Type in British Museum.

Bennettiles Sabyanus. Brook Point beds, Isle of Wight. Types in British and Oxford museums.

\section{JURA.}

Cycadeoidea (Crossozamia) Morenui (Pomel). St. Michael, France.-Amtlichter Bericht, xxp. Versam, d. Gesell. deutsch. Naturforscher und Aertzte, I849.

Cycadeoidea (Crossozamia) Buvignieri Pomel. St. Michael, France.

Cy'cadeoidea sarlatensis (Saporta). Upper Jura or Sarlat, Dordogne, France.-Saporta. P1. Jurass., vol. II, p. 293; pl. cxxin, figs. I, 2.

Cycadeoidea Trigeri Brongniart (Tableau, p. 59). Upper Jura of Mons (Sarthe), France. Type in -

Cycadeoidea micromer $\alpha$. Corallien of Tonnere (Yonne), France.-Saporta. P1. Jurass., vol, 11, p. 262: pl. cxvirI, fig. $\mathrm{r}$.

Cycadeoidea mamertina Crie. Bathonian of Mamers, Sarthe, France,-Crie. Les Ancien Climats et les Flores Fossiles de l'Ouest de la France, pp. I5, I8.

\section{PURBECK.}

Cycadeoidea megalophylla Buckland (r7). Isle of Portland, Dorsetshire, England. Type, a silicified trunk originally in the Sowerby collection.

Cycadeoidea microphyylla Buckland (I6). Isle of Portland, Dorsetshire, England. Type, a silicified trunk originally in the Sowerby collection.

Cycadeoidex intermedia Carr (24). Isle of Portland, Dorsetshire, England. Type in British Misseum.

Cycadeoidea megalophylla (= Mantellia nidiformis) Brongn. (I3). Isle of Portland, Dorsetshire, England. Type in British Museum. Other specimens in Jermyn Street Museum, London; United Stares National Museum, Yale Museum, and elsewhere. 
Cycadcoidea siganlex Seward (I44). Isle of Portland (the "dirt bed "), Dorsetshire, England. Type in the British Museum (a magnificent silicified trunk).

Bennctiles fortlendicus Carr (24). Isle of Portland ("the dirt bed "), Dorsetshire, England. Type in the Museum of the Geological Society, London.

\section{OXFORDIAN.}

Bennetlites IIorierci. Saporta et Marion. Vaches-Noires (falaises de Villers-sur-Mer), Calvados, France. Type in Museum of University at Caen, Normandy.

Cycadeoidea fictavicnsis Saporta. Montanaise near Poitiers, France.-Figured by Schimper, plate LxxI, fig. I2 (I 3 I).

\section{OÖLITE.}

Milliamsonic Blcufordi. O. Fst. M. (47). Kukurbit (20 miles north by a little west from Bhoof), Kach, India. Type in collection of Geological Survey, Calcutta.

\section{Middle Oölite.}

Iatesia (or Bucklandia?) crassa Carr. Brora, Sutherlandshire, Scotland. Type in Dunrobin Castle Museum.

Yatesia (or Bucklandia?) Joassiana Carr. Brora, Sutherlandshire, Scotland. Type in Dunrobin Castle Museum.

Bucklandia Milleriana Carr. Brora, Sutherlandshire, Scotland. Type in Dunrobin Castle Museum.

Bennettites Peachicuns Carr. Helmsdale, Sutherlandshire, Scotland. Type in the British Museum.

\section{LOWER OR INFERIOR OÖLITE.}

ITilliamsonia gigas (Villiamson) Carr. Scarborough, Cliffs of Hawkser and Runswick, Yorkshire, England. Type in British Museum.

Bucklandia squamosa Brogn. Stonesfield, England. Type in University Museum, Oxford.

Williamsonia Bucklandi Sap. Charmouth, Dorsetshire, England, and Coast of Yorkshire, near Scarborough. Type in collection of Oxford Museum.

IViliiamsonia peclen Carr. Gristhorpe Bay, Yorkshire. Type in British Museum.

\section{LIAS.}

I'alesia (or Bucklandia) sracilis Carr. Lyme Regis, Dorsetshire, England. Type in British Museum. Cycadcoidea fysmaed Lindley \& Hutton (66). Lyme Regis, Dorsetshire, England. Type astray.

Cycrdeoided micromyelex Mor. Near Tournay-sur-Odon, Calvados, France. Type in University at Caen, Normandy. (Probably Middle Lias. - Cf. 84.$)$

I'ilophyllum culchense. (Trunks, with their leaves and fruits?.) Amrapara, Puchwara Pass, India. Types in collection of Geological Survey, Calcutta.

IVilliamsonia grigrs (fruits). Golapili, near Ellore, in Godovari district, India. Amrapara, Puchwara Pass, India. Bindrabun, Rajmahal Hills, India. Types in collection of Geological Survey, Calcutta.

\section{HORIZON INDETERMINATE.}

Cycadeoidea Reichenbachiana (Göppert). Lednice, in a swamp near Weiliczka, Galicia. Type in the Museum at Dresden. Cf. Ward (I80).

Cycadeoidea Schulziana (Göppert). Found in Klodnitz Canal, near Gleiwitz, in Silesia. Type in the Museum at Breslau.

Cycadcoidea Bucklandi Corda sp. Locality also unknown. Supposed to have come from England. (33. pp. 38, I20; plate XviI, figs. I-Io.) 


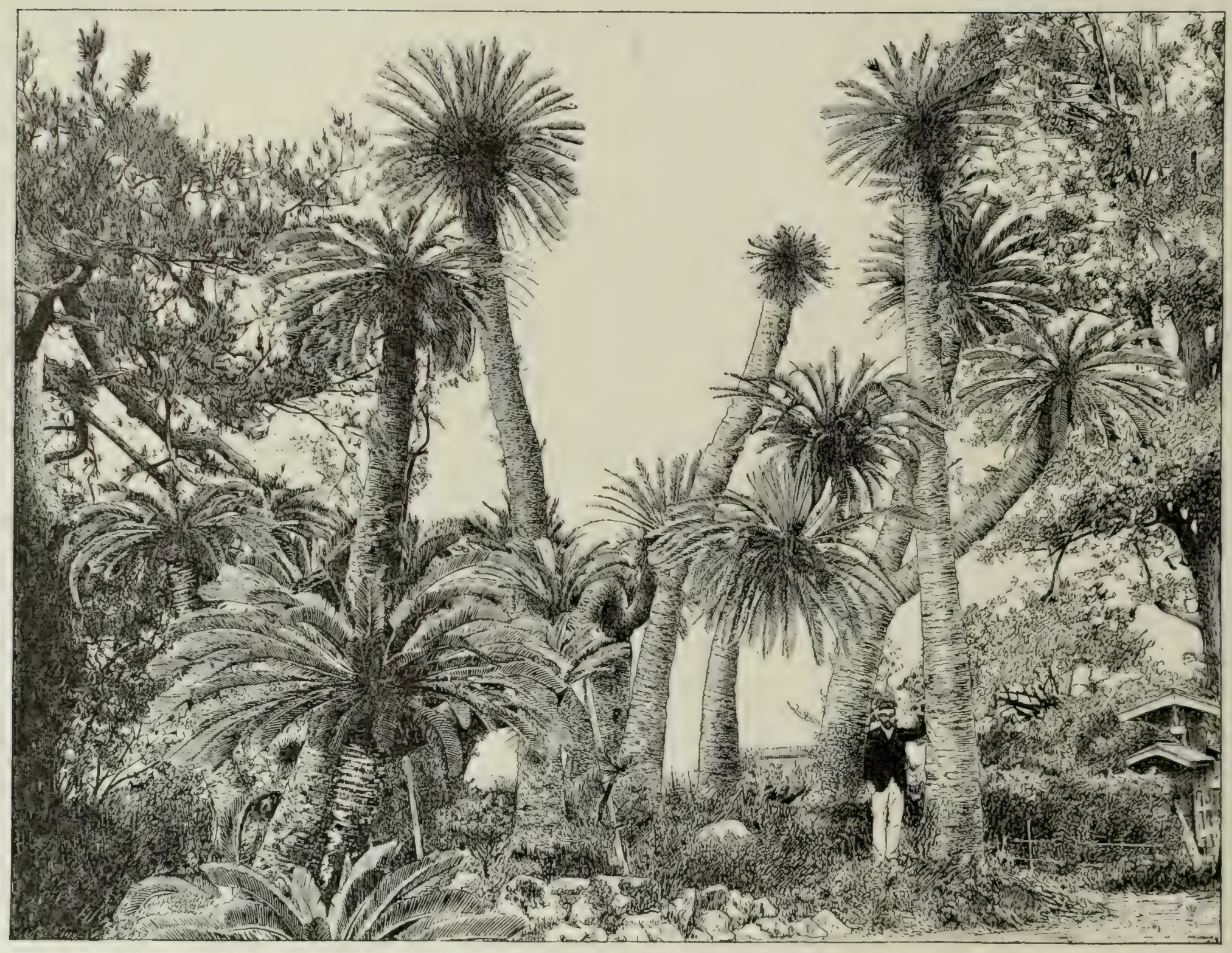

Fig. 3.-Tall Unbranched and Branching Trunks of Cycas revoluta.

The garden of the Ryungeji Temple in Shimizu, near Fjiri, about 120 miles west from Tokio. These are the largest cycads known in Japan. The trunk by which the man is standing is about 8 meters in height by 2 meters in basal circumference. Drawn from a pholograph taken specially for this volume by Professor Dr. S. Ikeno. 


\section{CHAPTER II.}

\section{PRESERVATION AND EXTERNAL CHARACTERS.}

\section{VARYING CONDITIONS OF FOSSILIZATION AND RESULTING TRUNK FORMS.}

The mineralization of entire plants as fossils is conditional, firstly, upon the tissue systems present, as connected with particular stages of growth, prefoliation, prefloration, or fructification. The secondary factors of control in the process are mainly: (I) the relative abundance and kind of mineralizing materials; (2) temperature; (3) the presence or absence of secondary reagents, such as iron, capable of replacing plant tissues and preserving their microscopic structures in finely differentiated form, but not necessary to the process of silicification or calcification, as the case may be; (4) the duration and rapidity of chemical activity; (5) the nature of the embedding rock material. These are the principal elements determining the clearness with which structural details are preserved and differentiated, the final results being in addition dependent upon the freedom from maceration or decay of the original plants at the time of their fossilization, as well as from subsequent chemical changes or compression in the containing beds after the early process of preservation is completed. Technically speaking, the silicified cycads are more or less perfect casts of the original tissue systems or "histometabases." The primary chemical reaction resulting in these casts is a separation of silica, at first probably in gelatinous condition, from solutions of alkaline silicates by cellulose. 'The minor reactions involved must be complex; but it ought to be possible to silicify complete trunks of existing cycads as well as their foliage and fructifications in laboratories.

Clearly, then, in dealing with any such highly organized plants as the cycads, it is scarcely to be expected that, even in the case of trunks from the same locality and of the same species, in themselves originally presenting many individual differences of growth, all these various factors of preservation will have acted in a uniform manner, to say nothing of different localities or geologic periods. Furthermore, the external appearance of specimens will vary greatly not only because of many differences in the nature and extent of their preservation, but because of differences in the process of erosion bringing them within the collector's reach. Later, under the head of trunk structure, will be shown in full detail the wide possibility of variation in external appearance dependent upon the relative position of the zone to which preservation has extended, or at which either secondary cinemical action or erosion has ceased.

Obviously, where it is wished to obtain more than initial knowledge of external features, it is in all cases indispensable to have constant recourse to polished 
and thin sections; for anyone who examines macroscopically a collection of quite I,Ooo fossil cycads must soon acknowledge himself well-nigh helpless in an attempt to arrange them in appropriate species with any full degree of certainty, without such aid. As macroscopic examination is, however, always the prelude to more exacting investigation, it is primarily necessary, when studying such fossils exteriorly, to constantly recall what the conditions and limits of preservation are, in order to fairly estimate the relative value of the macroscopic characters present. It is also of especial interest in this connection to note, in passing, the types and conditions of preservation in the three main cycad localities of North America; for although, as just explained, there are many individual differences in the case of trunks from the same locality, it is very interesting, after one has become familiar with the cycads of many localities, to note certain characteristic features which, in the majority of specimens, show at a glance the particular source whence they have probably come. No one would be likely to mistake the "bird's nest" cycads of the Isle of Portland, although cycads with very similar decayed or crushed summits are also common elsewhere, a few occurring amongst the usually far more symmetrical and completely preserved trunks from Minnekahta, South Dakota. The group from the Potomac formation of Maryland, with some "crows' nests," is likewise a very characteristic one. So are the much-crushed but otherwise beautifully silicified trunks from Dakota and Wyoming, constituting the genus Cycadella.

The single cycad (Cycadeoidea nigra Ward) from near Boulder, Colorado, it may be mentioned, shows, together with beautiful differentiation of its tissues and denseness of silicification, a certain toughness in grinding and a jet-black color, such as are seen in no other specimen known to me. Yet in form and in various minor details, particularly in the numerous fructifications in the axils of the leafbases, this trunk agrees in the most striking manner with certain Maryland and Italian trunks. Indeed, -in so far as macroscopic features go, it has always been a question with the writer if Cycadeoidea (Rammeria) Masseiana from the "scaly clays" of Italy, C. Uhleri from the Potomac of Maryland, and C. nigra from the Upper Jura (?) of Colorado, are not one and the same species.

In the case of the upper cycad-bearing horizon of the Black Hills, the main localities of which are at Minnekahta and Black Hawk, South Dakota, certain characteristic groupings may be readily made out, while the single trunks from isolated points some miles from these main localities present, as might be expected, certain intermediate general characters of silicification, coloration, compression, erosion, and density. The Black Hawk series is light-colored and much chalcedonized. It is a striking one in every respect, a fact which is, however, in part due to the unbranched columnar habit of most of the trunks, although there are some low round trunks, as at Minnekahta, and at least two species are common to both localities. Clearly these differences in general appearance, in large measure due to what might be termed the accidents of preservation rather than to actual difference in structure, have led to some unavoidable duplications of species before the series of trunks was as complete as at present. 
LOCAL CONDITIONS OF PRESERVATION.

In the Potomac Formation of Maryland, so far as determined from the surroundings, the cycad trunks now found isolatid were embedded in the "iron-ore clays," often somewhat arenaceous and generally supposed to be of brackish-water origin ( $5 a$ ). These trunks are not nearly so well silicified as those of either the Black Hills or Wyoming, although externally of much beanty. (See figure I, p. 4 , and $7, \mathrm{p} .32$.$) It is quite probable that the Maryland trunks were ail subjected$ to more or less maceration, under estuarine conditions, although rather better preserved than the most of the trunks from the Purbeck beds of the Isle of Portland, where the "crows' nest" forms, or trunks with decayed and crushed summits, are probably often found in the original position in which they grew.

In the Black Hills Rim there are, as has been stated in the chapter on clistribution, two clearly distinct cycad-bearing horizons. 'The lower of these horizons is doubtless equivalent to that of the Freezeout Hills of Carbon County; Wyoming, and lies near the base of the sliales and sandstones of the fresli-water Jura or Atlantosaurus beds of Marsh. The cycads of this lower level weather out of the shales, so far as known, together with much silicified coniferous wood which has, in common with the cycads, a very characteristic habit of weathering dirty white, and like them shows a very dark surface when freshly fractured. Both are dense of texture and must be studied from very thin sections. Evidently they grew in much the same situations and were preserved at the same time and in relatively the same manner. In the cycads in particular there is considerable evidence of maceration. The trunks are quite frequently much flattened, and the anmor is often crushed out of position and very variably preserved, as the direct result, no doubt, of compression, while the siliceous material replacing the original plant tissues was still in a more or less gelatinous condition. Yet, although far from having the symmetrical appearance of the Maryland trunks, the differentiation of tissues is often of much greater and rare beauty. The copious growth of ramentum was particularly susceptible to silicification, and in some instances, as will be seen, the structural details approach and in some respects, surpass, in distinctness and perfection, those of the thin sections from similar tissues of living plants. Of course, in making the latter we are at a disadvantage because of the difficulty of firnly embedding woody, woolly, or scaly material for the cutting of thin sections of considerable area. It is not improbable that there was a more abundant source of alkaline silicate solutions than in the iron-ore beds of Maryland-some steadier flow as well as the presence of more iron. So far as yet determined, in addition to the bones of Dinosaurs, the plants of the Atlantosaurus beds, including large logs and the cycads, were brought by streams into the ox-bows and estuaries abont a large and, as has been commonly supposed, deep fresh-water lake. Whether or not the plants were immediately silicified is, of course, difficult to say, although it is probable that chemical action was not long deferred. The required silica may perchance have been derived from siliceous ash of volcanic origin, from diatoms, from siliccous sponges, or from deep-seated thermal waters, the former presence of which is suggested by certain siliceous cores the writer has observed projecting from the shales 
of the lower cycad horizon on the eastern side of the Black Hills in the Piedmont region. These cores are composed of indurated materials best accounted for as having accumulated along the course of deep-seated and probably hot and silicaladen waters as these made their way to the surface. But that any such extensive thermal action occurred as may be observed in the Yellowstone Park at the present time, where in the vicinity of the geysers and hot springs wood may be frequently seen in various initial stages of silicification, would seem unlikely; for such chemical activities would probably leave indubitable evidence of their former presence at many points. However, it is noteworthy that on the southern side of the Black Hills, hard by the great Minnekahta cycad locality, are some layers of chalcedony or onyx, a foot or more in thickness, interpolated in the shale at the base of the Atlantosaurus beds; and these, considered together with the siliceous cores just mentioned, certainly imply some abundant and unusual local sources of silica in the Black Hills mountain knot region, as girdled by the lower and the upper and more important cycad horizon which has yielded the magnificent Minnekahta and Black Hawk series of trunks.

Aside from the sources of silica mentioned, thermal action on a siliceous matrix is a remaining and perchance the most likely possibility. While in both the Black Hills cycad horizons there is much similarity in the preservation of the cycads and the accompanying stems of trees, the nature of the trunk matrix and actual conditions of deposition are best known in the upper horizon. It has been the writer's good fortune to discover numerous cycadean trunks, accompanied by much silicified wood, in both the main localities of the upper horizon. At Minnekahta the cycads are distributed through sandstone to or more feet in thickness which caps a highly characteristic bed of blue clay 30 or more feet thick, and thus forms a well-marked hill-top, in this instance so fortunately spared by the vicissitudes of time. The upper part of the Io feet of sandstone here referred to is, in places, of quite light to flesh color, and the silicified stems from it are likewise of lighter color and often more or less chalcedonized. In the lower part of the bed the sandstone is highly colored, its yellowish hue, due to iron oxides, often being visible for long distances, especially so 4 miles to the east along the prominent outcrop on the precipitous walls of Hell Canyon. There are irregularly or locally interpolated in this lower portion many thin layers of clay, and from this mixture of sand and clay most of the trunks of darker color seem to have come. In some cases the trunks are embedded in the sandstone layer as interspersed with clay seams, but actually rest on the heavy clay layer beneath. Evidently this clay formed the bottom of a freshwater lake, along the shores of which patches of cycads and great groves of Arancarias were prominent in the forest facies; and with some change in estuarine conditions the clay bottom was in some places thickly strewn with cycad trunks and a few Arancarian logs, in others with numerous logs and occasional cycads which were quickly covered over by an inrush of sand, carrying with it further scattering cycads and a few tree trunks, all of which were doubtless early silicified. Aside from the possible action of silica-laden waters already suggested, this covering of sand may have furnished the source of silica, as the clays have not been found 
to consist in volcanic materials or to contain diatoms or siliceous spicules; but what in such case were the exact conditions permitting chemical activity is difficult to conjecture. Those trunks lying on the clny surface are usually very dark in color. Those from a little higher up in the sandstone are somewhat lighter or yellowish on the outside, and those from the highest points in the bed the lightest in general coloration.

In the Black Hawk locality, 60 miles northeast of Minnekahta, as has been stated, the conditions are very much the same as at Minnekahta, except that there is less clay in and near the cycad-bearing horizon. The sandstones in which the cycads and numerous silicified logs of immense size occur are not always so much iron-stained, and, as might be expected, the embedded silicified plants show less tissue differentiation. Many of the cycad trunks in particular seem to liave been subjected to the steady action of an abundant source of nearly iron-free silicic-acid solutions, resulting in some cases in a close approach to chalcedonization. In fact, there may be seen in the specimens of this locality nearly every gradation from complete differentiation of cell structure, or histometabasis, to structureless chalcedony casts.

The conditions of silicification in the Freezeout Hills of central Wyoming varied but little from those of the lower cycad-bearing horizon of the Black Hills. This much is certain from the great similarity in general surroundings, as evidenced by both the character of the strata in which the cycads are embedded and the other fossils present. Although these two localities are quite 200 miles apart, there is here a case in which there is general coincidence in all features of form and preservation, instead of the variation seen in most other as widely separated localities.

Finally, it is to be noted that, although the conditions of preservation may have varied considerably in the three main North American cycad regions, as just described, in none of them do they seem to have made possible the silicification of mature fronds in connection with or even adjacent to the trunks which bore them. This lack of foliage preservation would still leave a nearly unbridgeable gap in our knowledge of these plants were it not for the abundant silicified nonemergent young fronds often preserved in such marvelous detail in the Black Hills specimens, as described at length in Chapter V. In general, where trumks, fronds, and fruits are represented in the same beds, as in the case of the Wrilliamsonias of Hawkser and Runswick, it is only as casts or impressions, though we do have, as previously mentioned, the single instance of the Plerophyllum leaves attached to their silicified trunks in some of the Indian beds.

But, as bearing on future field work in the Black Hills, it is to be bome in mind that, despite the number of trunks already obtained as eroded out in the slow course of time, little is known of their matrix, the few trunks observed in sity by the writer being the only ones so found thus far. In the case of one of these, however, traces of pinnules were present in the surrounding clayey sandrock; so that it is probable that adequate excavation would occasionally reveal impressions of fronds, although such can never be expected to resist the action of frost while weathering out of an imperfectly consolidated matrix. 
RARE OCCURRENCE OF CONDITIONS REQUISITE FOR MINERALIZATION OF CYCADEAN TRUNKS.

That no cycad trunks have been found thus far in the Upper Cretaceous and Tertiary is noteworthy, for not only are the rof enumerated living species widely distributed, but the genus Cycas represents an ancient type, doubtless as abundant in the 'Tertiary as at present. From the evidence at hand we must hence conclude that all of the conditions adduced as necessary to silicification, calcification, or ferrization of cycads have seldom existed concurrently, and that mainly because these plants were so abundant over all the land areas of the globe during the middle Mesozoic do we find them sparsely represented in strata of that period. It would seem as if cycads were then present wherever conditions chanced to make possible their preservation, and that later not only were these plants less abundant, but that conditions requisite to their preservation or that of similar plants seldom occurred. And it must be likewise regarded as a fact altogether eloquent of the many vicissitudes attending the preservation of the structural details of these trunks and their fruits, that almost the only other plant remains ever found accompanying them are the trunks of conifers with scarcely a remnant of their branches, leaves, or fructifications left behind. Evidently the peculiar structure, oils, and resins of the cycads make their preservation mechanically and chemically possible; and were it not for the protected position in the armor of old leaf bases of the young leaves and mature or nearly mature fruits, both ovulate and staminate, as surrounded by and immersed in the luxuriant growth of ramentum, favoring siliceous infiltration and preservation in minute detail, it is very doubtful if any exact knowledge of their organization would ever have been gained. The general fact is that not only are the individual differences in such specimens very great, but the exigencies of preservation equally so ; for while the abundance of the imprints of cycadean fronds in nearly all plantbearing strata of Jurassic age, wherever found on the globe, indicates that cycads dominated the vegetation of that period, trunks with structures preserved are relatively exceedingly few in number. In speaking of this subject elsewhere (I9I) the writer has said:

"Notwithstanding their wide distribution in latitude and time, our knowledge of the ancestry of the living cycads has hitherto been slight, because the fossil remains have, with few exceptions, consisted only in imprints of isolated leaves and fruits. Silicified or calcified trunks with their microscopic structure in any degree preserved have always been among the rarest of fossils. It is, too, a singular fact, showing how precarious have been the chances for the complete preservation of these plants in the fossil form, that all but a very few of the trunks known are distributed betreen the middle Jurassic and the lowermost Cretaceous. Moreover, though the various cycadaceous forms which have existed since the Triassic may include many families, the trunks known represent only a single offshoot from the main cycadean line, as at present understood, but withal marked by very unusual characters."

TRUNK FORMS DUE TO COMPRESSION DURING OR AFTER FOSSILIZATION.

The external appearance of fossil cycad trunks, as one immediately notes in the case of any considerable number of specimens, and, as has already been mentioned, is usually much dependent upon the inequalities of compression to which they have been stibjected during or after fossilization. In fact, scarcely any other 
cause produces such wide variations in general appearance or makes specific values more difficult to distinguish. It is a matter of common observation that even after mineralization is complete fossils of any kind are subject, as relatively solid bodies, to more or less plastictransformation. And it may be well, since we are herce dealing with rigidly silicified stems, to cite the fact well illustrated by $\mathrm{H}$. Reuscls (Fossilführende Krystallinischen Schiefer von Bergen, Leipzig, r883), that as the result of strong compression the pebbles of certain conglomerates, usually of the hardest and most resistant quartz, have been flattened and ranged in parallel planes. In some instances this process of pebble-flattening has gone so far that the original conglomeratic nature can scarcely be detected. From such facts as these it is readily. seen that one might expect that a mineralized fossil trunk which has not suffered some compression would be the exception. Especially would this be true of any plants with a large central body of soft homogeneous tissue like the pith of the cycads, since mineralization doubtless more often proceeds from without, and the pith in its central and protected position might long remain in a partially mineralized and distinctly plastic condition. Nor is it always an easy matter to detent the results of compression, because most trunk-forming plants are subject to certain irregularities of growth, so that a region of laterally narrowed xylem cells, for instance, might or might not mean alteration of their original form by compression. Bearing in mind the foregoing remarks, some of the more conspicuous results of compression may now be given.

Vertically shortened trunks.-These are very frequent, though more difficult to detect, unless there has been much crushing and decay at the summit at the time of fossilization, resulting in the familiar "crow's nest" form. In the splendid branching specimen (Yale cycad No. 300 ; cf. plate XII), with four branches of ver: large size, the effects of both vertical and oblique pressure may be readily observed. The largest and evidently the parent trunk of the group, narked $a$ in plate XIr, is considerably foreshortened, crushing having affected the form and position of the lateral leaf bases somewhat; while either after some solidifying had taken place or before decay the summit was crushed down into the medulla-the resulting appearance being as if a portion of the medullar tissue had been forced upwards in a distinctly hydrated and viscid condition, so as to partly flow out orer partially preserved portions of the crown of leaves. Some of the marked lateral compression of two of the branches, but by no means all, may have been present in life. (See plates XII and xiIr.)

Obliquely compressed or sheared trunks. - In a few instances, where leaf bases are seen to droop instead of occupying their normal more or less ascending position it is permitted to assume that some alteration in position has taken place as the result of a lateral or circumferential shearing pressure. In some cases the entire trunk has been subjected to a shear, with greater or less distortion and crushing, so that the leaf bases of one side droop, while those opposite ascend more sharply: than in life. Of course a shearing force might come from either a vertical or a horizontal direction, and hence affect a trunk embedded in either an npright or inclined position in much the same manner. 
Transversely elliptical trunks.-It has at various times been suggested or believed that some of the Cycadeoidex were characterized in life by a more or less uniform transverse ellipticity. This idea seems to have originated with Robert Brown, who stated in I85I (I5) that his specimens of Cycadites "all agreed in having an elliptical ontline unaccompanied by any inequality in the woody ellipsis." Later, Carruthers (24), in founding for these and several other specimens his genus Bennettites, distinctly assigns transverse ellipticity as one of the generic characters. Since the work of Carruthers this character has been either cited (I57), doubted (I44), or left in abeyance as requiring further examination (II3). But it is again recalled by Lignier's recent description of Cycadeoidea micromyela (84), the type of which, although flattened by pressure, shows distinct transverse ellipticity of its medulla and xylem in a direction oblique to the only pressure plane noted. It only needs to be pointed out that, as Lignier suggests, this specimen may be a branch of a larger trunk. As such it may have been slightly flattened in life. But when a large number of both branching and non-branching trunks fairly representing the Cycadeoidean series is examined, it at once becomes obvious that none of the Cycadeoideæ ever developed a normally compressed habit of trunk growth.

In the first place, the trunks of the genus Cycadella, histologically speaking, afford an example of one of the most beautifully preserved series known; yet they have suffered more vertical, lateral, or other distortion than any other American specimens, these trunks, with but a few exceptions, being compressed to from twothirds to one-half of their original thickness. Nevertheless, in any but the largest thin sections the results of compression are but little noticeable.

Again, in Cycadeoidea Jenneyana and $C$. ingens, as so well represented in the Yale collection by fully $25^{\circ}$ Black Hawk specimens, fragmentary and complete, we have an excellent example of what is to be observed in the case of more or less tall and columnar trunks, doubtless uniformly embedded in a horizontal position in soft sandstones. The type of $C$. ingens ( $c f$. plates I and Ir), a large and superbly conserved trunk with finely preserved bisporangiate strobili and a partially emergent crown of leaves with all their characters indicated, is strongly flattened, as better shown on plate II, without any very noticeable distortion of any of its parts. Some bases of trunks of this same species are, however, so nearly cylindrical that we must regard the lateral compression of the greater number as secondary. Likewise in the case of the more numerous series of specimens assigned to C. Jenneyana, while the greater number are more or less compressed, not a few, including some trunks of the largest size, are so nearly cylindrical as to require close measurement to detect any slight transverse ellipticity that may be present. Another Black Hawk species with columnar trunks, but remarkable for the small size and great number of its leaf bases with but slight development of ramentum, is C. rhombica. No one could mistake specimens of this clearly distinct species; yet, of the two good examples, Nos. 625 and 623 of the Yale collection, the former is strongly compressed, while the latter is perfectly cylindrical. On turning now to certain of our American specimens which must be included in the genus Bennettites, if valid, and which agree most closely with the English specimens, the same facts are observed. The 
type specimen of Cycadcoidea Wiclandi is compressed and elliptical in outline; but the Yale trunks 393, 745, 77 I, and 797 may be cited as more or less complete specimens positively of this same species, which are plainly cylindrical and uncruslied. Of these, No. 393 deserves especial mention as bearing numerous lateral orulate fructifications of the type agreeing so closely in structure with those of Bemellites Gibsonianus, and as being one of the most beautifully preserved cycads ever discovered. ( $C f$. plate Xxi.) It must hence be finally concluded that if any of the Cycadeoideæ exhibited transverse ellipticity in life, this has been merely occasional or the result of growtin as a branch in a restricted or oblique position, and that this character can not be considered as having either generic, specific, or even varietal value.
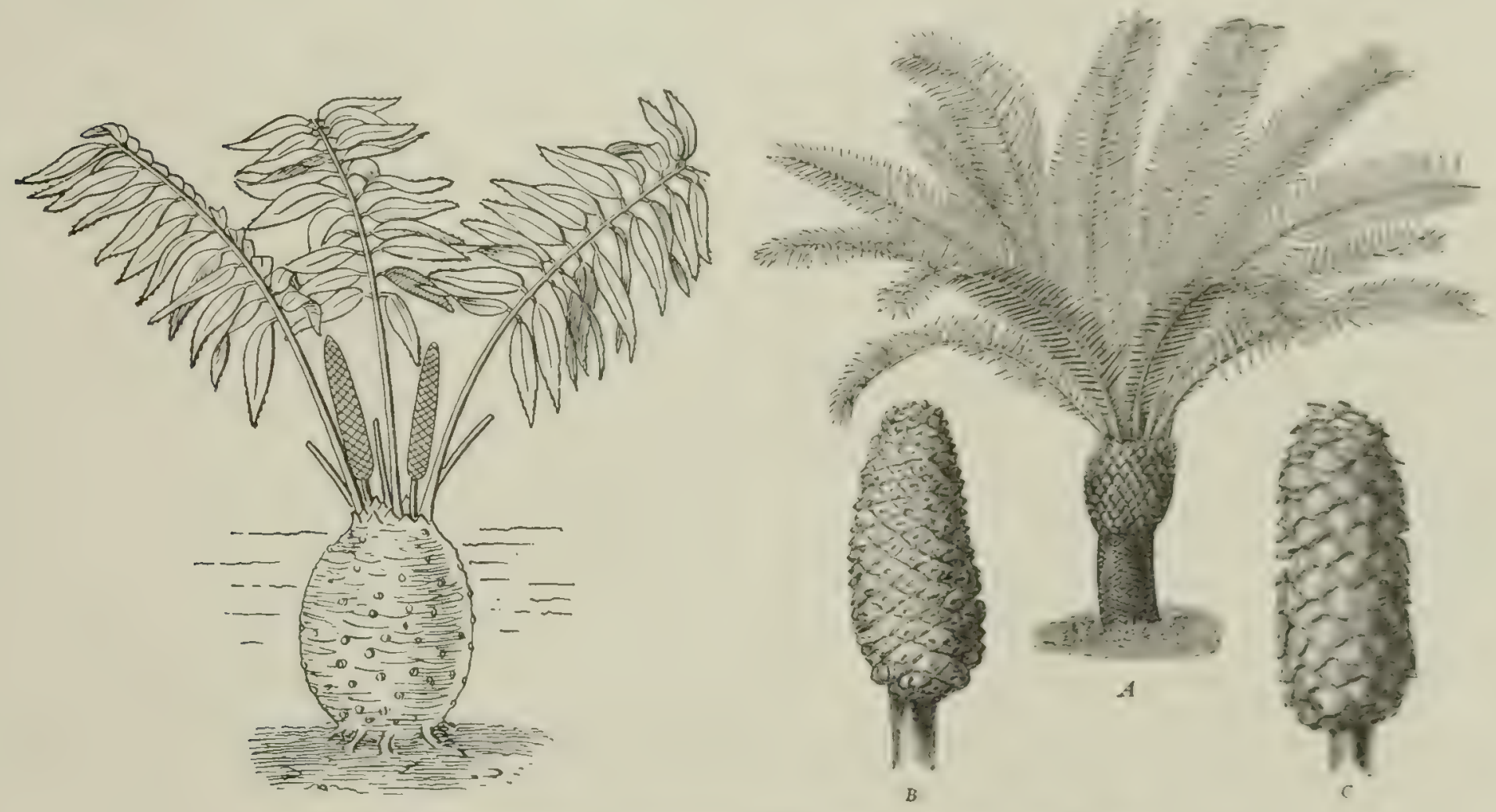

Fig. 4.-Tuberous and Low-growing Columnar Cycadean Trunk Types.

To the left.-Stangeria paradoxa. A staminate plant bearing two cones. Tuberous, subterranean, nearly armorless trunk, with fern-like foliage. About one-twelfth natural size. From Warming.

To the right.-Encephalartos Hildebrandtii and E. villosus. A, low columnar armored irunk; $\mathrm{B}$, cone of $\mathrm{A}$; $\mathrm{C}$, ovulate cone (of $\mathrm{E}$. villosus). $\mathrm{A}$, one-sixteenth, and $\mathrm{B}$ and $\mathrm{C}$, one-eighth natural size. From Engler and Prantl. (Cf. figures 5, 6, etc.)

TRUNK TYPES.

The cycadean type of trunk, as described in greater detail in the succeeding and ninth chapters, is a generalized one, characterizing as it does a great plant alliance: which has been abundantly represented since Permian time. Its chief features-a large central pith followed by a thin, woody zone enveloped by a cortical parencliyma traversed more or less regularly by leaf-trace bundles, and an outer annor of leaf bases inserted in spiral order-are seen in the widest variations of structural detail and relative development. In addition there is present in the older forms, as in tree ferns, a more or less abundant ramentum, and, in the more recent forns, series of abortive or scale leaves altemating with the normal foliage leaves. The scale leaves 
are also distantly, though distinctly enough, analogous to the bracts surrounding the fruits of the Cycadeoidex. (Cf. figures $4-6$ and various illustrations in the ninth and other chapters.)

It is, however, in fructification that extraordinary diversity is found, although, perforce, the further back we go in the cycadean, cycadeoidean, and cycadofilicinean series, the more nearly do the respective sporophytes agree with the accompanying foliage leaves, and the more pteridophytic becomes the structure position and form of both. Moreover, in the most specialized of the existing forms, as well as in the Cycadeoidex, both male and female fruits are to be regarded as much modified branches with elongate stems or peduncles. In the Cycadeoidere the peduncles,

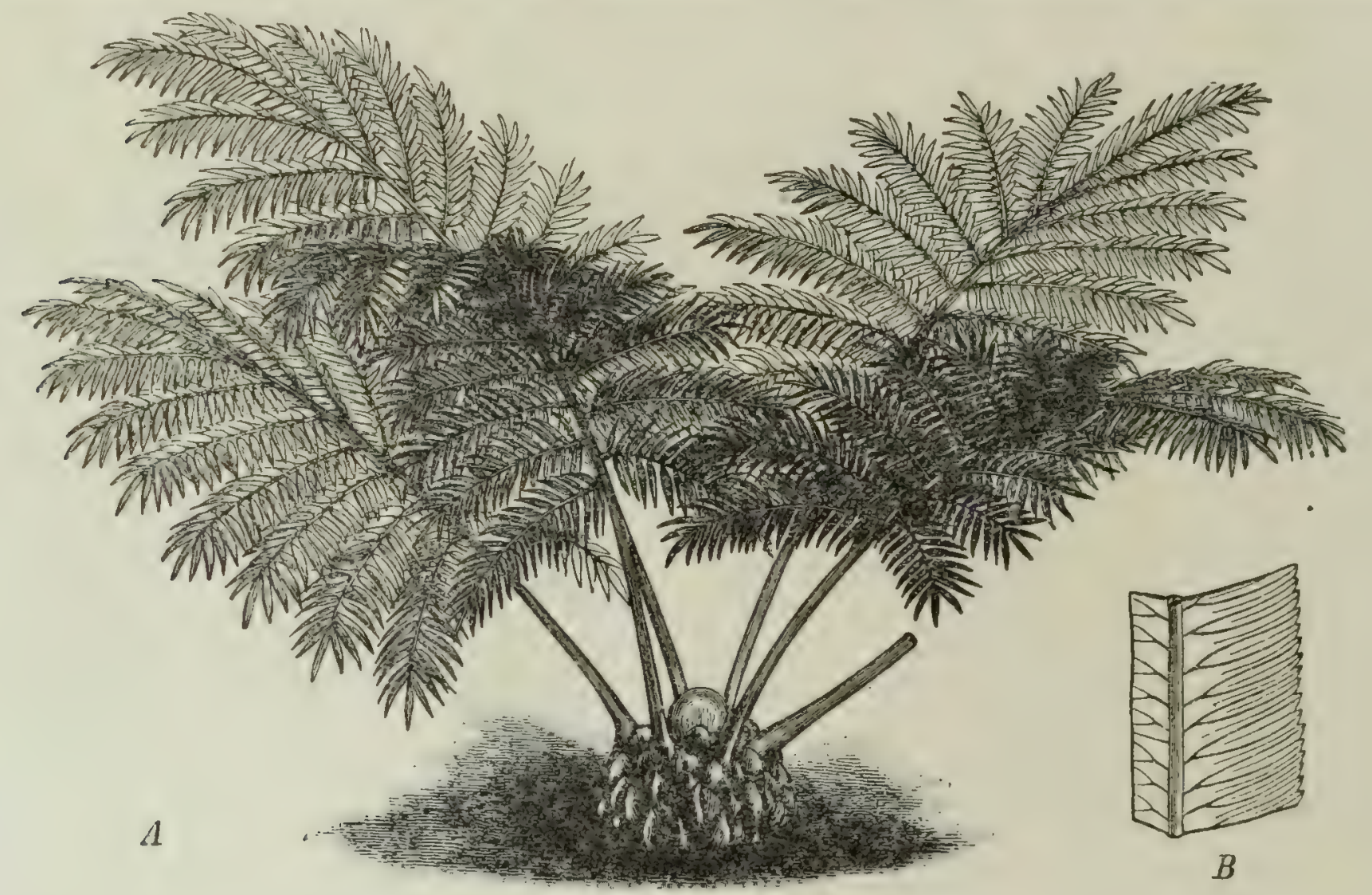

Fig. 5.-Angiopteris Teysmanniana de Vriese. $\times \frac{1}{18}$.

A, medium-sized spherical to conical trunk for comparison with the preceding forms. Fronds bipinnate as in Bowenia, venation (B) as in Stangeria, From Engler and Prantl.

being interpolated among the leaf bases, thrust these aside and finally destroy their regular order, so that it should be possible to determine whether a given trunk has ever borne fructifications or not. Later in the rolume this point will be discussed more fully in treating of the generic value of Cycadeoidea and Bennettites, the former having been hitherto considered as being without and the latter as having lateral fructifications; for the present it is merely intended to consider the varions simplestemmed trunk forms, branching types, and liabits of growth.

'The fossil cycads, like the living forms, although tearing wide-spreading fronds, are, as compared with other trunk-forming plants, small or even pygmic. In the living forms the extremes lie between the epiphytic Zamias of Panana and eastern Peru, together with the small undergromed and much-branched trunlss of the Florida Zanias on the one hand, and on the other the East Indian Cycas, which 
reaches a height of 20 to 23 meters and a maximum diameter of nearly I meter. In the fossil forms no such a relatively considerable size is indicated, the existence of trunks exceeding 2 meters in height only being inferential-the great majority of forms not reaching more than a few feet in length, although exlibiting some highly interesting types of branching.

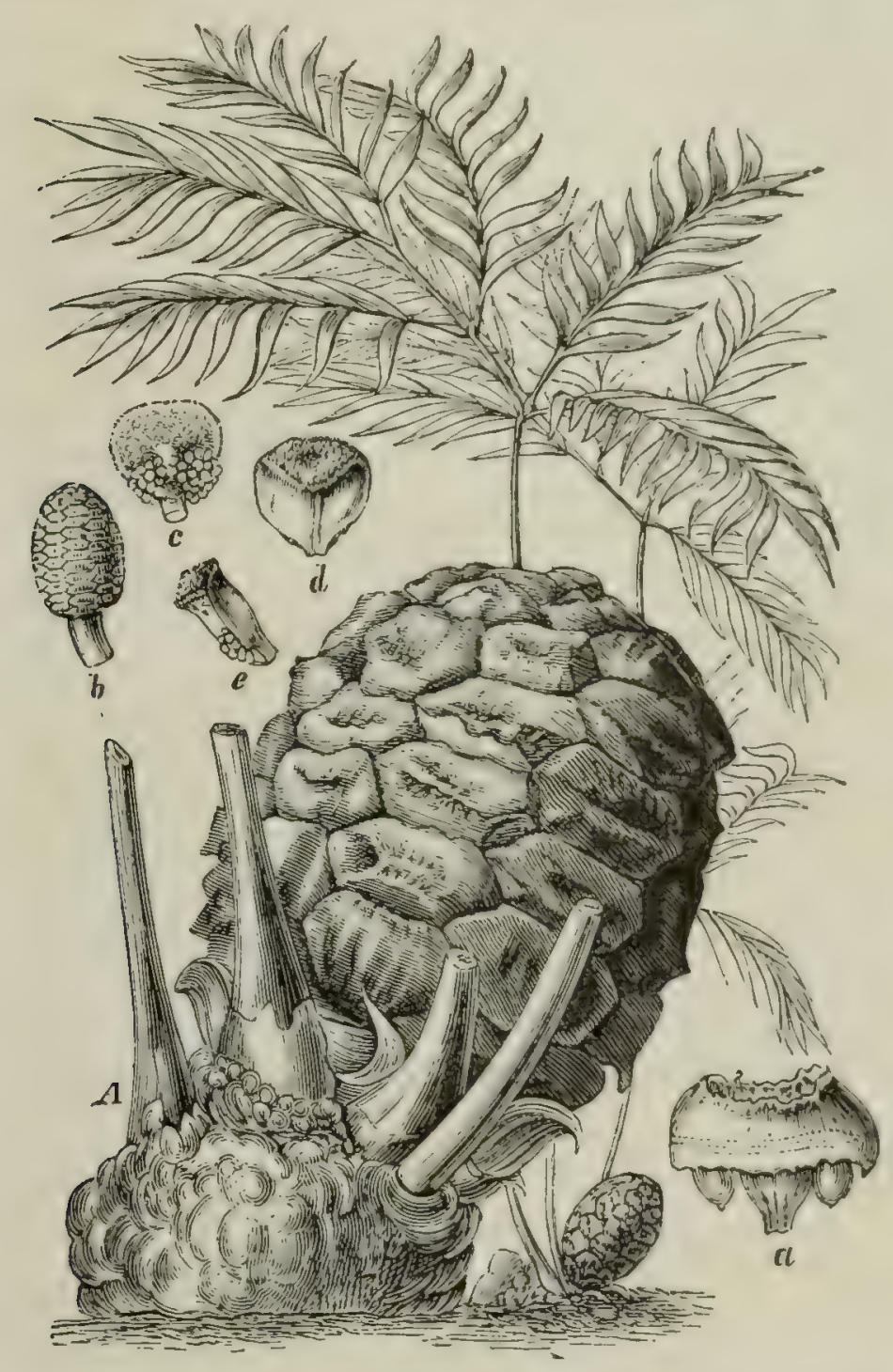

Fig. 6.-Bowenia spectabilis.

Ovulate plant, subterranean, tuberous; only existing cycad with bipinnate fronds. Much reduced to the right; to the left, cone half natural size. a, megasporophyll ; b, staminate cone, with microsporophylls in inferior, superior, and lateral view at c, d, e. From Engler and Prantl, after Bot. Mag., Pl. 6008.

We may next take up in more detail some of the most important fossil trunk types, beginning with the monaxial and smaller forms.

\section{LOW-CROWING UNBRANCHED TRUNKS,}

Only among the cycads from the Black Hills do we find numerous and well-marked branching trunks. But the frequency with which such trunks occur there, when taken together with the rarity of branching trunks in most other localities, is partly due to the fact that branches are likely to be broken apart and scattered during the course of erosion from the containing beds, so that we fail to observe what was the true habit in this respect. Thus Lignier (84) is of the opinion that the type specimen of Cycadeoidea micromyela may well have been a small branch of a larger trunk. Among the living cycads the lowgrowing trunks of Stangeria and Bowenia, as well as many species of Zamia, are not much given to branching; and likewise among the fossil forms smail, simple-stemmed and low-growing, though apparently. mature trunks, are present in nearly all localities, being in a few the characteristic type. Of course, only where a considerable number of specimens are present can we reach any conclusion as to what the limits of size are. The most typical series of pygmy and, so far as we can say; unbranched trunks, is that from Carbon County, Wyoming, upon which Professor Ward has based his genus Cycadella, as so profusely illustrated in the Status of the Mesozoic Floras ( 178 ). The average size of these specimens is usually about 35 $\mathrm{cm}$. in height by $20 \mathrm{~cm}$. in diameter, or scarsely more than a fourth of the bulk of the Black Hills specimens of Cycadeoidea. The next larrer series of simple-stemmed trunks is well displayed in the Maryland Cycadeoider, which are mostly interme- 
diate in size between the Cycadellas and such Black Hills species as Cycadeoidea dacotensis. (See illustrations on plate VI.) The largest specimens from Maryland do not exceed $50 \mathrm{~cm}$. in height, but are mostly of robust habit, as in figure 7 . One

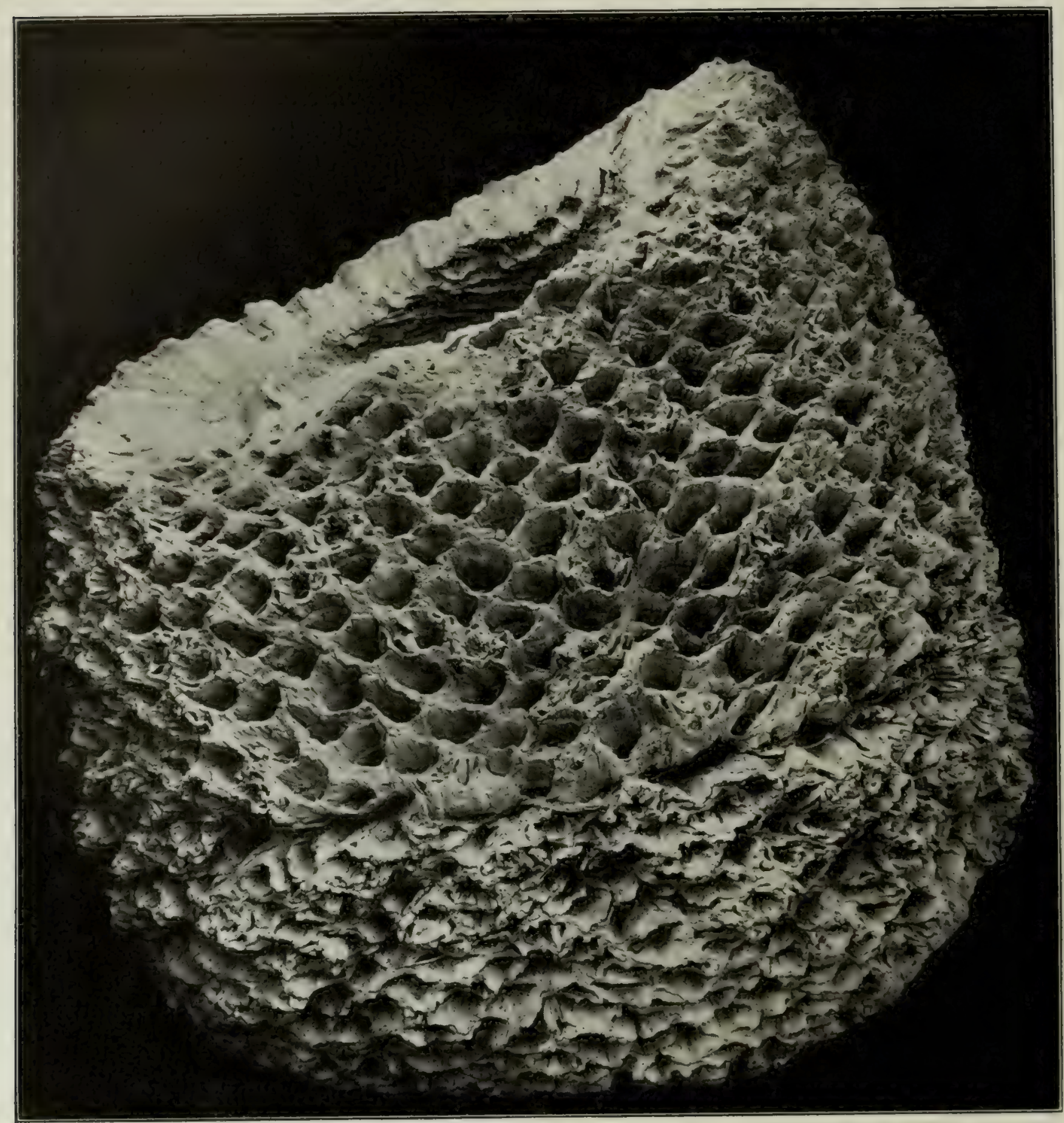

Fig. 7.-Cycadeoidea Goucheriana Ward (type).

An unbranched silicified trunk from the iron-ore beds of the Potomac Formation of Maryland. Many very young fructifications are present, as disclosed by the broken tips of grouped bracts, but fruit growth is in an earlier stage than in Cycadeoidea marylandica type, as shown in figure 1 , and the leaf-base spirals but little disturbed by the emergence of the young and small strobili. Weight of specimen about 100 pounds. Collection of Woman's College of Baltimore. (From U. S. Geological Survey Monograph XLVIII.)

species, C. Uhleri, suggests a more columnar form, and, as already noted, bears a striking resemblance to the Italian C. Masseiana. But the other Italian cycads are also much like the usual Maryland type, the resemblance between the two groups being marked. 
With these low-growing, robust trunks also belong such Purbeck species as $C$. megalophylla and microphylla; and it may be said in conclusion that the majority of fossil cycadean trunks are of a low, conicai, and robust habit, not exceeding a half meter in height and a third of a meter in diameter.

\section{SHORT COLUMNAR TRUNKS.}

Of short columnar trunks there are a considerable number, varying in size from the trunks just considered to a meter or over in height. The first to be mentioned are represented in the Black Hills by the species C.rhombica (plate V, photo. 4) and C. Stillwelli (plate vi, photo. 4), not known from complete trunks, but of very regular cylindrical habit and with infrequent lateral fructifications. Also, some of the Minnekahta, South Dakota, specimens, with fruits so much like those of Bemellites Gibsonianus, are medium-sized trunks over $50 \mathrm{~cm}$. in height and about $25 \mathrm{~cm}$. in diameter. Next are the Maryland and Italian trunks C. Uhleri and C. Ranmeriana, which so markedly reseinble the recently described C. nigra (I78), supposed to have

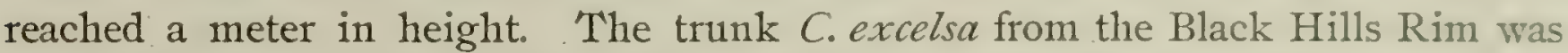
certainly a meter in height and about $25 \mathrm{~cm}$. in diameter, being comparable to the strikingly similar Purbeck stem C. gigantea Seward, with a height of I.I8 meters and a girth of $\mathrm{I} . \mathrm{O} 7$ meters. Doubtless the far more robust $C$. Reichenbachiana approached both these specimens in height. Hence these several trunks compare quite closely in height with the existing genus Dion.

COLUMNAR TRUNKS DISTINCTLY MORE THAN ONE METER HIGH.

In his restoration of Williamsonia gigas, Williamson has indicated this plant as of tall habit, supposing it to resemble the modern Cycas, as may well have been the fact. But it is to be emphasized that the restoration is based on parts of associated casts of trunks, about $60 \mathrm{~cm}$. in length and $10 \mathrm{~cm}$. in diameter, so that all we can actually say is that some of the Williamsonias from Hawkser and Runswick were probably of relatively taller and slenderer habit than most of the Cycadeoidere. The tallest known unbranched and complete Mesozoic trunk is Cycadeoidea gigantea Seward, just mentioned as r.I 8 meters in height ; but direct eviảence of trunks much more than I meter in height is afforded by the American specimens from Black Hawk, which have been referred to Ward's Cycadeoidea Jenneyana.

Obviously in localities where the only specimens obtainea have slowly weatlered out of the strata in which they were embedded, complete, tall tree-trunks are not likely to be recovered, even though portions of such be present in abundance. Especially is this true where the broken and disengaged parts slowly settle down over steep slopes or are mixed among the débris of a talus. Thus the silicified trunks of the tall-growing Araucarioxylons (of which there are such vast numbers in the cycad-bearing horizons of the Black Hills Rim, where talus conditions are the rule) are seldom found in lengths of more than a few feet, but are cccasionally seen in succession along the hill-slopes, much as if they had been broken from the same trunk 50 or even more than roo feet in length, the loose order of the parts being quite like that seen after woodmen cut a long, large log into lengths which roll first to one, then to the other side, or lie sometimes close together, sometimes a 
few feet apart. Similarly it would appear from the occurrence and character of the specimens from Black Hawk, by far the greater number of which have been referred by Professor Ward to Cycadeoidea Jenneyana, that this species must have reached a considerable height. The fact that no complete trunk belonging to it has yet been obtained, and that among more than one hundred complete specimens more or less certainly referable to it there are only two summits, both being well preserved, indicates that we have here to deal with forms reaching a length of several meters. Moreover, among the Yale specimens, No. IOI, although a meter in length and a half meter in diameter, represents only a middle segment of a trunk and is without tapering. Again, Yale specimen No. IO2 represents a handsome cylindrical base $36 \mathrm{~cm}$. in height by $46 \mathrm{~cm}$. in diameter, while No. $55^{\mathrm{I}}$ is a quite similar basal section, without tapering above, and $50 \mathrm{~cm}$. in height. The latter specimen is also approximately $50 \mathrm{~cm}$. in diameter, which is doubtless the maximum of this measurement. The two summits mentioned above are remarkably alike, each measuring $45 \mathrm{~cm}$. in height by $40 \mathrm{~cm}$. in greatest diameter. Tapering slowly, they hence show that they have belonged to distinctly columnar trunks. Moreover, none of the specimens that can possibly be referred to $C$. Jenneyana show any evidence of branching. Also, the least assignable length of $C$. Jenneyana type is given by Professor Ward as I.30 meters, whence this species is the tallest of known cycads, not only from direct inference but as actually determinable from known specimens. Regarding the approximate maximum height of this species as based on the actual length and form of the various incomplete specimens reaching the maximum diameter of half a meter, we may-beyond reasonably assigning a height of 2 metersonly conjecture, though some further evidence is furnished by a series of fragments suggesting that they originally belonged to a trunk of very considerable height. At the Cycad Valley locality north of Black Hawk the writer found associated with one of the C. Jenneyana summits above mentioned many additional fragments clearly belonging to the same trunk as the summit and scattered over the surface of the ground for a considerable distance, much as in the case of the broken Araucarioxylon trunks so numerous in the same locality and horizon.

It can only be said, therefore, that $C$. Jenneyana was, as compared with other Mesozoic cycads, easily the tallest known species, possibly reaching a height of 3 or 4 meters. But there is no reason to suppose it very likely that a height of 8 or Io meters could have been reached or that by any possibility any of these stems could have even approached any such great height as that of 20 meters attained by Cycas Normanbyana. The tallest of the stems seem rather to have compared quite closely in size with such genera of the Zamire as Macrozamia and Encephalartos, reaching an average height, respectively, of 2 and 3 meters. They hence fall far behind the proportions reached by the great trunks of Cycas revoluta cultivated in the grounds of the temple Ryûgeji in Shizuoka prefecture, about I 20 miles west from Tokio. These cycads, as I am informed by Ikeno, are the largest and tallest yet known in Japan, one trunk of the group being 8 meters in height and another 6 meters in height, with the enormous diameter of 1.6 meters. A figure of the entire group faces page $2 \mathrm{I}$. 
It may be casually noted that the Cycadere owe a portion of their greater height, in the case of the female plants, to the fact that in fructification, as one may say, the summit grows forward, continuing the trunk structure as an immense strobilus. The carpellary leaf bases also being persistent and alternating with the scale leaves and the foliage leaf bases, then form a third armor-making series. In the Zamiex, ou the contrary, only the relatively few peduncle bases are left behind to add to the alternating series of scale and foliage leaf bases forming the armor. Contrariwise, it is not probable that a trunk of the Cycadeoidean type would ever reach any great height; for the heavy growth of ramentum about the leaf bases, together with the disturbance of the armor due to the emergence of the lateral fructifications which were certainly present in C. Jenneyana, the tallest known member of the group, would not favor a tall habit.

Plainly the limits of size in plants with a large pith, a weak woody column, and a cortex and armor occupying more than one-half of the area of the transverse section of the trunk must be distinct. Any failure of the leaf bases, peduncles, or fruits, or the copious ramental hairs borne by and enveloping these organs, to fairly occupy all the space exterior to the cortex would not only give opportunity for decay, but weaken the trunk itself; and in accidents or arrests of growth, or destruction of immature fruits, due to the attack of animals to which these plants may have been subjected, there is suggested a very direct cause of such failure. Aside from any physiologic reasons, ordinary mechanical factors are therefore suggested in strictest accord with the conclusion reached in a later chapter that the production of numerous lateral fructifications was the culminant and closing event in the life of many of the trunks. Again, the roots of these plants were doubtless diffuse or filamentous, a fact likewise more or less unfavorable to their reaching great size. Hence it is interesting to find that some of the more distinctly columnar trunks compensated in part for the weakness of the armorial zone by an immense development of xylem. The lower interior portion of a trunk secured at Black Hawk, $20 \mathrm{~cm}$. in diameter and almost denuded of armor and cortex, looks markedly like the stump of some hardwood tree-trunk with an unusually large pith. (See upper photograph of plate XIV.) At the basal end the medulla is $5 \mathrm{~cm}$. in diameter and the xylem zone fully Io cm. in thickness. At the summit of the fragment, $30 \mathrm{~cm}$. above the basal end, the medulla is not quite $6 \mathrm{~cm}$. across, and the xylem about $8 \mathrm{~cm}$. in thickness. This does not, however, necessarily mean tapering of the complete trunk, but rather that the cortex and armor of large leaf bases formed after the trunk attained its full diameter are relatively thicker, the actual diameter of the trunk remaining quite constant, as seen in the various bases and segments of trunks mentioned above, thus fulfilling the requirements of strength. That is to say, with increase in height there is a compensating strengthening of the xylem at the base, just as in an ordinary tree-trunk.

It is only necessary to add that the limitations in size among the cycads are very much the same as are seen in the tren ferns. The short and robust Angiopteris evecta ( $f f$. fig. 5), with trunks approaching a meter in diameter and a meter more or less in height, compare very closely in size with such trunks as Cycadeoidea 
ingens and C. gigantea. Balantium antarcticum, $40 \mathrm{~cm}$. in diameter by 3 meters in height, suggests a size possibly reached or exceeded by Cycadeoidea Jenneyana; and Alsophila excelsa, reaching a diameter of $60 \mathrm{~cm}$. and a height of 22 meters, closely agrees in its stately proportions with the Australian Cycas Normanbyana.

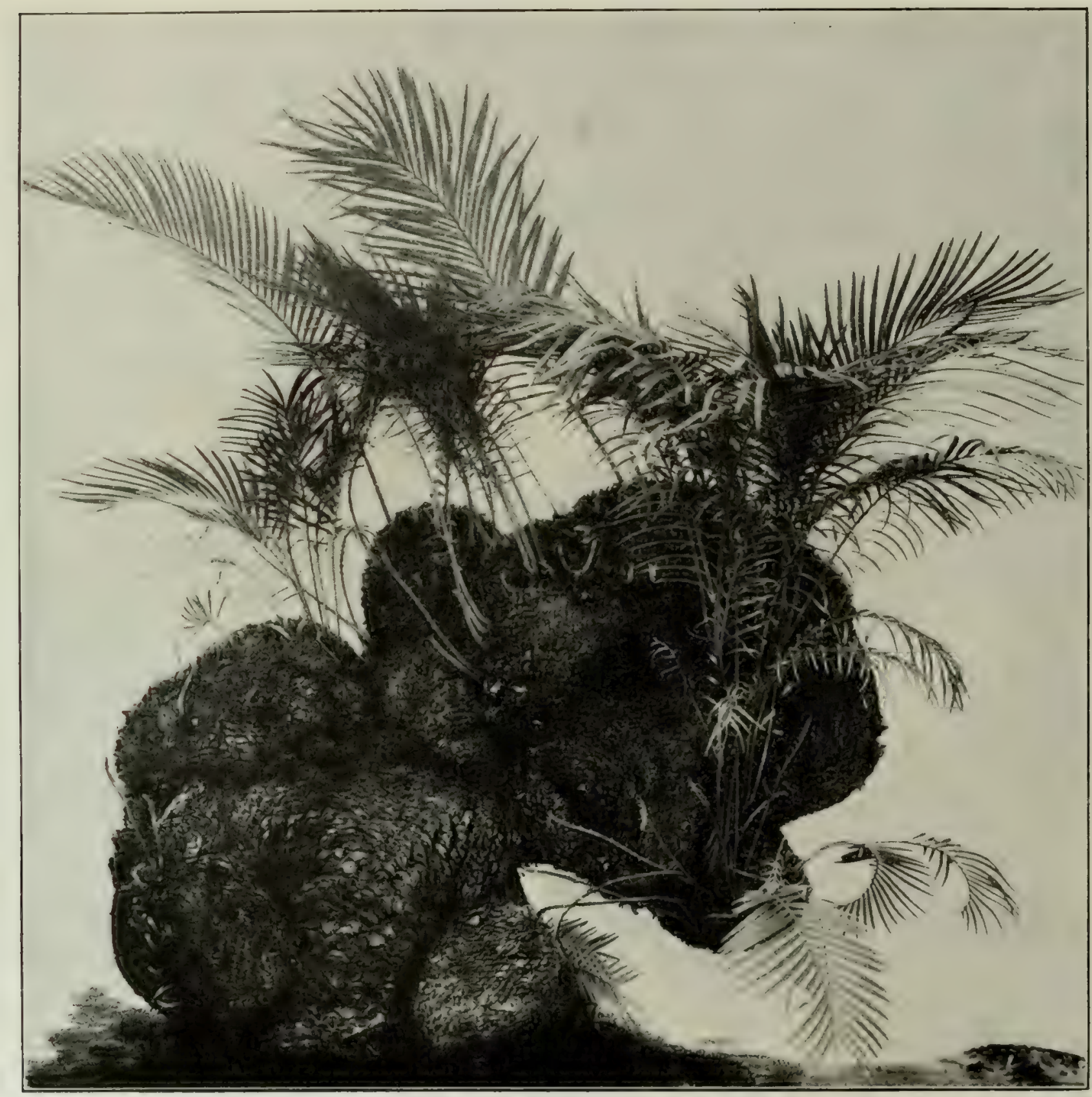

Fig. 8.-Cycas revoluta. - "Shishi" or lion's-head variety.

As grown by Japanese gardeners and made to branch artificially, the resultant form exactly paralleling silicified Mesozoic trunks like Cycadeoidea Marshiana. Not in full leaf. About one-tenth natural size.

BRANCHING TRUNKS.

The cycadaceous series of plants, like the vegetation of palm-like form, is primarily simple-stemmed and never exhibits the free branching seen in the Lepidodendrons, Sigillarias, and Cordaitales on the one side, and the more recent freely ramifying trees on the other. But at the same time branching is even characteristic in certain of the cycads, while fine examples of branching palins, comparable in this respect, are to be seen in Borassus flabellifer and Cocos mucifera (I). The branching of tree ferns is fairly common. 
The trunks of the living Cycas after reaching a certain age usually branch, and Japanese gardeners, taking advantage of the branching habit of the native species Cycas revoluta, dwarf this plant and cause it to branch far more profusely than it ever does in nature. The singularly beautiful plants thus obtained sometimes bear as many as twenty crowns of leaves, and some of them are said to have a recorded age of several hundred years. Some of these interesting results of horticultural art are shown in text-figures 8 to Io, and present curiously exact parallels of size and

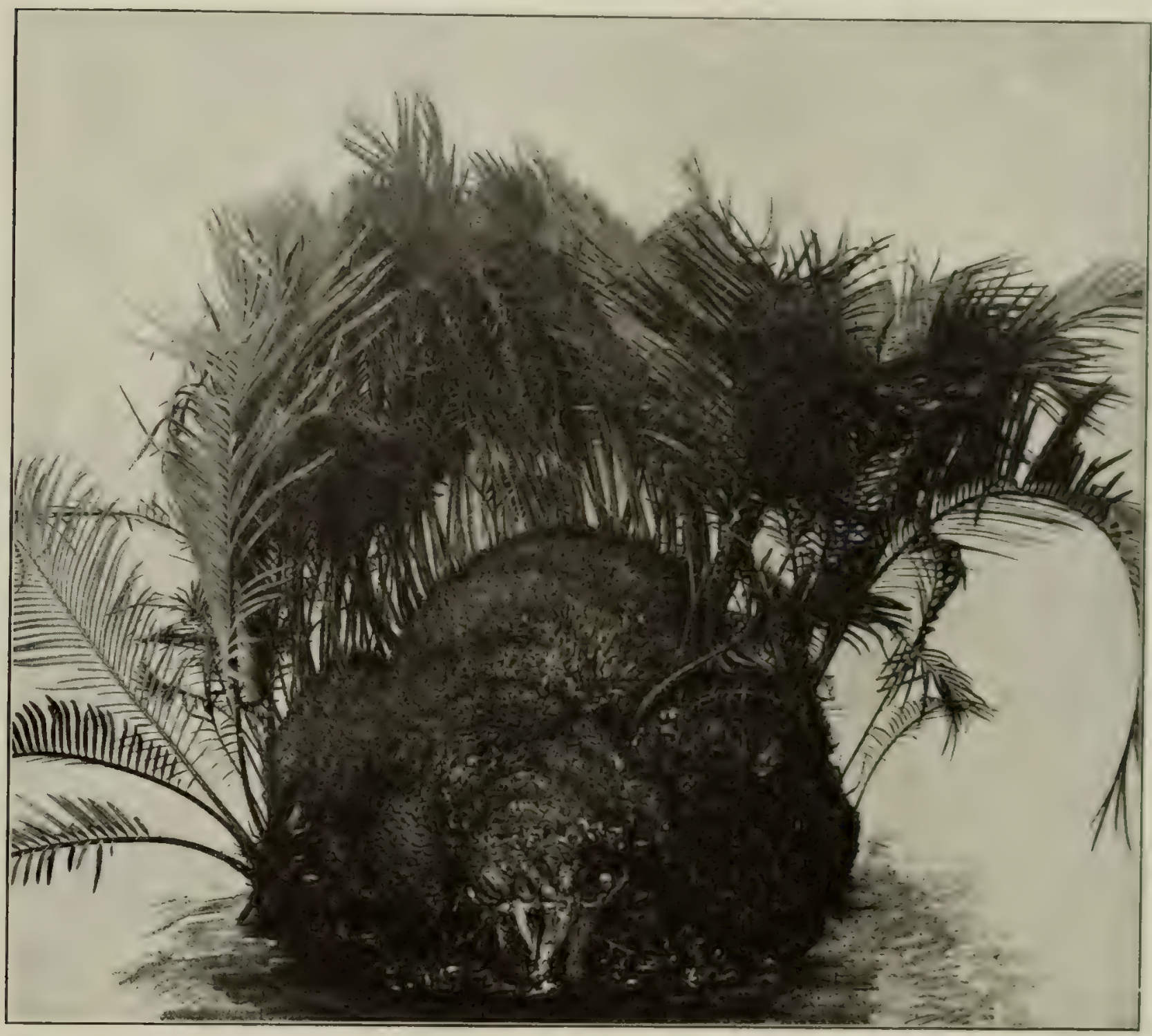

Fig. 9.-Cycas revoluta. - "Shishi" or lion's-head variety.

A specimen similar to that shown in the preceding figure and recalling the form and habit of Cycadeoidea superba. (Cf. Plate X.) These unique plants serve fairly well as restorations of branching Cycadeoidean trunks.

form to the branching types of Cycadeoidex. Figures 8 and 9 represent truly magnificent ornamental plants about a meter high, which have reached a veneiable age of more than five hundred years. This is the so-called "shîshî " or "lion's head" variety, with numerous short and thickly-set branches. Regarding this fanciful resemblance, it is a singular coincidence that in his original description of the ty pe of Cycadeoidea Marshiana, Professor Ward spoke of its resemblance in a certain position to "a huge animal;" and that to the writer, long before he casually 
learned of the aged "shîshî" of the Japanese gardeners, this fossil cycad trunk always recalled to memory the famous "lion of Lucerne" statue to the Swiss guards! The "hoso," or "tree-formed palm," with much more diffuse branches, shown in figure $\mathrm{IO}$, is even more extraordinary. Planted in a Ruri pot of the eighteenth century, it is seventy-five years old and has a height of $75 \mathrm{~cm}$. The general appearance is in this case more that of a branching tree. Some of the branches are secondary, and there are in all fifteen distinct crowns of leaves. This trunk recalls quite vividly the still more distinctly branched Cycadeoidean plant Anomozamiles minor from the Trias of southern Sweden, as restored by Nathorst.

The branches of Cycas grow out from both above and below the surface of the ground, in the latter case affording a parallel to our Florida Zamia, with a tuberous underground trunk, which branches with the greatest freedom, often forming considerable clumps of male or female trunks. Encephalartos Altensteinii, a species with a distinctly columnar trunk much like but not nearly so tall as Cycas, also branches. An example in the palm house at Kew is mentioned by Seward as bearing a large lateral branch with a well-developed crown of leaves (r44). Few handsomer examples of branching cycads have come to the writer's notice than the little-known green-house species shown in figure II.

From the facts just cited, free branching among some of the fossil forms might, in the absence of any other evidence, be considered well-nigh an implied certainty. Yet we have not hitherto learned of such a profusion of characteristic branching cycad trunks as that now to be described. The only fossil cycadaceous plants exhibiting other than simple columnar outlines mentioned previous to the discovery of the Black Hills cycads are the wonderful Anomozamites minor, with Williamsonia fruits, as described by Nathorst (IO4), and the forked fruiting branch shown by Williamson in his restoration of Williamsonia gigas, but mentioned by him as only once observed and possibly anomalous. Albeit Anomozamites (cf. figure I2) is rather more suggestive than any other type of the varied trunk habit, we may expect to meet in the ancient members of the Cycado-Cordaito-Ginkgoalean alliance, which perchance, as will be again mentioned, may well have included the ancestors of the Angiosperms within its widely set limits.

The great branching trunks from Minnekahta constituting the type specimens of Professor Ward's Cycadeoidea Marshiana and C. minnekahtensis were the first of the larger and more typical cycadeoidean forms brought to light which fully paralleled the branching habit as seen in the living cycads. But owing to the fact that the early collectors in the Black Hills realized neither the extent to which branching trunks are represented in the Minnekahta series nor the importance of securing complete specimens, it was several years before the wealth of branching trunks included in it was more fully understood. Instead of isolated examples, we now see that in the case of the Minnekahta cycads those which did not branch were rather the exception, and that many of the groups reached a size and beauty that were at first scarcely suspected. The writer may here state that when he began this investigation there were in the Yale collection I 33 specimens, while at the present time there are nearly 800 , many of which were collected by him personally. Early in the course 
of the work it became quite obvious that not a few of the cycad trunks had been broken up by persons casually wandering about the great Minnekahta locality before

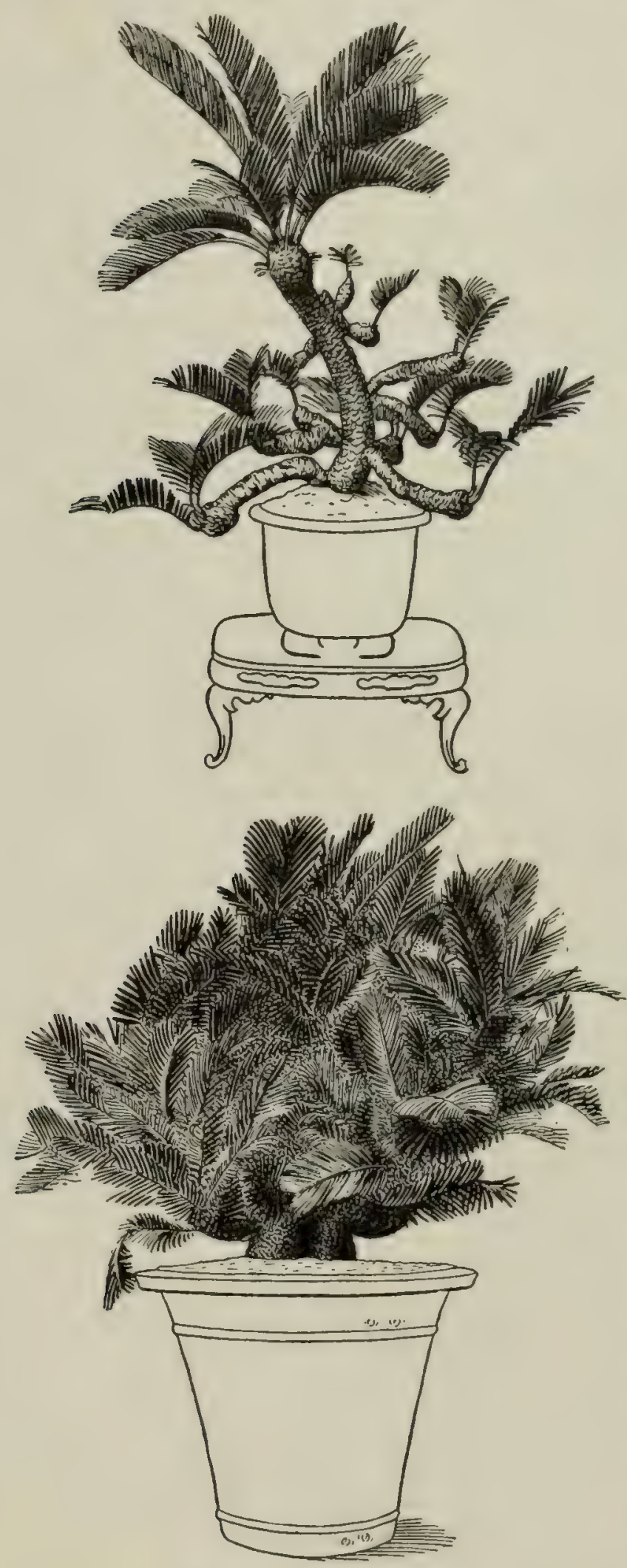

Fig. 10-Cycas revoluta.

As grown by Japanese horticulturists. The "hoso" above affords a suggestive comparison with the yet more freely branching Triassic Anomozamites. (Cf. figure 13.) it had been brought to scientific notice. These trunks had been mostly eroded out and lay exposed within a mile of a railway siding, which had been in use for ten years before the first specimens were secured by the United States National Museum and the State University of Iowa. It also became evident that, in addition to the ordinary vicissitudes of erosion and time, not only had different collectors taken away parts of groups, but handsome and solid trunks had in a few instances been broken apart to secure the best-preserved branches. The writer accordingly made, with not a little success, the most strenuous efforts to bring together again, so far as possible, the branches and parts of trunks thus unfortunately separated. He spent two months after the collections had been made fairly extensive, studying isolated branches and fragments of trunks, fitting together such as he could and noting the character of the missing parts. This work completed, at the very earliest opportunity lie resumed the exploration of the several Black Hills cycad-bearing horizons, examining them with great care, discovering several new localities and securing from localities already known a large amount of additional material, mainly belonging to groups of trunks or branching trunks already in the Yale collection. Some of the more striking of these new or reconstructed (?) specimens, exhibiting various stages of branching, may be described here at some length.

Various trunks from Minnekahta show a late development of branches in which there is a well-marked centra ${ }^{1}$ or main trunk, with various minor branches. A very fine example of this kind is afforded by Yale specimen I29, the largest central scem of which bears five wellmarked lateral branches. 
Yale cycad 220 represents a huge central stem weighing I 33.2 kilograms, which plainly bore three great low-growing branches nearly as large as the central stem and projecting from it nearly at right angles; but of these I have only been able to find one among the other Yale specimens, namely, No. 264, weighing 83.4 kilograms, and thus indicating a total weight of nearly 400 kilograms. In certain other instances from three to five branches were early formed, each of these growing out more or less symmetrically as a large trunk, as in the existing Zamia. (See plates XII and XIII.) The tendency in such cases was for the group to separate more and more as time went on and thus break up the originally symmetrical central

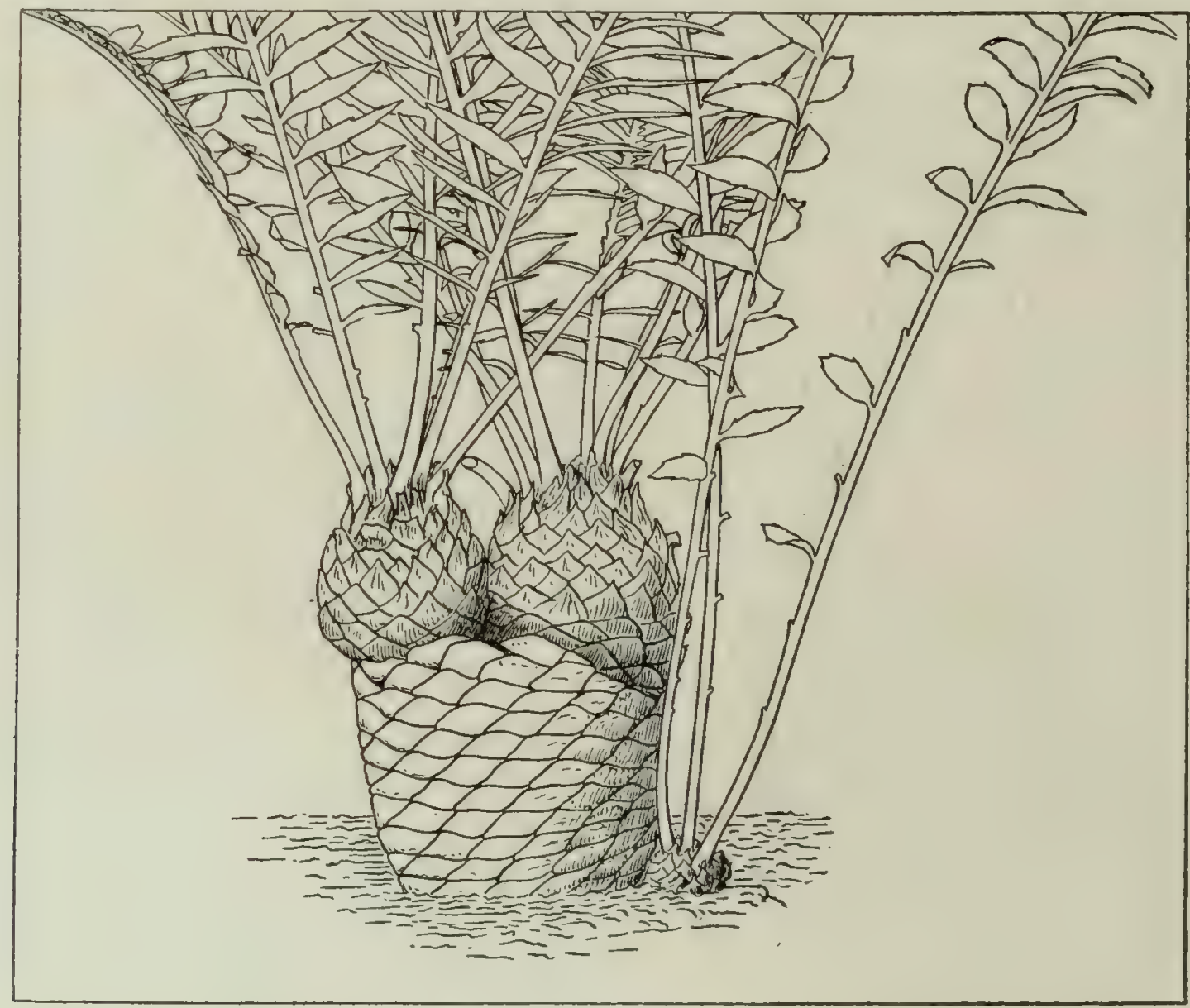

Fig. 11.-Zamia vernicosa. $\times \frac{1}{10}$.

An exceptionally beautiful greenhouse example of branching in an existing cycad either as the result of injury to the terminal bud or perchance the destruction of the apical meristem of the main axis by cone growth. (In conservatories of Miss Helen Gould, Tarrytown-on-the-Hudson, N. Y.)

woody zone into distinct segments corresponding to the several branches. One beautiful example of this kind in the Yale collection consisted in four trunks of quite equal size growing out obliquely; but only three were recovered, although it is certain the group was complete when first eroded out.

A similar group of great interest is indicated by three trunks of C. Marshiana coliected by the writer at Minnekahta. Their discovery was led to in an unusual manner. Some minute trunk fragments scattered about a small excavation showed where a branch or, perhaps, several branches-uncovered by erosion-had been earlier obtained by some one making a hasty and unskillful collection. Evidently these were secured with the thought that they were isolated surface specimens, and 
that no more of an original group remained; but further excavation in the sandrock brought to light three trunks from about equal intervals outside the position of the earlier excavation. These specimens are all of the same stage of fructification, and of the same general appearance, so that in any case the inference that they are the slightly separated branches of the same group is very strong. The larger of the three branches weighs I 47.3 kilograms; it is the heaviest single Cycadeo:dean branch ever recovered and is finely conserved. This magnificent specimen is shown on plate $\mathrm{V}$, figure $\mathrm{I}$, where the side on which it was attached to other members of the clump to which it belonged will be at once noted. The connection of the members of the group had, however, with the attaining of such great size on the

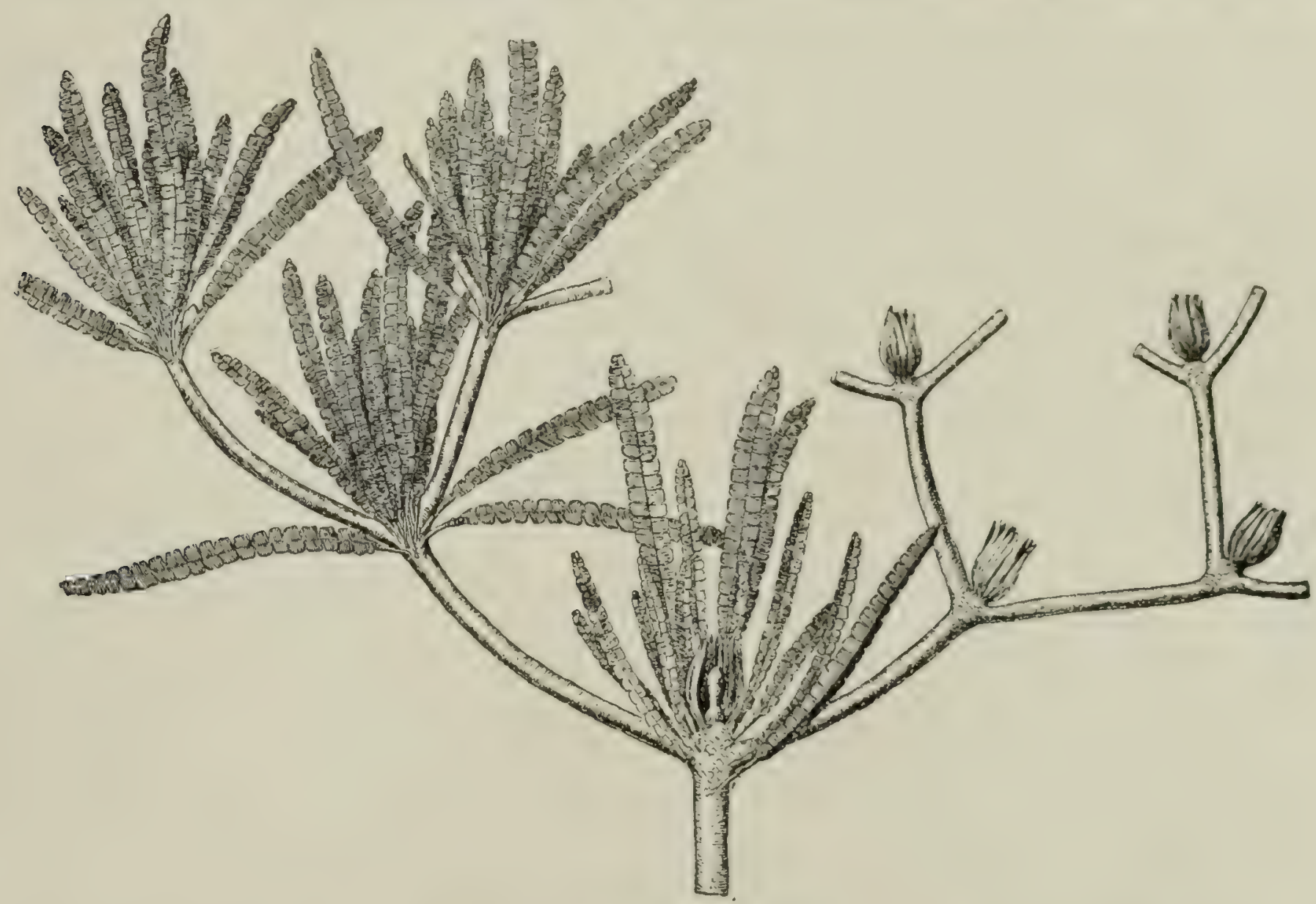

Fig. 12.-Anomozamites minor Nathorst.

Triassic of Southern: Sweden. The foliage is Nilssonia-like, and various ovulate cones of the true Williamsonia type are produced in bifurcations of the much branched stem. About one-fifth natural size. From Nathorst. (Cf. figure 10.)

part of a single branch, begun to be obliterated. It is very unfortunate that it has proved impossible thus far to determine which were the other trunks originally associated with these three specimens. The entire group may have included six branches with a total weight of more than 500 kilograms.

A compact, low-growing cluster of branches of rare beanty, all of whicis spring from a central trunk, is that numbered ${ }^{6} 64$ in the Yale collection, a typical C. Marshiana, figured on plates viI and VIII. Six of the nine distinct branches forming this specimen cluster about its two main central trunks, and it may be readily determined from the size and position of the branches with respect to the basally exposed xylem that the entire group arose thus: First, the larger main 
axial stem or No. I, denoted by $e$ in plates VII and VIII, early gave rise to the larger branch $(a)$ or No. 2, which is therefore the primary basal branch. Secondly, stem No. I gave rise to four basal branches $(c, d, i, f$,$) three of which are of nearly$ equal size; the fourth (marked $i$ ) being crowded between two others ( $d$ and $f$ ), was partially suppressed in its growth. Thirdly, the main branch, that is, stem No. 2, early gave rise to two strong secondary basal branches ( $b$ and $g$ ). And lastly, the axial stem of the group slowly gave rise to a slightly projecting crown just below its summit, and directly over the position of the partially appressed basal branch ( $i)$ mentioned above. As thus closely compacted this branching trunk is a symmetrical one. The basal view given on plate vin shows well how remarkably complete has been its preservation, and likewise clearly displays the relations and much of the structure of the several parts, as well as their closely set arrangement. The xylem zone of the central and axial stem, as denoted by the letter $x$ in the lower photograph of plate VIII, is seen to share in part with that of the largest or first main branch, as a projecting subelliptical ridge, no traces of the roots yet remaining. The comparatively small size of this xylem ellipse will be noted, its long and short diameters being only I 6 and II cm. respectively, while the nearly flat base of the group as formed by the central stem and the under surface of the branches growing out from it occupied a ground area of $60 \mathrm{~cm}$. square. Originally the xylem outline must have been nearly circular, but its present strong ellipticity is clearly seen to be due to the early formation of the first main branch or trunk No. 2 of the group, this being the only branch with its xylem extending in so as to share directly in the formation of the base.

The downwardly directed basal leaf bases of the axial stem are well preserved, as are those of the lateral branches, thus showing that no portions other than the roots are absent; and one can readily see from the position of the leaf crowns of the branches, all of which were evidently in equally active growth, as well as from the configuration of the base of the trunk, as shown in the plate, that the entire plant must have rested quite nearly upon, or certainly not more than 3 or 4 inches beneath, the surface of the ground.

A close inspection of the present specimen shows that in spite of the profusion of branches, the growth of these was adjusted with the greatest nicety to the space so compactly occupied. The arrangement of the branches for growth in their closely set position being so perfect, the plant in life must have been of exceeding grace and beauty; hence it is of more than passing interest to note some of the vicissitudes to which this gem of the Mesozoic was subjected after erosion had brought it to view. Originally it had been absolutely perfect; but Indians or others attracted by its curious form and slight resemblance to the groups of dwarf melon cactus, common in the vicinity, and to which the early settlers of the Black Hills referred the cycads, had slightly damaged the lateral portions of the two main summits, as well as that of one of the larger basal branches. Then three adjacent and connected basal branches made their way to the Yale Museum, receiving the number I64. A year later another shipment of heterogeneous trunks and trunk fragments was received from the Minnekahta locality, and my subsequent examination showed that of these, numbers I43, 267, 28I, 285, 392, 4I I, 224, 240, 256, and 4 IO were all parts 
of cycad I64, firmly attaching themselves and nearly completing the group, the missing parts being half of the main branch (stem No. 2), with one of the secondary branches projecting from it. Two years later, however, I had the great good fortune to secure this important missing portion, cycad 739. The entire specimen, now among the handsomest ever discovered, is therefore, barring the minor defacement of several of the crowns as mentioned above, practically complete after having been received mainly in fragments not originally collected as belonging to the same plant, these having arrived at the Yale Museum at different times during a period of four years, thus happily completing a record of fortunate chance almost unparalleled.

Cycadeoidea superba (plates $\mathrm{IX}-\mathrm{XI}$ ). - The type of this species is one of the handsomest of all branching cycads, but, as in the previous instance, was not at once obtained entire. Three only of its five branches, bearing the numbers I37, I46, and I47 of the Yale collection, were at first received as isolated specimens, and upon these the species was based. While it was quite obvious from the close similarity of general characters and preservation that these three specimens had grown in the same group, their exact relation to each other was not clear. In the absence of intervening parts, Professor Ward thought they represented separate trunks which had grown close together in an appressed position (I79), but they now prove to have sprung from an original single woody cylinder, and thus to have strong organic attachment. On my first visit to Minnekahta I was much gratified to find still embedded in sin in sandrock two other large branches and many more or less freshly broken fragments, which I at once recognized as belonging to the branches first described by Professor Ward. The hope that these additional portions might be matched and form a complete trunk was fully realized. When unpacked in the Yale MIusenm all were found to join solidly together and form, with the portions I37, I46, and I47, a complete cycad, consisting of a large central stem and four closely appressed basal branches of nearly equal size, the entire specimen being in many respects the handsomest cycad trunk ever recovered. The base of this trunk is shown by the lower photograph, plate XI, where it will be noted that the medulla has increased greatly in size beyond what would be seen in a single trunk, and that likewise the xylem zone has enlarged, being shared in by the four lateral branches, much after the manner of the main first branch $(\alpha)$ of the preceding cycad. Evidently these branches formed early in the life of the plant. The summit of the older member of the group or axial trunk is preserved as a "crow's nest," doubtless as the result of some beginning of apical decay. Hence it is possible that had this plant continued to grow undisturbed the older central portion would have finally disappeared, thus leaving the remaining parts quite separate and free to form root systems and new branches of their own. In some such manner these plants might even have occasionally propagated themselves without the intervention of seeds, thus finally investing large areas by a continuous branching. As shown later, it is, however, more likely that fructification was usually the culminant event closing the activities of the individual plants. The general similarity in form of these fossils to the specimens of $C y$ cas revoluta shown in figures 8 and 9 is so obvious as to require no further present comment. 


\section{RÉSUMÉ.}

The Cycadeoidex have mostly bulbous to nearly spherical or little elongated trunks less than one meter high and are, like Zamia, much given to branching. Various unbranched species were present, however, and the Jurassic Cycadella and the existing Bowenia agree in being small and rarely branched. The low, freely branching Cycadeoidex are often larger than low-growing existing forms of like branching habit, but, on the other hand, the columnar types, like Cycadeoidea gigantea Seward and C. excelsa and C. Jemeyana Ward, have not yet been found

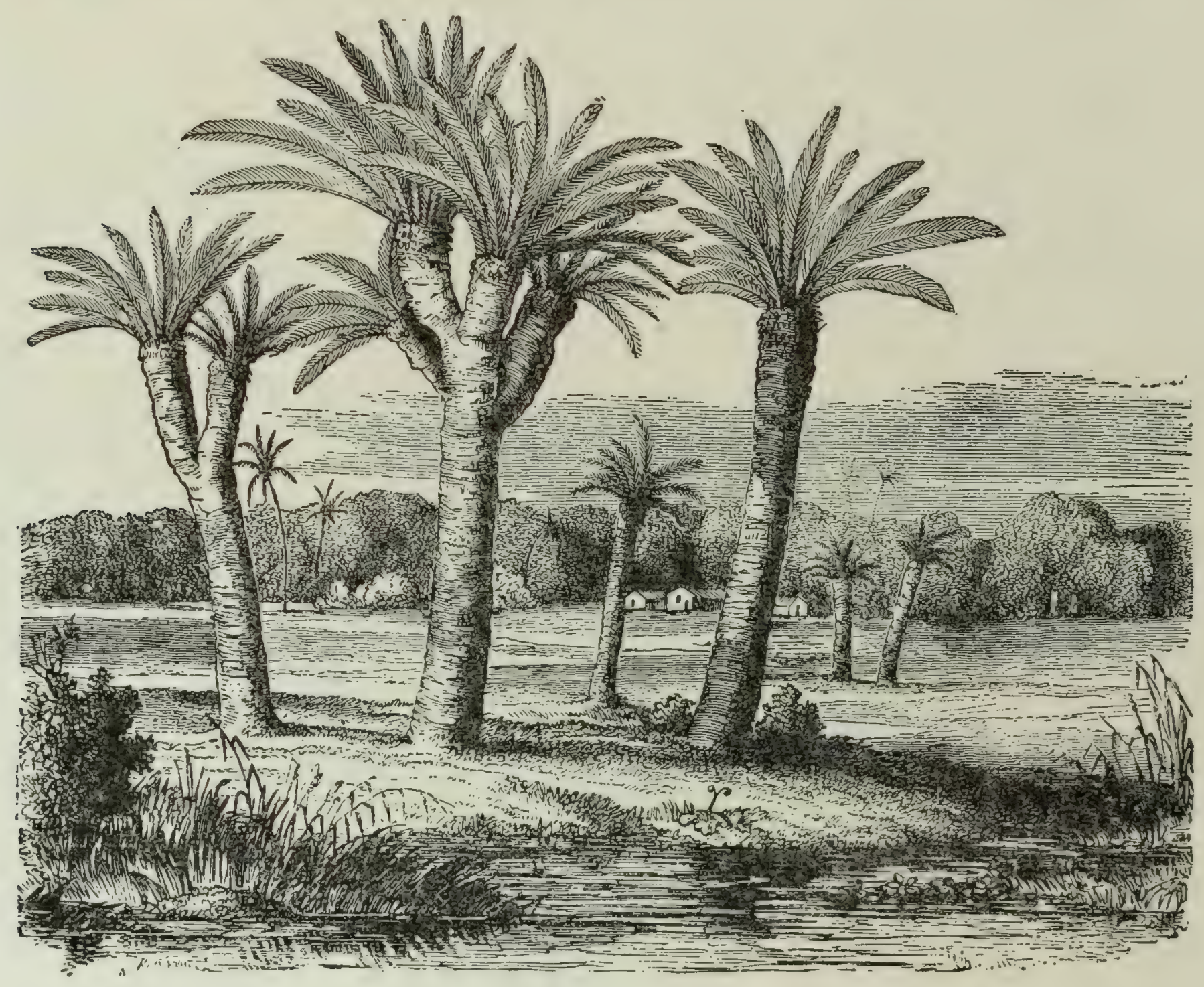

Fig. 13. - Cycas revoluta. The sago palm. Part of a plantation in Ceylon. From Warming.

either branched or so tall as the taller species of Cycas. They did, however, reach approximately the height of the larger of the more specialized Zamiex, with which they should rather be compared, since C. Jenneyana, the tallest known fossil cycad, certainly attained a height of I.3O and probably 2 or 3 meters. In their general limits of stature both the existing and fossil cycads are comparable to tree ferns. That the Cycadeoidex were far more diversified in general trunk form than the surviving cycads is shown by the Triassic Anomozamites, as approached only by artificially-grown cycads; though in general appearance and habit of trunk-growth both groups present a most profound and complete parallelism. 


\section{CHAPTER III.}

\section{ON THE METHODS OF SECTION CUTTING.}

In these extensive studies of solidly silicified and oiten bulky fossil plants, it was necessary to devise a new method of work in order to fairly preserve the original trunks and at the same time cut a large number of the fruits borne by them in the best form for sectioning. Hence an explanation of methods may appropriately be given before passing on to the description of the structures revealed.

In the case of cycad 2I4, the first fruit studied with care was chiseled out by the writer, but this proved a difficult and tedious work, requiring many days. Moreover, the continued strokes of the chisel finally jarred the fructification loose while a considerable portion of the peduncle yet remained embedded in the armor, although the upper portion was secured intact and none of the essential structures were lost.

It was then thought possible to make a series of small drill holes, parallel to each other and distributed about a fruit circularly or elliptically, and then chisel out the partitions between these holes and thus secure complete fructifications, as seated on the cortex, together with the connecting bundle system and its origin in the xylem. This process proved possible with drills run by compressed air, but much too slow for extended use.

Tubular drills were next tried; and these, with various devices for use on different shafts, have proved speedy and effective, though their use requires skill, time, knowledge of the general structures, and constant watchfulness, lest the cylindrical core containing the fructification be broken away and shattered into pieces before the drill can be stopped. No fruits were actually lost in this way. The drills were made of ordinary iron and steel tubing, steel being little or not at all better than iron. They varied in inside diameter from $35 \mathrm{~mm}$. to $75 \mathrm{~mm}$., with walls from 2 to $4 \mathrm{~mm}$. in thickness. Each drill was made $50 \mathrm{~mm}$. long, excluding $60 \mathrm{~mm}$. of the upper portion, as provided with a close-fitting sheath of suitable size for fitting the drill to a vertical $35 \mathrm{~mm}$. shaft revolving at the rate of Ioo or more revolutions per minute. Through the sheath, as set a little below the edge of the drilltube to form a trough about the revolving shaft, were drilled from two to four holes in order that the inside of the drill might be kept full of cool water flowing in a constant stream; this is very necessary. When, as in certain sizes, the shaft was of the same diameter as the inside of the drill, two rows of alternating holes were drilled through the wall of the tubular portion just below the lower end of the shaft. Into these a steady stream of water was then projected. This plan worked very well.

Before drilling, the trunk was carefully biocked up in a heavy box with reference to a particular fruit, then firmly cemented in with plaster and exactly oriented beneath the drill with reference to the estimated positicn and slant of the fruit and 
its penducle in the armor. Necessarily frequent remounting of a trunk was required for the cutting out of fruits at much varied angles. Before cutting, a cast of each fruit was taken, and the summit was then carefully embedded in "Meyer's stone cement," or the Meyerische Steinkitte, manufactured at Freiburg i. B. About three parts of admixed pulverized cycad were used to one of cement. In from four days to a week the cement set solidly, thus leaving the summit of the fruit smooth and firm, and avoiding the danger to the core caused by the breaking away of loose pieces of bracts and leaf bases, with resultant wedging or heavy jarring of the drill, while revolving at a rate of several hundred revolutions per minute. When thus cemented and properly set, the summit was surrounded by a low clay wall and quite covered with bits of chilled steel, the active drilling agent used. Carborundum would also doubtless do, but a large quantity would be needed. In drilling, a continuous even and firm but not heavy pressure is best. In other words, in addition to well-turned and well-set drills, the process requires time and constant watching, and can not be safely hurried, although a fairly rapid, if steady, revolution of the drill is best.

In the manner just described a dozen cylindrical cores, varying from 4 to $8 \mathrm{~cm}$. in diameter by from 5 to $5 \mathrm{~cm}$. in length, and extending into the medulla, were cut from various positions all the way from the base to the summit of Yale cycad trunk No. 2I4 (cf. figure I4). These cores were next broken out smooth and deep by means of small steel wedges dropped down to the bottom of the drill-cut and then forced by means of sharp mallet-blows against the core by a thin-bladed chisel. Necessarily the point of wedging and the method will vary a little in each successive instance. It scarcely need be again emphasized that constant inspection, good judgment, and skill are required in such a process, else much damage to both fruit and trunk may ensue.

The next step was to cement together again with the stone cement any fractures of the fruit originally present and partly developed, and also to fill up uneven places, or strengthen portions likely to break away in cutting. Following this the core was embedded in plaster in position for either a longitudinal saw-cut, as alway's made in a radial longitudinal direction to the trunk itself, or else for a series of transverse sections. Secondly, supplementary sections were made from portions of the fruit; or else, after the longitudinal sections were cut, the resulting halves of the core were cemented together again in their original position, as recorded by means of a mold, and the secondary series of transverse sections then made with the loss of the saw-cuts only. There has also been employed the reverse process of making transverse sections first, and then cementing together the resulting cylindrical segments and making a longitudinal section. The cement-filled saw-cuts which, of course, traverse the latter accurately indicate the position of the transverse sections.

It is believed that this is the first time in the study of any plants that virtually complete transverse and longitudinal sections have been made from one and the same fructification. Whilst these complete complementary sections are of great beanty, and desirable in a large series, it of course may answer ordinary purposes to first make a longitudinal saw-cut, and then a longitudinal section from the best or else the 
slightly larger half of the specimen. Secondly, after completing the longitudinal section, take the same half of the cylinder from which this longitudinal section was made, and then orient the supplementary series of transverse sections carefully in the light of what it shows. Otherwise, owing to the intervening saw-cut, it will always require more or less inspection to trace the several parts in the series of sections. Furthermore, although of minor scientific moment, correspondence of organs in the complementary serial sections is as desirable for the beauty added as the precision of examination thus permitted.

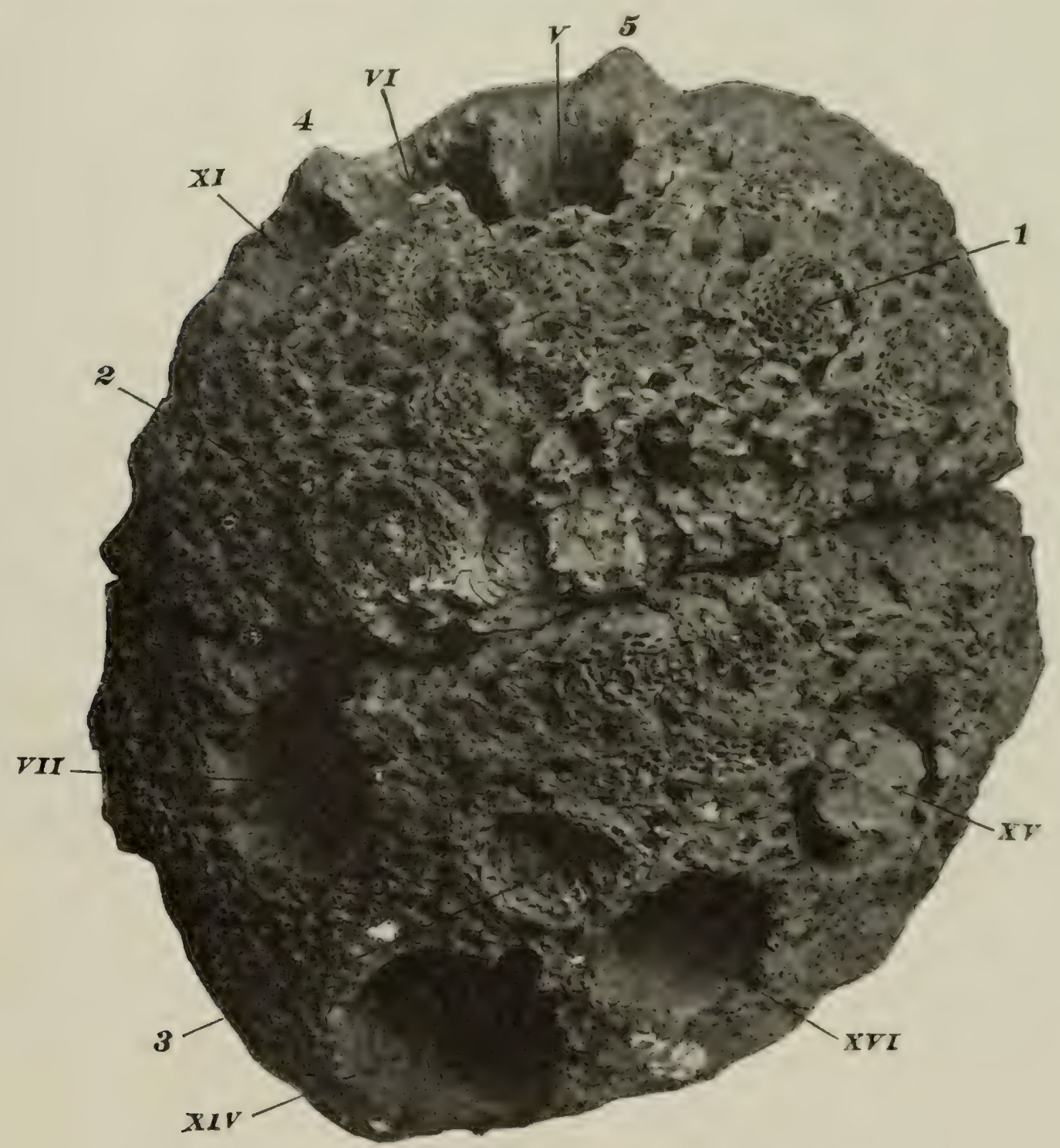

Fig. 14.-Cycadeoidea dacotensis. T. $214 \times 1 /$ nearly.

Side view of trunk after drilling out in the form of cylindrical cores the fruits numbered V, VI, VII, XI, XIV, and XVI. The numbers $1-5$ indicate similar fruits embedded in the armor and surrounded by bract systems. At XV a cylindrical core is shown after the drill cut has been made, but still in its natural position unbroken from the trunk. As may be noted in the figure the end of the core is protected by a cement covering. This consists in one part of the "Meyerische Steinkitte" to four of finely pulverized cycad, as employed in the later chiting. Other views of this trunk appear in later chapters. 
As yet no experiments with tubular bort-charged drills have been made; but stch revolved at a steady, even rate should yield even better results than the plain drill-edge and loose bits of chilled steel employed as above described. Whatever the plan used, or whatever the part of the cutting process that is being carried out, heavy thrusts, strains, or jars are to be avoided. It is quite interesting in this connection to recall that the Swiss lake-dwellers bored limestone with reeds having a large pith, by first pushing out this pith and then revolving the tube thus obtained in loose sand filled in about the cutting end, by means of a whirling-bow like that used in primitive fire-making. As shown by experiment, this apparatus cuts with fair rapidity. Cores nearly an inch in diameter and pieces of stone worked on by the lake-dwellers are in the museum at Zurich.

In closing the present brief description of methods it may be added that the difficulty of cutting sections and mounting them of course increases with their size. It is the writer's belief, however, that given time for the devising of simple appliances, it would be possible to cut thin sections from large entire trunks. To complete the polishing of the large sections made by the writer a fine carborundum whetstone was sometimes used. By this means dark portions may be thinned, so as to let the desired amount of light through without thinning out the more transparent portions too much, or losing thin, weak, or crumbling edges or parts of the section. This device will prove of occasional service; for it is not always possible to secure the best results by grinding or polishing all of the surface of a large section equally. By so doing the natural color effects are often partly lost, or even valuable parts of the section itself, long before all of the section is sufficiently thin. It was also found that instead of renewing the Canada balsam, as it wears away and exposes the edge of the section near the close of the polishing process, it is rather better to dissolve away with benzol the balsam from all around the section. This prevents relatively coarser particles of carborundum from rolling up over the balsam and shattering and cutting off the section borders, especially when the sections are of large area. All the larger sections are mounted on specially cut and ground plate glass of suitable thickness, and selected with reference to its hardness, toughness, and transparency. 


\section{VEGETATIVE FEATURES.}




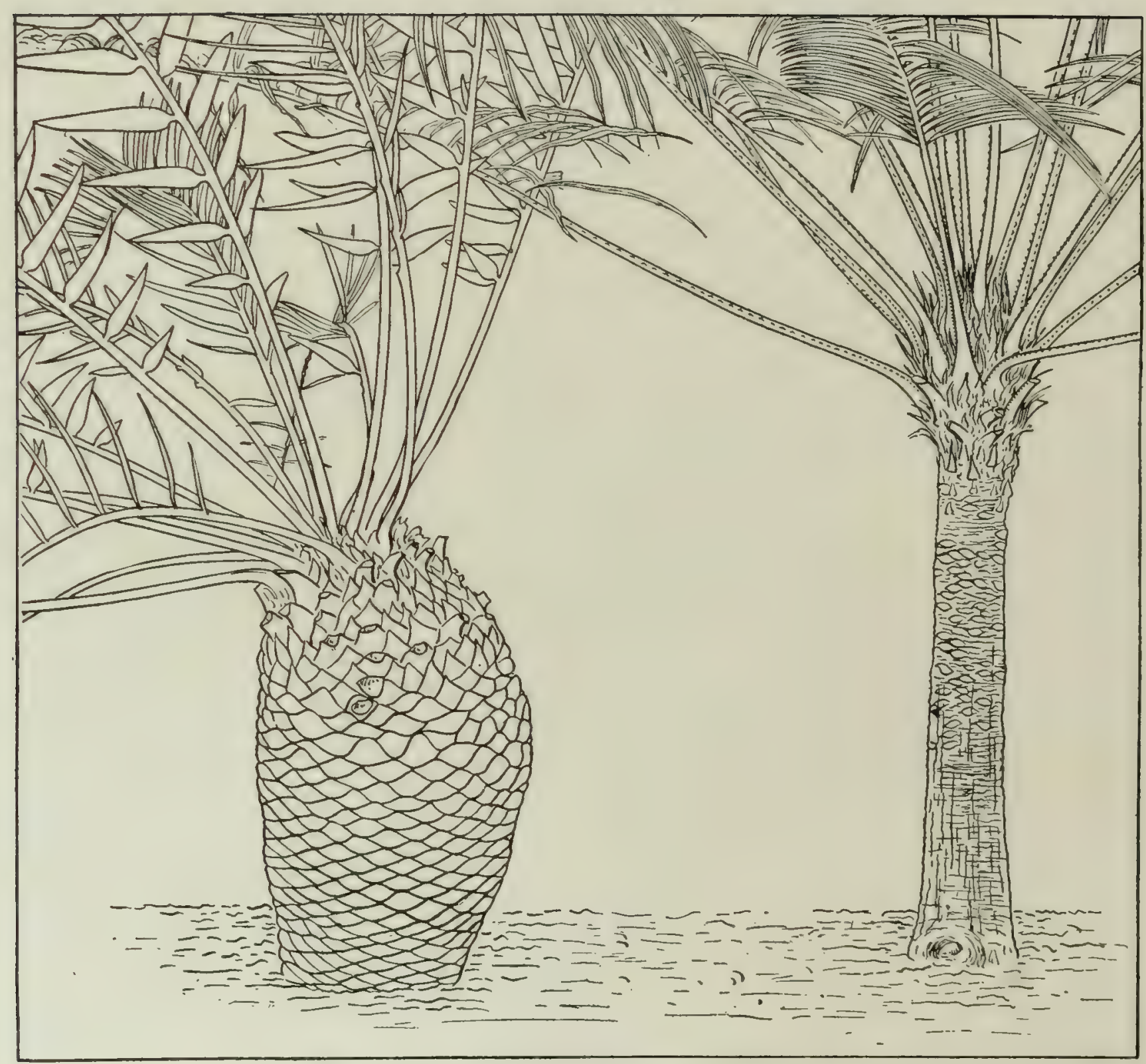

Fig. 15.-Armor development of existing cycadean trunks.

To the right, Cycas Riuminiana $\left(X_{z}^{1}\right)$, with all the lower portions of the armor of old leaf bases excised by comparatively rapid periaerm formation. To the left, Zamia (?) - $\left(\times \frac{1}{8}\right)$, showing retention of heavy armor. 


\title{
CHAPTER IV.
}

\section{TRUNK STRUCTURE.}

\author{
ARMOR
}

RAMENTUM.

A luxuriant growth of ramentum forms one of the conspicuous outer features of most cycadeoidean trunks. Borne over and densely packed between all the lateral leaf, peduncle, and bract surfaces, as well as thickly enveloping the entire crown and even drooping over and quite covering the trunk surface, as in some forms of Cycadella, the ramentum may make up quite half the entire bulk of many trunks. It is usually preserved in most perfect detail, doubtless the result, as already suggested, of the free percolation of silica-laden solutions through the hairy

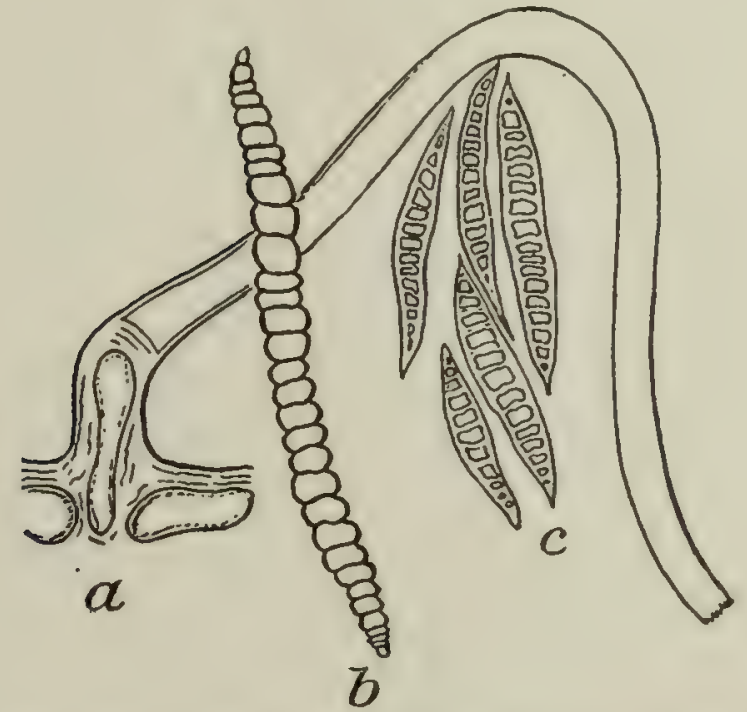

Fig. 16.-Cycad and fern ramental types. After Seward.

a, Dion edule. Longitudinal view of an epidermal hair, showing its base. $\times 150$.

b, Cyathea excelsa. Transverse section of a ramental scale. $\times 35$.

c, Cycadeoidea gigantea. Transverse section of a group of ramental scales. $\times 35$.

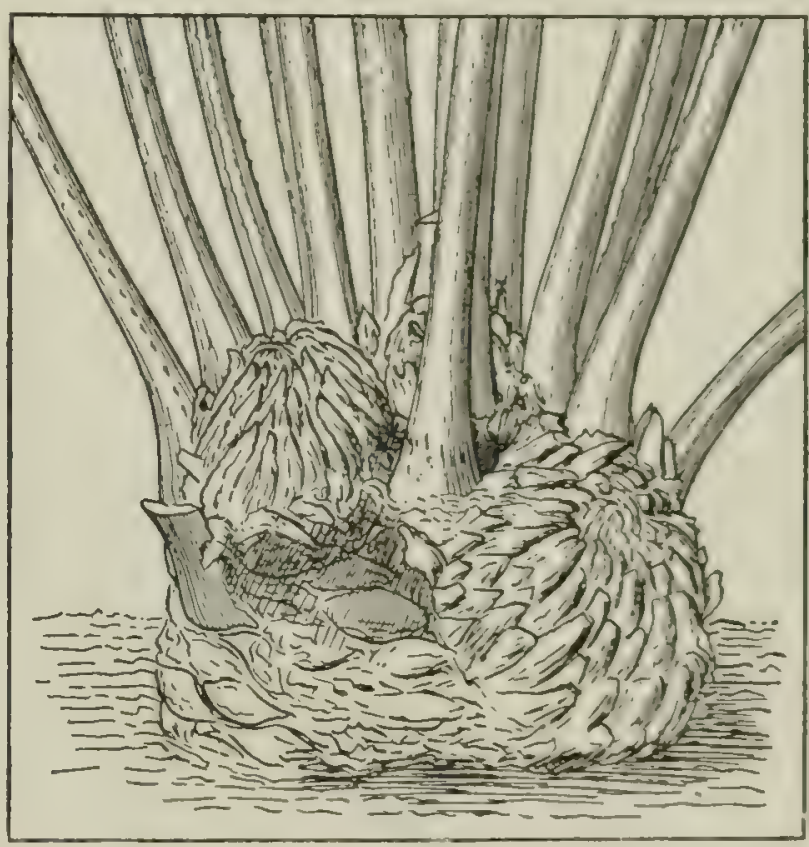

Fig. 17. - Encephalartos villosus. $\times \frac{\frac{l}{9}}{}$.

The woolly "Cafferbread," a branching cycadean trunk with three strikingly villous crowns, comparable to the ramentum-covered crowns of the Cycadeoidex.

to silky ramental mass. At least such solutions could not so readily make their way through the woody outer layers of the leaf bases before a breaking down of tissues began in the absence of silicifying action.

While ramentum has not been found absent in any of the Cycadeoider, some of the trunks bear but little, and present nearly as conspicuous a series of leaf-base spirals as the more directly comparable existing cycads without numerous scale leaves. In most species by far the larger part of the outer or amorial zoue of the trunk is made up of ramentum. The length of the ramental scales usually varies 
with that of the leaf bases, and the extreme regularity of the surface of some of the fossil trunks suggests that the ramental tips were subject to some form of excision, much after the manner of the leaf bases. In many specimens the distal ends of the leaf bases fail of preservation and are more or less exactly outlined as pits of varying depth in the ramentum.

The size and thickness of the ramental hairs, or rather scales, varies greatly in different species, and in conjunction with quantity will probably be found to afford within proper limitations one means of species identification that can be widely used. But, needless to say, no uniform data can be secured except from sections of considerable area, cut at a given distance from the cortex, and traversing in series both leaf bases and bracts, in order that the true size, cell structure, and relative number of the scales may be definitely determined. (In this connection, note photographs 3 and 4, plate xxxvir; also plate XVIII.) In the very characteristic Cycadeoidea nigra the ramentum of the leaf bases is quite uniformly one cell in thickness, as in C. Gibsonianus and in the tree fern Cyathea. In Cycadeoidea colos-

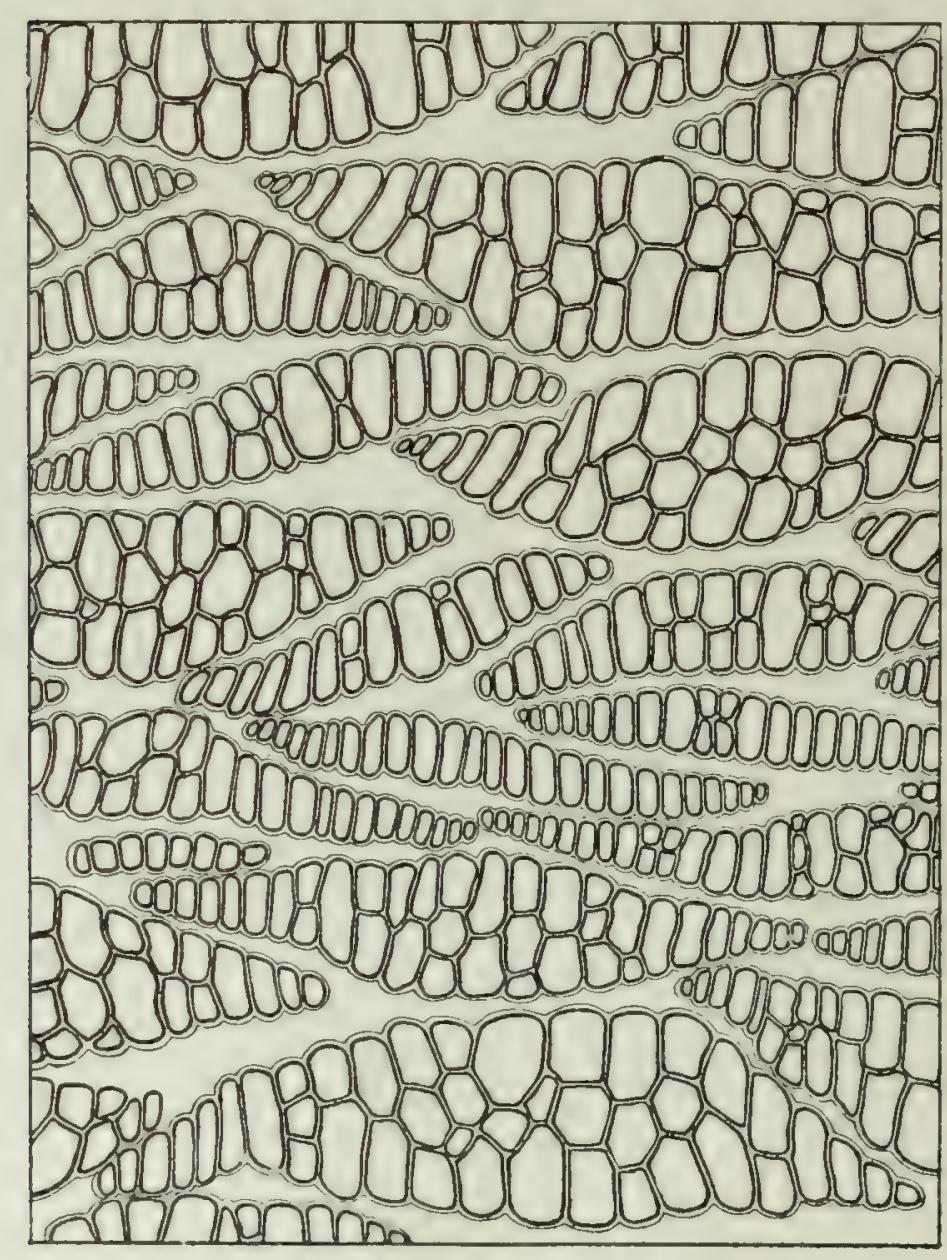

Fig. 18.-Cycadella ramentosa. Type.

Transverse section through ramentum of armor from laieral region of trunk, in which were found embedded several adventitious young fronds. S. $444 \times 100$. (Cf. S. 445 , Plate XVIII.) salis the ramentum surrounding the young crown of leaves is often several cells in thickness, but far more rounded and hair-like than in the other forms just mentioned. In Cycadella, the very thick and large ramental scales, as shown in figure I8, represent the most robust and abundant growth of ramentum observed in any of the fossil forms. In connection with the figure, reference should also be made to plate xxxviII, photograph 3 , since it may be that the continuous layer of cutin, as represented in the drawing, was never present, the outer cell alignment being absolutely the same as in the ramenta of the tree-fern Cyathea. In many of the Cycadella trunks the ramentum borne by the peduncles and young strobili droops down over the surface of the trunk. The general appearance may have been not unlike that of an "old man" cactus, and, taken with the small

trunk-size of this group of fossil cycads, may mean that the several species referred to it grew in some drier and less favored situation than did such huge trunks as are found in the eastern and sonthern Black Hills localities. 


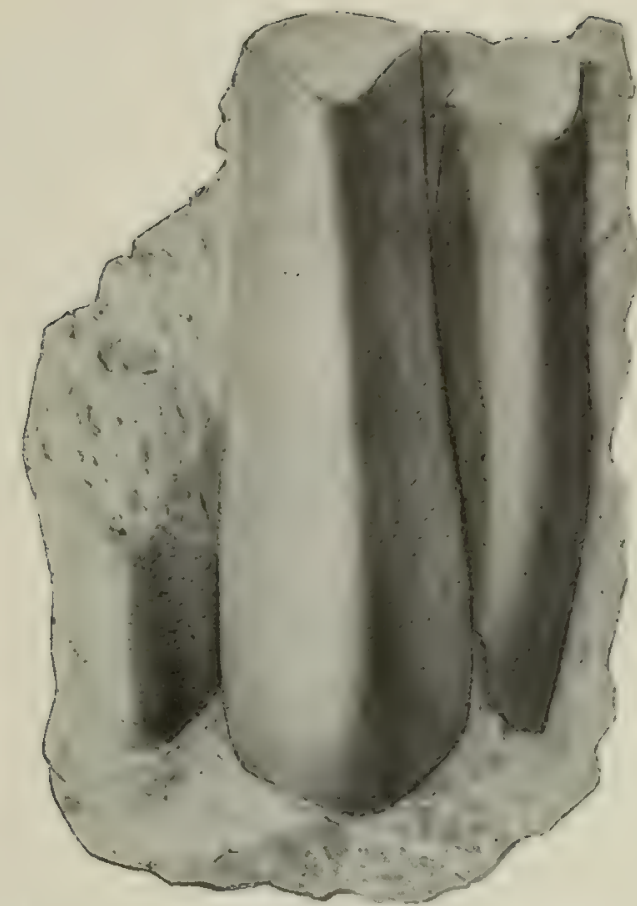

Fig. 19.-Cycadeordea ingens. T. 108**

Leaf bases as naturally eroded or rather broken out of a fragmentary portion of the armor of a large trunk so as to expose their under surface. One-half natural size.

Especially in the trunks referred by Professor Ward to Cycadeoidea dacotensis, C. minnekahtensis, and C: Marshiana there is a very dense growth of ramentum about the young nonemergent fronds of the summit. 'The preservation in many of these trunks is so perfert that the individual scales preserve their alignment with respect to the young organs beneath, and thus present a series of groups in regular helicoidal arrangement foreshadowing the leaf-base spirals. An example is shown in thin section in photograph 5, plate xix. In this instance none of the scales are more than one cell in thickness.

A hairy or scaly growth of ramentum, clothing the bases of the fronds, is primarily a feature of filicinean forms, especially tlose forming trunks. In a few ferns, instead of more scale-like structures, hairs or paleæ in the form of singlecelled filaments are present; in some other instances these are several cells in thickness. In

figure I6 a single ramentum from the petiole of Cyathea is shown, together with the obviously similar ramenta of Cycadeoidea gigantea from the Purbeck beds of

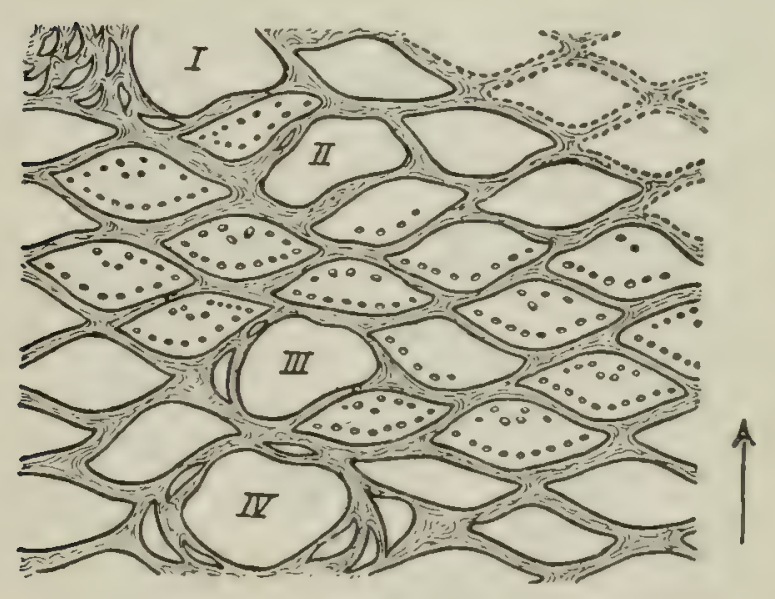

Fig. 20.-Cycadeoidea turrita. T. 15.

Tangential section through armor $2.5 \mathrm{~cm}$. distal to the cortex. Four fructifications are cut. Of these I and IV are well advanced in growth, the section cutting through their seed pedicels. $X_{3}^{2}$.

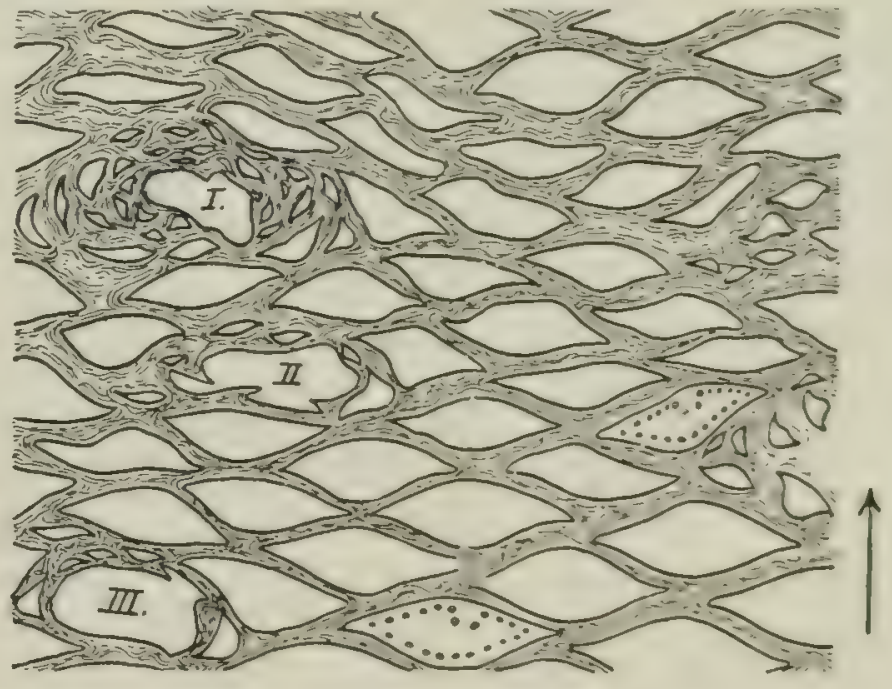

Fig. 21.-Cycadella (Cycadeoidea) ulopiensis, type. T. 727.

Tangential section through armor $2 \mathrm{~cm}$. out from the cortex, cutting various peduncles, the emergence of which has noticeat ly disturbed the sequence of the leaf base spirals. $X \frac{2}{3}$.

the Isle of Portland and a single filamentous ramental hair of Dion. The latter is seen to consist in a short, thick-walled stalk cell with a long teminal cell, but is wholly analogous to the more hair-like fern ramenta. Such vestigial,

* Throughout this volume the cycad trunks and sections of the Yale Museum collection are simply referred to by their catalogue number; $T$. denoting the trunks, anc $S$. the sections made from them or from other material. The number following either leiter denotes the catalogue number of the trunk or section, as the case may be. 
or else simpler, types of ramenta are present in most existing cycads, as in certain species of Macrozamia and Encephalartos (cf. text fig. I7); and it has been stated that in New South Wales they are, together with the chaffy scales of fern petioles, known as "pulu," and used as a stuffing for cushions.

The profuse and highly characteristic development of ramentum in the fossil cycads, when contrasted with its very reduced condition in the existing forms, might at first sight lead to the opinion that herein is a broad distinction of value in the definition of the separate great groups to which the existing and extinct Cycadales have sometimes been assigned. But such is not the view taken here, the presence or absence of ramentum being regarded as in actuality of scarcely more than generic value. Ramentum is, as noted, very abundantly developed in the Cycadellas, and also in Cycadeoidea dacotensis. But it is nearly absent in such forms as C. Stillwelli and C.excelsa; and were a trunk with some ramentum like that of Dion found accompanying either of the above fossils, no one would consider the difference, so far as this feature is concerned, as of more than generic value, or perhaps even-depending upon the temperament of the investigator - of more than specific value. Were all existing cycads without any traces of ramentum, and were all the fossil forms as densely enveloped in ramentum as $C$. dacotensis, the case would be more obscure. Plainly, however, the intervening stages between the extremes do exist, and the inference is virtually conclusive that the Cycadeoidere and Cycadacex have been alike subject to a progressive reduction of the profuse ramentun characterizing their common Palcozoic filicinean ancestry. In Meso-

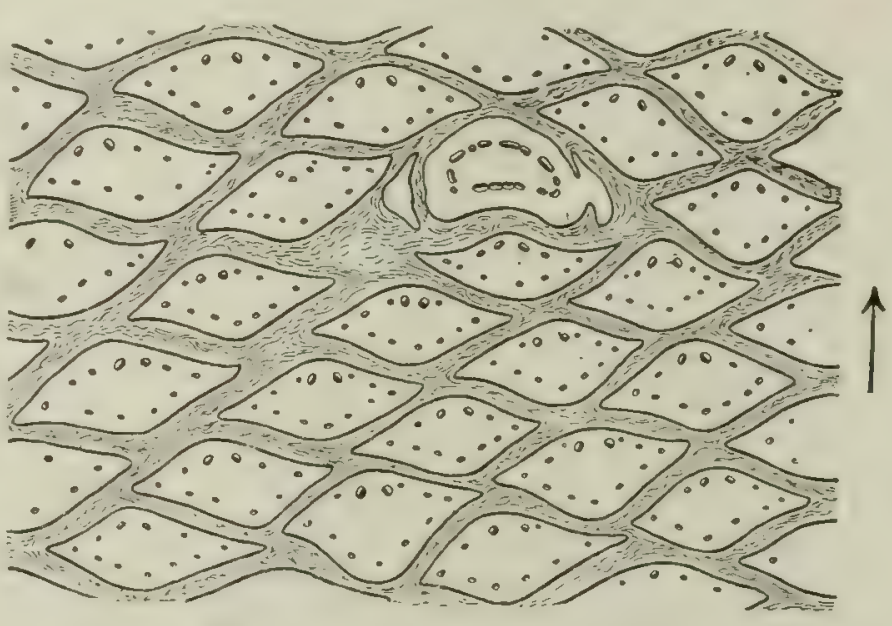

Fig. 22.-Cycadeoidea turrita. T. 269.

Transverse section of leaf bases surrounding an isolated lateral strobilar axis bearing two large basal bracts, one of which is cut at and the other a little above the insertion on the peduncle. Tangential to trunk near its base. The leaf base bundle systems are indicated. Note the pair of heavier bundles in the upper leaf base angle. Natural size.

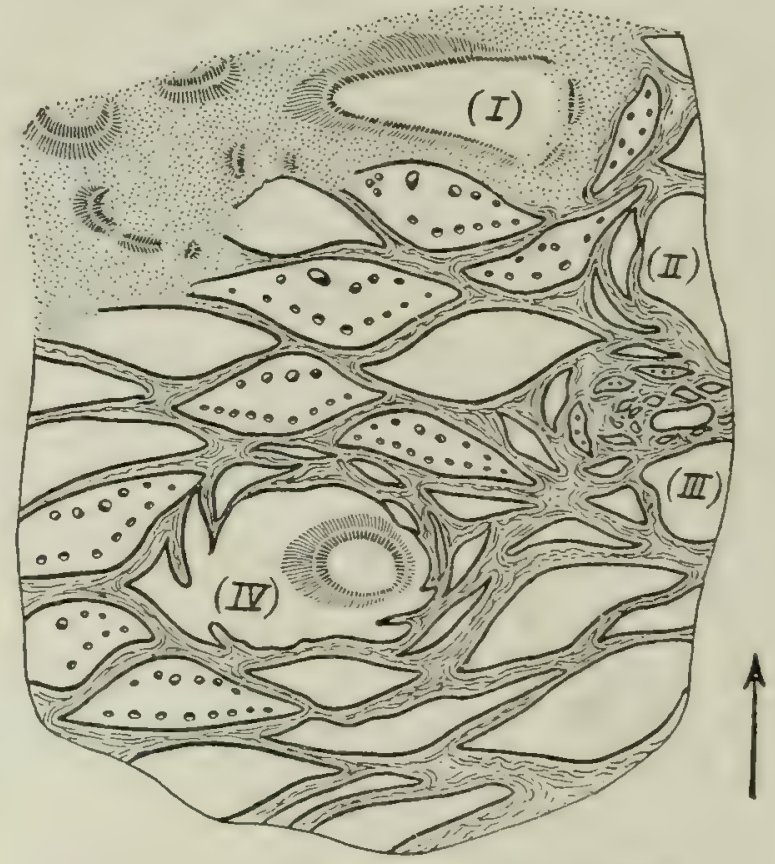

Fig. 23.-Cycadeoidea Wielandi. T. 393.

Oblique tangential section cut from near the base of a trunk bearing numerous ovulate strobili. The section plane passes through armor into the cortex. Lowermost leaf bases cut $1 \mathrm{~cm}$. distal to the cortex.

I, bundle trace of a peduncle; II and III, peduncles that may represent scaltering fructifications borne previously to the main series, or else abortive fruits: IV, a peduncle of one of the finely silicified fruits, stowing the woody cylinder. To the left of fruit axis I are shown heavy bundles of the outer cortex which are on the point of splitting up into the leaf base bundles.

zoic time reduction had simply not progressed so far. The causes of this disappearance of ramentum, of course, constitute another subject. Since the tree ferns 
have doubtless retained their free growtl of ramentum ever since the Paleozoic, it is scarcely sufficient to suggest the action of the simpler ecological factors alone; and it is not only the ramentum that has fail od to continue in most gymnosperns and in the angiosperms, but the entire armor-bark formation taking place rapidly and evenly over the entire stem, so as soon to excise not only all vestiges of ramentum, but the old leaf bases and scars as well.

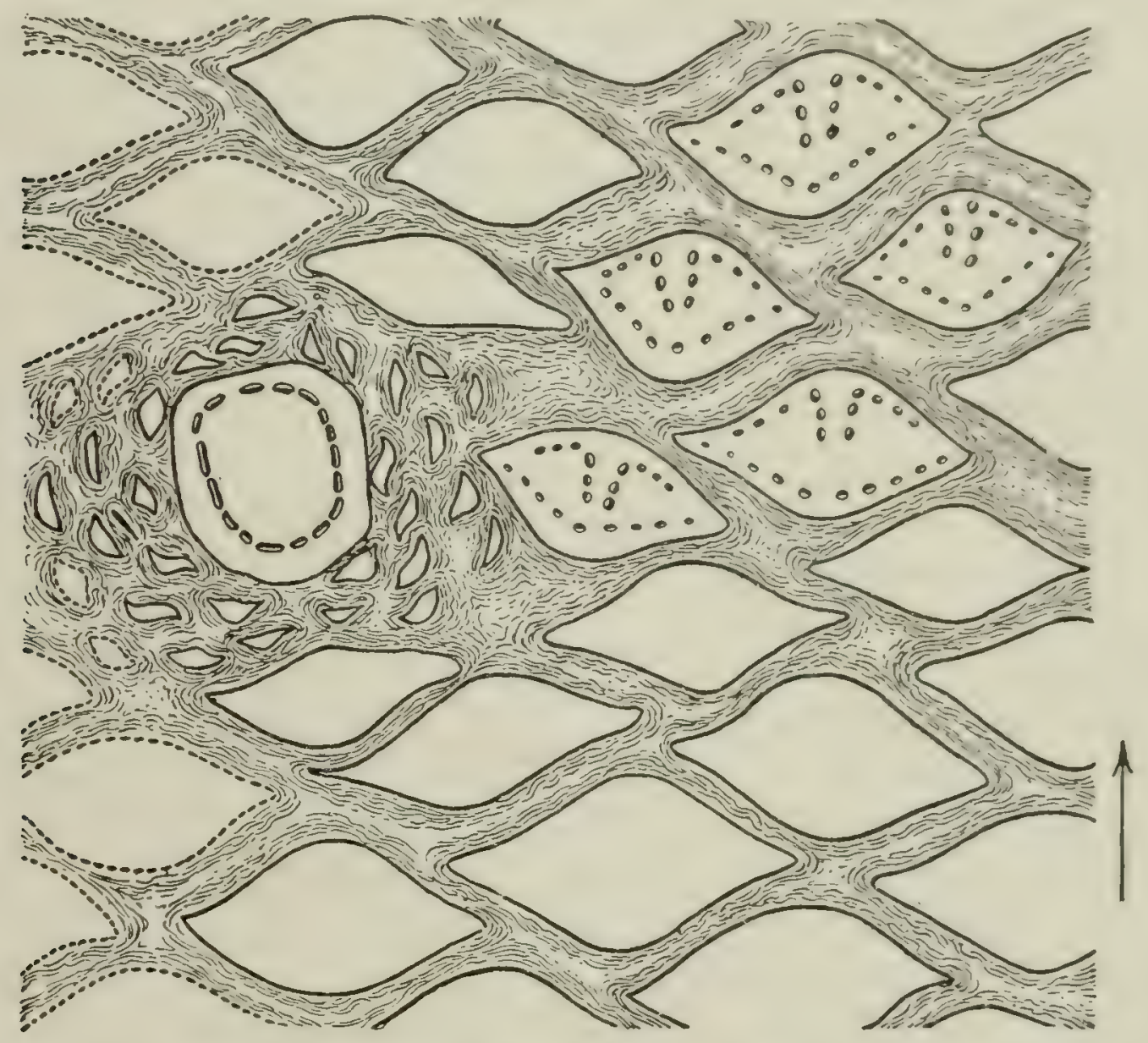

Fig. 24.-Cycadeoidea sp. T. 755.

Tangential section through armor about $4 \mathrm{~cm}$. exterior to the cortex. Leaf bases in but slightly distorted spiral order surrounding an isolated peduncle and its bracts. Peduncle and leaf base bundle patterns indicated. Natural size.

LEAF BASES.

Outer Features and Arrangement.-Figures ig-29.

Persistent leaf bases are especially characteristic of cycads and tree ferus. As the fronds of the leafy cycad crowns wilt down, layers of periderm arise in the bases some distance out from the cortex and give rise to thin protecting bark, which arrests further wilting after petiolar excision. The continuous enveloping "armor" of spirally arranged old leaf bases thus formed is the most striling outer feature of the cycadean trunk, although often slowly excised from abont the base by the further formation of successive layers of periderm, with formation of the variant types of figure I5, showing a heavy and a light amnored cycad. This progressive armor elision is more characteristic of existing than of extinct forms, a fact which well accords with the much more profuse ramentum and rather heavier armor 
of the latter, together with the extensive production of laterally borne fruits. Indeed there is among all the fossil cycad trunks from North America scarcely a single example of a completely excised armor. In many trunks the armorial zone is very heavy. (See figure r9.)

Owing to the much reduced and vestigial character of the ramentum in the existing cycads, and the regular order in which the leaves, scale leaves, or carpellary leaves appear, the only disturbance of the regularity of the leaf-base spirals that can occur must be due to the sparse appearance of the terminal cones, or scale leaf buds like those of Cycas. This is but slight, and very few trunks indeed exhibit any apparent disturbance in the regularity of the frond base spirals.

Such is not the case in the Cycadeoider. Only young trunks, or the occasional trunks which have not come into fructification, exhibit apparent regularity in their leaf-base spirals. As the profuse ramentum permitted free change in the position of the leaf bases during the emergence of numerous and large laterally borne fructifications, in full-grown trunks nearly all traces of the earlier spiral alignment are quite frequently obscured. But the true spiral order in which the fronds originally appeared can nevertheless always be determined, if all the leaf bases of a considerable arca are carefully ezamined and plotted. When this is done the exact

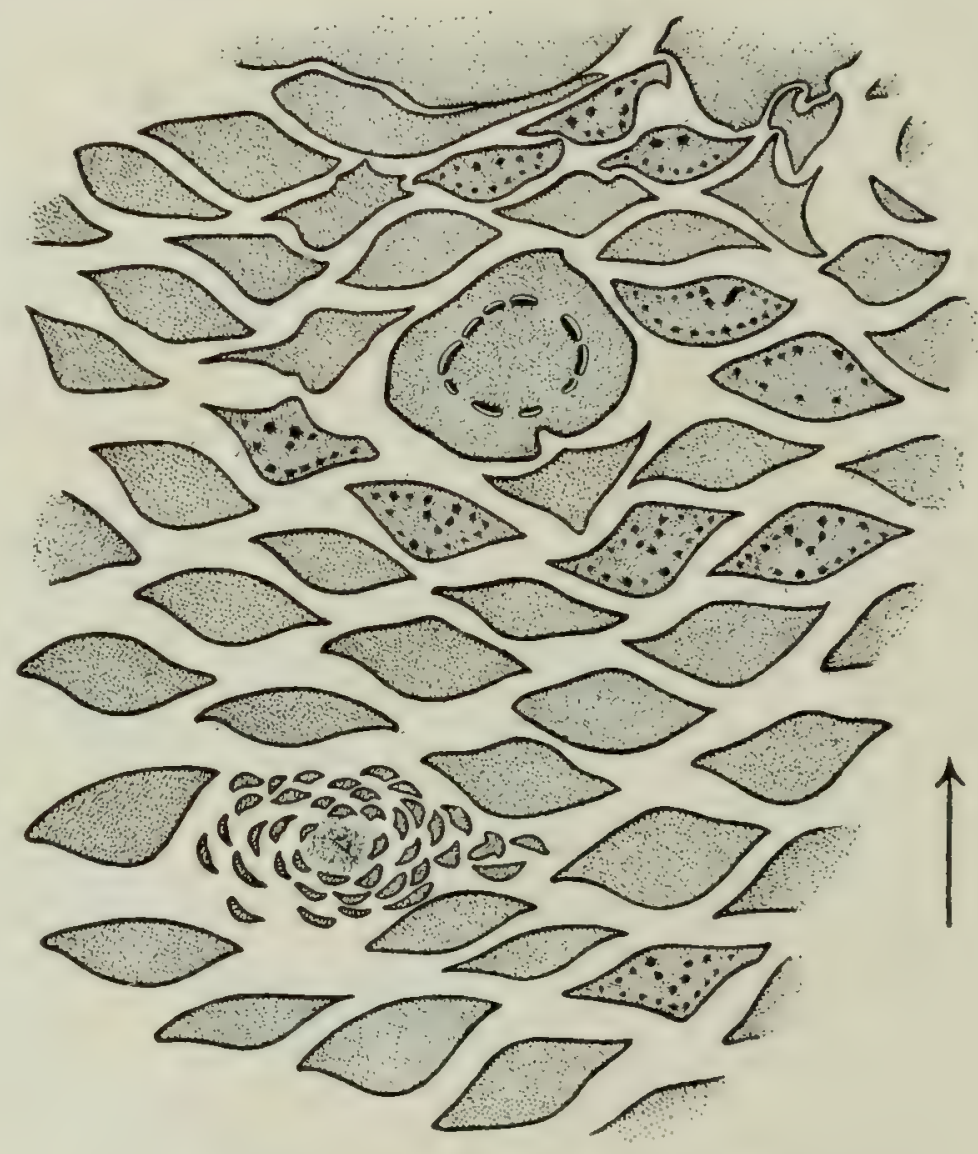

Fig. 25.-Cycadeoidea sp. T. 751.

Tangential section through a fragment from a trunk about $35 \mathrm{~cm}$. in diameter, cutting obliquely through the armor and into the cortex which appears on upper side of figure. Lower leaf bases cut $4 \mathrm{~cm}$. distal to cortex, the obliquity of the section compensating for upward slant of the leaf bases, so that they are cut in about a true transverse section. Ramentum not shown. Since the large peduncle above is cut several centimeters nearer the cortex than the lower fruit, it is not clear whether the latter, as at first appears, is younger or not. $X_{3}^{2}$.

The marked increase in the size of the transverse sections of the leal bases, the diminution in the quantity of the ramentum, and the increased regularity of the spirals are noteworthy features disclosed by the more deeply cut sections of the armor. Were the present and preceding sections cut by different observers from different trunks of the same species and from different localities, any difference noted might without due consideration be held of specific value; or if the peduncles chanced to be poorly indiconsideration be held of specific value; or it the peduncles chanced to be poorly indi-
cated or silicified the differences taken together might well be held of generic value.

amount of change can always be determined and the true original position of every individual leaf base always made out. Where this proves at all difficult, several sections cut at successively lower levels, as suggested by figures 18 to 29 , and more especially by figures 25 and 26 , will make the order clear.

As the insertion of the leaf bases on the cortex is approached, their area becomes larger and the amount of intervening ramentum correspondingly less. 
Moreover, in such sections the bundle patterns are usually present and unfailingly serve to orient the several leaf bases. In the illustrations accompanying the present topic examples are shown representing varicus stages of regularity, passing step
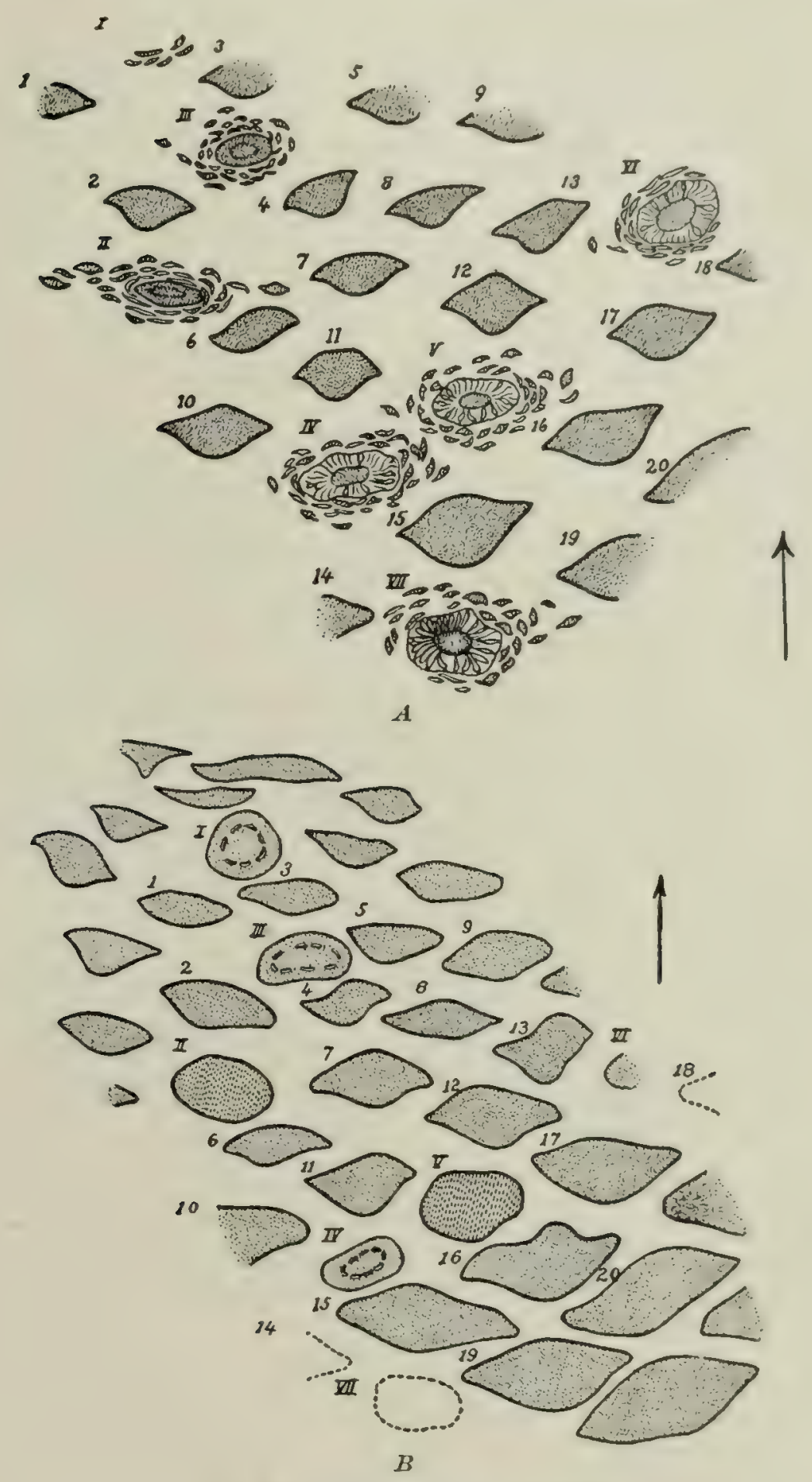

Fig. 26.-Cycadeoidea sp. T. 758.

Fragment of a trunk estimated to have had a diameter of from 30 to $35 \mathrm{~cm}$. showing a characteristic growth stage. $\times \frac{2}{3}$.

A. Slightly oblique tangential section cutting armor about $2 \mathrm{~cm}$. beneath its surface. I-VII, fruits in a fairly well advanced stage of growth, young seeds appearing in $\mathrm{I}_{\text {, and }}$ III-VII. Nos. 1-20 denote the leat bases as much thrust aside by the emergence of fruits. The high angled or left-right spirals are represented by leaf bases $1 ; 2,3 ; 4,5$; $6-9 ; 10-13 ; 14-18 ; 19,20$, respectively. The low angled of right-left spirals are represented by leaf bases $3,5,9 ; 1,4,8 ; 13,18 ; 2.7,12,17 ; 6,11,16,20 ; 10,15$, 19; and 14.

B. Transverse section through armor, passing $2.8 \mathrm{~cm}$, beneath the section shown in $A$, with lear bases and peduncles similarly numbered. Note the increase in the size of the transverse sections of the leaf bases and the marked decrease in quantity of ramentum. by step from the normal undisturbed spiral order seen in figure 18 to an extreme of disturbance in the spirals of a profusely fruiting lateral trunk surface like that shown in figures 27 and 29. In the latter case a still larger area, or else a tangential section cut near to the cortex, would be required to make clear the original leaf-base spirals. It is therefore evident that in the Cycadeoidex the degree of regularity in the leaf-base spirals is, independently of a knowledge of the particular stages of fructification and growth represented, of no value whatever in the determination of genera or species.

The second cause of great variations in the general appearance of the armor is the particular level at which periderm formation has taken place, as in part no doubt dependent on the age of the trunk at the time of fossilization, taken together with the extent to which erosion has removed the ends of the leaf bases.

Thus on two sides of the same trunk an entirely different appearance may be presented, due to the difference in the level of the surface of preservation with respect to the insertion of the leaf bases on the cortex. 
Two further differences, due rather to abnormal features of preservation than peculiarities of growth, require mention. Owing to the frequent failure of the ends of the leaf bases to silicify, they are often represented by cavities more or less encroached upon by the surrounding ramentum before complete silicification took place. Also, in some trunks in particular, there is a much greater ridging and furrowing of the leaf bases than appears to be normally present. This would seem to be due to some kind of contraction during or else to desiccation previous to the process of silicification. In figure I9 an example of a normal leaf base of Cycadeoidea ingens is shown. But this and the closely related $C$. Jenneyana frequently present the very greatest variations in transverse sections, as is well illustrated in figure 27. As there shown, a few normal transverse sections of leaf bases are present, but most of the bases have undergone very pronounced changes in size and form, so that taken by themselves it would be impossible to determine the true form or species. When now the varying height at which leaf bases may

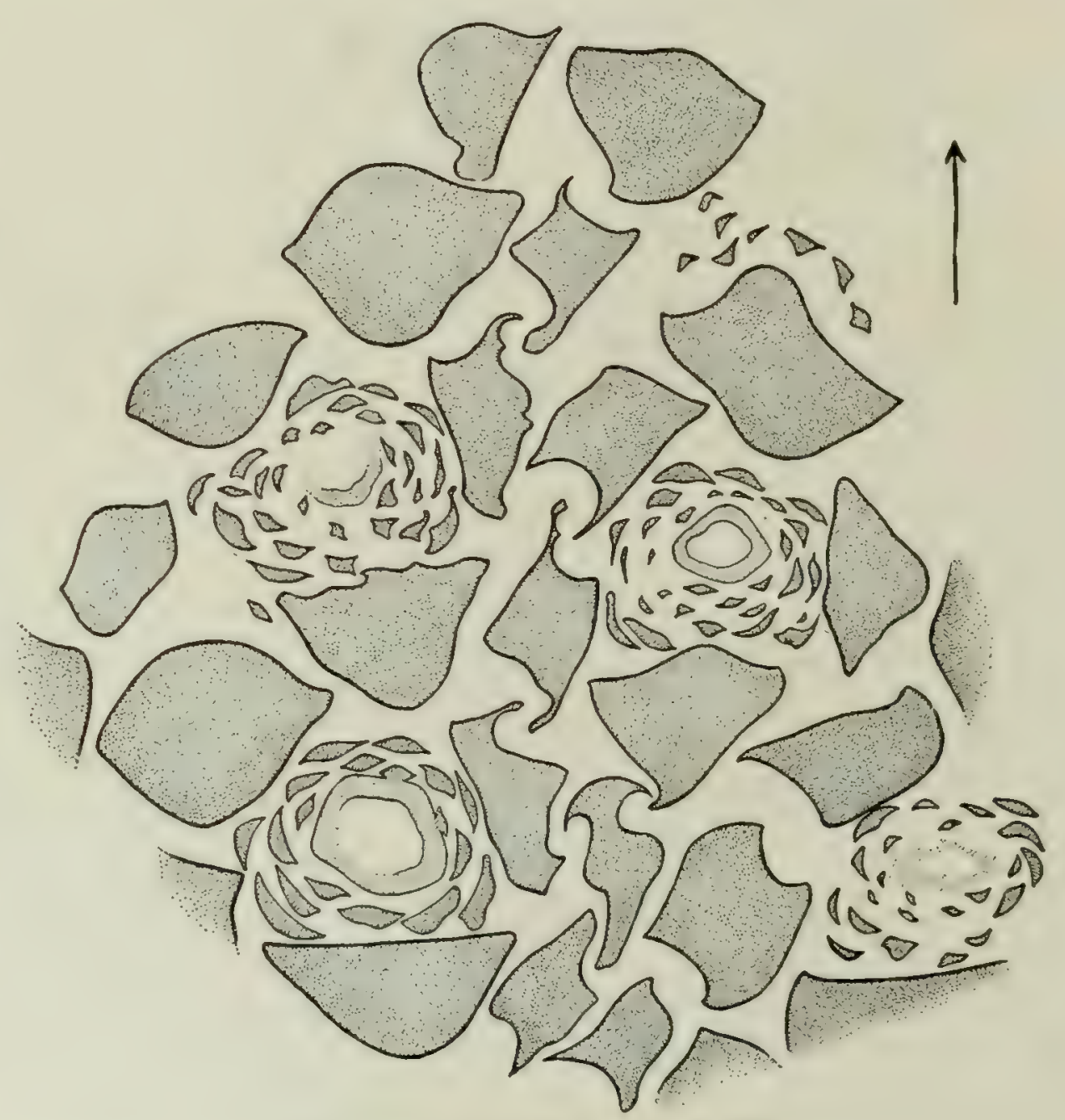

Fig. 27.-Cycadeoidea ingens. T. 568.

Transverse section of armor of a trunk about $40 \mathrm{~cm}$. in diameter, cutting several young fruits and showing much irregularity in the form of the leaf bases. Tangential to cortex at a distance of 5.7 to 6 centimeters. $\times \frac{2}{3}$.

be preserved in different species from widely separated localities is further considered, together with variations in size and age of individual plants, it will be fully clear that size and regularity of leaf-base spirals are most inconstant. Subject to such endless variation, leaf base features must hence only be used as specific indices with the greatest care and circumspection, supplemented by the study of thin sections. As macroscopic leaf base characters have been so much used in establishing species in both Enrope and America it has been deemed of importance to insert the series of drawings, figures I8-29, showing how subject the armor sections of fossil cycads are to variation and how little they may in themselves be relied on in establishing species. As will be noted, in many cases the leaf-base bundle patterns are indicated 
and show considerable variation in the same section. With regard to the specific names of the sections figured it is to be added that these are simply those that have been used thus far as a necessary, though arbitrary, convenience. A few supplementary photographs of such sections are slıown on plate XVII.

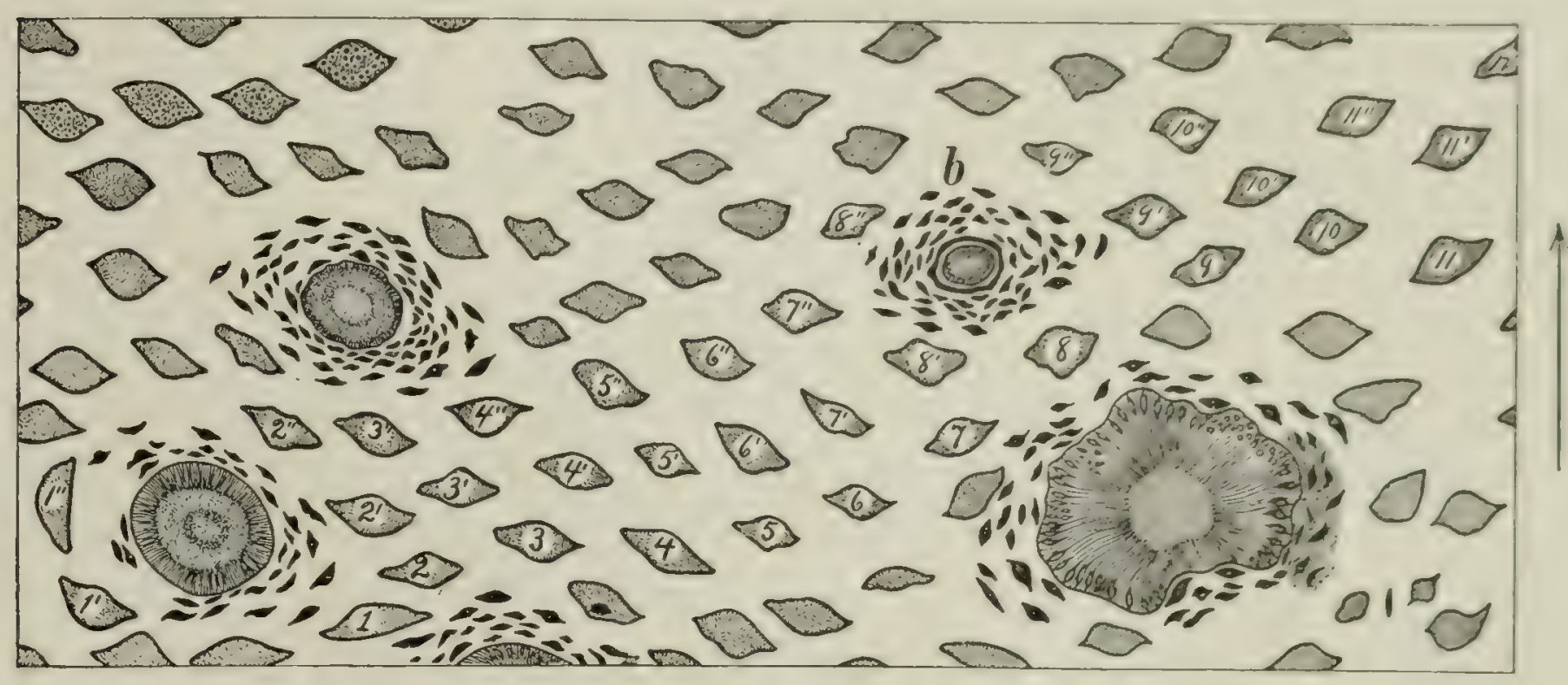

Fig. 28.-Cycadeoidea dacotensis (?). T. 505. $\times \frac{9}{16}$.

Tracing made from polished columnar surface of trunk, illustrating distorted symmetry of the old leaf base spirals due to fruit growth and emergence.

Three of the originally symmetrical leaf base spirals running from left to right are numbered $1-11,|1-1| 1,111-1] 11$, - the right to left order beng $1-11 ", 2-2 ", 3-3 "$, and so on. The smallest axis of fructification (b), is bisporangiate, and the three larger of the four distinctly ovulate cones present are so far advanced in growth that if all the cones borne by the trunk are of the same season, a monoecious rather than a functionally bisporangiate condition would be indicated. The bundle patterns of the four leaf bases of the spiral above and to the left are shown. (A layer of armor 1 to $2 \mathrm{~cm}$. in depth was polished away to secure the surface traced. Cf. figure 26.)

\section{Leaf Base Bunde Grouping.-Figures 30-33.}

The general form and grouping of the leaf bases as thickly beset by and packed in ramentum having been considered, it is next in order to take up structure; and the most prominent feature in this connection is the bundle arrangement, which can often be readily observed on the naturally weathered or eroded ends of the leaf bases without the aid of thin sections. The illustrations of bundle grouping shown in the accompanying figures include all of the characteristic types observed. In general the more or less concentric or horseshoe-like bundle, or pair of bundles, which enters the leaf base first splits up into from ten to twenty mesarch bundles, forming in transverse section a round to elliptical pattern with the xylem directed inwards. But a depression soon forms on the superior side of this pattern and gradually deepens, the final stage, as can be observed in the sections of the petiole and rachis of young fronds, outlining a heavy $V$, with a tendency for the ends of the arms to approach each other. (See figures 30 and 33.)

There are, finally, so far as observed, two other types of bundle arrangement of far more infrequent occurrence than that just described. In $C$. ingens ( $\mathcal{f}$. fig. 33, No. I2) and, as is also evident from the figure of a portion of a leaf base, in C. gigantea from the Portland Beds of the Isle of Purbeck (as given by Seward, I 44, plate V, fig. I8) there is no definite bundle pattern, as the result most likely 
of the breaking up of a simple and normal series of bundles much after the manner shown in the accompanying text figure 32,5 to characterize Encephalartos. This irregular form is also present in Cycadeoidea Jenneyana.

In C.nigra, as ontlined in figure 3 I A, a much rarer form of bundle grouping is present, thus far only observed in the single specimen on which this species is founded. In this case two accessory groups of bundles, or else two single brokenly concentric bundles, lie in the upper angle of the leaf base, just outside the V-like depression in the main continuous series of bundles, which is in other respects of the usual cycadeoidean pattern.

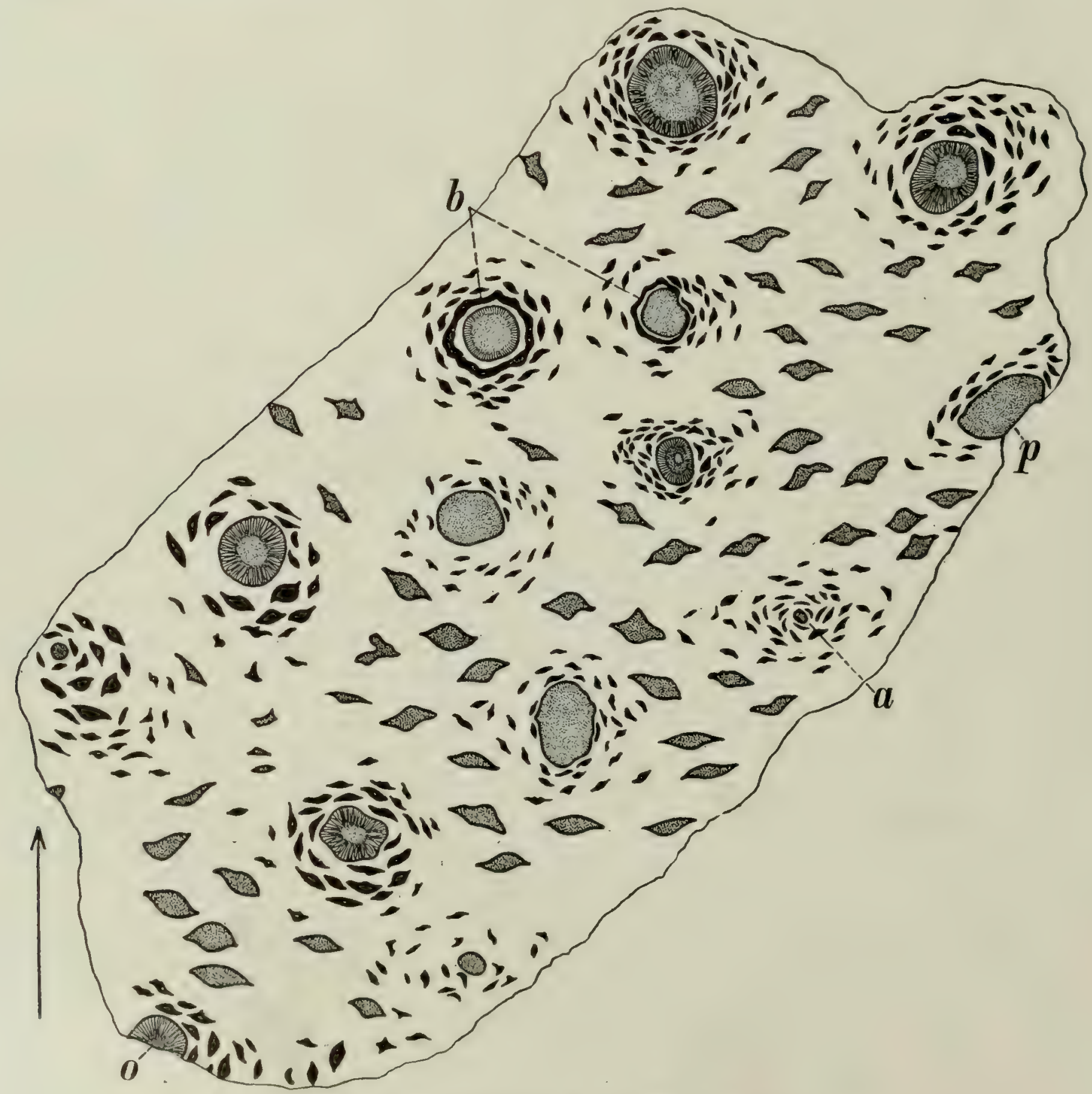

Fig. 29.-Cycadeoidea sp. T. 750. Y.

Tracing from polished surface of trunk, illustrating distortion of leaf base spirals by fructification.

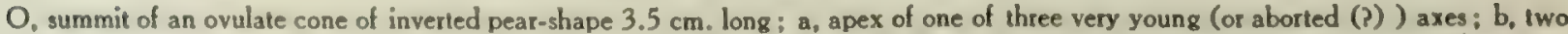
bisporangiate axes, of which the larger bore apparently full grown sori. Section of staminate disk in solid black; $p$, one of three nonconserved axes, which, from the rather small size of their bracts may be young, rather, than the elongated peduncles of matured or nearly mature fruits. (On the basis of this section alone it is impossible to say whether the fruits present represent one, two, or three seasons of growth, or whether a monoecious, bisexual, or mixed flowering habit is indicated.) 
Before discussing bundle types it should be noted that evidently, in studying the leat-base bundles of a trunk, it will always be necessary to cut at least three serial sections from several adjacent leaf bases - preferably from a given portion of the armor-in order to definitely trace the progressive changes undergone by the bundle pattern and in the distribution of xylem and phloem. One of these sections should lie near the cortex; the second should be cut near the middle, and the third from the peripheral region of the armor. The accompanying petiolar form may of course be determined by a section through the crown of the trunk when

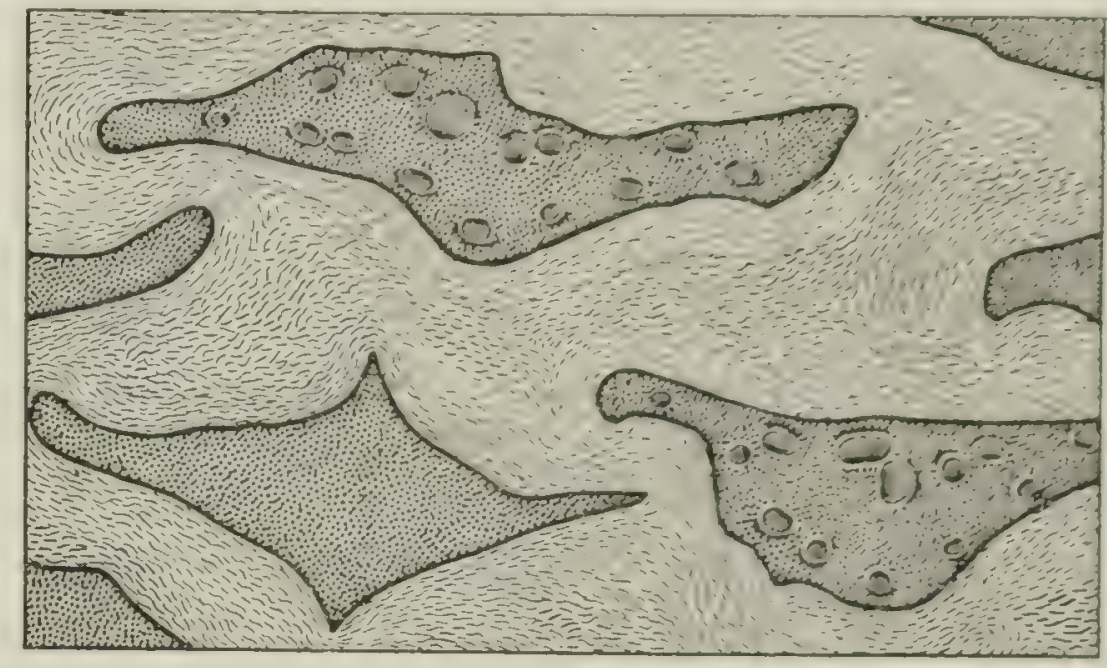

Fig. 30.-Cycadeoidea dacotensis.

Showing bundle pattern of younger leaf bases and the heavy development of centrifugal xylem. S. 506. X 4. Fr. V, T. 214. young fronds are present, as is fortunately the case in scores of the trunks from the Black Hills. Further serial sections would also be required to determine the exact order in which the leaf trace splits up in the outer cortex and in the leaf-base insertion to form the bundle pattern. Though such have not been prepared from any of the American specimens, a certain degree of complexity may be expected, since Lignier has shown that in $C$. micromyela (84, fig. I9) the single cortical leaf trace first trichotomizes; then the median of these three main branches subtrichotomizes to form

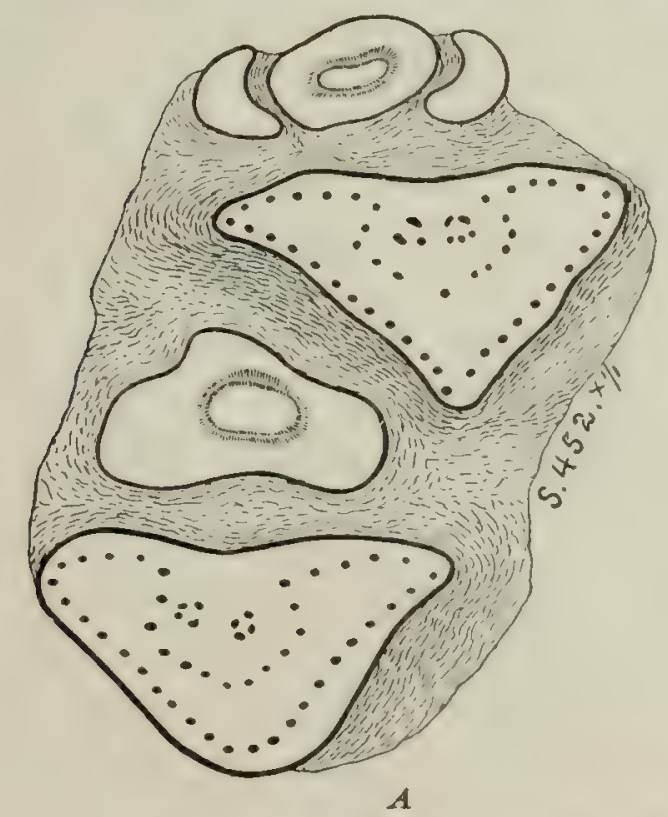

Fig. 31.-Cycadeoidea nigra, type. Boulder, Colorado. (A) Natural size; (B) $\times 3$.

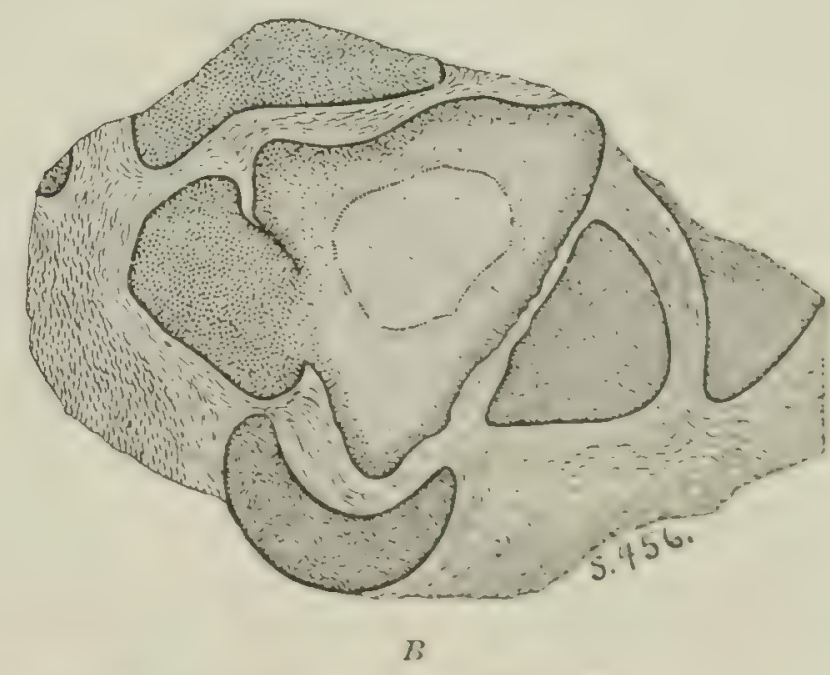

(A) Transverse section through the armor, cutting two adjacent leaf bases and their axillary peduncles at a distance of several centimeters from the cortex. The two lowermost bracts, or perchance pollen-bearing frond bases, of the upper peduncle are inserted a little beneath the level of this section, while the lower peduncle is cut beneath the insertion of the $\mathrm{l}$ wermost of is lateral organs. The cylindrical bundle of the peduacle and the bundle grouping of the leaf bases are both shown. (The remarkable trunk from which these sections were cur bears similar peduncles to those here shown in the axil of every frond over large areas of the lateral surface, but no basal portions of strobili semain.)

(B) Transverse section cut distally parallel to preceding, showing five large bract or microsporophyll (?) bases surrounding central peduncte. 
the three bundles in the lower angle of the leaf base, while each of the lateral branches dichotomizes twice in such a manner that the fourth bundle formed swings from beneath into the upper angle of the leaf base, there to form with its mate and the other lateral and median bundles a regular peripheral distribution.

An interpretation of the cycadeoidean leaf-base bundle patterns may best be made if it first be recalled that the petiolar bundles form a closed or simple circular pattern in Stangeria and Bowenia, and are irregularly distributed in Encephalartos; while in most, if not all the other genera of existing cycads the pattern of an inverted omega is finally assumed (cf. figs. 32 and 33). Normally the xylem is interior or inverted, using this word in the sense of inturned, while the phloem is everted or out-turned. But in Encephalartos (fig. 32, No. 5), excepting the peripheral layer of bundles with inverted xylem, extending around most of the under side of the petioles, the numerous bundles have no distinct xylem orientation, and the grouping is a mixed one, presumably obscuring an omega pattern. Moreover, the simple or Bowenia form develops into the omega pattern by simply opening out above. The two outer branches then give rise to the pinnule supply by simply spreading upward and outward till their xylem comes to be superior.

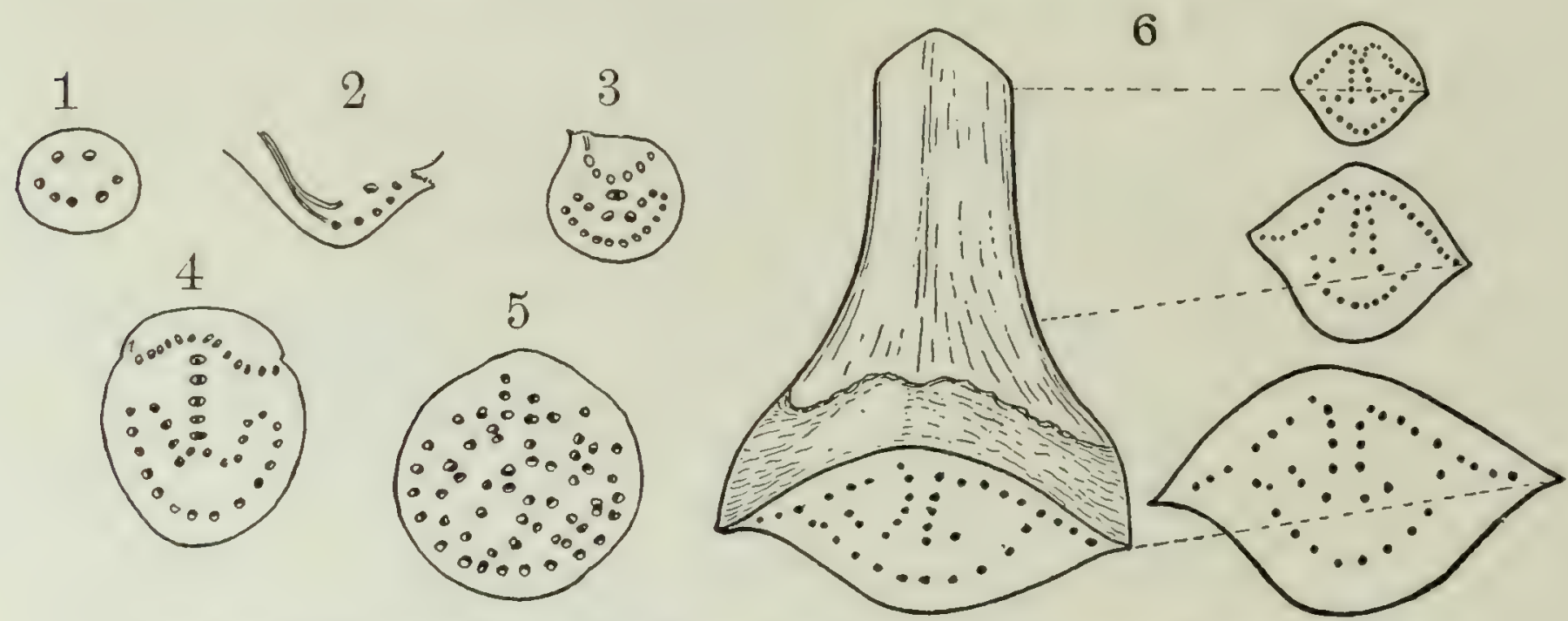

Fig. 32. - Typical bundle patterns and features of the petioles and petiole bases of existing cycads.

1. Bowenia spectabilis. $\times 11 / 2$.

2. Zamia foridana. Leaf base near cortical insertion showing the emergence of the right-hand girdle leaf trace from the cortex.

3. Zamia Roezlii, showing a bundle trace as given off to a pinnule.

4. Encephalartos (?) cycadifolius. $\times 2$.

5. Encephalartos V.roomi. $\times 2$.

6. Cycas celebica. $\times 1 \frac{1}{2}$. Basal portion of petiole, and three serial transverse sections of the same, showing origin of inverted omega bundle pattern from a simpler form. In the lower section 38 bundles are cut, these increasing to 42 in the middle section, and this number continuing the same in the upper section.

In the Cycadeoidex the necessity for comparing the leaf base rather than the petiolar pattern in many cases prevents a close comparison; but the data at hand indicate, as has just been noted, a more fern-like closed pattern to be the characteristic one, with a pinnular bundle supply arising from the upper sides of the system, as left by a depression of the middle upper bundles into a deep $U$-shaped valley, instead of a parting of the series as in the omega form. There is also, as has been seen in C. Jenneyana, C. ingens, and C. gigantea, a mixed distribution, much like that of Encephalartos; while in C. nigra the two additional groups of bundles circularly arranged, or else two single brokenly-cylindric bundles in the upper U-like 
depression outside the main continuous series, must indicate the origin of the pinnule supply. This unique arrangement thus really represents a transition form.

It is also probable that the simple closeci or Stangeria and Bowenia type must have been more widely present in fossil forms. Hence the closed cycadeoidean as contrasted with the open or omega pattern, characteristic alike of the ancient Cycas
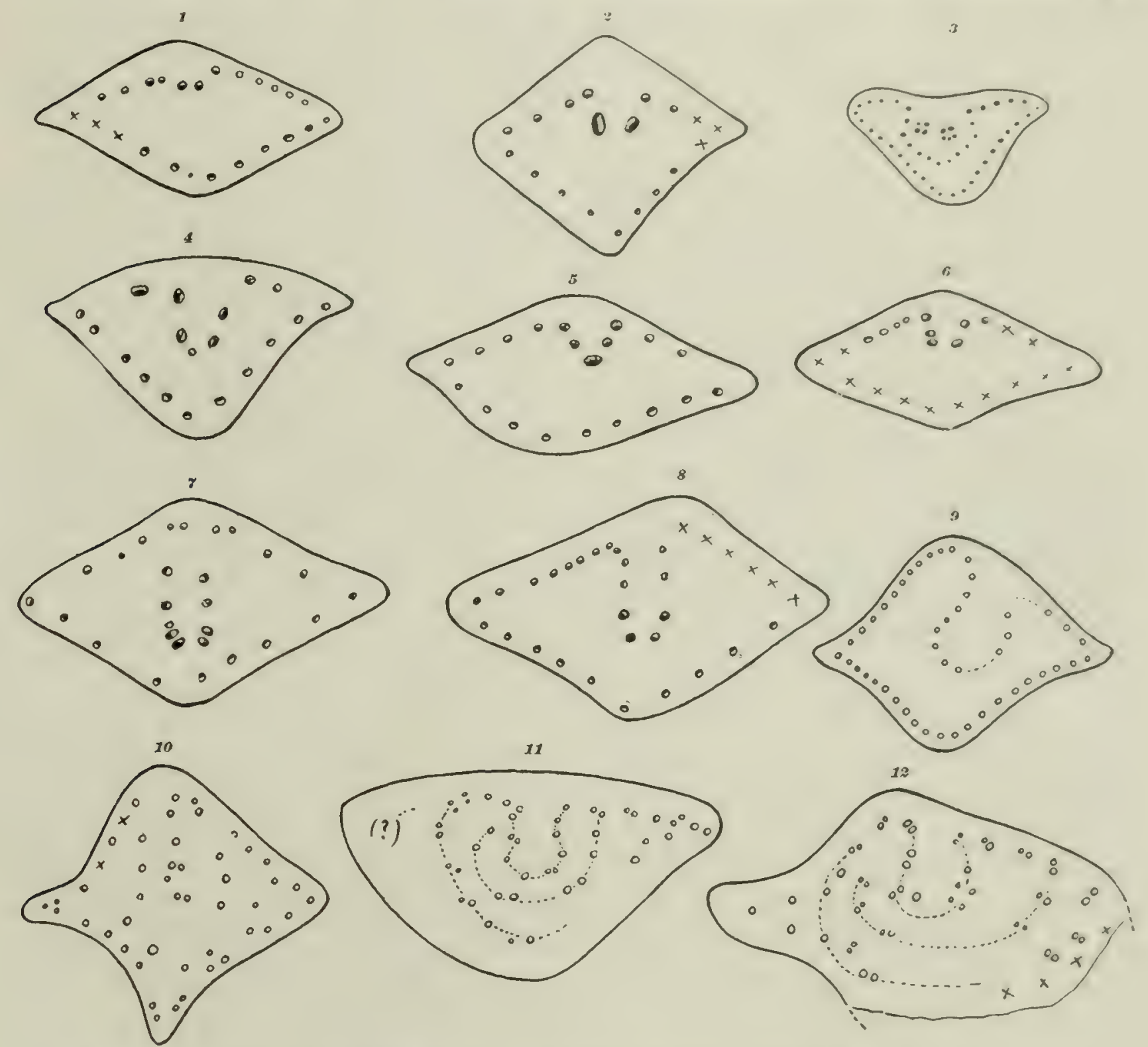

Fig. 33. - Leaf-base and rachis bundle patterns of various cycadeoidean species as seen in transverse sections.

1. Cycadella (Cycadeoidea) utopiensis, type. S. 339. $1 \mathrm{~cm}$. distal to insertion of leaf base on cortex. $\times 2$.

2. Cycadeoidea Stillwelli, type. From fractured surface $1.5 \mathrm{~cm}$. distal to cortex. $\times 2$.

3. Cycadeoidea nigra. Cut several centimeters distal to the corlex. Natural size.

4. Cycadeoidea Macbridei. T. 18. S. 318 and 319 . Several centimeters distal to cortex. $\times 2$.

5. Cycadeoidea dacotensis. S. 201. $\times 2$.

6. Cycadeoidea turrita. S. $24 . \times 2$.

7. 8. Cycadeoidea superba. T. 147. S. 337 and $338, \times 2$.

9. Cycadeoidea ingens, type. S. 173. Cut well out on the basal portion of a pinnule-bearing rachis, and hence not directly comparable with the other sections. $\times 2$.

10, 11, 12. Cycadeoidea ingens. T. 208. Natural size. From polished surfaces. No. 10 is farthest distal, and 12 lies near leaf-base insertion. Rapid increase in number of the bundle: by forking is seen to occur at level of 11 and 12 . without distinct grouping.

and the more modern Zamice, can not be considered as fundamentally different, although forming a distinction of considerable taxonomic value. The omega type of bundle distribution results in a heavy continuous ridge between the two rows of pinnules, while the closed type would appear to produce closely-set pinnules with the nearly-overlapping bases seen in such forms as Ptilophyllum and Otozamites. 


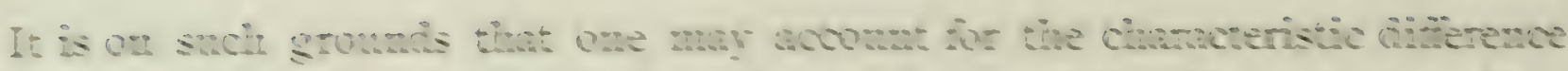

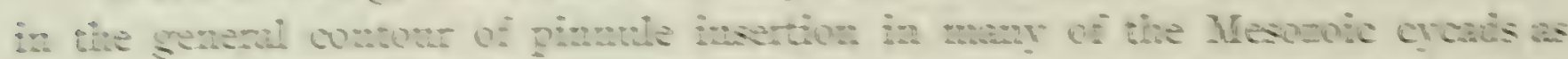

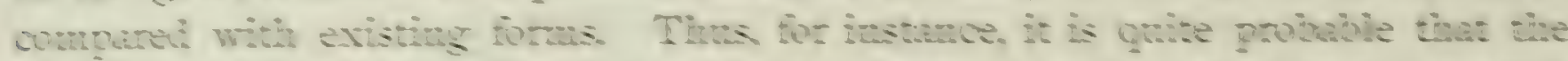

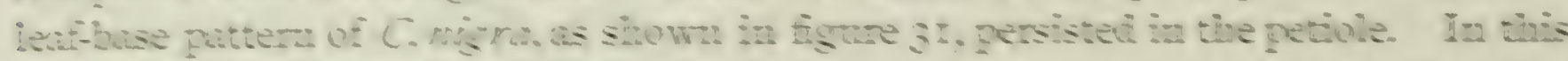

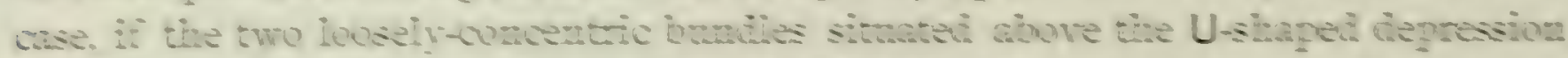

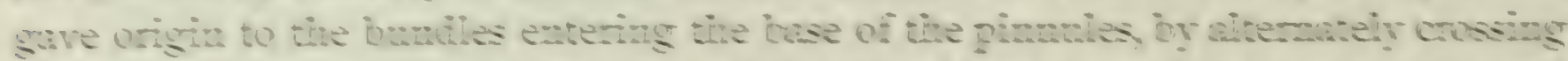

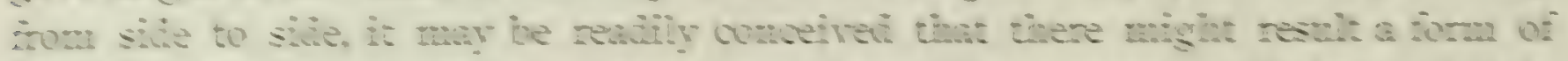

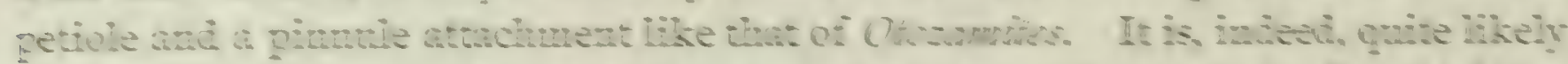

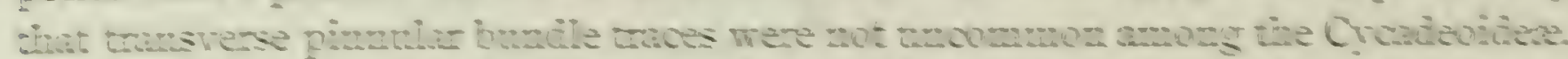

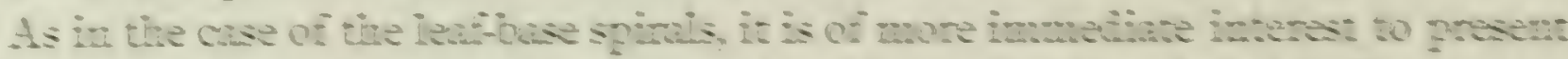

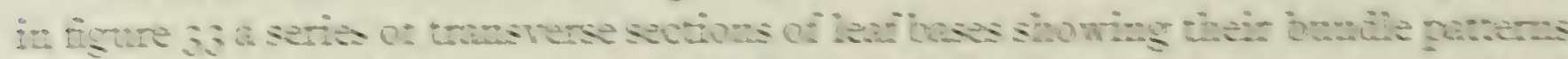

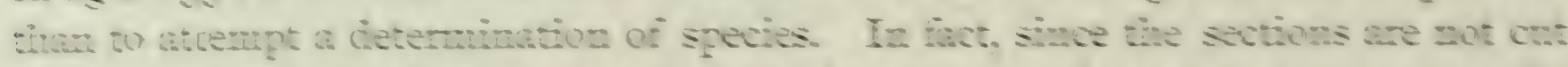
At the sume approximate level and from the same trumb regions provise specitio

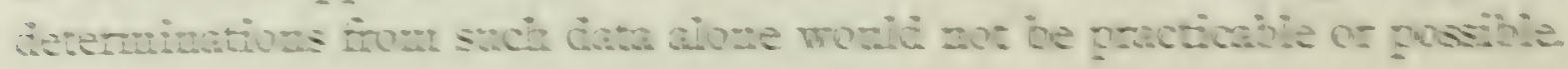

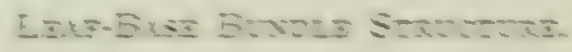

Pasing by the len-buse parewchyma and the Cermi and hyoviermal scierew-

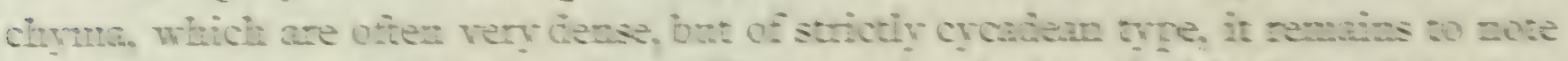

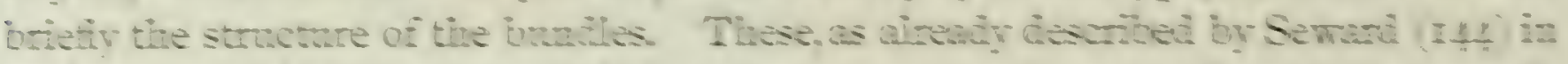

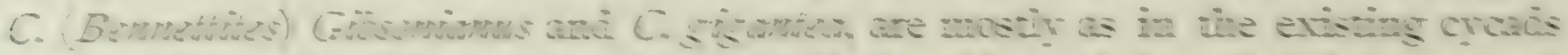

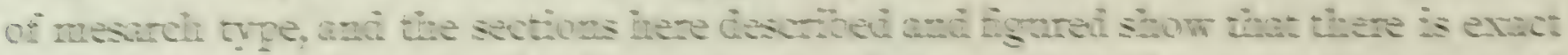

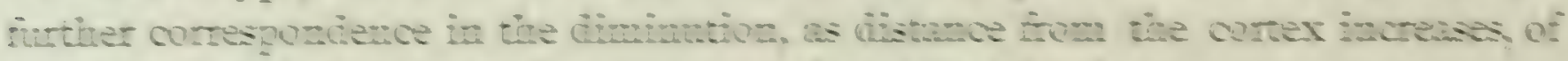
centrifugail with a correspondirs increse of centripetai xylem.

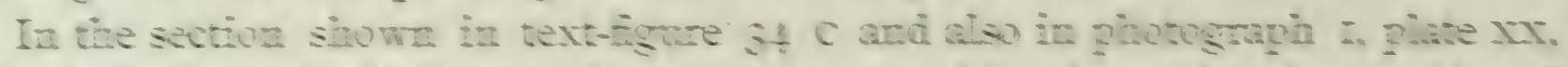

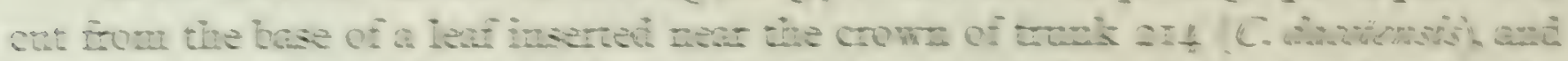

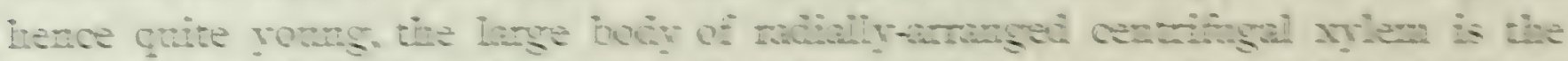

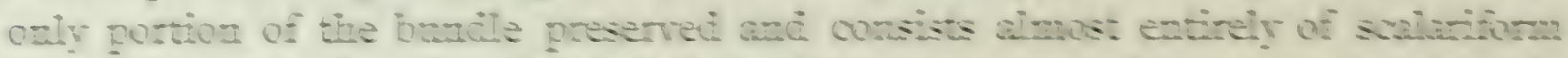

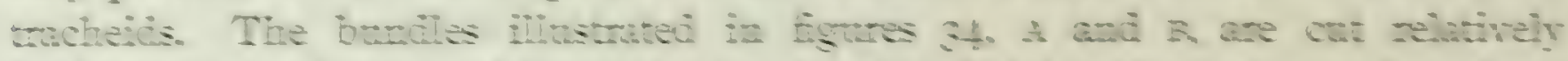
Either oft at a cistance of Eom 2 to 3 centimeters Gistal to the cotex. and are fiom

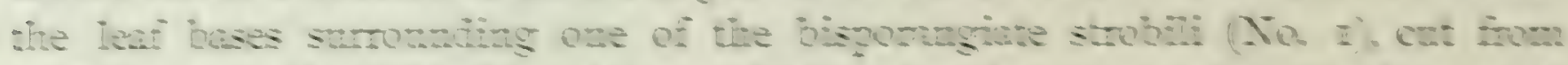

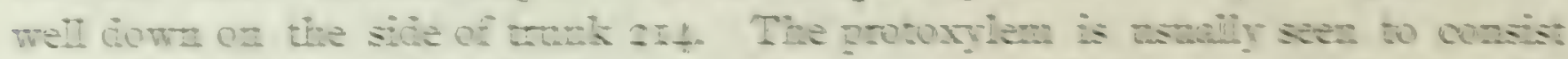

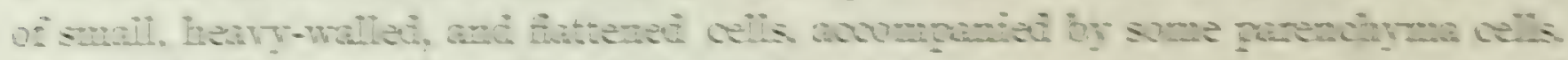
Interior to these are the ce"ls of the cemtrigetal xylem. varying moli in site and

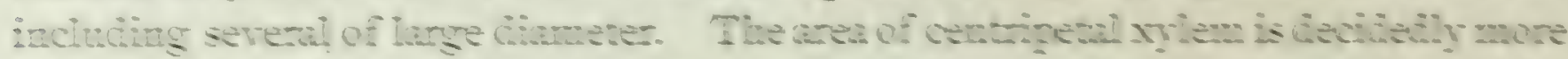

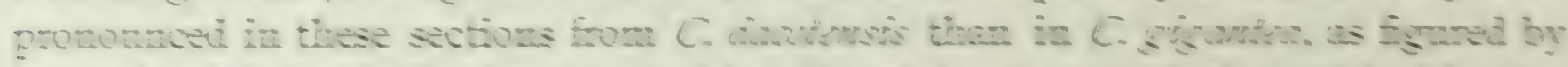

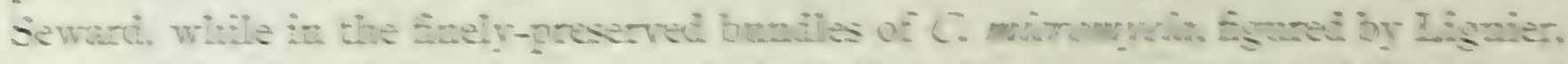

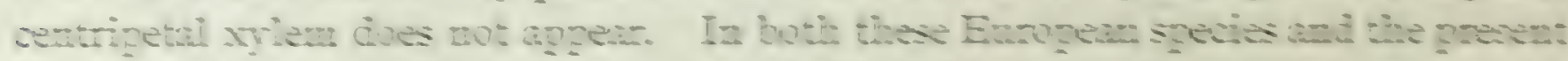

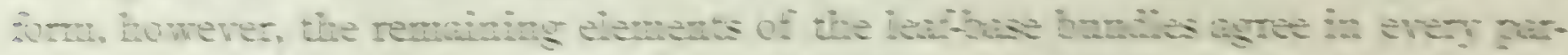

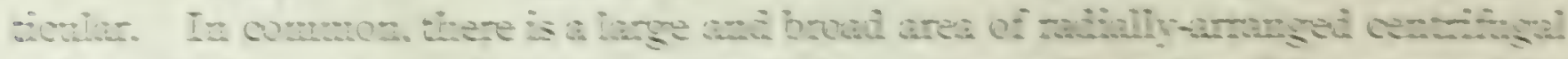

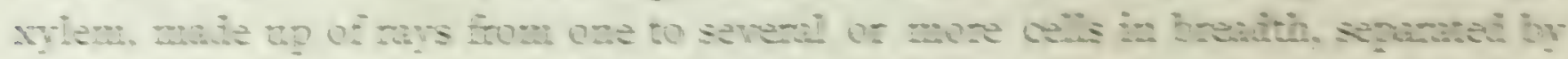

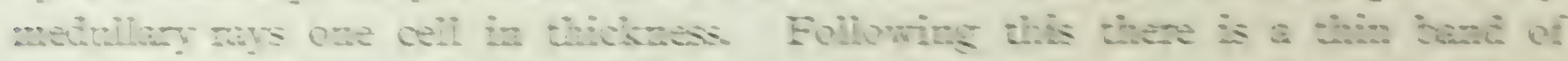

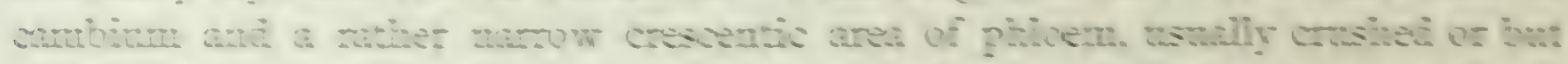

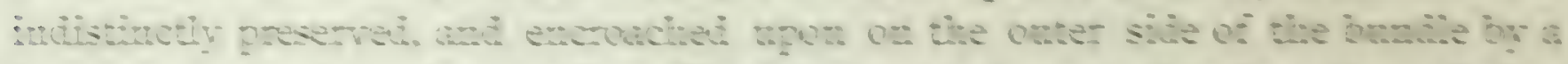

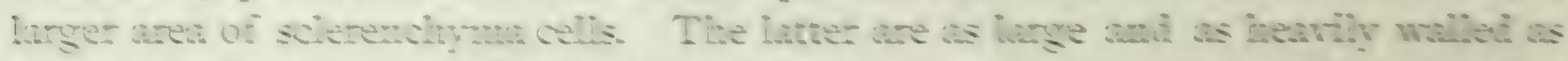

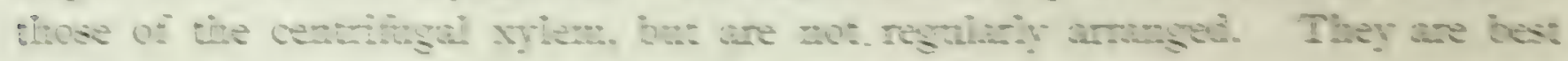




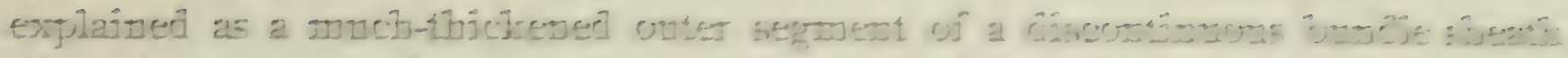

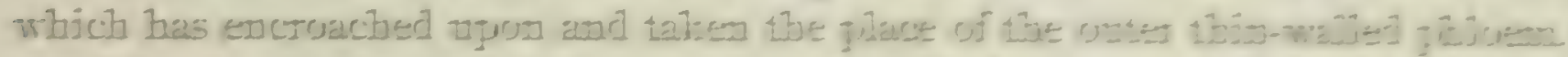

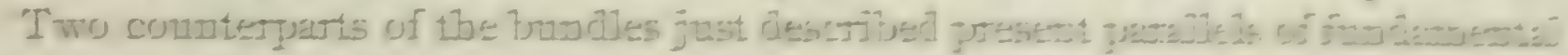

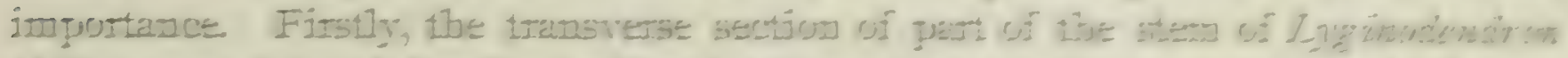

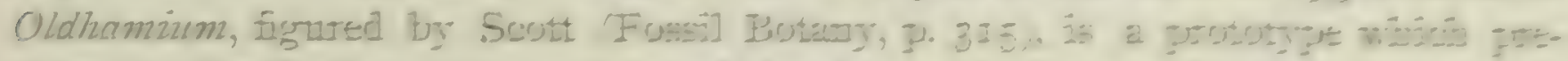

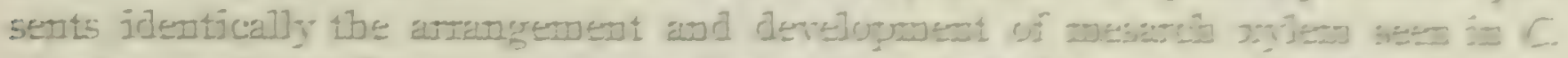

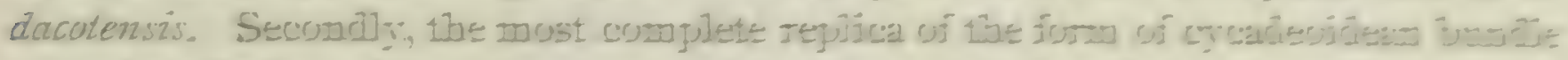

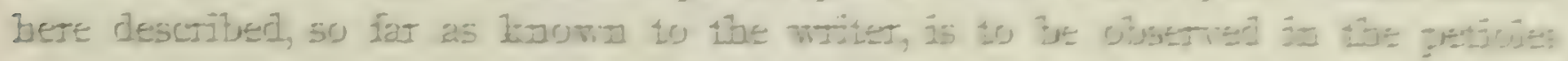

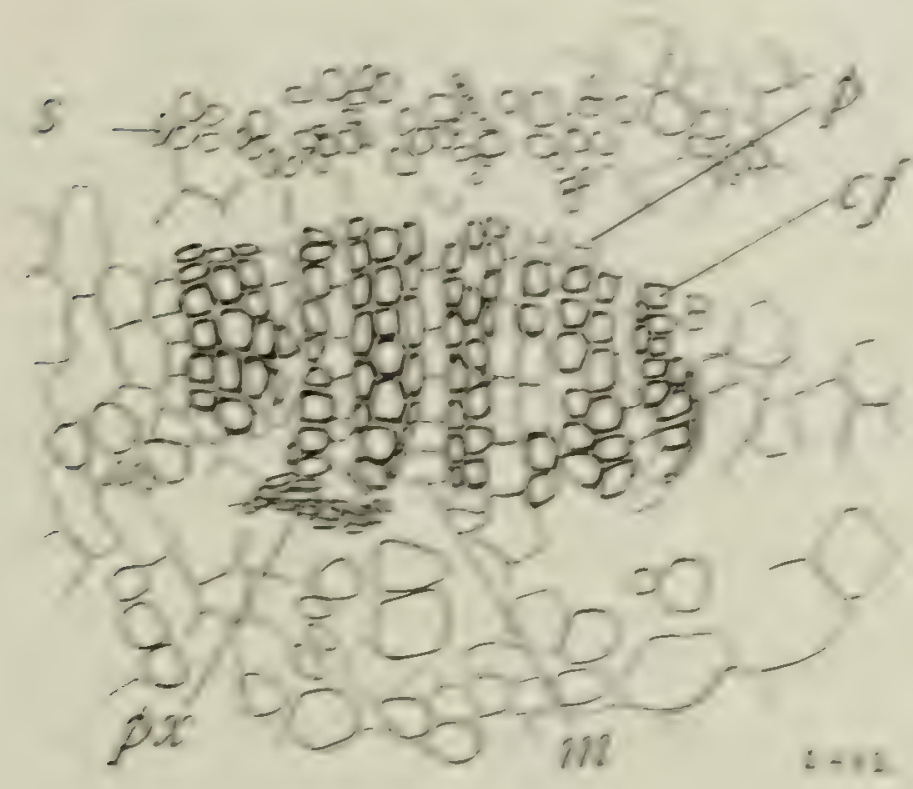

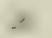

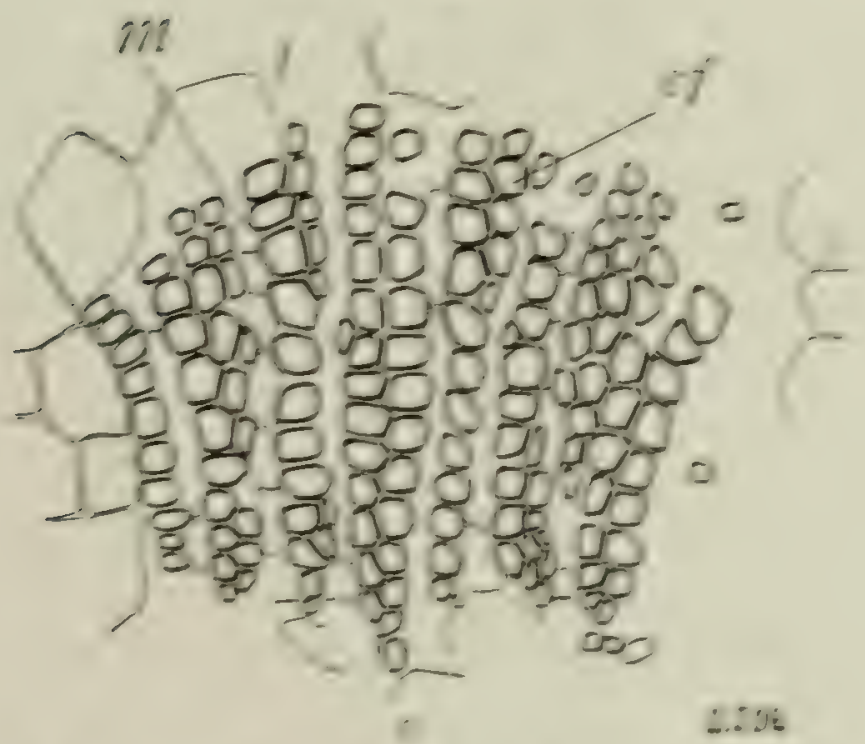

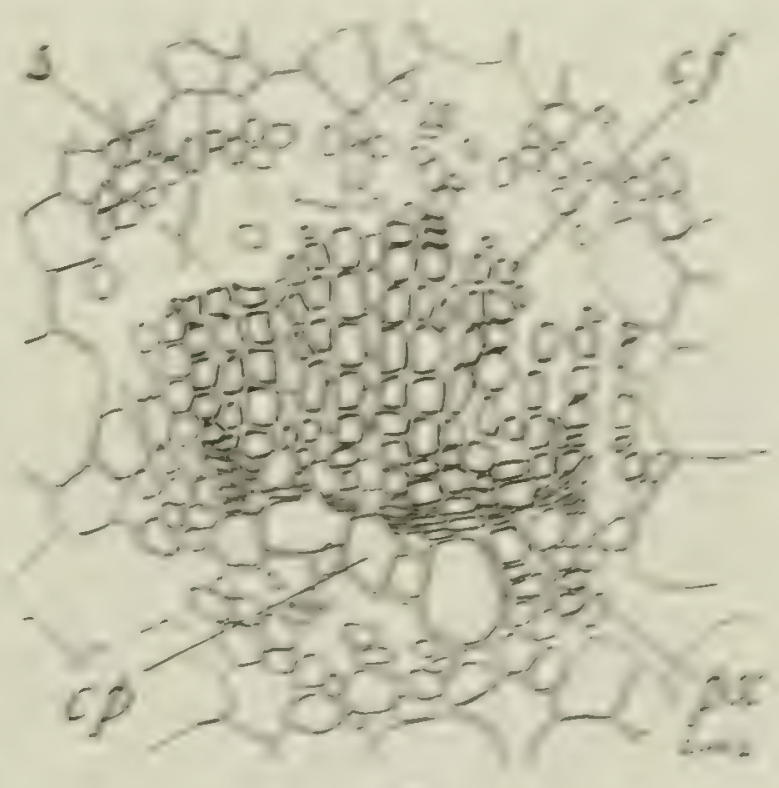

$:$

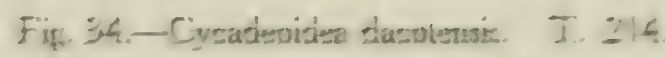

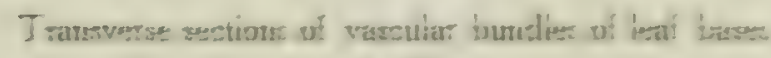

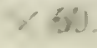

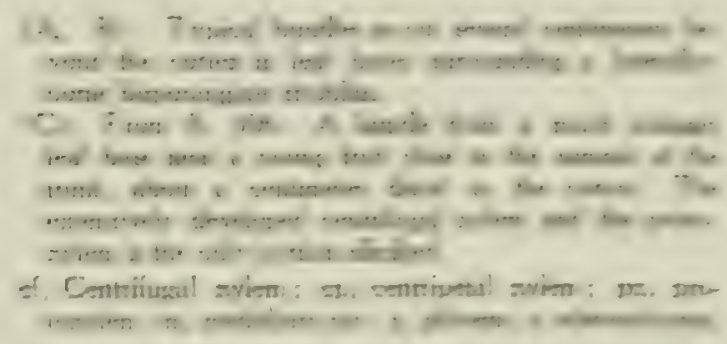

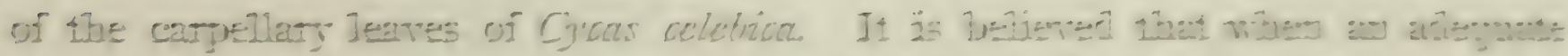

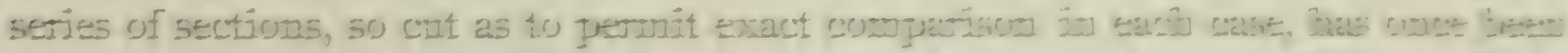

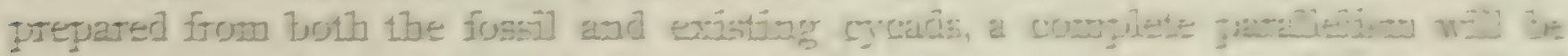

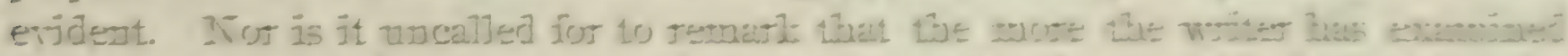

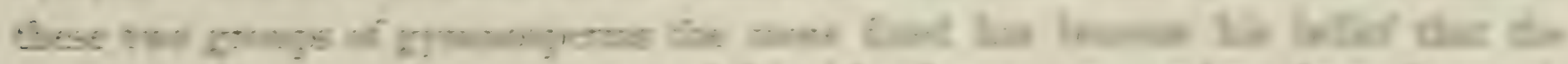

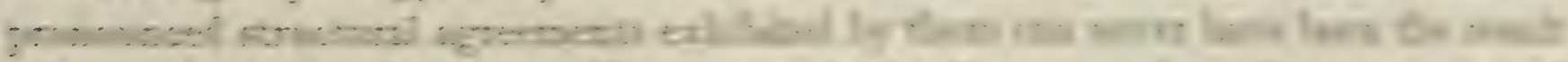

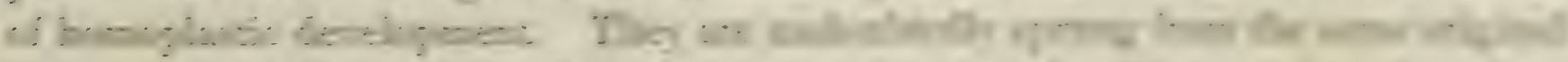

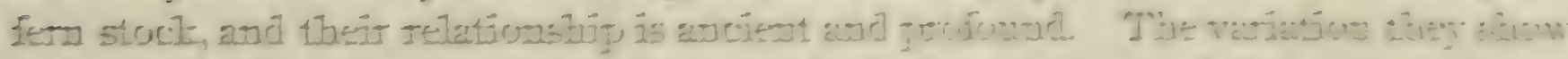

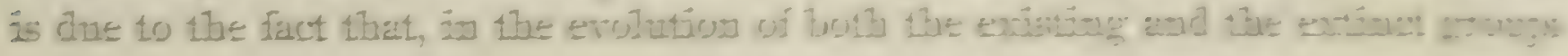


of cycads, nature seems invariably to have seized upon the reproductive organs and to have found them the most plastic and susceptible of change. In the one case the much greater change went on in the megasporophylls, and there was evolved a form of true flower exactly suggestive of the types of change in reproductive organs that resulted in the angiosperms. In the other both types of sporophylls were seized upon and carried forward through the same stages of reduction, save for that single, wonderful, and marvelous survival from the Paleozoic, that analogue of the staminate frond, the carpopliyll of Cycas.

CORTEX.

GENERAL FEATURES.

In the existing cycads, as was first fully described by Mettenius (92), in order to supply each leaf base, two bundles take their origin near together on the stele or

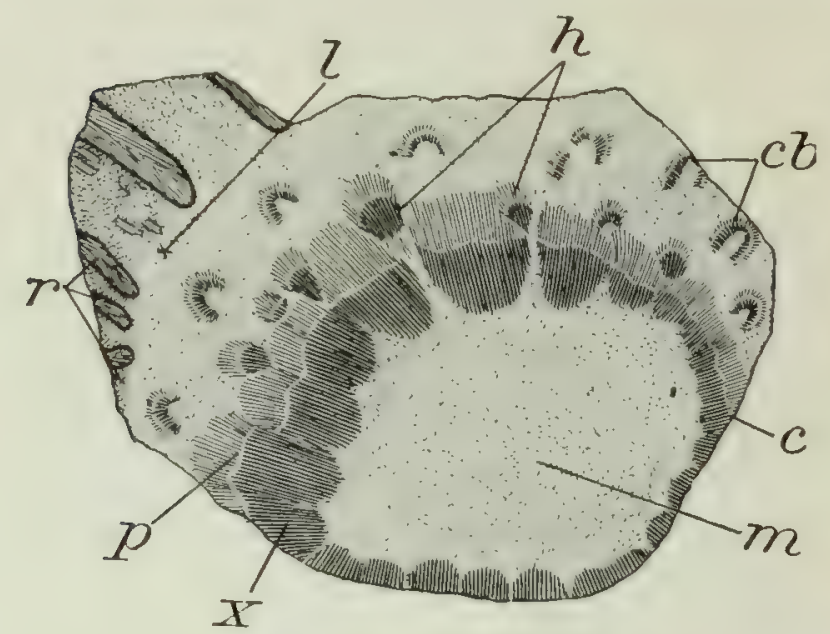

Fig. 35.-Cycadella sp.

Transverse section through the summit of a small silicified trunk from the Freezeout Hills, Carbon County, Wyoming, showing the medulla, woody cylinder, cortex, and a portion of the enveloping armor of old leaf bases. Natural size.

$m$, medulla ; $x$, xylem; c, cambium; p, phloem; $h$, leaf (or peduncle) traces arising from the xylem or woody cylinder; $\mathrm{cb}$, horseshoe-shaped cortical bundles, or leaf traces; 1 . insertion of leaf base in cortex; $r$, ramentum of leaf bases. woody cylinder, and then curve round the trunk in opposite directions, thus passing outward and upward through the cortex for a long distance, in some forms nearly I $80^{\circ}$, or quite to the opposite side of the trunk, before entering the leaf base. Here subdivision takes place, the resulting bundles soon aligning themselves, as has just been fully illustrated, in an omega or else a circular order, as seen in transverse sections. All along the course of the curving traces through the cortex there is much anastomosing, not only between bundles of the same leaf base, but between those of different leaf bases, as well as with the woody cylinder. The peduncle traces, owing to the apical position of the cones, pass in to the medulla, the trunk literally growing through and past them.

Traces of simpler structure are not, however, wanting in very young trunks; but in view of the generally complex development of the cortical region it is of the highest interest to determine to what extent variations from a simple structural type may have been present in the Cycadeoider.

Very clearly the course of the leaf traces of the existing cycads is a recent development, possibly of post-Cretaceous origin, bearing in mind the simpler type of all the fossil forms known, as well as the fact of deviation from the simpler more fern-like cycadofilices. Consequently it can not be expected that amongst the Cycadeoidere any strongly marked departure from simpie types will be found. For generally considered the lateral peduncles, or fruiting branches, certainly find a not very remote analogue in the small and often numerous scale-leaf-bearing branches of Cycas; whence it may be said that the cycadeoidean trunks, aside from the order of the fruit-bearing branches, only differ at all widely from those of the existing 
cycads in their simpler cortex, all the other main features of structure and arrangement presenting a striking agreement.

Course of leaf trace through corlex.-'The usually direct course of the cycadeoidean leaf traces was first described by Carruthers (24). In his description of the new genus Bennettites he says:

"The vascular tissue for each leaf springs from the woody cylinder in a single large compact bundle [ $c f$. the present text-figure 35], which as it passes outward breaks up into the different bundles required for the service of the leaf."

Concerning the lateral fructifications it is added:

"The axils of a large number of the petioles bore short branches. These axillary organs are important features in this group of fossil plants. In some fragmentary specimens every axil is occupied by a bud, as described by Mr. Brown; but more frequently the majority of leaves are without them. . . . These organs, however, are not properly buds, for although they do not appear to have pushed themselves beyond the permanent bases of the leaves, they are fully developed organs, and differ from the secondary axes of Mantellia, which are generally broken off beyond the surface of the permanent bases of the petioles, and show there a woody cylinder agreeing in structure with the principal axis of the plant."

These are interesting observations. A much more extended description was,

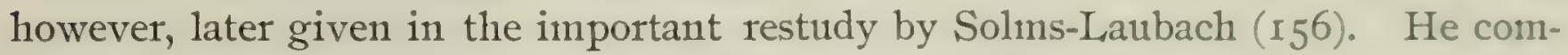
ments on the general resemblances of the woody cylinder to tree ferns, and while in the main showing the correctness of Carruthers' description, suggests the likelihood of the presence of a more complicated arrangement as follows:

"The lateral fruit-bearing shoots of Bennettites are, according to Carruthers, of axillary origin, as previously noted by $\mathrm{R}$. Brown. They are by no means present on every leaf axis, but on the contrary in most cases absent.*

"I may also remark that while this conception is most probable and certainly near the fact, the absolute conditions are well-nigh impossible to determine, though it is but a short time since they were wholly understood even in the living cycads. So far as I can determine from the sections at hand the position of the axes of fructification is wholly irregular. In places they emerge singly from the armor, and at other points they are in actual contact in thick-set groups. In the latter case one can not escape the impression that there may be lateral branching of the more advanced axis. Were this the fact, bushy systems of closely set axes could be formed with occasional isolated axes passing out between the leaf bases of the armor. An absolute proof of such a condition could not be readily made, even if unlimited material were at hand for the cutting of serial sections. The leaf bases lying between the fruits are for the greater part much deformed into variously irregular transverse sections, and the identification of both kinds of organs side by side is usually impossible. Where the fructification axes occur singly, there is always an exactly underlying leaf base, which is in other cases thrust entirely aside. But the pressure of the closely set organs of the armor upon each other must have obliterated most of the original contours. While, however, the material present does not permit an absolute determination of the axillary branching, there is absolutely nothing to indicate that the entire stem, as in the living cycads, is a sympodium. For there has not been found in the case of any Bennettites sections at hand a single trace of the characteristic bundle systems which enter the medulla of living cycads and indicate their apical fruiting."

* This is, of course, true of Bennettites Gibsonianus and the more closely related species, but not of such forms as Cycadeoidea nigra (cf. figure $3 \mathrm{I}$ ), and notably C. Stcmloni from the Californin Cretacenus 
It may at once be stated that in no specimen studied by the writer has there been found evidence of lateral branches bearing groups of cones only without intervening leaf bases, though such might certainly occur anong the Cycadeoideæ. In all the American specimens the cones occur as simple and single short axillary or nearly axillary lateral branches; and in the case of branching trunks, like that shown in photograph IO, plate VI, it is interesting to note that the fructifications borne by the main stem and branches alike are of the same stage of growth.

\section{CORTEX OF TRUNK 393.}

With the unsurpassed material bronght together by successive expeditions at hand, the hope was early conceived, in the course of the writer's studies, that the difficulties in the way of tracing in detail the course of the cortical leaf and peduncle traces, as above explained by Solms, might be overcome. It was accordingly decided to attempt the preparation of a series of thin sections which would show whether or not it is possible clearly to trace the entire conrse through the cortex of associated peduncle and leaf traces from their origin on the central stele to their entrance into peduncle and leaf bases. This was done, and the results are certainly of sufficient interest to merit presentation, although not entirely complete.

The trunk selected as the first basis of this study is number 393 of the Yale collection, representing Cycadcoidea Wielandi, already mentioned at considerable length in connection with the subject of ovulate fructification. It is illustrated on plate Xxi. As may there be seen, it is very distinctly of the C. (Bennettites) Gibsonianus type, and bears numerous finely preserved lateral ovulate cones, in reality short axillary branches, quite similar to those of the Isle of Wight specimens. The dimensions of trunk 393 are as follows :

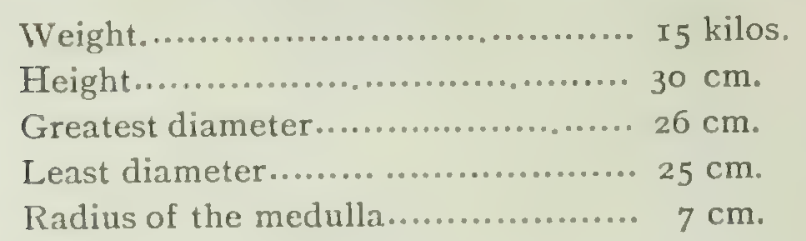

Thickness of wood or xylem zone.... I. $2 \mathrm{~cm}$. Thickness of cortical parenchyma... I. $5 \mathrm{~cm}$. Average thickness of armor......... $4 \mathrm{~cm}$. Width (tangential) of woody wedges $1.2 \mathrm{~cm}$.

The number of ovulate cones present and more or less completely intact and actually bearing seeds, let us recall, is sixteen. But originally there were upwards of forty, mostly belonging to the same season of fructification. Some of these, in addition to the sixteen nearly complete fruits, are partly preserved, the loss through exigencies of erosion from the cycad horizon having been a little more than half.

In the study of the cortical system of the present trunk, one of the fruits to be seen in the left-hand view (plate xxi), with the upper half cut away, was first selected for the purpose of tracing the peduncular bundles in to their origin on the xylem zone. Transverse section 25I was next cut from this fruit, which may be designated as $I$, and then the longitudinal section 2 I5 was cut from the basal portion of the peduncle to determine exactly its insertion on the cortex. Following these two sections further sections, mostly transverse, were cut consecutively through the continuation of the peduncular bundle supply in the cortex. Twelve of the more important of these, in most of which the main features are preserved with diagranmatic clearness, are shown in figures 36,37 , and 38 . Of the sections 
illustrated, Nos. 2I6, 243-246 are cut successively at a distance of from I to $3 \mathrm{~mm}$. apart, these numbers thus tracing nearly I centimeter of the outer cortical conrse of the peduncle and leaf traces. Each of these sections is cut obliquely to the stem, so as to strike the bundles at approximately a right angle to their outward and upward course through the cortex.
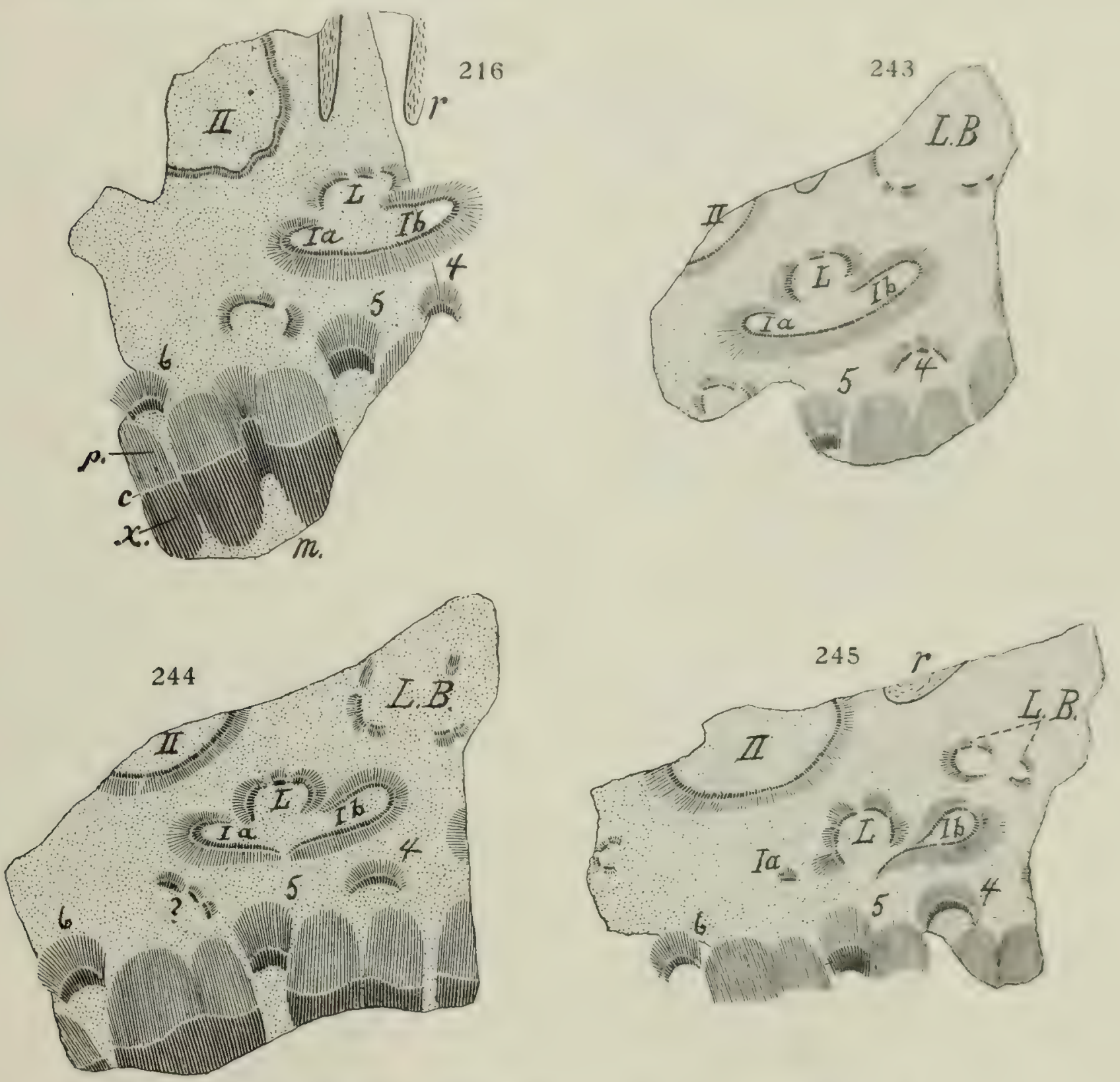

Fig. 36. - Cycadeoidea Wielandi Ward. T. 393. S. 216, 243-245. X⿳3.3.

Transverse sections through xylem, cortex, and basal portion of arınor, cut at successively lower levels from 1 to $3 \mathrm{~mm}$. apart, beginning with S. 216. Series continued in the next and succeeding figures, which are uniformly lettered.

la, Ib, Peduncular bundle as traced directly from a seed-bearing cone (I); II, peduncle trace of a second cone: L. axillary leaf trace of peduncle trace I; L. B., a lateral leaf trace which finally appears to fuse sith a branch of peduncle trace I: 3-6, leaf or peduncle traces near their origin on the woody cylinder : $x_{0}, c_{0}$ and $p$, xylem, cambium, and phloem of the collateral bundles o? wedges forming the woody cylinder of trunk; $m$, medulla; $r$, ramentum at base of armor. Parenchyma stippled.

A longitudinal section numbered 249 was next cut through the adjacent flattened peduncular bundle $(I I)$ at exactly a right angle to No. 246 , and in the position denoted by the line $S S$ in figure 37 (S. 246). 'This section thus cuts part of the peduncle bundle supply throughout its remaining conrse, being a nearly true radial longitudinal section. Following section 249, a further series of transverse sections was cut parallel to and beneath S. 246. 'These sections, therefore, also lie at right angles to and on the right-hand side of 249. Of these, Nos. 247,250 , 
256-258, 260, and 26I are figured. They are cut from I to $3 \mathrm{~mm}$. apart; and with the transverse sections preceding 246 they afford a series covering a vertical distance of nearly $3 \mathrm{~cm}$, this being sufficient to include all the downward course of the peduncle $(I)$ and surrounding leaf-trace bundles in question, through the cortex to their origin on the collateral bundles forming the woody cylinder of the
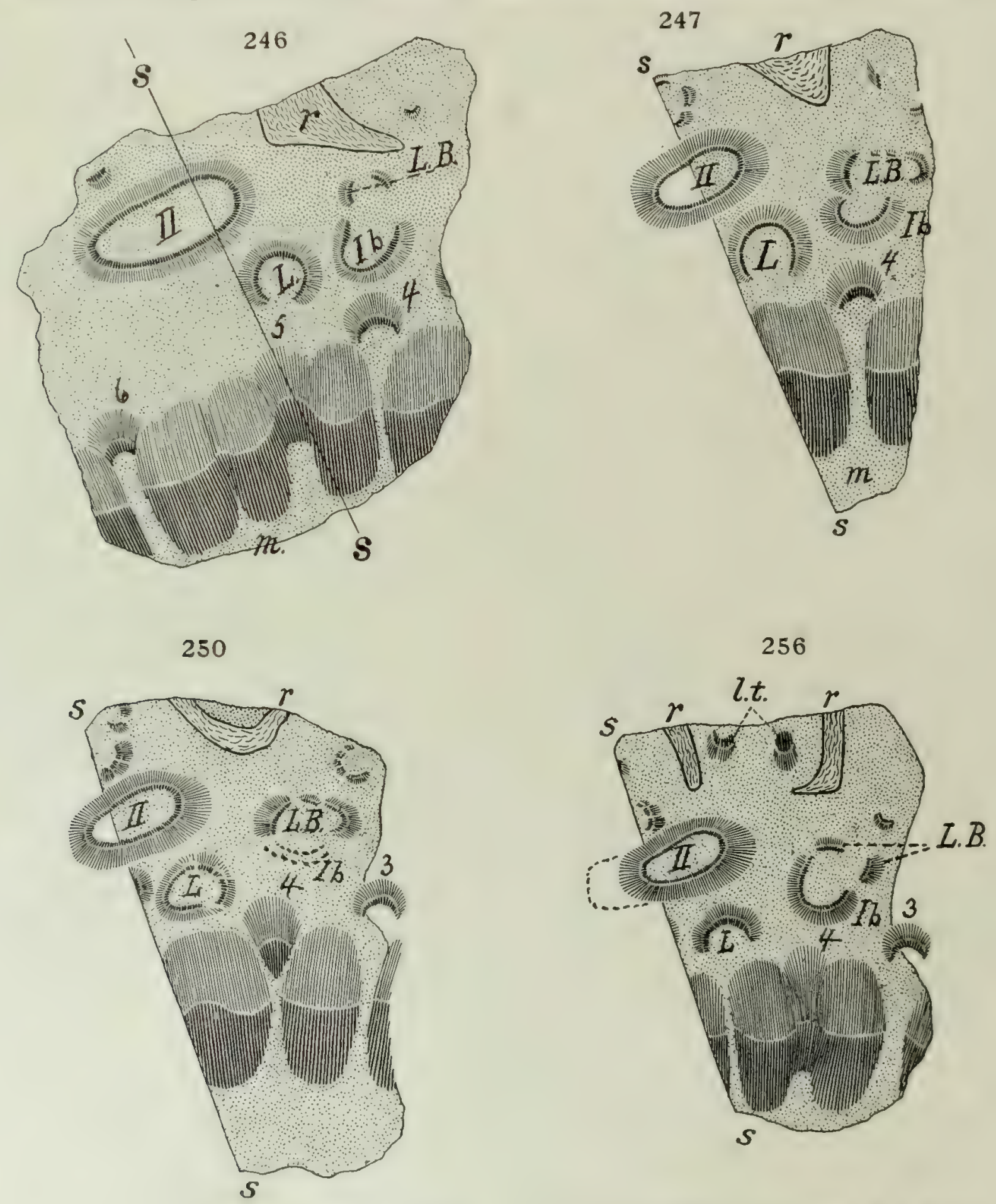

Fig. 37.-Cycadeoidea Wielandi Ward. T. 393. S. 246,247, 250, 256, as cut parallel to those shown in the preceding figure and at successively lower levels from 1 to $5 \mathrm{~mm}$. apart. $\times \frac{3}{2}$.

S S, in section 246, line marking position of longitudinal section 249; s s in 247 et seq.o line of saw cut. Other letters as in preceding figure.

trunk. The longitudinal section 249 has not been figured, since the loss due to the saw cut prevents exact correspondence with the edge, $s, s$, of sections 247,250 , etc. The appearance of the section is entirely similar to that of the cortical portion of a large radial section (392) traversing a neighboring cone. (Cf. photograph 4, plate xxIV.) 
Having explained how these sections were cut for the purpose of tracing through the cortex the bundle supply of a particular cone and the leaf bases surrounding it, one may best understand what this course proves to be in the present instance by inspection of the serial figures. And this may best be done by taking up the several features in succession.

257

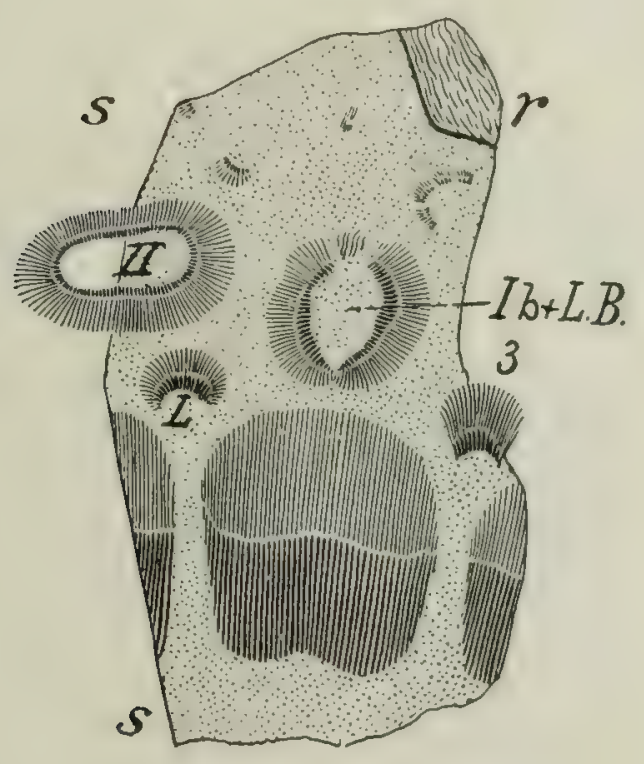

260

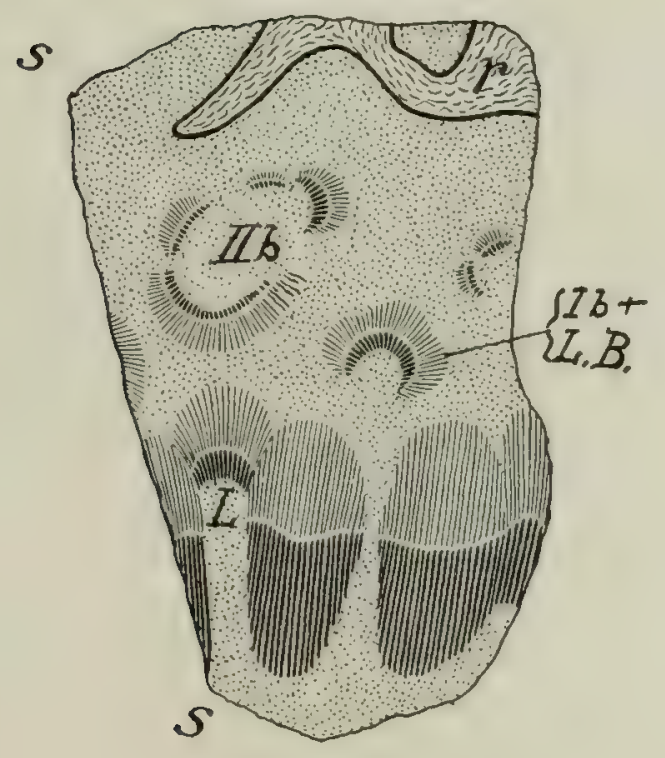

258
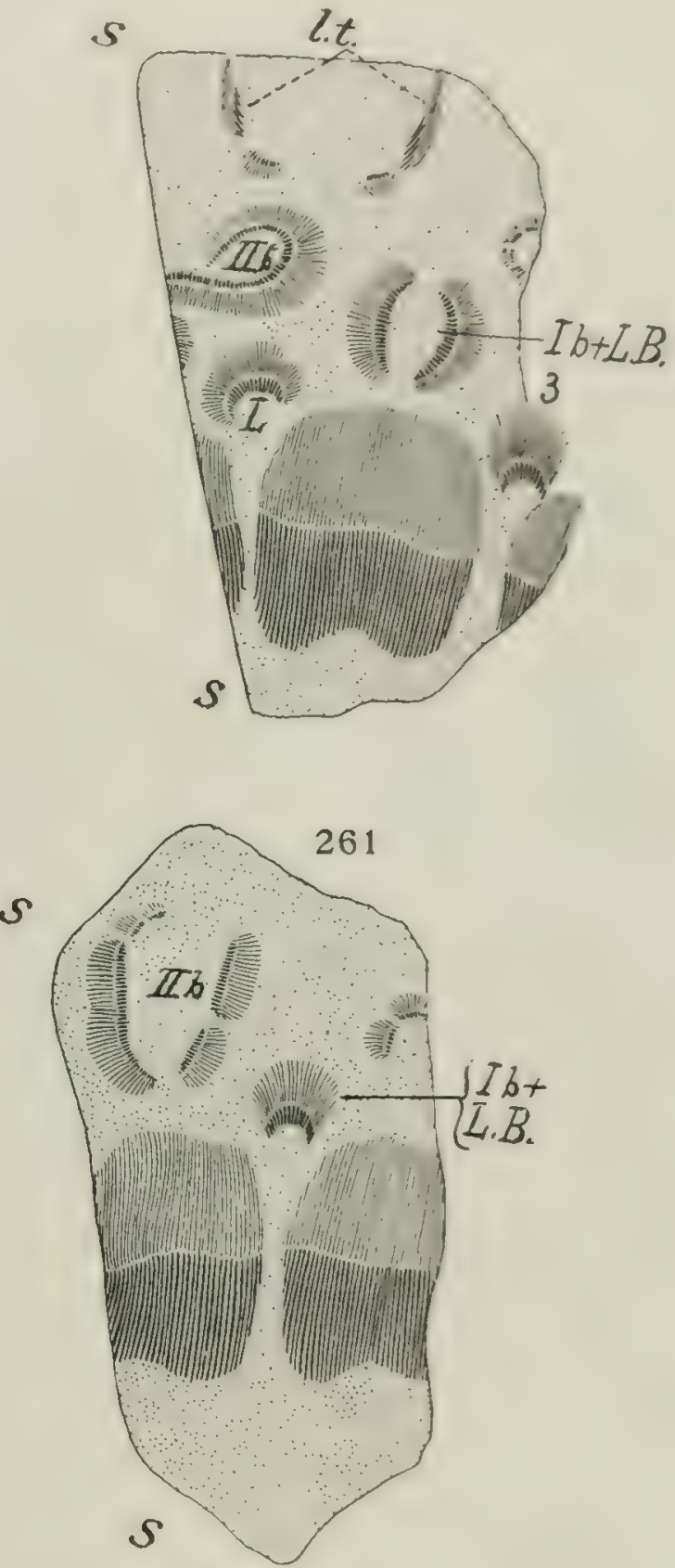

Fig. 38.-Cycadeoidea Wielandi Ward. T. 393. S. 257, 258, 260, 261. $\quad \times_{2}^{3}$.

Continuation of series shown in the two preceding figures. Lettering of bundle traces same as in preceding sections of series, so far as considered possible to identify. Vertical distance traversed by entire series, about $3 \mathrm{~cm}$. (Cf. the succeeding figures $39 \mathrm{~A}-\mathrm{C}$, showing the structure of the peduncular trace IIb, of section 261 ; also figures 40 and $41 \mathrm{~A}$, showing xylem of $\mathrm{S} .260$.)

In section 216 , figure 36 , the peduncular bundle marked $I a$ and $I b$, is that traced as related in an exact and definite manner from a particular cone. It here presents a highly characteristic transverse section, the bundle $(L)$ being that of the subtending leaf base. The structure of the cortical peduncular bundles is shown in detail in figures $39 \mathrm{~A}-\mathrm{C}$, and photographs $3,4,6$, plate xvi. 
In the next lower section, 243, there is" little change, but in S. 244 the peduncular bundle is seen to be in process of division, which is still more pronounced in S. 245. In S. 246, figure 37, the branch (b) is no longer recognizable as connected with $L$; while a does not appear, because, of a considerable patch of clear, structureless silica, which is not indicated in the drawing. 'The further course of branch $b$ is found upon inspection of the remaining sections to lie side by side, if not in actual union, with another leaf trace marked L.B. Both apparently originate as a single bundle to be seen near its origin on the woody cylinder in section $26 \mathrm{r}$.

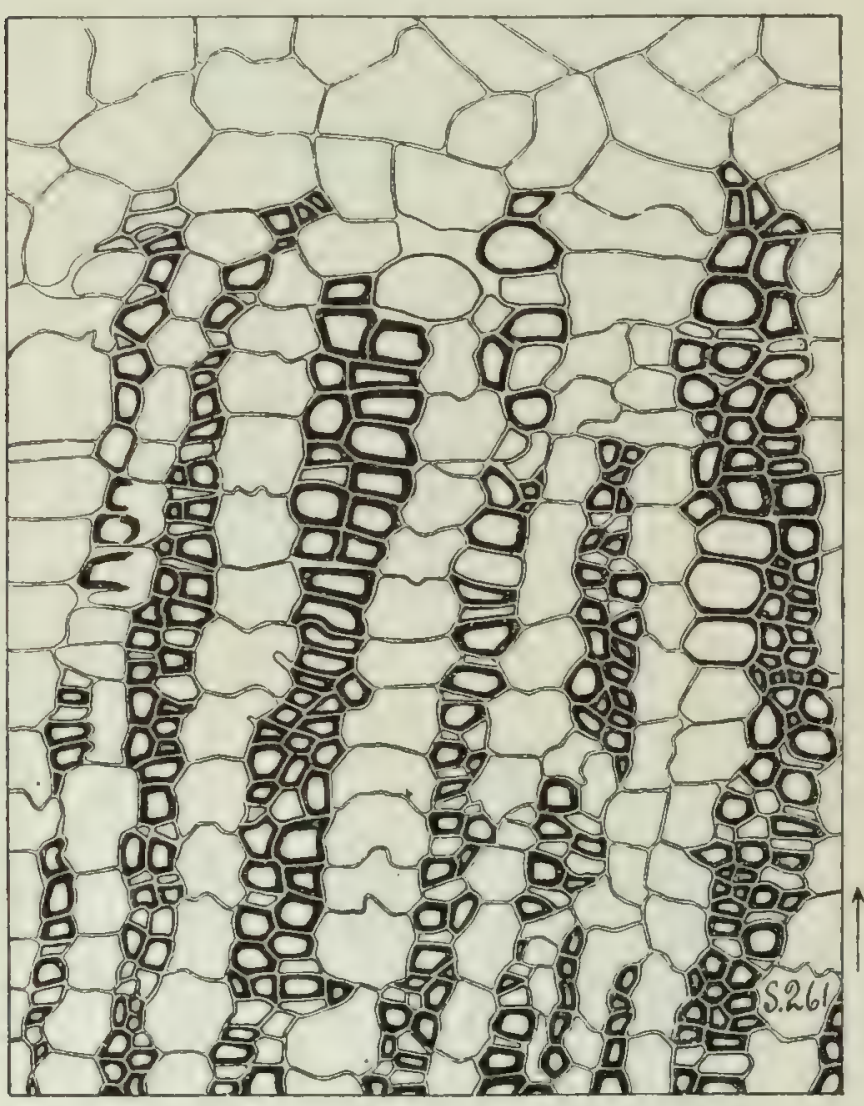

1

A. Outer region of phloem of same bundle shown in figures $39 \mathrm{~B}$ and C. (Walls of thicker-walled cells shown a shade too heavy.)

Fig. 39 A-B.-Cycadeoidea Wielandi. S. 261. T. $393 \times 100$.

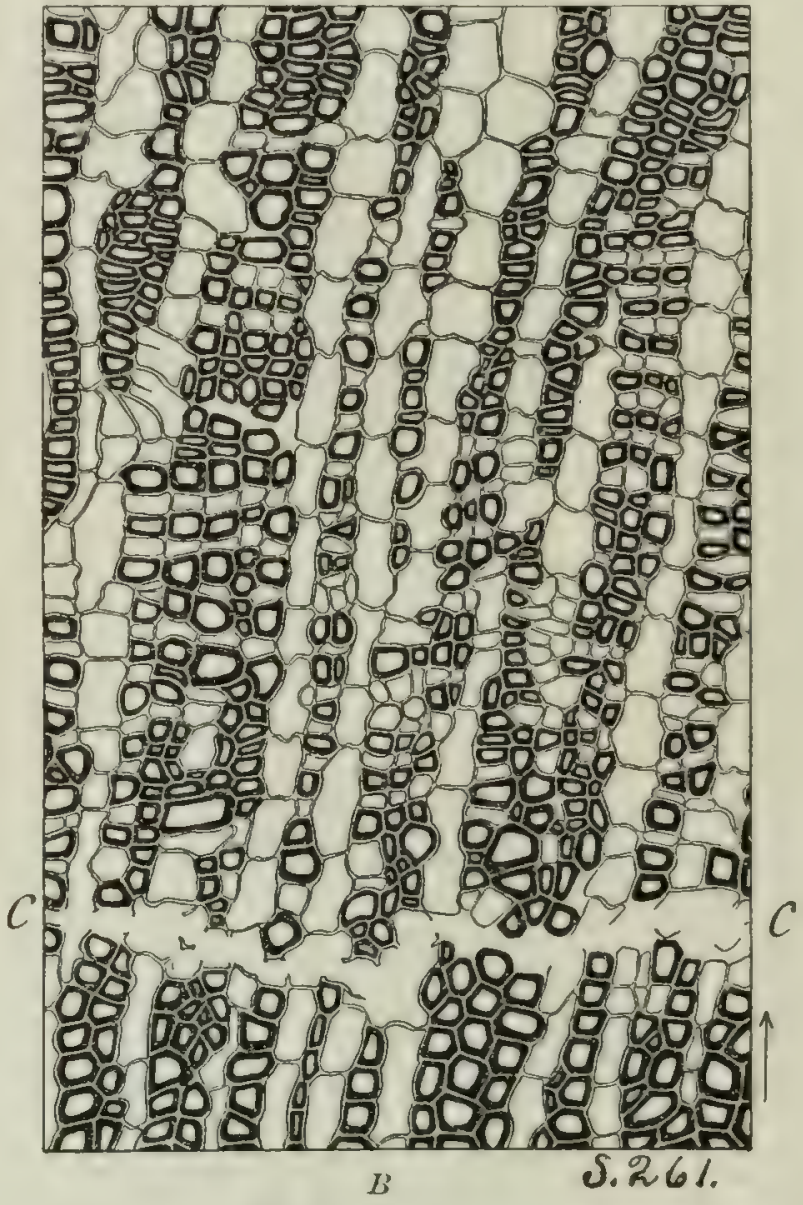

B, Xylem, cambial line $(c-c)$, and most of phloem of same bundle shown in preceding figure.

Transverse section through peduncle trace. Cut a short distance above the origin on the woody cylinder of the trunk from a portion traversing the middle region of the cortical parenchyma. Placed tandem, these and figure $39 \mathrm{C}$ traverse the entire xylem and phloem regions of the peduncle.

Reviewing, it is seen that the peduncle trace $(I)$ is not shown to be in actual union with its subtending leaf trace, although it forms with it the singularly characteristic axillary pattern, noted not only in sections $243-245$, but in various others. On the contrary, the peduncular bundle in the instance before us certainly divides into two branches, of which that denoted $I b$ passes to the right and finally becomes separable with difficulty from and then confluent with a lateral leaf trace.

Let attention now be fixed upon the second peduncle trace $(I I)$ which appears in these sections and is cut throughont its lower conrse by longitndinal section 249. In section 2 I 6 peduncle trace $I I$ is cut very obliquely and almost exactly at the point of its emergence from the cortex, or at insertion of peduncle and leaf bases on the cortex as forming the base of the armor. Passing by the successively lower sections, 
in which only a part of peduncle bundle // appears, a complete peduncle-bundle section is first to be seen in S. 246 , whete the bundles of the subtending leaf base do not closely approach. Beyond - that is, beneath the level of section 246-owing to the cutting of longitudinal section 249, only the riglnt lalf of peduncle bundle // is present. In section 247 the adjacent leaf-base bundles lie closer to the peduncle trace, as also in the succeeding sections down to 258 , where the branch $I I b$ is analogous to branch $b$ of peduncle $I$ in section. 245. Note especially that in sections $216,243-246$ peduncle trace $/ I$ is cut relatively more distal than is peduncle

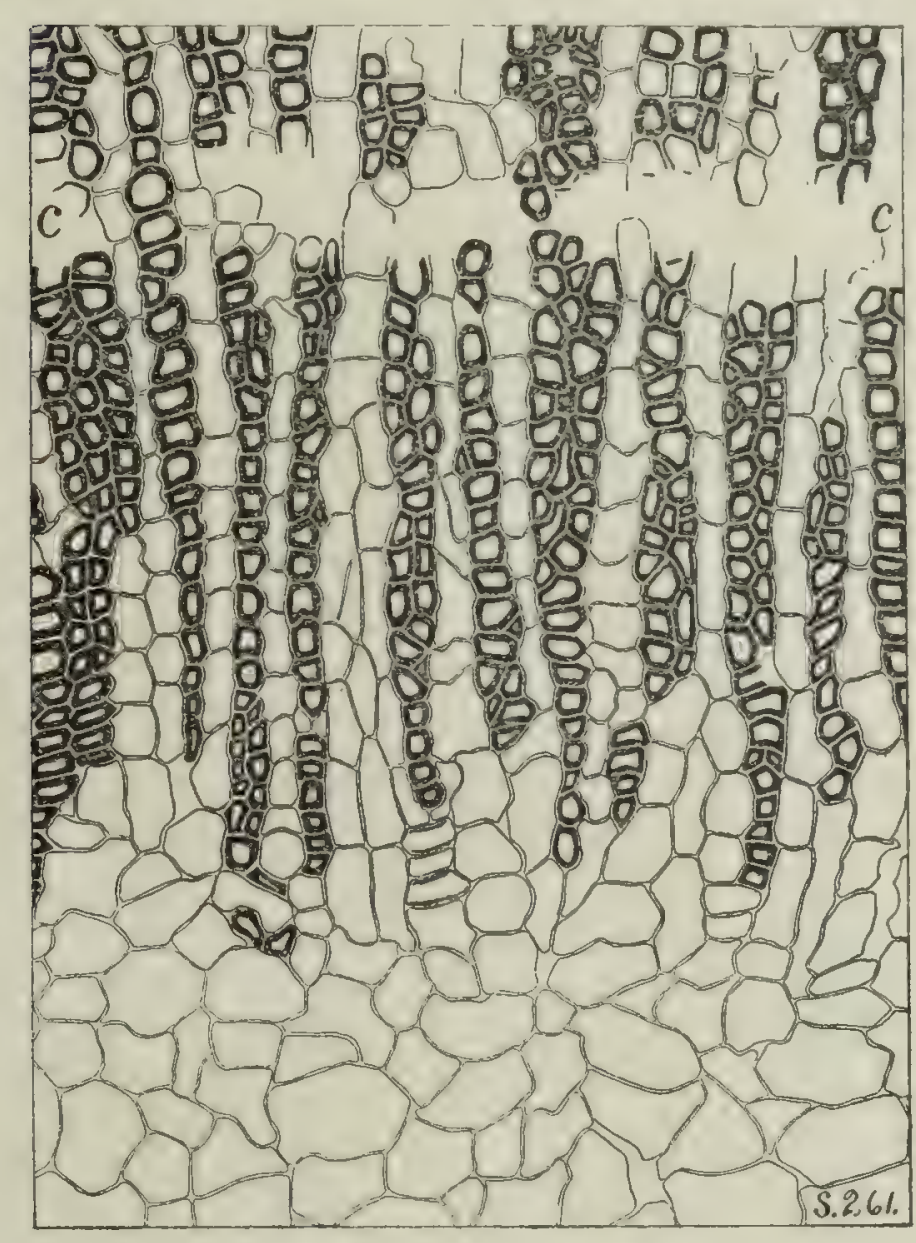

C

Fig. 39 C.-Medullary region, xylem, cambial line, and part of the phloem of the peduncle bundle or woody cylinder. Nearly continuous with $39 \mathrm{~B},(\times 100$. trace $I$ in section 2 I6. Below section $25^{8}$ branch $b$ of peduncle trace $I I$ tends to split up and at the same time align itself more concentrically; but its final course has not been traced beneath S. 26I. 'Tuming hack to longiturinal section 249 , it may be determined that the bundle supply of a subtending leaf actually gives off a brancl which passes into peduncle $I Y$, a condition not found in the case of leaf base $L$. Whether there is an additional connection of $I I$ with a lateral leaf base, the preient series of sections does not disclose.

The general conclusion is that the peduncular bundle is formed from the union of several different bundle strands in the lower part of its course through the cortex, and that these strands consist primarily of a main branch arising directly from the woody cylinder, which may, however, be connected with either lateral or subtending leaf traces. The leaf traces appear in general to arise from the woody cylinder as horseshoe bundles, with the phloem outside, these bundles soon assuning a more or less brokenly-circular form in the most of their course through the cortex before dividing up in the leaf base.

The result obtained is to the writer an unexpected one, difficult to explain. The apparent connection of the peduncle traces with leaf traces would seem to indicate a renewal of growth activity of not only the woody zone of the trunk, but possibly of the cortical traces, over all the lateral area of the trunk after the wilting down of the leafy crowns of successive seasons. Of course, the order iin which the fruiting meristems arose in the paripheral cortex can as yet only be surmised from the distribution of young fructifications of appreciable size.

It is only fair to myself to call attention to the fict that the above series of sections was prepared when there was at my disposal only the rock-cutting machine 
built by Professor Benjamin Silliman, the first used in America. This mounts a 6-inch saw, and is run by foot power, so that the sections that could be made upon it were far more limited in area than those cut on the Dwight petrotome, which was later most generously given for the work on the fossil cycads by Professors E. S. Dana and G. J. Brush. Nor was the writer at the time of this earlier work acquainted with the stone cements later used. It accordingly did not occur to him to employ the method of double sectioning, later so satisfactorily introduced in the study of fructification. The results described would, in short, be far more complete had the sections been large and had the parts resulting from the making of longitudinal sections, with as little loss of material as possible, been then cemented together again in their true position before making the complementary transverse
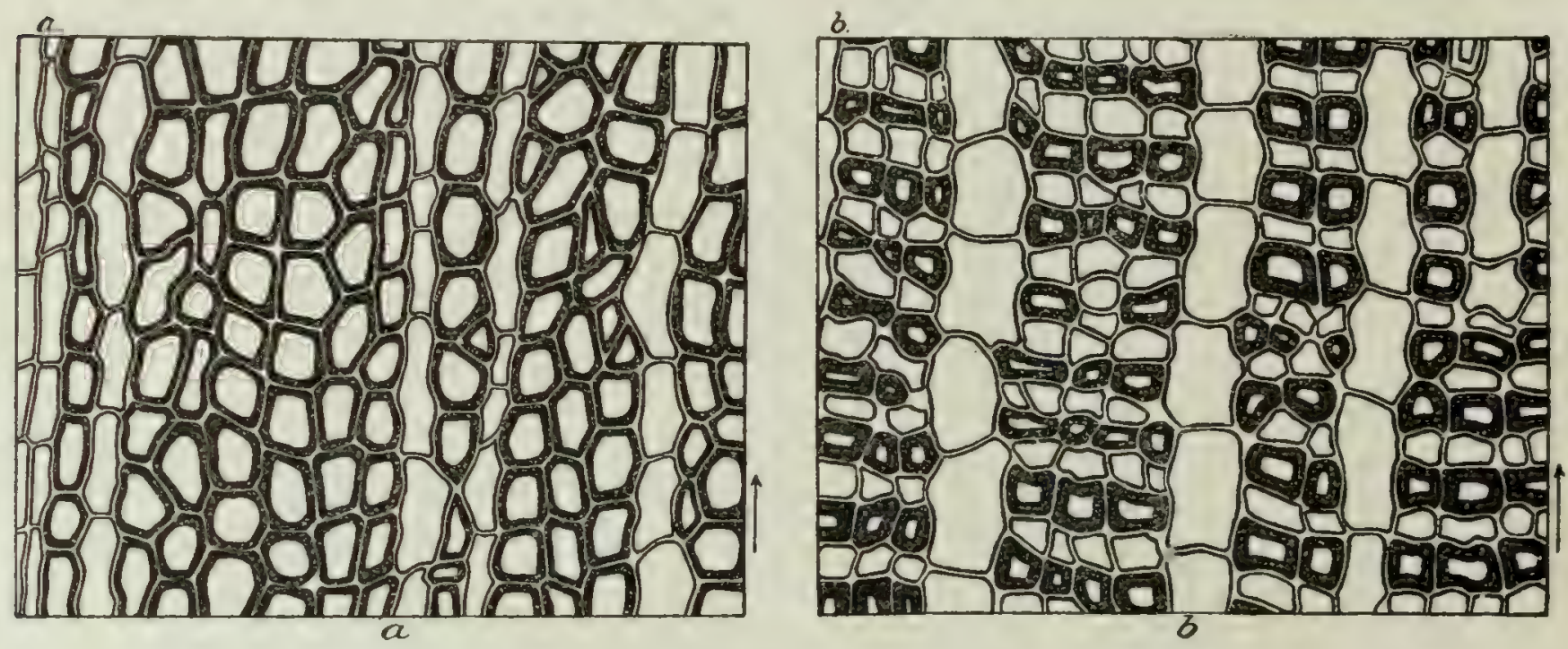

Fig. 40.-Cycadeoidea Wielandi Ward. Structure of the xylem zone or woody cylinder of trunk 393. Transverse section through middle of xylem (a) and phloem (b) of S. 260. $X$ about 150.

series complete less the saw cuts. The resumption of the study of the cortex after the working out of better laboratory methods was, however, on the score of relative urgency, deferred.

\section{XYLEM ZONE.}

The series of cylindrically arranged collateral bundles inclosing the large medulla and forming the xylem zone or woody cylinder has already been illustrated in the description of the cortical region. It is typically cycadean, and its development as a simple zone, as seen in trunk 393, is quite characteristic of all the fossil cycads studied by the writer, with the notable exception of $C$. Jenneyana and $C$. ingens, described below.

In trunk 393 the collateral bundles or "woody wedges" form the usual typical cylindrical trellis, from the lower angles of the openings or meshes of which the leaf and peduncle traces arise, as already shown in macroscopic detail in figures $36-38$. Each bundle of the cylinder is composed of the inner xylem and outer phloem in abont equal areas, separated by a narrow line of crushed or imperfectly preserved cambium. The cells of the xylem are quite equally heavy-walled throughout, as shown in the several figures, although it may be that in these accompanying figures the walls are shown relatively too heavy. (See also the photographs of the same 
thin sections, plate xvi, I and 5.) The radial rows of xylem cells, as separated by medullary rays from one to two cells in thickness, are from 30 to 60 in number in each main bundle segment, and increase from a single cell in width, where abutting on the medulla, to from two to five cells in width on the outer cambial side. The medullary ray cells near the inner origin of the xylem rays are of very regular, somewhat flattened, oblong form, several times as long as broad, and lie with their greatest length tangential to the trunk. Further out these cells are longer, and their greatest length is in the radial direction. The xylem is composed mainly of scalariform tracheids. Spiral cells are present next to the medulla, birt are not numerous. Idioblasts are occasional. No pitted tracheids have been noted, although preservation is such as would presumably enable ready recognition without staining, were such present in any of the several radial or tangential sections cut. They may,
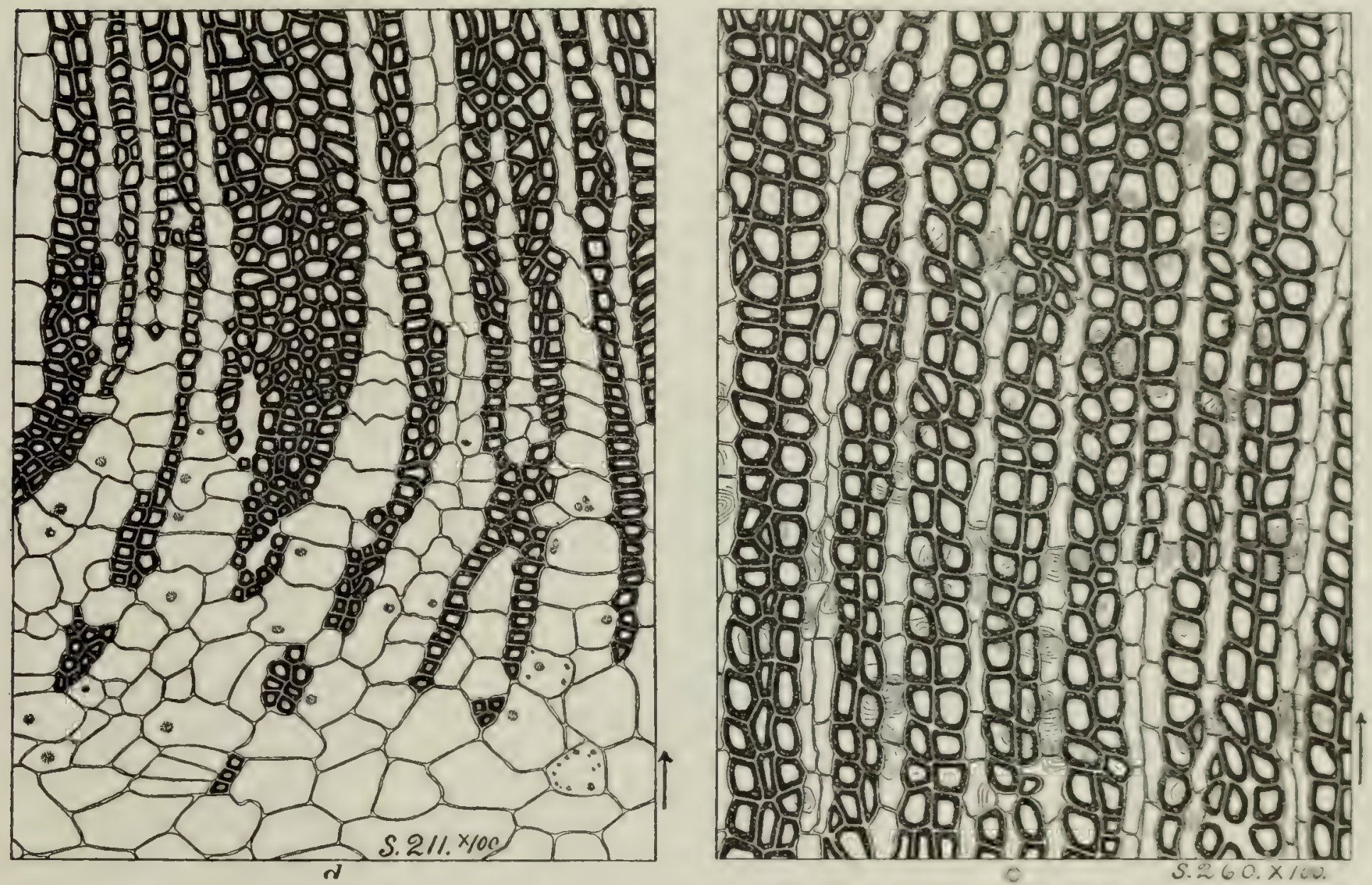

Fig. 41.-Cycadeoidea Wielandi Ward. T. 393. S. 211 and $260 . \times 100$.

c. Middle region of xylem cut transversely, showing distinctly hexagonal phenocryst patterns extending through the cell walls as secondary structures formed in a solid or plastic mass behaving as a solution.

$\mathrm{d}$, Abutment of a woody wedge on medulla as seen in transverse section. A nucleus-like, if not nuclear, body is present in nearly every medullar parenchyma cell.

perhaps, appear in further sections in agreement with those observed by L ignier in Cycadeoidea micromyela, in which the pittings on radial longitudinal surfaces are cross-slitted, as are those of the tracheids of Araucaria brasiliana and Cordates Neitberryi. The xylem is both greater in quantity and markedly denser than in the weakly developed woody cylinder of the Flurida Zamias, and the predominance of scalariform elements is quite in contrast to $Z$. floridana, where the main body of the 
xylem is exclusively made up of spiral tracheids. In the more ancient form Cycas, however, scalarifonn tracheids are also abundant, and it is very evident from the great variability in the relative amounts of xylem, and proportion of spiral, pitted, and scalariform elements, as seen in isolated sections cut at random, that no very
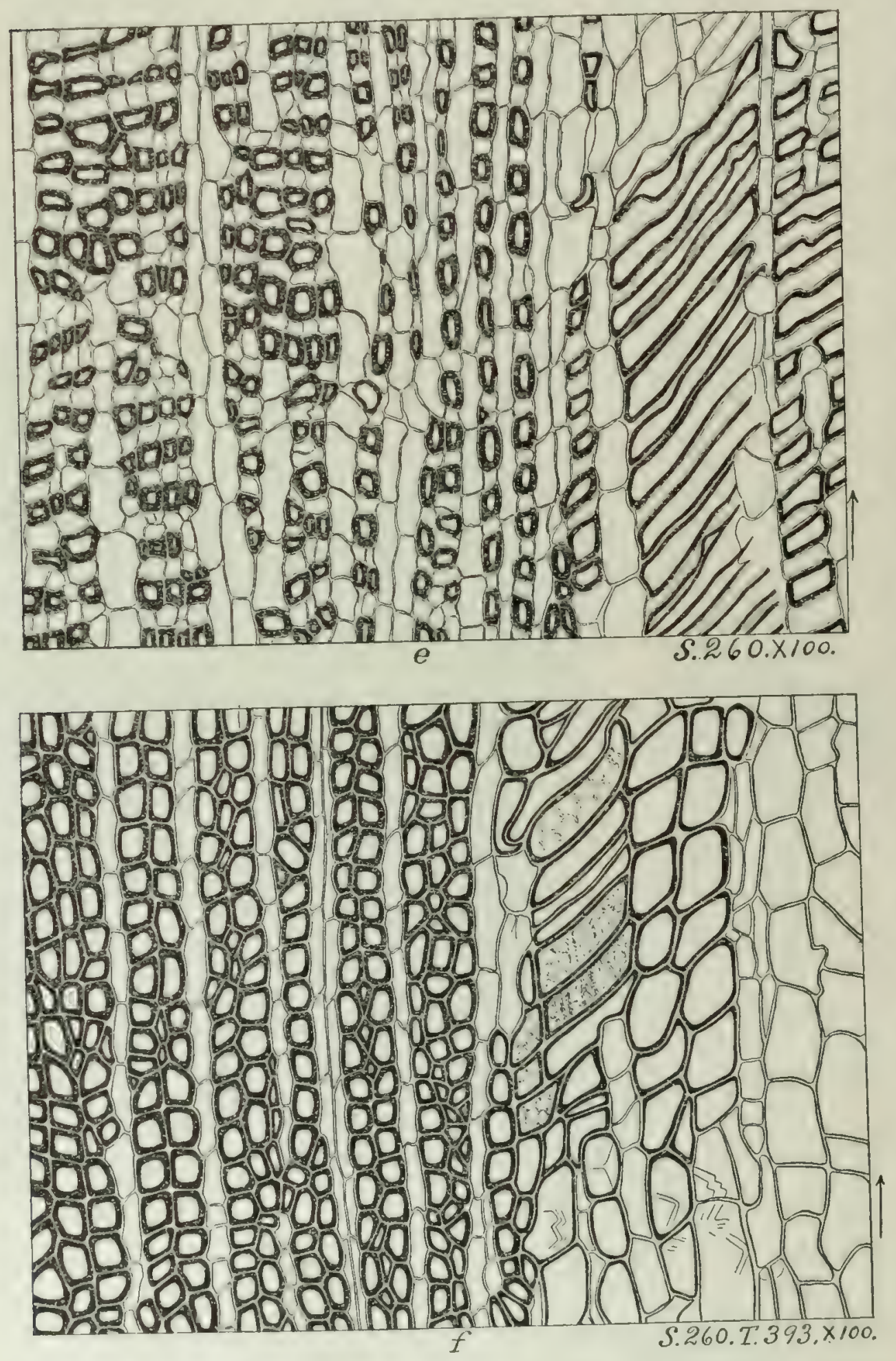

Fig. 41 A.-Cycadeoidea Wielandi. T. 393. S. 260. × 100. Continued from fig. 40 .

$\mathrm{e}$, Transverse section through the phloem, showing the origin of the phloem of a horseshoe bundle. $\times 100$.

$f$. Transverse section through xylem showing a part of the origin of the xylem of one of the bundles passing out from the woody cylinder into the cortex. $\times 100$. The innermost obliquely set cells have sub-hexagonal pittings in their walls. Further out the initial bundle cells present more and more cribriform and finally scalariform patterns, direct comparisons or conclusions have yet been reached concerning tracheidal organization in the Cycadales, Cycadofilices, and Cordaitales. To yield exact comparisons of value in generic, to say nothing of specific determinations, the relative age and development would have to be known and carefully oriented sections cut from the several trunk regions found to be representative throughout a long and varied series of existing and extinct genera. An interesting agreement between the tangential sections of the xylem zone of Cycadeoidea and Cordaites Nerobcrry $i$ is illustrated by the accompanying figures 42 and 43. Aside from a difference in the relative size of the medn1lary ray cells, a close parallel is afforded.

Phloem.

The parts of the phloem are in reverse alignment to those of the xylem-that is, the pliloem rays decrease in width and the cells 
of the medullary rays increase in size toward the cortical parenchyma, as in other cycads. The heavier-walled elements of the phloem alternate with the thinnerwalled with marked regularity in the transverse section. A sufficient number of well-cut tangential sections is not at hand to give all the structural details.

THE MEDULLA.

The preservation of the medulla is quite complete in most of the Black Hills cycads. In nearly all the medulla is very large, and so far as known is wholly without vascular structures. In a few of the trunks there is, however, in the middle region a large conical cavity varying in diameter from a third to more than half that of the entire medulla, and apparently due to the separation of the parenchyma which once filled the space by an excision zone. No sections have been cut determining this point, but these conical cavities are doubtless due to the formation of bands of internal periderm, such as occur abnormally in the stems of recent cycads. Similar medullar cavities have been observed in the Italian Cycadeoidex and thus explained by Solms-Laubach (22).

No very distinct systems of gum canals have been observed. Instead of gum canals there appear to be very irregularly distributed large secretory sacs, three or four times the diameter of the cells of the ground parenchyma and more or less elongate. These may occur tandem to each other, and especially near the leaf bases there are canallike lengthenings. The sac contents are usually dense, with brownish staining like that of the cell walls.

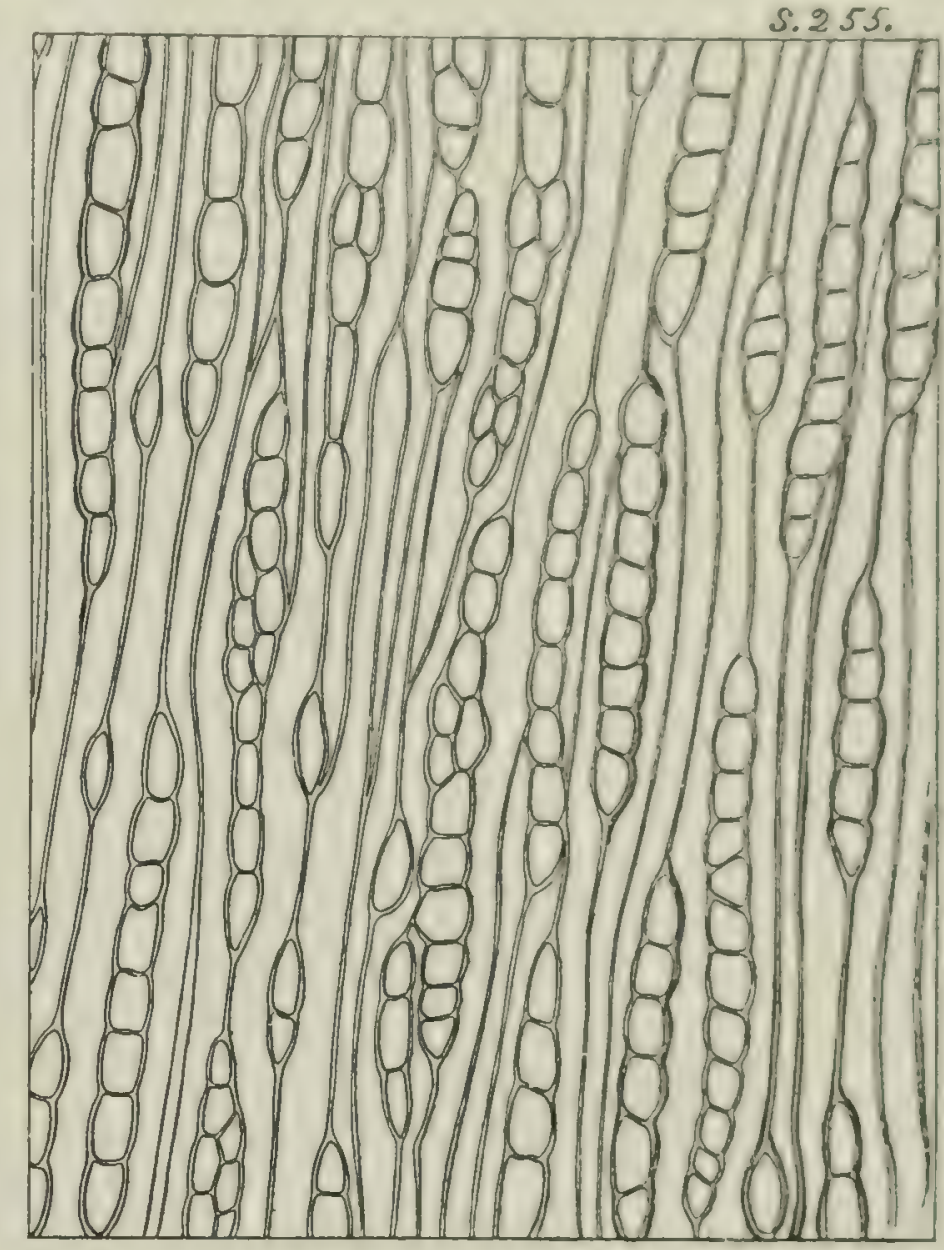

Fig. 42.-Cycadeoidea Wielandi.

Tangential longitudinal section through xylem, showing the structure of the medullary rays. Drawn from a photograph displaying the fact that the walls of the tracheids, owing to the manner in which the scalariform markings are naturally iron stained, do not appear so dense in longitudinal as in transverse sections. (Cf. figure 43.) $\times 100$.

Occasionally, however, there is a quite dark coloration as if during silicification there had been left over a slight residuum of carbon derived from resinous contents. In yet other instances the secretory sacs are filled with a distinctly vacuolated mass, which may also be a secondary form of the original contents.

In the cells of the ground tissue three kinds of bodies are to be observed. Particularly in Cycadella (S. 50) large numbers of starch grains are present, quite filling the cells over large areas. Also, in the several s?ctions of trunk 393, granules or vacuoles, rather larger than starch grains, and of more variable size, are often 
present. Lastly there is present with great regularity in every cell of the ground tissue over large areas of the medulla of this same trunk 393, a single and conspicuous dark-yellow body with a nearly black mass at its center, believed to be the cell nucleus with perchance the nucleolus. (See fig. 4r, $d$ ). It is of interest that Seward observed markings in the medulla of Cycadeoidea gigantea which were like-

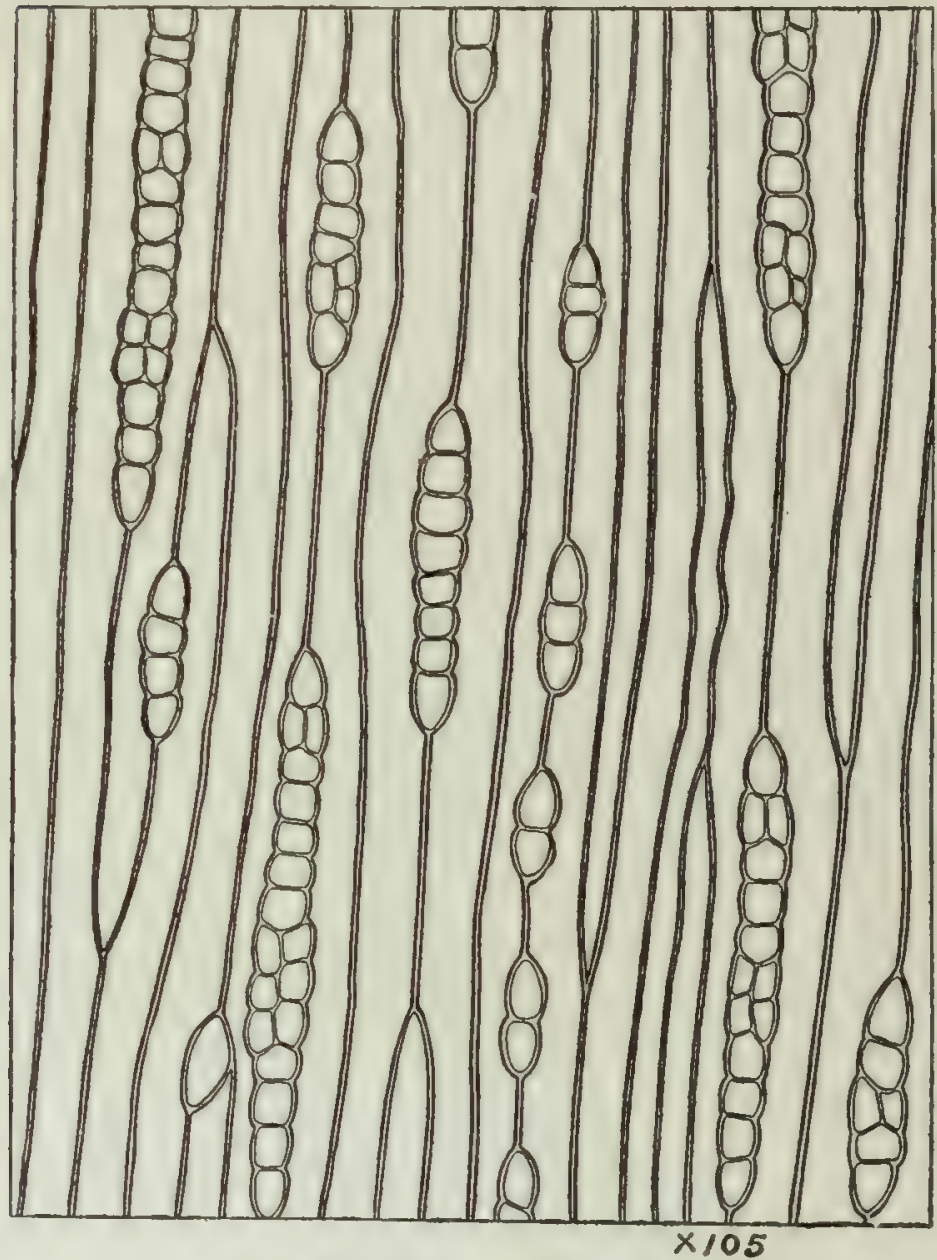

Fig. 43.-Cordaites Newberryi.

Tangential section from trunk. Upper Devonian of Indiana. $\times 105$. wise suspected to be nuclei. There are, of course, in some of the cells other more or less vague markings as the result of various odd causes, which might be confused with what are believed to be the cell nuclei. The exigencies attending nuclear preservation must certainly be great, since the case of $C$. gigantea is the only recorded instance, aside from the present, where such preservation has even been suspected; but the fact is that over considerable areas precisely the appearance is presented that the writer has observed in sections of existing cycads showing the nuclei, and he believes the bodies in question to be fossil nuclei. Since these bodies present such a very regular appearance over considerable areas of the ground tissue, and are not found as a rule on any particular side of the cell, the greater difficulty is involved in any other explanation. They may, therefore, be considered the first fairly clear instances of silicified nuclei.

\section{CYCADEOIDEA JENNEYANA AND C. INGENS.}

The trunks from the Piedmont-Black Hawk locality of the Black Hills region referred to Cycadeoidea Jenneyana exhibit, in addition to other special features, both vegetative and reproductive, the heaviest growth of wood and the most advanced degree of polyxylism yet observed among either existing or fossil cycads.* In fact, the polished section of the lower end of a basal cylindrical segment of a trunk, probably referable to C. Jenneyana and photographed on plate xIv, reveals a

\footnotetext{
* Taken all in all, these features are of generic value. If they are finally found to occur in Buckland's original types of Cycadeoidea, then the genus Bennettites is perfectly valid, although for other reasons than those that have been hitherto assigned. If, on the other hand, the Buckland specimens in the main agree with Bennettites, so called, and it is here deemed a strong possibility that they do, the name Bennettites is invalid, and the American specimens referred to $C$. Jenneyana and $C$. ingens, together with the magnificent Isle of Portland trunk C. gigantea Seward, constitute a generically distinct group.
} 
woody structure as extensive and compact as that of Cordaites. This specimen is $35 \mathrm{~cm}$. in length by $25 \mathrm{~cm}$. in diameter, and the curvature of the basal end and small diameter of the medulla show that it is from the base of a distinctly columnar trunk. Although the armor and cortex are mostly eroded away, some proximal ends of leaf bases on one side prove very conclusively, in conjunction with the other characters present, the cycadean nature of the specimen and show that the cortical parenchyma was but slightly developed, or rather replaced by the heavy woody zone. This remnant of armor, while not showing the original thickness, of course indicates that periderm excision of the leaf bases had not progressed so far as often seen in various existing cycads of columnar type. The unusual characters of the present specimen, as well as the convenient form for handling, led the writer to have the upper end polished, and the result was a most agreeable surprise. The very light outer coloration was found to give way to more pronounced shades in the interior, which bring out the larger structures with great clearness and beauty, and, as it happens, in shades that render the photograph and the reproduction in the plate virtually representations in natural colors. An extreme hardness and toughness not unlike but exceeding that of chalcedony, as well as some doubt as to the advantage of so doing, has, in the presence of so many other points pressing for solution, deterred the writer from making thin sections from the trunk. However, with regard to the special structural features that appear in the transverse section (plate Xrv) it may be noted that the successive woody rings closely abut, and that, as in the case of secondary rings or anomalous wood zones in the existing cycads, the outer ones are very narrow; though the relative amounts of xylem and phloem can not be determined either in the figure or by macroscopic inspection of the original specimen. Nevertheless, it appears more likely that secondary cambial formation has intervened and resulted in the development in the cortex exterior to the initial woody cylinder of a dozen or more of successive exterior collateral bundle systems, simulating annual rings much after the manner of old trunks of Cycas and Macrozamia among the modern cycads, but with extremely narrow medullary rays, resulting in as solid a wood zone as if mainly consisting in a growth of secondary xylem from a persistent cambial cylinder, as in conifers and dicotyls. The highest number of anomalous wood zones recorded in the existing cycads is twelve in an old trunk examined by Miquel. The even greater number and very complete lignification of additional rings of growth in the present case thus give the medullar proportions and solidity of cordaitean stems.

On the other hand, there is a bare possibility that there has actually been a persistence of the primary cambium with seasonal augmentation of the secondary xylem. Should it be proven later that in any of the Cycadeoider such a condition is present, it would certainly indicate a most unexpected feature of these trunks, so like cycads in all other respects. Such a dicotyledonous feature would, too, in coujunction with the angiosperm-like arrangement of the bisporangiate strobili, represent an assemblage of advanced characters not found in any other group retaining as many primitive features as the present. It is of much interest that Seward (I 49) figures a fossil stem from India with Ptilophylhum cutchense fronds attached, in 
which the wood zone, though not nearly so broad as that above described, is very compact, with medullary rays as narrow as in conifers. In this instance, too, it is not finally decided what the true structure is-whether there has been accretion of secondary wood from a persistent cambium, or formation of one or more anomalous zones in compact order.

If, however, as we suppose, a heavy wood zone was really developed in some of the Cycadeoidex from successively formed cambiums, there is afforded yet another fundamentally significant vegetative similarity between the two great cycadean groups. Such a fact would go far toward removing the last barrier in the way of regarding these groups as homogeneous, and indicating that their separation as two great groups would be subversive of the most approved methods of classification. For, indeed, if the evidence were as fragmentary as it was a half dozen years ago, and such structural similarities were ascribed to homoplastic and independent origin, would it not be at the expense of that other claim of paleobotanists that trunk structures are conservative and persistent? It is on this very idea that much dependence has, as we believe, been justly placed on the investigation of fossil plant stems.

So far as the trunks of $C$. ingens, which occur so closely associated with $C$. Jenneyana at Black Hawk, are concerned, no additional facts bearing on the present question have yet been observed. These trunks of immense size and symmetrical elliptical form, so much recalling that of Macrozamia cylindracea of tropical Australia, have a large medulla with a single inclosing cylinder of collateral bundles, usually of great size, just as the trunks are very large, as well seen in trunk 6I4. In this fragment of an enormous specimen nearly as large as the type (plate I) the single woody cylinder, as seen at a distance of $37 \mathrm{~cm}$. above the base, is composed of very heavy collateral bundles I cm. in lateral or tangential breadth, with the xylem $2.5 \mathrm{~cm}$. and the phloem $\mathrm{I} .5 \mathrm{~cm}$. in radial thickness. Toward the base of the trunk the woody cylinder appears to increase to $8 \mathrm{~cm}$. in thickness, but the tissues are too much chalcedonized to show structure clearly or indicate that sectioning wonld be profitable; although it is probable that the entire thickness belongs to the original single bundle ring. Similar features and development of an immense initial bundle ring are also to be observed in the fine trunk base (trunk II 7 ). 


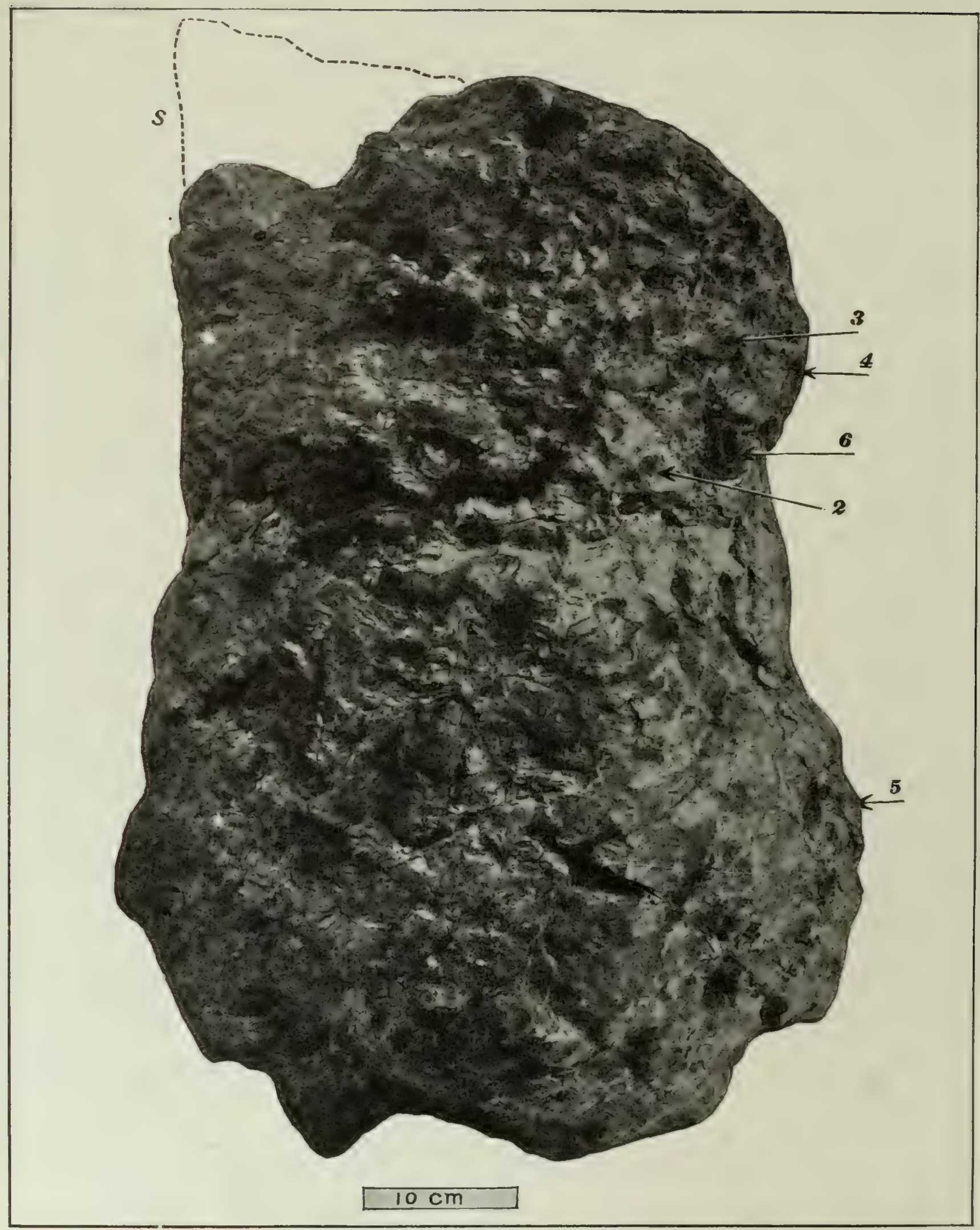

Fig. 44.-Cycadcoidea ingens (T. 208).

Large columnar silicified trunk from the northern end of the Cycad Valley, Black Hills Rim, East of Piedmont, South Dakota. Collected from in situ position illustrated by lower photograph of Plate XLIX. Height, inclusive of segment (S), $87 \mathrm{~cm}$. Weight, $139.6 \mathrm{~kg}$. Remarkable for naturally polished transverse sections of prefoliate adventitious fronds with microscopic structure preserved. Position of fronds indicated by Nos. 2-6. The fronds at 3 , 5 , and 6 are further illustrated by figure 5I, and by photographs $6,7,8$, respectively, of Plate XIX. For the dimensions and number of pinnules of these several leaves see tablc at the bottom of page 95. 


\section{CHAPTER V. \\ FOLIAGE. \\ (Plate X1x.)}

It is generally held that cycadaceous plants culninated in the Jurassic; and, in fact, they seem to have been quite the most ubiquitons of seed-bearing plants throughout all of Mesozoic time to the Upper Cretaceous. Even then they were still present in the Arctic area, though as a fast-disappearing remuant already beginning its long and gradual retreat toward present isothermal limits. Nevertheless the abundant and widely distributed remains of this vegetation consist almost entirely in disconnected and isolated leaves, trunks, and occasional fruits, of necessity hitherto described under separate generic and specific names. It seems that but very rarely have conditions favored the preservation or detection of organically connected leaves or fruits and stems of these plants. Indeed, among all the fossil remains from the plant-bearing horizons of the globe of all ages, until recently, but a single wellauthenticated instance of a stem with leaves attached could be pointed out. As early as 1834, however, Williamson (200) expressed the opinion that Zamites gigas and Williamsonia were to be regarded as probably leaf and fruit of one and the same plant. And by I870, as the result of long and keen observation, this able paleobotanist was confirmed in his belief in the organic connection of the stems, leaves, and fruits included at various times under the names Zamites and Williamsonia gigas. The restoration of the plant bearing the latter name as given by Williamson in I870 (202), at first received the confirmation of Brongniart, and is now known to be essentially correct, although it came to be for a long time regarded, particularly by Saporta, as resting on insufficient fossil data. The opinion of the latter, given in connection with his description of various Paris Museum specimens of the James Yates collection from the Lower Oölites of Whitby, published in I875, is very interesting. For in giving his views, Saporta ( 25, p. 55) not only rejects the organic connection of the stems, leaves, and fruits of "Zamia gigas" as unlikely, but calls in question the affinities of the fruits as follows: "C"est une certaine conformité apparente entre les appareils floraux auxquels on peut laisser le nom de Williamsonia et le Zamites gigas tel que le fait voir ia remarquable empreinte de la collection du Muséum de Paris (Voy., P1. 8I, fig. I). Nous avons tout lieu de considérer les Williamsonia comme représentant l'inflorescence d'une monucotylédone primitive, révélant un type de Pandanées plus ou moins aralogue aux Yuccites, aux Podocarya, aux Eolirion de Andrae, etc." Saporta's view was, at least in so far as the independence of the fossils in question was concerned, rather widely hela for a time, Nathorst (IOO) having even tentatively suggested a relationship between Williamsonia and the parasitic broom-rapes so remarkably developed in tropical regions. 
Later Count Solms says:

"The only cycad, as far as I know, in which the stem with the leaves attached can be determined with certainty, is Zamites gigas Morr. The specimen of this plant came from the upper Jurassic sandstone of Yorkshire, and was obtained from its owner, James Yates, for the Paris Museum, where I saw it. A figure of it is given by Saporta (Plantes Jurassiques, vol. II, pl.8I). The stem bears a lateral bud enveloped in handsome leaves; in this respect and in habit also it recalls Stangeria" (I 57, p. 94).

Latterly, Seward has made a careful reexamination of the English cycadean material. He also mentions, as follows, a Williansonia specimen in the Paris Museum, showing a stem with not only leaves, but the basal portion of a peduncle attached, and evidently the specimen mentioned in the above quotation from Solms:

"At the base we have a stem about $5 \mathrm{~cm}$. broad, with the surface features indistinctly preserved, but showing a number of imperfert scale leaves. To one side of the stem, $5 \mathrm{~cm}$. from the bottom of the specimen, are attached the petioles of two clearly preserved fronds of Zamites gigas, and above these occurs part of a third frond apparently in its natural position, but without the petiolar attachment. The stem is prolonged obliquely upwards to the left in the form of a branch about $3 \mathrm{~cm}$. broad and I $4 \mathrm{~cm}$. long. This branch is thickly clothed with hairy leaf scales and terminates in numerous spreading leaf scales of a narrow linear-lanceolate form. The position and surface features of this branch are very inadequately and incorrectly reproduced in Saporta's figure. If we now turn to the specimen figured by the same author as a peduncle of Williamsonia (Saporta, Pal. Franc. Plant. Jurass., vol. II, p. 55), and which terminates in what appears to be a closed Williamsonian inflorescence, we find the characters are identical with those of the branch of the stem bearing Zamites fronds. Specimens of peduncles in the British Museum, and others in the collections of Whitby and Scarborough, afford similar proof of the identity of the detached peduncles and the obliquely placed branch of the leaf-bearing stem. There can be little doubt that the terminal bud-like structure on these peduncles is a young and unexpanded Williamsonia, but even if this be disputed, there can be no question as to the identity of the typical Williamsonia scale leaves and those of the terminal bud on the peduncles" (I 45 ).

Considering the great number and variety of "cycadophytes," this scantiness of direct evidence as to the connection of stem and leaf as shown in the foregoing review is striking indeed; but all the more satisfactory, from both the biologic and taxonomic viewpoint, has been the writer's discovery that many of the silicified cycad trunks from the Black Hills and Wyoming bear wonderfully preserved crowns of prefoliate to partially emergent young leaves, as well as occasional isolated or adventitious leaves, the cell structure in most instances being indicated in great detail.

The first description given of a crown of silicified leaves was based on that borne by the type of Cycadeoidea ingens, which, as elsewhere noted, likewise furnished the first evidence as to the true character of microsporangiate fructification in the fossil cycads (I88). Later the leaves of Cycadella ramentosa, one of the fine series of silicified trunks from the Freezeout Hills of Wyoming, were figured and briefly described by the writer for Ward's Status of the Mesozoic Floras (I94). 

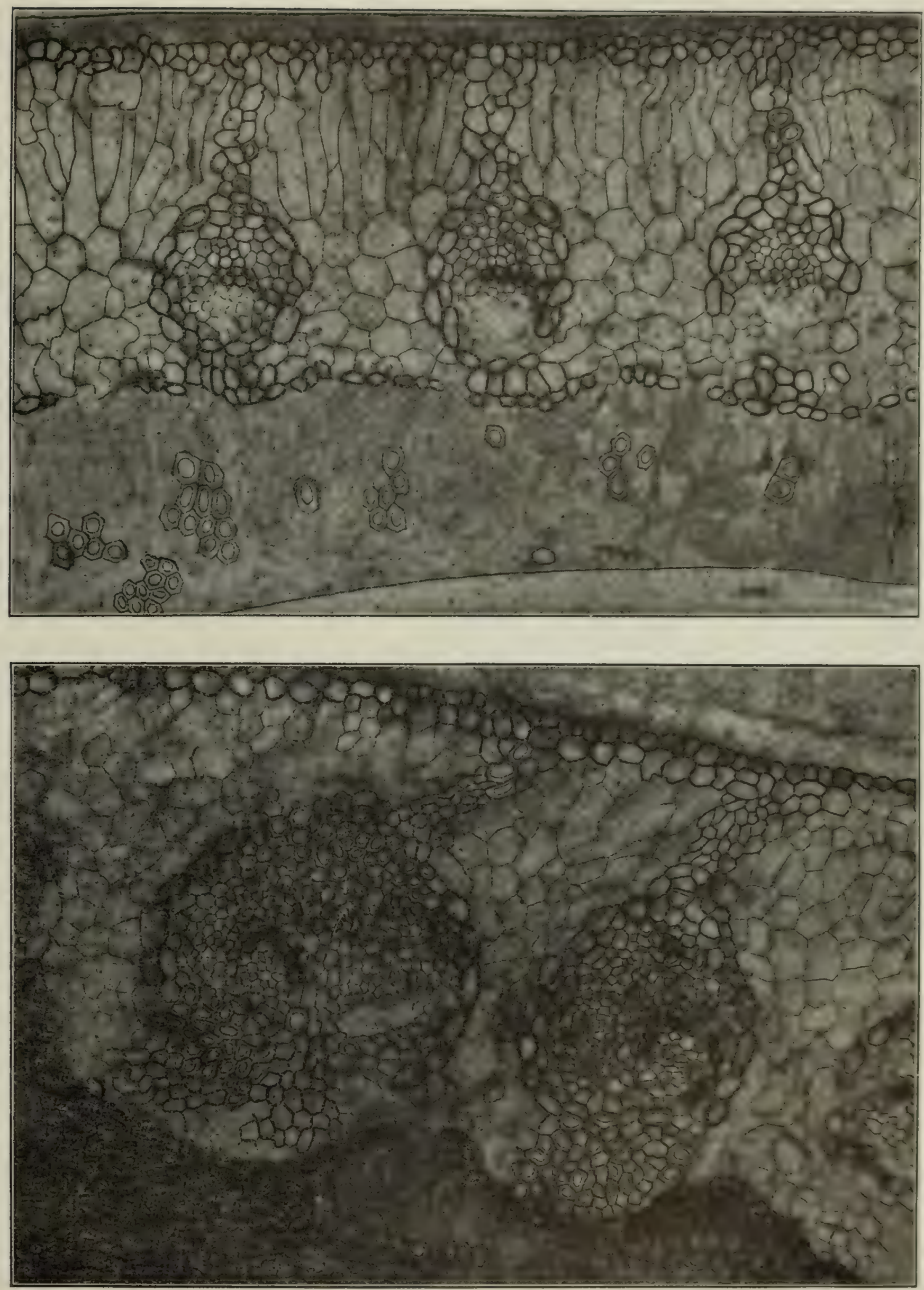

Fig. 45.-Cycadeoidea ingens (type). Transverse sections of entire pinnules, showing the struclure of the pinnule bundles as drawn diagrammatically on microphotographs, enlarged about 140 times. The upper figure is from thin section 46 , cutting through the tips of the pinnules of a very young erectly prefoliate frond. The lower figure is from thin section 170 (cf. photograph 6, Plate XXXI), cutting through the base of a pinnule of a larger young and partly emergen! frond. In both sections only occasional cells are clearly conserved in the heavy sclerenchyma region occupying all the space beneath the bundles. 


\section{THE FOLIAGE OF CYCADEOIDEA INGENS (TYPE).}

The type trunk of $C$. ingens is of large columnar to barrel-shaped form, somewhat flattened, as are most Black Hills and other cycadeoidean trunks. It is a magnificent flower and leaf bearing specimen, complete less the roots, and has a height of $85 \mathrm{~cm}$., with a girth of $\mathrm{r} 7 \mathrm{~cm}$. and a weight of 304 kilograms. (See plates I-III.) The leaf-base ends or "scars" are unusually large, being 3.5 to $5 \mathrm{~cm}$. wide and 2 to $3.5 \mathrm{~cm}$. high, with the lateral angles drawn out to sharp points

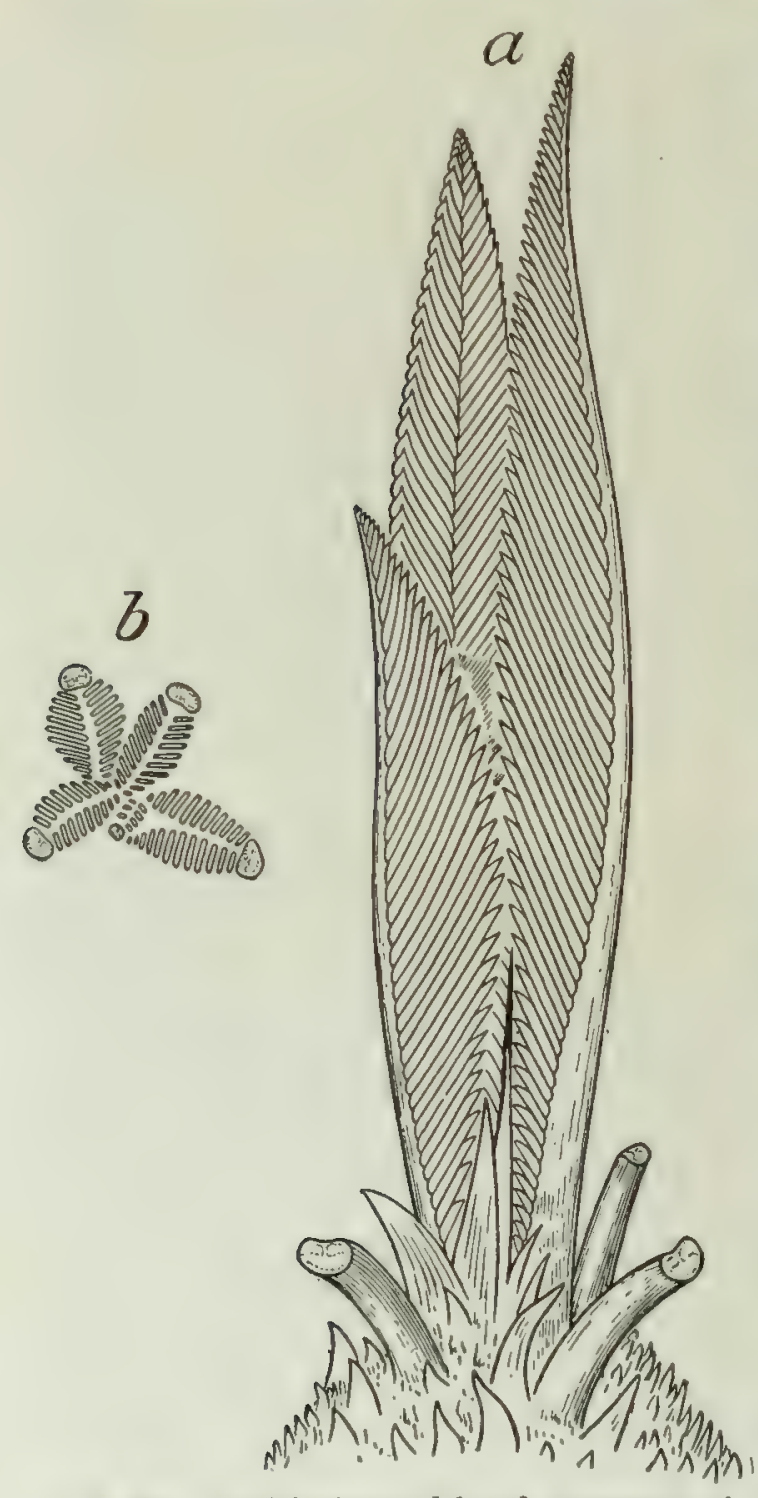

Fig. 46.-Prefoliation and frond emergence of existing cycads. Type 1.

Dion edule. Summit of trunk with mature fronds cut away so as to show five emergent young fronds (a). Transverse section of same (b). The rachis and pinnules of the erectly prefoliate fronds undergo simultaneous elongation and growth. Both figures are natural size. by the incurving sides. In life, bisporangiate strobili were embedded between the leaf bases at various points, and a number of basal portions of such are readily to be noted; but only one such strobilus was preserved entire. This, as stated, was removed for study and described in I899. Its position near the summit of the trunk is shown in plate I. All the portion of the summit above this flower bud may be considered the true crown of the trunk, the surface being rounded rather than conical, and of elliptical outline with a long diameter of $25 \mathrm{~cm}$. and a short diameter of about $20 \mathrm{~cm}$. This crown is made up of a dense mass of ramentum, in which are embedded, just above the flower and older leaf bases, various half-grown and partially emergent fronds, and still nearer the summit a number of young fronds as yet entirely immersed in ramentum. Of the latter, five have been found in the portions of the summit removed, three being shown in thin transverse section on plate XIX, photographs I to 3 . Of the half-grown fronds one was secured with its lower pinnules not yet emergent, as in the transverse section shown on plate XxxI, photograph 6. It is thus seen that a completely preserved and nearly mature bisporangiate strobilus was present among the full-grown leaf bases near the summit of the trunk, and that a considerable number of such strobili, some of which had possibly matured, were seated on the lateral trunk surface, though for the greater

part broken away; while above the uppermost strobilus or flower are partially emergent fronds, and still more nearly apical than these a number of very young fronds, with their pinnules quite well developed, but with their rachides as yet short and of only sufficient length to bear the closely ranked pinnules. The full number of these smaller fronds has not been determined, but at least half a dozen are present. Plainly, after having formed its blossoms this cycad was again actively 
putting forth its energies in the unfolding of an additional series of leaves. Happening to be fossilized at such a critical time in its life under the most favorable conditions, there thus came to be preserved a wealth of characters, scarcely rivaled by any Mesozoic plant of which there is a record. This specimen alone affords material for a restoration.

The first searching examination of this wonderful trunk showed that, as found in the field, it had been subjected to the erosive action of sand-laden winds on the hillside

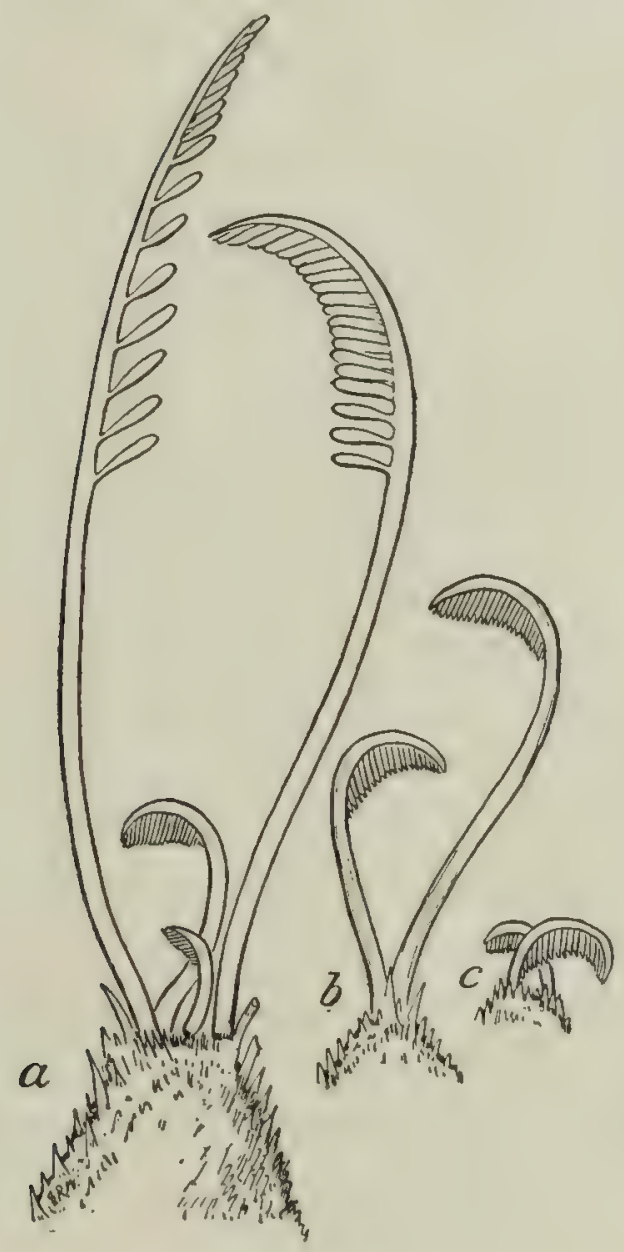

A

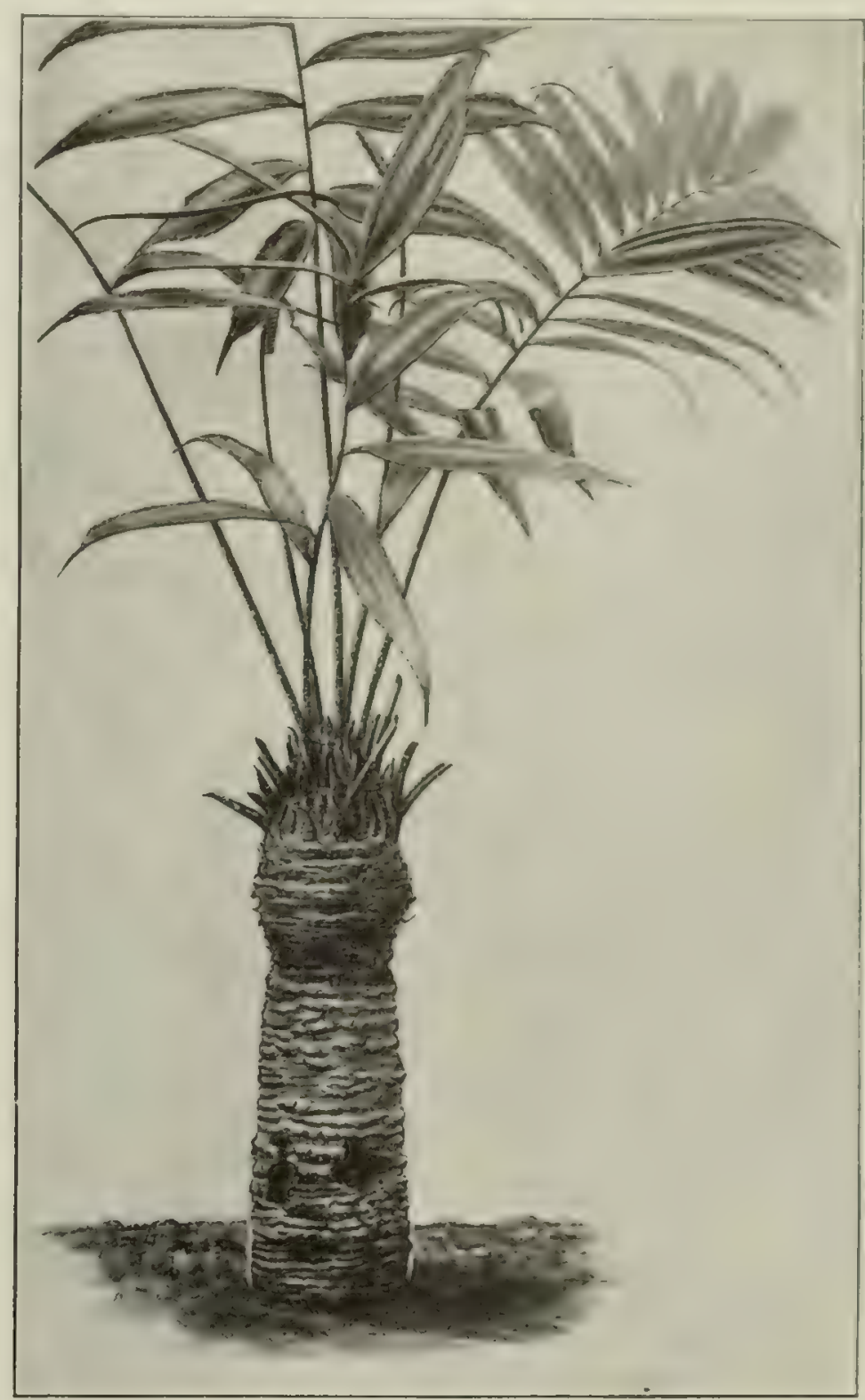

B

Fig. 47.-Prefoliation and frond emergence of existing cycads. Type II.

A. Zamia floridana. $X \frac{2}{3}$. Summits of three trunks $(a, b, c)$, with all old fronds wilted down, and showing only the young fronds of semi-fern-like habit of emergence, in which the pinnules lie straight and the rachis is once deflexed. Rachial elongation mainly precedes pinnule growth. (Author's plants.)

B. Zamia Lindeni. $\times \frac{1}{8}$. Armorless type of cycadean trunk bearing two emergent young fronds, the petioles of which are fully elongated, while the rachis is yet short and the straight-ranked pinnules minute, although clearly to be seen in the figure. The slight inward curvature of the young rachis shows that it was earlier once deflexed, as in A. (Conservatory of Miss Helen Gould, Tarrytown-on-tne-Hudson.)

where it lay, and that æolian polishing had partially exposed, in exquisitely clear transverse section, the tips of two adjacent young leaves plainly belonging to the normal helicoidal series and just ready to emerge at a distance of about 5 to $8 \mathrm{~cm}$. from the apex of the trunk. Several pairs of these leaves as enveloped in ramentum were removed for study, and the disposition of their parts with reference to the trunk determined from the requisite sections. 


\section{PREFOLIATION.}

As removed, each leaf, with its still folded, non-emergent pinnules, formed an erect subcylindrical or spindle-shaped body with a long diameter of ${ }_{5} \mathrm{~mm}$., coinciding with the radius of the trunk, and a short diameter of $\mathrm{I} 2 \mathrm{~mm}$. at right angles to it; all being deeply embedded in the luxuriant growth of ramentum. The rachis was erect and distal to the mass of attached pinnules, the latter being

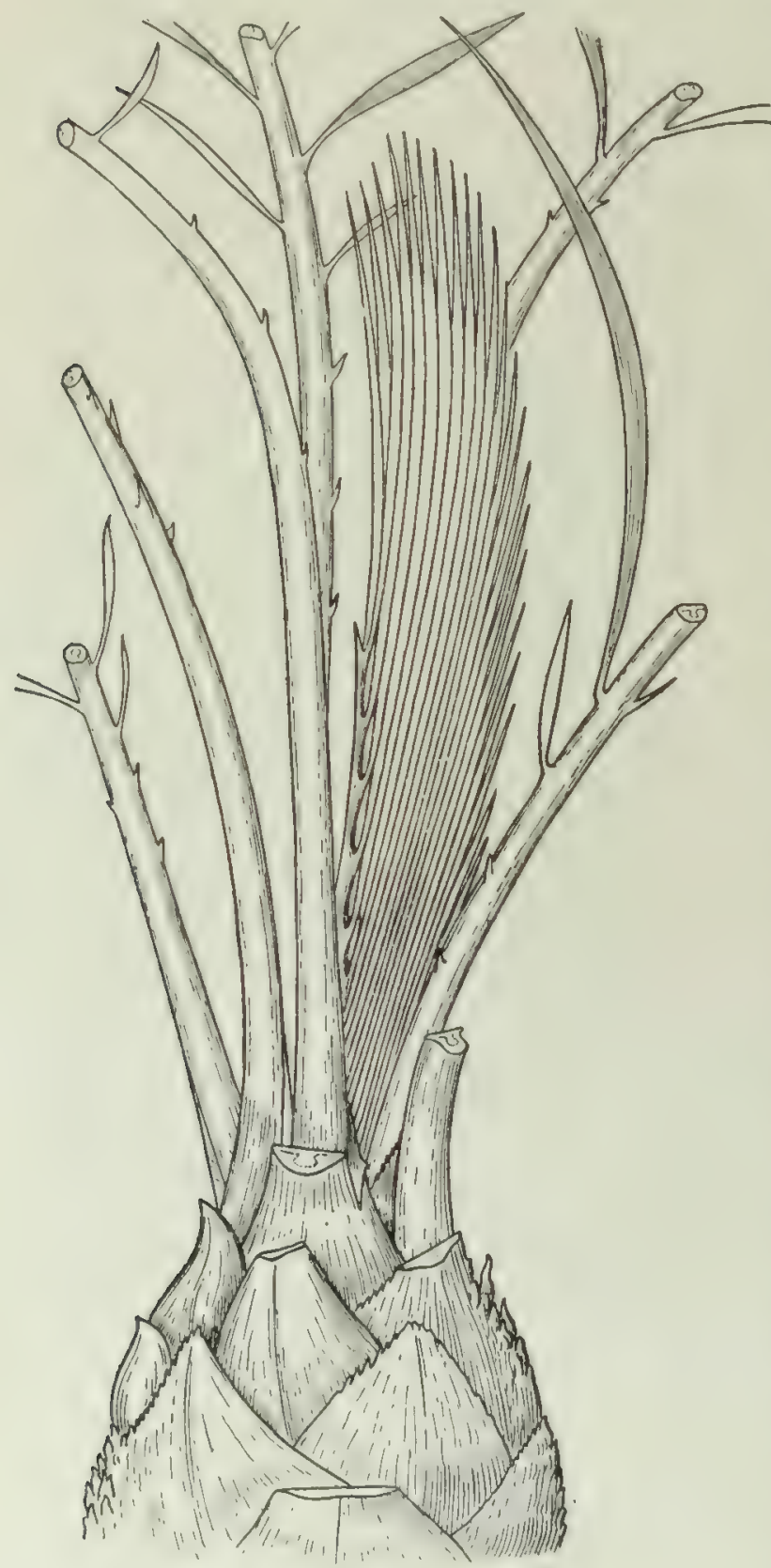

Fig. 48.-Prefoliation and frond emergence of existing cycads. Type III.

Macrozamia spirali (?). $\times \frac{5}{6}$. Summit of trunk bearing a partially emergent erectly prefoliate young frond, with the surrounding older fronds partially or wholly cut away. The fronds of this specimen appear to emerge one at a time and nearly continuously, with the production of few or ro scale leaves. The pinnules reach a nearly mature size before the main rachial elongation takes place, this being the type of frond emergence characterizing Cycadeoidea and Cycadella. folded inward in two closely packed imbricating ranks in such manner that their upper surfaces all faced towards the axis of the trunk. That is, each pinnule stood erect with its dorsal surface appressed at full length to the ventral surface of its next higher neighbor on the same side of the rachis, as in all erectly prefoliate, once-pinnate cycad fronds.

To parallel this disposition of parts, then, imagine the several pinmules of a normally expanded, once-pinnate frond of a living cycadean trunk to be folded inward with their dorsal surfaces toward the axis of the trunk, so as to form two vertical ranks side by side, one on each side of the rachis, just as in figures 44 and 46 , showing emerging fronds of Dion and Macrozamia. The hypothetical frond with a reduced number of pinnules, shown in figure 49, I, also illustrates the present erect entirely simple type of prefoliation.

Let us next observe that in some species of the erectly prefoliate Macrozamia, the still folded pinnules reach a nearly full size, while the rachis yet remains short and entively embedded in the armor. The final growth and emergence of the frond in this genus therefore consists largely in rachial elongation with a lateral outward and forward swing of the pinnules into their normal foliage position, in sharp contrast to Dion, in which, although erectly prefoliate, the rachis begins to elongate markedly while the pinnules are yet quite small. But from the comparative size of various pinnules borne on non-emergent rachides of Cycadeoidea ingens (type), as will be shown presently, an intermediate condition is indicated. These pinnules would have increased markedly in size after emer- 
gence, but not relatively so much as in Dion. Hence it may be said that Cycadeoidea exhibits characteristics of erect prefoliation and frond growth seen in both Dion and Macrozamia. Also, had the young frouds had the prefoliar habit of Zamia (fig. 47) in which petiolar growth takes place early, they would mostly have projected beyond the zone of preservation, and shared the fate of the older foliar organs. In such case, therefore, only very young fronds would have been silicified, and such could not yield the handsome transverse sections shown on plate xIx. (Cf. figs. 46-48, showing the three chief types of prefoliation in the existing cycads.) Scale leaves are not believed to be present in $C$. ingens, but are also absent in some of the Macrozamias.

\section{FORM AND STRUCTURE OF FRONDS AND PINNULES,}

The above-given facts concerning prefoliation may in reality be determined without the aid of thin sections; especially since among the specimens in the several American cycad collections there is at hand much supplementary material showing the emergent or broken rachis or petiole tips and the ranked pinnules, all the evidence going to indicate that, as in the existing cycads, the apically borne and helicoidally arranged young fronds emerge in both crown-forming groups and the successional or nearly continuous growth order. In the former case as many as a score or more of fronds may be present; in the latter a lesser number.

When, in addition to the macroscopic study of such specimens, the finer structures are considered, the entire arrangement of parts becomes very clear. For convenience a hypothetical frond with a reduced number of pinnules, the uppermost of which project beyond the short rachis, as in the fossil forms, is given in figure 49, I. By reference to this figure the relative position of the thin sections represented in figures 49, 2-4, may at once be determined, as well as the disposition of parts and the orientation of the vascular bundles. The thin section of a folded frond tip, shown in figure 49,2, passes well above the rachis, while that shown on plate XIx, photograph 3 , is cut from the same frond perhaps a centimeter lower down, or more proximately to the trunk, though not enough so to pass through the tip of the rachis. There are in the latter section ten more pairs of the transversely cut tips of pinnules than in the preceding one. Again, photographs I and 2, plate XIx, show sections of two adjacent fronds at as high a level with respect to the crown as either of the foregoing, but yet low enough to strike the rachis well beneath its tip. The latter fronds are hence a little more advanced in growth than the first mentioned, and their position in the helicoid of emerging leaves therefore distal. Finally, photograph 6, plate XxxI, shows the transverse section of the most nearly emergent frond of all those in the crown of $C$. ingens type actually observed to bear pinnules. In this frond but seven pairs of basal pinnules are cut; and from inspection of the specimen itself it may be determined that not more than a few, if any, inmer and therefore lower pinnules were present. It is hence clear that of all the pimmules borne by this nearly emergent frond possibly no more than seven and certainly not more than three or four additional basal pairs were still ranked and folded in the ramentum of the crown, although to detemine the exact number would require the making of several sections very difficult in this instance to obtain for the sake of 
such a minor point. Hence it can only be stated that at the time of its silicification this frond was an almost completely emergent one, although its petiole was scarcely half the mature thickness and as yet comparatively short.

The foregoing sections furnish important testimony as to the size and appearance of the mature fronds. First, as to the number of pinnules: In section 168 thirty-eight pairs of pinnules are cut, and this is the highest number seen in any of
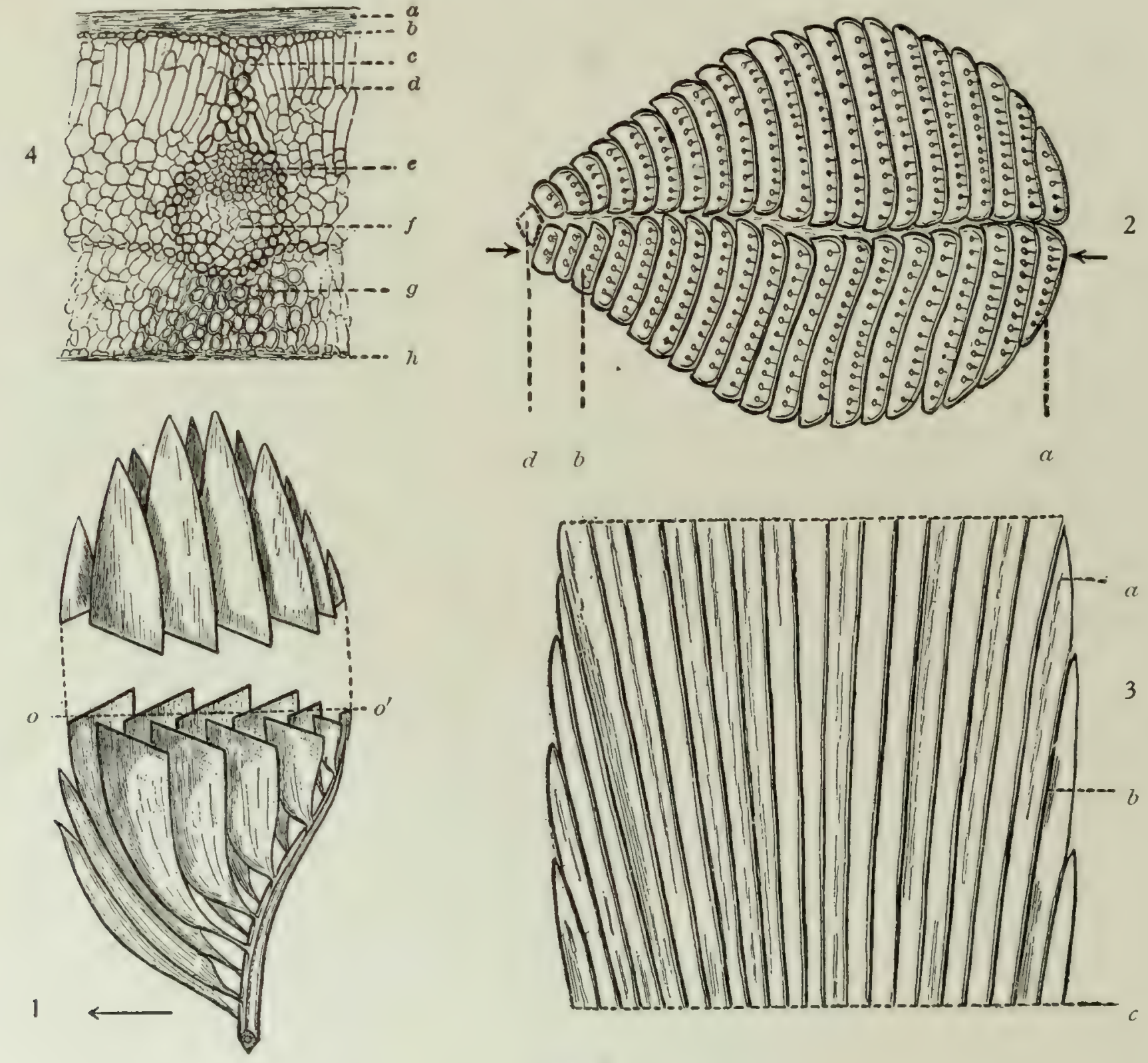

Fig. 49.

1. Diagram of a hypothetical leaf, with reduced number of pinnules, showing positions of sections represented in 2 and 3. $0,0^{\prime}$, Plane of transverse section, figure 2; also approximately marks base of longitudinal section, figure 3.

2. Cycadeoidea ingens Ward (type); transverse section (No. 46) through upper portion of young leaf. $X 4$. For relative position, see figure 1. a, Upper side of an inner pinnule cut near summit ; b, fibro-vascular bundle of pinnule cut near base; $\mathrm{d}$, axis of growth of rachis. The arrows indicate approximately the base line, $o, o^{\prime}$, figure 1 .

3. The same specimen; longitudinal section (No. 47) through summit of young leaf. $\times 4$. For relative position, see figure 1, also line indicated by arrows in figure 2. a, Summit of a pinnule near apex of leaf; $\mathrm{b}$, Upper side of pinnule; $\mathrm{c}$, base line of section indicated in figure $1, \mathrm{o}, \mathrm{o}^{\prime}$.

4. The same specimen; transverse section through a single pinnule, showing a fibro-vascular bundle. $\times 60$.

a. Upper side of leaf ; b, hypodermis; $c$, sclerenchyma connection of hyportermis with fibro-vasculas bundle; $d$, paliade parenchyma : $e$, xylem; $f$, phloem; $g$, sclerenchyma and spongy parenchyma region; $h$, epidermis of under side of leaf. The centripetal xylem is marked by e. Beneath are several cells of centrifugal xylem, and to the nether side of the bundle sheath on both sides outlying cells supposed to represent a transfusion tissue. 
the sections from the present trunk. But the only means of determining how many pairs in excess of 38 were commonly present would be to cut several fronds lengthwise a little to one side of the line of pinnulz insertion; and this has not been done, partly because it was hoped that it might yet be more expedient to do so in the case of some other specimen, and partly because, as is well known, the number of pinnules may vary greatly in a given species of living cycads from year to year, as well as in the leaves of the same year on the same plant. As the mass of pinnules is closely packed, however, and the rachis is about $5 \mathrm{~cm}$. in length, it is likely that not less than sixty, and possibly a hundred or more pairs of pinnules were borne by each of the once-pinnate fronds, as here seen emerging in their normal position at the summit of the trunk.

As determining the general form of the pinnules, it is next to be noted that in transverse sections like those shown in plate XIX, photographs I and 2, the pinnules
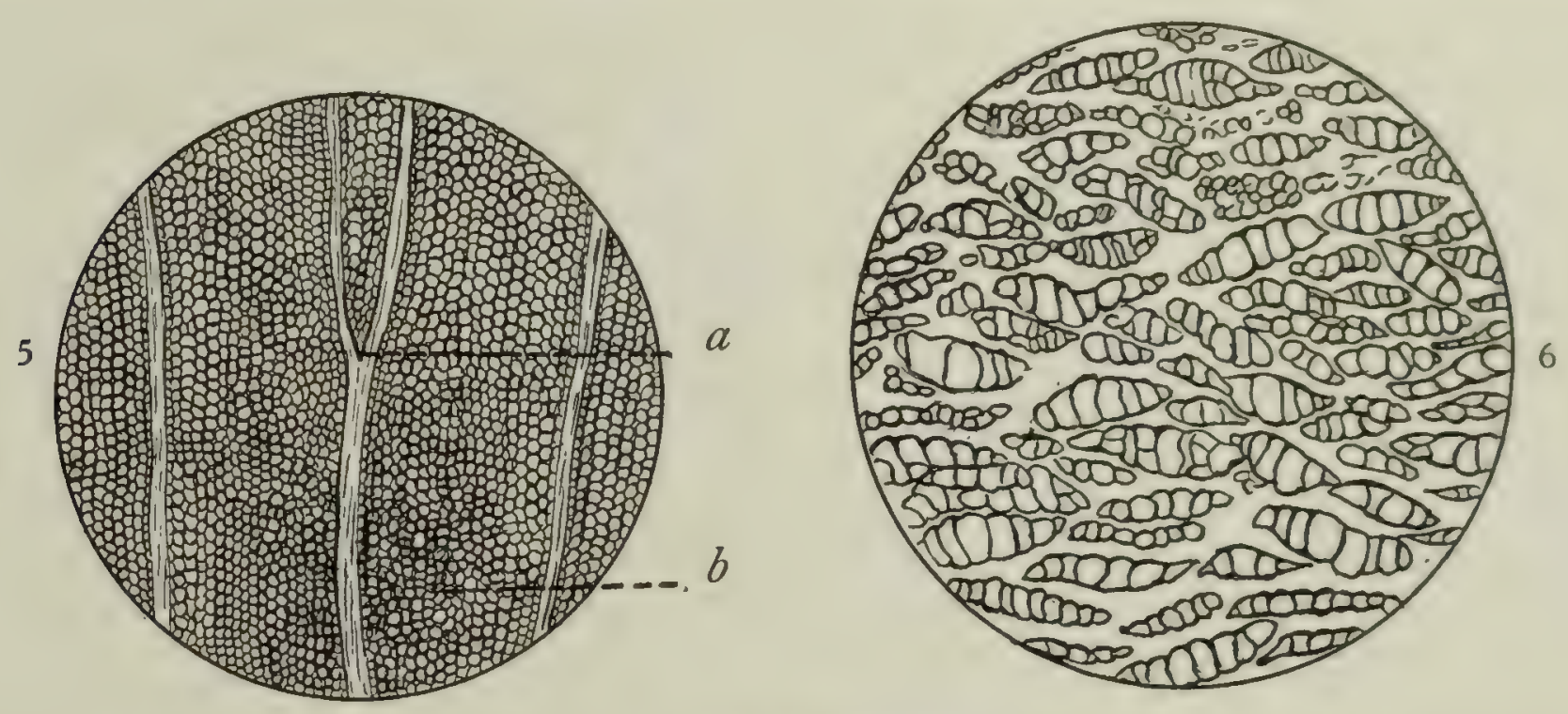

Fig. 49-continued.

5. The same specimen; longitudinal section through a pinnule, cutting the palisade parenchyma just beneath the hypodermis. $\times 35$. a, Forking vein; $b$, palisade parenchyma.

6. The same specimen; transverse section through the ramentun surrounding the young leaves. $\times 60$.

next to the rachis are necessarily cut through or close above their insertion, while the pinnules distal to the rachis-that is, at the inner side of the folded frond-are cut near their tips. It follows that in these and similar sections (as may the better be understood by reference to text-figure 49, I, of the hypothetical frond) there is a consecutive series of pinnules cut transversely at successively higher levels from base to tip; whence the transverse sections through the ranked pinnules of the folded erectly prefoliate fronds here described virtually afford serial mounts of pinnule sections, such as would be obtained were one to cut serially from base to tip of a single pinnule as many as 38 transverse sections, these being placed in close order one after the other, and oriented alike. Again, each of these sections of silicified fronds, cut low enough to strike the rachis, shows virtually the general form of the result that would be obtained if a single pinnule from a living cycad frond were sectioned transversely and serially from base to tip 38 times, more or less, and the individual sections mounted together in the exact order in which they were cut, as well as the most com- 
pact and elegant manner possible. Also, since in the transverse sections of the fossil fronds the pinnules as cut at successively higher levels increase in width slowly and decrease but slowly, and since the broadest sections of pinnules are usually about two-thirds out along the entire number cut, as counted from the side on which lies the rachis, it is clear that at this stage of growth there is indicated a linear to very slightly spatulate outline, partly recalling some of the large and long spatulate leaves of certain species of Cordaites. The number of pairs of pinnules, as seen in transverse sections of five of the fronds from the crown of $C$. ingens type, together with measurements of rachis and pinnules, is shown in the table here appended.

\begin{tabular}{|c|c|c|c|c|}
\hline Leaf. & $\begin{array}{l}\text { Pairs of } \\
\text { pinnules } \\
\text { cut. }\end{array}$ & $\begin{array}{l}\text { Vertical } \\
\text { thickness } \\
\text { of rachis. }\end{array}$ & $\begin{array}{l}\text { Width of } \\
\text { pinnule near } \\
\text { its base. }\end{array}$ & $\begin{array}{l}\text { Greatest } \\
\text { width of } \\
\text { pinnule. }\end{array}$ \\
\hline I & 20 & $\begin{array}{l}m m . \\
(a)\end{array}$ & $\begin{array}{l}m m . \\
\text { I. } 5\end{array}$ & $\begin{array}{l}m m . \\
6\end{array}$ \\
\hline II & 31 & $(a)$ & I. $5+$ & 7 \\
\hline III & 37 & 3 & 3 & 7 \\
\hline IV & 37 & 6 & 5 & 7 \\
\hline $\mathrm{V}$ & $7+$ & 8 & 6 & $8+$ \\
\hline
\end{tabular}

$a$ Section passes above apex of rachis.

The length of the individual pinnules is estimated to be about $5 \mathrm{~cm}$. in the case of leaf $\mathrm{I}$, and those of leaf $\mathrm{V}$ were much longer, having reached a length of fully ro $\mathrm{cm}$., and possibly $20 \mathrm{~cm}$., this doubtless being, as already suggested, nearly the adult size. Since it can not be known with entire certainty what was the relative amount of rachial and pinnule increase during the subsequent growth and expansion of the fronds, the exact length and form of the mature pinnules can only be surmised. But as the vertical thickness of the largest rachis actually bearing pinnules is $8 \mathrm{~mm}$., about one-third the size of the fronds borne by the mature leaf bases is indicated by this comparative measurement; for the vertical thickness of the leaf bases does not decrease rapidly in all the outer portions of the armor and is nearly the same as in the lowermost portion of the petiole and rachis. Evidently, therefore, frond $\mathrm{v}$ was about to enter upon a final stage of growth consisting mainly in petiolar and rachial elongation, while the pinnules may even approach the mature size.

So far as comparisons with living forms go it may be estimated that the mature fronds of $C$. ingens type were about Io feet in length. Regarding the general form we may not be wholly sure as to whether it was truncate like the fronds of Zamia foridana, that is, with several of the apical pinnules shorter than those next below them, or lanceolate like the fronds of Dion and Cerotozamia. But this much is certain: The young silicified fronds here described are distinctly truncate, as may be proven by reference to the longitudinal section given in text-figure 49,3 . This is a careful drawing of section No. 47 , which was cut from the same frond as section 46 (fig. 49, 2), and above and at a right angle to it, as well as in a radial longitudinal direction to the trunk (see also line $o o^{\prime}$ in fig. 49, I, of hypothetical frond). Now, in this longitudinal section, pinnule tips regularly emerge at about the same level, both on the side next to the rachis and in the usual position opposite to it or next to the axis of the trunk. It follows, since pinnule tips are seen to appear on both sides of a longitudinal section at an altitude above the extreme tip of the rachis, that the frond is truncate; that is to say, the apical pinnules were successively shorter, so that the fourth or even fifth pinnule below the apex of the rachis projected beyond 
the remaining three or four pinnules borne above it. The general condition is strikingly like that shown in figure 48 of the emergent and truncated frond of Macrozamia with a short petiole and rachis and nearly full-sized pinnules. The mature frond of this plant, however, finally assumes an elliptical form, the pinnules increasing but little in size during the final period of petiolar and rachial elongation and emergence; whence, in the absence of comparison of all the details of frond emergence in a considerable number of existing species, it is not possible to determine from the data at hand whether or not the mature fronds of $C$. ingens retained their prefoliate truncation.

Regarding the insertion of the pinnules or attachment to the rachis it may be noted that the pinnule bases are cut a little obliquely near the top and middle line of the rachis, which does not have as prominent a middle ridge as that of most living cycads. The general relation of parts is, however, the same, and the base of the pinnules broad rather than rounded and stem-like, just as in most existing cycads. It may be concluded, therefore, that the midrib of the rachis was not pronounced and that the general appearance of the dorsal surface of the fronds of $C$. ingens when mature and laid out flat was intermediate between that of Podozamites and Witliamsonia, and possibly identical with one of the species of leaf imprints already described under one or the other of these generic names.

Preservation of Microscopic Features.

Under the subject of leaf bases the general facts concerning the structure of the older leaf bases of Cycadeoidea have already been given. Although as yet no young leaf base and petiole of $C$. ingens type has been found with the cell walls naturally stained with sufficient distinctness to afford satisfactory photomicrographs, or readily admit drawings, the cell structure is actually present in great perfection, and it is believed that artificial staining methods similar to those employed by Lignier (79) may yet be resorted to with success, should naturally stained and differentiated sections not finally be found. The coloration or lack of coloration of the specimens is not always uniform, so that clearer sections than those thus far made will doubtless yet be secured. Nevertheless enough may be seen to determine that the bundle pattern outlines a heavy V, very nearly or wholly like that seen in another species, represented in figure 52. The coloration of the cell walis in the pinnules is much more distinct, although the general tone is rather light. It is, however, clear that cell preservation in the pinnules, barring the very slight lack of color differentiation in the sections thus far obtained, is also distinct and complete.

It has been already explained how the transverse sections of the folded fronds virtually present numerous serial sections of the pinnules. This fact, coupled with their fine preservation, makes the study of their main anatomical features an exceedingly simple and satisfactory one. Even in the naturally polished sections from the lateral trunk surface most of the details may be made out with the aid of a lens, nearly every bundle outline being distinct, and the coloring of the larger tissue zones often of most beautiful clearness. As may be seen by referring to plate IIX, photographs 3 and 8, the preservation and coloring of the transverse frond sections of trunk 208 are the same as in the type of $C$. ingens. In both instances, since 
we have the rare advantage of so many serial transverse sections with all their bundles present, it is possible to plot whenever desirable the plan of pinnule nervation, which, as in the existing cycads, is of the strictly dichotomous type.

\section{Pinnule Structure and Comparison with Existing Cycads.}

The structure of the pinnules of $C$. ingens, as represented in the extensively retouched photographic figure 45 , is essentially that of leathery to dense and woody cycadaceous foliage types. Each bundle is surrounded by a prominent more or less continuous sclerenchymatous sheath, an extension of which passes out from the upper or xylem side to the epidermis and spreads out beneath it as a layer of hypodermal sclerenchyma several cells thick opposite to the bundles, but diminishing to a single cell in thickness between them. Beneath this upper hypodermal sclerenchyma there is a layer of palisade parenchyma one cell thick, followed by rounded and large parenchyma cells filling all the space between and as far as the lower side of the bundles. Finally, through all the space beneath the bundles the tissues are dense and woody to the nearly complete exclusion of parenchyma, but are for the greater part indistinctly indicated, owing mainly to the lack of natural staining rather than of preservation. Especially just beneath the bundles large areas of sclerenchyma, not very sharply outlined, may be noted. The upper boundary of this lower area or zone of indistinctly stained tissue appears in all the transverse sections as a distinct line evenly curving beneath and hence uniformly waved as many times as there are bundles.

The bundles are of mesarch collateral structure without radial arrangement of either xylem or phloem, and the prominent surrounding sheath is made up of an inner smaller-celled and an outer larger-celled "peridesmic" (?) layer, confluent, as mentioned, with the hypodermal sclerenchyma. The inner elements of the sheath are reinforced to a thickness of from three to four cells on both the xylem and phloem sides of the bundles, more especially near the base of the pinnules; and scattered among the outer sheath elements one notes occasional very heavy-walled cells, as in Bowenia spectabilis. Also from the lower side of the bundle a layer of transfusion (?) tissue a cell in thickness extends out, ala-like, underneath the roundcelled parenchyma of the middle pinnule and above the lower region of mainly sclerenchymatous elements already noted. Evidently these cells are in part responsible for the sharpness with which the two zones they separate have been delimited by the natural course of silicification.

Owing to the absence of radial cell grouping, and the extensive and complex development of sclerenchymatous ensheathing tissue, the exact extent and position of the centripetal as compared with the centrifugal xylem, and the limits of the phloem, are not easy to determine, a difficulty that is obvious enough in the accompanying diagrammatically-retouched photographs of transverse pinnule sections. But in the absence of better naturally or artificially stained sections, and especially in the absence of a study of the pinnules of all the existing species of cycads, it is sufficiently exact to describe these bundles as of mesarch collateral structure, with extensive secondary sclerenchymatous development and modification, as in Cordaites (cf. I6I) and Encephalartos. 
Turning briefly to the existing cycads it is, however, instructive to note one of the least modified forms of pinnule structure, as seen in Bowenia speclabilis, with bipinnate fronds and an exceedingly thin pinnule blade. (See fig. 50.) Here both

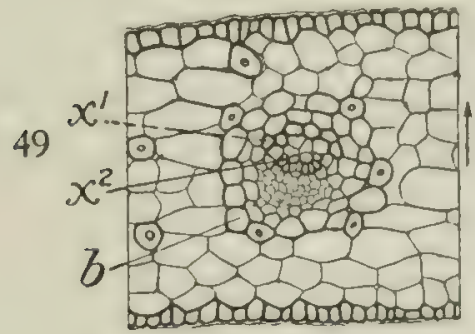

Fig. 50.-Bowenia spectabilis. $\times 125$. Transverse section of pinaule, showing a simple bundle form with centripetal xylem $\left(x^{1}\right)$, centrifugal xylem $\left(x^{2}\right)$, and a more or less distinctly double bundle sheath (b).

the dorsal and ventral epidermis are alike formed by a characteristic single layer of cells with heavy outer and somewhat thinner inner walls. The bundle sheath consists of a double layer of cells, the outer layer being larger and thicker than the inner, just as in Cycadeoidea ingens, with occasional very heavy-walled cells scattered about the outer sheath or in the surrounding parenchyma. The minute bundle is of mesarch collateral structure, with the centripetal xylem cells of larger size than, but nearly the same number as, the cells of the well-marked centrifugal xylem, neither xylem nor phloem being radially arranged. Beyond this simplest type there is, however,

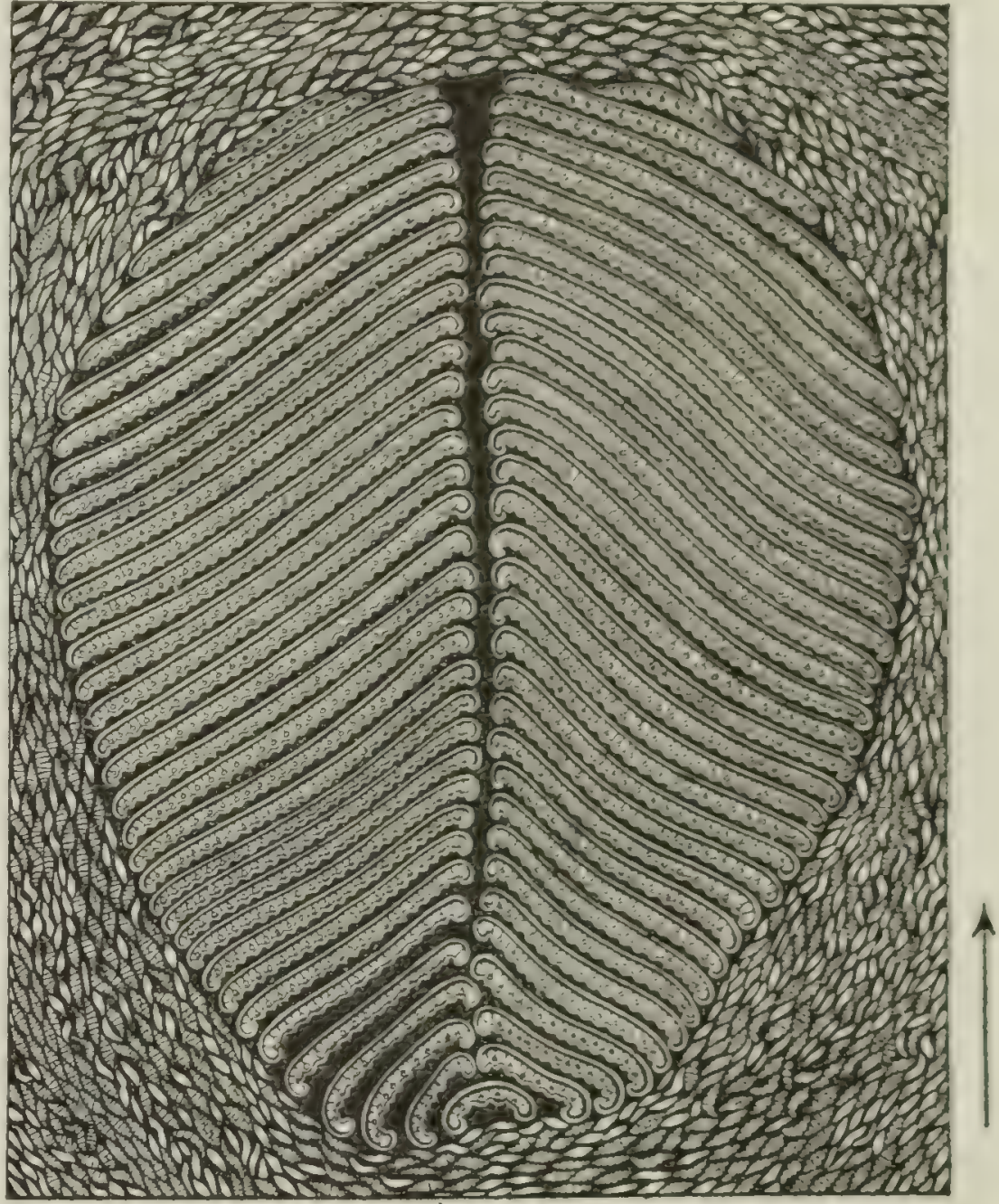

Fig. 51.-Cycadeoidea ingens. T. 208. Transverse section of partly emergent but still folded frond deeply embedded in ramentum. $X$ about 4.

Arrow points toward axis of trunk. The rachis lies to the nether side.

This section was polished without removal trom the trunk. The siliceous matrix of the ramental hairs and pinnules is shown in solid black; the dermal layes as a narrow white bend; the heavy upper layer of palisaded hypodernal sclesenchyma by a heavy, and the thin lower sclerenchyma by a lishe continesus tine: the vascular bundles by a light line marki $x$ the bundle sheath and its connection with the hypodermal sclerenchyma. A few cells appeas to project from the lower hypodermal sclerenchyma between the bundles, as in various recent cyesds. but the series of lines indicating such should not be shown as if crossing the entire thickness of the parenchyma. The section cuts the folded frond just above the tip of the rachis, above whicls there hence project 34 pairs of pinnules. The total number of pairs may have been less than 50 . (Cf. photograph 8 , plate XIX.)

in the various existing cycads a long series of modifications in the presence, amount and grouping of hypodermal bands of sclerenchyma, the presence or abserce of palisade parenchyma, the general character of the ground parenchyma and of the bundle sheaths, and in the disposition and amount of centripetal and centrifugal xylem and of the phloem. The most leathery and lignified forms are to be seen in Encephalvrtos, certain forms of Zamia, etc. ; and if one combines the nain characters of Encephalartos cycadifolius, which has palisade parenchyma above and a heavy sclerenchyma zone below the bundle sheaths, with those of Zamia furfuracea, which has a bundle sheath confluent on its xylem side with the hypodermal sclerenchyma, a replica of the 
pinnule structure of Cycadeondea ingens will be afforded. In summation it is then to be noted that the prefoliation and general form of the frond of $C$. ingens agree in all essential features with existing cycads; while it is not unlikely that among the pinnules of species as yet not figured or examined there may be one or several with microscopic structures quite completely homomorphic to those of Cycadeoidea ingens or other cycadeoidean forms. Were one to adjudge the taxonomic position of the fossil species on the basis of its foliage only, one might, bearing in mind the general absence of scale leaves, place it near Macrozamia or Encephalartos.

ON YALE CYCAD NO. 208 (A COTYPE OF CYCADEOIDEA INGENS) AND ITS ADVENTITIOUS LEAVES.

(Figs. 44 and 5o, with Photógraphs 6-8 of Plate XIX.)

Trunk No. 208 of the Yale collection of fossil cycads was discovered by the writer in September, I898, under somewhat exceptional circumstances. It is a specimen of Cycadeoidea ingens, and is mentioned in the Nineteenth Annual Report of the United States Geological Survey, page 564, by Professor Ward, who, in company with the writer, inspected it while still in situ, about $4 \frac{1}{2}$ miles east by south of Piedmont, South Dakota, at the north end of the Cycad Valley, as the deep depression in the Piedmont-Black Hawk cycad area may be called. A map of this region is given in the Nineteenth Annual Report of the United States Geological Survey, opposite page 564 , with a brief discussion of the stratigraphical relations. At the south end of the valley is the old cycad locality, 3 miles north of Black Hawk, from which most of the specimens from this section of the Black Hills Rim were obtained. As coming from the north end of the Cycad Valley, the present trunk is of distinct value in extending the Black Hawk cycad locality as at first known, and thus aiding to delimit the extent and character of the cycad horizon to which it belongs. Also, being the only specimen from the Piedmont region found nearly or wholly in place, a brief mention of the segment of the Black Hills Rim from which it came may be interpolated. As very well shown in the views of the Piedmont-Black Hawk region given on plates XLVIII-L, the "rim" is here quite complex; while following the huge escarpment of Jurassic and Cretaceous rocks forming the outer wall beyond the Triassic "Red Valley" extending all round the Black Hills, as so well known to all students of the geology of that wonderfully interesting region, there is a deep syncline followed by a prominent anticline producing a series of valleys and ridges. East of Piedmont the series of rim ridges as thus made up is nearly 4 miles wide. But these ridges disappear to the south and southeast, the rim again becoming a simple main monoclinal ridge northeast of Black Hawk. There is thus formed a triangular area of rough and broken or hilly rim country with its base east of Piedmont and its vertex about 2 miles north of Black Hawk. From this vertex the Cycad Valley extends northward 3 miles, being deeply scooped out of the eastern or cuter and anticlinal portion of the rim, with the marine Jurassic and finally the "red beds" exposed at its base.

After making an examination of the old locality at the south end of the valley, the writer decided that cycads might perchance be found at the northern end. And as so much interest attaches to the relative position of the Atlantosaurus and cycad horizons, repeated efforts were made to find material that would in a measure confirm 
the apparent position of the cycads, which were, without exception, found eroded out as loose boulders at the old locality. As a result specimen No. 208 was discovered nearly or precisely in situ in a sandstone stratum not more than a few feet below the Dakota sandstone and about I25 feet above the Atlantosaurus beds of Marsh.

Trunk No. 208 is large, flattened, much worn, and somewhat pear-shaped with the large end basal, the top being wholly broken away and smoothed by either water or more likely æolian erosion. It has the following dimensions:

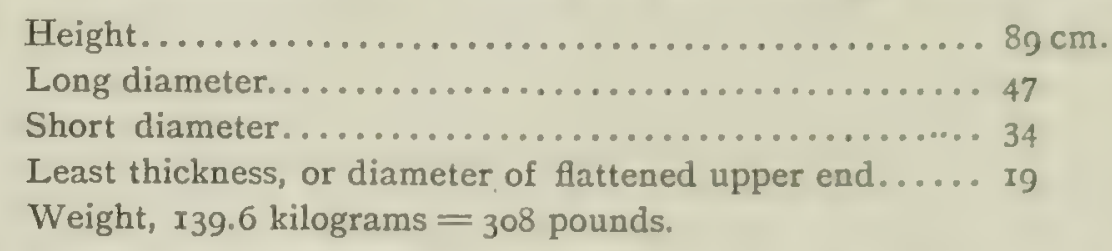

Of far more interest than its precise stratigraphical position are the structures present. As collected, the trunk bears, laterally or adventitiously, ten or more young leaves, which are marvelously preserved, still folded, and not yet emergent. In the case of six of these the naturally polished transverse sections are in plain view, but were not at once observed. When first examined the trunk was dustcovered, and later, being a huge and otherwise most unpromising specimen, it was not closely scrutinized, its wonderfully preserved leaves finally being found by accident, after leaves had been noted in various other species. None of these leaves have yet been thin-sectioned, but the following descriptions-based solely on transverse sections, in part polished naturally, and in part by means of carborundum bricks without removal from the trunk, which remains intact as when collectedfully testify to the beauty of leaf preservation exhibited. (See fig. 51.)

The second striking fact concerning these adventitious leaves is their isolated distribution laterally among the very old leaf bases, with but little or no indication of their having arisen from lateral buds, such not having been once observed with certainty, in either Cycadeoidea ingens or the closely related C. Jenneyana, although both species are known from many specimens and freely bear the lateral fructifications usually seen in the cycads from the Black Hills. Orientation with reference to the axis of the trunk is nevertheless as regular and exact as in case of leaves in normal apical series; though the lowermost leaf of the young abnormally situated series is borne far down on the trunk and quite isolated from the others, which are mostly scattered over an area of some Io by $5 \mathrm{~cm}$. The

\begin{tabular}{|c|c|c|c|c|c|}
\hline No. & $\begin{array}{l}\text { Height } \\
\text { above base } \\
\text { of trun's. }\end{array}$ & $\begin{array}{l}\text { Breadth of } \\
\text { transferse } \\
\text { section } \\
\text { (tangen- } \\
\text { tial). }\end{array}$ & $\begin{array}{c}\text { Length of } \\
\text { transi arse } \\
\text { secticn } \\
\text { (radial). }\end{array}$ & $\begin{array}{l}\text { Pairs of } \\
\text { pinzules } \\
\text { cut. }\end{array}$ & $\begin{array}{l}\text { Greatest } \\
\text { number of } \\
\text { vascular } \\
\text { buadles of } \\
\text { a single } \\
\text { pinmule in } \\
\text { tramsrerse } \\
\text { section. }\end{array}$ \\
\hline & $\mathrm{cm}$. & $\mathrm{cm}$. & $\mathrm{cm}$, & & \\
\hline $\begin{array}{l}I \\
2\end{array}$ & $\begin{array}{l}50 \\
50\end{array}$ & $\begin{array}{l}0.5 \\
1.0\end{array}$ & $\begin{array}{l}0.4 \\
1.0\end{array}$ & $\begin{array}{r}5 \\
14\end{array}$ & 20 \\
\hline 3 & 58 & I.3 & I. 5 & 22 & 30 \\
\hline 4 & $5^{8}$ & I. 3 & I. 3 & 27 & 29 \\
\hline 5 & 30 & I. 3 & 2.0 & $3 I$ & 30 \\
\hline 6 & 50 & 2.5 & 2.5 & 34 & 35 \\
\hline
\end{tabular}
distances of the several young leaves above the base of the trunk, which, as noted before, is $87 \mathrm{~cm}$. high and incomplete, together with the chief features and the dimensions of the several transverse sections of the leaves as arranged according to their size, are tabulated herewith. 'The unusual number and vigorous growth of these adventitiously borne leaves may well be accounted for on the theory that 
the plant had been grazed upon by some animal or had been otherwise injured and was attempting to recover itself.

In all the sections, whether naturally or artificially polished, the bundle system is fairly well indicated by natural iron-oxide staining as well as other features of the leaf. It is specially to be noted that the sections all apparently lie above the summit of the rachis. It will be recalled that in the crown of leaves borne by Yale cycad IOo, several leaves are present which may have emerged one or more feet above the summit of the trunk, so that only basal pinnules remained unexpanded.

The bundle system indicated by the present transverse sections of folded young leaves of trunk 208, together with that of several similar leaves of $C$. ingens (type), next follows.

Number of Vascular Bundles Counted in the Blades of Successive Pinnules in Transverse Sections of Various Prefoliate Leaves of Cycadeoidea ingens (TYPE) AND C. INGENS (TRUNK 208).

\begin{tabular}{|c|c|c|c|c|c|c|}
\hline \multirow{2}{*}{$\begin{array}{l}\text { No, of } \\
\text { pin- } \\
\text { nule. }\end{array}$} & \multicolumn{3}{|c|}{$\begin{array}{l}\text { (a) Cycadeoidea in. } \\
\text { gens (type). }\end{array}$} & \multicolumn{3}{|c|}{$\begin{array}{l}\text { (b) C. ingens } \\
\text { (truuk 208). }\end{array}$} \\
\hline & (S. $\left.{ }_{46}\right)$. & (S.169). & $\mid \begin{array}{l}\text { III } \\
\text { (S.170). }\end{array}$ & IV. & v. & VI. \\
\hline I & 3 & 3 & $\ldots$ & 7 & 3 & 6 \\
\hline 2 & 7 & 5 & 17 & IO & 7 & 7 \\
\hline 3 & 8 & 7 & 22 & I2 & I I & II \\
\hline 4 & 9 & 9 & 24 & I3 & I2 & I3 \\
\hline 5 & II & 9 & 25 & I7 & I3 & 17 \\
\hline 6 & I3 & IO & 25 & I8 & $I_{4}$ & I9 \\
\hline 7 & I3 & I I & 25 & I9 & $\times 5$ & rg \\
\hline 8 & I2 & I I & 25 & 22 & I7 & 22 \\
\hline 9 & I2 & I3 & $\ldots$ & $2 \mathrm{I}$ & I9 & 24 \\
\hline IO & I3 & I4 & $\ldots$ & 22 & 22 & 27 \\
\hline I I & I3 & I 7 & $\ldots$ & 24 & 23 & 28 \\
\hline I 2 & I3 & I7 & $\ldots$ & 27 & 25 & 29 \\
\hline I3 & I3 & 17 & ... & 26 & 26 & 29 \\
\hline$I_{4}$ & I3 & I7 & $\ldots$ & 25 & 26 & 30 \\
\hline I 5 & I4 & 18 & $\ldots$ & 25 & 27 & $3 I$ \\
\hline I 6 & I4 & 20 & ... & 24 & 25 & 30 \\
\hline I7 & II & I7 & ... & 24 & 28 & 32 \\
\hline I8 & 9 & 18 & ... & 20 & 30 & 33 \\
\hline I9 & 8 & I6 & ... & I9 & 29 & 32 \\
\hline 20 & 5 & 20 & $\ldots$ & I8 & 30 & 34 \\
\hline $2 I$ & $\ldots$ & 20 & ... & 6 & 27 & 35 \\
\hline 22 & ... & 20 & $\ldots$ & $\ldots$ & 29 & 34 \\
\hline 23 & $\ldots$ & 20 & $\ldots$ & $\ldots$ & 26 & 35 \\
\hline 24 & $\ldots$ & I7 & $\ldots$ & $\ldots$ & 27 & 34 \\
\hline 25 & $\ldots$ & I6 & $\therefore$ & $\ldots$ & 24 & 34 \\
\hline 26 & $\ldots$ & I5 & ... & $\ldots$ & 24 & 33 \\
\hline 27 & $\ldots$ & $\mathrm{I}_{4}$ & $\ldots$ & ... & 20 & 30 \\
\hline 28 & $\ldots$ & 12 & $\ldots$ & ... & I7 & 28 \\
\hline 29 & $\ldots$ & 12 & ... & $\ldots$ & 6 & I9 \\
\hline 30 & $\ldots$ & 9 & $\ldots$ & $\ldots$ & $\ldots$ & 12 \\
\hline $3 I$ & $\ldots$ & 7 & $\ldots$ & ... & $\ldots$ & ... \\
\hline 32 & $\ldots$ & 5 & $\ldots$ & $\ldots$ & $\ldots$ & $\ldots$ \\
\hline
\end{tabular}

(a) Cycadeoidea ingens, type specimen:

I. From tip of one of the younger leaves of crown. Dimensions of section $1.25 \mathrm{~cm}$. in tangential by $1.60 \mathrm{~cm}$. in radial direction. Pinnule tips cut both proximally and distally. (S. No. 46.)

II. Parallel to and $3 \mathrm{~cm}$. beneath, that is, proximal to preceding, but also passing above tip of rachis. (S. No. I69, photograph 3, plate xIx.)

III. Larger leaf than either of the preceding, in which the rachis is cut and has a vertical thickness of I cm. Only the basal pinnules are non-emergent and traversed by the section, the remainder having grown out beyond the armor and failed of preservation. Both rachis and petiole have begun to elongate. (S. No. I7o, shown in photograph 6, plate Xxi.)

(b) Cycadeoidea ingens (cotype T. 208):

IV. Adventitious leaf borne $43 \mathrm{~cm}$. above base of trunk. Horizontal width of transverse section I. $5 \mathrm{~cm}$. Vertical height $1.4 \mathrm{~cm}$. This section was naturally polished in place on the trunk and passes well above tip of rachis. (Photographed on plate xix.)

V. Naturally polished transverse section of adventitious frond with transverse measure $1.3 \mathrm{~cm}$. and vertical measure of $2 \mathrm{~cm}$. (Photograph 7 , plate $\mathrm{xIx}_{\mathrm{x}}$ )

VI. Section of leaf polished in natural position on trunk. Pinnules are the largest yet observed in any of the young leaves. Section passes above tip of rachis. (Photograph 8 , plate xIx.)

It is evident that the several leaves of Cycadeoidea ingens, as seen in trunk 208, represent varying stages of growth, with the exception of Nos. 5 and 6 , which are in almost identically the same stage of development. A study of the leaf expansion of the several species of Macrozamia may teadily be made and will perhaps more exactly than in the case of any other genus furnish interesting comparative data. The slight increase in the number of bundles in leaf No.6, notwithstanding its 
relatively much greater size than the others, is a partial indication that the number of bundles in transverse section of the adult pinnule is here approached. A comparison of the near numerical agreement in the hundles of sections 167,168 , and 170 from $C$. ingens type, all of which traverse rachi of varying size, leads to a similar conclusion. Moreover, here, as in some living cycads, the young leaves have largely perfected their conductive systems when ready to emerge from the protected position within the armor or apex of the trunk in which they have taken their long, slow, early stages of growth. Only the petiole remains short, fleshy, and immature; but in life when once emergent, rapid increase in size and length took place, the adult form soon being reached.

A Method for Plotting the Pimnule Outline and Venation of C. ingens.-As has been previously explained in the description of the fronds of Cycadeoidea ingens, any one of the single ranks of pinnules in any of the transverse sections of prefoliate fronds may be considered as a single pinnule cut serially as many times as there are pinnules present, the more basally cut member of the series being external and the most apical internal or next the axis of the trunk. The number of bundles present in the successive pinnules of a rank-that is, those borne on one side of the rachis-is therefore of interest as representing the bundles in the lamina of a pinnule from base to tip, and thus affording exact data conceruing venation; whence it follows that from any of these transverse sections of prefoliate fronds, passing through or near the rachis, an almost wholly correct figure of the renation and form of a single pinnule may be plotted from the data in the preceding table by assuming the pinnule length, if not actually determined either from eroded surfaces or from sections.*

The method for the plotting of an approximately correct figure of the outline of one of these young pinnules from the data above given is a simple one. First lay down a vertical series of parallel lines distant about equal to the distance between the pinnule bundles. Next, in the absence of the exact length of the pinnules as determined from sections, lay down the estimated length on one of the lines of the ruled paper taken as a median line; then divide this line into as many: equal parts as there are pinnules cut in one of the ranks of a transverse section of the folded leaf which passes near or through the rachis. Through each of these divisions of the median line draw lines at right angles, marling off on each the corresponding number of pinnule bundles, beginning with the basal pinnule section. Count off successively on each side of the median line as many lines as half the bundle numbers and mark and unite the points so determined. The line thus obtained will be the approximate pinnule outline. The approximate renation can next be indicated by laying down lines corresponding to the initial bundle number; and dichotomizing at the successive divisions as many times as required tn indicate the bundle increase until the broadest part of the pinnule is reached.

\footnotetext{
* The venation of the plotted figure will be quite correct, but it is to be noted that the sections not bning from the same, but the successive pinnules, there will be every here and there a pinnule section which, though distal in position to the one preceding it, may have a less number of bundles in transrerse section. Such gaps occur, for instance, in section $\mathrm{I6g}$. Were the sections all actually cut from a single pinnule, increase and then decrease in number of bundles cut would of course be wholly uniform from base to tip.
} 


\section{CYCADEOIDEA COLOSSALIS (TRUNK 133).}

The general foliar form and relations just described in Cycadeoidea ingens are repeated in fully as complete and clear detail in several of the Yale specimens referred to Cycadeoidea colossalis, a quite different trunk type from either of the preceding. Of these, Yale specimen No. I33 is noteworthy. This trunk not only bears a lateral bud with very small fronds, the minute pinnules of which, with their bundle systems, are indicated, but, succeeding the old leaf bases in regular sequence, a fine crown of nineteen helicoidally disposed young fronds. Interior and apical to these are some fifty segregated ramental areas representing yet younger leaves and completing the usual apical helicoid foliar arrangement. The older of the fronds of the young leafy crown were well advanced in growth, and in life projected beyond the ramentum, although here as elsewhere most projecting portions of young fronds have failed of preservation or the tips have been broken or eroded away. The more and more apical of the fronds-that is, the successively younger members of the series - are less and less advanced in growth, and at last fail to emerge from the enveloping ramentum. In the absence of sections it can only be said of the larger fronds that they bore rather fewer pinnules than in $C$. ingens, and that the pinnules are of linear acuminate outline, and 5 or more centimeters in length, the breadth being less than half a centimeter.

Further characters of these silicified leafy crowns are, however, remarkably well shown in thin sections made from a stray bud, evidently from the crown of a trunk of this same species, or, if not, from one of $C$. minnekahtensis. This specimen (No. 520 of the Yale collection) is from the same locality as the preceding, and is of the same general form, appearance, and type of preservation, being simply an isolated crown of young leaves broken away from their insertion at the apex of a trunk, above the old leaf bases, and on the line of the cortex. A careful drawing of a transverse section, conveniently cut $5.5 \mathrm{~cm}$. beneath the summit, is shown in figure 52. At the periphery of the section a single one of the old leaf bases is seen to have remained attached to the bud as broken away. Then follows a series of sixteen young and yet folded fronds disposed in two nearly complete circumvolutions of the frond helicoids, the section doubtless passing above the tips of several still younger fronds in sequence with and of the same season as the sixteen. Interiorly - and therefore apically to the fronds, which actually appear at the surface-there is, however, an additional series of ramentum areas disposed in the same continuously helicoidal system as the larger fronds, and in turn followed by a circular zone of clear silica $5 \mathrm{~mm}$. wide, which incloses centrally a somewhat asteriated area of ramentum. This on closer inspection appears to belong to nine deeply seated incipient fronds, inserted close around the true apex of the trunk.

Since in the various transverse sections of the fronds only from eleven to eighteen pairs of pinnules are cut, though some of the sections pass through the rachides, the fronds of the present species have only about half as many pinnules as those of $C$. ingens. It must be noted that scale leaves are not believed to be here present. All the leaf axes appear to be very young or else actually bear wellpreserved pinnules. 
CYCADEOIDEA COLOSSALIS (TRUNKS 2 AND 10).

It is of interest to note that the huge branches of C. colossalis Nos. 2 and Io of the Vale collection bear once-pinnate young fronds of the $C$. ingens and Jenneyana form, though smaller and with apparently fewer pinnules. Especially to be mentioned is trunk Io, which bears, just beneath its large and well-conserved terminal helicoid of ramentum groups, a single partly emergent folded frond, with upward of twenty pinnules in each rank, as seen in the eroded transverse section. The only means of studying this frond would be to first remove it in the form of a cylindrical core, as has been done in the case of various strobili; and there is every indication that this would be well worth doing. While the bundle system is indicated in the

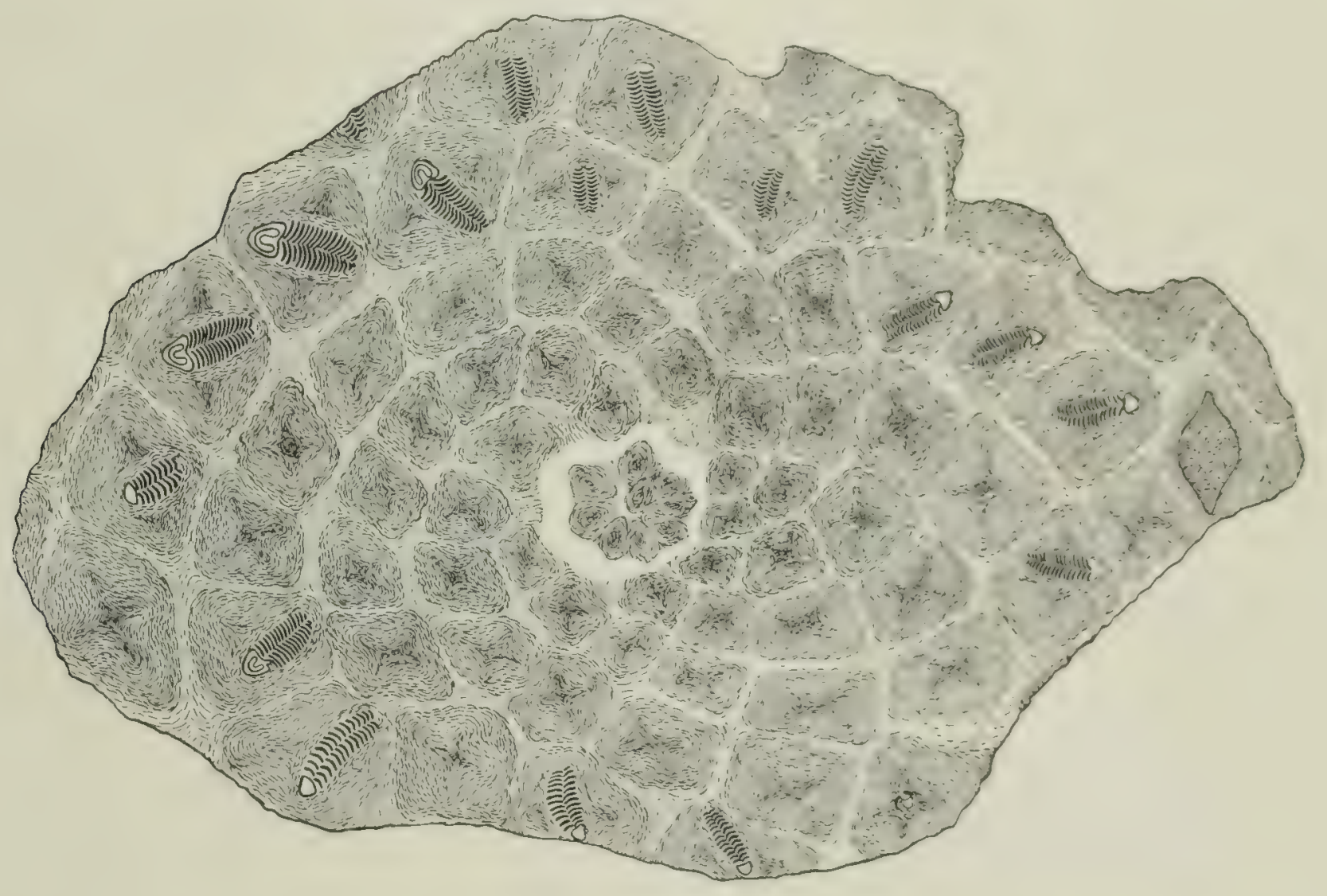

Fig. 52.-Cycadeoidea sp. S. 407. $\times 1$ 1.36. Transverse section through summit of a trunk, showing numerous erectly prefoliate leaves emerging in a crown. A single older leaf base is seen to the right. The bundle pattem of the rachis outlining a heavy $U$ is to be noted in three upper left-hand fronds. The more apical helicoidally arranged ramental areas within the crown of emergent fronds may belong to scale leaves or to a succeeding crown of fronds, two, if not three seasons of foliar growth possibly being indicated.

weathered section by tiny pits marking the position of each bundle of the individual pinnules, there is every likelihood that a centimeter or two beneath the surface of the trunk preservation is more complete, with excellent color differentiation.

It is an open question as yet whether or not these trunks are not rather to be referred to $C$. dacotensis; but in either case it is equally satisfactory to know that there is at hand a series of trunks illustrating the foliage of the great branching forms, and clumps of trunks shown on plates V-XII, although time has not as yet sufficed for more than an initial study of all this material.

Fortunately, as may here be added, the material now in the several musems of this country will in the end be found to permit the determination of the prefolia- 
tion and frond structure, and in the main the habits of foliage-crown formation of nearly every North American cycadeoidean species. The leaves of several other species than those above described have already been observed, but as their characters are not essentially different it is not deemed necessary in this more distinctly biological study to more than mention the fact that further forms are known.

\section{CYCADELLA.}

It has been pointed out in Chapter I that one of the most important of the several American series of silicified cycadeoidean trunks is that included within the genus Cycadella, as erected by Ward for the reception of the series of rather small forms from the Atlantosaurus beds or Morrison formation of the Freezeout Hills of Carbon County, Wyoming. As since found by the writer, trunks of the same general character as the Carbon County forms also occur in relatively the same horizon of the Black Hills Rim, accompanied by the skeletons of huge saurians (Barosaums, Diplodocus, Morosaums, Brontosaurus, etc.); although associated plant remains are meager in number, consisting almost entirely in numerous silicified Araucarian logs and billets, with occasional imprints of fronds of the primitive cycad Nilssonia (I94-6). This occurrence of Cycadella in the Black Hills, I5o or more feet beneath the horizon in which the Cycadeoidea series of trunks is embedded, in surroundings so similar to those of Carbon County, Wyoming, nearly 200 miles farther west, shows the genus to have had a considerable lateral range. It is, however, of greater interest that we are thus enabled to examine a supplementary genus closely related to Cycadeoidea, but separated by a considerable interval of time; and among the vegetative parts affording opportunity for this comparative study none are more interesting than the silicified young leaves, their structure and prefoliation being as exquisitely shown in this rather dwarfish genus as in the more robust Cycadeoidea.

\section{CYCADELLA RAMENTOSA.}

(PLATE XVIII.)

The type specimen of Cycadella ramentosa gives no promise exteriorly of the young leaves borne by its middle segment; but as figured by Ward ( 178 ), the summits of several fruit axes are plainly to be seen scattered over the lateral surface of the trunk, whence it was supposed that a section through a small ramentum-covered boss, noted on the middle of the three segments into which the trunk was broken as originally collected, might yield evidence as to the fructification. On making a section tangential to the trunk, however, instead of a young fruit, I unexpectedly secured in transverse section several finely preserved non-emergent fronds, as shown on plate xvin. These fronds are thus seen to have been borne adventitionsly among the old leaf bases, as just described in C. ingens ('T. 208), and the fact is again emphasized that the cycadeoidean trunks produced from the axils of the old leaf bases, very freely indeed, either leaves, branches, or fruits.

Prefoliation is direct and the frond once-pinnate as in Cycadeoided. But since in each of the transverse sections through the folded fronds a much smaller number of pinnules are cut than in the similar sections from $C$. ingens and C. colossalis, it is quite safe to say that the number of pairs of pinnules present is mucl under fifty 
and it seems that in general appearance the mature expanded frond may have been quite comparable to that of Zamia floridana, with truncate fronds and twenty to thirty pinnules on each side of the rachis. In several of these fronds but a few millimeters across, as cut in folded-up or prefoliate position and figured by the writer (I95, plate IXII, fig. 2), the bundle system is already quite well developed, so minute may be the fronds and yet clearly display their main structural characters.

Rachis.-The fluted character of the rachis as seen in the plotograph of the transverse section (plate XVIII) is probably not constant, since the young frond cut on the same level about a centimeter distant shows a nearly round section, of much the same size and form as the young frouds of Zamia foridana. In this younger frond of Cycadella the bundle system is but little developed, the well-preserved tissues showing that they are young, well stored with nutritive material, and ready for rapid elongation and bundle development. In the larger of the fronds, however, the rachial bundle system is clearly indicated by the well-preserved xylem, and the bundles dispose themselves in the form of a closed ontline of a heary $V$, as was suspected in the fairly well grown rachis of Cycadecidea, and as partly indicated by the course of change in the leaf-base bundle pattern.

Histology.-Owing to the small size of the fronds, there is some difficulty in securing exactly transverse sections of the rachis and pinnules; yet this must be done if the very best results are to be secured. In the sections cut, however, there is a close approach to the ideal result which will answer all the requirements for description of the main structural features, bearing in mind that at best in such young growths as these it can scarcely be expected that all of the tissue zones would, as the result of any natural iron staining, show cell structure equally well throughout, although the differentiation of structure is on the whole surprisingly satisfactory. The upper surface of the frond is formed by a heavy cuticle; The epidermal cells are large and distinct and overlie a more or less continuous layer of hypodermal sclerenchyma a single cell in thickness. The parenchyma beneath may have developed a palisaded layer during subsequent growth, but preservation is indistinct. In any case the parenchyma is not interrupted by the sclerenchymatous extension of the bundle sheath seen in Cycadeoidea. The free bundles are all distinctly enveloped by a well-conserved cylindrical bundle sheath several cells in thickness, nearly as in Cycadeoidea. The xylem is well preserved, with small protoxylem cells at the center of the xylem area, indicating typical mesarch structure without radial arrangement of the centrifugal wood. No phloem is preserved. The spongy parenchyma is indicated beneath the bundles by a narrow, deeply stained band. The nether portion of the pinnules is made up of one to two layers of sclerenchyma cells, with slight traces of thickening between the bundles. In size and development of all their tissue regions the pimules of Cycadella are very near to those of the existing cycad Bowenia spectabilis, as shown in figure 50.

From the preceding description it will be noted, first, that while the leaf structures of Cycadella present certain differences from those observed in Cycadeoidea, there is a general agreement, just stich as one might expect to find in two closely related genera of living cycads. Secondly, the structure of the pinnules of Cycadella is found to be almost identical in general disposition and development of 
parts to Bowenia and has some features near to Zamia vernicosa, a very doubtful species known only in cultivation. As in Cycadeoidea ingens, the parallel in structure to the living cycads is thus once more seen to be so close as to recall generic or even specific likenesses of leaf structure.

\section{REMARKS ON GENERAL CHARACTERS OF CYCADEOIDEAN FOLIAGE.}

Our knowledge of isolated fossil imprints of mature cycad fronds is now supplemented with remarkable completeness by the fortunate discovery of young adventitious fronds and leafy crowns in various stages of growth, as borne by a number of silicified trunks from the Black and Freezeout Hills. Indeed, with all the collateral evidence at hand, thus including not only the mature imprints-which in the course of time can no doubt be referred with accuracy to the genera and species of silicified trunks-but exact details of prefoliation and frond structure as well, the picture of Cycadeoidean foliage becomes unexpectedly complete. Especially is this so when it is recalled how abundant the imprints of cycadaceous forms are, and yet how rarely both trunks and leaves occur associated as in Williamsonia, while unquestioned organic connection of foliage has been seldom determinable hitherto. In general it may be said that in the light of this completer knowledge it would in many instances be well-nigh impossible to separate isolated fronds of the Cycadeoidex from any forms like those of the Cycadacex unless perchance the structure of the rachis were indicated in both. Moreover, it becomes a reasonable conclusion from the closeness of this parallelism that it is far more probable that the main features of leaf structure in the fossil and existing cycads were developed in a common ancestry than that there has been independent homoplastic development of similar foliar structure of more or less xerophyllous type in two longseparated groups of cycads.

It remains, however, to draw some inferences as to the seasons to which the above-described foliar growths belonged, and as to the general habits of trunk growth. In all the specimens lateral organs of all kinds, whether flowers, bracts branches, or leaves, were preceded on the surface by a dense surrounding and enveloping growth of ramentum. Indeed it is largely to this peculiarity that we owe the silicification of these various organs. Had any of the organs been exceptions to this habit of growth it is doubtful if a record of such would have been left.

Owing to this profuse initial growth of ramentum it often happens that what at first sight appear to be terminal helicoids of leaf bases are found, on making a thin section, to consist simply in masses of ramentum, the individual scales of which are five or more centimeters in length and oriented to the successive young leaf axes hidden beneath. Such a section through a profuse terminal growth of ramentum is shown in photograph 5 , plate xix. This large and handsome transverse section was cut $5 \mathrm{~cm}$. beneath the summit of a branch referred to Cycadeoidea Marshiand. The tips of several fronds have failed of preservation, but, with this exception, the entire mass is seen to be composed of the transversely cut scales arranged in helicoidally disposed areas. In such cases only a large, deeply cut section of the terminal bud will disclose the organs thus deeply embedded and hidden in a luxuriant growth of young ramentum such as is only fully paralleled 
in the ferns. From these explanations the need of serial sections through a larger number of terminal buds very clearly appears; although the varied stages of foliar growth already described shed much light on the appearance in life and the general habits of foliar growth exhibited by the Cycadeoideæ. The extent to which proliferation is found may first be commented on.

In Cycas there are often produced in the axils of old leaf bases of old trunks numerous lateral buds made up of scale leaves, which may or may not later produce foliage leaves; and very similar buds, as apparently made up of ramentum-covered scale leaves and destined to form branches, appear in the Cycadeoider. But the

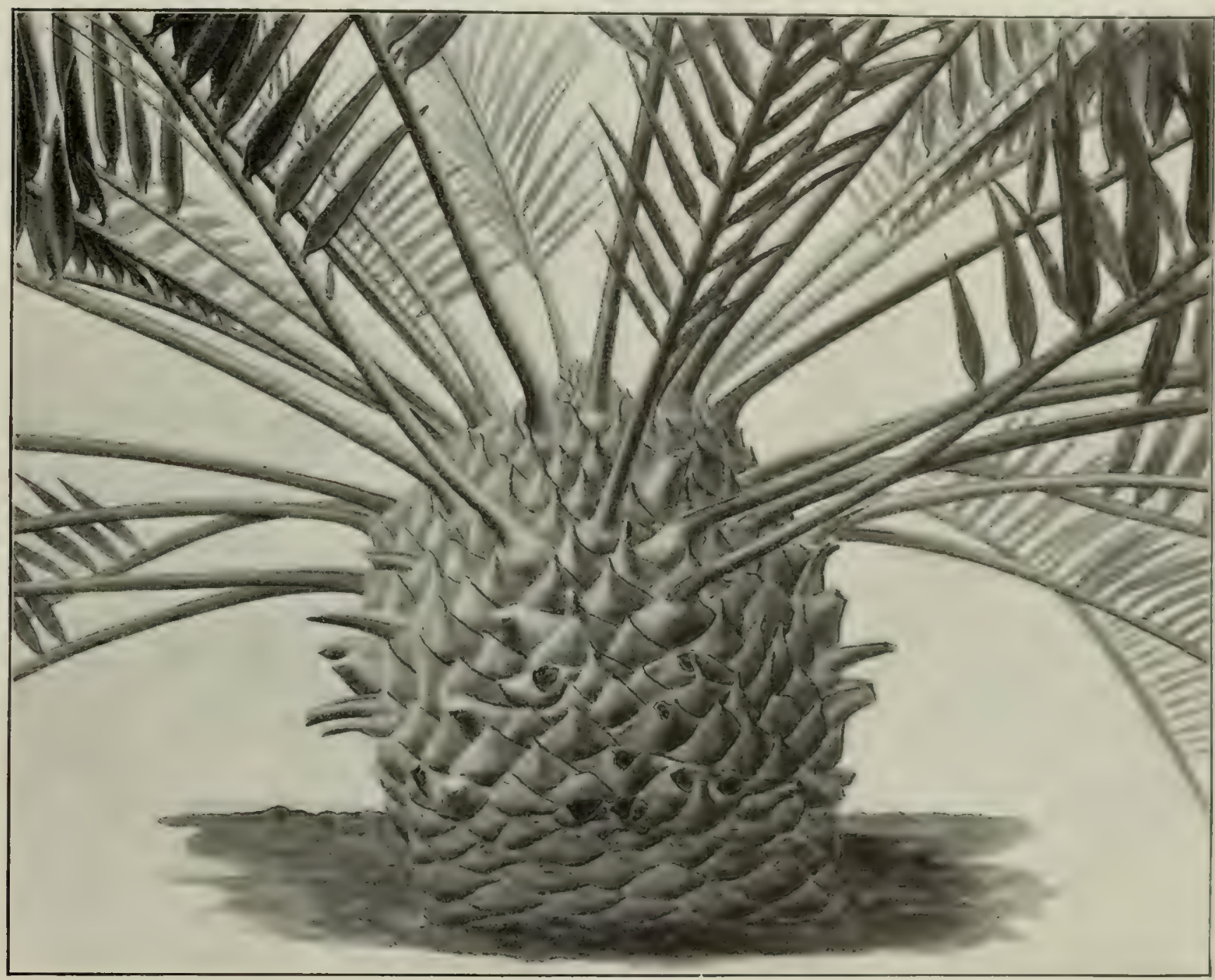

Fig. 53. Zamia Vroomi. $\times 1 / 6$. Sub-spherical to slightly columnar type of cycadean trunk of the same form as various Cycadeoidean specimens from the Black Hills; but markedly differing in the presence of numerous scale leaves which in direct contrast to the Macrozamias with few or no scale leaves appear to exceed the foliage leaves in number. The terminal bud may especially be noted as exactly of the general form seen in the large silicified branch from Minnekahta shown on Plate V, photograph 1; although is the present plant scale leaves, and in the fossil trunk ramentum borne by young leat axes, or occasional (?) scale leaves, makes up the main bulk of the armor.

point on which stress is to be laid is that so long as the scale-leaf buds of Cycus consist of imbricating scale leaves only, as they often do, they are exactly analogous in position, form, arrangement of parts, structure, and appearance to the young fruiting branch in the Cycadeoidex. Almost the only difference is in the less pro- 
fuse growth of ramentum, although the remnant of a once heavy growth is certainly present. Proliferation of a simpler type is exhibited by the free production of adventitious foliage leaves quite directly and with little or no lateral bud development in such forms as Cycadeoidea ingens (trunk 208) and Cycadella ramentosa; and in this respect the parallel with existing forms is absolutely complete.

The even color and rock-like outer surface of Cycadeoidea ingens (type) make the precise disposition and number of the leaves forming its crown difficult to determine in the absence of large sections. Moreover, the large size of the trunk and its excessive hardness and toughness-exceeding chalcedony in these respectswould make such sections extremely difficult to cut; but those above described display the main features. It is, as stated, clear that several circumvolutions of young fronds are emerging, and that interior and apical to these there is a heavy crown of terminal ramentum at the base of which the fronds of another season of growth may already be developing; but owing to the far smaller size of the more apical fronds it is not impossible that frond growth was more or less continuous throughout the year, with partially emergent fronds nearly always present, in which case such will be found on most well-preserved trunks of this species. Indeed it might even be that while in the existing cycads continuous frond emergence is rather rare, the reverse may have been true of the fossil forms.

The relations of frond succession are clearer in another species, Cycadeoidea colossalis, as observed macroscopically and in the handsome transverse thin section shown in figure 52. Here, as noted, there appears to be more or less of a hiatus in growth between the series of partially emergent fronds and the ramentum areas immediately succeeding them, these also being of about the same number as the pinnule-bearing fronds. Hence we can not doubt that in many of these plants growing amidst the generalized tropical conditions of the Upper Jurassic as far to the north as the Black Hills $\left(44^{\circ} \mathrm{N}\right.$.), the wilting down of old leaves and the growth of new crowns mainly proceeded with the seasons. The facts, therefore, as thus far correlated and at present understood, do not indicate the rate of foliar and trunk growth of the fossil to have been either more or less rapid than that of the existing cycads, and as in the latter mainly dependent upon the leaf and scale-leaf succession. 
REPRODUCTIVE STRUCTURES 


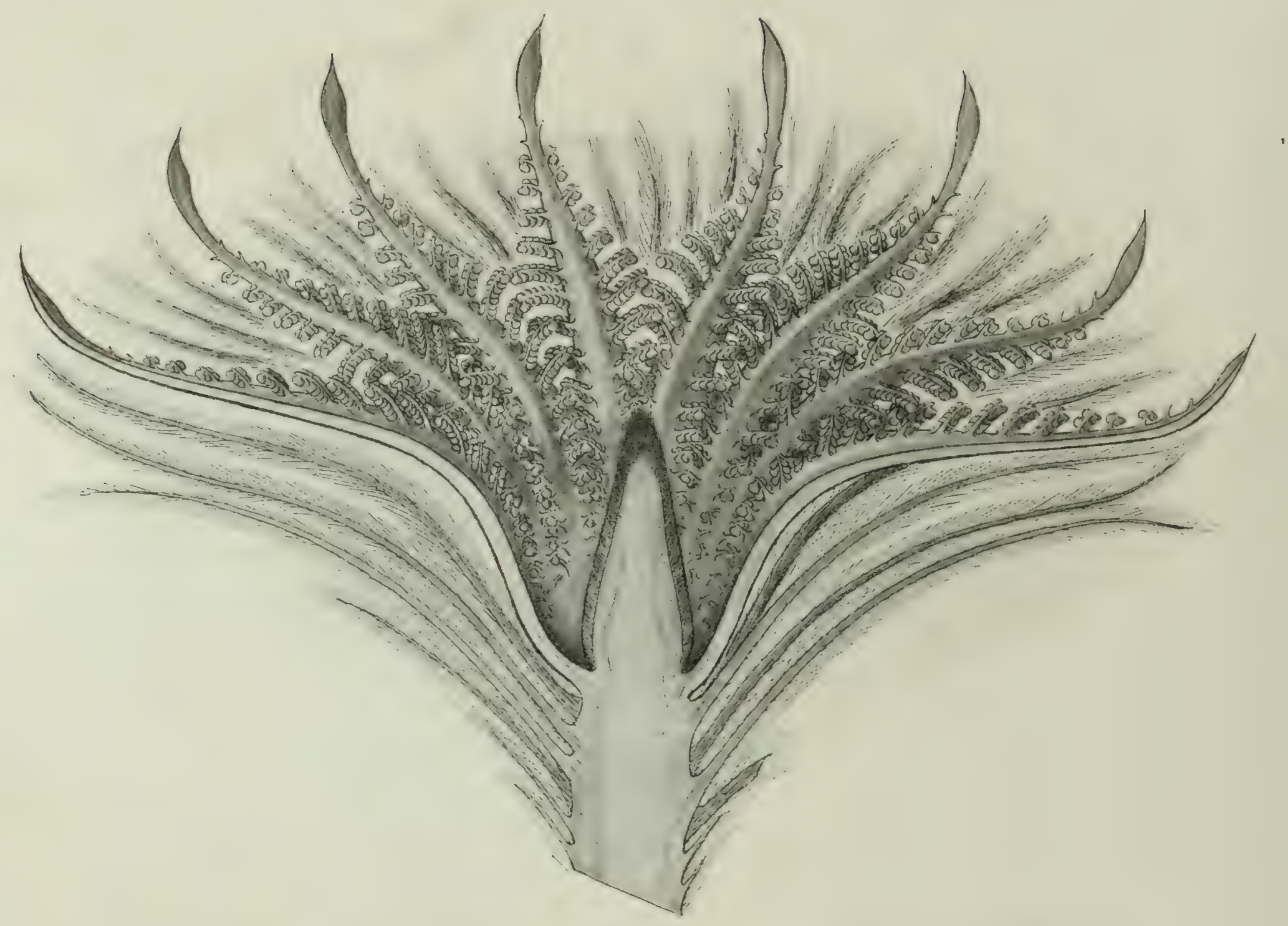

Fig. 54.-Cycadeoidea ingens. Restoration of an expanded bisporangiate strobilus in nearly longitudinal section. About four-fifths the natural size of the silicified and approximately mature flower bud borne by the type trunk shown on Plate I. 


\title{
CHAPTER VI. OVULATE CONES.*
}

\author{
HISTORICAL.
}

The silicified trunks of Mesozoic cycads, as noted in the introductory chapter, have been known for more than a century, while their earlier scientific study was begun fully seventy-five years since. But the true nature of the majority of these trunks was for a long time scarcely suspected. In 1856 or 1857 , however, there was collected in the Lower Greensand at Luccomb Chine, in the Isle of Wight, a remarkable silicified trunk of far more importance than any previously discovered. For, a dozen years later, when studied in thin sections-doubtless the first ever made from fossil cycads-this specimen was discovered by William Carruthers to bear laterally, in the axils of its old leaf bases, numerous marvelously: preserved, bract-inclosed ovulate fruits of ovoid shape and widely different structure from those of any other known cycadaceous plants, living or extinct. The essential structural features of the trunk, and of the fruits it bears, were described in 1869 under the name of Bennettites Gibsonianus in Carruthers' important memoir on Fossil Cycadean Stems from the Secondary Rocks of Britain (24).

Subsequently, Count Solms-Laubach restudied the preparations of Carruthers, he himself making additional thin sections from the type specimen. He added certain details concerning the "seed-stems" and "interseminal scales," and discovered the dicotyledonous embryos, the first observed in any fossil plants ( 1.56 ).

Later still, Lignier (82) studied the dehiscent fruit originally found by Morière in the Oxfordian Jurassic of Vaches-Noires (falaises de Villers-sur-Mer), Calvados, Normandy, in 1865, and which had in I88I been made the type of Williamsonia Morierei by Saporta and Marion. The microscopic features of this fruit, which is generically if not specifically allied to Bennettites Gibsonianus, and of the same general type as Cycadeoidea Wielandi Ward, are preserved in iron carbonate with marvelous delicacy of detail, as described in Professor Lignier's memoir with that completeness and exactness which might be asked in the case of a living form.

The next contribution to the subject of ovulate fructification in the Cycadeoider was made by the writer in I899 as one of the results of the preliminary structural study of the remarkable Black Hills series of silicified cycads (IS9). A large number of these trunks were found to bear ovulate fruits of various new species or genera of the Bennettites Gibsonicmus and B. Morierei type, in far greater profusion than had been previously observed, the histologic structure also being in

* Were it not for the fact that the younger cycadeoidean fructifications can only be readily" understood after consideration of maturer forms, it would have been deemed preferable to depart from the order of study and take up the subjects of Chapters VI-VIII in th.e normal or botanical sequence-young fructifications, bisporangiate or pollen-bearing axes, and ovulate fructifications. 
many instances preserved in unrivaled perfection and exhibiting many important features hitherto unknown, together with complete habitus details. On the basis of this newly discovered material, observations on general habits of growth were added, and it was shown that the fruits of several of the Black Hills species were very closely related to the English and French species, $B$. Gibsonianus and B. Morievei, thus further illustrating the cosmopolitan distribution of the Cycadeoidex. Still more recently Scott has given, in his Studies in Fossil Botany, a compact and excellent description based in the first place on Bennettites Gibsonianus (I35).

It has already been remarked that the great essential for the preservation of these cycadean fruits in organic connection with the parent plant is that they shall not be protruded much beyond the protecting armor of leaf bases before reaching a fairly mature stage of growth. The ovulate fruits of the closely related English Bennettites Gibsonianus, the French B. Morierei, and the American Cycadeoidea Wielandi, etc., meet this requirement more nearly than in the case of any others yet discovered; and for this reason among the specimens from the Black Hills mature or nearly mature fruits of this type are more frequent than in the case of other species. There are, I may say, hundreds of examples of nearly full-sized strobili, while those of other species borne on longer peduncles, and hence usually preserved, if at all, in a less mature stage of growth, are less frequent. It appears possible that in some cases staminate flowers must, on the contrary, have been borne on rather long peduncles. In any such instances partial or but scanty evidence of fruits may be expected, as the main portion of the inflorescence would project beyond the zone of preservation. Habits of growth very favorable to preservation are to be seen in $C$.dacotensis with heavy armor and short peduncles. In this species, despite the far shorter period of the year during which male flowers present a stage of development favorable to preservation, a considerable number of such axes in the unexpanded condition are preserved, with only a minor number of the well-developed and entire ovulate fruits, though younger forms are frequent.

By far the best examples of fertile trunks from the Black Hills bearing finely preserved and numerous ovulate fruits have been referred by Professor Ward to $C$. Wielandi. Our consideration of ovulate fructification in the American cycads will hence begin with the fruits of this species. Following, other types closely allied, but differing in various features, will be described.

\section{THE OVULATE CONE OF CYCADEOIDEA WIELANDI WARD.}

(Plates XXI-XXIII.)

The splendidly preserved trunk 393 of the Yale collection is in all respects strikingly similar to the type of the present species (Yale cycad 77), and has already received extended notice in connection with the subject of trunk structure. As the specimen had been originally broken into several pieces, a half dozen of the quite mature fruits it bears were the more readily removed for study, and afforded the main material for the following description. 
GENERAL FEATURES.

The ovulate cone is a laterally borne branch which arises from between the old leaf bases or else from their axils in part, at an": point between the base of the trunk and the youngest series of leaves. The time and order of appearance will be considered later. Each of these specialized branches consists in an egg-shaped apical cone, borne on a short peduncle and completely incased by a series of numerous imbricating hair-covered bracts, as clearly shown in the drawing of a longitudinal section (fig. $5^{6}$ ). The bracts arise in spiral order from all of the lateral surface of the peduncle, and close well in over the apex of the fruit. In trunk 393 the armor is $4.5 \mathrm{~cm}$. in thickness and the cortex $1.3 \mathrm{~cm}$. in the middle portions of the trunk. The peduncles are usually $2 \mathrm{~cm}$. in length by $1.5 \mathrm{~cm}$. in thickness, and the length of the approximately full-sized cones is from 4 to $4.5 \mathrm{~cm}$, whence the larger forms protrude a centimeter or two beyond the armor. The greatest strobilar diameter, which is somewhat distal, is from 2 to $2.5 \mathrm{~cm}$., exclusive of the covering of bracts, which is from 2 to $3 \mathrm{~mm}$. in thickness.

Before passing on to the study of the microscopic structure of the strobili it will be of no little interest to see what may be learned from such fruits without the aid of thin sections, since the paleobotanist must so often depend on casts and impressions alone. And, indeed, from an examination and comparison of superficial features

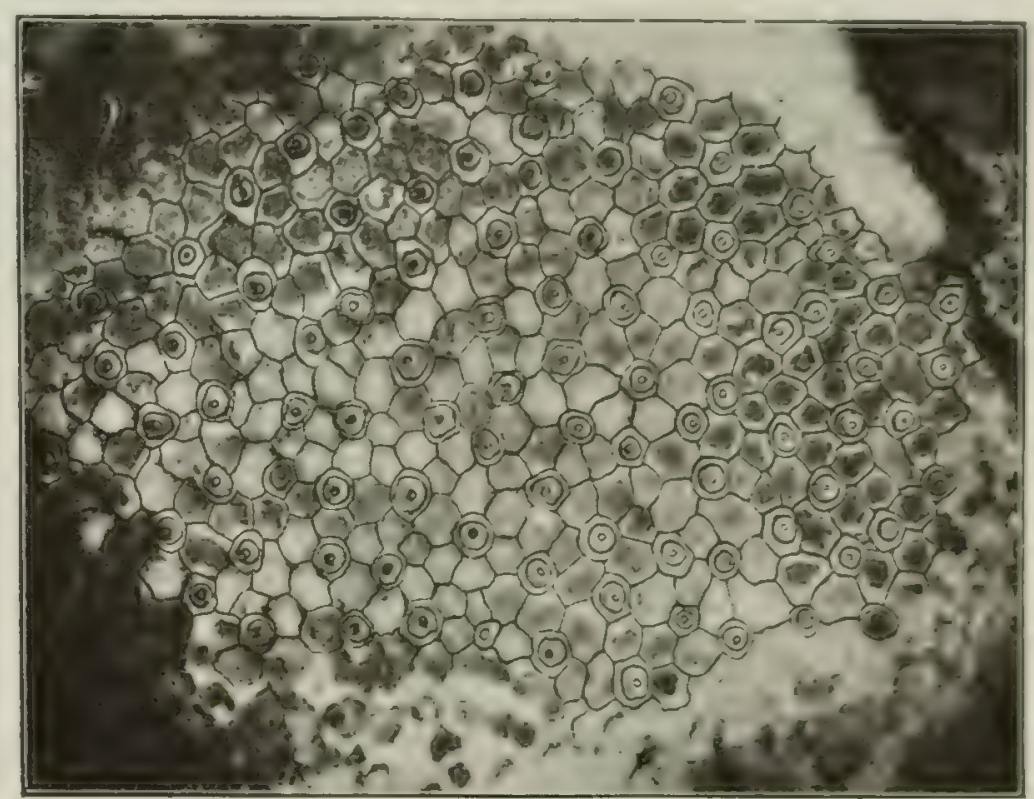

Fig. 55.-Cycadeoidea sp. (T.750). Surface sculpluring of young ovulate cone, $2.5 \mathrm{~cm}$. in diameter. The ends of the micropylar tubes clearly appear between the heavy polygonal ends of the interseminal scales. Enlarged about ten times. From a photograph. (CF. figure 29.) only, as seen in a considerable number of these ovulate fruits presenting the various stages of erosion and fracture to be met with in the large cycad collections now brought torether, it is possible to determine their essential structures without thin sections. The bract-bearing peduncle, as may be seen in the case of numerous dehiscent fruits and fractured surfaces, terminates in a fleshy expanded and slightly convex receptacle or "paren chymatous cushion," as Carruthers called it, strongly reminding one of that seen in the Compositæ. Upon this receptacle, usually of much lighter silica, is inserted the compact, dark-colored, brush-like mass of interlocking, slender, and abortive sporophylls, now and then split open lengthwise, as in the original type of Bennettites Morierei (cf. plate XLVII) and in many Black Hills specimens. Each of the fertile sporophylls bears a single apical and erect seed, which terminates in a lcng micropylar tube. Each abortive sporophyll ends in an expanded tip. 'The centrally' inserted sporophylls are longest, and rise quite directly; but in rising from the more 
and more peripheral insertion both sporophylls and interpolated scales decrease in length and assume a gracefully increasing outward curve, thus producing a more or less egg-shaped cone. Near the base of the fruit the surface is seen to be composed of the expanded tips of the abortive sporophylls only, and, further up on the sides

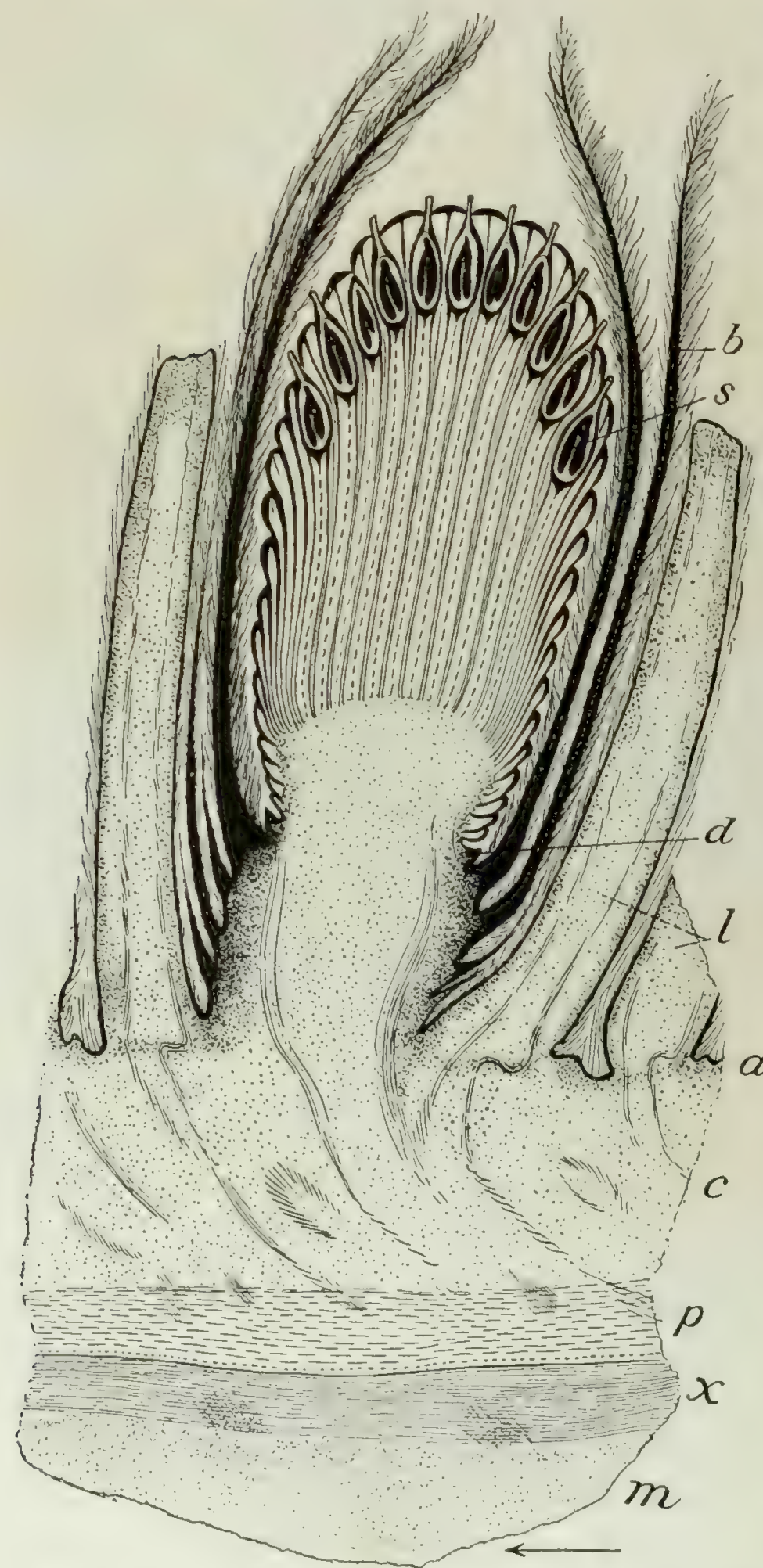

Fig. 56. - Ovulate strobilus of Cycadeoidea. A drawing of radial longitudinal section 391 (T. 393), with partially restored bract tips. (Compare with photograph 3, Plate XXIV.)

The arrow indicates direction vertical to the trunk, the section passing through the exact median and vertical longitudinal plane of the axis of fruclification. $m_{0} x_{,}, p_{0}$ and $c$, respectively, the medulla, xylem, phloem, and cortex of trunk as cut in radial-longitudinal section; $\mathbf{a}$, insertion of armor on cortex, I, old leaf bases; $d$, inserion of dehiscent hypogynous disk ; s, erect seed borne at summit of seed pedicel inserted on convex receptacle; $b$, hair-covered bract. and summit, of rosettes of expanded sporophyll tips grouped about the ends of the long micropylar tubes of the seeds, which are hence layered in a continuous pericarp. The surface of the fruit, wherever conserved, thus completely displays the arrangement of both kinds of sporophylls, as seen not only in the present but in other species and shown in figures 55 and 57 , and in plates XXIII and XLVII. But more often, as the result of erosion and the breaking away of the tips of the bracts, the layer of seeds is exposed directly to view, those at the summit standing vertically to the surface of the fruit and the lateral ones nearly so, or at a slightly increasing angle, these features being especially clear in several of the strobili photographed in longitudinal thin section (plate XXI). All of these details, including the number and arrangement of the bract husks, may be determined by macroscopic study unaided by a single thin section. The description of the structure of the ovulate cone, as seen in thin sections, now follows.

In transverse thin scctions cut well beneath the summit of a fruit two closely packed peripheral rows of obliquely-cut seeds are usually to be seen, as in plate $\mathrm{xxv}$, photograph 4, while interior to these is the mass of interlocking interseminal scales and seed pedicels. In passing from the center of such a section to the peripheral row or rows of seeds the pedicels and 
scales are necessarily cut more and more apically, each transverse section of a fruit being, with respect to these organs, for all ordinary purposes of observation, the equivalent of a set of serial sections of a single seed pedicel and its surrounding interseminal scales throughout all but their basal portion. Likewise, interiorly to the more or less complete rows of seeds various seed bases are cut, and exteriorly micropylar tubes, at varying heights and degrees of obliquity, as clearly appears in figure $60 \mathrm{~A}$, from another species than the present. In the seed zone the interseminal scales are very much flattened, but, as already seen, the extreme periphery of the
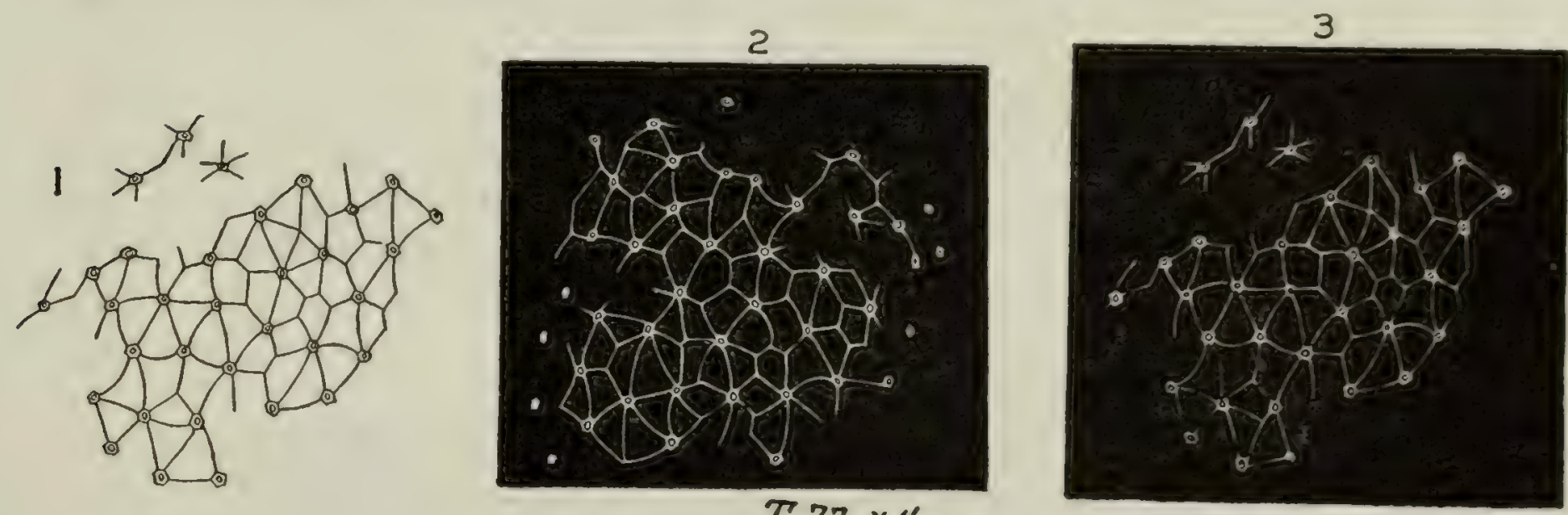

T. $77 . \times 4$.

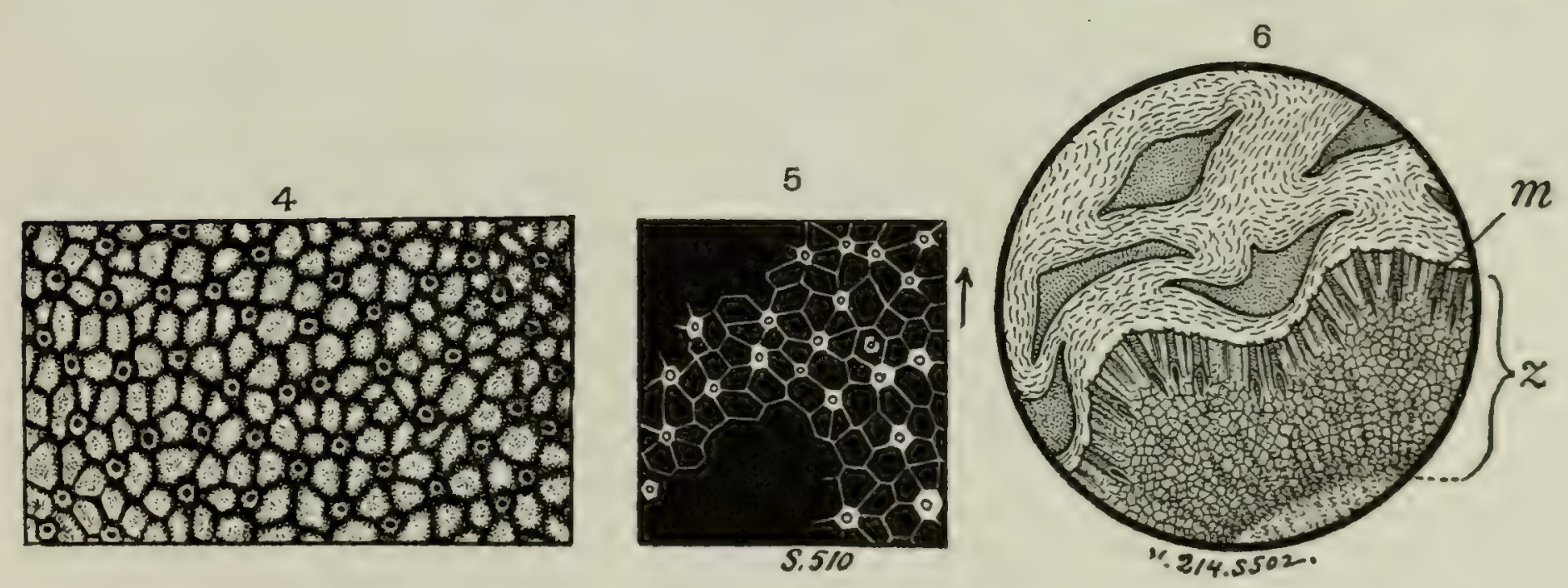

Fig. 57. - Surface pattern and sculpturing of ovulate cones of Cycateoidea.

1-3. Surface pattern of a nearly full-sized ovulate strobilus of C. Wielandi. T. 77. $\times 4$. On the cone itself the division lines are of light quartz with the silcified scale tips nearly black

4. Surface sculpturing of a much younger fruit of a different species from the preceding. $\times 10 . T .61=\mathrm{C}$. dacolensis (?). It is to be noted that the interseminal scale tips are relatively small.

5. C. dacotensis. Surface sculpturing of ovulate cone shown in 6 , as seen in a thin tangential section cut with a few ramental scales lying over the surface of the cone and embedded in nearly clear silica. (S. 510, Fr. V, T. 214.) $\times 10$.

6. C. dacotensis. Portion of transverse section II of Fruit V of T. 214. Enlarged six times to show granular replacement of most of the seed zone $(z)$, with preservation of the obliquely-cut micropylar tubes $(m)$. Bracts stippled.

fruit is composed of their expanded tetragonal or pentagonal shaped summits and the rounded micropylar tubes. The summits of the interseminal scales form, as it were, a continuous envelope or pericarp, through which project the tips of the long micropylar tubes of the embedded seeds. 'The transverse sections cut beneath the lowermost seeds exhibit the highly characteristic appearance shown in the diagrammatic figure $5^{8}$ and the corresponding photographs of plate xxv. Enveloping 
the fruit is the husk of hair-covered bracts, several layers deep, and beyond these the leaf bases.

In the most favorably cut median longitudinal sections-that is, in those cut radially and longitudinally to the parent trunk and carefully oriented with respect to the axis of the fruit itself, as in that shown in text-figure 59 and in photograph 4, plate XxIV - the relation and form of the several parts become wholly clear. Various of the seeds making up the seed layer are seen to be cut more or less tangentially and a few mesially from the seed base to the summit of the micropylar tube, while the individual seed stems and the interseminal scales or sterile pedicels may each be traced to their insertion on the convex "cushion" or receptacle beneath. Exteriorly in such sections the bracts are usually quite evenly cut lengthwise from base to summit, as in section 39I ( $c f$. figs. $5^{6}$ and 59). Likewise, the insertion of the peduncle on the cortex axillary to a leaf base is clearly to be seen, as well as

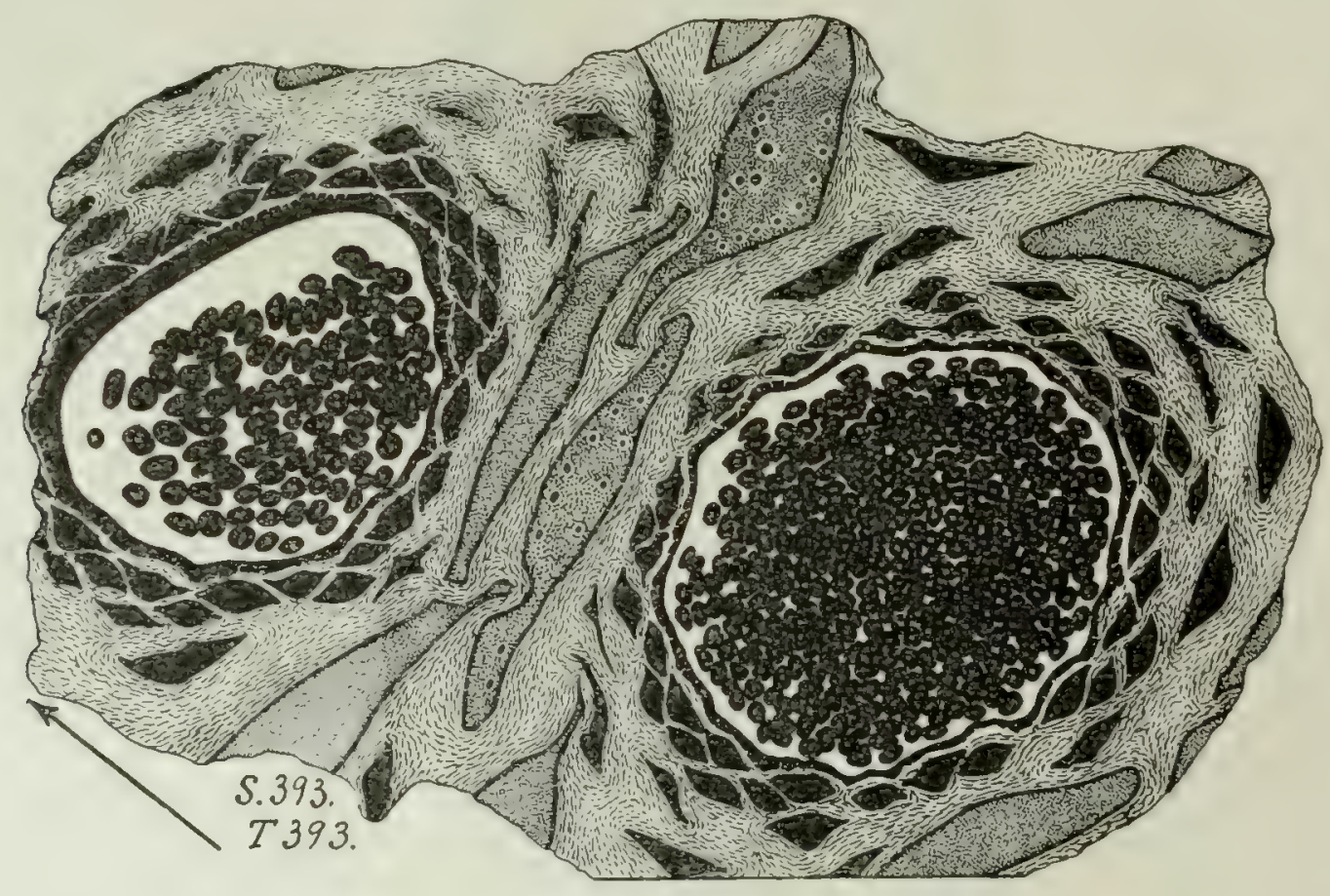

Fig. 58.-Cycadeoidea Wielandi. T. 393. S. 393. X2. Transverse section through armor, cutting two adjacent ovulate strobili and their surrounding bracts and leaf bases. The section passes through the seed pedicels beneath the lowermost seeds and not far above the insertion of the pedicels on the parenchymatous receptacle.

Leaf bases stippled, bracts and pedicels in solid black, with the space occupied by the surrounding interseminal scales left blank, except the outer row of tips marking the surface of the cone. It is of especial interest that the cone to the left bears relatively few seed pedicels, many interseminal scales occupying all of the left outer portion of the cone.

the cortical bundle traces, which in some instances may be traced to their origin on the xylem zone of the trunk. All these features appear with diagrammatic clearness in section 392, figtre 59, and in the photograph of the same (plate xxrv, No. 4).

Having now given, both on the basis of external examination alone and thin sections, the disposition of the several organs of the ovulate fruit, detailed description based on various cones borne by trunks 77 and 393 may best be taken up in the following order: Peduncles; bracts ; interseminal scales ; seed pedicels ; seeds ; embryos; pre-embryonal structures. 
THE PEDUNCLE。 INCLUDING A DESCRIPTION OF ITS BUNDLE SUPPLY.

The peduncle as seated on the cortex is of flattened barrel-shape, and may approach in dimensions and bulk the fruit it bears. As seen in various large sections cut carefully through an entire fruit in the radial longitudinal direction to the trunk, and passing into and including a portion of the medulla ( $f f$. photographs 3 and 4, plate xxIV, and figures 56 and 59), the peduncle is inserted axiliary to a leaf base, or doubtless at times in a position somewhat oblique to several adjacent leaf bases. [Further details concerning the origin and cortical course of the peduncle and surrounding leaf-trace bundles, based on a study of the bundle supply of other cones borne on the same trunk (No. 393) as the present examples, have already been given at length under the head of Trunk structure.]

The structure of the peduncular and bract bundle system is on lesser scale, as already noted, a repetition of the xylem zone of the trunk and the cortical leaf-base bundle system. Likewise, in the peduncle itself, the distinct woody cylinder or

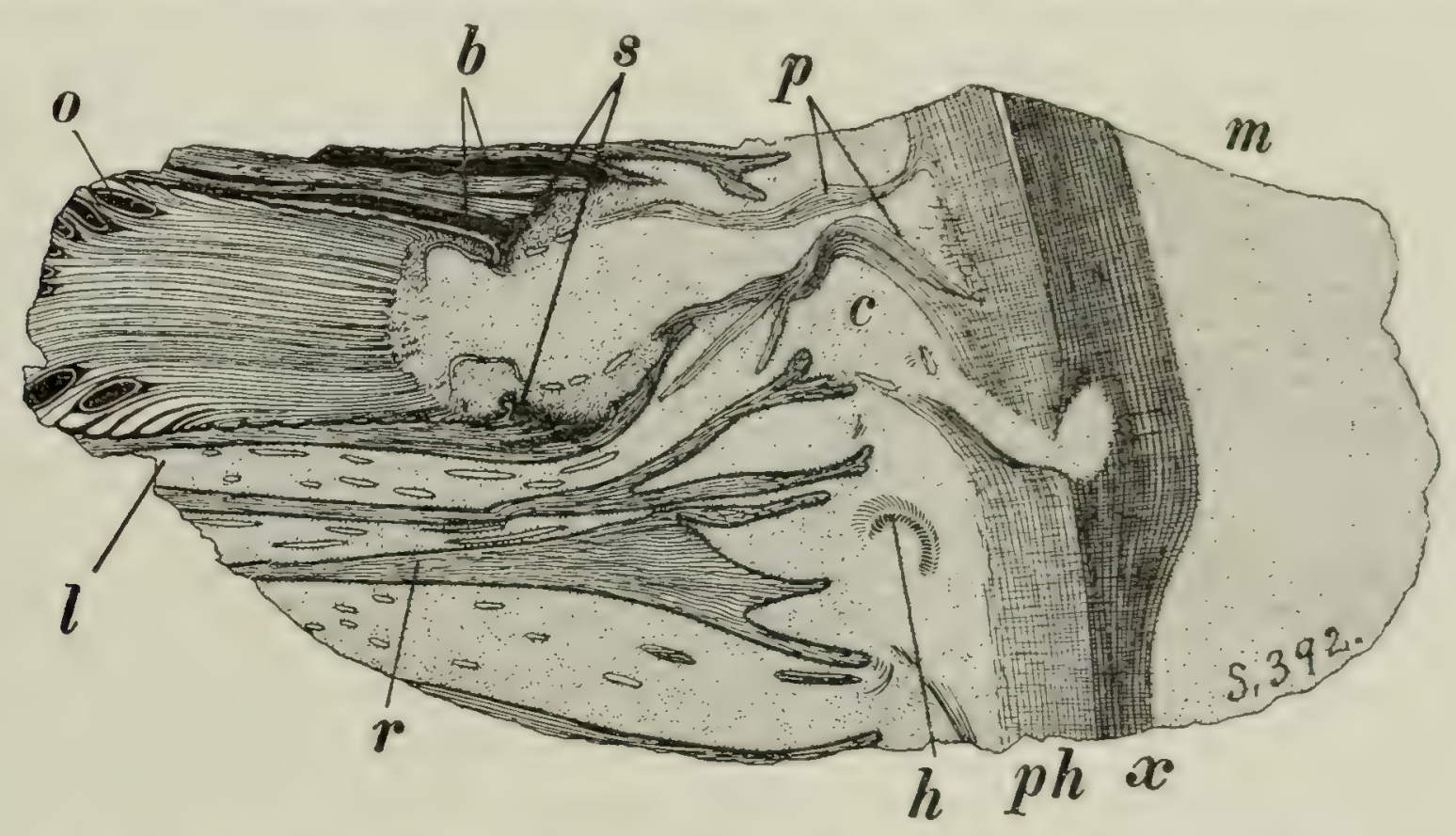

Fig. 59.-Cycadeoidea Wielandi. T. 393. S. 392. Radial longitudinal section through middle portion of trunk, cutting through the armor, cortex, woody cylinder, and into the medulla; also through entire length of a lateral fruit-bearing branch or ovulate strobilus and its peduncle, thus showing the direct course of peduncular bundles through cortex and their origin on the xylem. $\quad \times 1 \frac{1}{3}$.

$o$, Megaspore; $b$, bracts surrounding ovulate cone; $s$, insertiou of dehiscent staminate disk at base of ovulate cone: $p$. branches of peduncular bundle supply passing out from xylem zone through the cortex and into the base of the ovulate

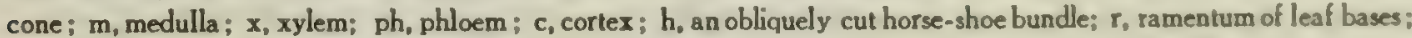
1. leaf base to which the peduncle is axillary. Note that the lower branch of the peduncular bundle supply is either directly connected with or envelops the supply of the leaf base (1).

xylem is markedly like that of the trunk. There is the same well-marked xylem, separated from the lighter phloem by an indistinct cambial line of darker color. But while both the xylem and phloem regions of the peduncular cylinder are as a rule well differentiated by coloration and striation, the individual cells, thongh often well conserved, are not usually distinct, with the exception of the spiral and scalariform tracheids of the xylem, which seldom entirely fail of preservation. The structure and relative development of the peduncular xylem and phloem of the outer cortex are illustrated by photographs 3 and 4 , plate xvI, and in addition 
a transverse section from the base of a most beautifully conserved peduncle is shown in photograph I, plate xxxI.

The pithy ground tissue of the lower portion of the peduncle is not as a rule well preserved, but has given rise to characteristic mineralization and coloration, as have most of the tissues failing of exact cell differentiation. In the lateral or cortical portion of the peduncle, beneath the bases of the bracts and the annular disk insertion described below, and finally in nearly all that upper portion of the peduncle which expands into the convex receptacular region, the ground-tissue cells gradually assume a more elongate form, as much or more than two or three times as long as broad, and are very uniformly cross-lined or scalariform; these scalariform cells continue with further increase in length into the bases of the bracts as their ground tissue, and in modified form even into the peripheral and terminal portions of the interseminal scales of the fruit.

Evidence indicating former presence and dehiscence of hypogynous disks. - It is of fundamental importance to note that in all these strobili, above the lateral bractbearing surface of the peduncle and just beneath the terminal ovulate cone, there is an annular offset or shoulder with more or less distinct traces of some earlier borne and dehiscent or else abortive or wilted disk. This disk or zone of annular growth is thus seated on the receptacle above the bracts, but in relatively the same manner on the same semi-woody groundmass of scalariform cells as the bracts. Moreover, bundle strands pass out to it from the woody cylinder of the peduncle, as may be seen in photograph 2, plate xxxI, the structure plainly indicating a bundle system entering a dehiscent annular growth or former staminate disk. (The photograph cited as showing the dehiscent disk bundle supply is from the region marked $S$ in photograpl 2, plate XxIV, of the same cone. After giving off these disk strands the cylinder of the peduncle extends a short distance farther and then anastomoses in the convex parenchymatous receptacle, on which are seated the seed pedicels and scales, the anastomosing system thus formed being more prominent in all cones with short than in those with more elongate receptacles.)

The insertion line or shoulder-like offset just described is more or less distinct in all ovulate strobili yet examined from the Black Hills, and is indicated (by $S$ ) in many text-figures and photographs of the plates. In many cases where it is reasonably certain that, as in some of the fruits of cycad $2 \mathrm{I} 4$, a staminate disk has just been shed, the shoulder is prominent and, as will be described later in other forms, conserved basal parts of shed or wilted disk may actually remain. In some other cases the hypogynous annular shoulder is much less noticeable, and there seems good reason to believe that the fruit is simply ovulate. But the condition in the great majority of the cones thus far examined is such that one is forced to the conclusion that all the known Cycadeoidex are descended from bisporangiate forms, and that of all the considerable number of fruits of Cycadeoidea and Bennettites Gibsonianus, or allied species, far the larger portion were actually bisporangiate and discophorous. That this conclusion has not hitherto been reached from actual evidence, and but rarely suggested in modified form by others, must be due to the fact that there have been available only sections showing but imperfectly, for the 
greater part at least, the median longitudinal section of the cone. And this, too, would be a matter of some surprise did we not know how loath museum custodians may be to the sectioning of such and such "' landsome trunk," forgetting the great labor involved and the necessity for using absolutely the best material first, within, of course, safe methods of work. We have shown that much may be learned of the structure of cones like the present from the study of surface features alone; but after all, almost any trunk will do for general "exhibition purposes," although a single large and well-cut section from a finely conserved trunk may show more of critically important detail than could be learned from the macroscopic examination of a pyramid of such trunks as large as Cheops, however often repeated. The dictum of petrographers, that, "Ein Gestein muss immer zuerst mikroskopisch untersucht werden," is as true of silicified plants as of non-fossiliferous rocks.

BRACTS.

The ovulate cone was in life completely inclosed, not unlike an ear of corn, in a heavy husk of imbricating hairy bracts, several, or in places many layers in thickness. These are borne more or less closely in spiral order on the lateral surface of the peduncle throughout the greater portion of its length beneath the discophorous shoulder just described. Although the summits of the bracts are usually broken away so as to expose the seeds at the apex of the fruit, there are various prettily preserved examples of fruits in which the inclosing husk is nearly complete. Such a cone of Cycadeoidea Paynei is shown on plate Xxrv, photograph 6. The basal bracts plainly lack but little of the length of the upper ones next the seed cone, and the supposed relative length is shown in the partly diagrammatic figure 56 . The bract bases have usually nearly the same shape in transverse section as the leaf bases, but are often much expanded and heavy toward the tip, though varying greatly in this respect in different cones. They are quite uniformly thickset all over their surfaces by long hairs or ramentum, of about the same structure as that borne by the leaf bases, but mostly smaller. (See photograph 4, plate xxxirr, showing the transverse section of the bract of a cone of Cycadcoidca Marstiana.)

It is said that stomata (I49) have been found on the bracts of Bennettites Gibsonianus, but none have been detected in the specimens before us, the epidermis not being usually well preserved. The ground tissue of the bract bases is seen in many sections to consist in much-lignified cells, elliptical to elongate, several times as long as their diameter, and everywhere exhibiting regularly disposed transverse markings. The length of these cells rapidly increases, however, till near the bract tip, where shortening again occurs, the transverse marking persisting throughout. Also along the inner face of the bracts-that is, next to the fruit-the cells are very heavy walled, less distinctly striate, much smaller, more elongate, fibrous and bast-like. The amount of this dense upper zone of the lignified mesophyll may vary considerably in different trunks. In certain cycads, as, for instance, Yale cycad 272 , as shown in figure $60, \mathrm{~A}-\mathrm{C}$, the bracts are very large and tine lower zone of striate mesophyll of the tips much rounder celled than usual. Distributed through the lower striated mesophyll are varions gum ducts ( $f$. fig. $60, \mathrm{~B}, \mathrm{c}$ ). In the central part of the bract beneath the dense upper mesophyll, and disposed on a plane 
parallel to the upper surface, there are from three to five small vascular bundles comparable to those of the leaf bases, though much reduced. In the much-lignified condition and presence of the very peculiar striate mesophyll, however, the bract structure varies markedly from that of the leaf bases.
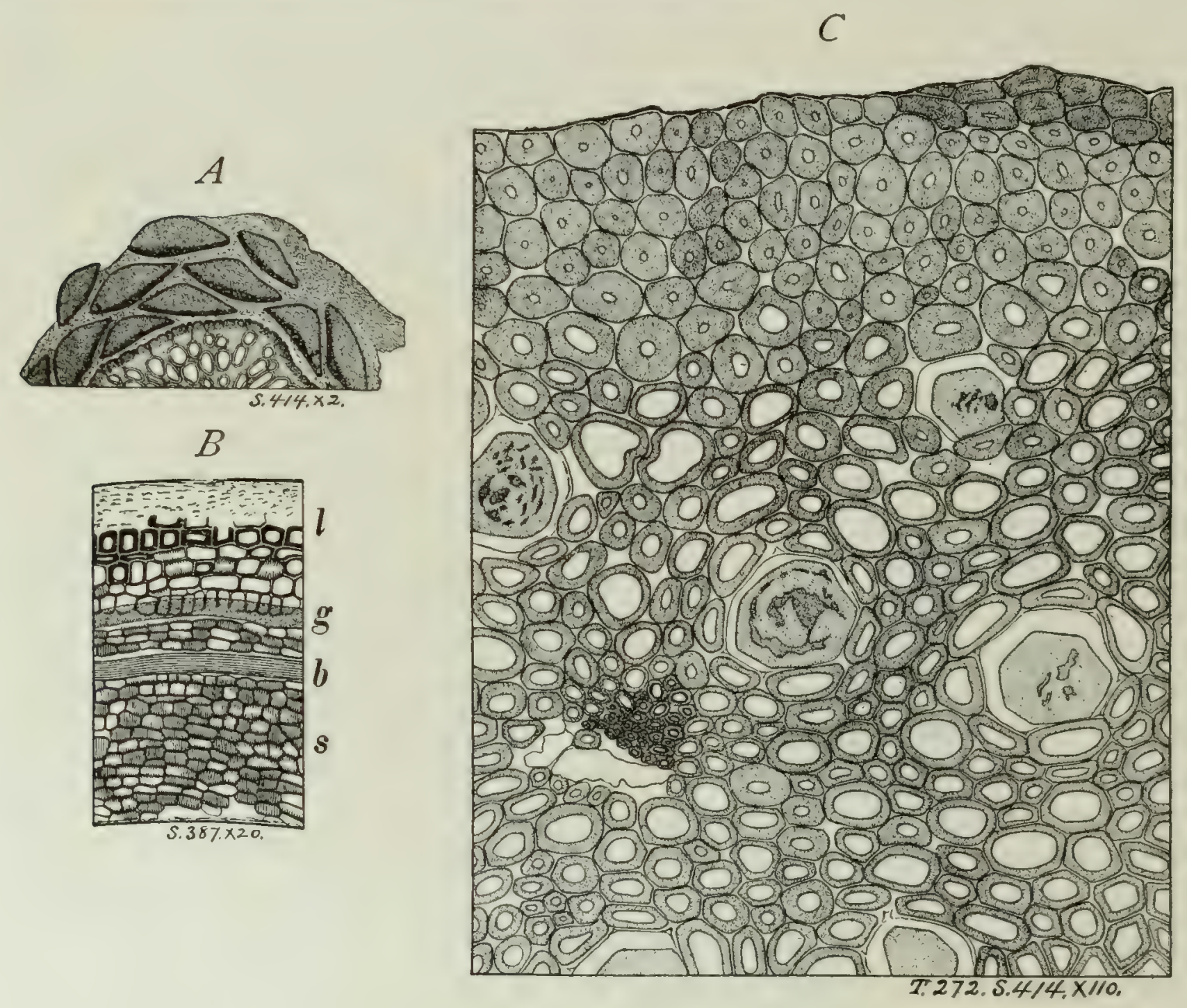

Fig. 60.-Cycadeoidea Paynei (?). T. 272. S. 414. Details of bract structure.

A. Transverse section through upper seed-bearing portion of ovulate strobilus, cutting imbricating bracts and showing by darker shading the relative development of the heavy-walled tissue of the bract, facing toward the seed cone. $\times 2$.

B. Slightly diagrammatic vertical longitudinal section through much-expanded distal portion of bract, as shown in $A$ lying appressed to the summir of an ovulate cone. $\times 20$. Further towards their bases the bracts are slenderer and all the cells of the ground tissue lengthen greatly, in particular the subepidermal cells, which are smaller, long, bast-like, and with far less closely placed or no scalariform markings. I, Upper lignified and only partially preserved region next to cone ; 8 , gum duct; b, vascular bundle: $s$, scalariform ground tissue.

C. Same section as A. Portion of a single bract, greatly enlarged, showing the heavy-walled hypodermal sclerenchyma, and beneath it the much-lignified ground tissue traversed by gum canals and a vascular bundle with only the xylem preserved. The non-sonserved phloem area beneath the xylem is left blank. $\times 110$.

\section{INTERSEMINAL SCALES.}

Distribution and form.-As already noted, the space between and about the seed pedicels is everywhere solidly packed with interseminal scales. Normally five or six of these scales surround each seed pedicel throughout the central portions of the cone, but towards the periphery the pedicels increase in number to the entire exclusion of fertile organs, the outer portions of the cone in all cases at last entirely consisting of scales packed in close order from several to many layers deep, the 
number of these layers varying with the fruit and the species. Aside from the usually regular distribution described, the scales may be unequally distributed in patches, or on certain sides of a fruit there ma: be outside the outermost pedicels large areas made up exclusively of small and densely packed scales, sometimes amounting to a third or even a half of the bulk of the entire fruit. (See fig. $5^{8}$ and plate XXVI.) Likewise certain smaller pedicel structures must be abortive, and must fail to develop seeds, although much advanced beyond the reduced condition of the scales. The outer and thus more basally borne scales are of shorter and shorter length. At the point of their insertion the scales are thin and filamentous, but they slowly increase in thickness to the region of the seeds, where they are on any or all sides scooped out so as to form the cavities in which the seeds lie closely enveloped. Beyond the seeds the scales again expand into the more or less regularly prismatic tips so closely surrounding the micropylar tubes and thus giving to the surface of the fruit the characteristic pattern already noted and shown in figures 55 and 57 . Beneath the lowermost of the seeds the ends of the interseminal scales assume a more regular tetragonal to hexagonal form, regularly decreasing in size to the sterile basal region of the cone. It is a surface view of the cone base, showing the pattern formed by the ends of the interseminal scales which Seward has figured in the Jurassic Flora of Yorkshire (I49, text-figure 35), as the "surface view of the base of a flower" of Williamsonia pecten (Phill.). The form of the seed stems with the apically-borne seed and of the adjacent interseminal scales is clearly outlined in all the accompanying figures of longitudinal sections. In all transverse sections of entire cones the interseminal scales appear to vary greatly in size because cut at a constantly varying height, the larger sections being mostly from centrallyborne scales, and the smaller and flatter mostly from peripherally-inserted scales.

Histology. - As shown in figure $6 \mathrm{I} \mathrm{B}$, in all the middle portions of the fruit beneath the seed layer, in those rarer instances where preservation is so wonderfully complete, as in most of the ovulate strobili of cycad 393, the transverse section shows the interseminal scale to consist in (I) a central group of elongate lignified cells that may be considered a typical bundle xylem; (2) phloem cells on the edges of the central xylem not always forming well-marked areas of cells, but sometimes more prominent, depending on the altitude at which the scale is cut; (3) largecelled elements surrounding the central bundle region similarly to those of the heavy outer woody zone of the seed stems, but with thinner walls than in the latter; (4) heavy cortical cells; (5) the outer layer of the interseminal scale, composed of small, elongate, heavy-walled cells one cell thick. The true nature of this layer is not at first apparent. Wherever the interseminal scales abut on the seed pedicels there is what appears to be a very characteristic layer of small outer epidennal cells, forming a common boundary between these two organs ( $c f$. fig. $60 \mathrm{c}$ and photograph 2, plate xxviI). That this epidermal sheath forms the true outer layer of the interseminal scales, although a structural arrangement hitherto overlooked, is, however, very clear, because of the fact that it is double wherever two of these siles abut on each other, and always single between a scale and an adjaient seed pedicel.

In such sections as 393 ( $f f$. plate $\mathrm{xxvI}$ ), 394, also 3,7 , and 220 , preservation is confined to lignified elements, and the arrangement of scale boundaries just described 
produces with the pedicels an exquisite lace-like pattern. As the summits of the interseminal scales are approached the chief change in the several tissue systems is observed in the number, form, and distribution of the large, almost duct-like sub-epidermal or cortical cells. These cells occur singly or sparingly in all the lower peripheral portions of the scales, but increase markedly in number and shorten toward the summit, the expanded portion of which is finally made up of short to elongate and much-lignified cells with scalariform marking, grouped more or less radially to the few-celled central xylem strand, which may be traced, if the section cuts through the true median longitudinal plane of the scale, quite to the surface of the fruit.

In longitudinal sections of fruits it is not always easy to detect the structures of the interseminal scales, so much are the tissues of which they are composed like those of the seed pedicels; but since the position of the seed pedicels may be so readily picked out, one may see, as very clearly shown in longitudinal section in photographs I and 2, plate XxIx, that the outer layer of the scales is always inserted deeper on the receptacle than is that of the outer pedicel layer, a fact which might perchance be construed as indicating each pedicel to be somewhat shoot-like. It is not possible to pick out any short, distinctly parenchymatous cells surrounding the central bundle. The characteristic part is the summit, with the central xylem strand or bundle of the scale continuing into the tip and the more and more strongly lignified cells of the cortex ranged radially to it with more or less regularity. That the lateral walls of these latter cells are everywhere transversely striated like those of the ground tissue of the receptacle and the mesophyll of the bracts is a very important fact, going far in connection with the other structures to indicate the homology of the bracts and the interseminal scales, and finally of the seed stems.

A further fact indicating such homology is the presence of three or more bundles disposed like those of the bracts in a horizontal plane in the basal scales of Bennettites Morievei, very recently observed by Lignier. In the American forms but a single bundle has been observed to traverse the scales, as just described, although plural bundles will no doubt yet be found. The fact that the interseminal scales exhibit dorsi-ventral as well as radial structure is most interesting, and denotes not only homology to the bracts, but the probable presence in the Cycadeoidere of transition forms of megasporophylls with dorsi-ventral rather than radial structure.

\section{THE SEED PEDICELS.}

The seed pedicels, as thickly borne by all the central surface of the receptacle, are of cylindrical to subcylindrical form, their sides being closely appressed with the surrounding interseminal scales en masse. The length of the pedicels varies very greatly, as noted in the description of the longitudinal section of the ovulate cone, in the fruits of the same and different species, it usually being easy to trace the outline of the pedicels throughout their entire length. The diameter of the pedicels is nearly constant throughout, except just beneath the apically-borne seed, where there is a distinct constriction, with compensating expansion of the interseminal scales, above which the stem expands to form the seed base. The diameter of the seeds is about a third greater than that of the stems. 
Histology.-A transverse section cut exactly at the level of insertion on the receptacle shows, wherever the tissue of the latter is preserved and has not been disrupted during fossilization, that the numero's lignified elements of the pedicel are seated over parenchyma cells of large size ( $c$. plate xxcin, photograph 7 ). Throughout the pedicel runs a single central concentric vascular bundle surrounded by a well-marked bundle sheath, which is enveloped by a wide outer region of elongate
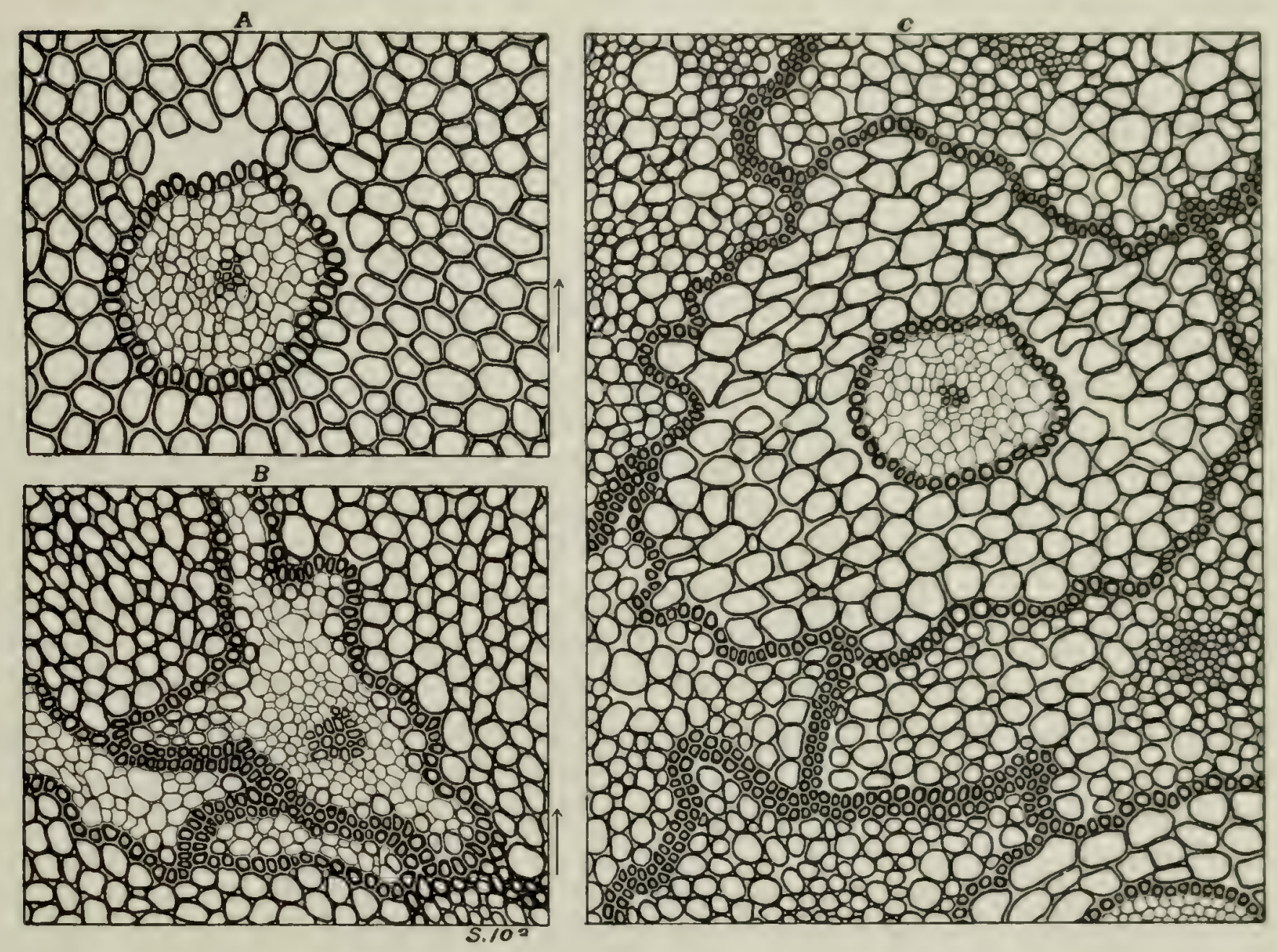

Fig. 61.-Cycadeoidea Wielandi. S. 103, T. 393. X 100. Transverse sections showing organization of the seed stems, or pedicels, and interseminal scales, as cut a short distance beneath seed zone.

A, Seed stem, consisting in a single concentric bundle inclosed in a bundle sheath enveloped in a heavy larse-celled corlex, not all of which is shown. See C.

B. An interseminal scale as inclosed by the cortical region of two seed stems above, and by sweral other interseminal scales below. Note that the interseminal scale ends in an outer heavy epidermal layer. This layer belongs to the sterile organs or scales, because it is double where these are adjacent and single where a seed stem adjoins. The sterile scales hence consist in a central concentric bundle inclosed in a few cortical cells and a heavy epidermis.

C. A single seed stem cut near its summit and surrounded by interseminal scales with diminished phloem and marked increase in lignification.

sclerenchyma cells or cortex. As already explained in the description of thie interseminal scales, just outside this cortex is the closely appressed layer of smaller epidermal cells, which is a true portion of the interseminal scales and only appears to be the final outer portion of the seed pedicels, because the latter are entirely enveloped in scales. Throughout the apical region of the pedicels the cells of the cortex are large, but quite regularly decrease in size and correspondingly increase in number all the way to the pedicel base. The central bundle is seen to consist of a 
group of small xylem cells, followed by a wide area of enveloping phloem, with a surrounding bundle sheath composed of very regularly disposed cells of slightly less diameter than those of the succeeding cortex, as shown in the various photographs of transverse sections of fruits from trunk 393. Aside from the presence of a sheath, the central bundle very nearly agrees in structure with that of the interseminal scales.

The relations between the pedicels and scales clearly appear in figure $6 \mathrm{I}$, together with the fact that serial sections throughout all the upper portion of both sets of organs are afforded by one and the same transverse section of the cone, if cut at or just beneath the lowermost seeds. Thus in subfigure $\mathrm{A}$ of figure $6 \mathrm{I}$ the seed pedicel, as cut near its middle region several centimeters beneath the apical seed it bears, has a broad cortex ten or a dozen cells thick; while the more distally cut pedicel in subfigure $\mathrm{c}$, from the periphery of the same transverse cone section, is seen about $5 \mathrm{~mm}$. beneath termination in the seed base, and has a cortical thickness of from three to six cells. Finally, there is to be noted in the area at the lower right-hand corner of $\mathrm{c}$, which lies nearest the periphery of the cone, a pedicel cut at its most constricted point beneath the seed base, where the pedicel cortex is but two or three cells thick. As explained more fully below, these few remaining cortical cells continue on above the seed base and thin out, as a sort of cup-like seed support. Conversely, comparison of the subfigures $\mathrm{B}$ and $\mathrm{C}$ of figure $6 \mathrm{I}$ shows the corresponding increase in size and degree of lignification of the scales.

The main difference between the stem region of the fertile and the sterile or scale series plainly consists in the fact that the former have lost their epidermal ensheathing layer and the latter the bundle sheath and most of the cortex. Aside from this balanced form of reduction, as it were, the stem organization of both appears to be fundamentally the same. In so far as such a comparison may be made to express anything, the structure of the scales is much more like that of the pedicels than is the structure of the enveloping bracts like that of foliage leaf bases. It is, above all things, possible that related forms have existed in which the organs represented by the scales, though perhaps present in much fewer number, were all fertile. Moreover, the extensive reduction of both scales and pedicels is conclusively indicated by the occurrence of the plural bundles in the basal interseminal scales of Bennettites Morierei (86a).

SEEDS.

The fertile pedicels bear a single orthotropous seed, the size of a small grain of rye. The xylem of the central vascular bundle of the pedicel ends in a salver-like chalazal region made up of scalariform cells, the outer of which continue into the thin nucellar wall. The exterior phloem and the enveloping bundle sheath severally give rise to the double-layered integument. The wide outer cortex, instead of passing over into an outer integumentary layer, forms a cup-shaped supporting basal husk which rapidly thins out along the sides of the seed as its diameter increases until in the middle region only a few tubular cells may be left lying as loose ends on the true outer surface of the seed, as formed by the transition of bundle-sheath cells into the squarish or polygonal forms shown in the drawing (fig. 62). The seeds in the sections before us, as cut from a number of different fruits borne by cycad 393, are supposed to approach the mature size and are, exclusive of the 
micropylar tube, usually $5 \mathrm{~mm}$. in length by $3 \mathrm{~mm}$. in diameter in the radial, and sometimes as the result of lateral compression only I $\mathrm{mm}$. to $\mathrm{I} .5 \mathrm{~mm}$. in the tangential direction to the fruit. This lateral compression, however, varies greatly in extent. Sometimes one side of the seed may be markedly flattened, but the middle transverse section is usually quite regularly elliptical, the long diameter being a little less than twice that of the short. A characteristic peculiarity of form is that the vertical longitudinal section is subrhomboidal, the seeds thus tending to arrange themselves in an appression series, as shown in plate $\mathrm{xxv}$, photograph 6. The micropylar tube, which projects stigma-like a little beyond the pericarp of expanded interseminal scales, adds to the total length of the seeds about $2 \mathrm{~mm}$., or not quite so much.

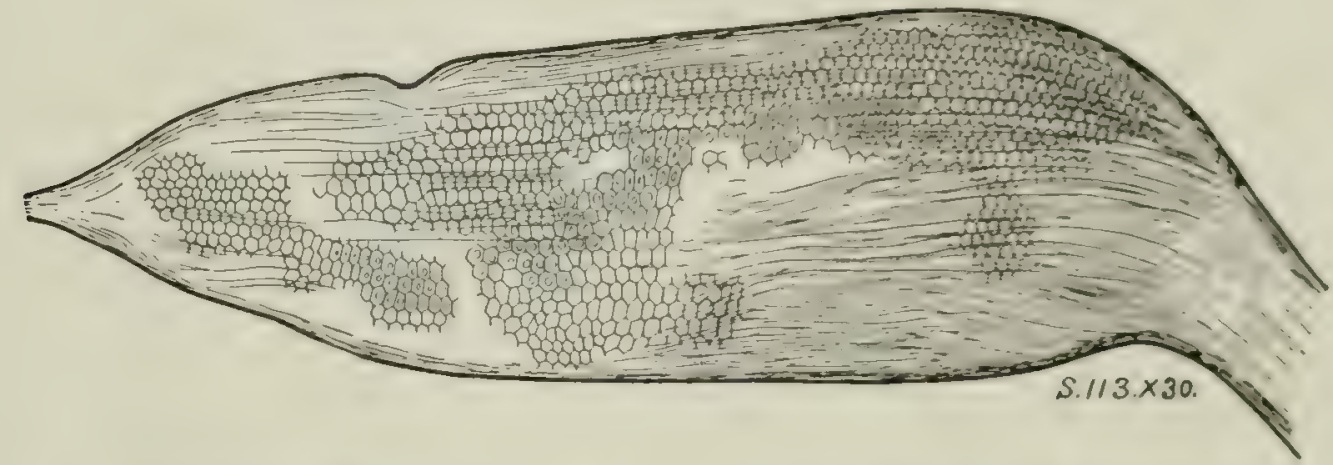

Fig. 62. - Cycadeoidea turrita. S. 113. $\times$ 30. Surface of a single seed as seen in a section tangential to an accidentally appressed and flattened side, showing prismatic layer one cell thick covered by outer husk of stringy cortical cells several cells deep at seed base and thinning out toward tip.

The seed husk is formed simply by the extension of the cortical region of the pedicel, the prismatic layer by the extension and shortening of the cells of the endodermal or sheath region of the pedicel bundle. When shed the loose seed, about the size and form of a small grain of rye, would be disengaged from the husk, the true outer integumentary surface being formed by the more or less distinctly hexagonal cells of the prismatic layer as arranged with approximate regularity, suggesting the appearance of a short ear of corn. The figure is drawn from a photograph thirty times natural size.

Exclusive of the basal outer husk the testa inclosing the nucellus is singlewalled and double-layered. What is here regarded as the true outer layer of the seed, or outer layer of the shed seed, is made up of large, much-lignified cells, of squarish outline in longitudinal section. In tangential section these cells are seen to arrange themselves in rows, and are of pentagonal to hexagonal outline. They are very heavily walled, the interior wall being by far the heavier. Sometimes they may be seen over a considerable area where a seed is chit along a flat, more than usually pronounced appression surface, as shown in figure 62. These cells are not to be confused in any way with the rows of thin-walled cells of the embryo ground tissue in Bennettites Morierei ( $c f .82$, plate Iv, fig. 54). The tissue of the inner of the two layers of the testa is usually preserved in these sections as a narrow, deeply iron-stained zone, probably of collapsed cell walls. Following these two testal layers there is commonly a zone of clear quartz, bounding the nucellar wall, which is usually very well outlined in all sections. The onter layer of thinwalled elongate cells continues on into the micropylar tube as its innermost layer or wall, and is frequently to be seen in longitudinal sections. A possible example of a preserved lateral surface of the nucellar epidermis is shown on plate xxvin, photograph 3 , and the continuation into the micropylar tube is clearly to be seen in 
photograph No. 2, plate xxviII. The nucellus thus fills most of the interior cavity of the thin-walled seed. Inside it is a megaspore membrane. The description of the seed walls as now given applies throughout their entire length, the wall of the basal portion of the micropylar tube differing scarcely at all from the lateral wall of the seed. Further sections from cones of various trunks are yet to be made, but there is no indication in any of the fruits with a fairly complete pericarp of inter-
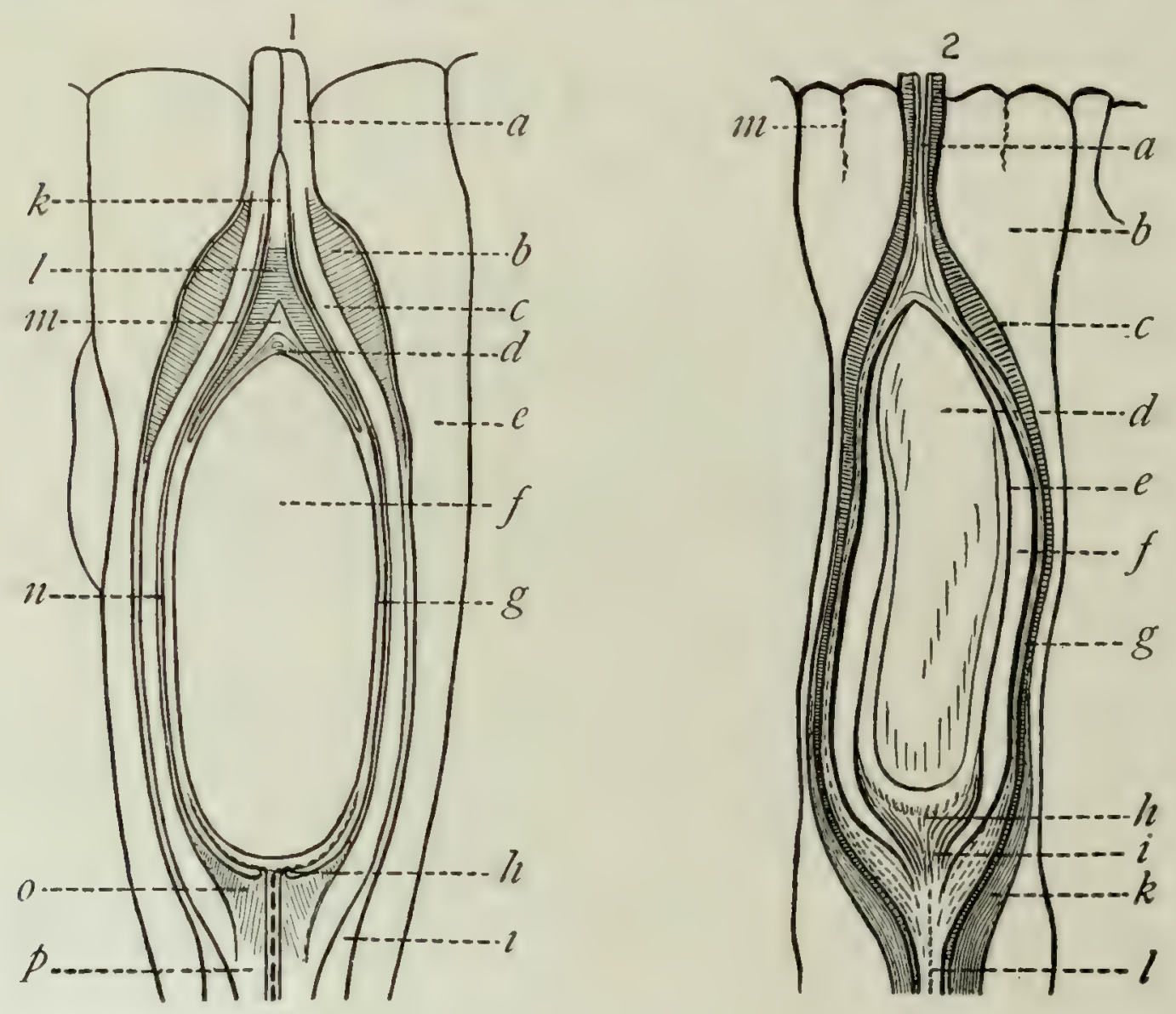

Fig. 63. - (1) Bennettites Morierei Saporta et Marion. Longitudinal section of seed. From Lignier.

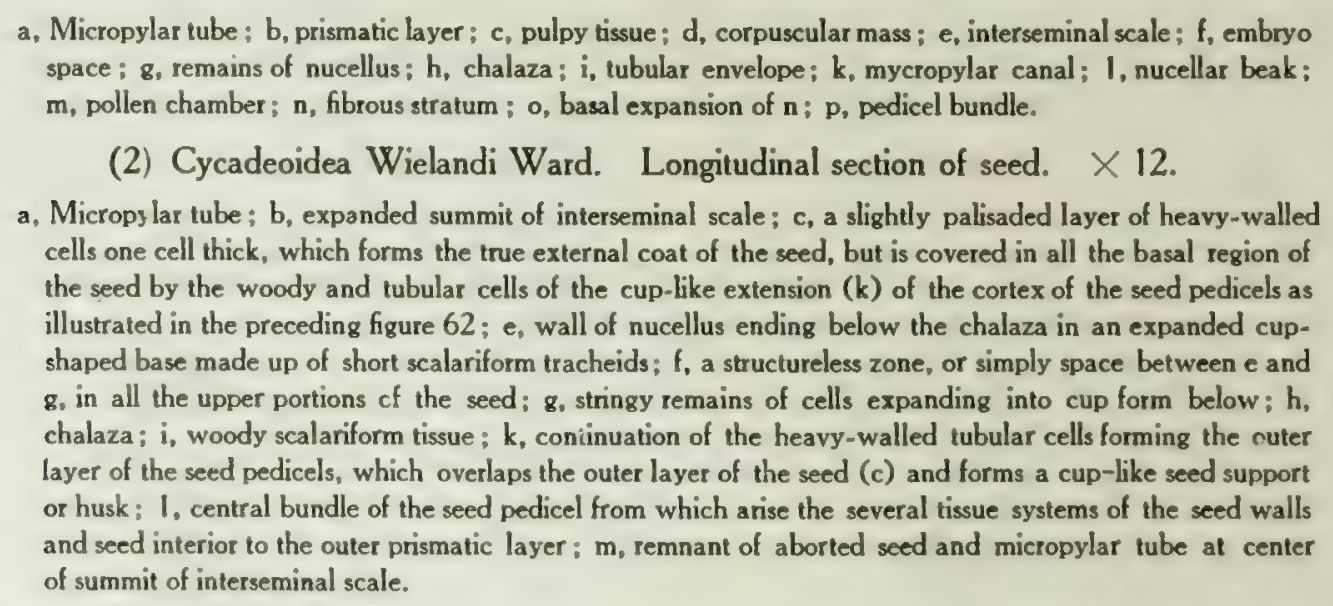

seminal scale heads, of as complex structure of the integument as in the seeds of Bennettites Morierei, although the interior layer of the micropylar tube, as in that form, is regarded as a continuation of the wall of the nucellus.

The nucellar wall is the only structure thus far certainly observed to inclose the megaspore region or the embryo, as the case may be, in Bennettites Gibsonianus and Morierei. Hence it is of importance to note that in some of the C. Wielandi 
sections certain traces interior to the nucellus may represent a tapetum, and that in various instances, notably in section IO3, etc., a strongly developed megaspore membrane is clearly indicated. Such a membrane lying interior to a tapetum has been found quite universally present in the gymnosperms, evidently being a slowly disappearing structure inherited from a pteridophytic ancestry, since it is of vestigial appearance in forms like the Gnetales, more prominent in the primitive members of the group like the cycads and Ginkgo, and most highly developed in the seeds of the Cordaitalean complex $(\mathrm{I} 67 a)$. As this membrane is also prominent in the Paleozoic seed-bearing quasi-fern Lagenostoma (rog), it may be assumed to have characterized all of the Cycadofilices. Since a megaspore membrane was so evidently present in the ancestral Cycadeoidex, it would not likely have become wholly obsolete in any of the group by the Mesozoic. Its indubitable preservation being atbest fortuitous, need not, however, be expected in all the genera; and perchance just as this recondite pteridophytic structure has waned in the Gnetales with more suggestions of angiosperm contiguity than the conifers, so the assumption by the Cycadeoidex of the angiospermous juxtaposition of floral organs may in some forms be found to have been correlated with a similar spore-coat reduction.

Integumentary structures and homologies in Bennetlites Morierei and Cycadeoidea Wielandi.-The structure of the integument of the seed before us will be seen to compare in the main with that of the already well-known Bennetiles Gibsonianus and $R$. Moricrei, but not within the limits of closely allied species, as I formerly thought, unless, indeed, thickening of the apical layers of the testa took place after the growth of the embryo.* The seed coat or integument of Bennettites Morierei Sap. et Mar. is single-walled and consists, firstly, in an outer simple and highly characteristic enveloping layer (b) strongly palisaded above; and secondly;, in a more complex inner layer of soft tissues $(c)$, made up of a single layer of cells having the appearance of a palisaded parenchyma followed next to the nucellus by: a layer of rounded, thin-walled cells several to four or more cells thick above. But outside the integument, as thus described, are certain tubular cells (i), which Lignier considers to belong to the seed coat, although they may better be assigned to the outer layer of the interseminal scales. The seed coat is, therefore, excluding these tubular cells, primarily double layered, with the inner layer the more complex.

The integument of $C$. Wielandi Ward is also single-walled and two-layered, but there are some striking differences from $B$. Morierei, making it very difficult to homologize the layers in these two species with certainty. Both layers are much thinner, making the comparison in each case with seeds containing embryos. The outer or epidermal layer $(c)$ ( $c f$. figure 63 ), which lies next to the tubular cells of the interseminal scales above, or the outer cortical and basal husk below, as the case may be, is one cell thick, the cells varying from more or less cubical to seven or eight

* Fortunately I have been able to give my own description with some small but otherwise very beautiful and representative sections of the historically important Benneltiles M/orierei before me. The duplicate sections were made by Professor Lignier, and loaned to Professor Ward, who brought them from France. Later, with Professor Ward's permission, I effected an exchange with Professor Lignier of sections from Black Hills material for these important sections of the type of bermellifes . Iforierri, which are now in the collection of the Yale Museum. 
sided forms, with heavy walls on the embryo side. Interior to this layer is a thin tissue $(g)$, unfortunately quite without exception indistinctly preserved, but seemingly made up of elongate to stringy elements, only a cell or two thick. The structure of the seed coat of $C$. Wielandi Ward is hence quite exactly comparable to that of Lagenostoma, and it appears that ( $f f$. section I08, plate xxvIII, photograph I) the palisaded layer ( $b$ ) of Bennettites Morierei, of the Oxfordian Jurassic, has been eliminated, the integumentary variations from the latter in such case being of generic rather than specific value. On the other hand, Bennettites Gibsonianus is an intervening form which more nearly resembles $B$. Morierei, the layer $(b)$ of the latter being represented by oblong cells not palisaded.

It remains to add that of all forms existing and extinct thus far discovered the most striking structural parallel to the American Cycadeoidea seeds is afforded by Lagenostoma. In both these genera the seeds are incased in an outer palisaded layer, the entire integuments being strikingly similar in organization, barring the fact that in the far more primitive seed Lagenostoma there is an apical complication of the integument forming a hollow fluted dome about the pollen chamber. This is, however, plainly explicable as a vestigial structure; for integumental folds, chambers, flutings, or other attachments would be more evident in the primitive seeds of the Paleozoic than in the later forms on the hypothesis of Engler, now so fully sustained by paleontologic evidence, that all cycad seeds are in reality single giant spores inclosed in an integument derived from an indusium and a synangial wall of Marattiaceous type. As the Cycadeoidea seeds are of such pronounced radial symmetry and many times smaller than those of Lagenostoma, comparable in size to a small hazel nut, it is scarcely to be expected that a nucellar-bundle ring can be so well marked or pronounced as in the latter form.

Embryos and Pre-embryonal. Structures.

In both the European species Bennettites Gibsonianus and B. Morierei, and in the American species Cycadeoidea dacotensis and C. Wielandi, the nucellus often contains more or less well marked dicotyledonous embryos, which more or less nearly fill its entire space, and indicate a nearly, if not a completely, exalbuminous condition. In size and general form these embryos, as figured by Solms (I57) in Bennettites Morierei, and by Scott (I35) in B. Gibsonianus, are strikingly like the embryos of Ginkgo biloba, except that in the basal region of the cotyledons of the species $C y c a-$ deoidea Wielandi (trunk $\mathrm{I} 3 \mathrm{I}$ ) small rounded protuberances are present, recalling Encephalartos. The individual cells of the embryo tissue, while not for the greater part very distinct, are often clearly present.

It is also of extreme interest that in the sections prepared by the writer from cycad 393 there is represented an earlier or pre-embryonic stage which has never been found preserved in any other specimen, or hitherto observed in any other fossil gymnosperm or other plant. In many of the seeds, as seen in the several different cones of trunk 393, the nucellar space is filled with clear quartz, in part crystalline. In others there is a staining present that must have been conditioned by structure, but definite tissues can not be determined. In still others it is of interest to note that the nucellar wall has collapsed and occupies a central posi- 
tion as two more or less sinuous bands of tissue; occasionally both the nucellar wall and that of the testa may be floated more or less evenly into a central position, and there be more or less vaguely preserved. But fortunately in various seeds collapse is only partial or has not occurred at all, the thin-walled nucellus and contents being normally preserved. In such cases the nucellus may be quite filled with large rounded and thin-walled cells, as photographed on plate xxx. Or these sometimes appear to surround an irregular interior cavity. In a few instances the testa appears to be ruptured and some of the large interior cells liave poured out and then been preserved, although such rupture and preservation is not unusual in silicified woods. In by no means rare instances the fully distended nucellar wall, in longitudinal as well as transverse sections, is filled out to the testa with the large rounded cells, the mass of tissue being irtegularly, though characteristically, traversed by bands, which under very favorable conditions are seen to be made up of small cells, possibly representing an initial stage of embryo formation. These bands appear in the photograph, plate $\mathrm{xxx}$, and are in nowise to be confused with the megaspore membrane, which is in various instances also conserved.

In the absence of the further sections and study so urgently required, the best interpretation of the pre-embryonic stages just noted would seem to be that whatever may represent the oöspore quite filled the nucellus; and that further, as is suggested by the nearly parallel condition in Ginkgo, there was no suspensor development, whence embryo formation must have taken place directly from the tissue here seen to fill the oospore, and thus represent a proembryo or protocorm. At least this is the interpretation recently given by the writer in a brief notice of these seeds, it being held that the cells are in size and general appearance proembryo-like, and that it is not likely that the large-celled tissue is prothallial, since it is traversed by bands or sheets apparently resulting from a division process unlike any preceding archegonial formation. The preservation is so perfect that were the archegonia still present when fossilization occurred, traces should appear in the seeds of the cones studied. Instead, as stated, a homogeneous tissue fills the entire nucellus, save that in some cases a cavity, resembling but much smaller than that of the Cycas proembryo, is suggested, while the bands are better explained as a cell-division marking initial embryo formation.*

Although it has not been found possible to treat this sub; inct on the basis of a fuller series of sections at present, there is more or less certainly indicated a suggestive analogy to Ginkgo, in which there is a much simpler form of embryogeny than in the other Gymnosperms. In this last survivor of an ancient and cosmopolitan line, with varions more or less distant cycadean and cordaitean affinities, proembryo, suspensors, and embryo proper are not differentiated in the oöspore. Instead, all these are merged together and germination of the oöspore begins by free nuclear division, with entire omission of suspensor development. As a resultant,

* If perchance the tentative view adopted be wrong, and the central tissue simply prothallial, then the accompanying structureless seed interiors, which are in a considerable majority, might represent a fertilizud series. In such alternative one might expect, however, ihat silicined embyos would he present in the series of cones in which these delicate preembryonal cells are so well conserved, and that the latter would show evidence of collapse, instead of having the appearance of normal tissue as capable of further growth as any other present. 
there is a filling of the oöspore with a compact protocorm tissue like that here observed to quite fill the entire nucellus. From this the embryo arises and then encroaches upon the endosperm by the growth of the whole mass (87a). In the Cycadeoidex there is evidently present an analogous and possibly still simpler condition. In any case, it is not surprising that the embryogeny of these plants should present features in common with Ginkgo. Doubtless the Cordaitales were also characterized by this most primitive type of embryogeny yet observed in the gymnosperms.

It is only the fortunate exceptional section which tells the most when it comes to the study in the fossil condition of such recondite characters as the present, and it is of course necessary for most searching comparison to have at hand all the facts displayed by all the specimens. Less may not ultimately suffice. I may hence only add that with the large amount of material so urgently awaiting further investigation it is, from the meager facts already observed, not extravagant to hope that completer study will reveal an outline of cycadeoidean embryogeny; and that if this hope be realized, the connected evidence will perchance prove to be the most important single paleobotanical chapter in the story of plant evolution that may be brought to light.

\section{CONE-BEARING HABITUS.}

(As seen in the three Cycadeoidea Wieiandi trunks, Nos. 393, 77, 131, and in the C. McBridei trunk No.76+375.)

The fruit-bearing habit of cycad 393 ( $c f$. plate Xxi) and the other trunks of the species to which it belongs is of the greatest interest. The lower half of this trunk bears three well-preserved ovulate strobili and nine others partly preserved or in part broken away, or shed, or that have failed of complete preservation. The upper half of the trunk-bears eight fine strobili, and about twenty-six more such have been broken away, together with their surrounding armor, being indicated only by the basal portions of their peduncles. The total number of ovulate fruits borne by the entire trunk is therefore seen to be nearly fifty, all these cones being in relatively the same stage of growth. In addition to those enumerated there are doubtless several smaller axes so embedded in ramentum that they have been overlooked, or that might not in any case ever have matured. The general stage of growth throughout the series is, however, so nearly uniform that the forty-six larger fruits distributed nearly equally over all the lateral surface of the trunk must be regarded as belonging to the same season. Moreover, it appears that no earlier series of fructifications was borne by this plant, and it is quite unlikely that other fruits than such as are included in the series just enumerated would later have been produced had fossilization not chanced to intervene. It would seem that, much like Corypha umbraculifera, the trunk never produced fruits until it reached a full maturity, and that all its energy of fructification was then put forth in an effort that at most lasted but a few seasons. How long it may afterward have continued its vegetative growth is a matter for some speculation, but as the present species seldom formed trunks more than 2 feet in height, and no series of old peduncles has been observed, it is not likely that it survived active fructification more than a season or two at the most. A fair estimate of the age of the trunk is about half that of a trunk of 
Cycas revoluta of the same size, or perhaps fifteen years, since the size of the fronds is about the same as in such a trunk. Perhaps this plant was relatively even younger when fossilized rather than older.

TRUNK I3I.

In the trunk just described scarcely a single fruiting axis is definitely and positively young; but in cycad $\mathrm{I} 3 \mathrm{r}$, which represents approximately the middle two-thirds of a trunk, as shown in plate xxir, and which has been referred by Professor Ward to the same species as the preceding trunk, a condition is exhibited which furnishes some very definite data, varying in part from trunk 393. This trunk is a taller one than 393, and the armor has been eroded away over a considerable portion of one side, while a further portion of the surface has suffered crushing when in a more or less plastic condition. Nevertheless, over nearly half of the cylindrical surface the characters of the leaf bases and axillary fruits are exceedingly clear; and on this portion of the surface, a typical area of which is clearly to be seen in plate xxII, a primary series of forty-two large and a secondary interpolated series of about sixteen quite small and young fruits may be counted. Of the primary series of fruits several are preserved entire, about a half dozen are partially preserved, and over thirty are marked by peduncles only, and were either not preserved or else were dehiscent-it being rather difficult to say which in some instances. The seeds of the cones are of approximately the mature size seen in Bennettites Gibsonianus and $B$. Morierei, and, as in the types of these species, young embryos are present. Hence it is not probable that the peduncles underwent further elongation. At any rate, throughout the entire series they are of very even length and bear the fruits with their tips just about protruding rom the armor, where this is preserved to its approximately normal length; but in all these forty-two fruits of the primary series there is a certain similarity which marks them as being of approximately the same age and seasonal growth.

In the case of the secondary series of fifteen small fruits some further sections may yet be made with great profit, especially from those borne nearer the summit, such being slightly in the majority; but the sections already made sliow that these fruits are ovulate and quite young and small, the largest being but a centineter long by a half centimeter in diameter, with a seed zone but a few snillimeters in thickness. No evidence of the presence of young staminate organs or the earlier shedding of an hypogynous disk has as yet been observed in any of these fruits, the young and small bracts and ramentum closing in densely over the summit of each.

TRUNKS 77 AND $76+375$.

On the basis of the features noted on the several trunks just mentionicd it can only be said that varying degrees of bisexuality, or of monocism or diøcism may be here conjectured, and that it is not wholly clear whether the immature fruits represent aborted series, or as is quite possible, the young stages of the orulate fruits of a second and far less active season of fructification. In either case there is suggested waning power to produce fruits after the first season of active fructification. In complete accord with such an interpretation is the condition to be seen in cycad 77 , the 
type of the present species. This fine trunk bears ovulate strobili more profusely than any other of its kind yet discovered (I89). It appears, from the eccentric position of the xylem at the base and the appression of the leaf bases on the side nearest the xylem, to have been a low-growing branch, or else one of a clump of branchlike trunks. The crown is entirely broken away, the recovered portion having a length of $30 \mathrm{~cm}$., a long diameter of $25 \mathrm{~cm}$, and a short diameter of $20 \mathrm{~cm}$. Notwithstanding this small size, this trunk bore embedded in its armor at the time of its fossilization no less than seventy-seven fruits of about the same stage of growth as those just described in trunk 393. Moreover, of these seventy-seren fruits no less than forty-three are still actually present and bear all or a portion of their seeds. A few are still quite surrounded by bracts, but usually the tips of the bracts have failed of preservation and likewise the outer pericarp of expanded interseminal scales, the seed layer thus being exposed in most instances. There is, however, one fortunate exception. One of the larger fruits projects well beyond the armor and is quite complete. On the surface of its pericarp the terminal ends of the micropylar tubes and the patterns formed by the surrounding scale tips are all preserved with delicate exactness of outline.

As showing how profusely the old leaf bases produced these lateral axillary strobili it may be noted that the most favorably located one-eighth part of the whole surface bears twenty-two fruits. Had all the surface been equally prolific the plant would hence have borne upwards of one hundred and fifty strobili. But in addition to the seventy-seven larger strobili present there are only a very few, perhaps three or four, young strobili, which, as in the previous case, may either have been abortive or may have matured during a succeeding season had the plant continued to grow. Taken in conjunction with the preceding instance it would, however, surely seem quite as likely that these few smaller axes were abortive, and that the wonderful series of fruits here preserved represented the culminant effort of the plant-an effort which, had not the exigencies resulting in silicification intervened, would have been followed by death as in Corypha. There is in this immediate connection one other exceedingly interesting specimen, which indicates that at least some of these plants did not produce fruits until late in life. In this cycad, No. $76+375$, a portion of a distinctly columnar trunk, shown in plate $\mathrm{V}$, photograph 5 , the beautiful regularity of the old leaf bases is undisturbed, save by a single small seed-bearing fruit, and it is perfectly clear that the part of the trunk preserved never bore any other than this single fruit shown in longitudinal section (plate xxV, photograph I). Of course the unknown summit may have borne many fruits, but such a fact would only add strength to the idea here suggested that the trunks of the species before us only bore fruits late in life, and then mainly but for a single season, or at least only with strongly diminished activity the second season. Almost the only feature that might be thought to militate against such a view is the slightly greater number of fruits usually found on the upper half of these trunks. But the difference in this respect is not great, since considerably more than a third of all the fruits of cycad 77 are borne on the lower half, where very naturally there is less freedom of late growth of either fruits or adventitious foliage. 


\section{CYCADEOIDEA TURRITA.}

('Trunk 364, section 113.)

A cycadeoidean fruit closely resembling those of C. Wiclandi (trunk 393) is shown in figure 64. This fruit was cut from a fragmentary trunk, and as divested of its surrounding bracts affords an excellent example of the appearance which many of these seed cones doubtless had when shed. An exact idea of the scais that would have been left by any such dehiscent fruits is to be had from many trunks, and more especially from I 3 I and 745, although the fruit scars of these and various similar specimens are more directly due to partial preservation, or to the subsequent exigencies of erosion from the beds in which these beautiful plants and fruits have been preserved since Jurassic time. In the fruit before us the outer layer of the testa of the fairly large seeds is especially well preserved ( $c f$. fig. 62 ), as are also the

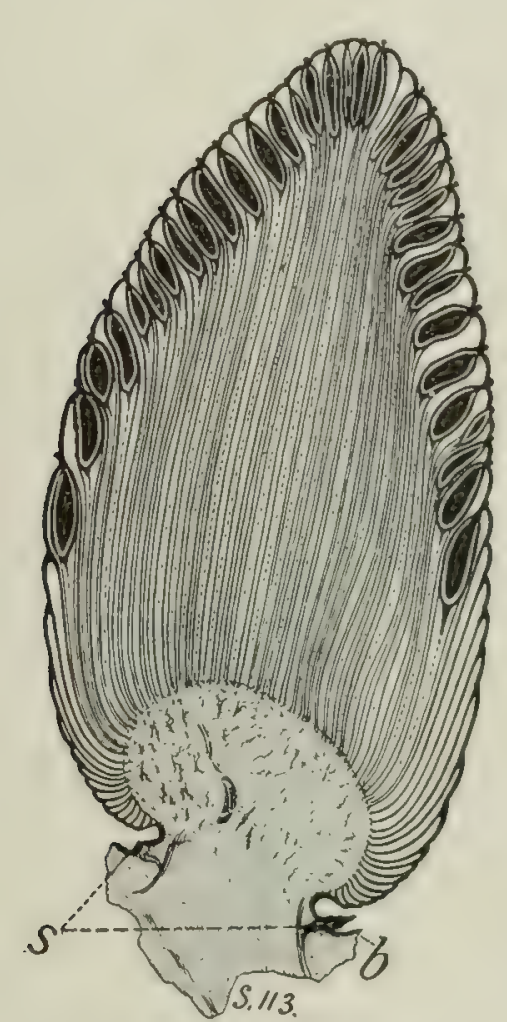

Fig, 64.-Cycadeoidea turrita. T. 364. S. $113 \times 1 \frac{1}{2}$. Longitudinal section through ovulate strobilus, showing shoulder left by the dehiscence of a staminate disk (s), and the bases of several of the enveloping bracts (b). (See photograph 2, Plate XXIV.) sieve-like to scalariform elements of the terminal parts of the receptacle, the bract bases, and the peripheral interseminal scales. Also, as in the case of various similar cones, there is between the uppermost of the spirally arranged bracts and the basal periphery of the ovulate strobilus proper an annular shoulder which receives a bundle supply from the main woody cylinder of the peduncle, as indicated in photomicrograph 2, plate XxxI. The condition of the tissues of this anmular region shows very plainly that an earlier abortive or much more likely a functional disk was attaclied hypogynously to the ovulate cone. The dehiscent line is annular, since in all longitudinal sections it is indicated in the same relative position on both sides of the peduncle, the condition in the fossil suggesting the wilting down of an earlier attached disk rather than a direct splitting off. This, indeed, is almost the only fact that might at first be construed as indicating an abortive condition of the early growth borne by the annular shoulder; for one might expect staminate growths to be sled bodily, much as are the stamens of Liriodendron. The isolated Wiliamsonia disks with sharply outlined insertion are also to be recalled in this connection. Yet it is to be noted that, althongh pollen-producing and fused basally into a disk, tile staminate fronds of the Cycadeoidex were in appearance and texture essentially: fern fronds; and every botanical student is familiar with the slow wilting of fertile fronds such as those of Osmunda, the stringy basal portions of which remain behind for many months after the ripening of the spores. Moreover, in these fossil fruits there is often in the slight remnant of the earlier growth from the annular shoulder a most striking resemblance to the wilted tissue of fern fronds, as well as partially conserved bundles. 
Aside from minor differences in form, such, for instance, as the slightly more globular shape of the receptacle, the principal point of distinction between the present fruit and those of trunk 393 is the much more prolific growth of seeds and far larger size of the bracts. These features are also to be seen in the fine longitudinal section of another fruit cut from a trunk referred at the present time to Cycadeoidea Paynei, and shown in plate xxiv, photograph 6. In this latter cone the enveloping bracts rise a full centimeter above the summit of the fruit, and are distinctly larger than those of the otherwise larger fruit of $C$. Wielandi, shown in plate XxIv, photograph 3. Structure is beautifully preserved and characteristic, as clearly appears in figure 60 , showing the main features of bract organization. The seeds may or may not have been fertilized. As in the several foregoing species, there are indications of the earlier presence of a basal disk.

\section{BISEXUALITY.}

(As indicated in the strobili of the closely related group of species, Cycadeoidea Paynei, C. Colei, C. McBridei, and C. turrita.)

It becomes a necessary convenience to add in the present connection a more definite statement of the evidence indicating the frequent occurrence of a bisporangiate condition in the nearly full-grown or mature strobilar forms just described, although this topic in part anticipates the descriptions of the completely preserved bisporangiate strobili given in the succeeding chapter. For although it was at first supposed that the type of fructification so richly illustrated in the foregoing trunks was simply ovulate, these later studies disprove the correctness of such an interpretation so far as most of these ovulate cones are concerned. As yet a trunk of the present species bearing male disks in any considerable number has not been found, although trunk 464, which is possibly of the same species, bears, in addition to some scars left by shed strobili, the same general bisporangiate type as Cycadeoidea dacotensis, and no other fruit. In this one, as described more fully in the next chapter, the ovulate axis has assumed considerable size, and it is clear that it continued its growth far beyond the stage seen in the possibly abortive young ovulate cones of trunks like I 3 I, and would doubtless have ultimately matured seeds had fossilization not intervened. A very pronounced feature is the fact that the outer layer of interseminal scales is almost entirely composed of scalariform elements. Likewise the enveloping bracts have the structure seen in those surrounding other and larger ovulate cones. The staminate disk has wilted down, leaving in the space over the ovulate cone a confused mass of sporophylls and fairly well preserved and distinct synangia, some of which contain pollen. The general type of the ovulate cone, which is much larger than any of the young cones of trunk I 3 , leaves it most heartily to be desired that among the many trunks to be investigated supplementary examples may yet be found. Now, on the basis of isolated fossil bisporangiate fruits, or even of single trunks bearing advanced stages of ovulate strobili, presumptively derived from bisporangiate axes, it must always prove difficult to determine degrees of bisexuality, monœcism, and diœcism. But the facts pointing to a solution in the present case may be repeated here:

(a) 'The structure of all the larger ovulate cones permits the assumption of the earlier presence of an hypogynous staninate disk. 
(b) In the case of the above-noted isolated bisporangiate strobilus the ovulate cone is much larger than in certain small cones, as seen in cycad I3I, where no evidence of the presence of staminate organs has yet been observed.

(c) The small ovulate fruits of the present trunks may be normally bisporangiate, and simply strobili, which not only failed to produce staminate fronds but were destined to abort. This would be the case if the belief expressed above, that fructification took place as the climax in the life of these plants, be correct.

(d) Young fruits with distinct traces of staminate disks have been observed in other species, and are likely to be found in the present species at any time.

From the foregoing facts, together with the structural features observed, it is held most likely that the present species are bisexual, and that a staminate disk was produced while the ovulate strobilus was yet young and probably not sufficiently advanced in growth for close fertilization. In this case after the disk was shed the ovulate axis continued its growth, and the megaspores were later fertilized by the pollen of flowers, perchance borne on other trunks.

\section{CYCADEOIDEA JENNEYANA (?).*}

The fruits borne by the handsome group of trunks from the Piedmont-Black-Hawk locality on the eastern rim of the Black Hills present essentially the same features as those from Minnekahta, although many of the trunks were of more distinctly columnar form. A very handsome isolated fruit (specimen 7IO) from the lower end of the locality to the north of Black Hawk is shown in longitudinal section in figure 65. This fruit is partially chalcedonized and exceedingly hard and tough, as are quite all of the specimens from the same region. Little carbon was separated out and little iron seems to have been present during the process of

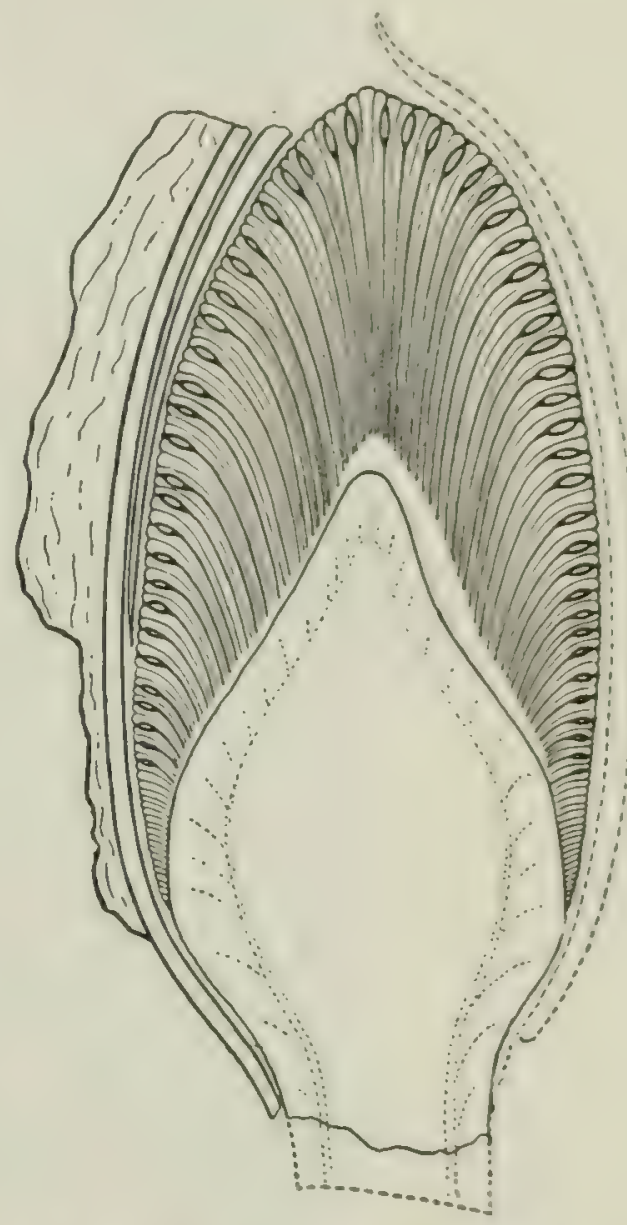

Fig, 65. - Cycadeoidea Jenneyana (?). Longitudinal section through an ovulate strobilus from I:. 710, an isolated trunk fragment from Black Hawk, South Dakota. $\times 1 / 2$. silicification, although this was controlled by the original plant structure. As a result, the finer structural details are rather faintly indicated and the ground tissues

* In the case of the present specimen only a small portion of the trunk is present, but the fruit is, as named, presumptively that of a trunk of C. Jcnncy'and. It should, however, be emphasized here that it is as yet wholly impossible to deal with the specific position of this and several of the other ovulate fruits briefly described, in any other than a wholly tentative manner. There are in the collections at hand literally thousands of fruits, if the various stages of growth be included. It will therefore be necessary to prepare a long series of representative sections from the fruits, trunks, and leaf bases of type and cotype material before any arbitrary statements concerning species can be made. A biologic study, it may be repeated, is all that is here presented, the idea being to further continue such study in connection with a revision and classification of the various forms on the basis of both microscopic and macroscopic features. 
have the appearance of quite clear chalcedony. It was found possible, however, to increase the differentiation of the main features by carefully boiling the fruit in a strong sugar solution for several days and then immersing for a considerable time in strong sulphuric acid. Some such method of procedure will doubtless be found available in bringing hidden structural details to light in yet other cases where structure is present but not differentiated by traces of carbon along the cell walls or by natural iron staining. Artificial staining methods used for agates are suggested.

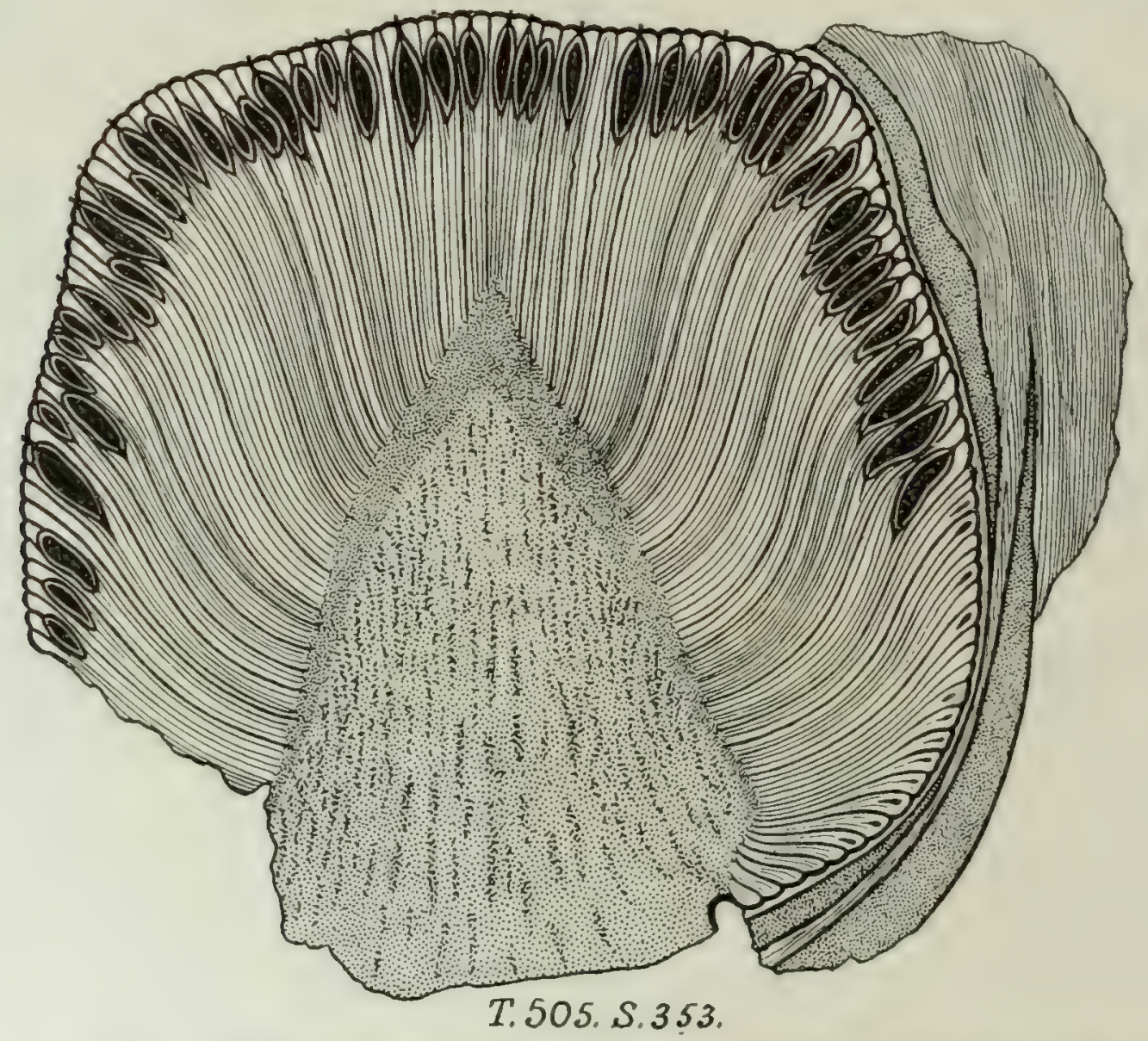

Fig. 66. - Cycadeoidea dacotensis(?). S. 353. T. 505. X 21/2. Longitudinal section through ovulate cone. This cone belongs to the same series as those shown in figure 29, having been removed before the remainder of the trunk was polished. The summit was even with the surface of the armor. (Cf. photograph of this section, Plate XXXII, also of the cone, Plate XLIII, No. 5.)

The fruit before us is of flattened elliptical outline and beautifully symmetrical. It is $55 \mathrm{~mm}$. in length, with a major diameter of $35 \mathrm{~mm}$. and a minor diameter of $25 \mathrm{~mm}$. (The figure shows the fruit as cut longitudinally on the short diameter in radial longitudinal direction to the trunk.) Bracts and bract hairs envelop most of the surface, but in places the characteristic surface sculpturing formed by the tips of the micropylar tubes and the surrounding interseminal scales is distinct. Below the seed zone and above the insertion of the bracts a belt of the receptacular portion about I cm. broad is prettily fluted to meet the appressed enveloping bracts. The young and small seeds are far more numerous than in cones of the preceding species. The seed stems do not vary greatly in length, as the receptacle is not simply convex or globular but of elongate inverted top-shape, relatively flattened to the same degree as the entire fruit. The cone is evidently half-grown or larger, although the earlier presence or absence of a staminate disk is not readily determinable. 


\section{CYCADEOIDEA DACOTENSIS (?). (Fig. 66.)}

A fragment of a nearly cylindrical trun' ${ }^{1}$ from Minnekahta (No. 505) bears various fruits, as shown in figure 28. Also, photograph 5 (plate $\mathrm{xLIII}$ ) represents a portion of the eroded surface of one of the cones, which displays very clearly the seed zone and the distinctly conical form of the receptacle on which the pedicels are borne; and plate XxxII with the opposite figure 66 shows the same fruit in somewhat obliquely longitudinal thin section, this obliquity causing the rounded appear-

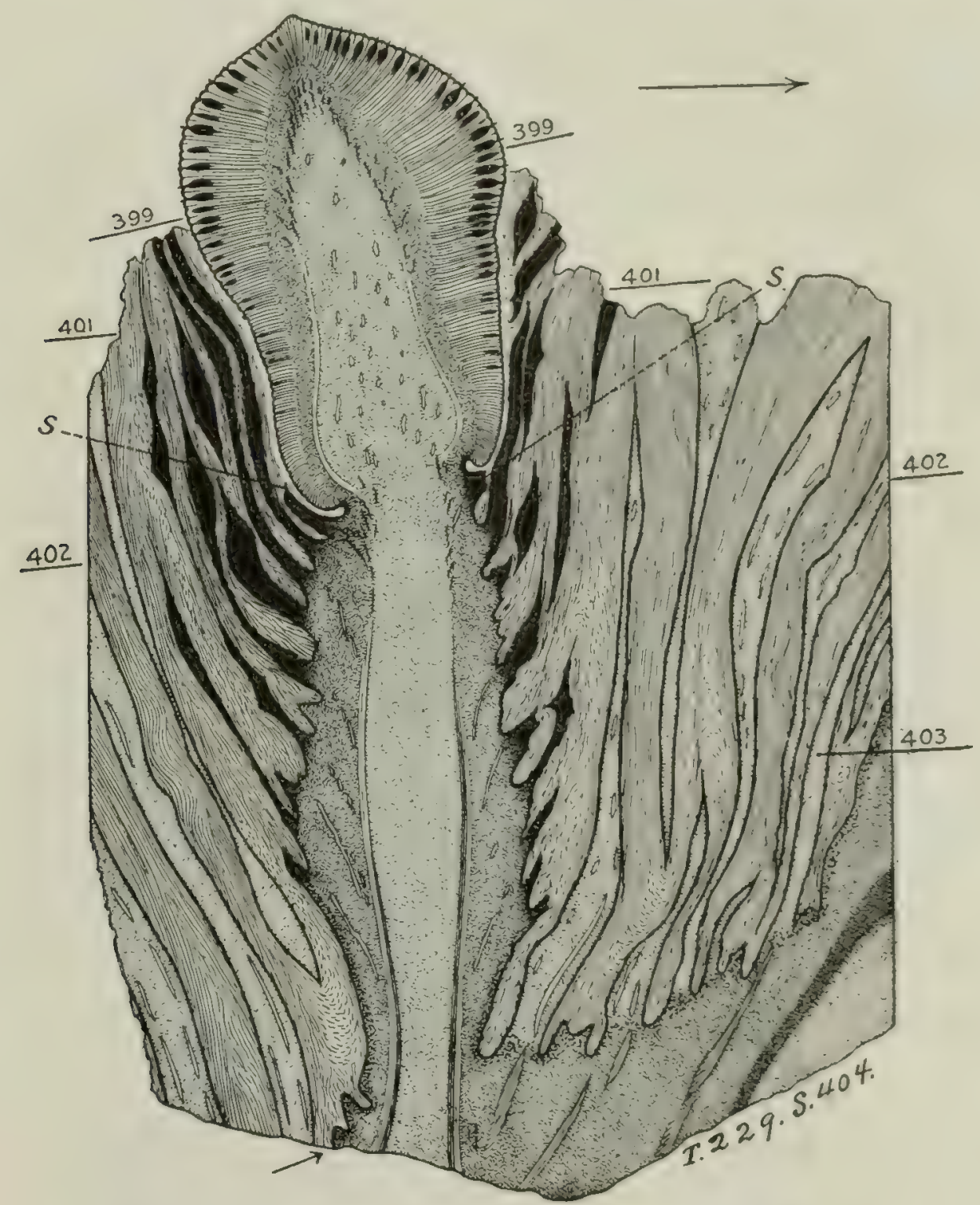

Fig. 67.-Cycadeoidea Marshiana. Longitudinal section 404 through ovulate strobilus cut from T. 229. Natural size. s, Remnant of dehiscent disk. The planes of the serial transverse sections accompanying are indicated by their respective section numbers. See figure $67 \mathrm{a}$.

ance of the upper portion of the truly conical receptacle as cut hyperbola-like. The seeds are $4 \mathrm{~mm}$. in length by I $\mathrm{mm}$. in diameter, and therefore relatively much more advanced in growth than those of specimen 7 ? 0 , just described. Nevertheless, in general form the fruit is shorter and more robust, the apical seeds especially being supported by relatively far shorter pedicels. No. 7 IO and the present form therefore 
present minor differences which, taken by themselves, are at least of distinctly specific value. The present cone will also be held by most paleobotanists to be specifically distinct from that shown in figure 67 ; nevertheless it is difficult to determine
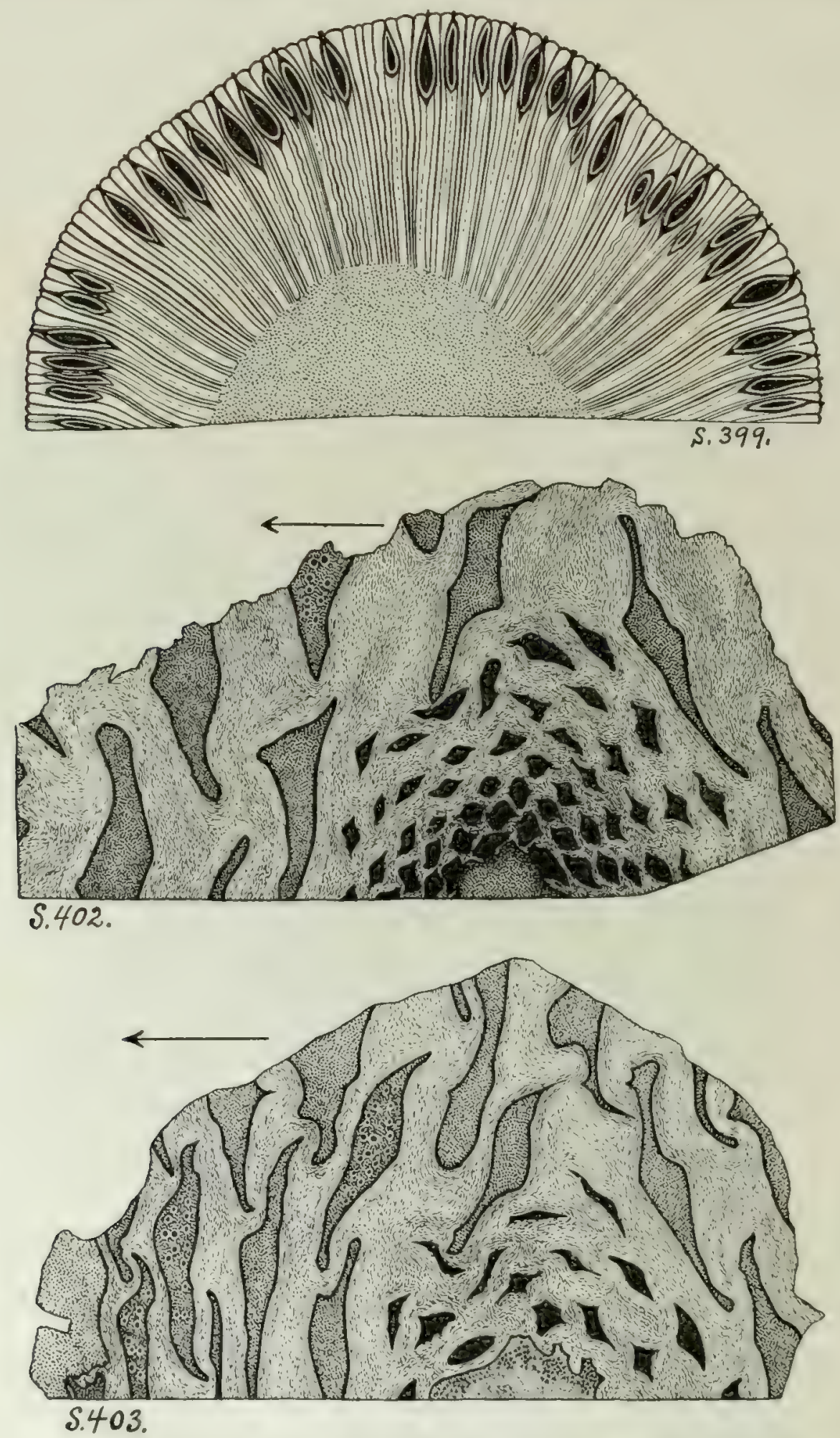

Fig. 67a.-Cycadeoidea Marshiana. T. 229. S. $399(\times 3)$, and 402 and 403 (each natural size). Serial transverse sections of ovulate cone shown in longitudinal section in the preceding figures, and cut on the planes there indicated. In S. 399 the seed stems and interseminal scales are in most instances cut throughout their entire length. The drawing shows very exactly the projecting stigma-like tips of the seeds. (CF. photographs of Plate XXXIII.)

its species, owing to the great variation of development in, and the extent of the series of cones with, the various types of elongate and conical, rather than globular, receptacles. At least this is not the usual form of the $C$. dacotensis fruits. 
CYCADEOIDEA MARSHIANA。 (Figs. 67 and 67a.)

(Plate Xxxin, sections 399 to 406 and 408 , all from same fruit.)

The remarkably handsome group of ro.just branching cycadeoidean trunks from the southern Black Hills, to which the specific names Cycadeoidea Marshiana, minnekahtensis, dacotensis have been given, is characterized by large ovulate strobili with short seed pedicels and elongate conical to pear-shaped receptacles, the reverse of the condition seen in C. Gibsonianus, Morierei, Paynei, etc. This fact is clearly' seen in the various thin sections from a typical fruit borne by cycadean trunk 229,

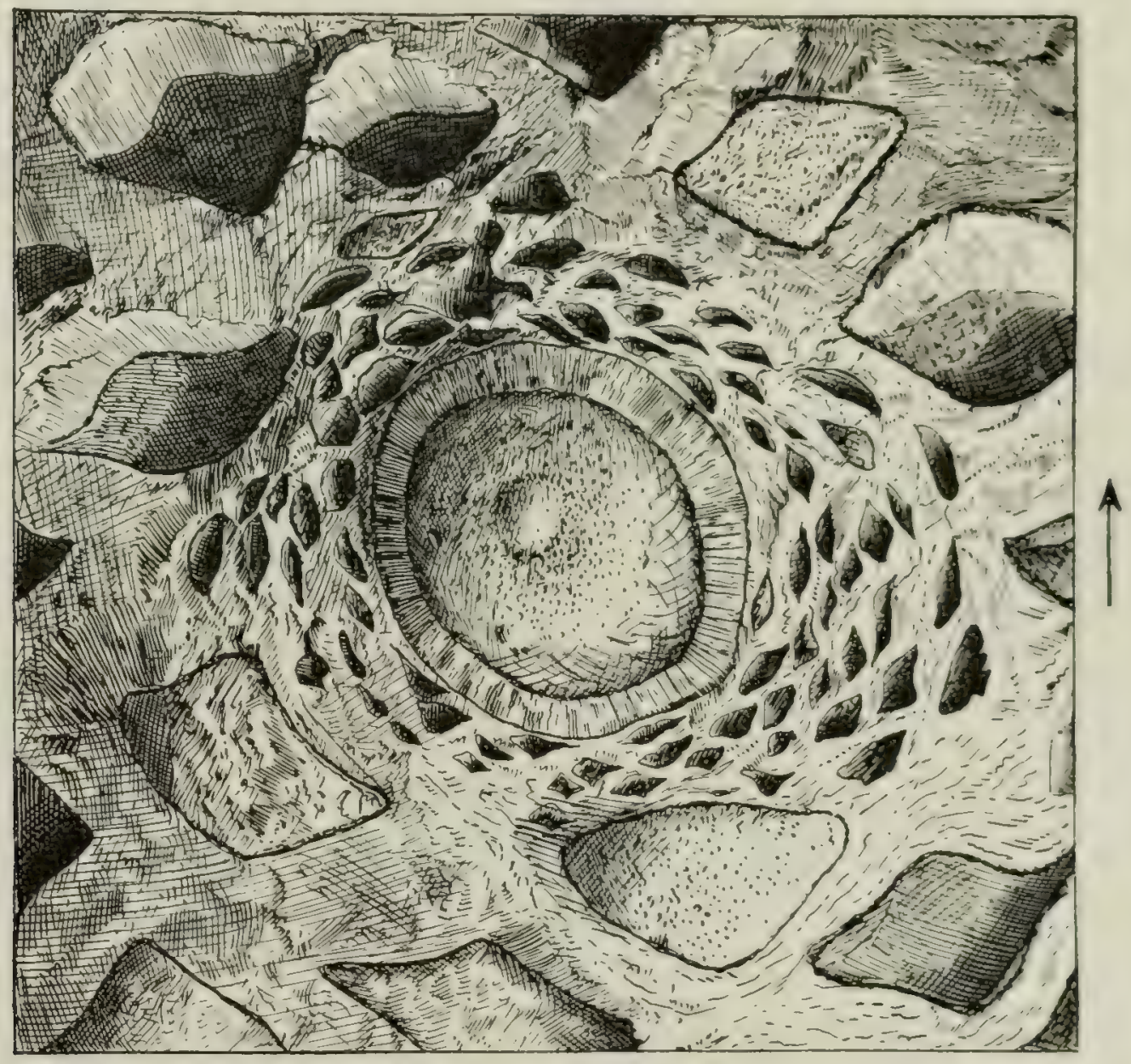

Fig. 68.-Cycadeoidea superba. T. 717. Portion of trunk bearing an ovulate strobilus surrounded by bracts and leaf bases. The strobilus has greatly increased in size aftur the shedding of the staminate disk (if such was earlier present); and were it not for the breaking or eroding away of all the apical seed stems and interseminal scales, would extend several centimeters beyond the ends of the leaf bases. The exposed portion of the receptacle is of globular to pear shape except for the low conical apex. Natural size. ( $\mathrm{Cf}$, the restoration given in figure 69.)

a handsome though but partially recovered branch at first referred to C. minnekr/htensis (?). The trunk and serial thin sections from a large ovulate fruit borne by it are illustrated in plate xxxm by photographs, the features of the strobilus beng further shown in the supplementary pen drawings, pages I33 and I34. Aside from size, relative proportion of parts and a rather greater number of surrounding bracts, no essential differences from preceding strobili are present. The shape of the fruit is quite exactiy that of a robust pear. The depth of the surrounding armor is $\mathrm{S} \mathrm{cm}$. and the length of the peduncle $6 \mathrm{~cm}$. The length of the partly projecting fruit is $5 \mathrm{~cm}$., its greatest diameter about $3.5 \mathrm{~cm}$. The length of the central receptacle is 
$4.5 \mathrm{~cm}$, its diameter $2 \mathrm{~cm}$. at the broadest point below. The depth of the seed stem and interseminal scale zone is, where thickest, about $8 \mathrm{~mm}$. The base of the fruit is fluted by bract appression, and there is the same suggestion of an earlier-borne basal disk, as observed in the ovulate cones described above. In agreement with the large size of the heavily armored parent trunk the peduncle is longer, so that the fruit is borne in the same relative position in the armor as in various smaller trunks. As shown in longitudinal section (fig. 67 ), the receptacle is of elongated conical shape, with marked lateral constriction, and is quite as long as the fruit itself. The terminus is slightly eroded away, but may have borne a few abortive pedicels. Most of the fertile pedicels are borne in the middle and upper region of the fruit, where there is more freedom from the compression of the surrounding armor, and both scales and pedicels stand in a vertical position to the receptacle throughout its entire

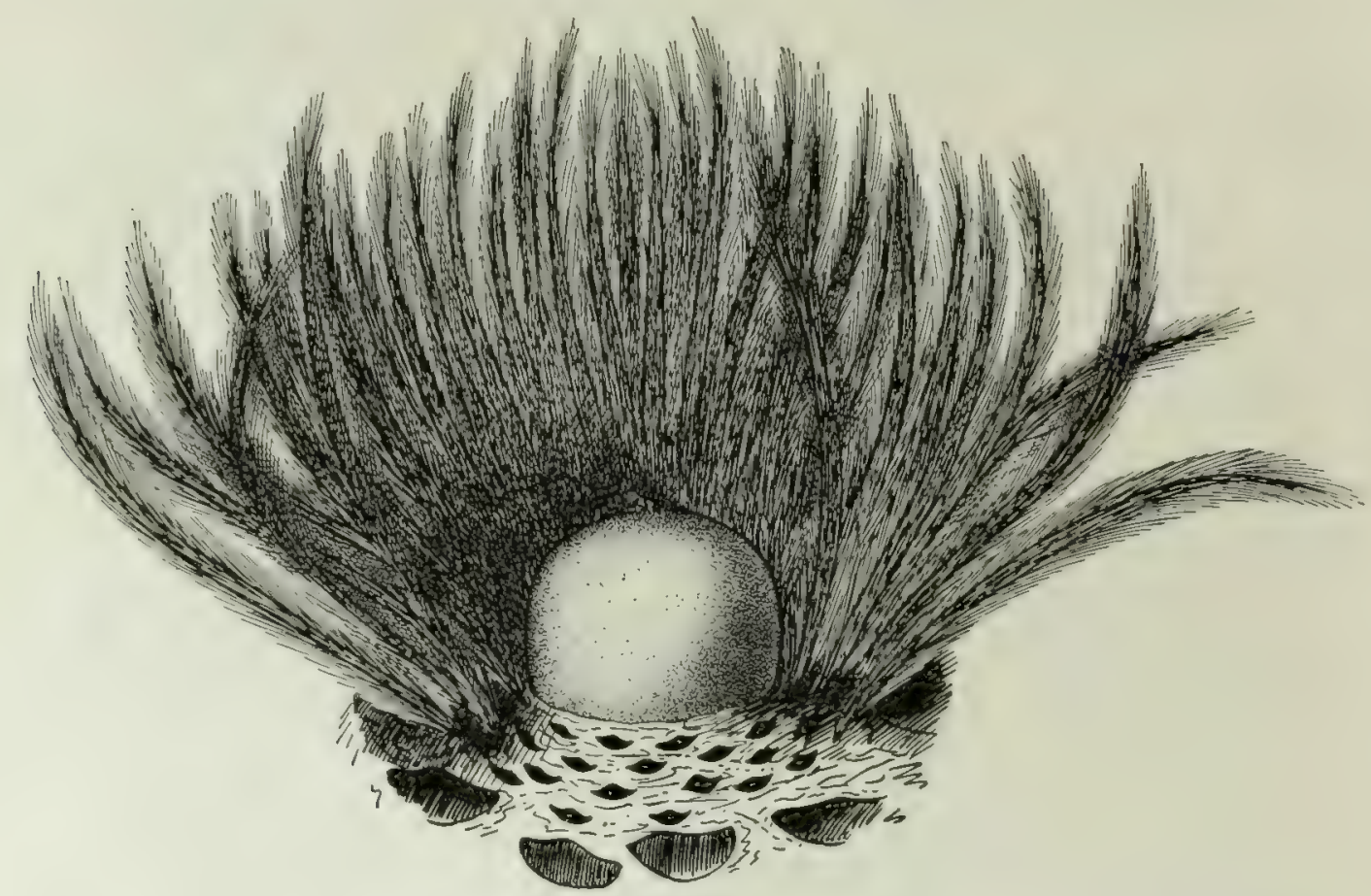

Fig. 69,-Restoration of ovulate strobilus like that shown in the preceding figure. Much reduced. The bracts, as shown partly removed, may perchance be represented much too long. In case an hypogynous staminate disk was earlier present the bracts may have been nearly, but not fully, as long as the nearly full-grown microsporophylls, or 8 to $10 \mathrm{~cm}$ in length.

length. Because of this vertical insertion of the seed pedicels they are, in the exactly transverse sections from the upper middle parts of the cone, cut lengthwise from base to apex, just as in longitudinal sections. ('This feature plainly appears in section 399, figure 67a). The seeds are fairly well advanced in growth. The nucellar contents are preserved in outline, but not differentiated, and the continuation of the nucellus into the micropylar tube is often neatly shown. Where the fruit is covered by the bract hairs the projecting stigma-like tips of the micropylar tubes are very distinct. It is believed that the present fruit is merely a more advanced stage in the growth of the central ovulate cone of a bisporangiate strobilus like those borne by the superb specimen of C. dacotensis (trunk 2I4), illustrated by various text-figures and further described in the next and succeeding chapters on bisporangiate strobili and young fructifications. 
RÉSUMÉ.

The best known of the short axillary seed-bearing fruits of the Cycadeoidere have hitherto been those of Benneltites Gibsonianus from the Lower Greensand of the Isle of Wight, and B. Morierei from the Oxfordian Jurassic of Normandy. In addition, during the past seventy-five years, many casts and imprints of the ovulate cones of various species of Williamsonia have been found on the Yorkshire coast, as well as in other European localities. Noteworthy, too, is the occurrence of these cones accompanied by foliage in the Jura of India (as figured in Chapter I); also in the Trias of Southern Sweden, as so fully described by Nathorst. Such fossils have in a most interesting manner amplified our knowledge of the cones with their structure so wonderfully conserved. Conversely, the latter make possible the exact interpretation of imprints.

In the present chapter four or more new species of cycadeoidean cones are described as borne in great profusion by various silicified trunks from the Black Hills fossil cycad localities, the richest thus far discovered. As based on this extensive new material many habitus details are added and a redescription of strobilar organization is given, in which the hitherto little or unknown features are described, especially the complete peduncles (with the cortical bundle system), the entire bract series, and the hypogynous anmular shoulder indicating the earlier attachment of a dehiscent staminate disk in all of the larger seed-bearing cones. It is concluded that fructification was a culminant event in the life of most of the trunks, since most either bear few fruits or young series of fructifications, while the seed-bearing cones approaching maturity often occur in very large numbers over all the lateral surface of the trunk and such branches as are present, with but few or no old peduncles or immature forms. It is also made clear that while a bisexual strobilus is primarily indicated, the form of fructification is precisely the one capable of most varied phases of monœcism and diœcism, which of course can not be determined short of the study of numerous fruits from different trunks of the same species. It should also be definitely stated that while diœcious and monœcious or mixed bisexual forms are suspected to be present, no such have actually been determined. The dicotyledonous embryos of the Cycadeoidere-the only ones known in any extinct group of fossil plants-are also present in some of the Americani specimens. Furthermore, pre-embryonal stages trave been observed in the latter, which exhibit a partial agreement with Ginkgo, in which there is no intervention of suspensors in the formation of the embryo from the homogeneous mass of large-celled tissue constituting the proembryo or protocorm. Of supreme interest is the fact that there is probably at hand material which, when once fully elaborated, will disclose the main ontlines of embryogeny in the Cycadeoidere. 


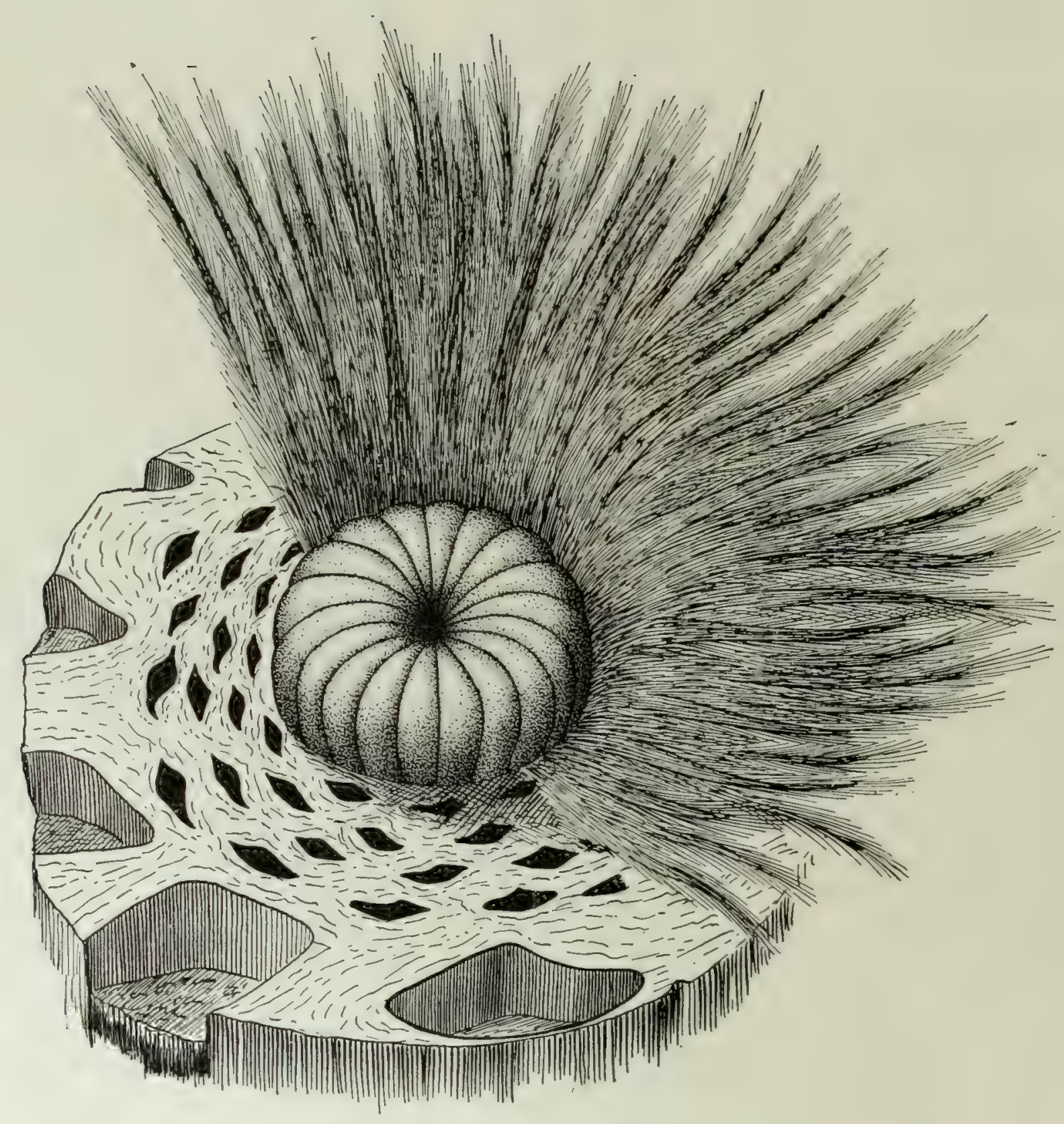

Fig. 70.-Cycadeoidea dacotensis.

Ideal view of emergent bisporangiate strobilus just previous to unfolding of the fertile microsporophylls and maturation and shedding of pollen. The bracts on the left are shown as usually eroded away evenly with the surface of the surrounding armor. Based on the various sections and strobili described in Chapter VII. About natural size. Compare with the restoration of an expanded bisporaugiate strobilus of $C$. ingens, figure 54, and with the plan of the same, Plate IV A. 


\section{CHAPTER VII.}

\section{BISPORANGIATE AXES.}

\section{HISTORICAL.}

It has been justly said by Scott that "the discovery of the Bennettitere must rank among the most striking and unexpected revelations of paleontological research." And our knowledge of this remarkable group may be considered to begin with the discovery and description of the ovulate strobilus of the species Bennettites Gibsonianus by Carruthers in I868, since, so long as trunks only were known, they were very naturally supposed to be much more closely related to the living cycads than then proved to be the fact. But the nature of the corresponding male inflorescence remained quite unknown for the next thirty years, the first definite information concerning the staminate organs having leen furnished by the writer in his preliminary study of the male flower of Cycadeoidea ingens in 1899.

In the meantime, the only clue as to the possible situation of microsporophylls was that gained by Capellini and Solms (22) in I892, in their study of that most ancient of all geological specimens, Cycadeoidea etrusca, from the Etruscan necropolis at Marzabotto. As in Bennettites, there are inclosed within the armor of this trunk a number of bract-surrounded fruiting axes, and in one of these which we now know to be an imperfectly preserved bisporangiate strobilus of the type presently to be described, Solms-Laubach found typical pollen grains which he held to have been borne by an "antheriferous tissue." This tissue apparently surmounted a central cone whose structure could not be determined, but which it was suggested might be analogous to the seed-bearing fruits of Bennettitcs. The investigation of this difficult material was made with such care, and the conclusions reached are so suggestive, that a translation of that portion of Capellini and Solns's study directly bearing on the present subject is given herewith (Capellini and Solms-Laubach on Cycadeoidea etrusca, with original references to plates and figures):

"As soon as I saw the magnificent trunks of Gycadeoidea etrusca and Maraniana, I conceived the strongest hope of being able to determine in them not only fruits similar to those of Bennettites Gibsonianus, but also the corresponding male inflorescence of the Bennettitex. The eroded specimen of Cycadeoidea intermedia could add nothing, since only the basal scale-bearing internodes remained. As may well be imagined, when, at the first cutting of the trunks in question, the young fructifications so much wished for, and certainly not concealing seeds, were exposed to view, m; joy was great. But unfortunately it was very soon dampened by the examination of the thin sections obtained; the spadices were indeed present, but so imperfectly preserved that in no instance could their sex be determined with certainty. What little their study 
yielded is so beset by doubt as to be of no great importance, and will require future verification and extension, based on fortunate discoveries which, I believe, will not be wanting. Nevertheless, I hold it somewhat to the purpose to describe the conditions as found.

"The best section obtained is like that shown in T. IV, figure I. It is the exactly median longitudinal section of an inflorescence of Cycadeoidea etrusca, and was fortunately exposed by the very first cutting, as made at Florence in the Royal Manufactory for Works in Hard Stone. It is to be seen on the polished surface of the original specimen at the Geological Museum of Bologna. From the other half of the same I had a thin section made which is represented in the above figure. One sees that the shoot had a thick and fleshy axis surrounded by scale-like sepalaceous leaves. The tissue of the axis is wholly destroyed; and of its leaves or bracts only the dense masses of ramentum are preserved, these being, as seen in longitudinal sections, traversed by structureless strix, representing the original ramentum-bearing scale leaves. The receptacle after becoming slightly smaller ends in an ovoid and slightly pointed spadix $\mathrm{r} \mathrm{cm}$. in length and $7 \mathrm{~mm}$. in its greatest diameter, the fleshy substance of which has likewise been destroyed. Above this spadix is to be seen a small free space filled with some sort of fragments to be mentioned later. A little beyond, the ramentum of the sepalaceous leaves closes in from all sides as a compact mass of considerable thickness, in which the irregular sections of the separate obliquely cut leaves appear as gaps. No communication exists between the space above the spadix and the exterior, though in the successive sections made from other floral shoots from the same specimen such must have been observed, if present. The entire surface of the spadix is enveloped by a layer a little more than a millimeter in thickness, which is composed of numerous parallel structures always standing vertically to the outer surface. These arise as separate cylindrical rods whose extremities spread out tuft-like and form a continuous surface. The transverse sections of these structures show here and there traces of tracheal tissue, which are, however, very indistinctly preserved. But in any case it is not to be doubted that we have here sexual organs closely appressed in a thick-set layer, and covering the terminus of a spadiciform receptacle. This is also confirmed by the study of transverse sections of the same organ, some of which were cut through the apex of the spadix, in which the structures may also be seen in oblique section. The representation of such a section is given in $T$. $V$, figure 4. It shows centrally the tip of the receptacle, with the rodlike radiating bodies which form the outer layer cut obliquely. In this section one recognizes numerous circular forms filling the gaps in some continuous mass of darkbrown color. These forms show a compact outer zone inclosing the much-altered remains of a feeble-walled tissue. Recalling now the structure of Bennettites, one is tempted to regard the organs of circular section as female, their supports as "cords" or seed stems, and the surrounding tissue mass as the interstitial tissue which exteriorly spreads out into a continuous layer inclosing the seeds or seed spaces. The entire stratum of flowers, in case this combination represents the actual condition, would at maturity have grown much larger, if it can be compared with the mass of peduncles, interstitial forms, and seeds, as borne by the receptacular cushion of Bennettites Gibsonianus.

"In the small inclosed space between the extremities of the central spadix and the inbending tips of the sepalaceous leaf scales, as above described, occur several further tissue forms which must for a moment occupy our attention. Here there are several irregularly shaped lobes of elongate form, consisting of lengthened cells, upon which lie scattered in every direction great numbers of little bodies of a peculiar form (T. 4, fig. I, at $a$ ). Any of these enlarged appear at first like a pair of needles pointed 
at both ends, lying side by side, with one or both pairs of tips touching. But close inspection reveals that these are bound together by thin membranous strix of a light yellowish-brown color. They therefore resemble little boats ( $T$. V, figs. $7,8,9$ ), the upturned sides of which must naturally appear as two darker lines. After having observed several of these little boat-shaped bodies attached to the sexual organs described above, I became convinced that they must represent elongated and collapsed pollen grains. And in the same section I also noted finally a free, thin-walled, obtusely ovoid, and still distended body which may likewise represent a better conserved uncollapsed pollen grain.

"If, as I interpret them, these bodies are actually pollen (and any one may judge this probability for himself by an examination of the original sections which are preserved at Bologna), they lead up to notable results. Because of the complete inclosing of the flower-bearing spadix by the tightly appressed bracts, as still further held in place by the surrounding leaf bases of the armor, it appears quite impossible that anther fragments could have found their way into the position of the interior cavity. One seems obliged to believe in this case that these anthers must have grown in the very place and position where found.

"We saw that every peduncle (Blüthenstiel) was apically branched into a tuft, these tufts forming a complete outer layer. Can they not have borne apically set anthers? As to whether the flowers of the spadix were male, hermaphrodite, or unisexual and interspersed is immaterial, it only being necessary to assume a protandrous development of the whole. And if perchance the fruit of Bennettites Gibsonianus was likewise in its earlier stages beset by similar staminate organs, these must also have been attached to the external areoles. The interstitial organs of the whole tuft- or bundlelike fruit which unite to form its exterior layer would then represent filaments."

The memoir from which this excerpt was taken was published only in Italian, and no part of it has hitherto appeared in English. I may explain that I have made this translation directly from Count Solms's original German manuscript, which was several years since presented by Senator Capellini to Professor Ward, who kindly loaned it to me.

The first American contribution on the fructification of the Cycadeoideæ was based upon a beautiful pollen-bearing strobilus borne by the superb Black Hawk trunk which was made by Professor Ward the type of his Cycadeoidea ingens. This strobilus projected well above the armor near the summit, as indicated in plate $I$. Being such a conspicuous object, and terminating above the summit of the bracts as a small circular eroded area curiously divided into thirteen nearly equal sectors, indicating unknown structure, the axis was one of the first objects selected for study when the writer began his investigation of the fossil cyads. As removed with most of the surrounding involucre of inclosing bracts, for cutting, the fructification was apparently solidly silicified and somewhat barrel-shaped, the length, including a considerable portion of the peduncle, being $73 \mathrm{~mm}$., and the basal, middle, and apical diameters 35,45 , and $25 \mathrm{~mm}$, respectively. When sawn through longitudinally the center was found to be occupied by a pear-shaped cavity lined by a quartz druse, while in all the large space between this central cavity and a denser zone resting against the sharply defined inclosing hairy bracts one conld plainly see the closely packed and regularly grouped Marattic-like synangia. The entire 
object was one of great beauty, and it was at once evident that the essential organs and structure of staminate fructification in the Cycadeoidex had at last been discovered.

The results of the writer's earlier study of this flower were published in the American Journal of Science for March, I899 (187). But that it was bisporangiate was not at once appreciated, although in a small area on the border of the crystallined cavity just mentioned a palisade-like structure of light-colored and chalcedonized material was noted, and at first regarded as an accident of silicification. Had we fully known how to interpret the evidence this would have been recognized as a portion of the apical ovulate strobilus which had originally occupied approximately the position of the druse-lined central cavity. The synangia-bearing axis was, however, correctly regarded as a disk composed of a series of fused fronds with their fertile pinnules turned inward, and the distribution of the synangia was described. Also their Marattiaceous structure was pointed out, as well as the exceedingly clear additional evidence which this unique type of fructification offered in favor of the current belief in the direct descent of the cycads from such tree ferns as the Marattiaceæ.

In conclusion, the writer said:

"It has probably been the opinion of all botanists, since it was discovered that Stangeria paradoxa is a cycad, and not a tree fern as originally described, that the relationship between the ferns and cycads must be an exceedingly close one. All later investigations have tended to strengthen this belief, and Scott has recently stated that the evidence in favor of filicinean ancestry of the Cycadeæ must now be considered 'overwhelming.' It was scarcely to be expected, however, that forms bearing strong testimony on this point should display such a marked combination of advanced as well as ancestral characters."

The next important step, the discovery of the bisporangiate character of male fructification and the strong possibility of bisexuality in some of the Cycadeoider, was made by the writer as soon as study was directed to the Minnekahta specimens, of which many were added to the Yale collection early in I899. 'These new observations, first made in the previous year, were briefly announced in the Yale Scientific Monthly for March, I900, at which time a somewhat extended examination of bisporangiate axes had already been made, but were not more fully discussed until June of the following year, when the subject was again resumed in the writer's paper on the microsporangiate fructification of Cycadeoidea (192). In this contribution a general statement of the results of the writer's study of fructification in Cycadeoidea was given. 'The bisporangiate strobilus of Cycadeoidea dacotensis was described, and the earliest statements as to disk organization and the Marattiacean structure of the sori or synangia fully verified, it being proved that, barring the fact of their pollen-bearing function, there was a cioser agreement with the synangia of Marattia than with those of any other known genus, living or extinct. The true nature of Williamsonia was indicated, it being made wholly clear that the "disks" from the Yorkshire coast, described by Willianson, must mostly be not "carpellary," but staminate, and identical in all essential characters with the staminate disks of the bisporangiate strobili from the Black Hills. Furthermore, it was pointed ont that 
the important structural unit in this new type of fructification was a true staminate frond, and it was also concluded that while the staminate disk surrounding an ovulate axis indicated primarily an evolution terninating, so far as then possible to trace, in the gymnosperms, the juxtaposition of parts was essentially angiospermous as well; although this latter conclusion had been foreshadowed by Saporta on the basis of the fact that the ovules of forms like Bennettiles were embedded in a coherent pericarp of expanded tips of interseminal scales. This was, then, the first time that reasonably conclusive evidence was offered concerning forms suggesting a possible method of reduction by which angiosperm evolution could have proceeded from a pteridophytic and indeed a filicinean ancestry; it being obvious that further reduction and specialization of parts in some such generalized type like the bisporangiate strobilus of Cycadeoidea could result in a bisexual angiospermous flower. Liviodendron, it was suggested for the sake of a definite point of view, might perchance have been in this way derived from some separate and remote filicinean ancestry.

\section{ORGANIZATION OF THE BISPORANCIATE STROBILUS OF THE CYCADEOIDEÆ.} MATERIALS.

The well-known structureless casts and imprints of dissociated Williamsonia disks, as now seen to agree with the silicified forms here discussed, are likely to be met with wherever plant-bearing strata of Mesozoic age occur on the globe. But, with the sole exception of the pollen-bearing fruit of Cycadeoidea etrusca, all the cycadeoidean material exhibiting male fructification with structure preserved has been derived from three much-restricted localities in the Black Hills. These are the "rim" hills, northwest of Sundance, Wyoming, and the Black Hawk and Minnekahta localities in South Dakota. From the first of these points only a single specimen has been obtained. From the Black Hawk locality have come several pollen-bearing Cycadeoidea Jenneyana trunks, and the type of C. ingens, as mentioned above; but the great majority, as well as the best preserved forms, are from Minnekahta. In all, about twenty-five trunks with one or more unexpanded and nearly mature pollen-bearing fruits are known, and the writer has had the opportunity to examine with more or less thoroughness all of this material. Fortunately too, nearly all the fruits illustrating staminate growth in the Cycarleoidex are preserved with an exquisite beanty and fidelity of detail that yields the most accurate and vivid conception of the organization of these long-extinct floral types, as well as of the appearance they must have presented in life when maturing on their parent trunks in the late Jurassic and early Cretaceous forests.

As described in the present chapter, the bisporangiate strobilus of Cycadeoidea as found in the silicified condition is borne on a short peduncle laterally emergent between the old leaf bases, and consists in a central and terminal ovulat: a cone, a surrounding hypogynous staminate disk of basally adnate, once-pinnate, synangiabearing fronds and an outer series of hairy overlapping and inclosing bracts. It is next in order to take up the detailed study of these several features as obse-ved in the best conserved forms, namely, the wonderfully preserved and abundantly represented male inflorescence of Cycadeoidea dacotensis. Afterwards other staninate forms will be described. 


\section{CYCADEOIDEA DACOTENSIS.}

(T. 2I4. Figure I4, and Plate Vi, Photograph 12.)

The descriptions which follow are based primarily on serial sections cut from two bisporangiate axes borne by Yale cycad No. 2I4, and a third likewise wonderfully preserved strobilus borne by a superb branching trunk of the same species in the collection of the State University of Iowa. The latter strobilus was cut in the fall of I900, with the kind permission of Professor Thomas H. Macbride, who originally collected the specimen to which it belongs. For the form and characters of these strobili consult plates XXXIV-XLV, where the photographs of the full series of thin sections cut from them are shown. As clearly seen in the plates and complementary text-figures, a nearly mature stage of staminate growth is indicated in each of these cones, structure and preservation also being remarkably alike in all three.

In Chapter VIII a brief description of the fruit-bearing habitus of trunk 2 I 4 is given, in connection with a consideration of various ovulate cones it bears. Here, however, for the purpose of limiting the present topic, only the structures of the remarkably preserved bisporangiate axes numbered I and III are taken up. These flower buds are almost identical in size and most features of preservation, and are illustrated by various photographs of plates xxxivxxxvir, and the accompanying text-figures. In addition, the

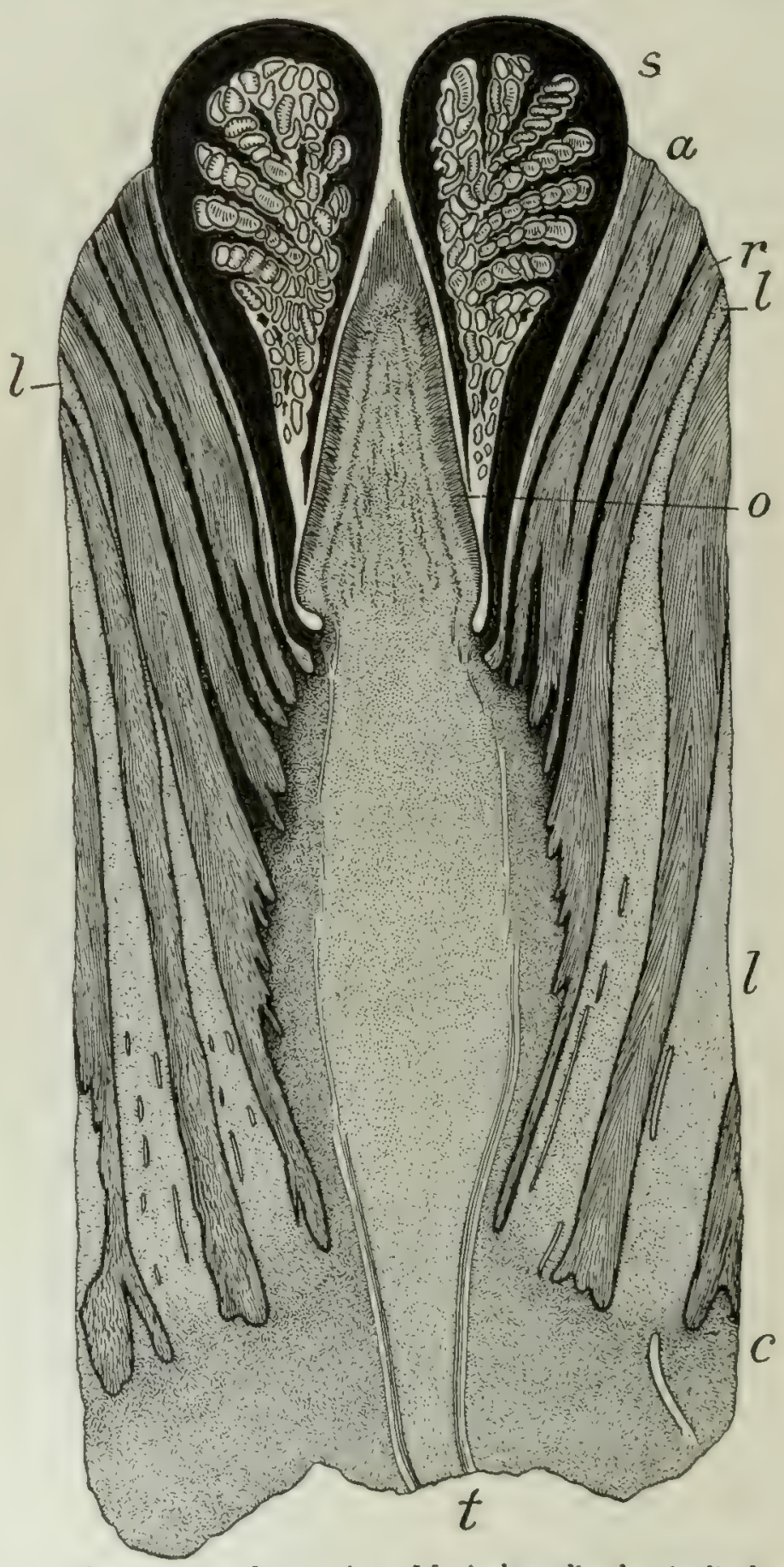

Fig. 71.-Cycadeoidea dacotensis. Vertical median longitudinal section of bisporangiate strobilus in' the same stage of growth as shown in figure 70. All of the peduncle, with the surrounding leaf bases and bracts, are drawn in the natural size from section 515 , shown in photograph 4, Plate XXXIX. But as the strobilar portion of that fructification is imperfectly preserved; the ovulate cone and microsporophylls are drawn from several other sections of similar strobili. s, Once-deflexed microsporophyll; o, ovulate cone; a, eroded outer border line of armor and bracts, or trunk surface; r, ramentum between outermost bracts and adjacent leaf base; $\mathrm{l}$, leaf base; $\mathrm{c}$, cortex; $\mathrm{t}$, peduncle bundle trace. very fine pollen-bearing fruit of this same species from the State University of Iowa collection just mentioned duplicates and confirms every structural detail, as illus- 
trated in plates xxxrv and xxxv, and especially in text-figure 74. These bisporangiate strobili, as shown in longitudinal section in figure 7I, are seated on the stem axillary to one or several leaf bases, with their yet folded staminate fronds enveloped by the numerous imbricating bracts. They are from 5 to $10 \mathrm{~cm}$. in diameter, this measurement often being much greater in the lateral direction, as the result of

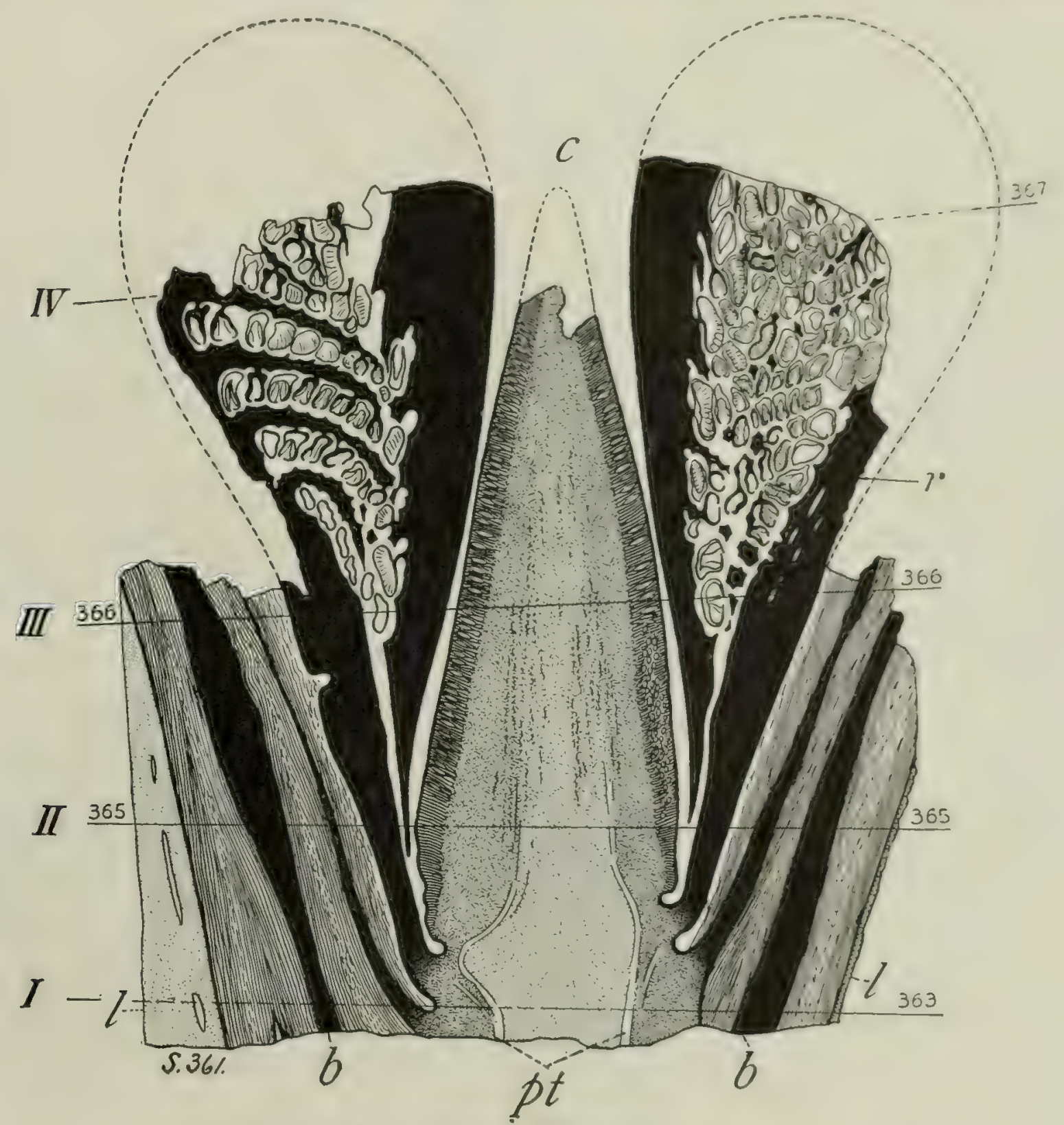

Fig. 72.-Cycadeoidea dacotensis. T. 214.

Bisporangiate strobilus in longitudinal section. A composite but in every respect exact figure drawn from the two faralle! sections, S. 360 and 361 . That on which the portion of the figure to the left is based cuts the incurved synangia.tearing pinnules throughout their entire length, while the staminate frond to the right is cut $\mathrm{cn}$ a sligt.lly diferent rlare, so it at caly. the closely packed synangia appear. Only the ascending and descending portions of the rachides of the staminate frords are preserved, the part not preserved being indicated in dotted outline. (Compare with pholograph I, Plate XXXVI.)

1. 1. Leaf bases originally close together but thrust apart by the emergence of the bract-enveloped strcbilus: b, b, kracts: pt, peduncle bundle traces which send branches into the hypogynous staminate disk and then pass on into the ovulate cone: c, the summit of the central ovulate cone, which may have been prolonged into a long terminal tuft of hair-like scaies. Nos. 363.365-367 [or I-IV respectively], position of serial sections shown in figure 73.

compression, and their length from summit to cortex is about I 2 cn1., of which the peduncle takes up about half. The upper two-thirds of the lateral surface of the peduncle bears the bracts in rather close spiral succession, and from Ioo to I 50 in number, as may be seen in transverse section (fig. 75 , etc.). The bract tips are not 
usually preserved, but in the case of other and younger axes they are sometimes quite complete. The entire series of hairy bracts covers the fruit at the surface of the armor to a depth of from I to $2 \mathrm{~cm}$. in the vertical direction to the trunk, to 2 or $3 \mathrm{~cm}$. in the lateral and less compressed direction. The diameter of the unexpanded fruit proper is from 3 to $3.5 \mathrm{~cm}$, and its length, as stated, $6 \mathrm{~cm}$., or about the same as that of the peduncle. The outline of the mass of unexpanded staminate fronds, as once-deflexed and closely folded and packed about the ovulate cone, is that of a robust pear; and this is also, as already seen, that of a well-grown ovulate strobilus of the present, or a very closely allied species, shown in figure 67 . That both the staminate and ovulate forms should successively assume this same ontline served to economize space in the production of fruits within restricted limits, tightly wedged in between the old leaf bases of the armor as these were.

\section{PEDUNCLE.}

The outlines of the peduncle readily appear to view when the serial figures 73 and 75 are examined, the peduncles near the summit of the trunk being, however, less flattened in the vertical direction than those borne lower down. 'The structure is, as in the case of the ovulate cones Fig. 73. - Cycadeoidea dacotensis. Serial transverse sections, 363, 365. 367, from the bisporangiate strobilus (III), T. 214. Enlarged twice. For exact position see figure 72 .

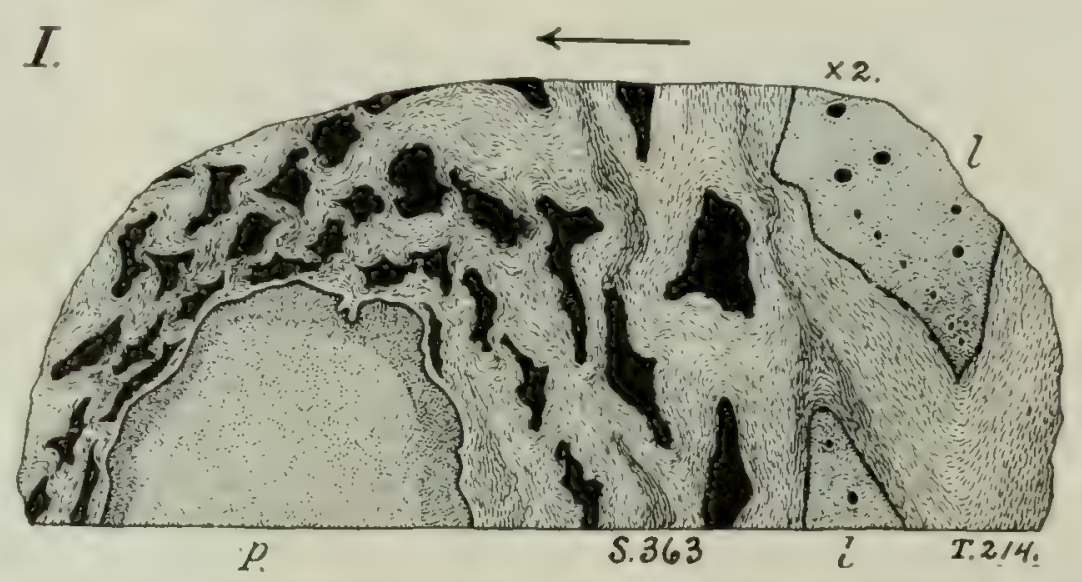

S. 363 cuts the upper end of the peduncle (p), the bracts (shown in solid black), and several leaf bases (1). As also indicated by the leaf-base bundles, the arrow shows direction vertical to the trunk which bears the strobilus.

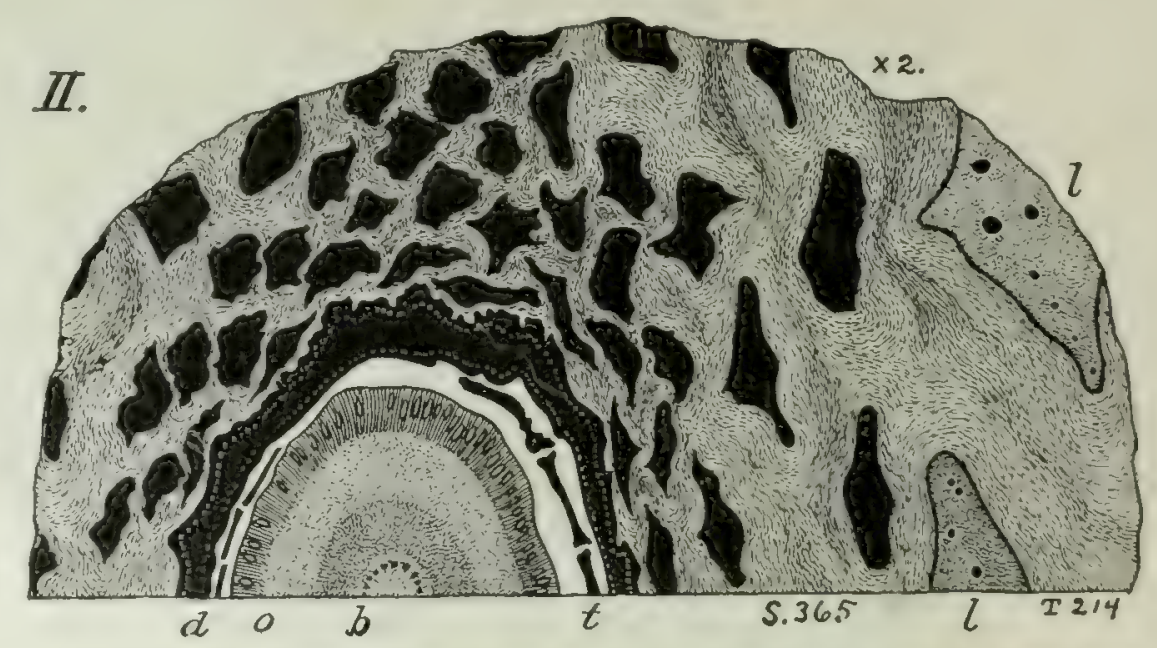

S. 365 cuts the lower portion of the ovulate cone (o), the frond tips $(t)$, and their fused bases forming a continuous disk (d), surrounded by the very numerous bracts; (b) is the bundle ring or cylinder of the cone. See continuation of these figures on next page.

described, a repetition on a minor scale of that of the trunk, the central woody cylinder giving off small bundle traces, which pass out directly to the bracts and staminate fronds instead of to leaf bases.

\section{BRACTS.}

These are of the same essential structure already described from the ovulate cones of the Bemettites Gibsonianus and B. Moricrei type, though larger and with a very long ramental covering corresponding to their larger size. Although the bract hairs and general outlines are nearly always clearly indicated, as a rule, the cell structure is not preserved in the severai bisporangiate axes thus far studied, 
and, being present in a few instances only, has scarcely been observed in longitudinal sections, which cut only a few bracts. But in the transverse sections, owing to the considerable number of bracts cut, preservation is more frequently observed, and in such cases found to agree with that of similar bract sections from large and simply ovulate cones.

\section{OVULATE CONE.}

The central ovulate cone is of elongate conical form, its height being $4 \mathrm{~cm}$. and the basal diameter about $1.5 \mathrm{~cm}$. The gently sloping lateral surface ends in a rounded tip, sometimes extended as a bushy mass of interseminal scales. As seen

Fig. 73-Continued.

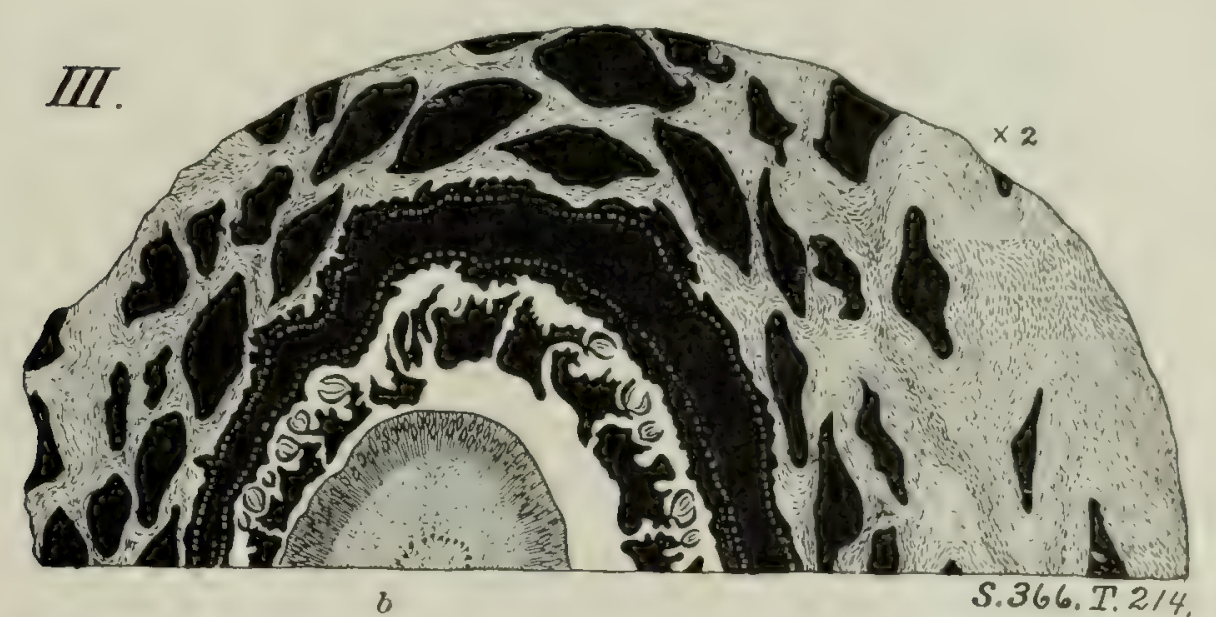

S. 366 cuts middle of ovulate cone and the fertile decurved tips of the staminate fronds, which at this height still fuse basally to form the campanulate disk.

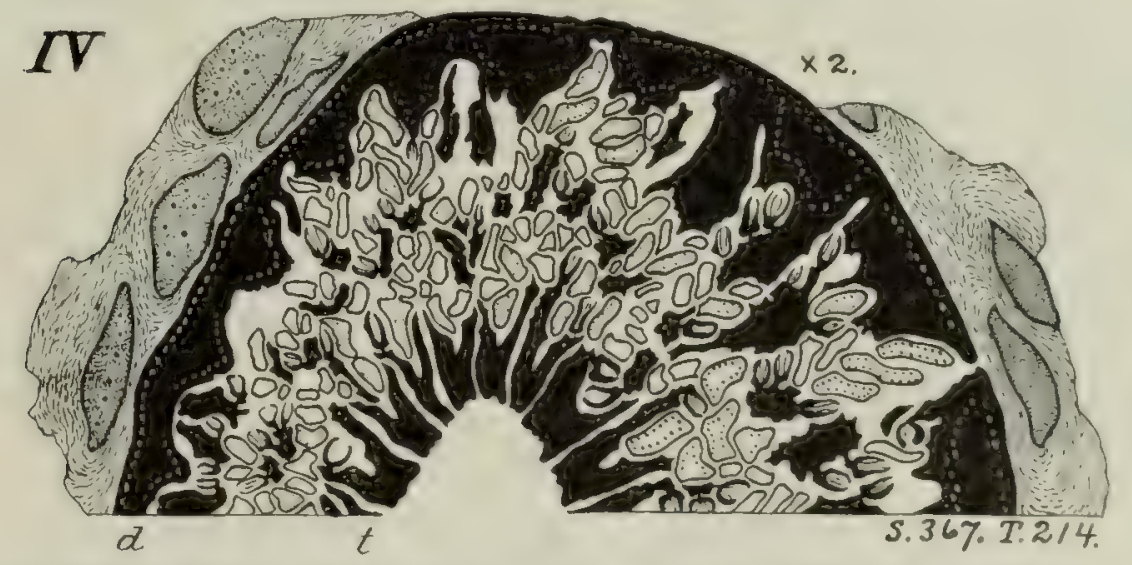

S. 367 passes just above summit of ovulate cone, and shows the disk beginning to divide into separate fronds, the tips of which ( 1 ) are much compressed laterally. O wing as much to slight obliquity of the section as to irregularity of the disk, division into fronds is not equal on both sides. (For relative position in longitudinal section see fig. 72.) in both transverse and longitudinal sections the central cone bears an ovillate zone entirely similar in general appearance to the ovulate region in various diskless ovulate cones in very early stages of growth, from which, to the nearly or fully mature ovulate cones, there is a reasonably connected series. Necessarily in so young a stage the cell structure of the seed pedicels and their apical orulate region with the intervening scales would be too imperfectly defined for fully. distinct preservation, although the general outlines of these organs are clearly present. 'The ovinlate zone is seen to be about 0.6 1mm. in deptl,

and the integumental, nucellar, hilum, and funicular regions of the minute seeds may be clearly distinguished in some instances, as shown in figure 72. Likewise there is clearly present the usual development and arrangement of incerseminal scales with the more or less expanded tips seen in the younger seed-bearing cones. Just at its summit the cone presents a brush-like appearance in longitudinal sections, due to crowding and elongation of the interseminal scales, there being no ovules interspersed for a distance of several millineters down the sides of the cone. Also at the base of the cone for a distance of a centimeter up its side there are interseminal scales only, the lowermost being short, with gradual increase to the 
normal length where the scales surround the lowermost normal-sized ovules. It is also noteworthy that these basal interseminal scales are largely composed of reticulate to scalariform tracheids, much as in the older ovulate cones of the very different species C. Wielandi. The length of the sporophylls and interseminal scales covering all the lateral surface of the cone between the basal seed-bearing region and apical-scale region-that is to say, over a lateral zone with a height of $25 \mathrm{~mm}$.is about $\mathrm{I} .5 \mathrm{~mm}$. and markedly uniform. It may be said that on a free and uneroded surface of one of these cones, precisely the same characteristic pattern as in other and larger ovulate cones would be found present. And, indeed, it is of much interest to observe that were there any especial need for a preparation showing these features, one could be readily made, because of the fact that between the decurved tips of the staminate fronds and the lateral surface of the cone there is usually a layer of clear silica fully $0.5 \mathrm{~mm}$. in thickness, as may be noted in plates Xxxv and xxxyI, photograph 2. Since the tips of the minute interseminal scales and the young micropylar tubes project into this clear silica but not nearly through it, it must be perfectly feasible to saw and polish down nearly to the outer surface of the cone and thus isolate absolutely perfect and uneroded examples. As some of the cones have a clear and resinous rather than a dark surface, every feature of surface sculpturing must stand out with absolute clearness in such a preparation; for even in the case of transverse sections the band of clear silica permits one to see somewhat beneath the surface, and get a glimpse of what would be clearly shown by an isolated cone. (In the case of older ovulate cones there is often so much apical fracture, or, together with basal fluting, such a close appression of hairy bracts, that a sharply delimited surface and perfect result like that just described could but rarely be secured.)

The ground tissue of the elongate and conical termination of the peduncle or "cushion" of the ovulate cone, or, more properly, the receptacle which bears the zone of seed stems, is not well preserved, although the general structural features are clearly indicated. There is first a central regularly disposed system of anastomosing guin ducts, and, secondly, the main conductive system, indicated by strands of well-preserved xylem, which extend in cylindrical order throughout the length of the cone and thus form a continuation of the woody cylinder of the peduncle. In these strands or bundles, however, the xylem elements are not radially arranged. The cylindrically disposed bundles as they take their course throughout the length of the cone send out towards the bases of the seed stems and interseminal scales great numbers of smaller traces, doubtless regularly arranged. The number of cells in each larger strand of the main bundle cylinder as cut transversely is twenty, more or less (see fig. $80 \mathrm{a}$ ). In longitudinal sections the strands are seen to consist almost entirely of scalariform cells, with some spiral forms, being structurally similar to the bundles from the corresponding portion of an ovulate cone shown in figure $80 b$. Just exactly what phloem cells were present is not clear, although there are some slight indications in the way of coloration and texture which indicate a main phloem mass distal to xylem. But whatever may have been the extent of phloem development, it is to be noted that in the examples before us there was 
no distinct tendency to preservation of the soft tissues of the receptacular region. While the smaller xylem elements may occur within the main group of xylem cells, they are a little more abundant at the inner angle in the normal proto-xylem position. As the spiral elements are small and all so distinctly marked and unstretched, these bundles may be regarded as young. 'The structures preserved show well the immature condition of the central cone, and indicate that it conld not have been close-fertilized, unless the pollen of the accompanying fronds retained
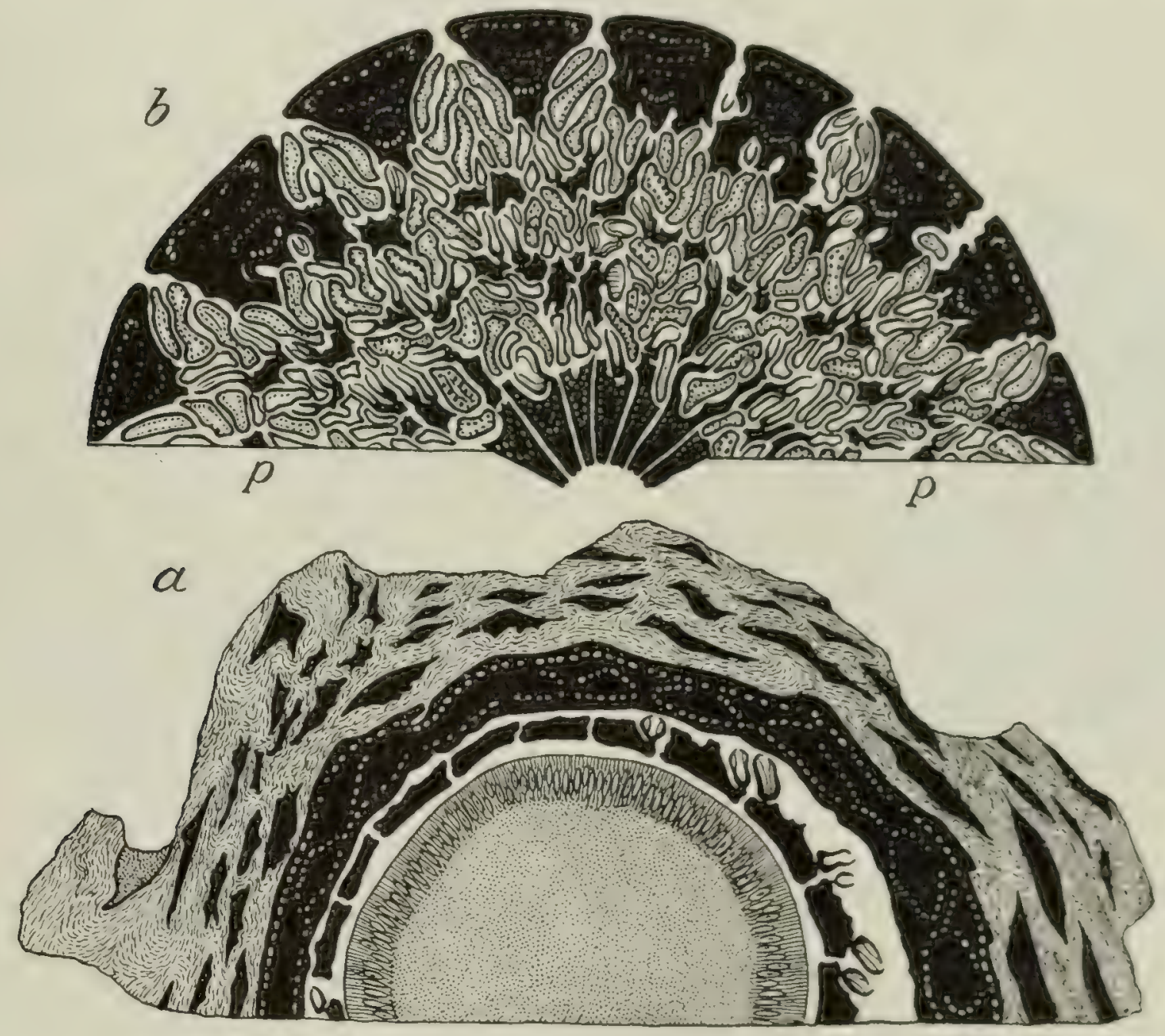

Fig. 74. - Cycadeoidea dacolensis.

Two transverse sections from a bisporangiate strobilus with a quite complete summit, the upper section being cut above the

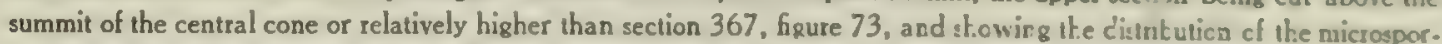
ophylls and their bundle system 3 with diagrammatic clearness. The lower section, which is nearly intermediate in rela tive position between sections 365 and 366 , figure 73 , shows the double row of bundles as seen in the disk base to be breaking up into the separate frond patterns. The exquisitely handsome sections from which these drawings were made belong to the museum of the State University of lowa. (See the photographs I, I a, Plate XXXV.)

its vitality for months after being shed, as does the polien of living cycads, assuming, of course, that the ovules are not abortive, but simply young, as indicated by comparison of various forms of young fructifications described in the nexi chapter. The considerable time gap between the maturation of pollen and orules may have made cross-fertilization the rule in these bisexual flowers.

\section{THE STAMINATE DISK.}

In all its essential structures the staminate disk is new to science, although in part, as we have already seen, long known in the form of isolated imprints of problematical function-sometimes held to be "carpellary," and sometimes apical and 
sterile. Since, therefore, these "disks" have been found as isolated structureless fossil casts or as imprints in so many different countries, an exact knowledge of their form and anatomy is not only of biologic importance, but enables us greatly to extend our knowledge of the distribution of the Cycadeoidex. In the examples on which we in the first instance base the present description, that is, on the flowers of Yale cycad 2I4, and the Iowa specimen, the central cones of which have just been described, the disk is still more or less strongly attached to the receptacular shoulder, just at the base of the cone, and is as yet unexpanded, although nearly mature and plainly approaching the time of expansion and dehiscence.
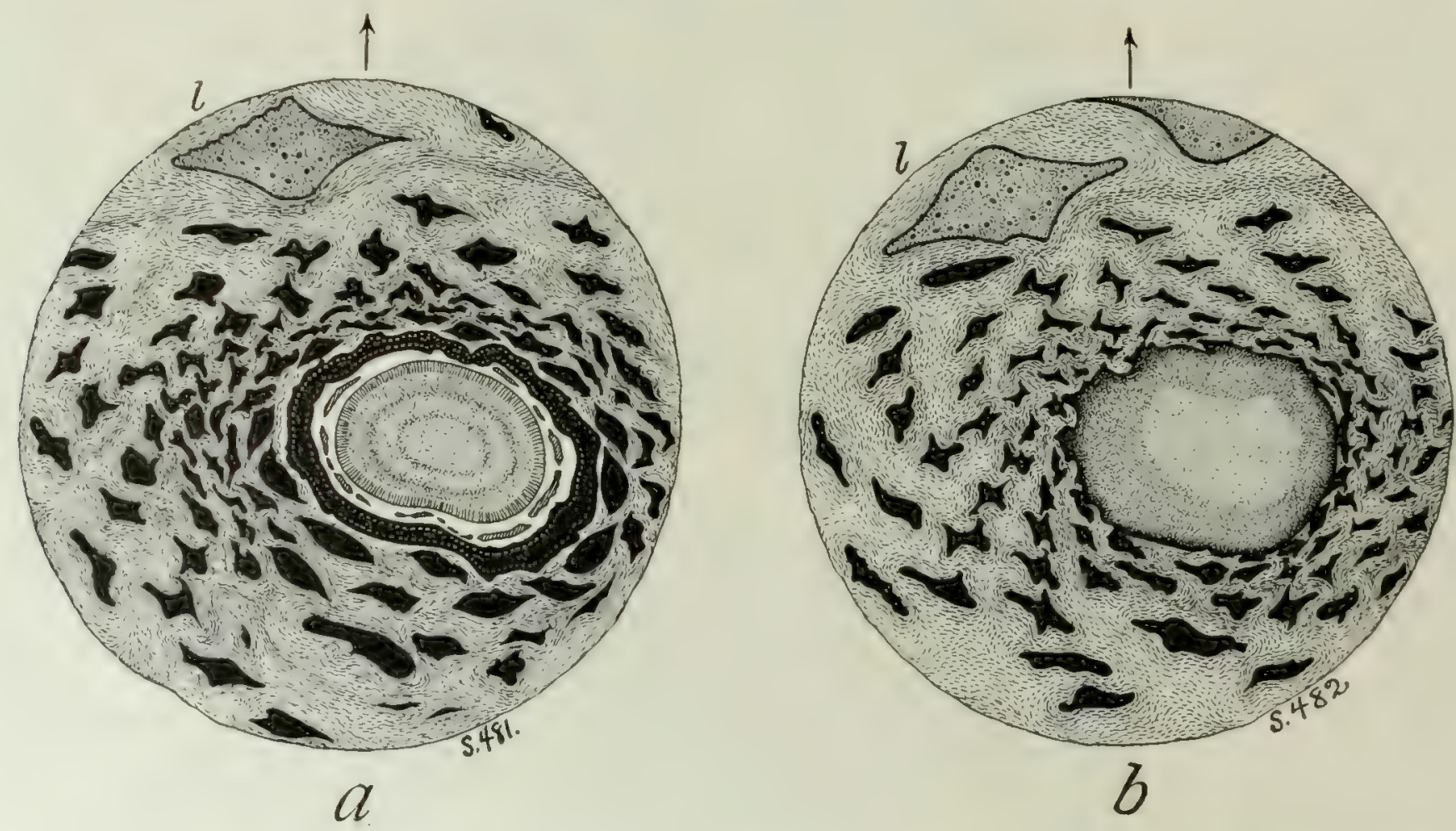

Fig, 75.-Cycadeoidea dacotensis. Fruit 1, Sections 481-484. T. 214. $\times 1 \frac{1}{3}$. Four successive transverse sections of a pollen-bearing bisporangiate strobilus cut from trunk in form of cylindrical core.

a. S. 481. This section cuts through the bract-enveloped staminate disk and the inclosed ovulate cone. At the center of the cone are traces of its bundle cylinder, and exteriorly the outer palisaded zone of interseminal scales and short seed stems about a millimeter in length. Between the cone and staminate disk a few of the decurved tips of staminate fronds are cut. The bundle system of the staminate disk is shown by the white dots in black ground color. The bracts are shown in solid black, and the only one of the surrounding leaf bases cut by the section in stippled surface, with its bundies as dots.

b. S. 482. Cut two centimeters (proximally) beneath the precedng section. In this section, which passes just beneath the insertion of the hypogynous staminate disk, nearly all the bracts appear, as well as two of the surrounding leaf bases.

If reference now be made to figures $72-75$, showing serially cut longitudinal and transverse sections, the general features of the non-expanded or preflorate disk will be apparent. In the longitudinal section a heavy petiolar and rachial axis $(r$, figure 72 ; rises from the base of the ovulate cone $(c)$ to some distance beyond its summit, and then curves inward and is once deflexed, so that the downwardly turned apical third of its length, which is at first narrow and then widens into a broad spatulate tip, rests on the surface of the central cone. Although the middle region of the rachis, that is, the part curving inward and then downward at the summit of the strobilus, is often eroded away, as the result of its being the highest and most exposed portion, the relations just described would clearly be seen to be the true ones, even if we did not know the intact disk of C. ingens type shown 
on plate III. In several of the present series of sections preservation of the middle region of the fronds forming the summit of the unexpanded strobilus is, lowever, nearly complete. The space interior to the once-deflexed fronds is densely. packed with well-developed synangia borne on slender pinnules, which are folded rankwise in the radial position in such a manner that it has been possible to carry the grinding of the median longitudinal section 360 to such a plane that all the fertile pinnules not only may clearly be seen attached to the rachial axis at regular intervals from its base to near its tip, but are mostly cut throughout their entire length, and alternate with rows of densely appressed synangia. But in this section only a few rows of synangia are seen attached, the most of the alternating rows being free, as clearly appears in photograph 2, plate xxxvI.
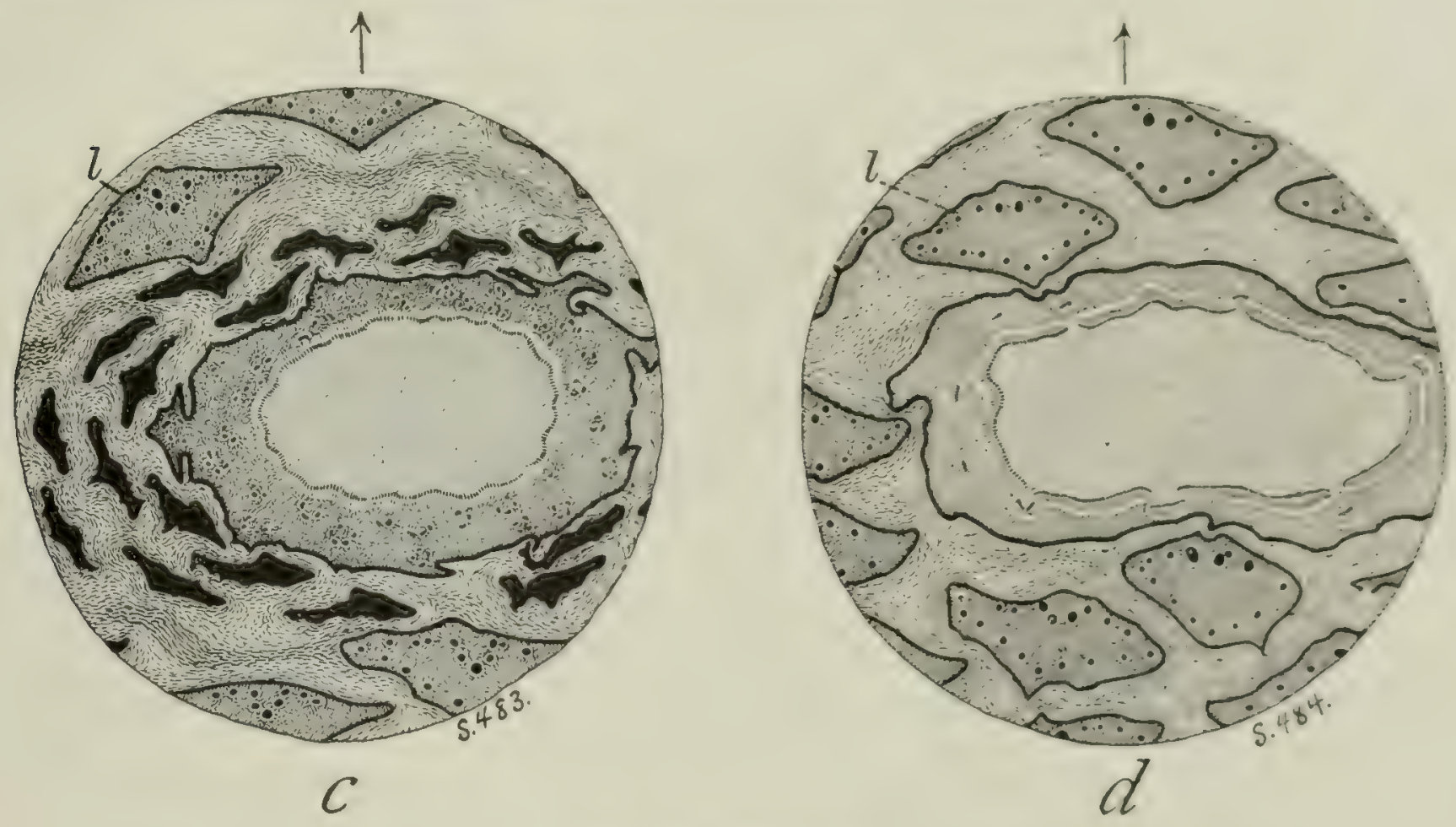

Fig. 75.-Continued.

c. S. 483, Cut 1.5 centimeters beneath S. 482, In this transverse section two additional leat bases are cut, or four in all, while only two rows-necessarily the lowermost-of the imbricating bracts appear. The peduncle is greally increased in size, and its woody cylinder clearly indicated, as well as the small bract-trace bundles which pass out through the peduncular cortex into the bracts. just as the leaf-trace bundles pass from the xylem of the trunk into the frond bases.

d. S. 484. Cut 1.5 centimeters beneath S. 483 and about a centimeter out from the insertion of the peduncle and leaf bases on the cortex. In this section only the leaf bases closely surround the broad, vertically compn sued peduacle. The peduacular medulla is large and the inclosing xylem zone only sends off a few lower and therefore outer bract traces.

Again, in making longitudinal section 36I (fig. 72) it has been possible to grind down to such a plane as to bring to view on the right side of the cone only the successive rows of synangia; while the rachial axis on both sides, as well as the sporophylls and rows of synangia on the left side, present the same general appearance as in the closely parallel preceding section, No. 360.

The sporophylls or fertile pinnules, as attached to the rachis, are not curved, but simply folded in radially at full length. Those borne by the ascending and incurved portion of the rachis droop more and more, while those of the deflexed part at first droop slightly downward and ontward, but as the summit is approached change their direction and are more and more upwadly tumed. Hence there is such a gradation of pinnule position from the base to the summit of the rachis 
that were the frond unfolded all the pinnules would lie in parallel succession in two ranks rising at the same angle to the respective rachides.

Let us now turn to the series of transverse sections cut from these same strobili, taking up, for convenience, first, the section cut basally just below the insertion of the ovulate cone and the surrounding staminate organs. (See fig. 73, I, and 75 b.) In this section it is seen that the receptacular region is not of large diameter and is followed exteriorly by the system of hairy bracts, and then by the leaf bases.

In the second transverse section, figure 73 , II, which is cut about I cm. above the strobilar insertion, the central cone is prominent, and all its parts well marked. Resting against it are the laterally oblong transverse sections of the free flattened rachidal tips, these being followed exteriorly by a broad annulus of deeply stained tissue. This latter is the transverse section of the peduncular region of the staminate series and shows at once in connection with the longitudinal sections just examined that the bases of the individual staminate organs are not free but fused into a heavy and strongly marked bell-shaped disk. Surrounding this are the copiously haired bracts, while exteriorly to these several leaf bases may also be noted. In

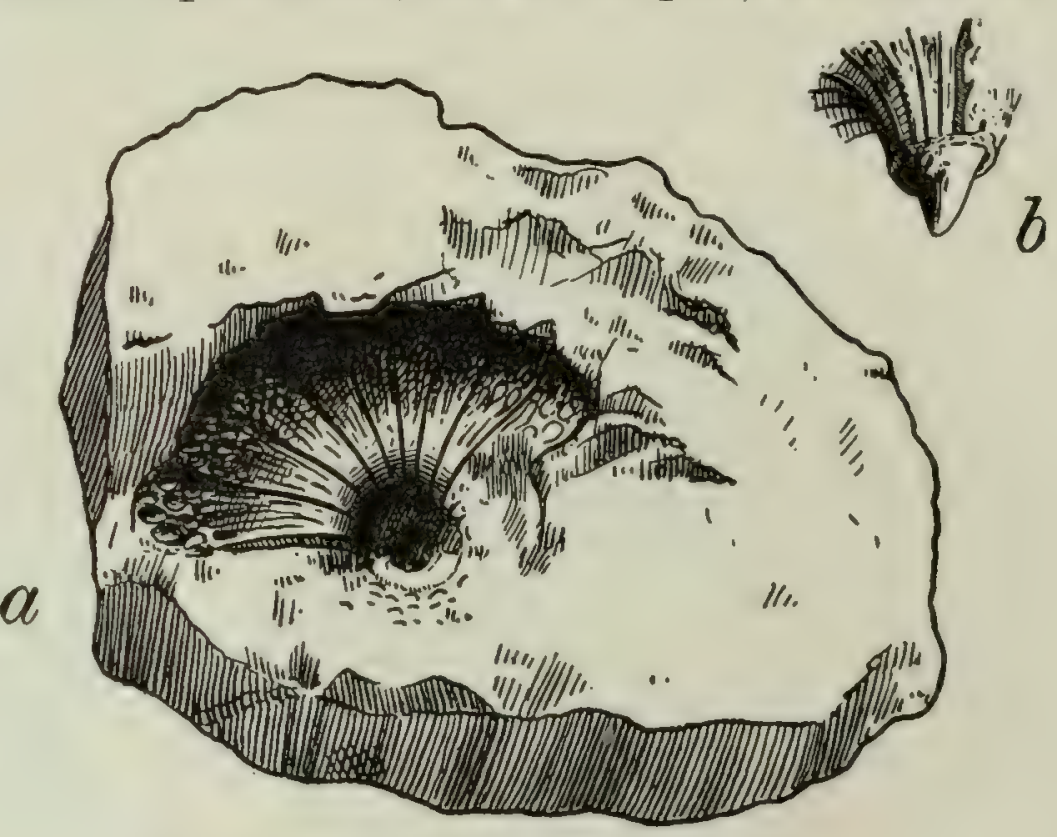

Fig. 76.-Williamsonia gigas. From Lignier (85). a. Specimen 2406 of the Paris Museum. $\times 2$. A bisporangiate strobilus showing apical portion of an ovulate cone surrounded by the regularly disposed unexpanded staminale fronds with the curved portion of their rachides broken away so as to expose the sori in undisturbed position. (See figures 70 and 88. .)

b. Cast of central portion of (a). This specimen is differently interpreted by Lignier, who adjudged the bodies here considered as sori to be seeds. the succeeding transverse section, figure 73, III, cut a centimeter above the preceding, the central cone is of markedly less diameter, and is succeeded by the laterally compressed irregularly rhombic transverse sections of the fertile frond ends, which mostly bear a single synangium on each outer (that is, ventral) angle. As thus ranged about the central cone these frond tips are 9 in number in the half circle, and show that the entire disk finally splits up into I 8 or I9 discrete fronds. The bases of these fronds are, however, in this, as in the preceding section, still strongly fused, and both the inner and outer borders are much wrinkled, showing that the disk surface was subject to irregular furrowing and crumpling during emergence. Exteriorly follow the bracts and leaf bases as before.

[In a hypothetical section $8 \mathrm{~mm}$. above III the general relations are the same, but it is especially to be noted that not only are the free tips of the fronds next the seed cone seen to bear synangia, but likewise an inner series of corresponding ridges of the still continuous base of the disk also bear synangia. The central cone is here cut near its summit and the tips of the fronds hence occupy a much smaller circle, and are more nearly rhombic in ontline.] In the succeeding section (fig. 73, IV), cut just beyond the tip of the central cone, and $4.5 \mathrm{~cm}$. above the receptacle, the 
relations are markedly different. The tips of the fronds are very much laterally: compressed, though still ranged close together in circular order. Their synangia are clearly set on much longer pedicels, so that there appears to be a median groove of the upper outer surface of the frond. The space occupied by synangia is markedly increased, and the transverse section of the campanulate disk base is no longer annular, but is partly split up into adjacent isosceles triangular segments, with their bases circularly arranged and their vertices corresponding to the inner disk ridges noted in the preceding section. The staminate disk, hence, plainly divides just above the summit of the central cone into a series of free fronds whose rachides are of isosceles triangular section, with the long base or flat side ontermost, although the adjacent rachides remain in close contact at their basal angles so as to form a closely set and compact flower bud. That in such a section as the present a few of the

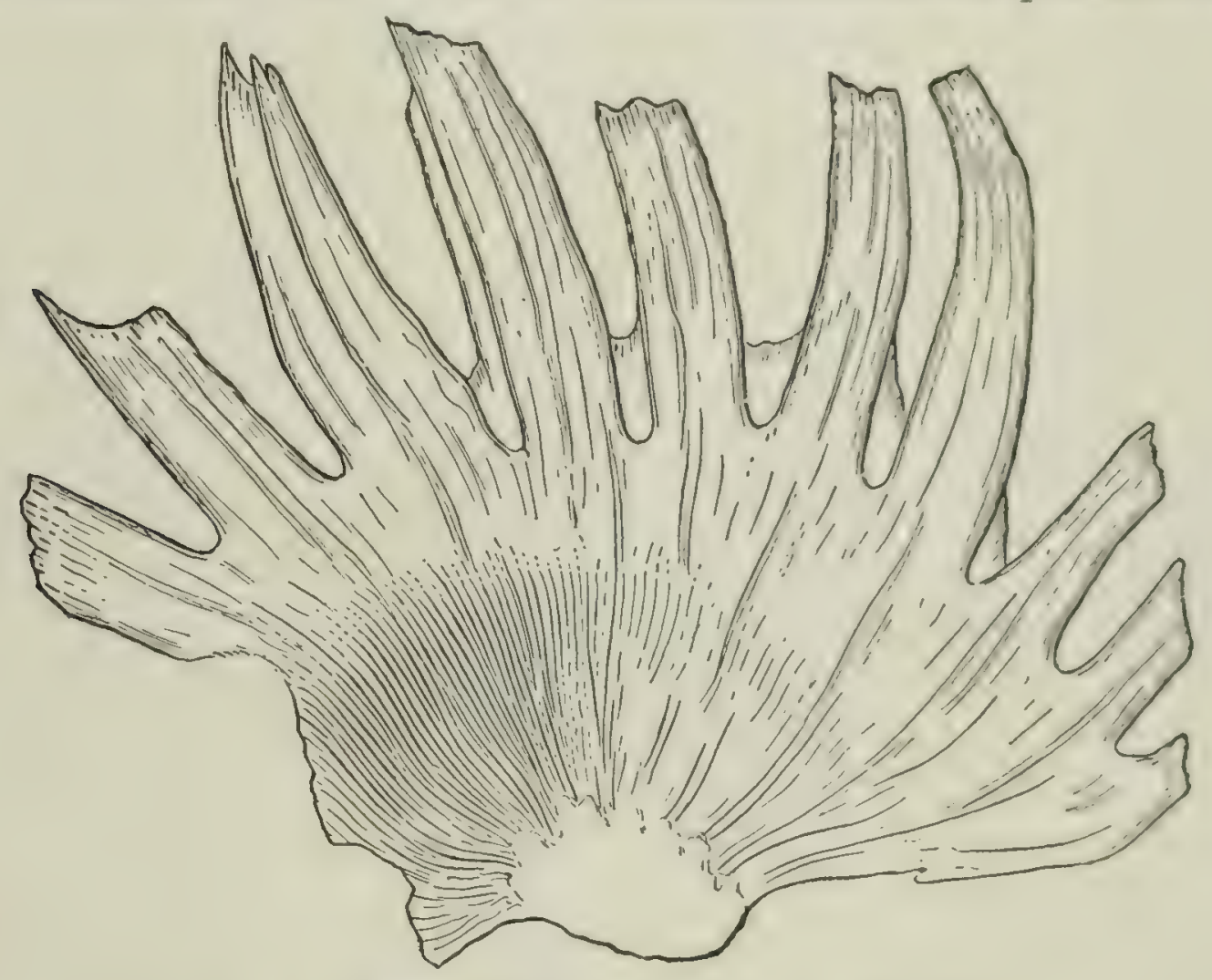

Fig. 77. -Williamsonia gigas (L. \& H.). Natural size.

A typical disk impression. If staminate, the pinnules were either very closely set or tehiscent From Seward's Jurassic Flora of Yorkshire, Part I, PI. VII, fig. I.

rachides are yet seen to be united, while others are free, may much rather be due to obliquity in cutting than to any lack of symmetry, but at the same time proves that the section closely indicates the exact height at which the disk splits up into discrete rachides. In these sections none of the tips of the fronds into which the dis? thus divides are absent, preservation in the normal unexpanded position being complete, except for the erosion of middle portions of rachides forming the apical region of the strobilus, as already mentioned.

The synangia are also preserved with great clearmess of outline and structure in normal form and position, and mostly form series of pairs arranged radially like successive $V_{S}$ set serially into each other in close order, with the arms of the Vs set distally and representing synangia. These radial rows of pairs of symangia alternate with the inner frond tips and their correspondingl petioles, and thus 
produce a very ornate appearance. Especially to be noted among the mass of synangia as thus distributed are the transverse sections of the successively cut pairs of slender sporophylls, figure $73, \mathrm{IV}$. In the succeeding section, cut well above the summit of the ovulate cone, and shown on plate Xxxvi, photograph $2 a$, the relations just noted do not change, except that all the rachides are free, though, as before, lying closely appressed and occupying all the available space to the extent even of more or less remodeling of adjacent parts, or formation of appression faces.

Obviously the great regularity of position and preservation in entirety of all these parts enables us to determine at once not only the form, but the attachment and number of the sporophylls, as well as the number and insertion of the synangia borne by each, thus making our conception of the form of the individual fronds and organization of the bisporangiate axis complete in every respect. In the first place, the successive transverse sections show the outline of each rachis throughout its entire length. The lower portion, after rising free from the disk, is triangularly

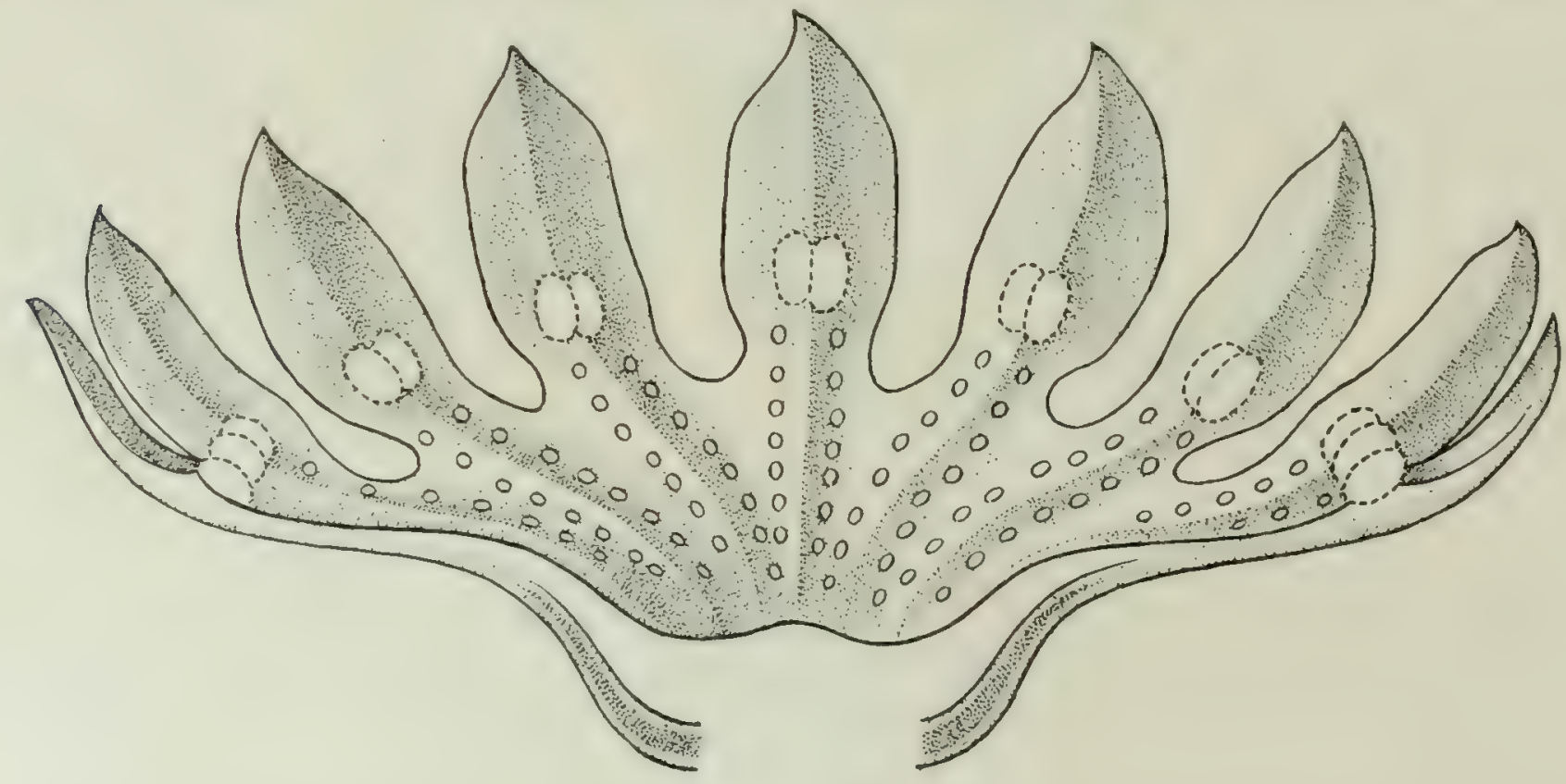

Fig. 78,-Zamia gigas.

"Restoration of half of carpellary disk, showing vascular exterior, superficial parenchyma, ovules in situ, and supposed abortive ovules." Enlarged about one-half. From Williamson, Trans. Linn. Soc., Vol. XXVI, 1870, Pls. 52, 53. For comparison with fig. 79.

prismatic, while the tip is at first laterally compressed and then expanded, this peculiar shape being chiefly due to the space arrangement of the floral parts and to the flattened ventral faces of the rachides which lie edge to edge, so as completely to inclose the central and conical ovulate axis, in the absolutely compact order so clearly shown in the restoration figure 70 and the companion sketch to the same (fig. 88).

The fact that sporophylls or filiciform pinnules are usually cut through their full length in longitudinal sections and are never seen to branch, and that in the transverse sections they are always cut in obliquely set pairs, shows that the frond is once-pinnate, with the pinnules alternating and folded back straight and distichonsly, exactly as are the pinnules of the similarly once-deflexed rachis of the oncepinnate young fronds of Zamia floridana. The fact that in longitudinal sections the synangia appear in rows, oftener nnattached than attached, while in transverse 
sections they appear in obliquely set interlocking pairs and are short-stalked, suggests that each filiform pinnule bears somewhat laterally two closely set distichous or alternate rows of synangia. This lateral attachment of virtually sessile synangia, as well as the very regular outlines of the fertile pinnules, however, appears with diagrammatic clearness in the tangential section shown in plate xxxvir, plotograph 2. Each frond, including the basally fused peduncle, is about ro cm. in length in $C$. dacotensis, and a little less in $C$. ingens, the number of pairs of alternate pinnules in both species being about twenty, including the barren basal and apical pinnules. The longest pinnules are $\mathrm{r} .5 \mathrm{~cm}$, in length, bear about twenty synangia, ten in each lateral row, and are borme just beyond the middle region of the frond, which, when expanded, must hence have been of typically filicinean appear-

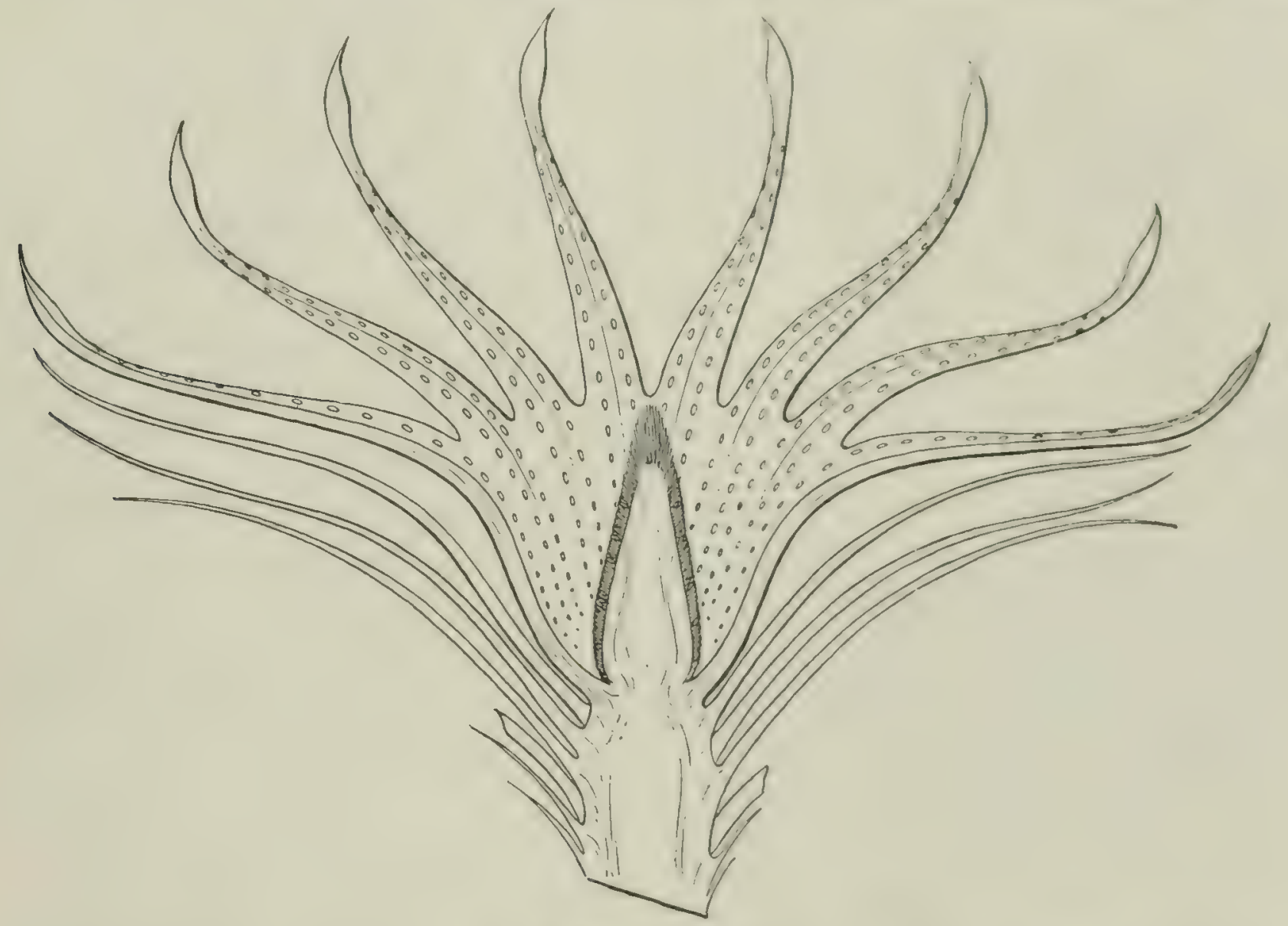

Fig. 79.-Cycadeoidea.

Bisporangiate strobilus, showing how the scars left by hypothetically dehiscent pinnules of the staminate fronds might produce the features represented in Williamson"s "carpellary disk." (See preceding figure.)

ance. Moreover, such a frond could readily result from the reduction of a bipinnate form, each synangium then representing a reduced leaflet.

EXPANDED STROBILI.

The expanded form of a flower such as that described is not difficult to conceive, and in the frontispiece to this section a reconstruction is given which, though based on a species with fewer fronds, doubtless very well represents the general appearance of the strobilus at the time of the shedding of pollen. In this restoration, however, the surrounding armor of old leaf bases is imagined as arbitrarily removed, contrary to the fact that since the peduncles did not elongate, only the distal half of the fronds could emerge when shedding their pollen. 
The curvature of the free rachides one readily imagines from the behavior of those of the once-inflexed foliage fronds of Zamia or the fertile carpels of Cycas. No doubt the drooping pinnules moved forward about the same time that the synangia began to dehisce. There is also a strong presumption that the pinnules were fugacious, leaving their scars on the rachides at the same time that the disk split away from its axis. This would account for Williamson's statements concerning the disk markings seen in figure 78 (202, fig. 2, pl. 53), with the exception of the supposed seeds. Dehiscent feri pinnules would leave such scars, and in spite of the fact that other observers have not confirmed Willianson's statements, it would seem quite probable that he did see sufficient evidence to justify most of the details he has figured. The general appearance which one of the present

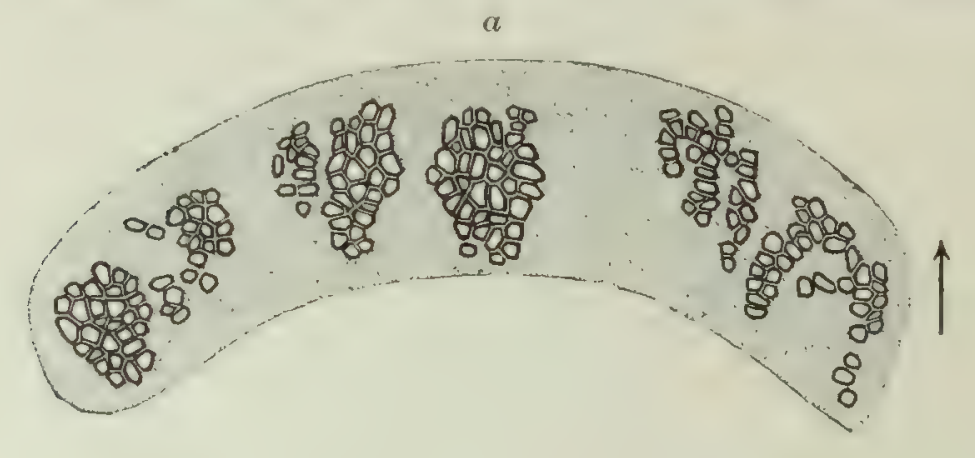

c
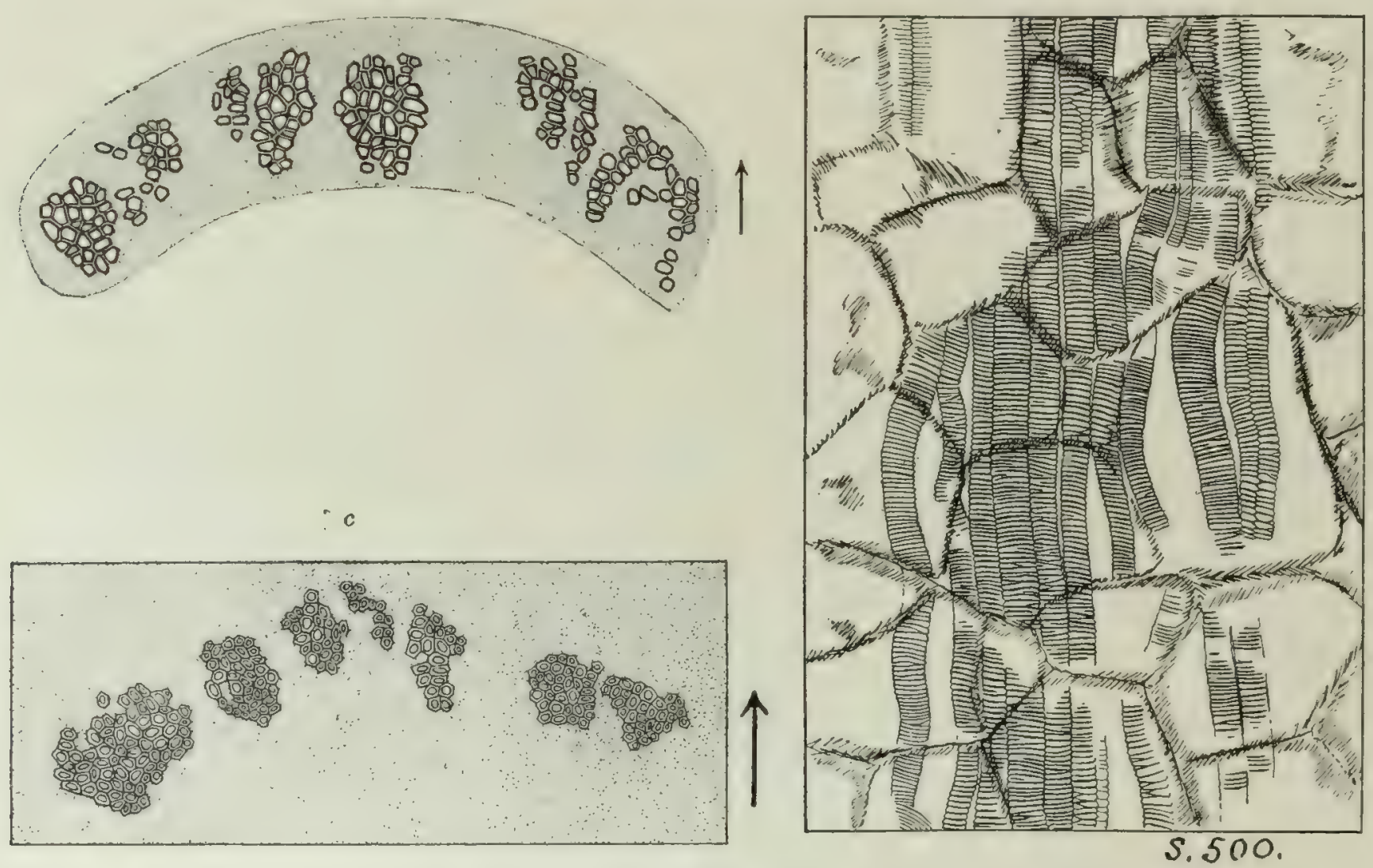

Fig. 80.-Cycadeoidea dacotensis. Bundle systems of the ovulate cone and fronds of bisporangiate strobilus.

a. Transverse section of the woody cylinder of receptacular region of cone of strobilus in bisporangiate stage, showing disposition of bundles, mainly indicated by groups of scalariform cells believed to be the centripetal elements of a mesarch system like that of Lyginodendron.

$\times 150$. For the corresponding longitudinal section see (b), from larger ovulate cone, which has doublless shed its staminate disk.

b. Longitudinal section through the woody cylinder of the receptacular region of the cone shown on Plate XL. X 100. A series of scalari-

form tracheids is seen to traverse a coarse secondary granulation of the siliceous groundmass. These tracheids are similar to those of the central ovulate cone of the bisporangiate axes actually bearing staminate disks, and are possibly centripetal wood only, corresponding to that of the mesarch stem bundles of Lyginodendron. The preceding figure is that of the transverse section of the corresponding cy linder of a cone from a bisporangiate axis in which the tracheids are much younger and smaller.

c. Transverse section throcigh the superior region of the rachis of a sporophyll, showing xylem elements of bundles only. As in the preceding

bundles from ovulate cones, mainly scalariform elements are preserved. $\times 60$. For entire sporophyll bundle patterns see figure 74 .

disks would present, if its pinnules were to dehisce, is shown in figure 79, and the striking similarity to Williamson's figure requires no further comment in the absence of precisely the specimens Williamson originally had before him. The French specimen, figure 76 , is also suggestive in the present connection. It appears that the Williamsonia disks were borne on long peduncles. At least it is clear that if any of these strobili were borne on peduncles longer than the old leaf bases, the decidedly flower-like appearance indicated in figure 54 would be presented at maturity, and that such flowers would scarcely be preserved at all, unless as detached and isolated imprints. 
HISTOLOGICAL DETAILS.

The disk.-The ground tissue of the disk is not well preserved, but its bundle system, as in the case of the central cone, is well marked by very similar xylem groups. In transverse sections these are seen to be composed of from 25 to 40 or 50 cells irregularly arranged, as shown in figure $80 \mathrm{c}$. In the longitudinal section spiral tracheids predominate, other cell forms of the wood being difficult to detect, mainly owing to the small size of the bundles. The grouping of these bundles as

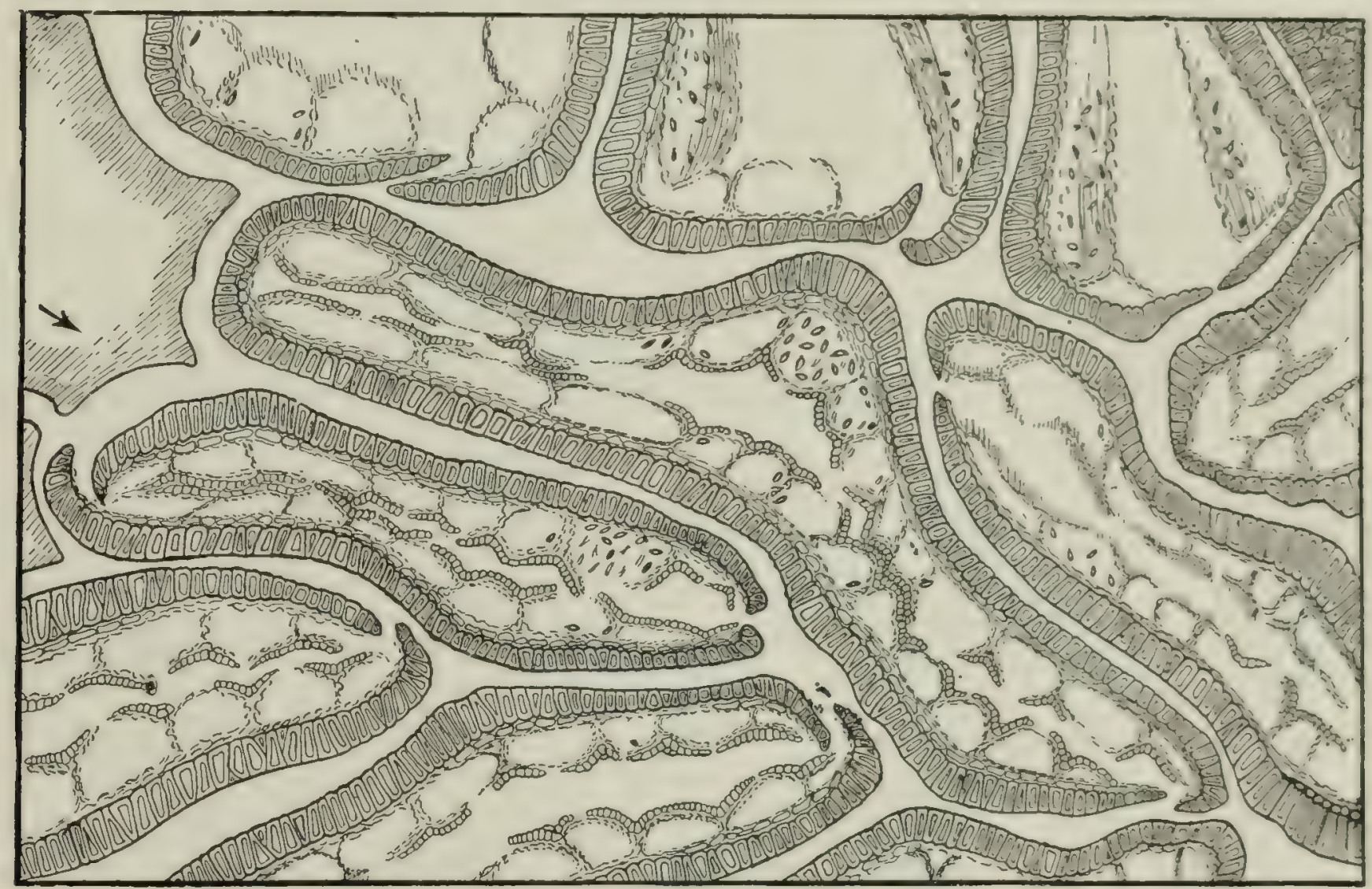

Fig, 81. - Cycadeoidea dacotensis Macbride. $\times 33$.

Portion of a transverse section through unexpanded microsporophylls of a bisporangiate strobilus, cutting a rachis and adjacent synangia. In the central synangium the outer covering of heavy-walled prismatic cells is seen to be followed by a thin-walled layer from one to several cells thick. to which adhere the sporangial loculi closely ranged in two rows-one on each side of the synangium. Each loculus is usually delimited by a thin band of collapsed cells with adherent pollen grains, and each row of loculi is bounded on the inner side by well-defined tissue a single cell in thickness, except between the angles of adjacent loculi, where there is a thickness of several cells. Thus are formed the two opposed inner walls of the two halves into which the synangium splits in dehiscing. Cut more obliquely the two inner walls niesent a striate appearance. The tips of the three synangia on the upper side of the figure are cut very obliquely, and comparison with the other synangia hence shows the position of the dehiscence slit in the outer wall. At the upper left-hand corner of the figure a portion of a transversely cut rachis is marked by an arow. (Camera lucida drawing by Wieland.)

seen in the lower portion of the disk is shown in figures 73 and 75 . Near the disk insertion the bundle system is formed by two concentric rows of bundles. Higher up, the pattern of the bundles as seen in figure $74 \alpha$ is more complex and foreshadows the bundle patterns of the individual fronds of the disk. Still higher, where the rachides are free, there is a more and more simple distribution, at last becoming peripheral and, as shown in figure 746 , in part comparable to Bocvenia (figure 32, I). Although the disk bundle systen has plainly arisen from a series of typical fern-frond bundles, the original form of the latter is no doubt much altered by the assumption of the cyclic arrangement and compression in what may well be called a "flower bud." 
The tissue of the filiciform pinnules is present, but not very clearly indicated, althongh traces of bundles with few elements are every here and there to be detected, as well as vestiges of the original ground tissues. This, together with the coloring, gives the tissue a very similar appearance to the unstained fertile pinnules of such ferns as Osmunda and Botrychimm.

The synangia.-The alternately attached and short-stemmed polliniferous synangia are several times broader than long, and do not differ greatly in size from the sporangiferous synangia of various species of the tree fern Marattia. The main

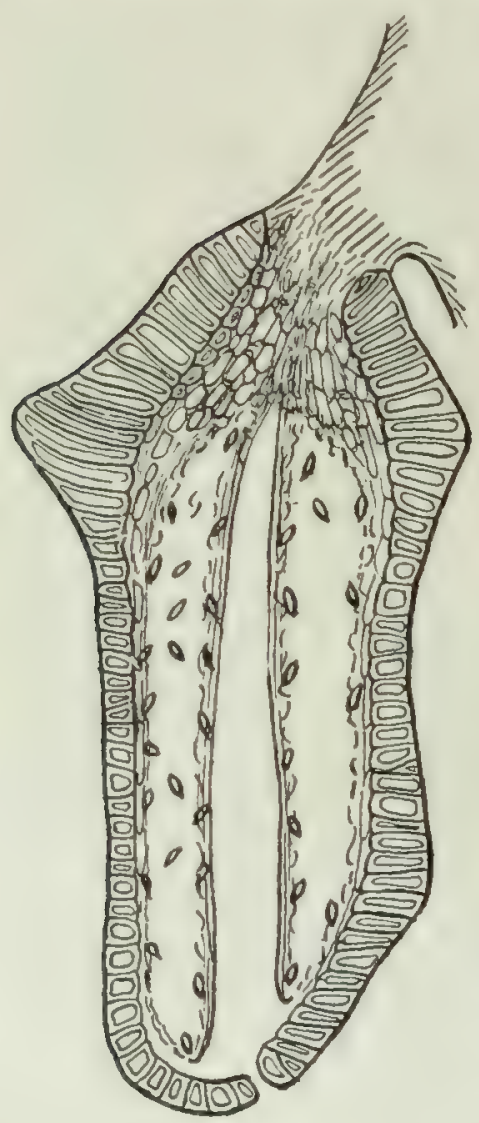

Fig. 82.-Cycadeoidea dacotensis Macbride. $\times 40$.

Longitudinal transverse section through a synangium, showing attachment to the sporophyll, the several layers of the synangial wall, its dehiscence, the attachment of sporangia, and intervening median sulcus or fissure. The basal buttressing of outer wall is characteristic. difference in outline from the latter is due to the fact that instead of being freely borne as in the ferns, these fossil synangia, being so densely crowded in the unexpanded flower nearly up to the time of maturity, exhibit, together with basal buttressing, varying appression faces and minor angles, and are usually subcrescentic in transverse section. Similarly to Marattia, there are two parallel rows of elongate spore sacs and a further close agreement in general structure, as will appear from the following description of the mature synangia. The outer layer of the synangium is composed of heavy-walled palisaded cells a single cell in thickness, and is thickest just above the synangial base, where it forms a heavy buttress, but gradually thins out to about half the basal thickness at the apical median line, which is that of dehiscence. Just inside this outer palisaded husk there is a layer of thin-walled hypodermal cells, usually a single cell in thickness, along the lateral wall of the synangium, where the individual cells readily collapse, but growing smaller celled and firmer about the bases of the sporangial loculi and widening out to form the principal ground tissue of the short stem of the synangium as it becomes confluent with the sporophylls. Next to this parenchyma layer lie the sporangial loculi in two rows, one on each half of the synangium. The loculi are usually delimited by deeply iron-stained bands made up of indistinct remnants of septal cells, with much adherent collapsed pollen. No other tissue than that indicated by these bands separates the adjacent sporangial loculi, of which there are from to to 20 in each of the two rows. On the inner side of each row of loculi; as so delimited, there is, finally, a well-defined layer of small elongate cells a single cell in thickness, or several cells in thickness, between the angles formed by the adjacent sporangia, and thus covering the entire inner face of the synangium, which was early cleft down to the sporangial bases.

On the inner middle surface of each sporangium the wall tissue weakens to form a well-marked dehiscent line, along which splitting is frequently seen to have taken place in the unexpanded stage of frond growth, though such premature deliscence may be due to the process of silicification. Recapitulating, the principal features of 
the synangium are: First, the outer palisaded wall-tissue; second, the delicate parenchyma layer, or chief ground tissue; third, the sporangial loculi containing much well-preserved pollen, but usually delimited only by desiccated pollen grains, or collapsed remains of wall cells; and, fourth, the thin, elongate-celled layer bounding the sulcus between the two rows of sporangia; dehiscence of the synangium taking place early along the median apical line, and of the sporanginm longitudinally along the inner median line as in Marattia. (Cf. figures $8 \mathrm{I}$ and 82 ; also plate XXXVII).

Regarding the character of the tissue bounding the sporangial loculi, a word yet remains to be said. The cells forming the yellowish-brown iron-stained band mentioned above as marking the locular walls are so uniformly collapsed that it is difficult to determine whether they are wholly septal or in part tapetal. It would

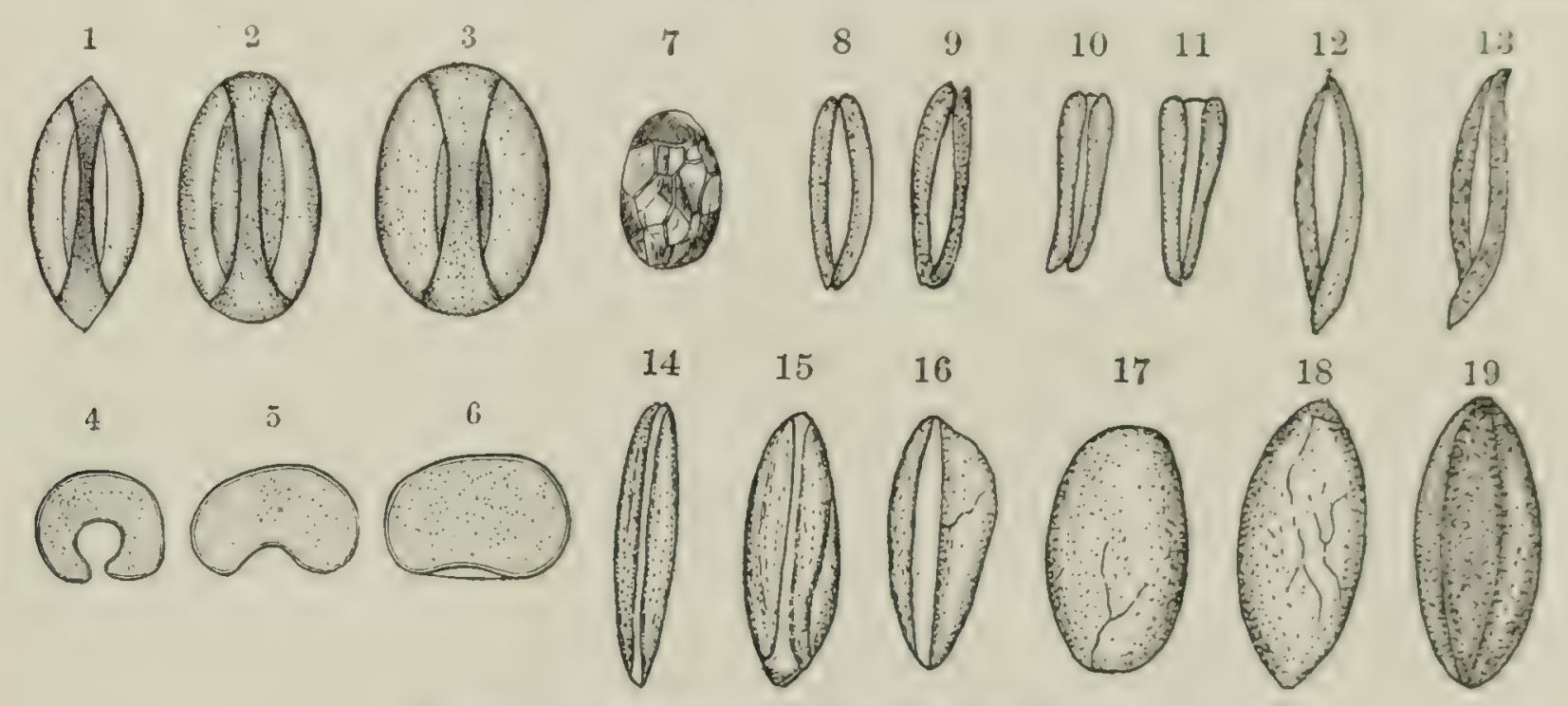

Fig. 83.-Pollen grains of existing and fossil Cycads.

Nos. 1-6.-Ceratozamia longifolia Miquel. $\times 500$. No. 1. mature pollen in dry condition; Nos, 2, 3, the same swollen in water: Nos. 4-6, the respective transverse sections or end views. After Juranyi (70).

No. 7.-Stephanospermum, showing supposed traces of internal structure, $\times 100$. From Renaul! (117).

Nos. 8-11. - Cycadeoidea etrusca. Somewhat desiccated pollen from a bisporangiate strobilus, as figured by Capellini and Solms.

Nos. 12.19.-Cycadeoidea dacotensis. A series of pollen grains, including both collapsed and distended forms, selected from various sections cut from Fruit No. I, T. 214. $X$ about 350. Observe that grains 17-19 are intermediate in size between grains 3 and 7 , in accordance with hypothetical reduction stages of the prothallium in geological time.

appear, however, that the sporangial wall was two cells in thickness rather than one, in this respect approaching the crushed double layer of wall cells observed by Lang (75) in Stangeria paradoxa.*

Pollen grains.-One of the most striking features of the silicified strobili of Cycadeoidea dacotensis is the presence of numerous pollen grains outlined in great perfection. As already stated, cycadeoidean pollen was first observed in the fructification of Cycadeoidea etrusca by Count Solms, and figured by him (22). In this

* If by any chance the colored band represents a long persistent, but finally crushec tapetum, the condition represented would be quite identical, layer by layer of cells (in the transverse longitudinal section only), with that seen in a similar section of a nearly mature sporangium of Angiofleris eicelu given by Campbell (20, fig. I43). The greatest difference would lie, of course, in the absence of a rudimentary: annulus and the strong development in the present forms of the outer prismatic layer with its prc;ection as two valves beyond the sporangia to meet lip-like in the line of dehiscence. But it would appear from the investigations of Bower (9) that the condition figured by Campbell is not the usual one observed in Angiopleris. If, however, it should approximate the condition seen in these fossil forms, we would then have indicated in them imperfect septation of the loculi carried to a high degree, an anomalous condition frequently noted by Bower (9) in both MIarattia and Dencer. 
case, however, the characters were somewhat obscured by the state of preservation, although there could be but little doubt as to the correctness of Solms' identification. Later the writer published the text-figures here introduced (I89), and noted the close agreement between the cycadeoidean pollen and that of the living cycads. In the various strobili from which the writer has cut sections, pollen has been nearly always found in more or less perfect preservation. Eivery stage of distension and desiccation is to be seen, and by searching one may, particularly in strobilus No. I of specimen 2I4, find beautifully stained grains which are outlined as sharply as in the case of preparations showing the pollen of living cycads. Such a grain is shown in figure 83, No I9. The pollen of Cycadeoidea, while far smaller than that of Cordaites, is significantly larger than that of the living cycads. Whether or not

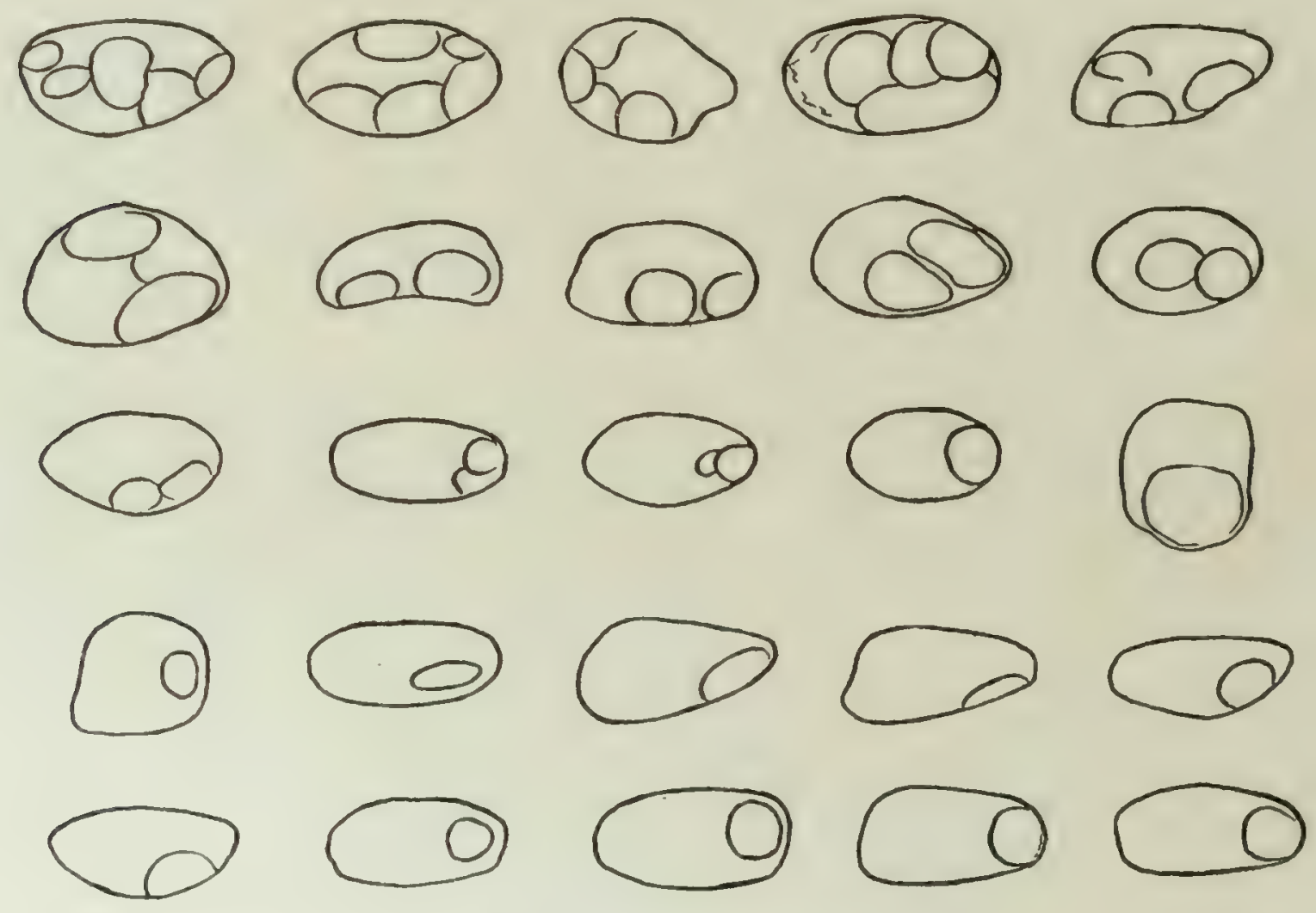

Fig. 84.-Cycadeoidea dacotensis.

Supposed structural markings on silicified poilen grains in sections 104, 110, and 314, cut from fructification I, T, 214.

there was a distinct increase in the size of the pollen grain at the time of fertilization as in Cordaites is as yet unknown, since no section of seeds yet cut traverses a pollen chamber containing pollen grains, although such are likely to be obtained in the course of future study. But obviously the cycadeoidean pollen may have normally passed through several months of cell differentiation after the stage in which it is here described.

The great majority of the pollen grains present no external markings; but every here and there, in addition to merely accidental breaks in the extine, markings may be observed which appear to represent cell walls, rather than to be entirely due to chance. A series of grains presenting such markings is arranged arbitrarily in figure 84 so as to pass from the simpler forms to the more complex. The most frequent form of marked grain has a circle or a slight circular pitting at 
one end, which may very well represent a large prothallial cell. In fact, the presence of an indicated prothallial cell or tube cell is less open to question than any of the other supposed cell markings here noted. In some other cases markings are present which may indicate several cells, and sometimes more, as many as five. If in such instances cells are indicated, rather than mere ruptures of the intine or extine, more numerous cells are present in this stage of pollinial development than in existing gymnosperms, but not so many as in the case of Cordailes, accepting the view that the markings seen in the pollen grains of that fossil are truly prothallial. Certainly one may readily imagine the three distinct cells to be seen alike in the mature pollen of Ginkgo and the living cycads-that is,

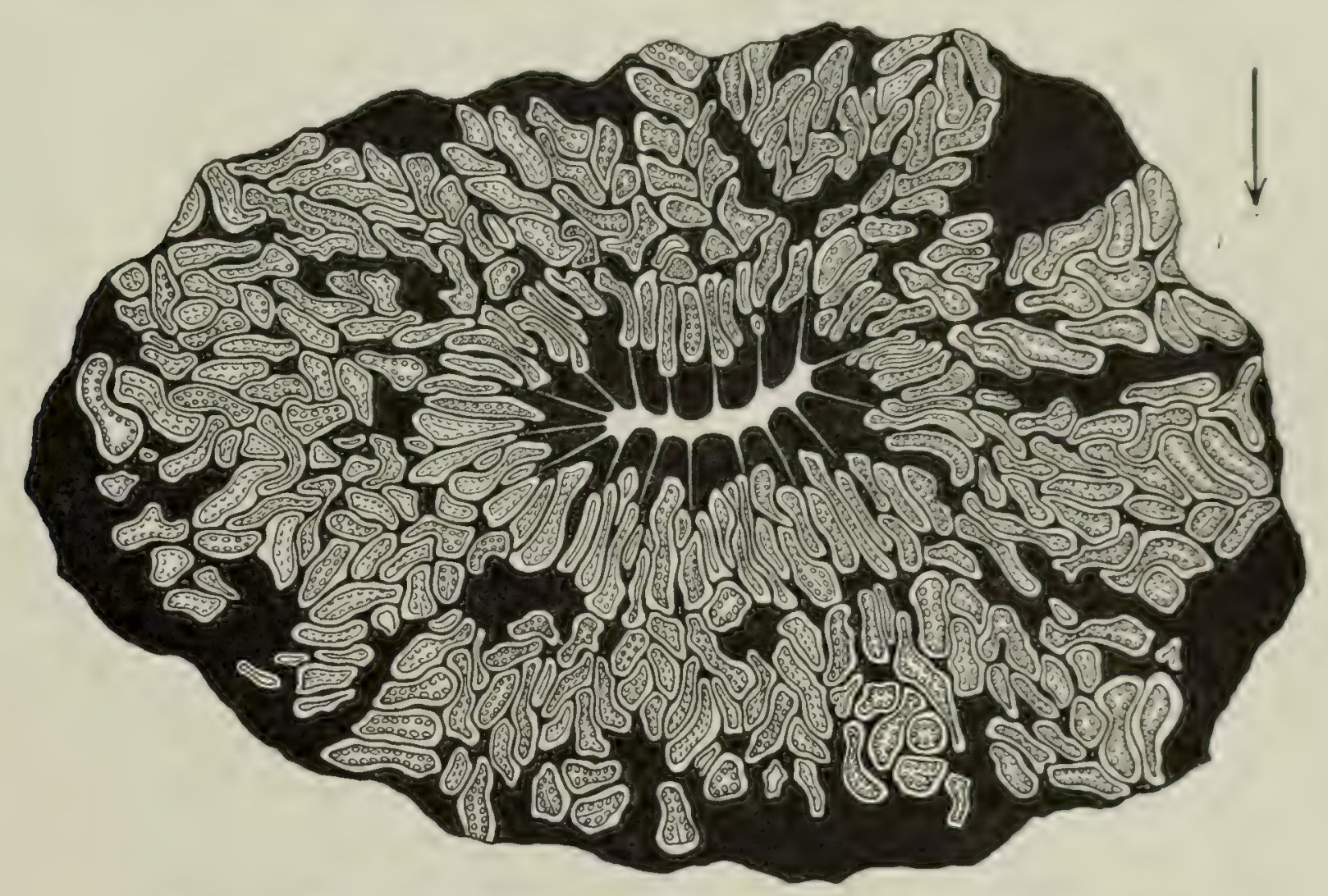

Fig. 85.-Cycadeoidea dacotensis. Transverse section of bisporangiate strobilus. $\times 3$.

Specimen from nine miles northwest of Sundance, Wyoming. Cut just above the apex of the ovulate cone. Siliceous matrix in solid black. At the center the outlines of the seventeen or eighteen decurved tips of the staminate fronds may be clearly seen, and around these tips a zone of narrow and compressed synangia borne by them. The coloration in the fossil itself is light but distinct, so that it was possible to tracs this drawing showing the distribution of the synangia directly from an enlarged photograph of the polished surface.

the vegetative or prothallial, the generative, and the tube cells-as outlining themselves by markings not unlike those seen in the present fossil pollen, if similarly fossilized. But on the other hand, such delicate cell walls may be better considered as nearly always failing of preservation, and as only being marked in the case of numerous pollen grains in a given specimen in exceptional cases. It is hence possible that some of the markings shown in outline, figure 84 , represent cells, and that some may be the result of chance is also likely. Plainly, however, if cells are in part indicated, there were more than three, and prothallial elinination had not proceeded so far as in the modern gymnosperms, but farther than in Cordaites. A five-celled stage is the most probable ( $c$. the grain shown in photomicrograph 4 , plate XXXI). While, of course, it is not possible to homologize on the basis of such meager evidence, the condition which would seem to be indicated is the one which 
we might on theoretical grounds declare was present in the Cycadeoidex; for the pollen grains being of markedly larger size than those of modern cycads, but not nearly so large as those of Cordaites, and being borne on frond derivatives, little else than a strictly intermediate stage of prothallial elimination could be surmised.

\section{CYCADEOIDEA HELIOCHOREA.}

Certain fragments of large trunks from the northwestern Black Hills Rim referred by Professor Ward to a distinct species (C. heliochorea) are found to present the same structural characters and essentially the same stages of fructification seen in the foregoing specimens of $C$. dacotensis, to which species they might justly be referred. Of these fragments, specimen 726 bears a bisporangiate strobilus agreeing not only in structure and stage of growth with fruits I and III of specimen 2 I4 (C. dacotensis), but affording, as the result of the eroding away of all the middle

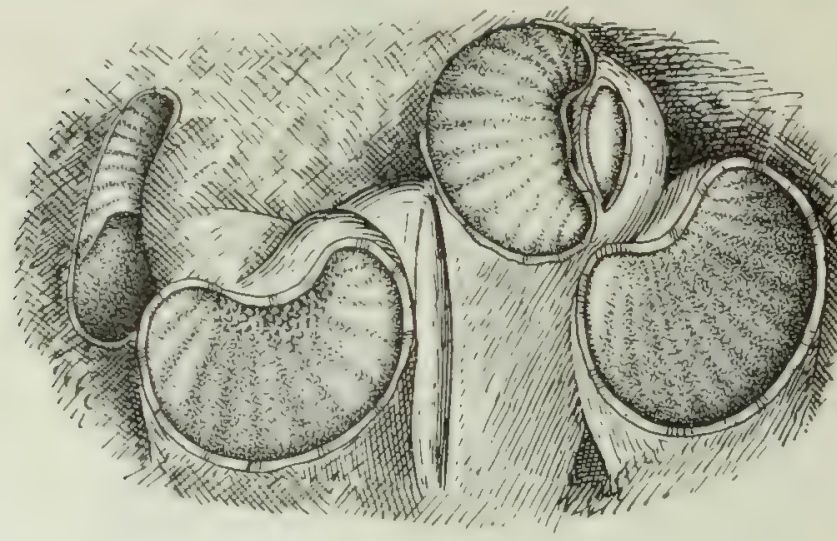

Fig. 86. - Cycadeoidea dacotensis. $\times 6$.

Synangia partially exposed by weathering out in their natural position near the surface of the strobilus shown in transverse section in the preceding figure. The palisaded synangial walls are mostly split off, thus leaving in full view the rows of elongate pollen-filled sporangial sacs. portions of the rachides of the staminate fronds, a most clear supplementary illustration of the main features of cycadeoidean sporophyll distribution and the manner in which the synangia are borne. The former position of the rachides of the fronds is indicated on the outer and upper portion of the mass of synangia by deep longitudinal furrows, at the sides of which the points of sporophyll attachment may be readily determined. Many of the synangia stand out in full relief as slightly arcuate bodies plainly attached sub-laterally to the sporophylls in pairs in the manner already described (see fig. 86 and photographs 2 and 3, plate XLV). A transverse section cut through the mass of synangia still attached to the sporophylls, and well above the central ovulate cone, is shown in figure 85 .

\section{CYCADEOIDEA INGENS AND C. JENNEYANA.}

The robust trunks of Cycadeoidea ingens and the taller columnar forms referred to C. Jonneyana, represented by many, magnificent specimens from Black Hawk, bear bisporangiate strobili of the same general type and structure as those of $C$. dacotensis, although the disks are divided up into fewer fronds. In C. ingens twelve or thirteen, and in a strobilus referred to $C$. Jenneyana only about ten fronds are present. But any such slight numerical variation would probably not in itself constitute a difference of specific value - certainly not if a distant analogy is afforded by Zamia floridana, in which the ranks as well as the number of sporophylls in each rank vary noticeably in both the staminate and the ovulate cones. Other differences are present, however. Aside from the lesser number of the fertile fronds, the strobili of the two species before us do not exhibit markedly different structural features from those already described in the better conserved strobili of $C$. dacolensis. 
The more or less chalcedonized condition of these fruits makes their study diffcult in thin sections, although the general features are often outlined with remarkable clearness on polished surfaces, as is explained and illustrated at length in the legends and photographs of plates I to IV. 'The bisporangiate strobili of $C$. dacotensis and $C$. ingens were the first to be discovered and described in the Cycadeoidere.

\section{CYCADEOIDEA PAYNEI.}

It is of more than usual interest that a single bisporangiate strobilus is borne by the cycadeoidean trunk No. 434; for this specimen clearly belongs to the closely related group of species which includes Cycadeoider Colei, C. I'aynei, and C. IVieIandi, with Benneltites Gibsonianus and B. Morierei. Although the preservation of the microsporoplylls of this strobilus is not so good as that of the pollen-bearing strobili described above, in the light of the facts already learned all the essential features may be determined. And it is fortunate that this should be so; for otherwise we should only be able to infer, from the characters of young fruits and the strobili of other species, the nature of the staminate frnctifications accompanying Bennettites Gibsonianus and B. Morierei and the American forms so closely related to these species. Doubtless, however, other and better examples may be found, the present strobilus having been noted only by accidental good fortune when searching for young fruits. The surface characters did not betray the fact that a well-advanced bisporangiate axis was present, and this was only learned after sawing through the axis, as removed, for study. As cut in longitudinal section and represented in plate XIIII, photograph 7 , the ovulate cone is seen to be quite large, having reached a stage of growth that very clearly indicates its functional character. Although not preserved entire, the central ovulate cone is fairly well ontlined, the convex receptacle fortunately being complete and of the characteristic shortened form seen in Bennettites Gibsonianus and allied species. Resting on the somewhat crushed summits of the seed pedicels there is a mass of broken-down tissue, among which are scattered the remnants of wilted sporophylls and a number of fairly well preserved synangia containing pollen and of the same general type as those of $C$. dacotensis and $C$. ingens. Also at the base of the ovulate cone the remnants of the staminate disk may be clearly made out, although presenting a string: appearance, as if wilted about the time of fossilization. Froni these meager details it may only be inferred that the disk was not composed of as many fronds as in $C$. dacotensis, and that the sporophylls were fewer in number and bore fewer synangia, the latter being of much the same size as in that form.

The question of the position and general character of staminate fructification in the Cycadeoidex was of course settled by the writer's discovery of the male inflorescence of Cycadeoidea ingens. But the present form leaves no further doubt that many or quite all the ovulate fruits of the older types like Bemellites Githsonianus and $B$. Morierei, and likewise all of the closely related Black Hills species, were also bisporangiate and mostly bisexual. It may be emphasized that even were the present bisporangiate fruit an isolated one, its form and structure wonld at once enable one to recognize its relationship to the ovulate cones so plentifully borne by trunks 77, I3 1 , and 393, as described in Chapter VI. The structure of the 
bracts, the peduncle, and, in particular, of all the basal portions of the cone, is quite identical in all these mature ovulate forms and the present functional bisporangiate axis. The conclusion is therefore a plain one, that thus far no clear indication of diceism has yet been observed in any of the present series of trunks, although, as will presently be recounted, it should not be overlooked that some very small cones borne by cycad trunk I 3 I are simply ovulate. Obviously enough it is under

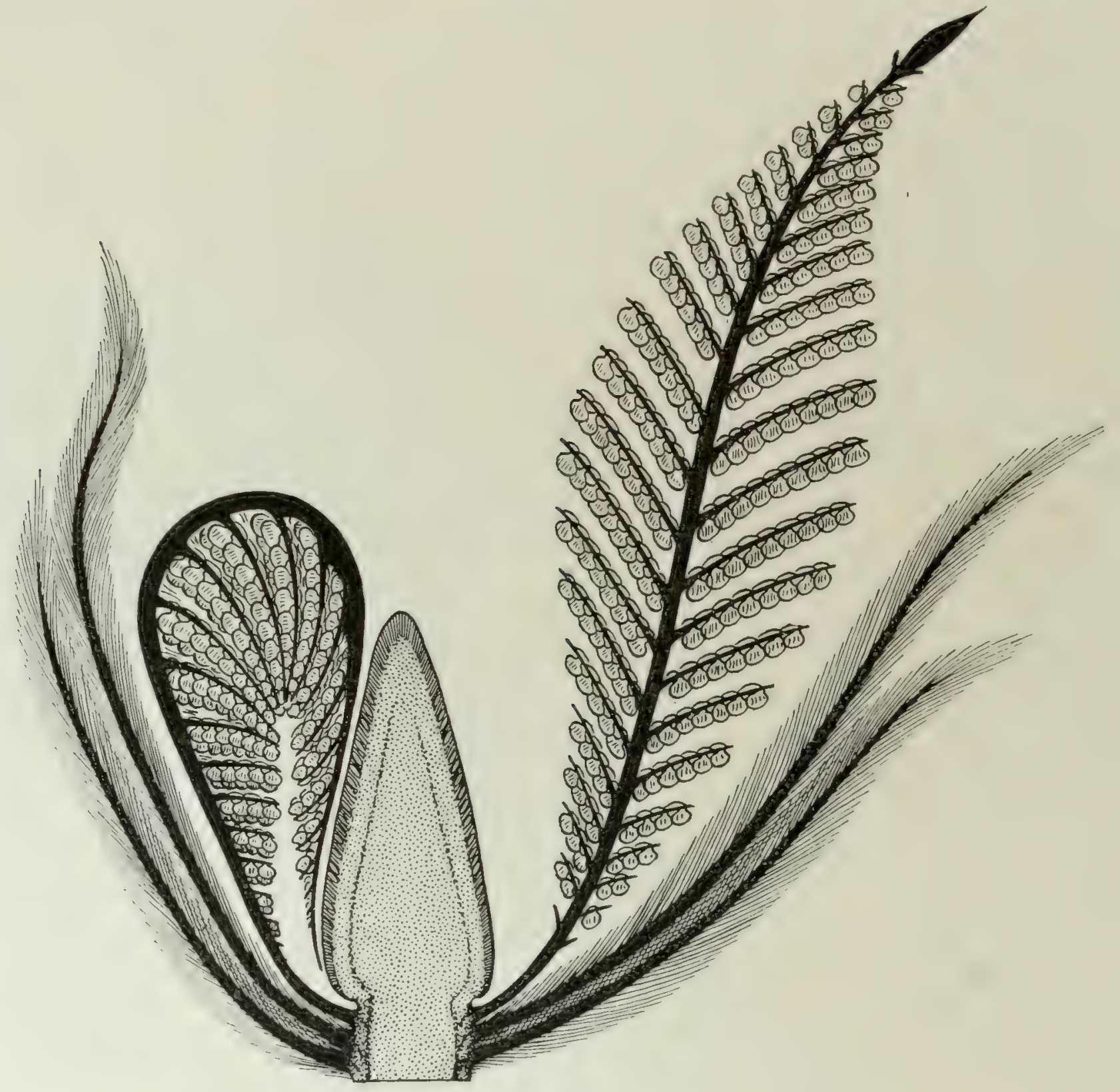

Fig. 87.-Cycadeoidea dacotensis.

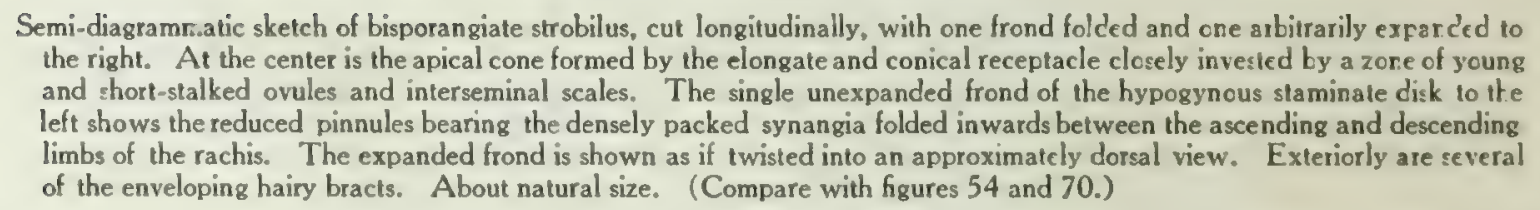

such circumstances difficult to say, on the basis of isolated strobili, to what extent the parent trunks may have been bisexual or unisexual, or certain species monœcious, or certain others diœcious. The structures present clearly permit or favor the utmost variation in these respects. (The presence of disks is further considered in connection with the subject of the more mature ovulate cones in Chapter VI, pages II 4 and I3O, as well as in Chapter VIII on young fructifications.) 
RÉSUMË.

The silicified pollen-bearing flowers of the Cycadeoidere at present known are all bisporangiate, unexpanded, and borne laterally on the main stem as altered branches or shoots, projecting but little, or not more than several centimeters, beyond

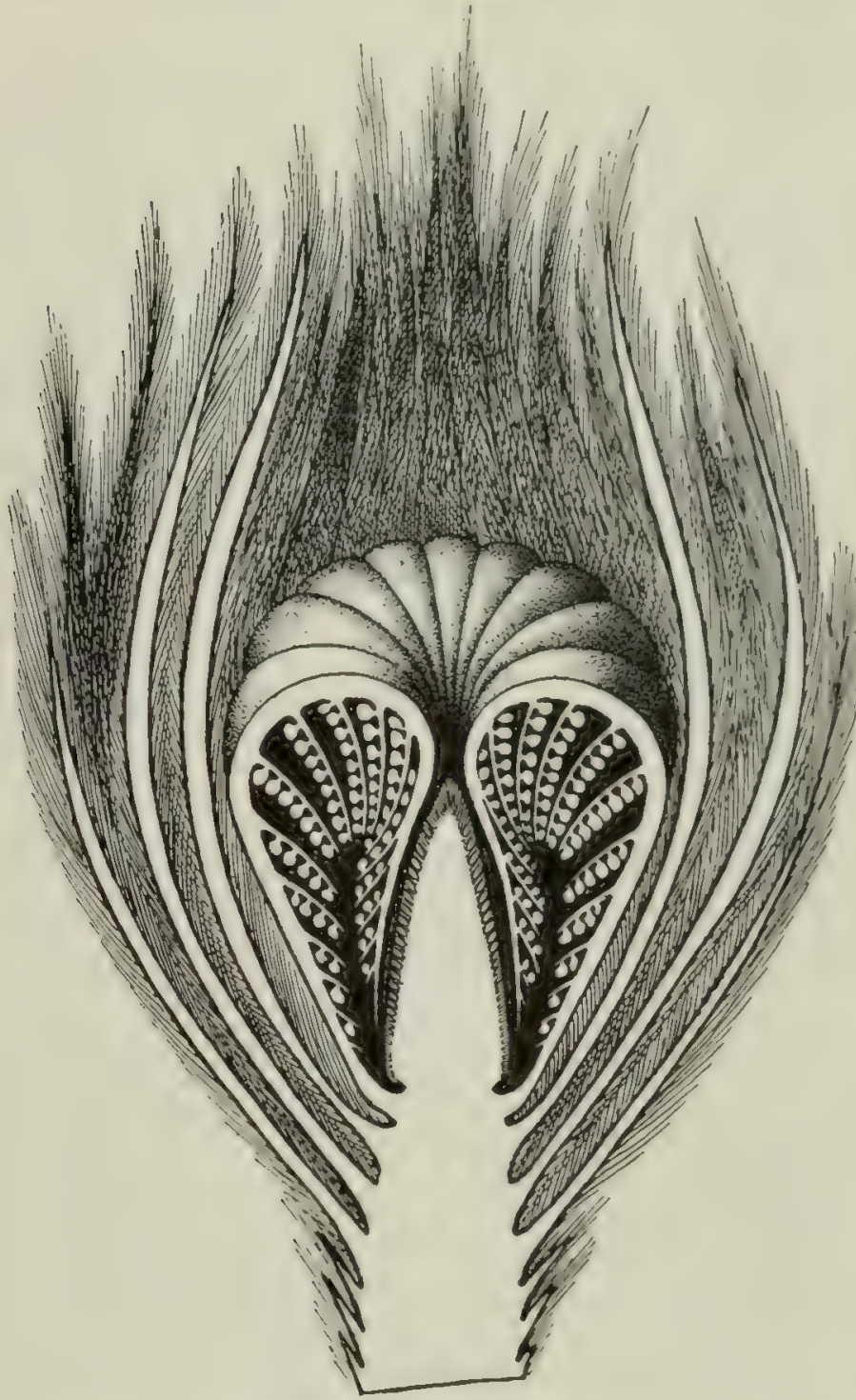

Fig. 88.-Cycadeoidea.

Restoration of an unexpanded bisporangiate strobilus, with part of the envel. oping hairy bracts removed. Eighteen folded fronds are shown as in Cycadeoidea dacotensis. About natural size, or not nearly so large as various examples. (Compare with figures 70 and 71. ) the surrounding annor of leaf bases and ramentum. The flower or strobilus as thus borne on a short and heavy peduncle consists in a terminal ovulate cone surrounded by an lypogynous staminate disk and an outer series of enveloping bracts, followed by the old leaf bases of the armor. The ovulate cone is elongate, and its ovules are young and borne on very short pedicels, the agreement in structure with young forms of various other ovulate cones being very close. The staminate disk is formed by a series of from ten (in C. Jenneyana) to eighteen or twenty (in $C$. dacotensis) once-pinnate fronds with a strong basal adnation of their petioles continuing nearly to the level of the summit of the central cone; whence the strobilus has the form of a campanulate flower. Each frond bears about twenty pinnules closely set with two sub-laterally attached rows of distichous and sessile synangia, and is of partially circinnate prefoliation (or prefloration), being once inflexed, so that the upper third of its length lies with the ventral surface of the rachis appressed to the central cone, the fertile pinnules being folded back in pairs between the ascending and descending limb of the rachis. And since the pinnules follow in close order, all this intervening space is densely packed with synangia, the sporangial loculi of which are often filled with pollen.

The compact bud-like form and fairly mature stage of growth in a prutected position, as may be noted in passing, were very important factors in preseriation. Even had the large and feathery staminate fronds of the disks been silicified in an nncurving or an expanded position instead of a closely folded one, they won? have been subject to crushing and breaking, with more or less comminution while yet embedded; or they wonld have been broken away and destroyed during the process of weathering ont, as the tips of the bracts often are. 
As a rule, the best preserved bisporangiate axes, from the larger trunk types, both columnar and branching, as seen in $C$. ingens and $C$. dacotensis, are, together with the bracts subtending them, from 5 to $7 \mathrm{~cm}$. in diameter, while the distance from the summit to the origin of the peduncle traces in the xylem is from io to I $5 \mathrm{~cm}$. in the case of the larger trunks. With due care it has hence been possible to cut radial longitudinal and transverse (tangential) thin sections, varying from 50 to $\mathrm{I} 5 \mathrm{O}$ sq. cm. in area, and showing not only entire axes, but the manner in which these are borne on the trunk as well, just as was done in the case of the more advanced stages of the ovulate strobili. Measuring from these sections, the length of the barrel-shaped peduncle is from 5 to 7 or more centimeters, and its median vertical diameter about $2 \mathrm{~cm}$, though frequently the peduncles are even larger and much flattened. The length of the flower bud proper, as consisting of the central ovulate strobilus and the surrounding inflexed pollen-bearing fronds, is from 5 to 7 and the diameter about $5 \mathrm{~cm}$. The central ovulate strobilus is usually about $5 \mathrm{~cm}$. in length by from $\mathrm{I} .5$ to $2 \mathrm{~cm}$. in diameter, and the fronds bearing approximately mature pollen are from 8 to Io or more centimeters in length. But in Cycadella young strobili have been observed less than a centimeter in diameter, or no larger than the minute silicified strobili of Cordaites from Grand Croix.

The form of the individual fronds of the disk has been greatly altered, conformably to space requirements in the unexpanded condition. While preservation is not so complete as in the case of young foliage leaves, the bundles of the fronds are often indicated throughout their course by the preservation of the xylem elements. Hence the disk bundle system may be clearly traced. This, too, has been modified in conformity to the assumption of an annular insertion, with basal fusion, into a disk of the originally discrete and spirally inserted or whorled once-pinnate fronds. The pollen-bearing synangia are identically comparable in theirsporangial grouping and structure with the spore-bearing synangia of the existing tree ferns of the genus Marattia. The pollen is considered to be five-celled, rather than fourcelled as in Ginkgo, or four to three celled as in existing cycads.

Following the wilting down of the disk of microsporophylls the central ovulate cones appear in most instances to have continued their growth; whence these strobili were functionally bisporangiate, and had so continued from the time when ancestral Marattiaceoid ferns attained heterospory, although the most varied forms and transition stages of monœcism and dicecism were doubtless exemplified by the various members of the great plant complex to which the existing and fossil cycads belong.

As an immediate result of these anatomical studies it is therefore clear that other and possibly much varied bisporangiate types may be expected in the older strata. And as we have seen, elaboration of the structure of the present new types of cycadean fructification has already accurately extended our knowledge of the hitherto obscurely known Williamsonia. The known species of cycadeoidean bisporangiate strobili now number upward of ten, distributed in four genera, indi- 
cating a virtually cosmopolitan range of this unique floral type througlout at least all of the older and middle Mesozoic, as follows:

I. Cycadeoidea etrusca Cap. \& Solms (22). Not structurally known, although with well-outlined ovulate cone and conserved pollen grains. (Italy.)

2. C. ingens Ward (I87). Ovulate cone and disk of thirteen once-pinnate, basally adnate fronds, fully known. This is the species on which the original discovery of the bisporangiate strobili may be said to rest. (Piedmont-Black Hawk region, South Dakota.)

3. C. Jenneyana Ward. Cone and disk of ten or eleven fronds, fairly well known. (Piedmont-Black Hawk region.)

4. C. dacotensis. Complete structure known from a large number of wonderfully conserved axes borne on various trunks. Disk fronds once-pinnate, and normally eighteen in number. (Minnekahta, South Dakota.)

5. C. superba. The number of disk fronds unknown. (Minnekalita, South Dakota.)

6. C. sp. Disks small, and probably with few fronds. Synangia very large. Observed in specimen figured on page 6o. (Minnekahta, South Dakota.)

7. C. Paynei. Disks small, ovulate cone large and certainly functional. Number of microsporophylls unknown. Species nearest of all American forms to Bennettites Gibsonianus. (Minnekahta, South Dakota.)

8. Cycadella wyomingensis Ward. Known from smallest and youngest bisporangiate strobilus observed; I cm. in diameter. Fronds of the disk thirteen in number, in agreement with the very different cycad Cycadeoidea ingens. Strobili too young to display minuter features. (Freezont Hills, Carbon County, Wyoming.)

9. Cy'cadocephahus Sezvardi Nathorst. Oldest bisporangiate strobilus known. From Trias of southern Sweden. Originally interpreted as ovulate. (Cf. fig. I, plate XLV.) Fronds of disk, seventeen or eighteen.

Io. Williamsonia gigas. Known inferentially from various disk impressions or casts. Fronds numerous-fifteen or twenty. (Europe, India, and elsewhere.) 


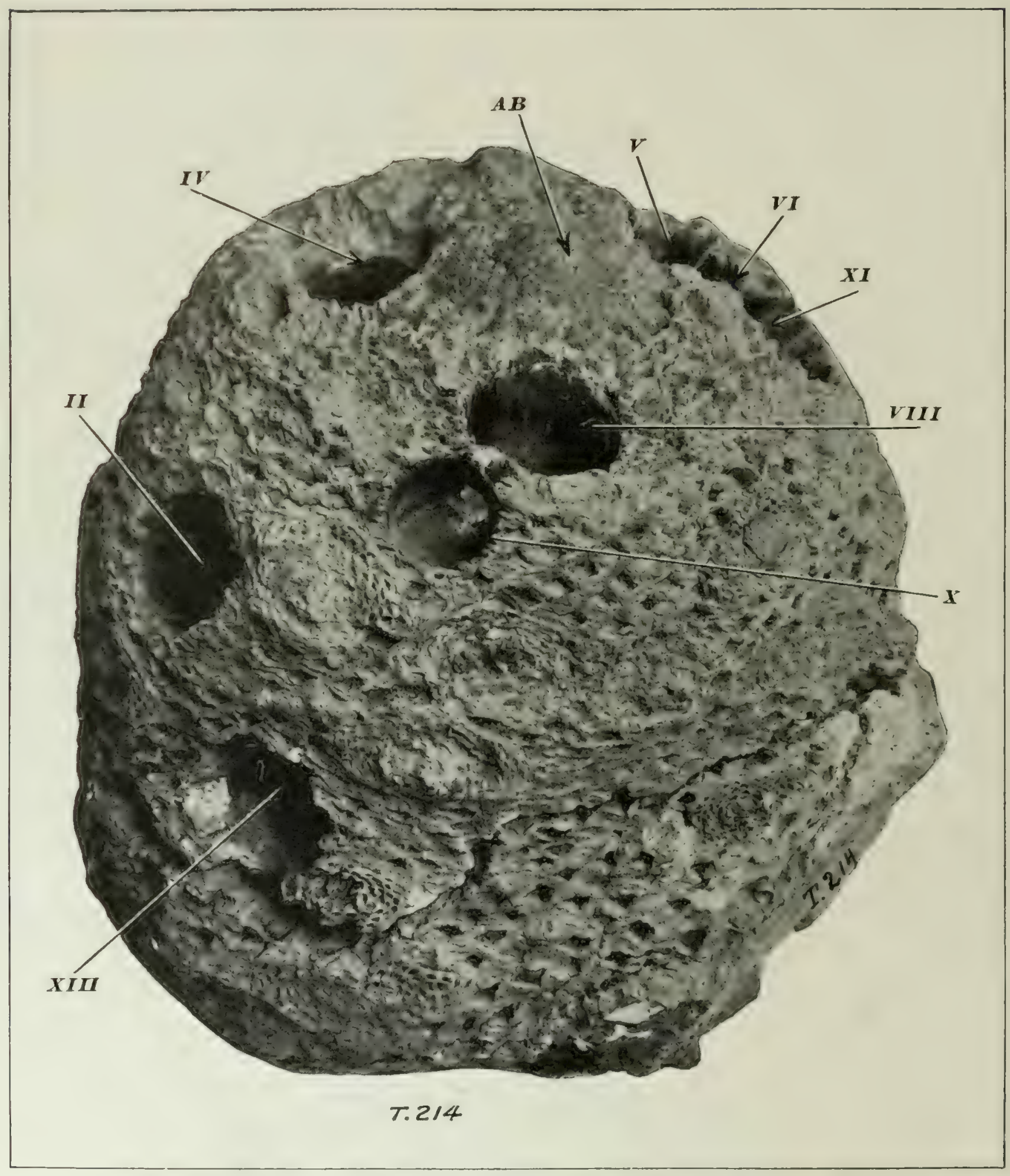

Fig. 89.-Cycadeoidea dacotensis. Trunk 214. $\times 1 / 4$ nearly. Side view of trunk after drilling out in the form of cylindrical cores the fruits numbered II, IV, V, VI, VIII, X, XI, XIII. AB, the terminal bud. See additional view, figures 14 and 94 , and the descriptions of the several fruits under their respective numbers in the seventh and eighth chapters. 


\section{CHAPTER VIII.}

\section{YOUNG FRUCTIFICATIONS.}

No more fascinating problems are involved in the study of the various features of the Cycadeoidere than those dependent on a knowledge of entire series of young strobili; for it is to the young fruits that one must turn if he would know much about habits of growth and modes of fructification in these interesting plants, the form of bisporangiate development seen in them being precisely the one capable of the most gradations of monœcism, diøcism, and bisexuality. It is hence a very fortunate fact that many of the trunks from the Black Hills bear finely conserved young fruits by the score and hundred. But this wealth of fossil evidence carries with it a heavy responsibility measured in time and resources for irvestigation. It therefore need surprise no one if there be now presented but a mere prodromus of the facts relating to the widely varied sex differentiation undoubtedly exhibited by the Cycadeoidere.

\section{CYCADEOIDEA SP. (SECTIONS 410 AND 411.) \\ (FIGURE 90, II.)}

The description of young or but partly mature forms of fructification may be begun by a brief notice of a quite small isolated fruit from the Minnekahta cycad locality. The longitudinal and transverse sections numbered 4 ro and the accompanying serial transverse sections numbered 4I I clearly display the larger structures of this small and young strobilus. The slender peduncle bears an elongate cylindrical and slightly tapering apical ovulate cone I $5 \mathrm{~mm}$. long by only $6 \mathrm{~mm}$. in diameter, surrounded by very young bracts. The sporophyll zone is already a millimeter and a half in thickness, and the comparatively large ovules, preserved in outline only, are seated on such short pedicels as to appear sessile or nearly so. An additional feature of especial importance is the presence just above the uppermost bracts of a basal disk or collar which, after rising to the height of a millimeter or two, is interrupted by clear and structureless silica, but is again indicated by unmistakable traces farther up on the sides of the fruit. The relation of parts is clearest in the transverse sections where the disk appears as a continuous band surrounding the ovulate cone. Above the summit of the ovulate cone there is inside the bracts a naturally stained capping of nonconserved tissue which evidently belonged to the disk. (See figure 90, II, and plate XI.IV, photographs I and 2.) That there is indicated here a young unexpanded ovule and disk-bearing strobilus cau not be doubted. That under favorable circumstances seeds would have been produced is also evident. But whether microspores would have been produced by the disk or not, and therefore whether the parent plant vas bisexual, monœcious, or dicecious, could not be affirmed on the basis of the present single and isolated fruit alone. 


\section{CYCADEOIDEA SP. (SECTION 389.)}

(FIGURE 90, 1.)

A very fine ovulate cone of much larger size than the preceding, and of a different species, but quite as young and deeply embedded in bracts, is borne by the fragment of a trunk numbered 764 . From this were made the longitudinal sections 388 and 389 , cutting through the entire fruit and also the peduncle for a length of $4.5 \mathrm{~cm}$. This ovulate cone is distinctly conical in form, 3 cm. long and I. $2 \mathrm{~cm}$. in diameter. The rather large enveloping bracts rise a centimeter above
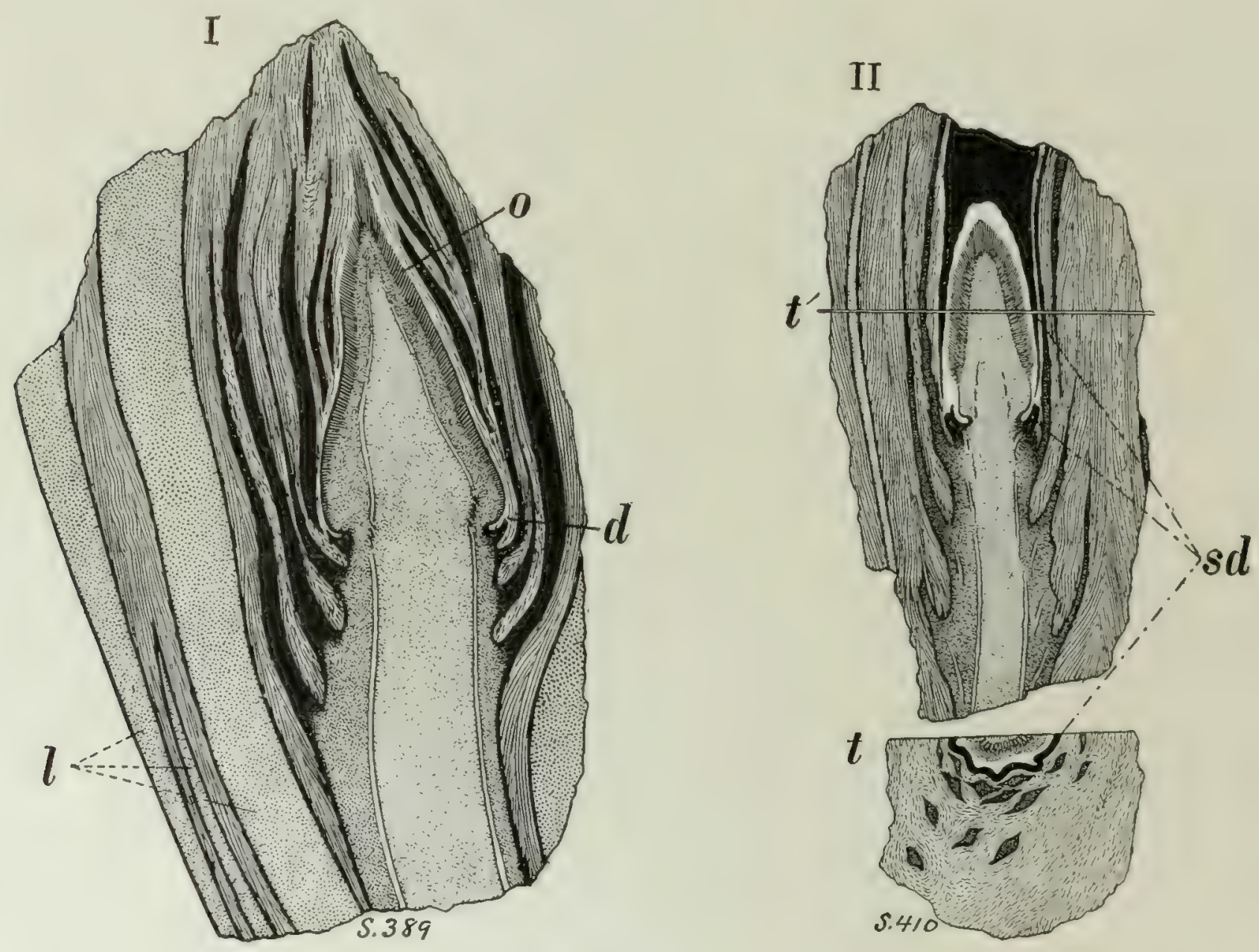

Fig. 90.- Young fructifications of Cycadeoidea sp. $\times 1 \frac{1}{3}$.

I. Longitudinal section through bract-inclosed ovulate strobilus. Bracts in solid black, leaf bases in heavy and peduncles in light stippled surface.

1. Leaf bases; $\mathrm{o}$, palisaded zone of seed stems and interseminal scales; $d$, the remnants of an hypogynously inserted disk. (This disk may have been abortive, although the form of the ovulate cone and rather wide space between it and the surrounding leaf bases also suggest the possibility of an earlier dehiscence of a matured functional staminate disk.) S. 389. T. 764 .

11. A longitudinal section of a bisporangiale strobilus, together with a transverse section $(\ell)$, cut on the line $\ell^{\prime}$.

The space occupied by the broken down tissue of the young staminate disk is shown in solid black, the bracts in very dark stippled surface. A single leaf base is seen to lie on both sides of the bract-inclosed fruit (the axilar and supra-axilar bases). sd, the staminate disk in both longitudinal and transverse sections. S. 410. Cut from an isolated trunk fragment.

the acuminate summit. The seed zone covers all of the lateral area of the conical receptacle very evenly to a depth of scarcely more than a millimeter, the seed pedicels being very short and the ovules minute. Beneath the seed zone the position of the annular shoulder, common to all cycadeoidean ovulate cones, may be made 
out, but there is, unlike the fruit just described from sections 4 I O and 4 I I, scarcely a trace of the earlier presence of staminate organs. It is possible that in this, as in some other instances, such were not developed. (See fig. 90, I.)

\section{CYCADEOIDEA PULCHERRIMA (?). (SECTION 409.)}

A trunk fragment of somewhat different appearance from the preceding specimen, 764 , and referred to the doubtful species Cycadeoidea pulcherrima (cf. p. I86), bears a strobilus with an ovulate cone much like that of No. 764 in shape and stage of growth, although much more robust. The surrounding bracts and leaf bases are beautifully preserved and rise well above the ovulate cone, at the base of which are the ummistakable remnants of the lower portions of an hypogynous disk. More-

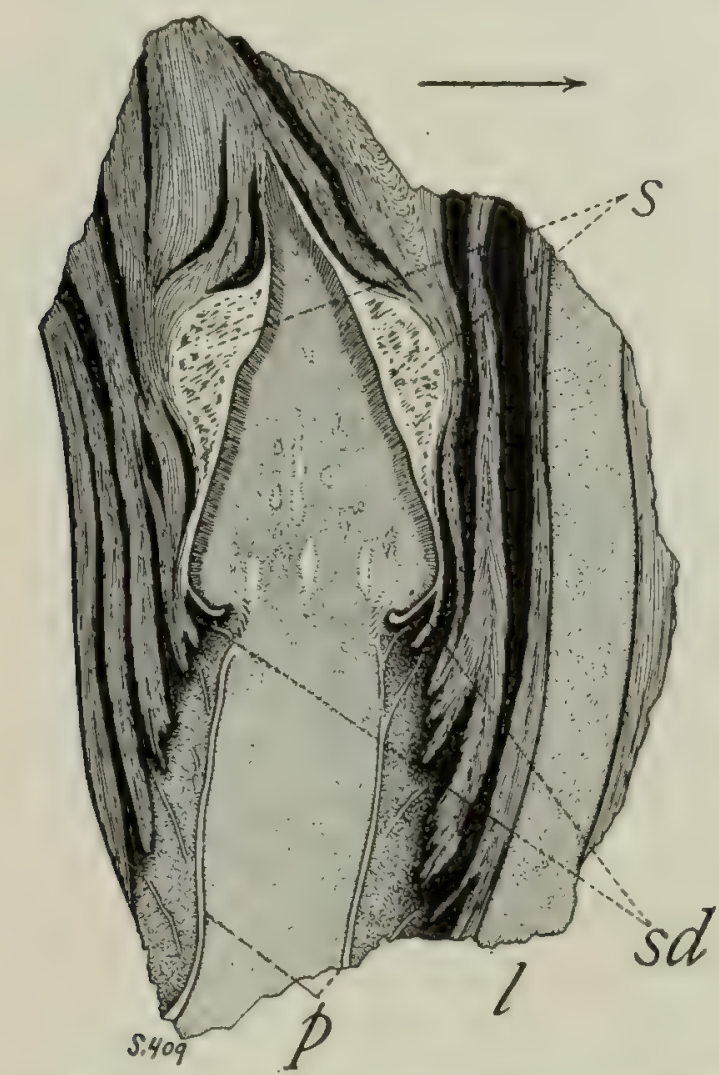

Fig. 91.-Cycadeoidea pulcherrima. S. 409. T. 719. Natural size. Longitudinal section through bisporangiate strobilus. The arrow points upward, taking the section as radial longitudinal to the trunk.

$s$, Space originally occupied by the staminate disk, the lissues of which were broken down or decarbonized before silicification took place; sd. insertion of the staminate disk, the lower portions of which are

1, the supra-axillary leaf base. Enveloping bracts

in solid black. Ovulate zone palisaded in appear-

ance, and $1.5 \mathrm{~mm}$. thick. Summit of cone tufted. partially conserved; $p$, peduncle bundle cylinder:

over, inside the bracts surrounding the upper portion of the cone there is a more or less well marked cavity of such shape and appearance as might have been left if the infolded mass of fronds of a medium-sized staminate disk failed of silicification. (See fig. 9I.)

\section{CYCADEOIDEA SUPERBA (TYPE)。(Plates IX-XI.)}

The interesting history of the magnificent type specimen $C$. superba has been recited in Chapter II, where it is explained that the large central trunk, terminating in a "crow's nest," early gave rise to the four lateral branches, which are large and even approach the parent trunk in size. But the most interesting botanical features exhibited by this trunk relate to the particular period of fruit development it had reached when chance led to its preservation in fossil form. In the first place, the central trunk and its immense lateral branches appear to have been the result of rapid and unchecked growth. Secoudly, the leaf bases are of large size and their spiral succession is exceedingly regular, never having been interrupted by the emergence of any other than the scattering series of young fruits that are actually present and can be located one by one. Nearly all are, though young and deeply embedded in surrounding bracts and ramentum, already prominent- the more especially so because of the fine preservation of the bracts and long bract hairs, which in a number of instances form a conical mass projecting above the tops of the surrounding leaf bases. The middile branch bears fifteen fruits, the four lateral branches fifteen, seven, six, and ten 
fruits. For so large a plant, fifty-three, the total number of fruits, as compared with the large number of mature fruits borne by some of the trunks described in Chapter II, is a very small number. Now, of these fifty-three fruits, only one, or at most two, borne by the central trunk, had reached a considerable size. In the case of the larger of these two more advanced fruits, only the basal portions are preserved, but they indicate an ovilate strobilus about $3.5 \mathrm{~cm}$. in diameter. Fortunately, however, a much more complete fruit of nearly the same age and size as the foregoing is borne by No. 7I7, a fragment of another C. superba trunk of about the same size as one of the branches of the type, and absolutely agreeing in not only its general features, but in minor peculiarities of silicification and preservation. In this supplementary example (shown in figure 68) the receptacle is markedly rounded and not conical as in a fruit of $C$. dacotensis (?) (cf. fig. 66), otherwise very nearly comparable in size and outer form with both the above fruits of $C$. superba.

All the remaining fruits of $C$. superba (type) are, as described, inclosed by prominent series of bracts forming masses from 3 to $5 \mathrm{~cm}$. in diameter, and must, with the possible exception of a very few - a half dozen at the utmost-have belonged to the same prefloral period. Nor is it wholly sure that the larger fruit (or two) of the middle branch was separated from this main series of fruits by nearly so much as a year's growth.

Three of the smaller axes of fructification borne by the present beautiful type have been studied in thin, but except in one instance not serial, sections. The first of these three axes is a robust spindle-shaped mass $3.5 \mathrm{~cm}$. in diameter, which was found loose by the writer when he first visited Minnekahta. On his return to New Haven it was found that this fruit belonged to the summit of one of the lateral branches of $C$. superba (type), where, in its original natural position, it forms a prominent object. In the transverse section $4 \mathrm{I} 2$, cut $3 \mathrm{~cm}$. beneath the tips of the bract-hairs, the space occupied by the inclosed and uncrushed young fruit is seen to have a diameter of I cm., but no distinct structure can be made out, although a small circular area at the center probably delimits an ovulate cone, and the granular naterial to be seen just outside it the space occupied by surrounding preflorate young microsporophylls. (See plate XLIV, photograph 6.)

In the case of the second smaller fruit, a section cut transversely several centimeters beneath the summit of the bracts shows only a mass of bracts and bract hairs, the young spore-bearing parts not yet projecting to the level of the section. In the case of the third fruit, although a rather small one, a series of sections at once brought to light the main structural features. The uppermost transverse section is cut just at the summit and presents an appearance much like that of the nearly similar section just noted. The lower transverse section (335), as shown in figure 93, II, cuts through a small but typical ovulate sone surrounded by a disk of relatively robust growoth, and undoubtedly staminate, although only outlines are preserved. One additional young fruit from which 110 sections were cut is simply ovulate.

Needless to say, the examination of these few axes must leave unanswered some very interesting questions concerning the character of fructification in this handsomest 
of silicified cycads. But when in its presence there is-to say nothing of the time required - a limit to one's wish to drill and cut, even by the perfected methods now available. The main facts thus far derived from the study of the young fruits and trunk features of C. superba follow in résumé.

(a) The central trunk early gave rise to four lateral branches, all of which developed at a rapid and nearly equal rate.

(b) The spiral succession of the leaf bases has been disturbed only by the appearance of the fifty-three young axillary fructifications distributed sparsely and about equally over the central trunk and its four branches; and most of the fruits or even all belong to the same prefloral stage. Only one or two are at all advanced in growth, and but a few remain very small. Three seasons of fruit growth are hence the most that can possibly be predicated, although most, if not all, of the fruits seem to be those of a single season.

(c) The only young fruit cut yielding good structure in thin section (though most of the fruits must be well preserved) is certainly of the usual disk-bearing cycadeoidean type.

(d) Two other fruits not cut are known to be ovulate. One is small, but like the young axes studied in serial section may have early borne an hypogynous

I

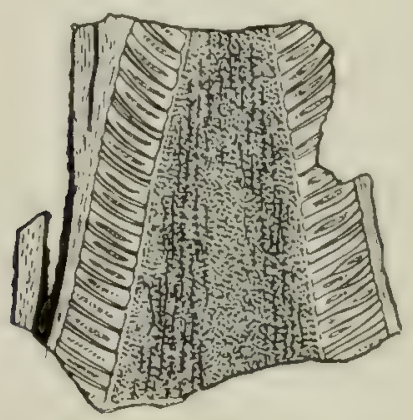

II

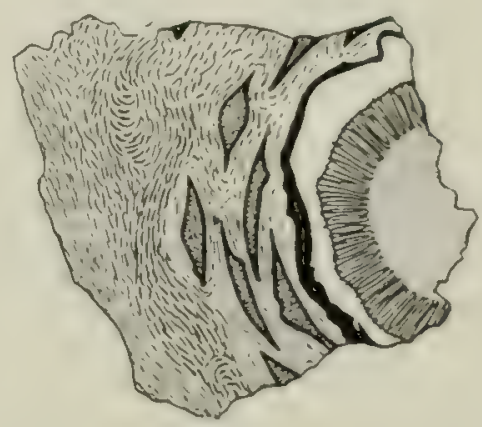

Fig. 92.-Longitudinal and Iransverse sections of young fructifications of Cycadeoidea. X 4. The longitudinal section (I) shows no outer disk, though the plainly indicated seed zone appears to be even younger than that shown in II, where there is a distinct outer disk. Both ovulate cones are, however, in a very early stage of growth, the seed pedicels being without elongation. staminate disk functionally microsporangiate or not. 'The other is of considerable size and might percliance have borne pollen a season earlier than would the young disk-bearing axis had fossilization not intervened.

(e) The presence of a bisexual floral type is the more probable, but degrees of monœcism or diøecism may be present. The acinal condition in this respect is only inferred.

$(f)$ The sparse number of fruits present may indicate, considering the present trunk alone, that the production of fruits would nornally have extended over a considerable time, or else that fructification would have been followed by rest and other fruiting seasons. Or it may also be that the fruits actually present are the only ones that would in any case have been produced, since the greate: number are in nearly the same stage of growth.

It may be well to mention here that had the basal portion of the largest or'thlate strobilus borne by $C$. superba (type) been detached with its surrounding bracts and preserved as an imprint, or, better, is a cast, it would have presented very 
nearly the appearance of a fruit of Williamsonia gigas figured by Saporta (125, plate 244 , fig. 3 ). In the latter case the bracts are broader. Moreover, the associated disk shown by Saporta (loc. cit., fig. 4) may have been shed by just such an ovulate fruit as either of the present ovulate forms when younger. Wherever such fruits are found isolated there is naturally a strong suggestion that they had longer peduncles than any of the Black Hills fruits appear to have had. But in any case stress may be once more laid upon the fact that there appears to be a close community of form between the fructifications of the great branching trunks like C. superba and others of its kind on the one hand, and Williamsonia on the other. These several genera must have belonged to the same family, but only when the various possibilities of form and association involved in the growth from the youngest stages to full maturity of such bisporangiate flowers as those before us are fully considered, can we gain a fair idea of how diverse such a family might be, and how difficult is the interpretation of the evidence afforded by a series of isolated and dissociated fossil stems and fruits, such as Williamson first studied.

\section{CYCADEOIDEA PAYNEI (?).}

A small fragment of a trunk of doubtful species, numbered 493 , bears several very young fruits of some interest, since one is simply ovulate, while the other consists in an ovulate center surrounded by a thin, structureless tissue zone, interpreted as a very young staminate disk. Both these young fruits are less than a centimeter in diameter. The zone of seed stems is plainest in the ovulate fruit, and several of the ovules are already well outlined, although very small. The enveloping bracts are small but distinct, and quite closely appressed to the ovulate surface. In the transverse section of the other fruit of trunk 493 the base of the central cone is distinctly fluted and surrounded by a thin, correspondingly fluted, structureless annulation that can not be satisfactorily explained as other than a very young disk ( $c$. photograph 2 , plate $\mathrm{XLIII}$ ). If these two fruits are characteristic, the trunk bearing them is of course monœcious. But in the case of such young forms from a fragmentary trunk the evidence is only a little completer than that afforded by isolated specimens, while so many categories of inquiry are left unsatisfied that it is well-nigh idle to speculate on them, all the more so because finely preserved trunks which will yield definite and comnected facts concerning their fruit habits await investigation.

\section{CYCADEOIDEA COLEI (?).}

A small trumk, No. 8o, somewhat doubtfully referred to Cycadeoidea Colei, bears the finely preserved and very young cvulate strobilus, from near the base of which has been cut the transverse section shown in plotograpin $I$, plate xLIII. The main point of interest here is that another example of an ovulate fruit is added in which, with vigorous growth of the very young seed zone, there is no direct evidence of the previous maturity of a staminate disk. But a disk annulation or sloulder is as usual present at the base of the ovulate cone, and it is by no means certain that a functional disk was not present a short time previous to fossilization. 


\section{CYCADELLA WYOMINGENSIS.}

(Figure 93, 1.)

The handsome group of silicified trunks from Carbon County, Wyoming, as noted elsewhere, affords in many instances wonderfully preserved structural details. Finely preserved laterally borne fronds have been found embedded in the armor of these trunks, and the discovery of the young strobili is hence all the more satisfactory as going far to complete our knowledge of both the vegetative and reproductive characters. A basal section through one of these strobili displays an ovulate cone several centimeters in diameter, but with very young sporophylls, no very great

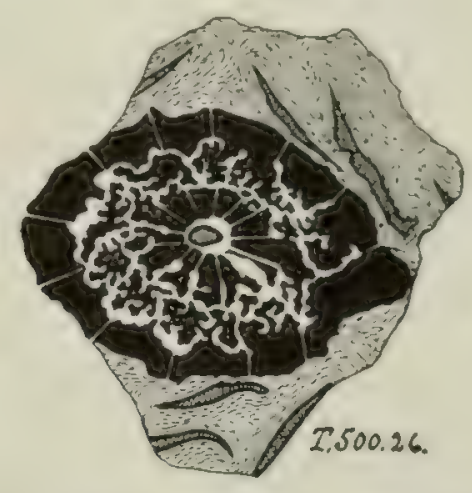

II

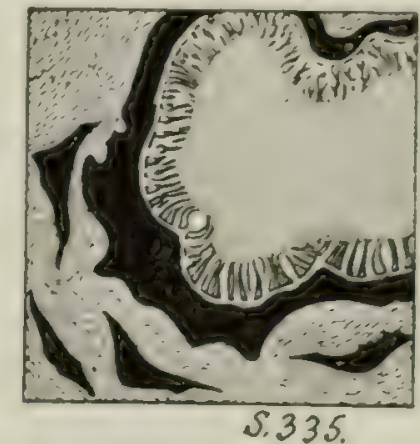

Fig. 93.-Transverse sections of young bisporangiate strobili of the Cycadeoidex.

1. Cycadella wyomingensis. $\times 4$. A very young fructification still folded and deeply immersed in ramentum. Exteriorly 13 discrete fronds are cut slightly above their monadelphous basal union, and interiorly the summit of the central ovulate strobilus is surrounded by the decurved tips of the disk fronds. The space between the frond bases and tips is densely packed with pinnules, there being a very distinct suggestion that a bipinnate condition is present. Distinct synangia have not yet appeared, or at least can not be distinguished. The number of fronds agrees with $\mathrm{C}$. ingens.

II. Cycadeoidea superba. S. 335. $\times 3$. A very young fructification deeply embedded in ramentum and cut through the continuous base of the staminate disk near the base of the central ovulate cone, the level being relatively inuch lower than in the preceding section. There is especially to be noted a tendency of the young and short interseminal scales to form groups or sufts, as of very short secondary axes. No seeds are apparent.

differences from other types of simply ovulate cycadeoidean strobili being evident. It is, however, probable that many of the Cycadella fruits protruded farther beyond the armor when approaching maturity than did those of most other Cycadeoidere.

It is of no little interest to note in this comnection that in a section throngh the basal region of an ovulate cone of Cycadella-trunk 500.88, cf. Ward (I $-S)$ the structure of the very young interseminal scales, the most reduced and minute yet observed, comes out with diagrammatic clearness. In these young scales, no more than $0.75 \mathrm{~mm}$. in length by $0.15 \mathrm{~mm}$. in diameter, the cells are thick-walled throughout and scalariform. In the basal region the cells are elongate-nearer thie summit less and less so exteriorly, the outer layer finally being made up of squarish palisaded cells one cell in thickness. Beneath this outer layer the cells are relatively large and heavy-walled to a depth of several cells, inclosing the innermost tissue composed of a group of about twenty small, much-lignified bundle cells very. prettily conserved, as seen in transverse section. Letween these minute scales very young intervening seeds are preserved in ontline only:

In addition to the preceding specimens sectioned and studied there was cut from the type specimen of Cycadclla wyomingensis the smallest bisporangiate stro- 
bilus yet observed in the Cycadeoidex. This fruit, as shown in the transverse section cut through its broadest portion, figure 93, is only $7 \mathrm{~mm}$. in diameter, and hence comparable in size to some of the smallest of the silicified cordaitean strobili from the flint nodules of Grand Croix. Although so minute, the central cone is distinct, as well as the series of thirteen fronds of the outer staminate disk, even the bundle system of the rachides being in part, if not entirely, indicated by preserved xylem cells. Whether the microsporophylls of the disk are bipinnate, or simply once-pinnate, with the synangia somewhat advanced in size and withont distinctly indicated structure, is not clear. It is, nevertheless, truly marvelous that so minute a fructification should show so much, and at the same time it is a gage of the rich reward that awaits the efforts of the patient student of the Cycadeoider who would know all about this wonderfully conserved and fundamentally important group of ancient plants.

Additional facts concerning young fructification are given under the head of bisporangiate axes. In the foregoing examples only a suggestion and merely initial study of very young fruits has been attempted. The subject must be again taken up. The object has been only to show the general character of axes which are distinctly young - that is, have presumably never produced pollen or that simply bear unfertilized ovules. However, these isolated examples show at once the richness of the material at hand and the practical impossibility of reasonably defining individual species and even genera in the absence of much wider study. Before such study has been made, specific and generic terms can be employed only in an arbitrary manner, though, nevertheless, they are a well-nigh indispensable convenience. Furthermore, in the absence of entire series of young fructifications cut in median longitudinal section from trunks in different stages of growth, it is very clear that we can have but an imperfect knowledge of the varied phenomena of fruit growth, and of monœecious, diøcious, and bisexual conditions in the Cycadeoideæ.

THE YOUNG OVULATE AXES OF CYCADEOIDEA DACOTENSIS.

$$
\text { (Study of Trunk No. 2I4. Cf. figure 94.) }
$$

In all instances of young fructifications described above the strobili are for the greater part young in the sense of presumably never having produced either mature pollen or ovules ready for fertilization. But we now come to the consideration of a wonderful series of strobili, including pollen-bearing flowers and ovulate cones, all from the same trunk and furnishing far more definite testimony than almost any number of isolated examples ever can. It was early seen that intensive study of the trunks from the Black Hills must yield far better results than a partial study of many forms. For this purpose trunk 2I4, photographed on plate VI, No. 8, was early selected. This specimen is nearly perfect in preservation, little or not at all crushed, sub-spherical in form, and abont $45 \mathrm{~cm}$. in diameter. An appression face at its base shows that it grew in a clump and must have begun as a low growing branch of a larger and older central stem. As collected the trunk was broken into two nearly equal closely fitting parts along a line roughly following its middle 


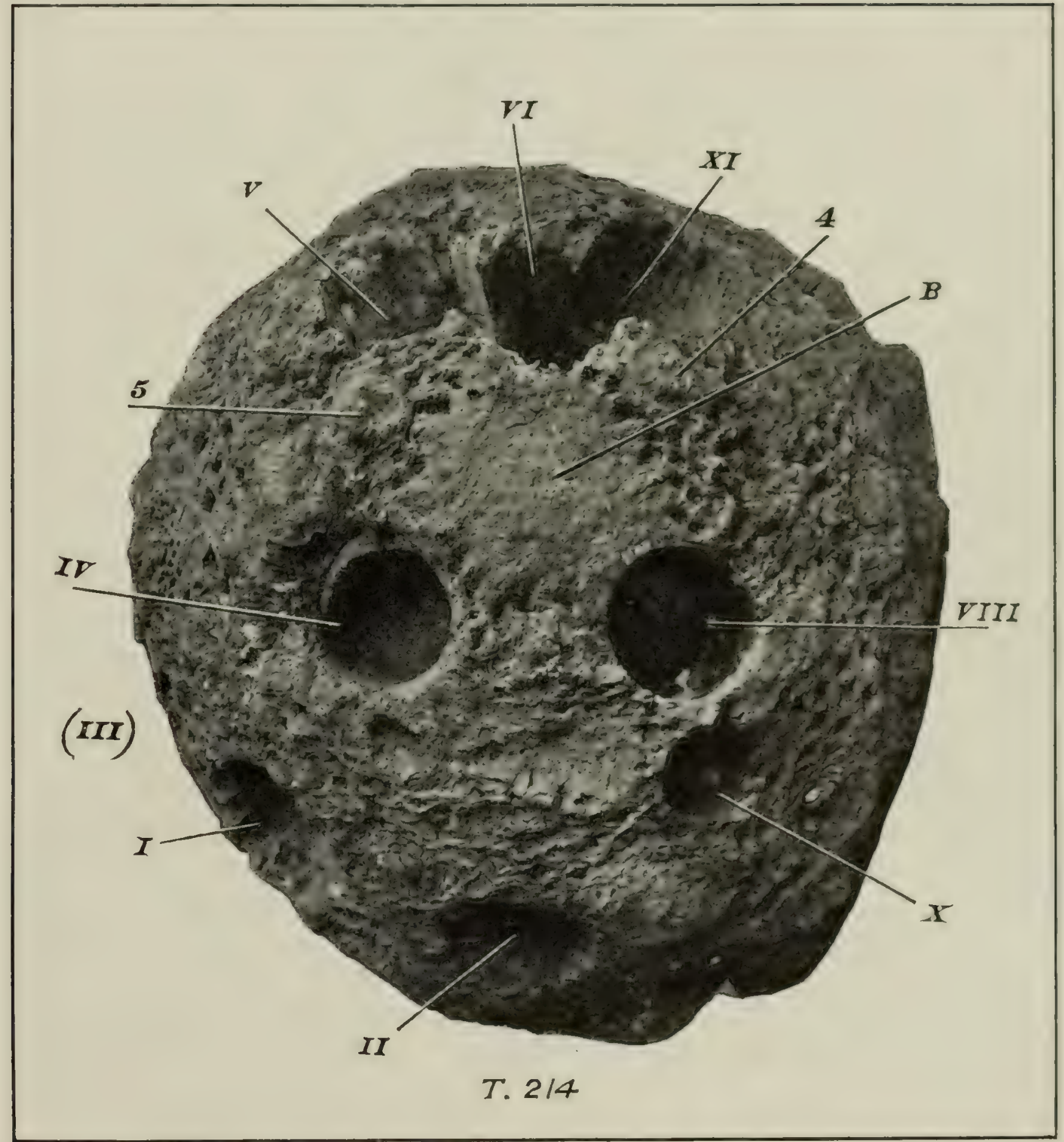

Fig. 94. - Cycadeoidea dacotensis. T. 214. $\times 1 / 4$ nearly. Summit of trunk after drilling out in the form of cylindrical cores the fruits numbered I, II, III, IV, V, VI, VIII, X, XI, 4 and 5, young fruits of the series encircling the terminal bud $B$. (Cf. figs. 14 and 89 , showing lateral views, and photograph of tr.ink as originally collected, Plate VI, No. 12.) 

circumference. It is also quite hollow, a considerable portion of the large medulla not being originally preserved; though conservation is in other respects of surpassing perfection and beauty. The apex is complete and 6I large floral axes are borne laterally and about equally distributed over the surface, the trunk, having at the time of fossilization, as will be described presently, just passed the main period of pollen maturation. Fortunately a number of the flowers or fruits yet bear pollen, and several of these, as not yet expanded and preserved entire, have already been described separately in the preceding chapter on bisporangiate axes. Noreover, the surface features of the other fruits present showed from macroscopic study that not only bisporangiate axes, but also ovulate and certain young axes, were present. These general features and the examination in thin sections of several of the fruits at once indicated, when these investigations were first begun, not only the practicability but the necessity of making the present trunk one of the main bases from which to proceed to the study of the larger series. Hence a number of the fruits were selected according to the variety of external features shown, and cut out in the form of cylindrical cores of various appropriate diameters ranging from 4 to $8 \mathrm{~cm}$. and extending through the entire armor into the medulla. The method of cutting employed is, as described in detail in Chapter III, a new one, especially devised during the course of the present investigation.

Sixteen axes of fructification in all have been either cut from trunk 2I4 or carefully studied and numbered I to XVI. Numbers I and III are the expanded bisporangiate flowers bearing nearly mature pollen, described in the preceding chapter. The descriptions there given must hence be borne in mind in connection with the present general and more distinctly biologic study.

It is believed that the study of the fructification of trunk 2 I4 conclusively proves the bisexual character of all or most of its strobili, and that the maturing of these numerous axes of inflorescence was confined mainly to a single reproductive period in the life of the trunk. The fruits studied in thin sections, verifying this conclusion, may be best described in series, beginning with the youngest and passing on up to the most advanced stage of growth exhibited. The fructifications selected for this order and method of presentation are numbered IX, VI, VIII, (I), (III), VII, $\mathrm{x}, \mathrm{XIV}, \mathrm{II}$, and $\mathrm{v}$, and their position on the parent stem, together with axes I and III is indicated in figures I4, 89, and 94. Their description follows:

\section{FRUITS IX, VI, AND VIII.}

The photograph of trunk 2I4, given on plate vi, No. 8, shows at the summit a series of well-marked conical masses of ramentum 4 or $5 \mathrm{~cm}$. in diameter and projecting to a height of about $4 \mathrm{~cm}$. The surface characters plainly indicated these to be the summits of fruits but little or not at all eroded away, and their position among the youngest of the leaves, next to the apical and non-emergent frond series that would have normally formed the next succeeding foliar crown, at once suggested, in the absence of thin sections, that the strobili inclosed must more likely be young than any others. Such has proven to be the fact. As photographed on plate xxxux, No. I, and plate xLI, No. I, the median longitudinal sections through 
these axes passing from the summit of the trunk to the medulla in the radial longitudinal plane show them to consist simply in heavy, flattened, barrel-shaped bractbearing bodies surmounted by long and dense ramentum. There is here in fact a nearly full grown peduncle, bearing rather small but long bracts throughout nearly all of the distal two-thirds of its entire length ; and the only suggestion of the subsequent development of a terminal fruit consists in some young, small, low, and not very distinct growtls, forming a sort of apical asteriation deeply packed in ramentum. This asteriation does not appear to be formed entirely of the youngest bracts, which of course form the terminal members of a spiral series, and hence may be held to mark the position where a fruit would eventually have formed under normal conditions of growth; though it nay well be that the growth of these particular axes has been in some way checked. In any case, however, it is pretty clear that early growth of the peduncles to a nearly normal length and size took place before any well-marked strobilar development, and it seems that this must have been the habitual mode of carly fruit growth and emergence in these plants.

The structure of the peduncle is essentially that of much more mature forms. There is the usual woody cylinder, inclosing a peduncular medulla, and surrounded by a cortex traversed by delicate bundles rnn11ing out to the bases of the bracts, but not nearly so distinct as are leaf-trace bundles. As in all the peduncles, this is practically a repetition of the trunk structure itself, whence these fruit axes are simply

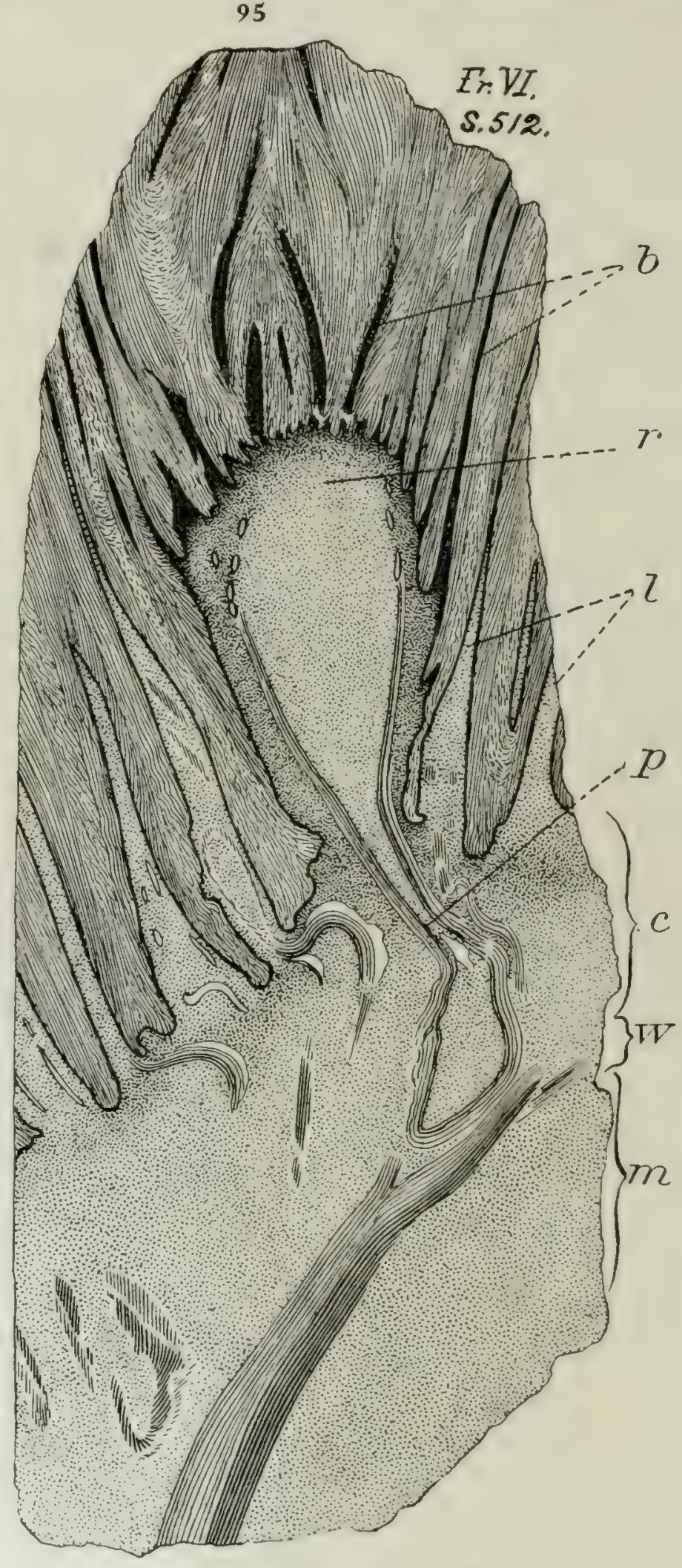

Fig. 95.-Cycadeoidea dacolensis. T. 214. F. VI. S. 512. Radial longitudinal section of trunk, and nearly median longitudinal section of young axis of fructification and surrounding leaf bases, as borne near the summit of the trunk. In about the same stage of growth as Fruit IV of T. 214. Natural size.

b. Bracts: $r$, large receptacle at the apex of which only the bracts are as yet prominent: I. leaf bases; $p$, bundle system of the peduncle as seen to extend through the cortical parenchyma : $c$ c corlex: $w$, woody cylinder: $m$, medulla. For transverse sections see figure $95 \mathrm{a}$. 
lateral branches modified for reproduction. The bundles which make up the woody cylinder of the peduncle take their origin directly on several different wedges of the woody cylinder of the trunk itself, and then pass obliquely upward and outward through the cortical parenchyma. In the longitudinal section of fruit vi, as may be seen in photograph I, plate XXXIx, both the lower and upper segments of the peduncular bundle supply are unbroken in their entire course through the cortex to their origin on the wedges of the woody cylinder of the trunk, and no connection with or appression to similar bundles of an axillary leaf base appears. In the

95a
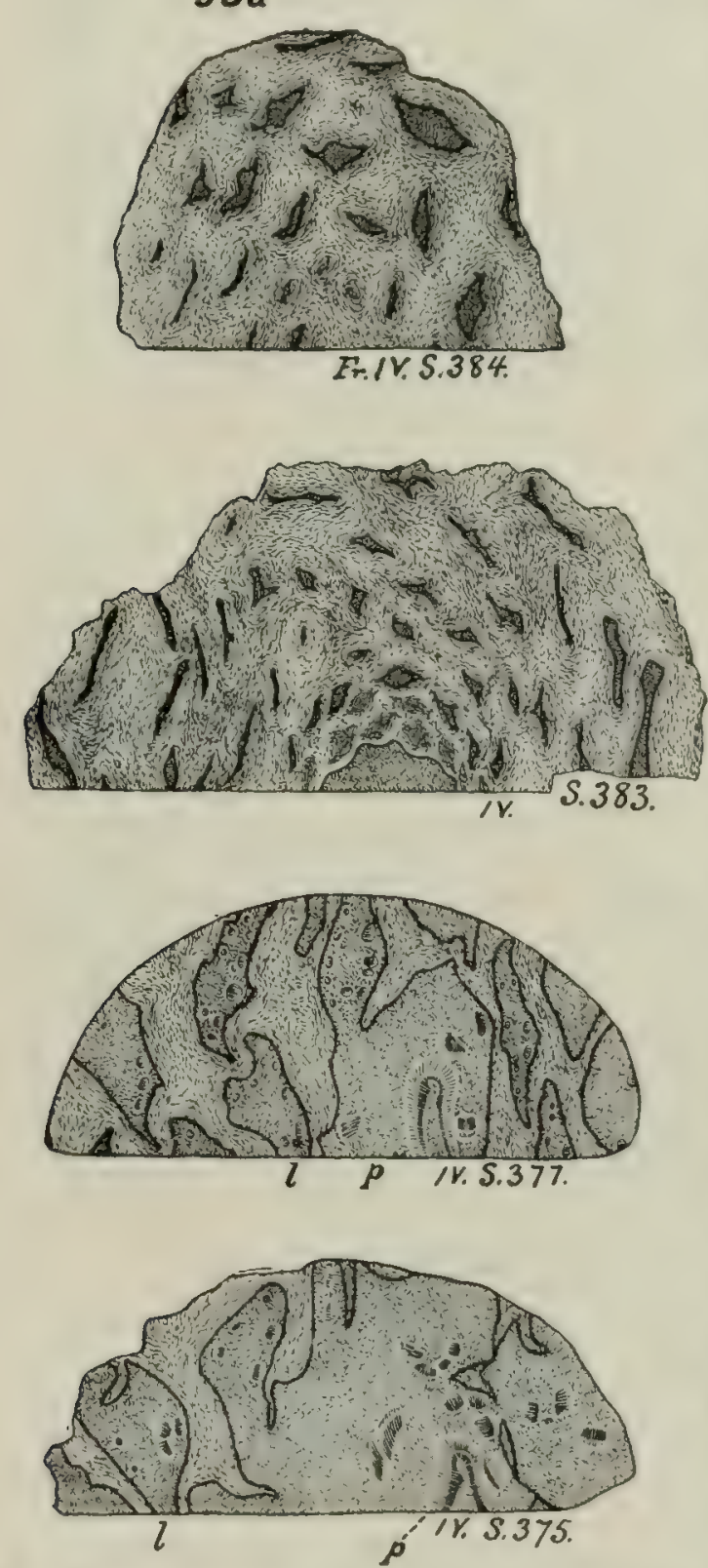

Fig. 95a. - Transverse sections from axis IV, which is in the same slage of growth as VI, and from relatively the same position near the summit of T. 214.

1. Leaf bases; $p$, bundle system of the peduncle as seen to extend through the cortical parenchyma. similar section of axis IV, photograph I, plate XI,I, the course of both segments of the bundle supply is not so direct, but is nevertheless nearly complete, and simply shows, were this not perfectly clear in transverse sections, that the different strands which finally take a cylindrical form in the base of the peduncle curl or curve about in places in their course through the cortex. In the latter section the axillary leaf base and its bundle supply are also quite distinct, although no direct connection with the peduncle trace is evident. But adnate growth between the peduncular and axillary leaf-base supply might be present at some point outside the plane of the sections made, or might form later on. The tracing of the entire course of all the segments or parts of a peduncular bundle supply from their origin has not been attempted in the case of the present trunk, though clearly there is a quite direct course of all the parts of each peduncle supply from a series of nearly adjacent woody wedges of the trunk. The general appearance in transverse section is, however, beantifully shown in figure 96, where two nearly superimposed peduncular supplies (fruit viII) are cutthe one just beneath and the other well within the cortex. In the upper peduncle the bundles of the axillary leaf base are distinct, but not in the lower. Here, although the flattened cylindrical peduncular trace is still pronounced, it shows simple appression to various isolated leaf-base traces and also incloses one inverted trace that is presumably, although not certainly, foliar. Even in the absence of further sections it may, however, be seen from such clear testimony that the several elements of a given peduncular bundle series which unite to form a sub-cylindrical or compressed pattern as they take their course through the cortex of the trunk must 
originate on an adjacent series of xylem wedges in some approximately circular position, or fairly definite order.

\section{FRUITS I AND III.}

As already fully illustrated and described in Chapter VII, these two fruits are bisporangiate and nnexpanded, but bear nearly or wholly mature pollen. Their ovulate stage of growth is an important starting point, since no example has been found on trunk 2I4 of a developmental condition intermediate between the present and the merely incipient stage of growth seen in the axes IX and VI, just described. The structure of the ovulate cone being already understood, it is only needed to repeat that the seed-stem region is but $0.9 \mathrm{~mm}$. in thickness in fruit $\mathrm{I}$, and about twice as thick in the slightly older fruit III. (See plate xxxiv, photographs I and 2, and plate xxxvII, photograph I, showing these strobili, which,

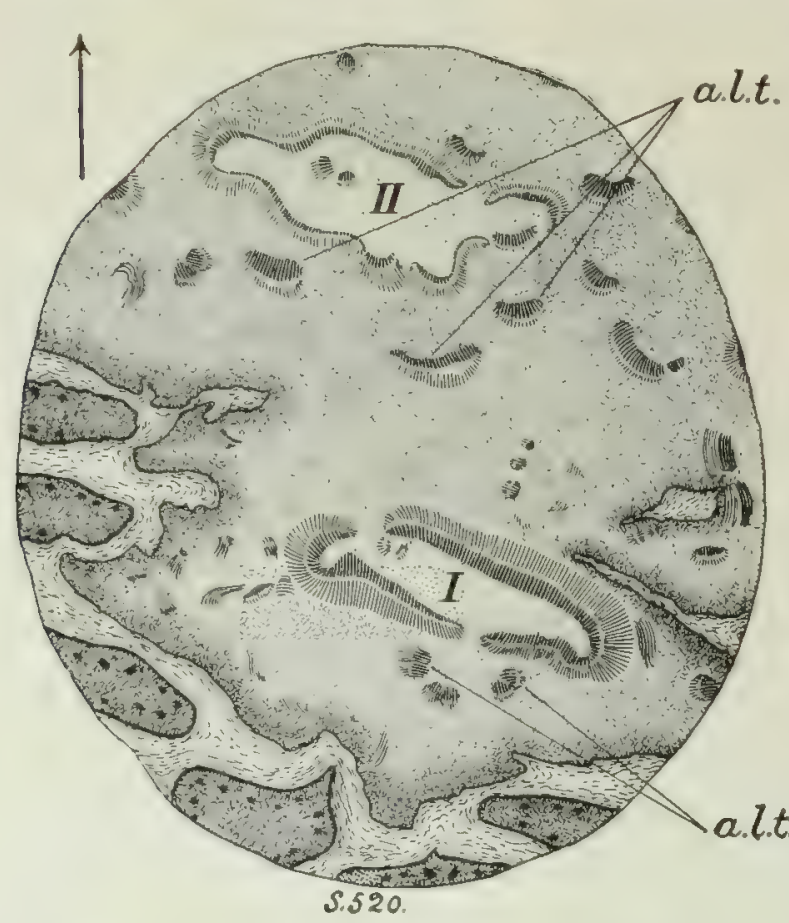

Fig. 96.-Cycadeoidea dacotensis. T. 214. S. 520. Fr. VIII. Natural size. Tangential section to trunk made by cutting a cylindrical core in a slightly oblique direction, producing an elliptical form.

The section passes from the peripheral cortex above into the basal armor below and cuts nearly transversely across the bundle trace of two axes of fructification, No. 1 being cut exactly at its point of emergence from the cortex. The surrounding and most nearly axillary leaf traces (a. l. t. ) are also indicated. The arrow indicates direction vertical to the indicated. The arrow indicates direction vertical to the
trunk. The two smill inverted bundle segments inclosed in peduncle trace II are unexplained, it not being understood whether they are a reversion to older forms or simply lea traces inclosed during the growth of the peduncle trace. according to our view, must in reality be younger than the strobili next to be described.)

\section{FRUIT VII.}

In this bisporangiate axis the staminate disk, as may be seen on plate xxxrx, photograph 4, was evidently about to expand. It has, however, failed of distinct preservation, and the exact condition of the (wilted) disk tissues at the point of insertion is of interest to note, because just such traces of tissue are more or less distinctly present at the base of the fruits next to be described, and have already been pointed out in the ovulate cones of several other species. (Cf. pages I29-I3I, I33, etc.).

\section{FRUIT $\mathrm{X}$.}

The summit of this finely preserved conical-shaped young ovulate strobilus, as in some of the other forms of about the same stage of growth, projected a very little beyond the surface of the armor. The general features and structure are especially clear in the transverse sections and the corresponding longitudinal section, which is entire less the saw cuts. These sections are shown in figure 97. The seed stems are a very little more advanced in growth than in fruit I. The former presence of a staminate disk is vouched for by the presence of the remains of its basal portion, and it is also interesting to note the presence in the more basal of the transverse sections of several synangia which lie between the cone and the surrounding ramentum. 'These isolated synangia are indicated in the figure. 
FRUIT XIV.

Fruit XIV exhibits identically the same stage of growth as the preceding; but the heavy covering of bracts, these being fully 125 in number, is prominent. The fact that this fruit is borne very near the base of the trunk is
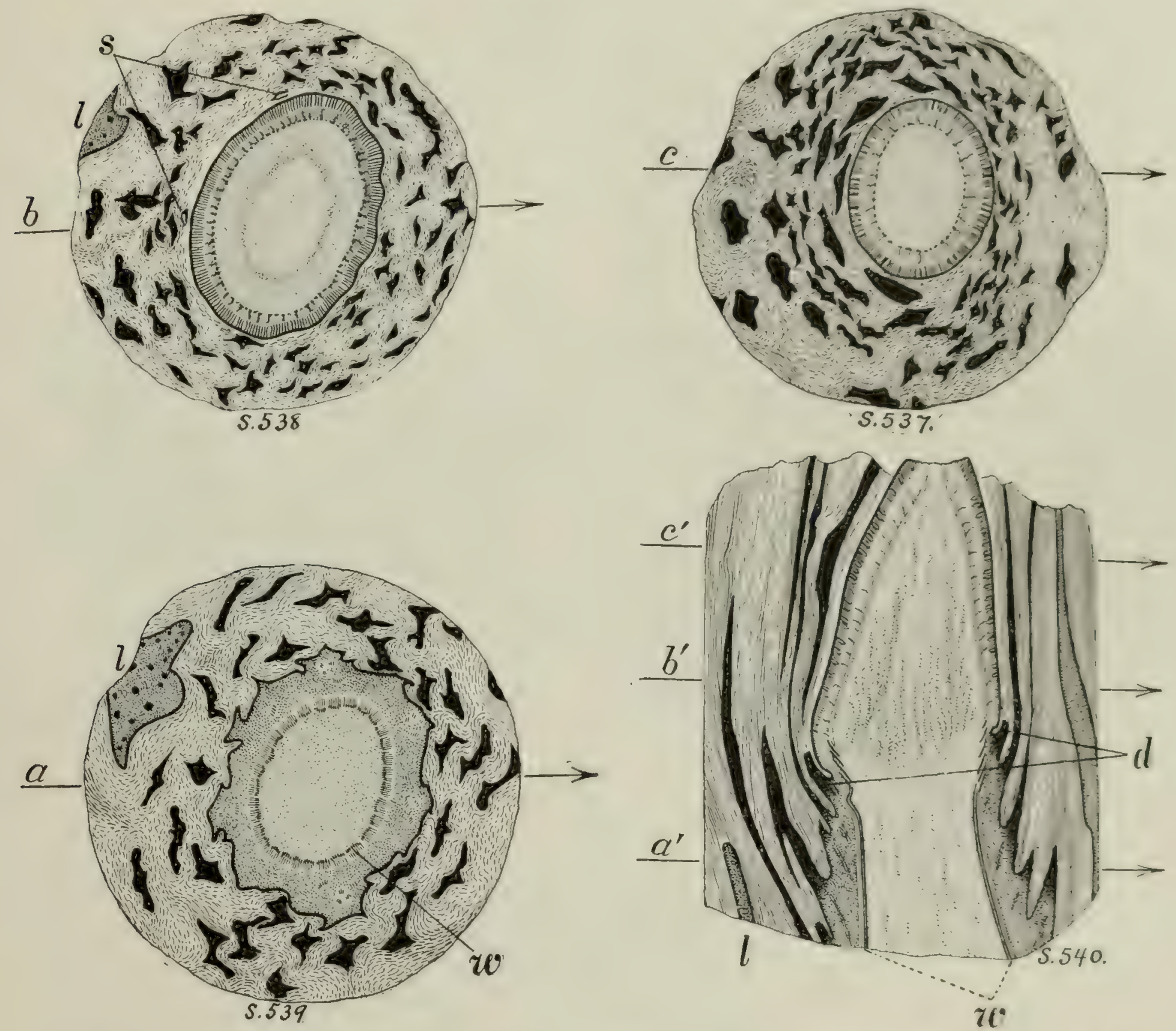

Fig. 97.-Cycadeoidea dacotensis. T. 214. Fruit X. Serial sections 537-540, cut from a cylindrical core drilled out of the armor. $\times 1 \frac{1}{3}$. The arrows in each case point toward summit of trunk, and indicate in the three transverse sections the plane of longitudinal section, and in the longitudinal section the plane of transverse section. (CF. Plate XLII.)

a. S. 539. Cut transversely through the peduncle and showing its bundle system, the bract traces, the lower (outer) bracts, and a single leaf base (I) with its bundle system. W. Woody cylinder of peduncle.

b. S. 538. Parallel to the preceding section at a distance of $1.8 \mathrm{~cm}$. Cutting near the base of the ovulate cone. So Two isolated synangia lying between the surface of the ovulate cone and the ramentum of the enveloping bracts.

c. S. 537. $1.2 \mathrm{~cm}$. distally parallel to the preceding section. This section cuts through the summit of the ovu!ate cone, the bundle system of which is indicated by the darker band $2 \mathrm{~mm}$. beneath the palisaded layer of young seed sterns and interseminal scales.

$a^{\prime}, b^{\prime}, c^{\prime}, S .540$. Longitudinal section through same fruit as preceding transverse sections. Obtained by cementing logether, in exactly their original position, the four portions of the fruit resulting from cutting transverse sections $\mathrm{a}_{0}, \mathrm{~b}, \mathrm{c}$. Arrows $\mathrm{a}^{\prime}, \mathrm{b}^{\prime}$, and $\mathrm{c}^{\prime}$ maris positions from which $\mathrm{a}, \mathrm{b}$, and $\mathrm{c}$ were cut. Likewise in the clits of the thre s preceding sections arrows $\mathrm{a}, \mathrm{b}$, and $\mathrm{c}$ indicate plane of longitudinal section.

1. Portion of nearly axillary leaf base; $w_{0}$ woody cylinder of peduncle; $d$, basal s vrtions of a wilted or dehiscent staminate disk

of interest because, although it chances to be very deeply surrounded by robust bracts, it is no more advanced in growth than the very similar fruit $x$ from near the summit, as just described and figured. In fact, the cone is small for so large 
an axis, and was perchance destined to abort following dehiscence of its large, earlier-borme basal disk. The stage of growth so well exhibited in these fruits, however, is apparently the average one reached when the series of events resulting in fossilization cut short further development. The lateral surface of the trunk was, then, quite evenly fruit-producing, and, while in the absence of thin sections there is no full certainty as to the actual number of cones in relatively the same stage of growth as fruits $\mathrm{x}$ and $\mathrm{xIV}$, this may well be more than forty; that is to say, fully or more than two-thirds of all the fruits borne by the entire trunk.
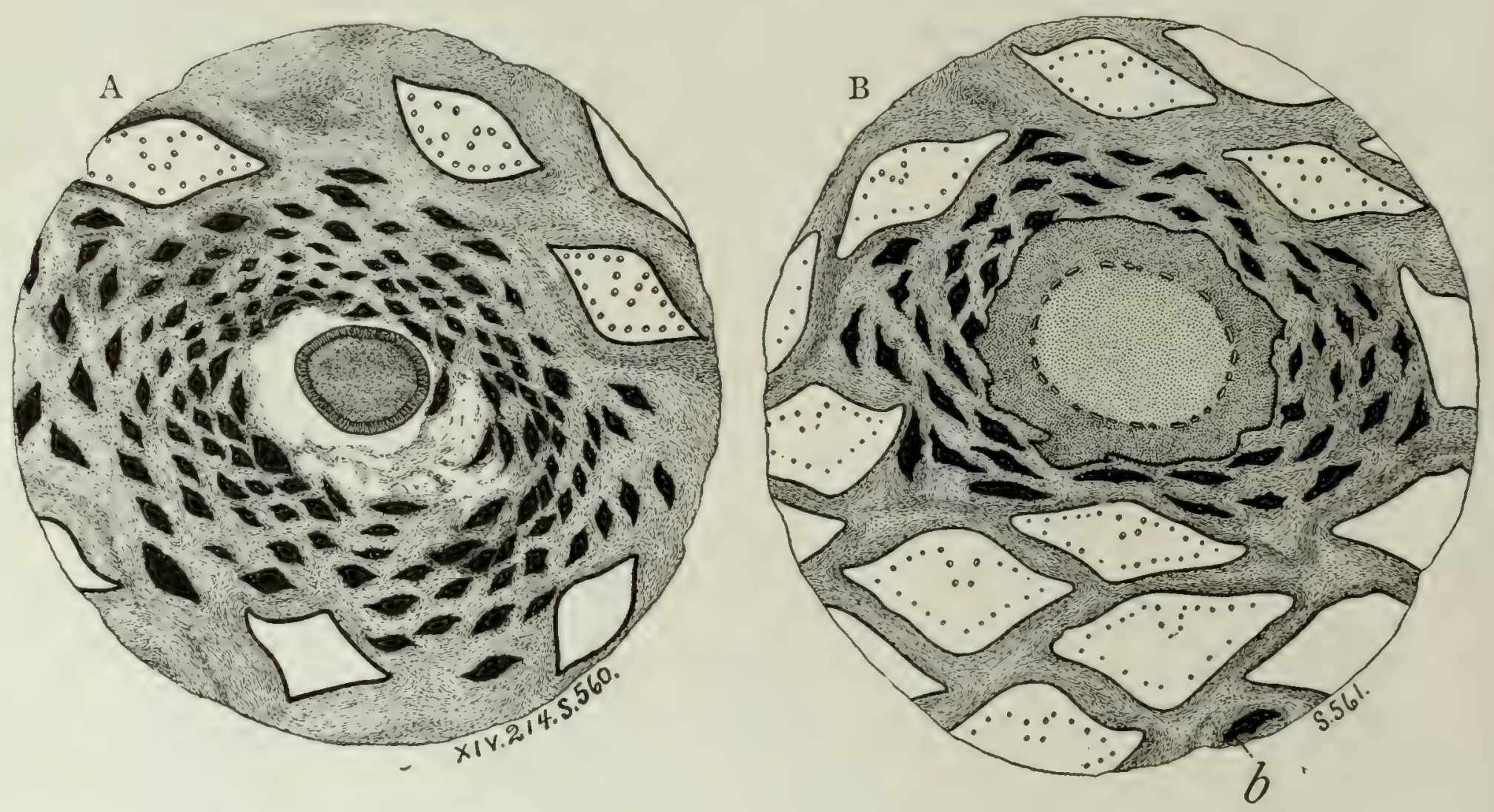

Fig. 98.-Cycadeoidea dacotensis. T. 214. Fr. XIV. Young ovulate strobilus. Natural size.

A. S. 560. Transverse section cut near the summit of ovulate cone and about $2 \mathrm{~cm}$. beneath the surface of the armor. Ramentum short lined'; bracts in solid black; size and position of bundle patterns of three upper leaf bases indicated.

B. S. 561. Transverse section cut $2.5 \mathrm{~cm}$. beneath $\mathrm{S}$. 560 . This section lies beneath the insertion of most of the bracts, and the peduncle is less flattened in the vertical direction than in most cases. $\mathrm{b}, \mathrm{A}$ single bract belonging to an adjacent fructification.

As may be seen in figure 98 and plate xxxvin, photographs I and 2, the transverse sections of fruit XIV and surrounding leaf bases as cut from a cylindrical core are objects of beauty scarcely surpassed among sections of silicified plants.

\section{FRUIT II.}

This ovulate cone (see fig. 99) is considerably larger than any of the preceding, and although the structure is poorly conserved, there is some evidence that the stage of growth is in advance of that of fruit $\mathrm{x}$, etc. Several other axes are borne by $2 \mathrm{I} 4$ in nearly the same stage of growth. The seed zone is estimated to have a thickness of about 4 1mm., or perliaps twice that of the most advanced of the preceding cones, while the receptacle is much larger. A few days, or, at most, a fortuight of growth might, nevertheless, produce all of this really slight difference, excluding of course Nos. IX and VI. 
FRUIT V.

In figure Ioo and plate XL there is shown the largest of the present series of ovulate strobili. This fine fruit was borne near the summit of the trunk, and is
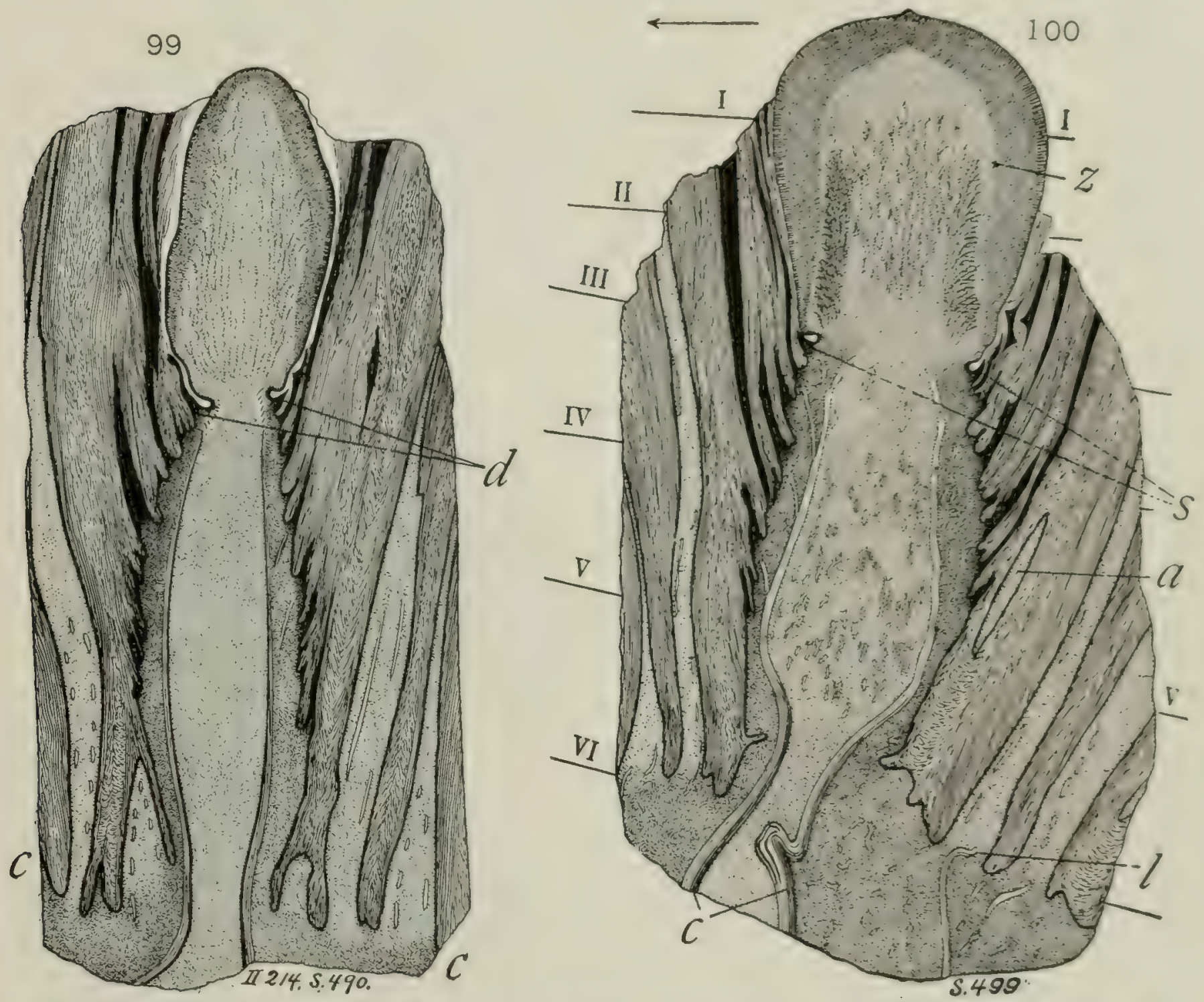

Fig. 99.-Cycadeoidea dacotensis. T. 214. Fruit II. S. 490. Natural size. Longitudinal section through an ovulate strobilus. More compressed and conical than No. V of this same trunk and probably somewhat younger. At $\mathrm{d}$ are remains of an hypogynous disk as in all ovulate cones of $\mathrm{C}$. dacotensis -in the present fructification rather more distinct than usual. c, c, Outer border of cortical parenchyma, on which are seated the leaf and peduncle bases -hence the true surface of trunk.

Fig. 100.-Cycadeoidea dacotensis. S. 499. Fruit V. T. 214. Natural size. Longitudinal section through ovulate strobilus, with surrounding bracts and leaf bases. ( $\mathrm{CF}$. photographic series, $\mathrm{Pl}$. XL.)

I-VI denote the successive levels of the transverse sections shown in figure 100 continued. $z$, Line marking the probable insertion of the seed stems and interseminal scales; $s$, basal portions of hypogynous disk, doubtess staminate and matured some time previous

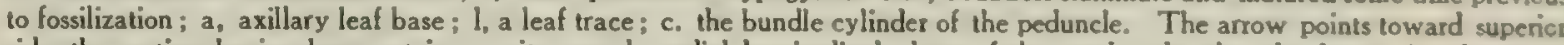
side, the section having been cut in a quite exactly radial longitudinal plane of the trunk; also that the bracts (as shows in solid black) are cut throughout their entire length on both sides of the fruit. This section is perfectly oriented and of rare beauty.

wholly symmetrical. It is of special importance as bridging the gap between the younger elongate conical forms and older robust pear-shaped forms with much larger ovules, as borne on other trunks. The seed-stem zone is not distinct, but preservation zones indicate its greatest thickness as 5 1mm1., or a very little greater than in fruit II. The present cone is one of the nearest of all to the summit of the trunk, and about its base are the usual traces of the earlier presence of an enveloping hypogynously borne disk. 


\section{BISEXUALITY OF CYCADEOIDEA DACOTENSIS.}

A careful consideration of the foregoing data must lead one to deem it evident that quite every one of the fructifications just described, as well as most of the others borne by trunk 2r4, were actually bisexual. That a few of the ovulate cones may have aborted after the production of pollen, and that conversely some of the sixty-odd fruits present may have been simply ovulate and have failed to produce fertile staminate disks is possible and even probable; but there is no direct evidence pointing to such a fact. Far down at the base of the trunk is one ovillate fruit of about the same size as No. Ir and further advanced in growth. Perhaps because of its restricted position such a fruit might have failed to produce a staminate disk and spent all its energies in ovule production, or perchance it is nearly a season's growth in advance of the others. As this cone must have been quite below the level of the ground one wonders how it would finally have been fertilized, to say nothing of many other bract-inclosed fruits, unless through the intervention of free-swimming antherozoids.

It is held that none of the cones just described were sufficiently advanced in growth to have been fertilized by any of the earlier borne pollen, unless, as in the living cycads, the pollen retained its vitality for a long time, several months perhaps, or was slow to reach the stage when actual fecundation took place.

THE FRUITING HABIT OF CYCADEOIDEA DACOTENSIS.

Perliaps the preceding study of a long series of young fruits from trunk 214 has revealed no more interesting fact than that all or all but a very few of its fruits are relatively of the same stage of development, it being likely that most of the flowers produced ovules subsequent to pollen
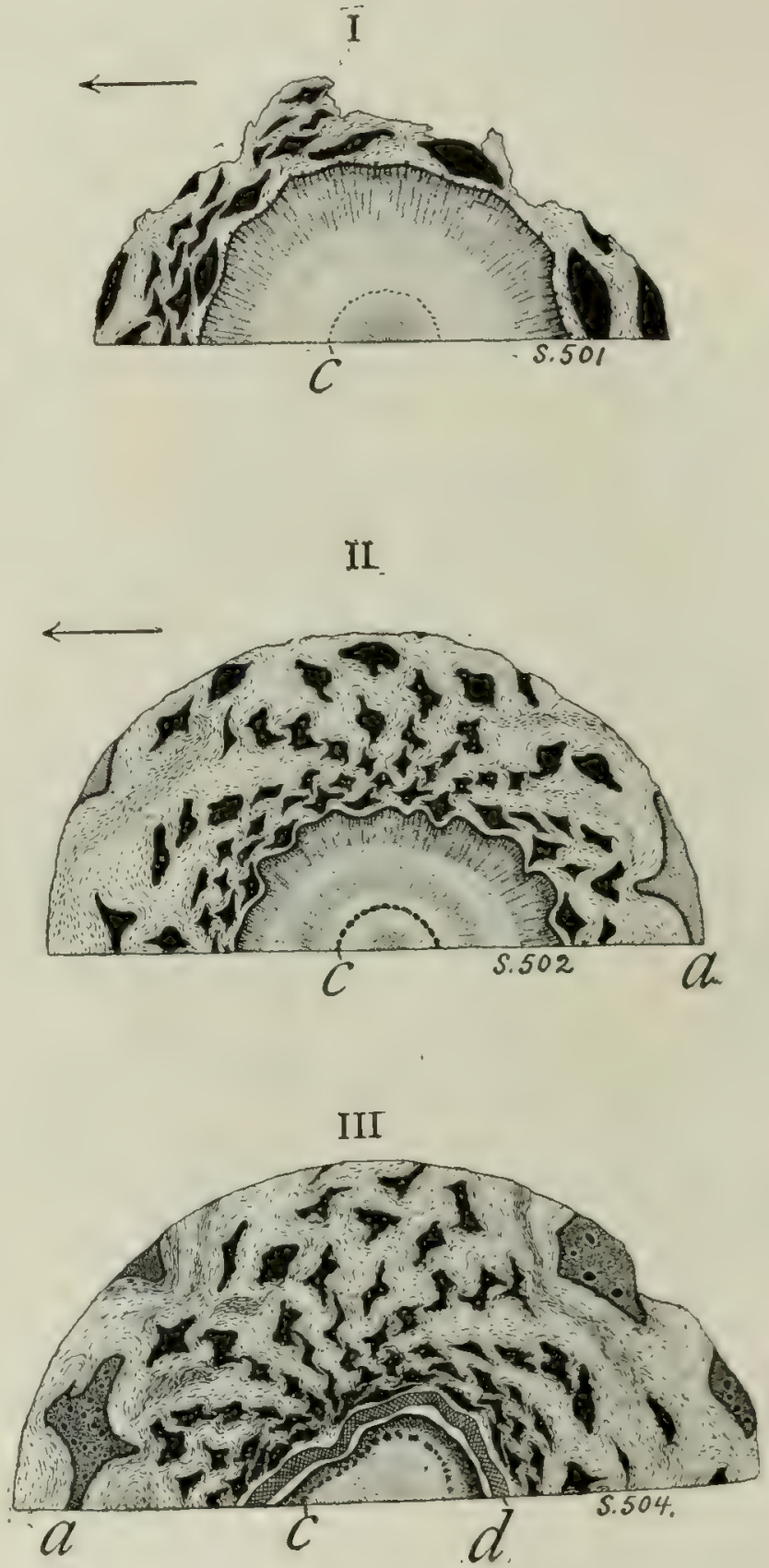
from fruit $V . T .214$. Natural size. The position of these sections is respectively shown by the lines I-VI, in figure 100 , of the accompanying longitudinal section.

$c_{0}$ in sections I-III, denotes the bundle cylinder of the ovulate cone, in IV-V that of the peduncle, and in VI the peduncle trace; $a_{\text {, }}$ in section IV, the axillary leaf base, and in section VI the bundle trace of this leat base as seen next beneath the peduncle trace in the outer cortex: $d$, the basal remnants of an earlier borne hypogynous disk, evidently staminate, and already matured and dehiscent at time of fossilization. The arrow noints toward the summit of the trunk - section III, as due to an oversight, having been drawn in the reverse position.

1. Section through upper end of ovulate cone at point of greatest diameter. S. 501.

II. Section through lower half of ovulate cone, showing the lateral surface fluting of the fruit due to bract appression. Most of the bracts and two leaf bases appear at this level. S. 502. the basal remnant of hypogynous disk and the complete bract series, presenting a distinct spiral succession; also four of the surrounding leat bases. S. 504 .
Fig. 100-Continued. The transverse series of sections cut

III. Section through receplacle or end of peduncle, showing also 
maturation. Whether the flowers required one, two, or three years to mature, after initial growth of a bundle supply leciding from the woody cylinder of the trunk or after their first appearance in the axils of the leaves at the base of the

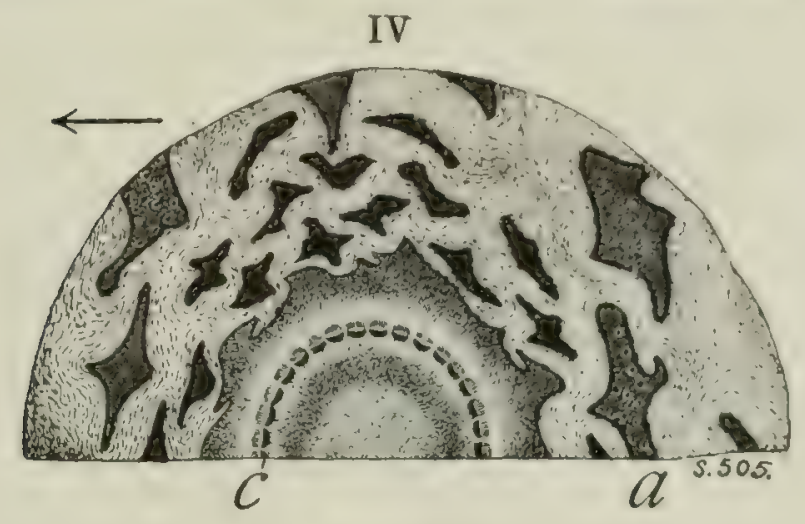

$\nabla$

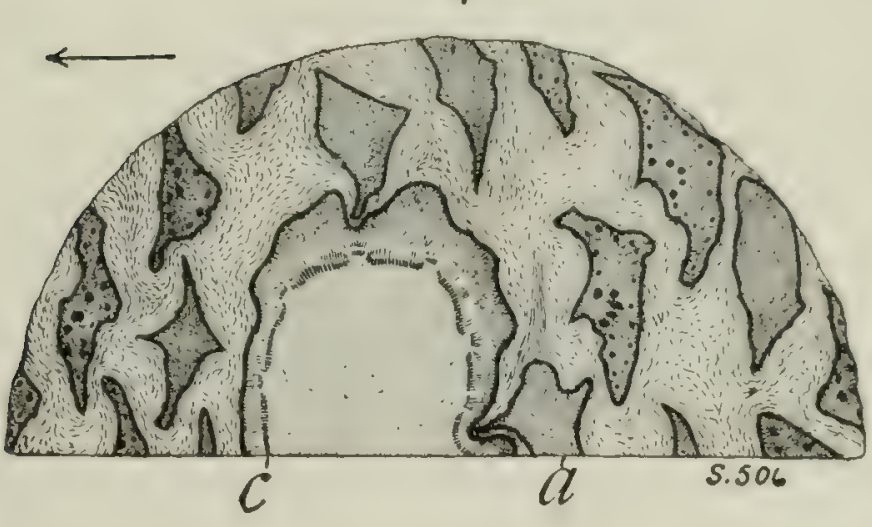

VI

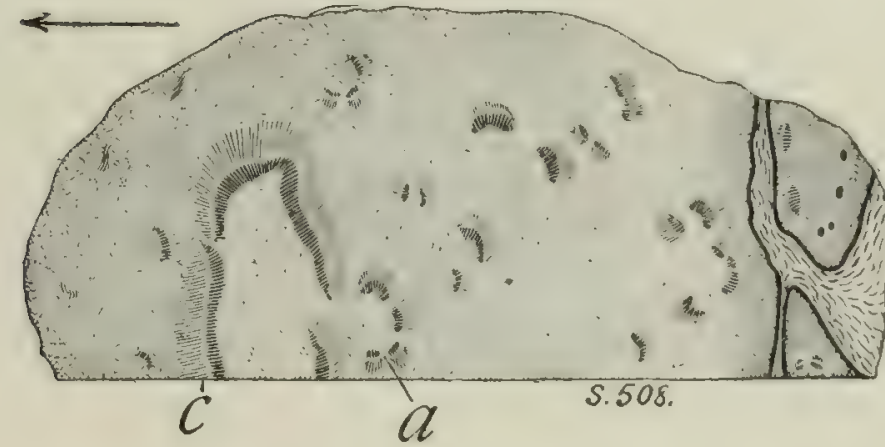

Fig. 100-Continued.

IV. Section cutting peduncle near the lowermost of the bracts. The complete series of surrounding leat bases is present and the bundle system of several is preserved as indicated. S. 505.

$V$. Section through peduncle cut beneath the insertion of the lowermost bracts and showing the large bundles of the woody cylinder of the peduncle. S. 506.

VI. Section culting obliquely through outer cortex, and on right side through two leaf bases near their cortical insertion. The large peduncular bundle traces, as well as that of the axillary leaf base and cular bundle traces, as well as that of the axillary leaf base and
various oiher leaf bases, in part seen in section $V$, are all distinct. various
S. 508 .

That a culminant mode of fructification characterized many of the Cycadeoidex, therefore, seems most probable from the study of the present and the very different species of the C. Wielandi, C. Paynei, and C.turrita group of trunks (cf. p. I26); while in C. Stantoni (I86 a) occupation of all axils had plainly ended fruiting after one or several very productive seasons. 
THE PULCHERRIMA STAGE OF TRUNK-GROWTH.

If it be true that many trunks, as in the case of No. 214, never produced a series of fruits until reaching a large size, then among the large collections of cycads at hand there should be some trunks of considerable size of the same or closely related species that bear no fructifications, and others that bear only young or, at most, but a very few well-advanced fructifications. In either of these cases there will be but little disturbance of the spiral succession of the leaf bases, owing to the emergence of the large axillary fruits; and consequently far more regular and ornate appearance will be presented than later in life, when in full fructification. Now, such stages are found to be well illustrated if one compares a sufficient number of trunks. The immense branching specimen on exhibition in the Yale University Museum, numbered 300, and the largest of its kind known ( $c$. plate XII), bears a considerable number of young fruits, though no earlier fruits than these appear ever to have been borne by any of the branches. As a result, the leaf-base spirals are still of pronounced regularity, and the same is even more conspicuously true of several of the trunks shown on plate V, notably trunk 74I, photograph I. Also to several very perfect and quite similar low-growing trunks of the branching type seen in $C$. dacotensis and $C$. Marshiana the specific name $C$. pulcherrima has been given. This species is, however, not a valid one, and is simply based on younger trunks of the several foregoing types, in which the helicoid arrangement of the leaf bases is undisturbed. The type of $C$. pulcherrima is in the United States National Museum collection, and is figured by Professor Ward ( 338 , plate LXxx). It is a most beautiful specimen, bearing a few isolated young fruits and various branches, while the arrangement of the leaf bases presents an undisturbed and striking regularity. But, plainly, these are only individual peculiarities and not in themselves true specific characters of young Cycadeoideæ. The trunk is simply a younger specimen of $C$. dacotensis, and, had its growth continued, would have formed the central member of a clump. Being already quite large, it was rapidly approaching its main period of fruit production when fossilized. This condition of robust growth and undisturbed regularity of leaf bases may be appropriately termed the pulcherrima stage of trunk-growth and fructification. 


\section{RELATIONSHIPS.}




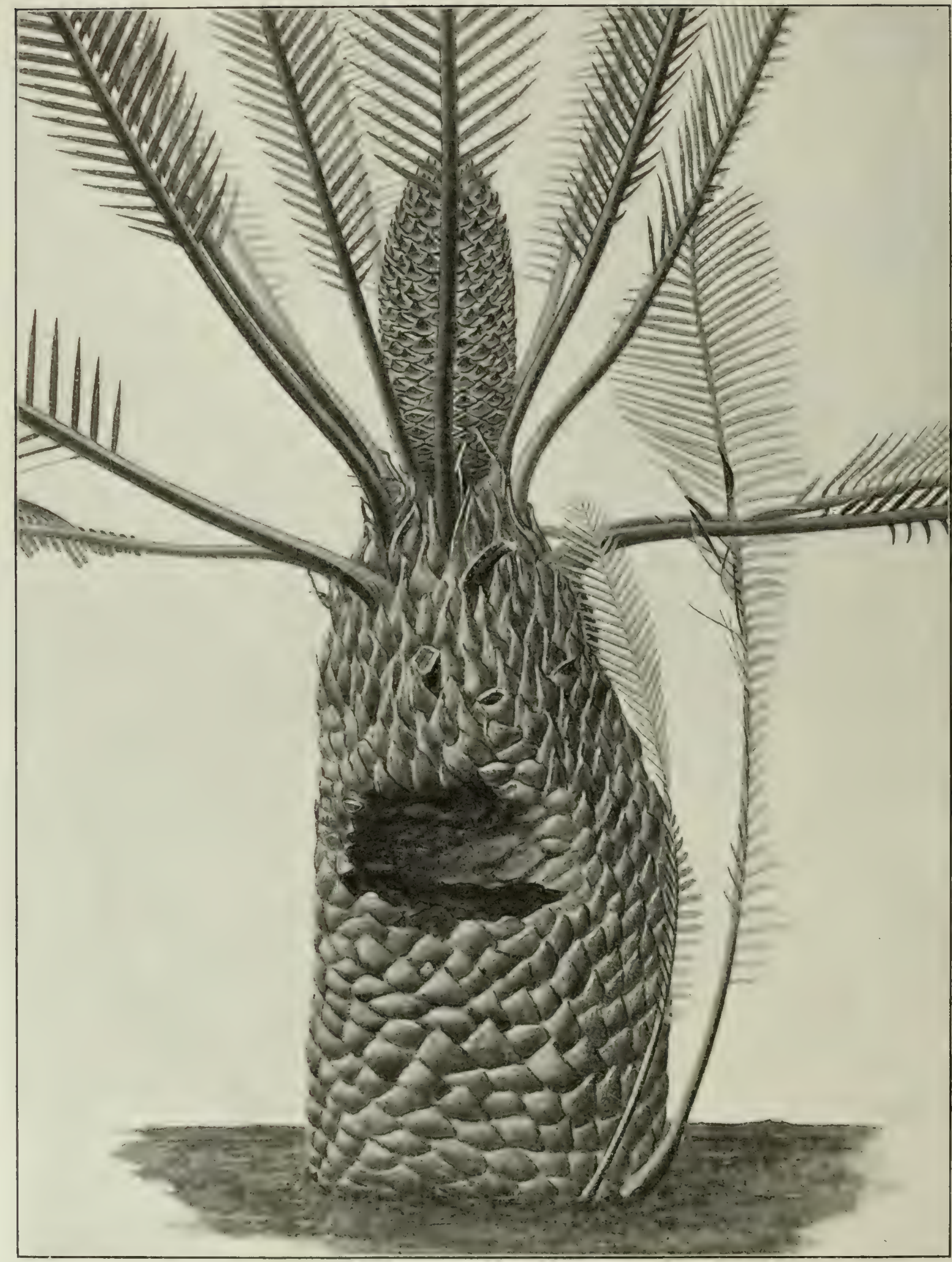

Fig. 101.-Dion edule.-Low-growing columnar and heavily armored type of cycadean trunk with markedly villose leaf bases and scale leaves and several adventitious basal fronds. Staminate plant bearing a single terminal cone $9 \mathrm{~cm}$. in diameter. The great reduction of the sporophylls leaves it physiologically impossible for the conical axis to serve as an integral extension of the stem after the maturity of spores as in ovulate forms of Cycas, limited growth of the axes of fructification being correlated with sporophyll reduction, 


\section{CHAPTER IX. \\ EXISTING AND FOSSIL CYCADS COMPARED.}

It has already been shown in the several preceding chapters that the main differences between the vegetative features of existing cycads and the Cycadeoidere consist in structural modifications in the cortex held to be of comparatively recent origin. And even were there no further analogies to judge from, the universally simpler structural type of all the extinct cycadaceous trunks thus far discovered would alone make such a fact probable. On the other hand, comparison between the types of fructification exhibited by the two groups can only be made in terms of much changed features, for the greater part separated by wide intervals of time. Before attempting the more formal consideration of the complex relationships involved, it is therefore a method of convenience, if not a necessity, to place in connected review the main facts concerning the distribution and organization of the Cycadacer, with especial reference to those details of the greater interest and value in making extended comparison with the Cycadeoideæ.

\section{THE CYCADACEÆ.}

DISTRIBUTION.

The existing Cycadaceæ form an ornate and compact group of gymnosperms, including nine genera and 107 enumerated species indigenous to tropical and subtropical regions (68). Of the genera, four-Zamia, Ceratozamia, Dion, and Microcycas - are natives of the New World. The other five-Cycas, Macrozamia, Stangeria, Encephalartos, and Bowenia - are the Old World forms. Mexico, with Ceratozamia, Dion, and many species of Zamia; Africa, with Encephalartos and Stangeria; and Australo-Malaysia, with various species of Cycas, Macrozamia, and Bowenia, represent the New and Old World regions in which cycadean vegetation is most markedly developed.

Occasionally cycads are abundant in particular localities. Thus Stangeria paradoxa, one of the smaller species, forms thickets on the Natal border, and in southeastern Australia considerable areas are closely set with Macrozamia spiralis. As a whole, however, the existing cycads, in genera, variety of species, and probable relative abundance as forest plants, play but an inconspicuous rôle as compared with that plainly indicated by the fossil record for the cycadaceous forms of Upper Jurassic and Lower Cretaceous time.

The most of the cycads are, for trunk-forming plants, low and inconspicuous, the extremes in size lying between the dwarf Zamias with underground stems and 
such forms as the Japanese Cycas revoluta and the Australian C. media R. Br. The first of these species has been reported as reaching a trunk thickness of I meter, whilst the trumks of the latter, though of somewhat lesser diameter, reach a height of 23 meters. Zamia Pöppigiana and Z. psendoparasitica are Peruvian epiphytes, the latter species also occurring in Panama. In relative size, outer appearance, and habit of growth, the cycads have changed but little since the Triassic. Such tall unbranched forms as Cycadeoidea Jenneyana, as we have seen, bear much

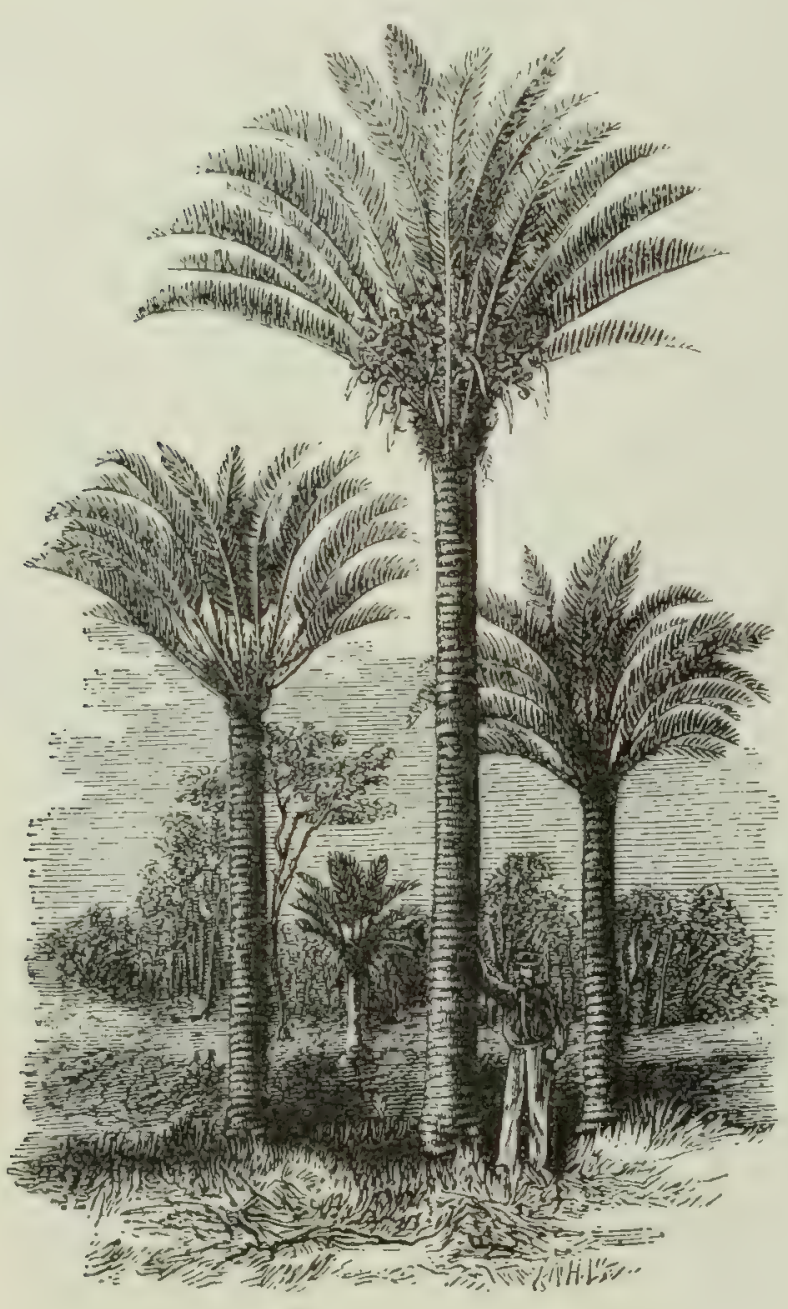

102

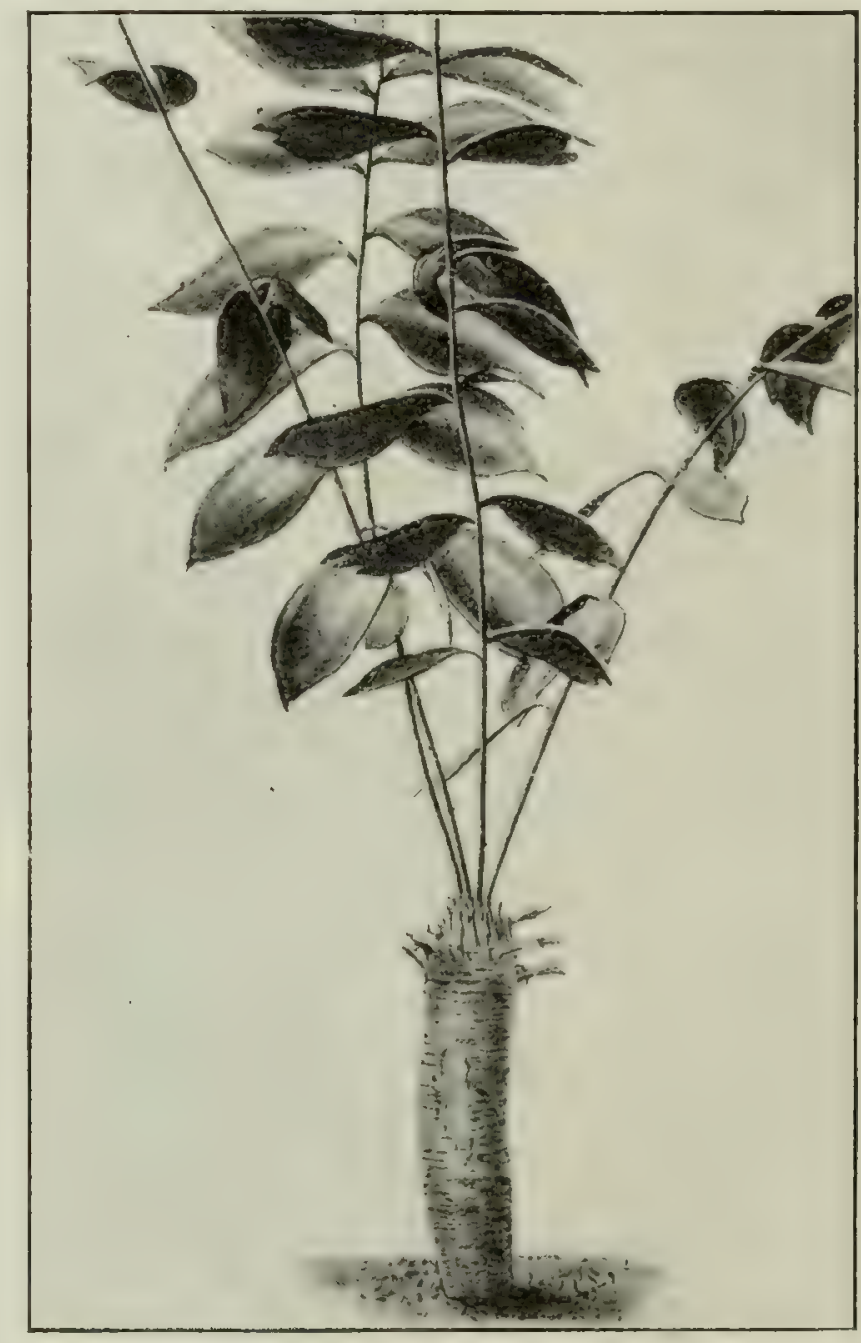

103

Fig. 102.-Cycas Normanbyana to the left. Cycas media R. Br. the two cycads to the right-that in foreground bearing numerous carpellary leaves. These columnar Australian species include some of the tallest forms known, C. media reaching a height of 23 meters, and greatly exceeding any known fossil cycad in this respect. (From Engler und Prantl, after F. V. Müll. Phyt. Austr., Bd. VII.)

Fig. 103.-Zamia van Houttei, $\times \frac{1}{9}$. Nearly armorless type of trunk. Pinnules with notably large and broad blades. Compared with Z. Lindeni, figure 47B, this trunk affords a fine example of foliage variation marking two closely related species.

the same relation to the lower-growing Cycadellas from the Black Hills Upper Jurassic [Wealden equivalent] as do the taller species of Cycas to the pygmy Zamias.

The profounder changes undergone by the cycads since Triassic time having been mainly in their fructification, it is usually difficult to identify fossil fronds with certainty in the absence of fruits. Hence it is not surprising that few of the living genera are positively known in the fossil condition. Encephalartos Gorceix- 
ianus Saporta is from the Miocene of Koumi, in Euböa, and the genus Cycas is very ancient, being represented by a number of uidoubted species, based on both leaves and fruits from the Mesozoic. Cycas Steenstrupi Heer, from the Upper Cretaceous of Atane, in Greenland, is of especial interest and beauty, the type consisting in a fine frond nearly two feet in length and a carpellary leaf with seeds attached, both leaf and fruit being closely placed imprints on the same slab, and unquestionably representing a rather dwarfish, extinct species of Cycas. Furthermore, it is very suggestive that a Cycas-like carpellary leaf, accompanied by Zamites-like fronds, occurs in the lower Ketper (3I), while characteristic leaves, with copious pinnation and linear-pointed pinnæe with one nerve, are found as far back as the Carboniferons limestone.

Though of great interest in the present connection, neither space nor time will permit a general survey of the generic and specific distribution of the existing cycads, considered especially with reference to appearance and habits of growth. In lieu of such extended_treatment it may, however, suffice to include here a series of habitus illustrations from the several genera, together with brief notes on Zamia, the most widely distributed and otherwise interesting of occidental forms.

ZAMIA.

The genus Zamia is

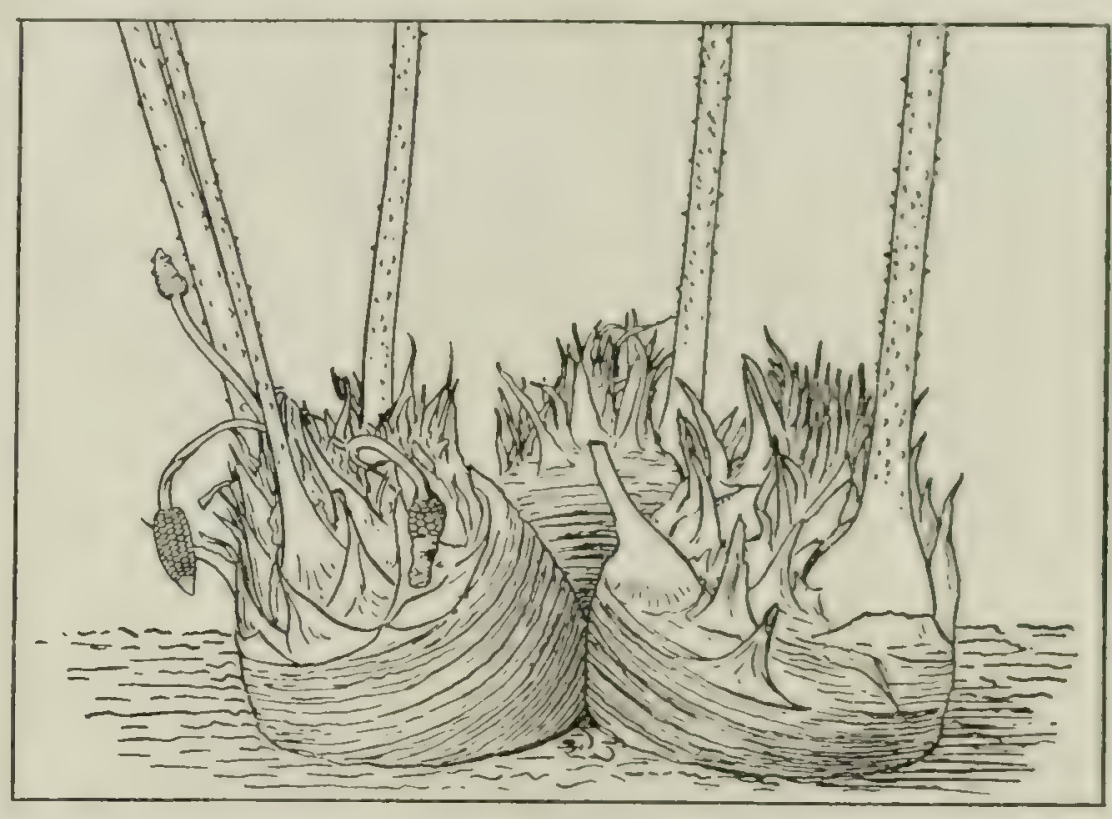

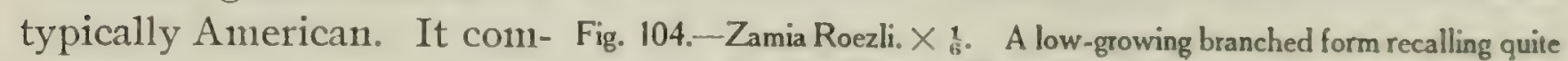
prises about thirty species, or rather more than are included in any two of the other cycad genera. It is well exactly some of the branching Cycadeoideas from the Black Hills. These trunks exhibit rapid excision of the armor, and the branch to the left bears three staminate cones. The fronds (fully 1.5 meters high) are relatively very large and the petioles are thickly beset with heavy, rather bluni-ended thorns or prickles.

represented throughont the West Indies and the Central American and Mexican mainland, which, together with Florida and the Bahamas and the northern portions of South America, constitute the limits of its habitat.

The Zamia trunks are mostly low-growing and freely-branching forms. Two, Z. pseudoparasitica Yates and Z. Pöppigiana, are Peruvian and Panama epiphytes (on tree trunks). Z. pygmaea Sims, of the Antilles, is the smallest of living cycads, its fronds being only Io or $12 \mathrm{~cm}$. long; and most species of the genus are lowgrowing, though some have large fronds. Various species, as Z. floridana, integrifolia, pumila, etc, are distinctly subterranean in runk habit. The pinnules of the Zamias present many gradations, from linear forms quite as narrow and long as pine needles to elliptical or somewhat spatulate, thick, and fleshy forms like those of $Z$. furfuracea, which strongly recall the blades of certain species of Cordaitere. 
The Floridian species are Zamia pumila and Z. floridana, these being the only cycads reported indigenous to the United States. Both these forms are mainly confined to southern Florida, having a far more restricted range than the palmettoes; and although both, when transplanted, thrive along the northern shores of the Gulf of Mexico, they are evidently subject to being driven south of this extreme northern limit by exceptional rigorous winters. It also seems possible that some of the Mexican species could temporarily extend into southwestern Texas, or up into the deep, warm cañons of southern Arizona.

Both the Florida Zamias are small plants of exceptional interest because of the enormous size of the ovulate, and the-for cycads-numerous staminate cones borne

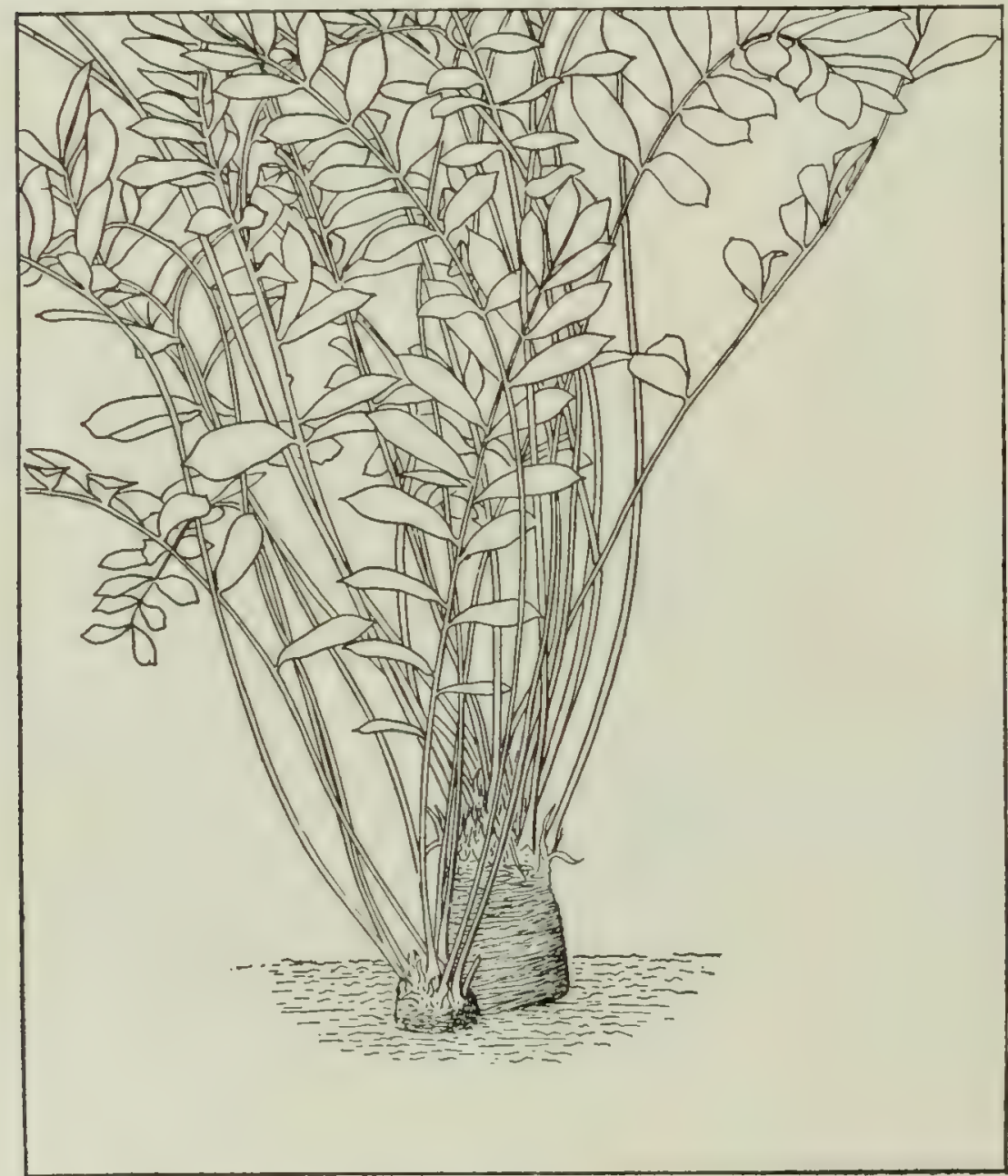

Fig. 105. - Zamia "glabra". $\times \frac{1}{12}$. Smooth-stemmed, low-growing branching cycadean trunk similar to preceding species, and like them bearing notably large fronds ( 1.25 meters high), with large and broad pinnules. by the profusely-branching underground trunks. $Z$. pumila is sparsely found in the forest depths of the "hummocks" or dense and often lofty copses of dicotyls so characteristic of the shores of Floridian lakes and banks of streams. Z. floridana is, however, the more typical species, and is often very abundant in the great reaches of pine woods of the southern half of Florida. In its habitat this plant thus closely parallels the manner in which many widely distributed cycadean species of the Mesozoic grew in the open dells of the great coniferous forests of that age. Moreover, the present cycad limit in North America of course marks the present line of a retreat begun in the Arctic arca in Cretaceous time (I98).

ZAMIA FLORIDANA. (Figs. 106-108.)

As a typical form of both local and general interest Zamia floridana merits further present mention. Usually, only the leafy crown is to be seen above ground. It consists in from a few to twenty or more fronds of ovate or ovate-lanceolate shape, but truncated, that is, evenly pinnate. The average length of the fronds is abont $50 \mathrm{~cm}$., the petiole being 20 and the leafy portion 20 to $30 \mathrm{~cm}$. long. A few more or less than twenty pairs of linear pinnules are commonly present. 
Trunks.-So far as can be seen on the outer surface, these Zamia trunks, as first dug up, are rather smooth, and do nct appear at first sight to possess the outer armor of spirally-arranged leaf bases so characteristic of other cycadean forms. Just below the petioles of the crown of leaves there is a thin and rough covering of scattering scale-like bodies and fine hairy material. Below this the trunks appear to be irregularly ridged horizontally, these ridges soon disappearing, so that the lower half or two-thirds is quite smooth in most places, and the armor of old leaf bases absent, the outer covering consisting simply in thin cuticle.

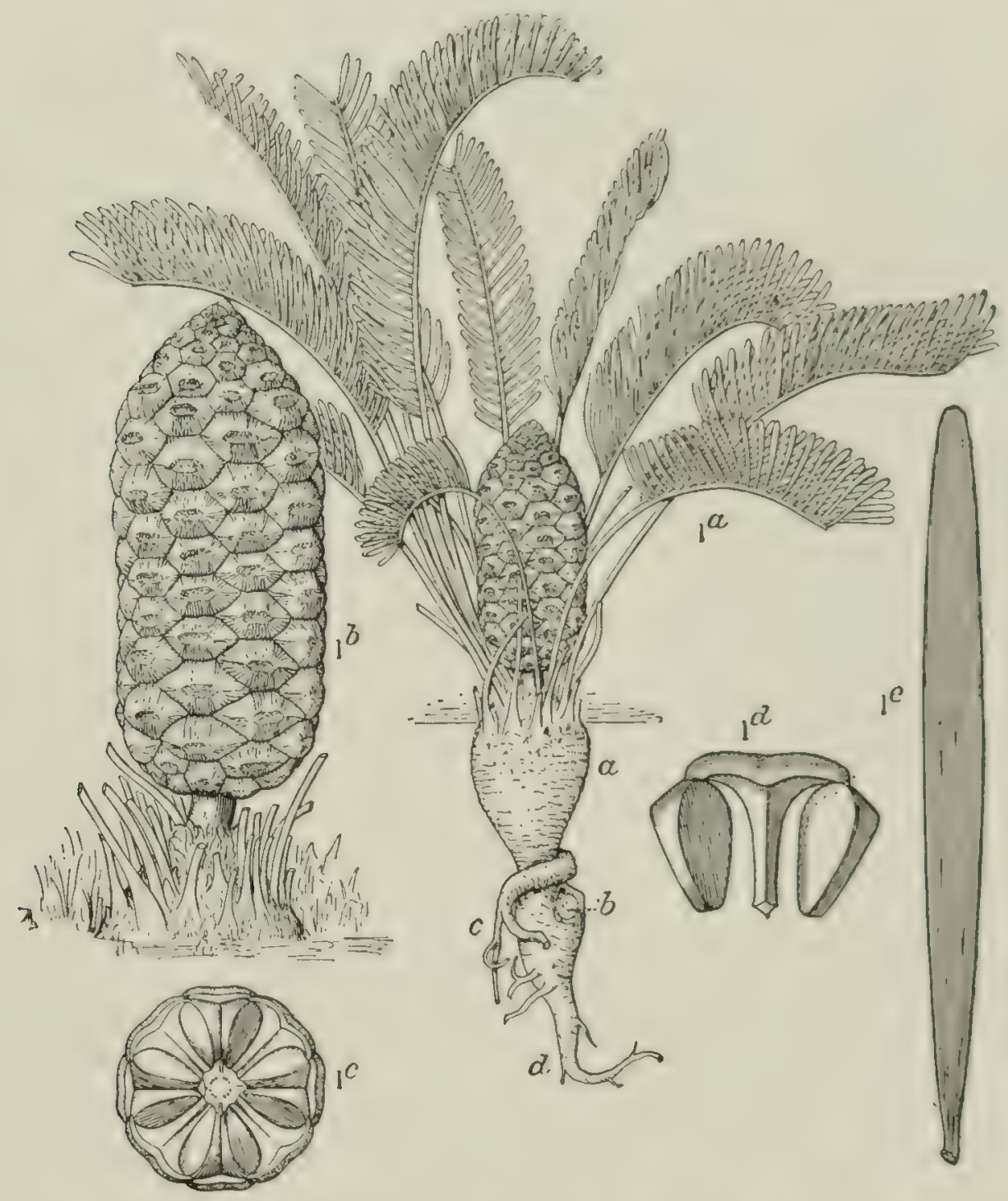

Fig. 106.-Zamia floridana DC. q. Miami, Florida, Nov. 15, fully six months previous to fecundation.

la, Entire plant. $X 1 / 8 . a$, main trunk (underground) ; $b$, position of an old branch; $c$, secondary tap-root running out from main foliage-bearing trunk, which is itself secondary; $\mathrm{d}$, primary or original tap-root.

1b. Cone (ten-ranked) seen in la. $\times 1 \%$.

1c, Transverse section of a different cone。 $\times 1 / 4$. Eight sporophyllar ranks are seen. These cones vary much in size as well as in number of sporophyllar ranks, which may be odd or even. The number of sporophylls in each rank also varie?

Id, Single sporophyll with ovules attached. $\times 1 / 2$.

le, Pinnule showing dichotomous venation. $\times 3 / 3$.

That these trunks do not differ greatly from other forms is shown in figure roS. The scaly material below the crown of leaves, and, lower down, the horizcntal ridges just mentioned, are the remnants of a true ramentum which is constantly disappearing below as the age and the size of the trunk increase. And when this ramental material is lightly scraped off above, preferably from a vigorous young trunk, the somewhat carrot-like or turnip-like appearance is lost, and the spiral 
order of the remmants of the leaf bases of former years is clearly to be seen. The trunks of the Floridian cycads are hence, notwithstanding their subterranean habit and unusual appearance, typical in every respect. The slow elimination of the old leaf bases is doubtless due, in their case, to growth in a protected underground position, and may hence be a trunk habit secondarily acquired. The subordinate position of these, comparatively speaking, dwarf plants as underbrush in large forests of pine and in the denser "hummocks" in the case of Z. pumila has, together with differential climatic change, probably, therefore, resulted in the course of

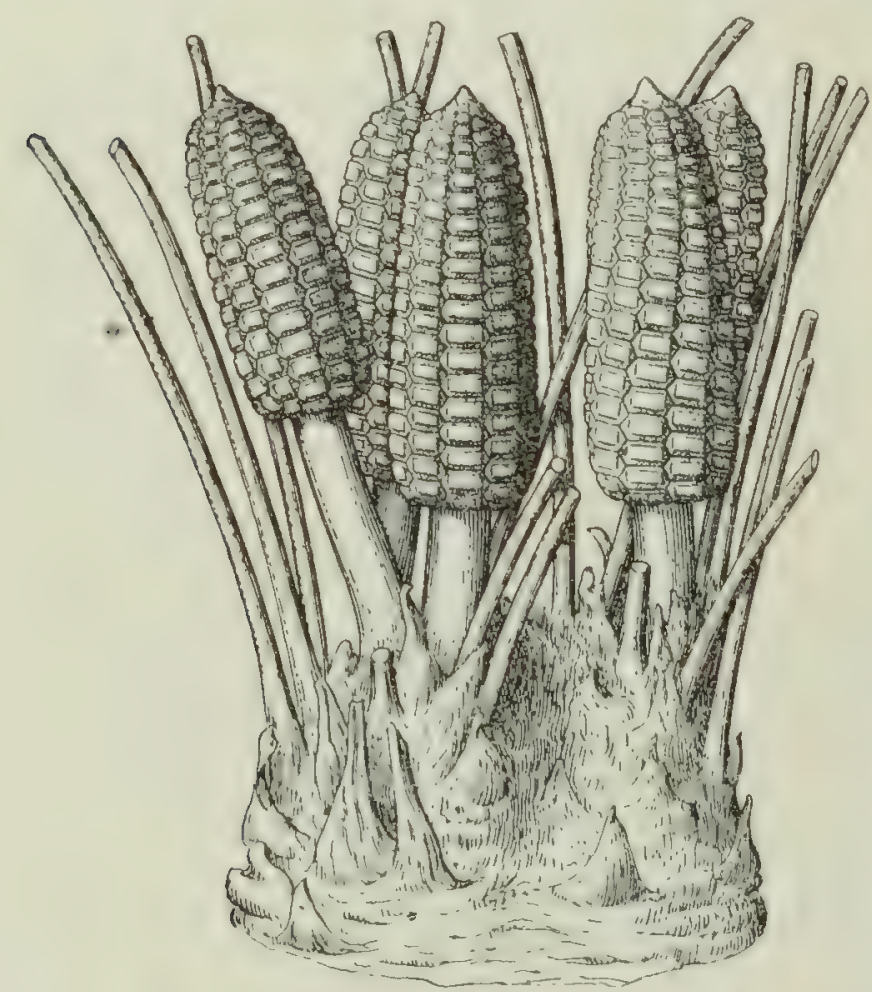

Fig. 107.-Zamia Floridana DC. 0 . $X \frac{1}{2}$. November stage of growth. Slightly bifurcate trunk bearing three staminate cones on the left and two on the right incipient branch. Trunk shown with leaves removed and as if cut away on the ground-level. From Wieland (193). time in some diminution in size, an underground habit, and nearly complete removal of the armor.

'The freedom with which these trunks branch is noteworthy, as recalling quite exactly the numerous branches of the noncolumnar trunks from the Black Hills. A male or female plant often gives rise to a whole clump of the same sex, and a series of closely-set branches has been observed to bear as many as thirty-nine staminate cones. This free branching, which is said to be supplemented by the power of new growth from "cuttings," is very clearly an important means of reproduction.

Cones.-The branching habit together with the relatively large size of the cones of both sexes in $Z$. floridana give the plants a striking appearance when in fruit. In figure 107 a group of cones forming a portion only of a staminate clump of trunks is shown. These cones vary much in size, number of sporophylls in the rank, and number of ranks, facts all having a bearing on the determination of related or otherwise analogous fossil species.

The ovulate cones are, indeed, unusual. As is well known, among the living cycads we find the largest ovules seen in the vegetable kingdom, though it is surely significant that these structures are comparatively small in the Cycadeoidex. In figure ro6 the curious fact is well shown that ovulate cones of $Z$. floridana, even many months before the gametopliytes are fairly mature, are often distinctly larger than the underground trunks which bear them. As a trunk may bear several ovulate cones, this contrast in size may become even greater. Large mature cones are several inches longer than the young unfertilized cones liere figured. As in all cases, however, where the sporophylls are closely organized into typical cones, appression faces form, and to a large degree remodel and thus partially conceal the original characters of the component parts, limiting especially the spaces occupied by the ovules. These do not hence approach the immense size of those 
borne free on the carpels of the less compactly set strobili of the genus Cycas, the mature seeds of which, though not very greatly larger than the ovules, reach in the species Cycas circinalis the size of goose eggs.

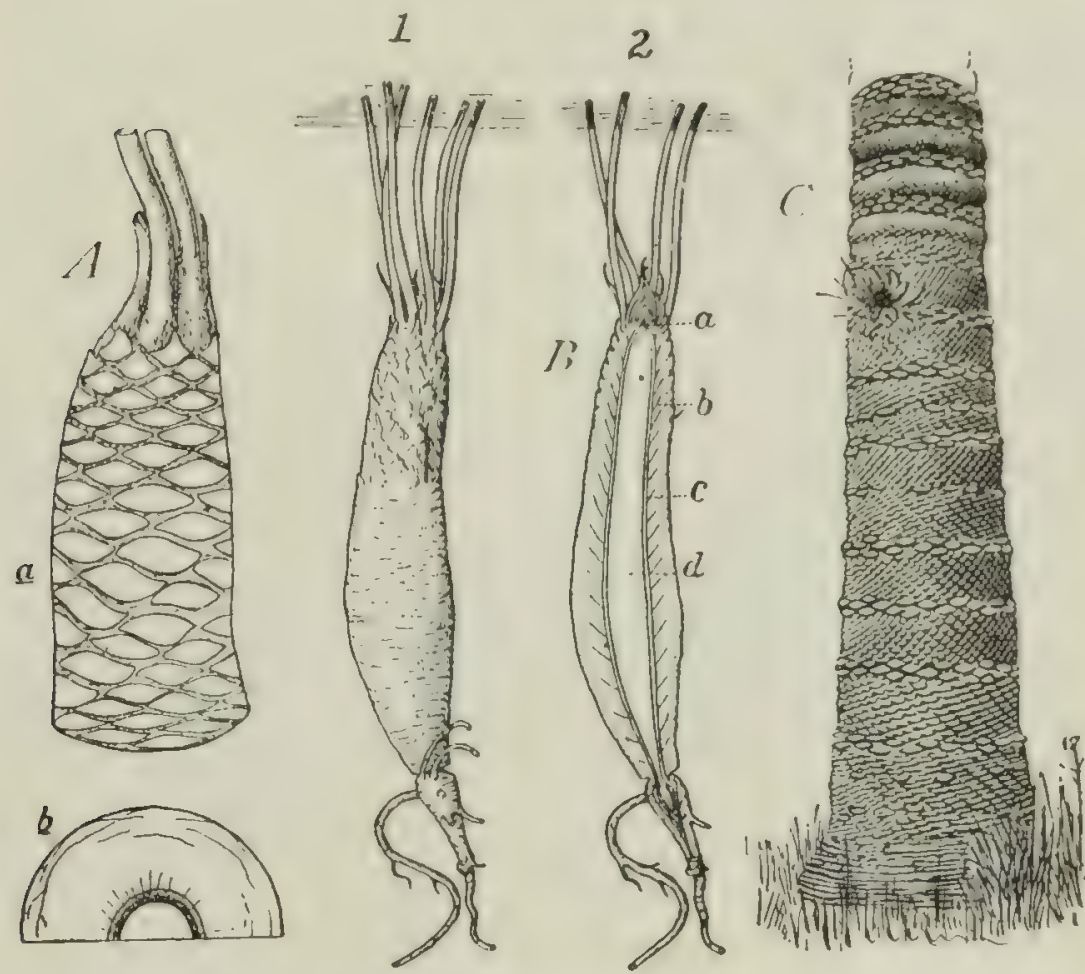

Fig. 108.- Extremes of variation in size and form of trunks of existing cycads.

A. Zamia floridana DC. $\times \frac{1}{3}$. Miami, Florida.

a. Upper third of long and slender young trunk with leaves cut away, and surface lightly cleared of scaly and hairy material to show the slowly disappearing remnants of old leaf bases. Further down, on lower two-thirds of the trunk, the leaf bases are indistinct. Entire trunk subterranean, as well as that portion of the petioles shown at summit.

b. Transverse section of the same trunk cut farther down at the thickest point, showing central pith or medulla, the xylem or wood zone, and the cortical parenchyma irregularly traversed by vascular bundles. There is no armor, this being replaced by a very thin corky layer.

B. The same as the preceding, showing the unbranched subterranean trunk with fronds cut away just above surface of ground. $\times \frac{1}{7}$.

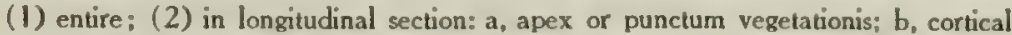
bundles in early and less curved portion of their course; c, woody or xylem cylinder; $d$, medulla.

C. Cycas circinalis. Basal portion of a columnar trunk about 8 feet high, showing a heavy armor formed by the succession of foliage and carpellary leaves.

The large scars are due to the excision of the petioles of the foliage, the smaller to that of the far more numerous carpellary leaves which actually form two-thirds of the armor of old frond bases. From photograph, by Professor Evans, of a trunk in Castleton Gardens, Jamaica.

of the diameter of the stem, being more strongly developed than in any other existing gymnosperms, and quite as prominently as in the Cordaitales and such tree ferns as Cyathea medullaris. Various species of Zamia, Dion, and Cycas afford commercial starch and sago in large quantities, whilst the pith of Encephalartos is eaten by the native. Kaffirs, whence the common name of this plant, the "Kaffir bread."

In the early stages of growth the pithy ground-mass of cells filled with starch grains is traversed only by gum canals, the only other structural modification being the more or less well marked upward and outward lay of the somewhat larger cells 
about and between the bases of the segments of the inclosing wood, this orientation marking the origin of minor and large or mesh medullary rays. Encephalartos and Macrozamia afford, however, an interesting exception. In certain, and possibly all the species of these genera, a separate anastomosing system of cauline bundles arises in the older portions of the pith and traverses its length and breadth in alnost every direction. These pith bundles lack protoxylem. Their phloem is always directed toward an accompanying gum canal, and where such a canal leads out into the cortex the bundle joins the normal wood zone.

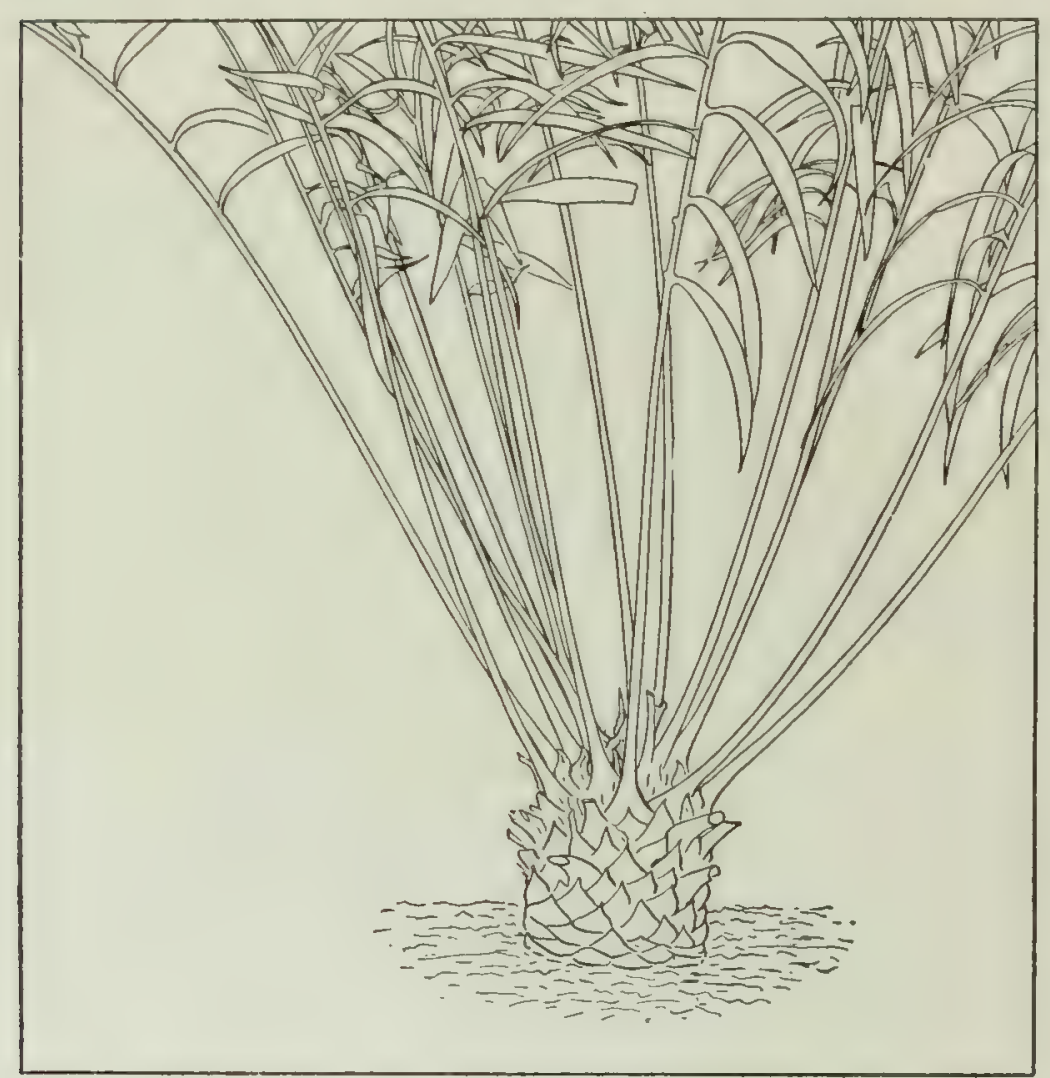

Fig. 109.-(?) Ceratozamia mexicana. $X \frac{1}{15}$. A cycad vegetatively much like the Zamias shown in preceding figures, but with markedly more persistent armor.

Yet further vascular structures that may be inclosed within the pith are connected with fructification. In Dion, Stangeria, Ceratozamia, Zamia, etc., the pith of trunks which have fructified contains a great number of regularly disposed vascular series, each of which consists in a cylinder of bundles leading out into a peduncle, situated laterally on the stem among the old leaf bases. This structure owes its origin and position to the following fact: A given peduncle originally formed the end of the trunk and contained the apical meristem, which, after destruction by the ripening of the strobilus, was again produced as a sympodial branch from the peduncular base, the latter being pressed to one side by continued growth and increase of trunk diameter. It is in this way that a succession of peduncular cylindrically arranged series of bundles comes to be embedded in the pith of an old stem. As these series must be thrust to the one side or the other when the apical stem branching occurs, they come as growth proceeds to be more or less nearly tangential to some one point of the vascular cylinder inclosing the pith.

The Vascular Zone.

Brongniart discovered the gymnospermous character of the wood of cycads in 1829 (I4), but he did not discern that a true phloem region follows the xylem. Two types of vascular zonal development occur in the existing cycads. In $(a)$, the simple and characteristic or monoxylic form, there is but a single xylem and phloem region; in (b), the polyxylic trunk, in addition to the normal bundle zone, anomalous series form successively. 
(a) In Zamia, Dion, Stangeria, Ceratozamia, and Microcycas (?) the large pith is inclosed by a thin cylindrical and more or less open network or trellis of anastomosing collateral bundles, followed by a conspicuous cortical region, as shown in figure II3. There is in this form of stem no further formation of cambium and no strongly marked secondary thickening. The phloem is usually well developed, and often approaches or even equals the xylem in amount. In this monoxylic stem, or in single woody cylinders of the polyxylic stem, the main structural features are as follows:

In transverse sections the xylem incloses the pith as a ring more or less evenly divided by broad mesh rays into bundles or segments made up of narrow wedgeshaped groups of cells, which are in turn separated from each other by few-seriate medullary rays. The subdivision of the xylem segments into these oroups, which

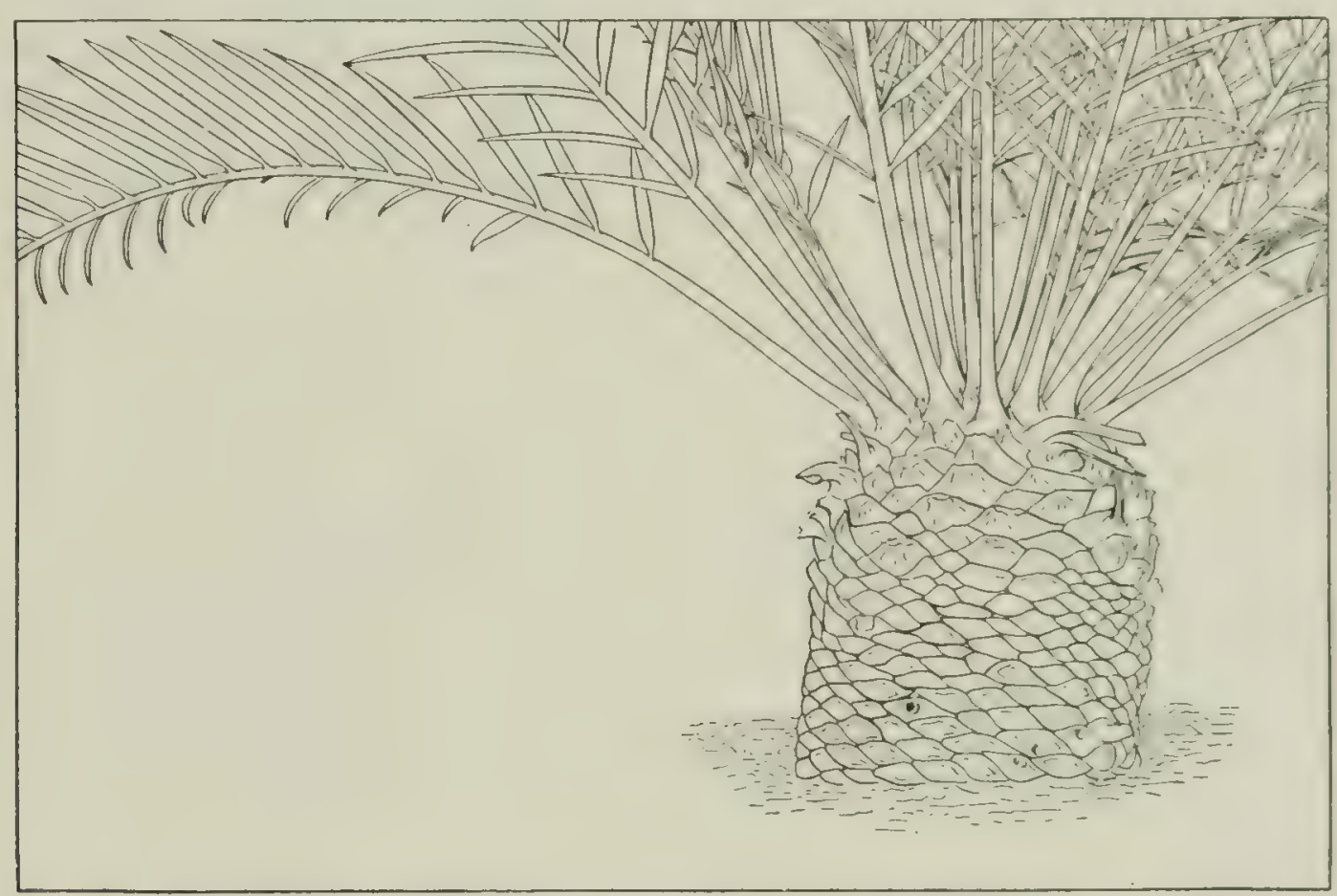

Fig. 110.-Encephalartos Altensteinii. $X \frac{1}{10}$. Low-growing columnar and heavily armored trunk with few scale leaves.

begin next the pith with a breadth of one or two cells and wiclen sometimes to four or more cells broad, is only a fairly regular one. External to the xylem is the wellmarked cambium, followed by the secondary phloem, which consists in a series of bundle segments precisely corresponding to those of the xylem and completing the collateral bundles of which the vascular zone is composed. The phloem segments, like those of the xylem, are divided by few-seriate pith rays into rather regular 2 to 4 seriate rows of cells made up of thin-walled, small-celled alements in the main trunk of Zamia floridana, etc, and Stangeria. But in the tap-root of Z. Foridana and in the trunks of Cycas, Dion, Encephalartos, Macrozamia, and doubtless most cycads, as likewise in the Cycadeoidex, sclerenchymatous elemcuts are more or less numerously and regularly interspersed among the row cells, thus adding much strength to the stem. In fact, it is not always easy, under low powers, to distinguish in the older stems of these forms the lignified fibrous elements of the phloem from the tracheids of the xylem. On the outer side may lie the crushed 
remains of the primary phloem. In addition to the elements named, scattered idioblasts may occur in both the row and ray cells of various genera; also spherical aggregates of klinorhombic (calcium oxalate) crystals. In Z. floridand these are very numerous in the mesh rays and the small medullary rays of both xylem and phloem.

Finally, it remains to note that in Cycas, etc., just inside the origin of the main portion of the xylem segments, interspersed in the pith, are groups of xylem containing from a few to ten or more ceils, in more or less regular rows. These lie in nearly the same relative position as the centripetal xylem of primitive steles and, as will be seen later, mark the innermost origin of the bundles passing out through the mesh rays.

In radial sections from adult trunks an absence of protoxylem is noted. The tracheids of the secondary wood often have the normal bordered pits like those of conifers on the radial walls (Cycas, Macrozamia, etc.), these sometimes grading into scalariform structures in the same cell, a peculiarity noted in Cordaites Brandlingi (III). Minute pittings may also be present in the tangential walls of these cells. But in a medium-sized trunk of Zamia floridana the xylem wedges appear to be entirely made up of spiral elements, and in Stangeria all the tracheids of this secondary wood have scalariform pits. In Cycas revoluta the wood tracheids are usually thickened by scalariform pittings, and but few have bordered pits, while spirally thickened walls are absent. The most prominent objects in the phloem are the greatly elongated fibrous cells, which distinctly add to the strength of a stem so largely built up of parenchymatous tissues. Side by side with these are the much elongated sieve tubes, on the oblique terminal and lateral walls of which are numerous well-inarked sieve plates of various shapes. The final prominent features of the radial section are the large sheets of ray cells and the numerous out-curving vascular bundles, the xylem and phloem of which mainly arise from these same respective elements of the wood, traverse the mesh rays, and then enter the cortex. Moreover, in describing the tranverse section, scattered xylem groups were noted as occurring in the pith well within the main portion of the xylem segments of the first vascular zone, and in the radial view these are seen to consist in spiral to scalariform elements forming a loosely anastomosing xylem system with each other and with the inner portions of the xylem segments, and at the same time representing the innermost origin of the bundles passing out through the mesh rays. Frequently in trunk forms duplicating the single original woody cylinder these inesh bundles are in the same thin section traceable through several vascular zones which have apparently grown around them.

In tangential sections the fusion of the bundles into a more or less open and regular network or trellis with vertically elongate meshes is clearly defined, as are also the two kinds of medullary rays, that is, the few-seriate segment rays and the broad mesh rays. In the lower angles of the mesh rays irregular strands of xylem frequently arise, marking in part the origin of the leaf-trace or cortical bundles. Or if the section be cut well out there is in each mesl: a transversely cut leaf-trace bundle with xylem directed upwards. Mucilage canals may also be present. In Macrozamia there is in most of the meshes a single canal both above and below the 
leaf-base bundle. The relatively small amount of woody fiber as compared with the parenchyma of the xylem zone itself is a stril-ing feature in the tuberous trunks of the Zamia type, quite in contrast with the solidly developed xylem and phloem regions often noted in the Cycadeoider. But to be complete and final, all such comparisons would have to be based on wood from the same serial portions of trunks of about the same age or development.

(b) In Cycas, Macrozamia, Encephalartos, and Bowenia the xylem zone does not remain single as just described, but is anomalously repeated a number of times in the cortex, although with less and less distinctness. Roughly speaking, this is

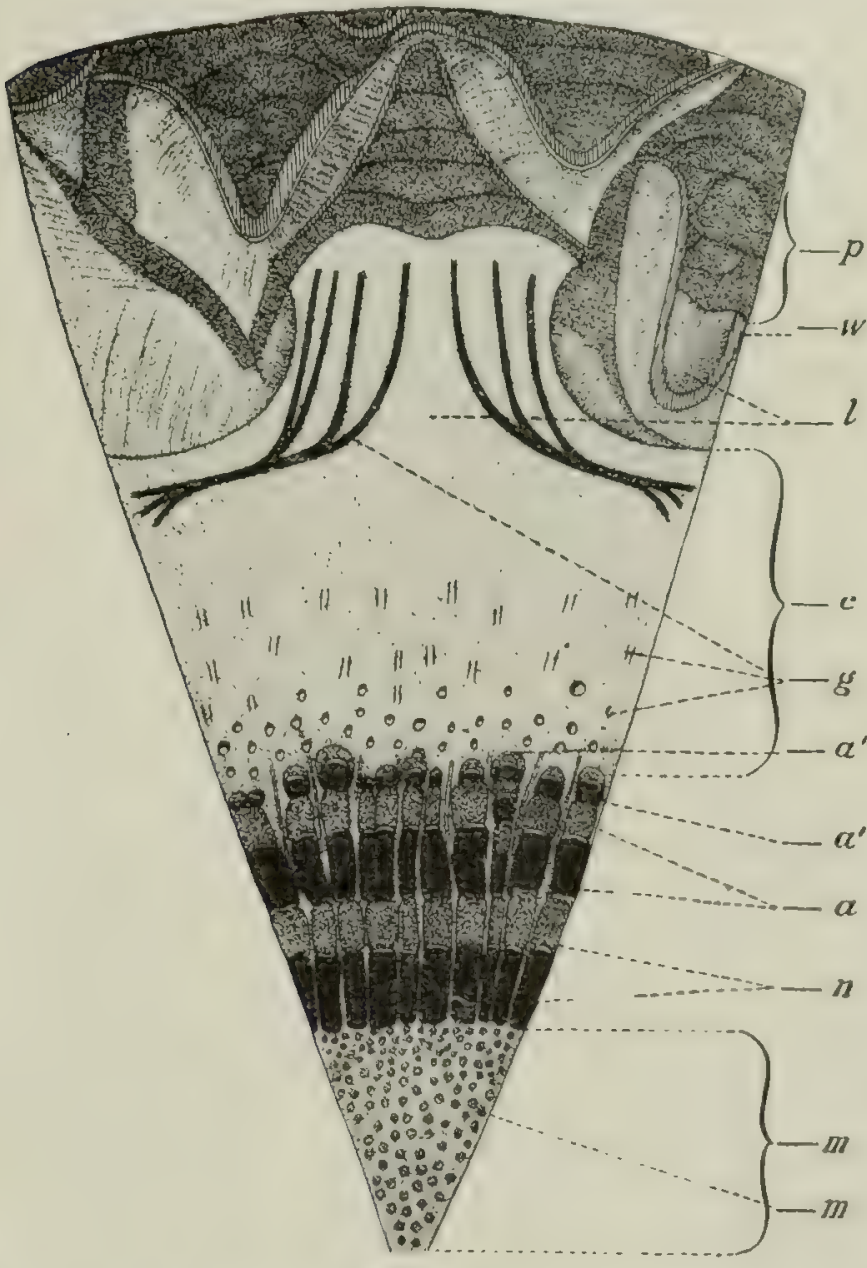

Fig. 111.-Macrozamia Fraseri. Transverse section of trunk. $\times 1 / 2$. (From Worsdell.)

p. Periderm in successively formed layers; $w$, wall of one of the leaf bases; 1 , leaf base; $c_{\text {, cortex; }} g_{0}$ girdle leaf traces; $a^{\prime \prime}$, isolated bundle of a third anomalous wood zone; a', second anomalous zone; a, first anomalous wood zone; $\mathrm{n}$, normal wood (xylem dark, phloem light); $\mathrm{m}$, medulla; $\mathrm{m}^{\prime}$, medullary bundle. a character of the cycads of columnar form, but, as we see, it is present in the low-growing Bozenia, while among the more cylindrical types Dion and Ceratozamia have but a single vascular zone. The polyxylic trunk is like the monoxylic form up to a certain age and size; then lateral but not apical growth ceases in the primary cylinder of anastomosing bundles, and there are successively developed, outside and concentric to it, from one to as many as a dozen cortical cambiums of diminishing power, from which arise the additional or anomalous vascular zones, these being strongest near the base of the trunk, weaker and weaker from within outwards, and of less and less strength toward their growing apices.

In transverse sections from the lower portion of well-growr. polyxylic stems there is seer to abut immediately on the normal vascular ring a second ring quite nearly or equal in width to the first, and, as in fig. I I , a third, and yet others of less and less size may

follow. The xylem of the second ring closely follows the first-formed phloem of the first, and so on, the structure and orientation of the consecutive parts being in general the same, although the segments of these several successive rings lie less and less evenly radial to each other. Occasionally also a wedge of the secondary wood is pushed out of line and lies embedded in a large pith ray so nearly between two segments of the next inner ring, whether this be secondary or primary, that it is not always at first easy to tell to which ring a given bundle segment belongs; and this kind of irregularity increases with the diminution in the size of the segments, so that there is less strength and less definition in the successive rings 
from within outwards. One rather significant structural variation remains to be noted. In Macrozamia (cf. fig. III) and Bowenia a tertiary cambium occasionally arises in the parenchyma between the normal and first anomalous or between any two of the anomalous vascular zones, and forms wood and bast with partly or wholly inverted orientation, that is, with the xylem more or less exactly adjacent to that of the next outer bundle zone. It has been suggested (205) that these inverted bundles may indicate a possible reversion in the direction of some ancestral Medullosan type with a cylinder of concentric bundles only, whence as the result of the functional weakening and final elimination of the inner meristem of such bundles there might arise the stronger and more compact existing type of cycadean stem with common collateral bundles.
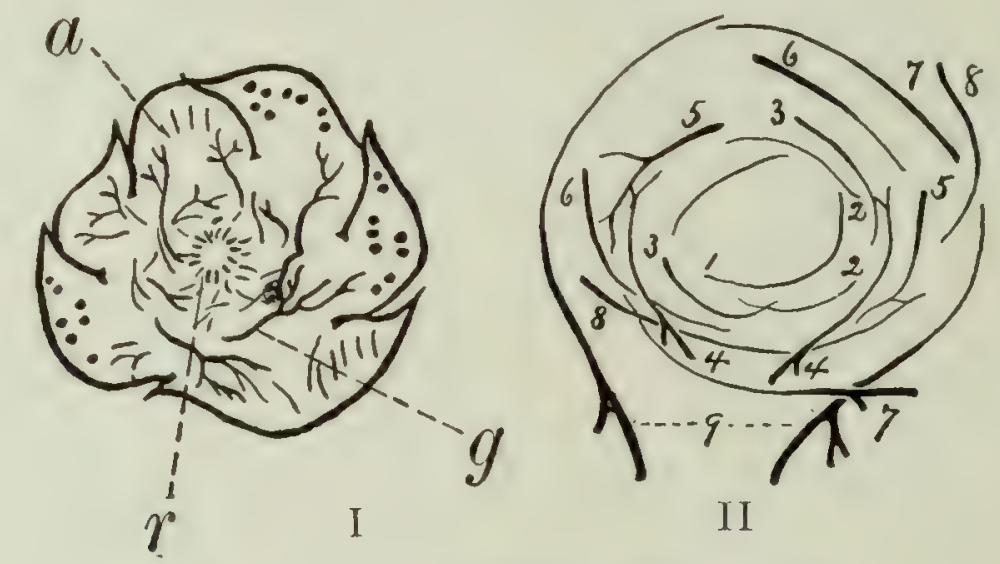

Fig. 112.-Cycas revoluta. From De Bary.

1. Transverse section through summit of young trunk. Natural size. a, Leaf insertion; $g_{0}$ girdle leaf trace; $r$, xylem zone.

II. Slightly enlarged thick transverse section cut just below the punctum vegetationis of a lateral shoot and cleared with potash for acroscopic view. Leaf-trace pairs of superposed planes drawn together in plane of paper and numbered at point of exit, beginning with the youngest (1) of nine successive leaves. The course of the bundles is shown up to the point where each curves sharply into the leaf base. Anastomosis of bundles in cortex but slightly developed.

That some of these irregularities in the alignment of the xylem and phloem may be mainly the counterpart of a more perfect connection, aside from that afforded by the leaf traces, between the several vascular zones of the stem is, however, apparent in radial sections of Macrozamia figured by Worsdell (205). In these, broad bands of wood and bast connect at intervals especially the normal and first anomalous vascular zones in both the upward and the downward direction, both kinds of connection occurring at times in close proximity, so as to form a complex kind of loop. The frequent passage of leaf traces from the inner zone all the way across the anomalons zones to the cortex is also noteworthy.

In general, the cycad stem, being such a loosely compacted one, undergoes much growth accommodation, its lower and older portions showing the most marked crowding and distortion from the normal order of the several segmental series of the vascular zones. So far as known the primary network of bundles is developed in its full complexity close below but not at the apex of the stem, and the successive transverse portions of the growing stem undergo further increase in thickness by expansion in the first place of pith and cortex, and later by the cambiogenetic duplication of vascular zones just described. 
The Cortex.

The cortex consists in the wide zone of parenchyma traversed by the leaf trace, girdle leaf-trace and peduncle bundles, and the mucilage canals. It incloses the xylem from which its bundle system arises, and is bounded exteriorly by the periderm below, and above by the armor of old foliar bases in so far as not cut away by the advance of the periderm. Its radial thickness is from one-third that of the entire trunk (including the armor) in Cycas to as much as two-thirds in the scantily armored Zamia floridana.

Cortical Bundle Distribution.-In the ferns the leaf traces pass out from their stelic origin obliquely upward into the bases of the fronds, and in the Cycadeoidere there is, as has been seen, a similar more or less direct course of the leaf traces from the xylem zone out through the cortex and into the leaf bases. But in the living cycads (see fig. II3) any such definite and primitive arrangement as might once have been present is now more or less obscured. The nearest approach to the simple bundle course is to be seen only at the apex of the young stem or in

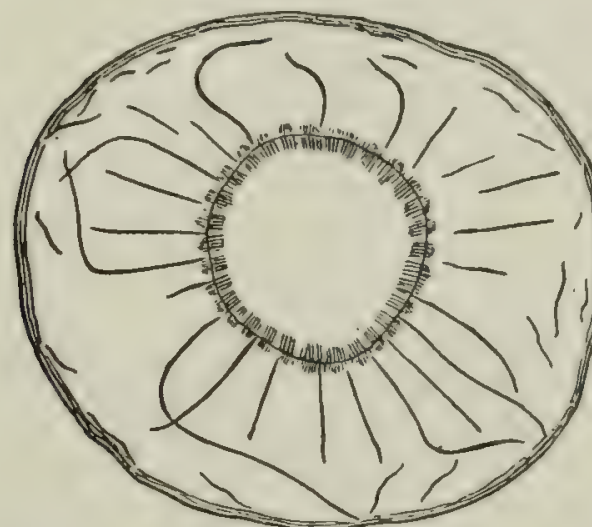

Fig. 113. - Zamia floridana DC. $\times 1 / 2$ Transverse view of stem as dissected out on an inverted conical surface inclined upwards about $35^{\circ}$, the angle at which the most of the leaftrace bundles rise in passing from the xylem to outer cortex. Several of the bundles are plainly seen to pass out all the way to the thin outer phelloderm and cork covering the stem. None of the girdles deflects laterally" through more than an angle of $60^{\circ}$, as mainly due to the advance of the periderm and excision of the peripheral corlex, in which bundle curvature is the more marked. peduncle traces, and the nost complex and involved course in the well-grown and heavily armored trunks of Dion, Cycas, etc., as first described by Mettenius (92). It appears, however, that various Zamias and Stangeria are not quite so complex as these. If the bundles of the cortex of a well-grown trunk of Zamia floridana be followed by dissection out from their origin in the xylem, they are found to pass almost directly outward and upward at an average angle of some 30 degrees for from two-thirds to rarely almost the entire width of the cortex, and then curve slowly upward either to the right or left through from a few to most frequently as many as 50 or 60 degrees of the cortical circumference, before being cut off by periderm (see fig. II3) or entering the leaf bases, each of which receives a pair from opposite directions.

Zamia muricata has a similar corticai system; and

likewise in the middle portions of adult Stangeria trunks, owing in part to the advance of the periderm, the leaf traces run out in the radial or nearly radial direction, with but little curving in the peripheral cortex. Lateral leaf-trace connections seldom occur in either this or the two preceding forms. Bowenia has not been carefully studied, so far as known to me.

In describing the cortical system of the markedly complex type, the terms usually used for the different courses of the leaf traces are as follows:

(a) Radial traces (Markscheidenbündeln of Mettenins), the bundles arising singly or as a branching and more or less anastomosing system directly from the xylem zone.

(b) Girdle traces, continuation of the radial trace bundles passing in circular course through the peripheral cortex into the leaf bases.

(c) Radial connections, bundle anastomoses involving the girdle traces. 
The radial traces or bundles (in Cycas revoluta), after taking their origin in the xylem zone, at first pass outward through the cortical parenchyma in a radial and upward course about equal to the height of a leaf-base insertion. In most cases, however, a division into two girdle branches soon takes place, sometimes even at the point of origin, and these branches usually give rise to still others, with more or less lateral anastomosis with other traces, as well as with younger traces above and older ones below. The complex network thus formed is then attached laterally and vertically to the more distinct girdle leaf traces, each of which, after its radial origin, takes a low, unwinding spiral course through the peripheral cortex in right or left direction nearly as much as $x 80^{\circ}$ and then turns sharply outward into a leaf base. A pair of such girdles leading from opposite sides, and even possessing a common radial origin and thus girdling the circumference of the entire xylem zone, constitutes the bundle supply of each leaf base. In consequence of this arrangement the two bundles of each leaf base pass successively the bundles of each other leaf base in a cycle of leaf bases. Moreover, as the cycles of leaves of successive years appear, there results a more or less distinct grouping into annular zones or girdles, but with more or less lateral anastomosis of radial and girdle connections throughout. Along their entire length the inner sides of the girdles are connected with the xylem by numerous successive radial traces, while the outer sides or those next the surface of the stem are many times inter-united by still other connecting bundles. In addition a quite complex bundle anastomosis may join the two girdles as they enter a leaf base, and this anastomosis may be further joined to the xylem zone by direct radial traces or receive cortical bundles. Also, after the girdles begin to split up in the leaf base they may still receive cortical or radial traces. The strength of the girdle leaf traces increases from their origin to the point of division in the leaf base.

The general course of the cortical bundles of Dion cdule is quite similar to that of Cycas. The girdle leaf traces may, however, depending on the extent of periderm excision, lie very near the surface of the trunk in this species; and those which finally enter the scale leaves are scarcely half the size of those supplying the foliage leaves. This difference occurs in very much lesser degree in Cycas, but may be general.

Finally, certain anomalous cortical strands of concentric structure have been noted in Cycas media, Stangeria paradoxa, etc. And bundles passing out rather directly from the xylem, and ranged arc-wise or forming an imperfect cylinder of bundles, as seen in tangential section of the cortex, also occur in Macrozamia (205), though it remains to study such anomalies in connection with the cortical course of the peduncular bundles. All peduncular series of bundles must present certain variations from those entering the leaf bases; but a searching comparative study of the leaf base, carpellary base, and peduncle bundle supply of all of the several cycad genera has never been made. The manner in which a series of peduncnlar bundle cylinders comes to be embedded in the pith of cone-bearing stems of Ceratozamia and Stangeria has already been mentioned. These series in the older portions of the stem pass through the xylem, cross the cortex to the base of the 
peduncle in a quite horizontal position, and occupy a less and less displaced, more and more vertical direction as the apex of the stem is approached.

Structure of Cortical Bundles.-The xylem of the girdles normally faces the xylem zone and the phloem the periderm. In their course through the cortex from their origin in the xylem zone to their entrance into the frond bases, the girdle bundles display various peculiarities of structure. In Cycas in particular there is often to be noted a quite well-marked concentric and distinctly primitive arrangement, a parenchymatous prism or pith being surrounded successively by

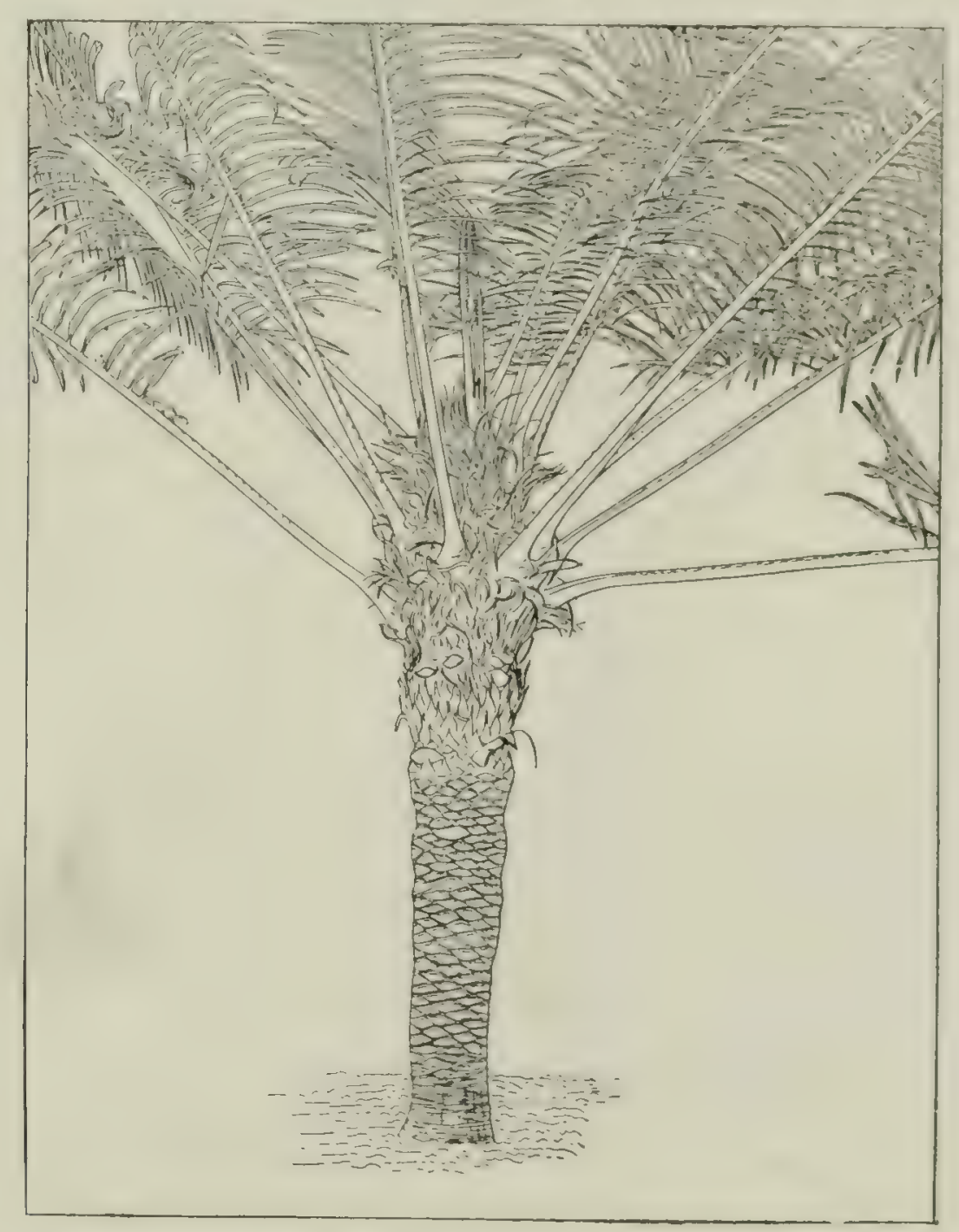

Fig. 114.-Cycas Rumphii. $\times \frac{x}{15}$. Plant bearing emergent young fronds with erect rachides and incurved pinnules. Armor moderately persistent and scale leaves long and curling.

the wood and cambium and a weak ring of bast. [These concentric traces may possibly be mainly carpophyllar supply bundles.]

Moreover, in addition to the cambiogenetic increase already discussed, the pith and cortex undergo expansion as the growth and increase in circumference of the stem proceeds; and as the primary network of bundles remains meantime permanent, the radial connections and especially the girdles of the peripheral curtex, because of their unique course, must be extensible and undergo stretching and increase in length continuously. Hence the presence of cells with dense spiral thickenings in the tracheidal walls of the secondary wood of the girdle bundles in 
old stems of certain forms (Macrozamia). Also, as was first observed by Mettenius, the spiral tracheids may be torn asunder by the tension of stem increase and finally become obscure; but the scalariform tracheids continue their growth. In the girdles of the young leaves the shortest measured $0.09 \mathrm{~mm}$., in older stems I.4 mm., and in the oldest examined $4.5 \mathrm{~mm}$. There may also be an increase in many of the tracheids of the secondary wood to twice the diameter seen in the cortical bundles of young stems. The thin-walled parenchyma rays traversing the wood and bast are successively increased as such thickening goes on. Obviously enough,

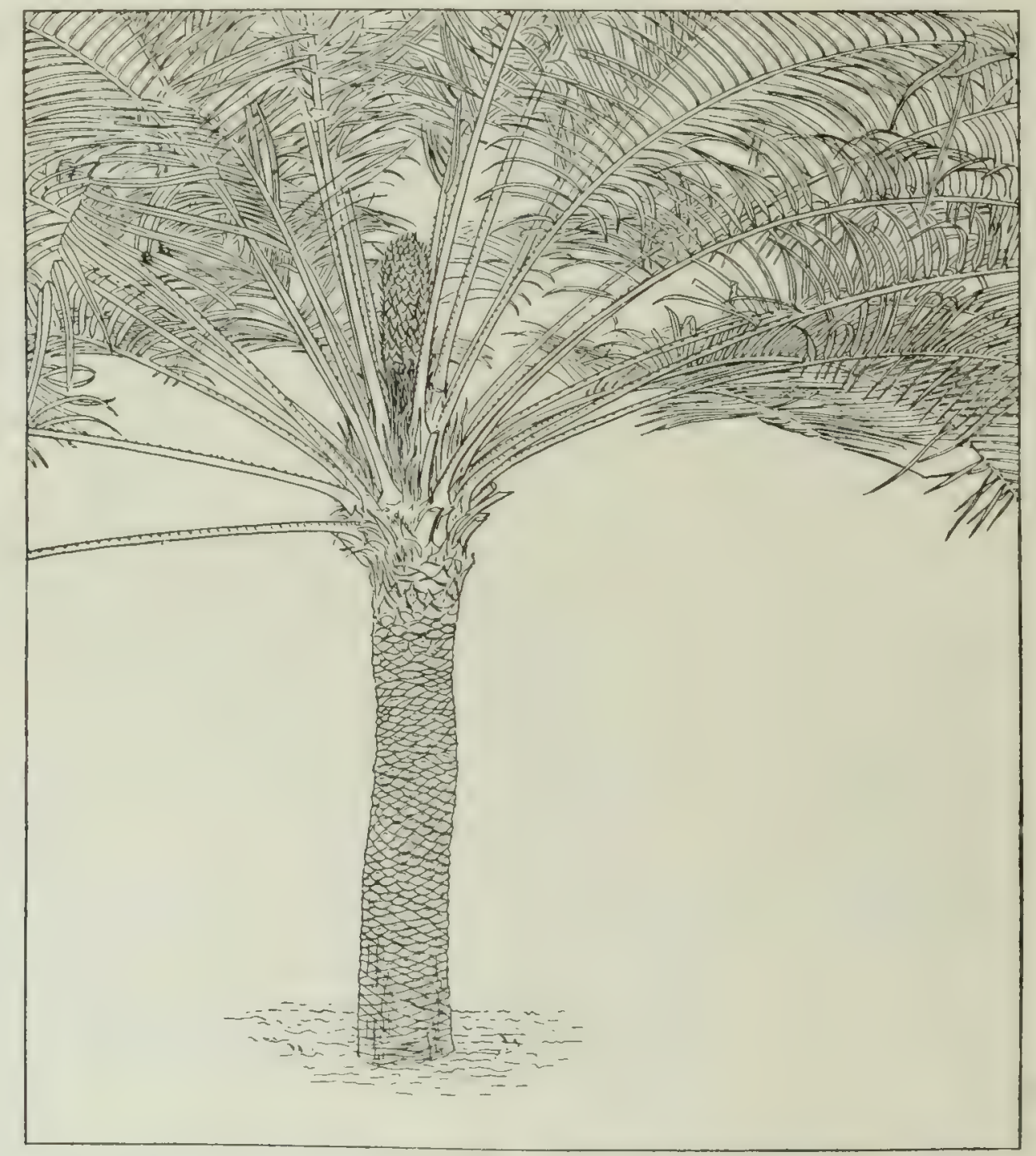

Fig. 115.-Cycas neo-caledonica. $\times \frac{1}{12}$. Staminate plant bearing a terminal cone. (Compare with the ovulate C. media, figure 102.)

the development of a strong anastomosing cortical bundle system must add greatly to the strength of the stem and in part compensate for armor excision. 'To say the least, it is not probable that in the absence of a secondarily strengthened cortex trunks could ever reach a height of 23 meters, as does Cycas Normanbyana. Conversely, the absence of cortical strengthening in the Cycadeoidere is in the strictest accord with their usually shorter trunk type.

'The cortical parenchyma, like all the other ground tissues of the cycadean stem, is freely traversed by gum canals. These branch freely, and may contain crystalline aggregates of calcium oxalate. Stone celis often occur. 
THF ARMor. (Figs. I5-28, and IOI, I08, III, II3, etc.)

The outer investiture or armor of the cycadean trunk consists in the palisaded and spirally arranged old foliar bases seated on the cortex and left behind as the successive crowns of foliage and fructification wilt down, together with such hairy material as these may bear. Beneath the wilted ends of the foliar bases a periderm arises in the still living tissue and from it cork and bark cells are formed as the onter and protecting surface of the armor. But as the formation of cork may go on indefinitely the armor comes to vary greatly in its amount and persistence, as explained below in connection with the description of the periderm. The armor, composed of the system of leaf-base and carpellary leaf-base spirals, or occasional interspersed peduncles, is the most characteristic onter feature of the cycadean stem, the one best known and first remarked upon. It is in every respect of ancient and fernlike character, and its variable development in the different species and strong tendency to disappear is probably increasing with the age of the group. At least with increase in height and age of the trunk the armor disappears from below, and is hence in any given trunk always thickest near the summit. It may be three or more inches in thickness in large trunks of Cycas, producing the very characteristic summits to be noted in various accompanying figures. 'The low-growing trunks of Encephalartos are also heavily armored. In some of the forms of Cycas and Macrozamia the

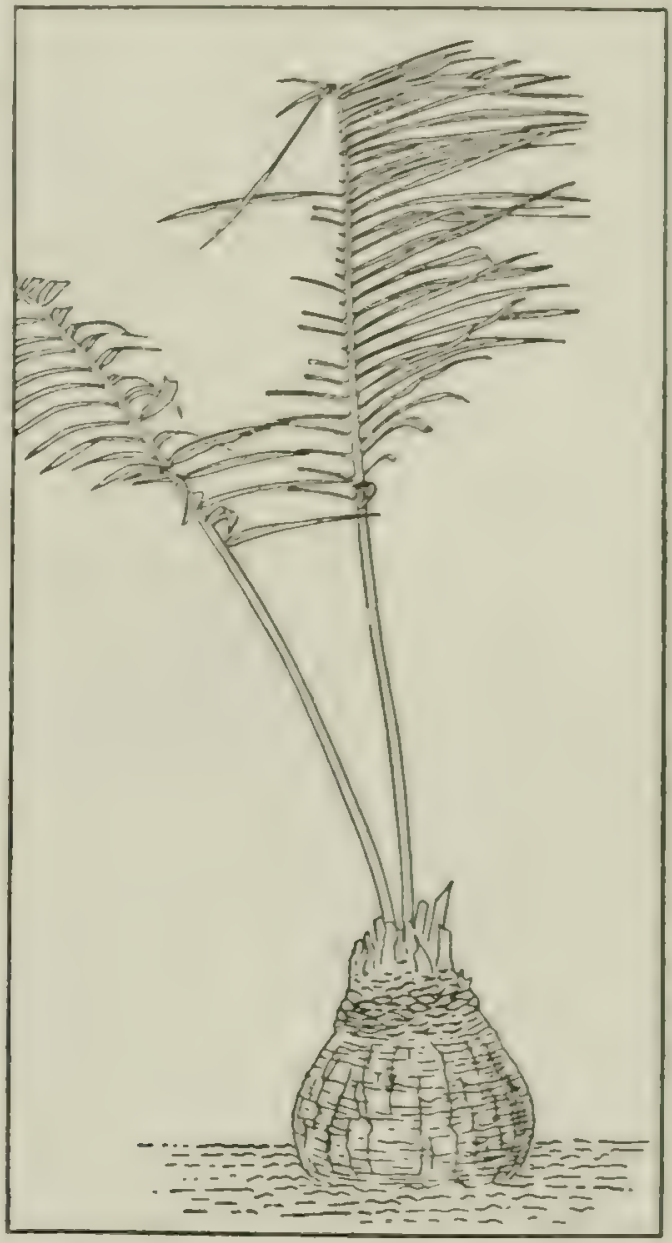

Fig. 116.-Cycas siamensis (?). $\times$ I/s.

This nearly armorless bulbous trunk affords a strong contrast to other heavily armored columnar trunks of the genus Cycas, and is in outer appearance and form closely comparable to the Sandwich Island palm Pritchardia Martii. It is also mue his like the subierra. Pritchardia Mas
nean Zamias. armor is little persistent, and in Zamia and Stangeria it is but very lightly developed for only a short distance beneath the leafy crown, the raked or "tuberous" trunk being covered by the periderm with its cork and bark after the manner next to be described.

\section{The Perinerm.}

The periderm is structurally made up of two layers-a thin outer layer of crushed cork giving rise to bark and a thicker inner layer of phellodern. It is a centripetally advancing and excising tissue. Below whatever amor is present, it forms with its cork and bark the final outer covering of the trunk. Its history in the cycads is this: As soon as a frond wilts down a transverse peridemal layer forms in the outer living portion of the base leit behind; and this is succeeded by another and another until all of the base is cut cway to the cortex, the peripheral portions of which are next similarly excised with the formation below of a 
stem-surface of bark. Thus the armor and outer cortex are continually removed from the base of the trunk towards the apex, with very greatly varying rapidity in the different genera and species. Thus it is, too, that the periderm, and such bark as it may give rise to, comes to be the final outer covering of the trunk from its base, where the peripheral cortex may be cut into, all the way to the leaf crown, just beneath which it ends in the tips of old leaf bases of the preceding foliar series. Upon the rate and regularity of periderm and bark formation (or conversely the vitality of the old foliar bases) must then depend the degree of armor retention. This explains how the cycads come to present every variation from the heavily armored species of Cycas and Encephalartos to the naked or tuberous Zamias and

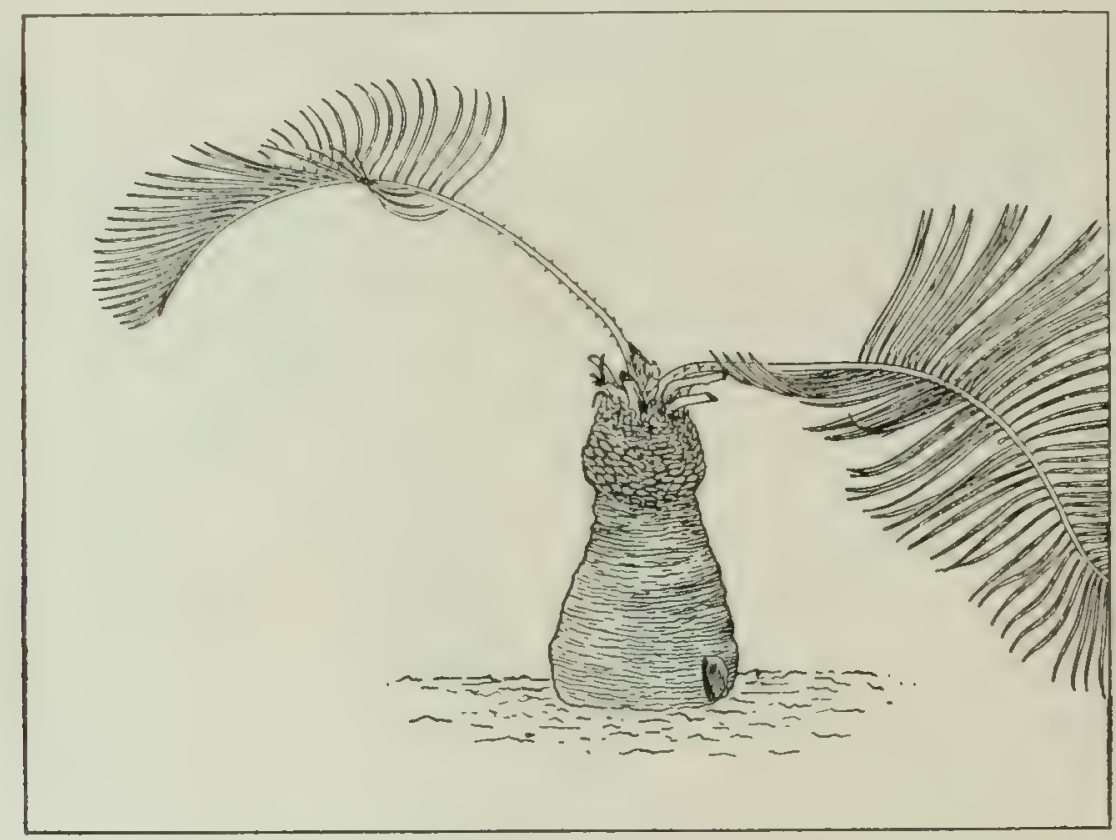

Fig. 117,-Cycas media. $\times \frac{1}{8}$. A small plant, showing rapid excision of the armor, whence it appears that persistence of the armor is not necessary to increase in trunk height, this speciés being the tallest known. (Compare with figure 102.)

Bowenias. In the latter genera there is a very regular and clean excision of the armor, and the cortex of all the lower portions of the trunk ends in the thin and even layer of periderm. In the case of an old trunk of Macrozamia Fraseri there is a very different appearance. In this cycad, according to Worsdell (205), the periderm is recognizable to the eye at the outer limit of the cortex as a conspicuous narrow white zone with an extremely irregular sinuous course, due to the fact that the successive peridermal layers arise in a very irregular manner and often in the phelloderm of the next older layer. As a result, the outer surface of the stem, consisting in either the remains of leaf bases or portions of cortex in which periderm excision has begun, is left very rough and jagged. The cellular make-up of the periderm is distinct, the cork layer being quite uniformly composed of crushed cells and the inner phelloderm layer of thinner-walled cells ranged radially with the cork and having interspersed varions thicker-walled cells and idioblasts. 
THE ROOT.- (Fig. 119.)

The cycads, nulike all vascular cryptorans, send down a primary root which continues as a tap-root and may be large and prominent, approaching the diameter of the trunk itself, as shown in the accompanying figure II9 of Dion edule. In subterranean trunks such as those of certain species of Zamia, the tap-root remains distinct and its lateral branches are relatively small, the trunk even assuming, as already noted in the description of Zamia floridana, a carrot-like form. But in most genera the root system comes to be quite filamentous, being largely made up of freely branching secondary or adventitions roots extending in every direction and often reaching the surface of the ground and spreading about in felt-like masses. The manner of branching in these secondary roots, we are informed, is only appar-

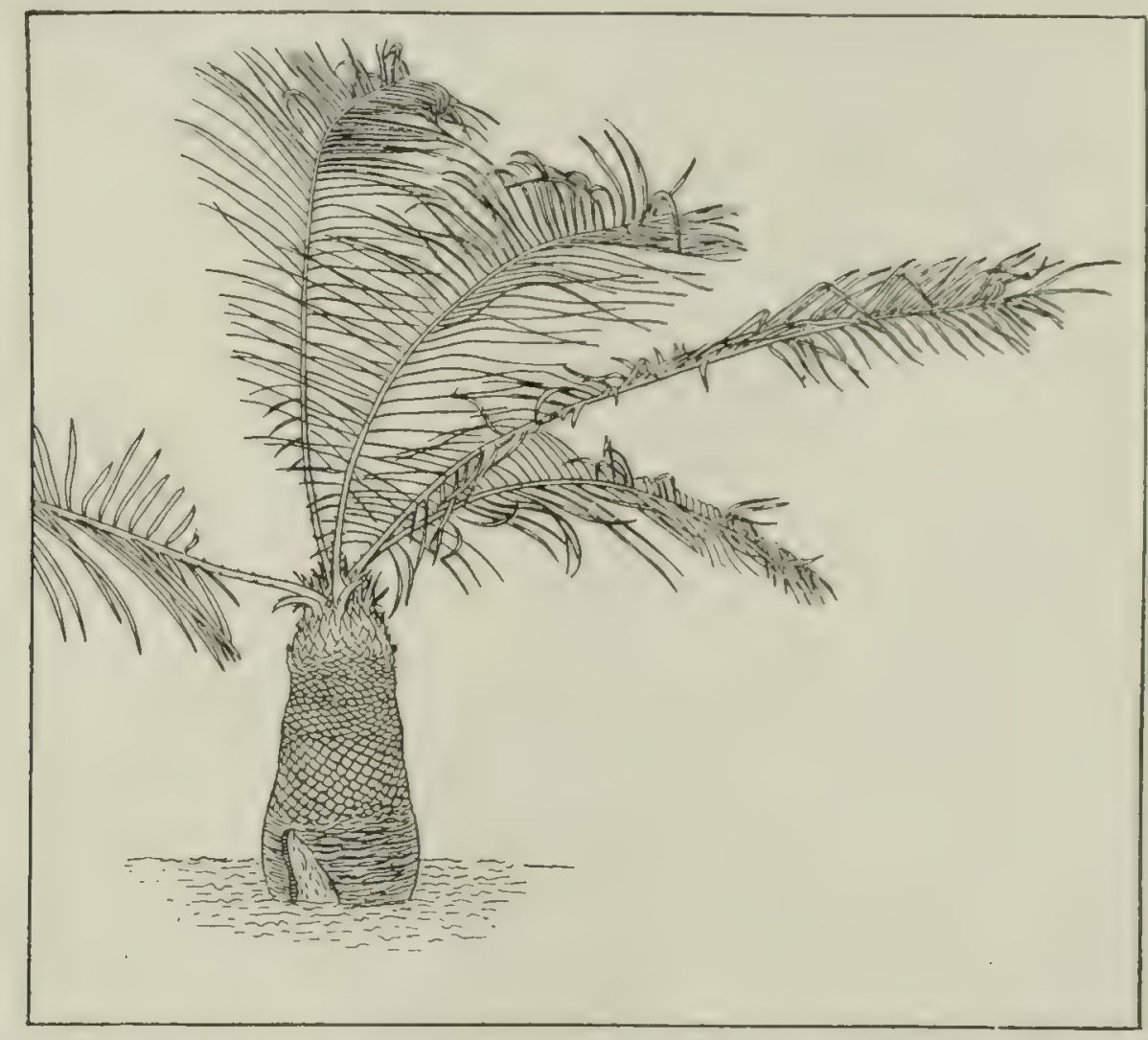

Fig. 118. - Encephalartos Ghellinckii. $\times i_{10}^{1}$. A South African cycad with molerately persistent armor. The exceptionally long and slender pinnules give the fronds a distinctly feathery appearance.

ently dichotomous as the result of the checking of the activity of the true apex. But it is also possible that a copious monopodial branching like that of the Marattiacex may in lesser degree be present in some of the cycads. According to De Bary the cycad root cap, as in other gymmosperms, arises from the splitting off of the onter layers of the periblem covering of the meristematic region, there being no true calyptrogen or dermatogen, as in the angiosperms. The "coral-like" or bushy dichotomous rootlets seen about the bases of most Cycas stems are an excrescent growth and may incidentally contain Nostoc forms in the cortical zone. The first cause of growth disturbance and excrescence is doubtless explained by the presence of bacterioid forms, which invade ever. the initial apical cells of the rootlets (78), although no microscopic structure has been observed directly connparable to that of leguminous tubercles. 
The first increase of thickness in the cycad root corresponds to that of dicotyls and gymnosperms, more especially to the fleshier forms. The structure of the secondary bundle elements is fundamentally similar to and a continuation of that of the stem. A periderm forms early, the primary outer cortex soon being thrown off. In those stems whose first cambium ceases activity and is succeeded by a sec-

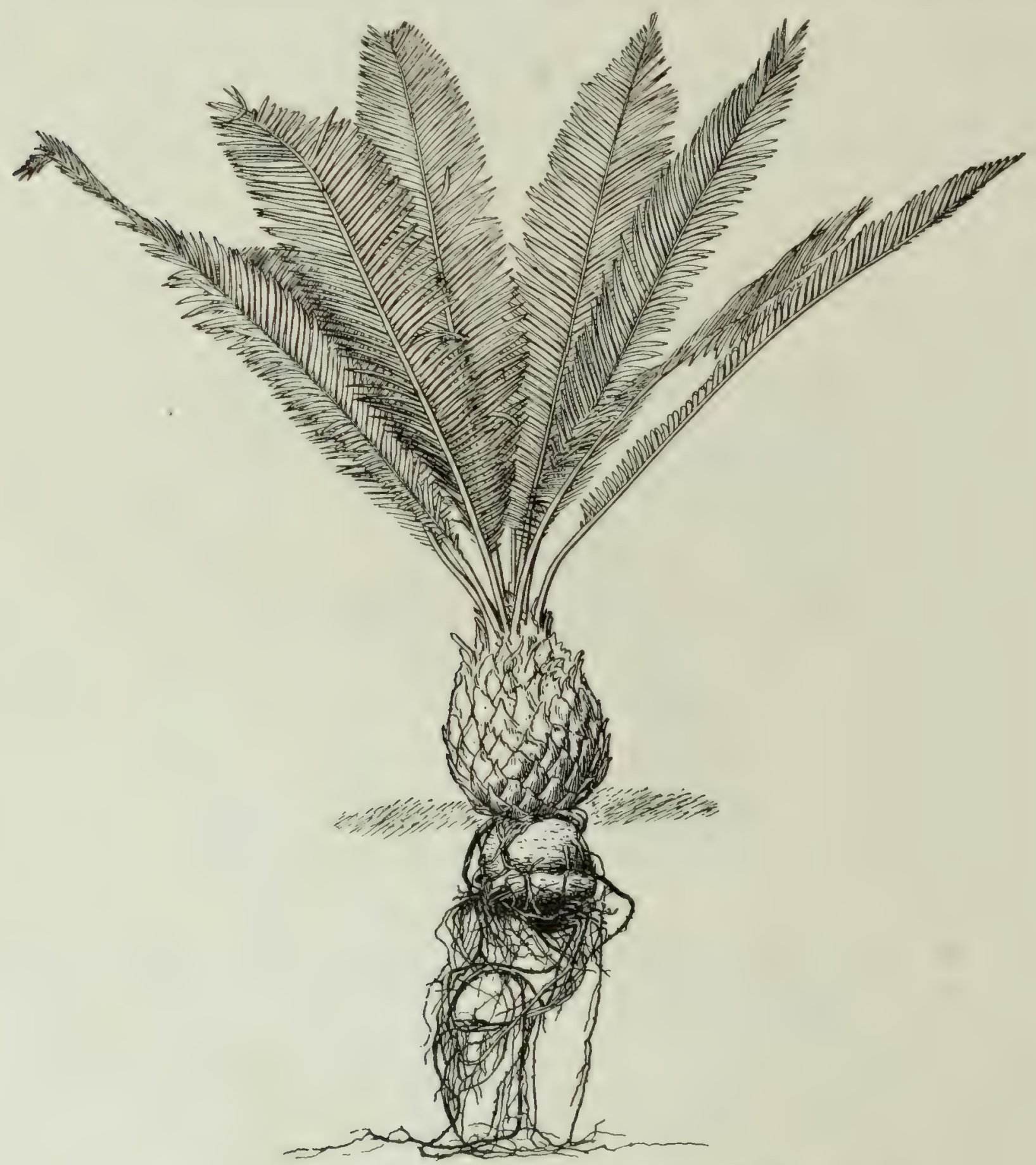

Fig. 119.-Dion edule. $\times \frac{1}{7}$. Showing the very robust tap-root, quite as large as the trunk itself, giving rise to a secondary filamentous root system.

ondary peripheral cambinm as described, an exactly similar growth proceeds in the roots as they become older. In the roots of Zamia floridana, the single xylem zone is relatively far heavier than in the stem, the form and process of zonal thickening possibly being similar to that seen on a far more extensive scale in such stems of Cycadeoidca as that slown in transverse section on plate xiv. 
THE LEAVES. (Figs. 46-48, and 120-123.)

The early development of the leaf strongly recalls that of fern fronds. In the young seedlings the vernation of the cotyledons is conduplicate, a condition that is further noted in the staminate fronds of the Cycadeoidex and the rachis of the Zamia fronds. The young leaf first appears at the apex of the trunk as a low and rounded hillock. Lateral wing-like expansions soon form at the base, and, as the frond becomes more conical in shape and a few millimeters in height, prolong themselves as low and rounded ridges running ont along each side of the

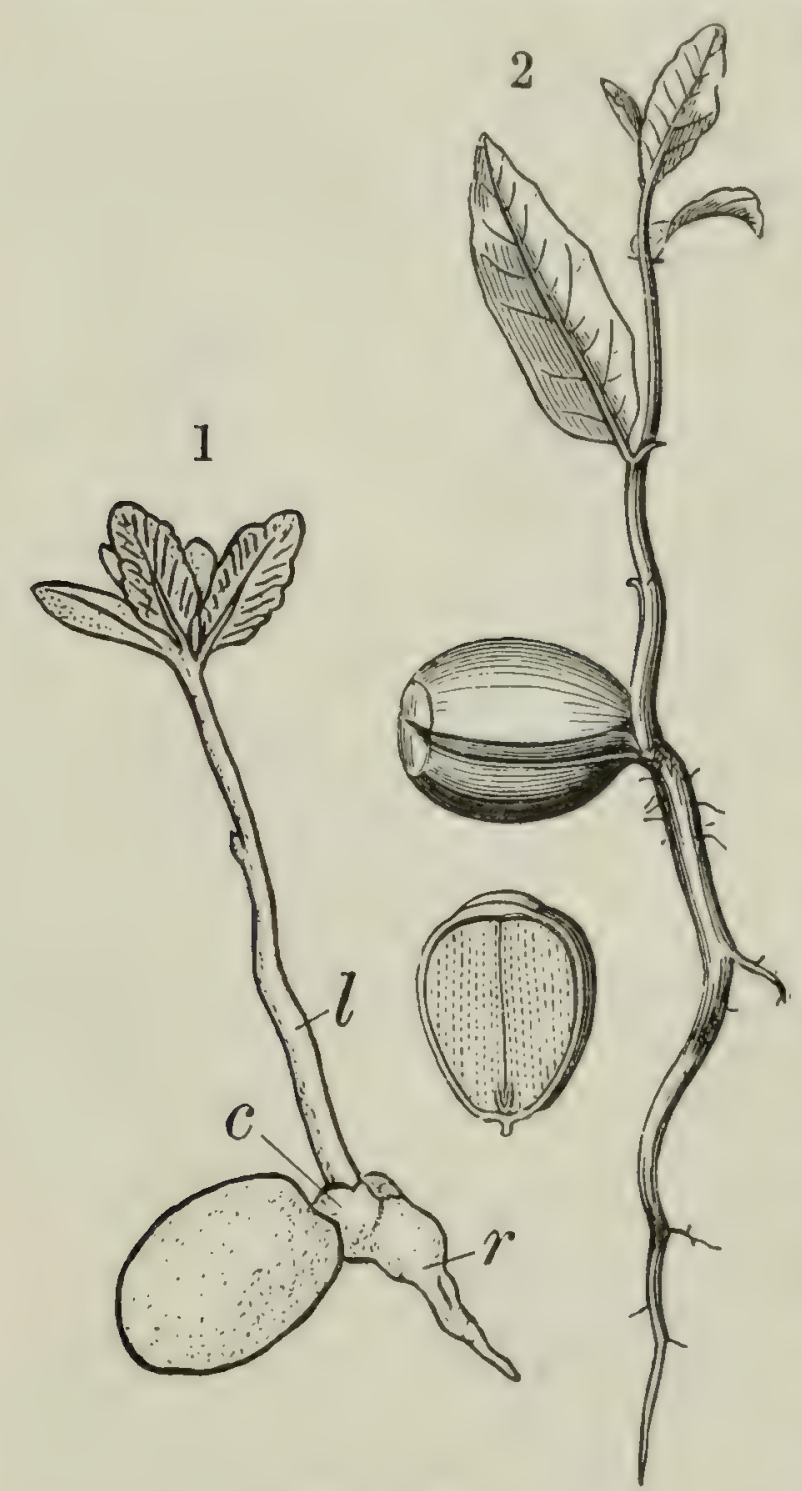

Fig. 120.

(1) Stangeria paradoxa seedling bearing the first foliage leaf (I), the radical (r), and the cotyledons (c) embedded in the megasporangium. (After Worsdell.)

(2) Oak seedling, showing hypogæous germination of a dicotyl. (From Gray.) middle portion or rachis. And on these ridges, as represented in figure $\mathrm{I} 2 \mathrm{I}$, about the time the frond reaches a length of from 2 to $4 \mathrm{~mm}$, the young pinnules begin to appear as rounded protuberances. In most cases the order of appearance is basipetal (from apex to base), as in the examined species of Encephalartos, Macrozamia, Ceratozamia, and Zamia. In Dion the order is mostly basipetal, but it seems in part acropetal (or ascending) at the apex. In Cycas Jenkinsoniana the order is divergent from about the middle of the fronds, and in $C$. Seemanni it is a mixed one. It is to be borne in mind that these statements refer to such stages as are shown in the text-figures. The scale leaves are at first similar to the foliage leaves, except that they possess ferrer pinnules, which soon abort. But while the lateral petiolar thorns of Cycas Jenkinsoniana, etc., are known to be aborted pinnules, those of Ceratozamia and various other forms are of an ordinary thorny distribution and character. By the time the entire frond has reached a length about equal to the thickness of the armor and is ready to emerge by the final rapid stage of growth, all the parts and the bundle systems are quite perfectly formed. But as a rule the pinnules are relatively much larger and more completely grown at this stage in such cycads as Dion and Encephalartos, which have very hard and bristly fronds, though in Macrozamia spiralis the acuminate but easily curling pinnules also reach a nearly fizll size before the rachis markedly elongates. In other cycads with soft or leathery leaves, as Cycas, Zamia floridana, and Stangeria the pinnules are more backward in forming. But there is every gradation between these two extremes, so that cycad fronds vary very greatly 
in habit of frond emergence from the armor, some having nearly fully grown pinnules while the petiole is very short (Dion, Macrozamia), others reaching considerable petiolar length while the pinnules are still immature (Cycas, Zamia). The presence of well-formed pinnules while the leaf is still within the armor is, as has been seen, a well-marked character of the Cycadeoidex, to which, in the case of silicified trunks, is fortunately due the not infrequent preservation of both isolated and entire crowns of young fronds in very great perfection. This is identically the condition in Cycadcoidca and Cycadella, and the erect position is also to be seen in the fern Botrychium. Prefoliation is direct in Dion, Encephalartos, Ceratozamia, and Macrozamia, the rachis being straight and the pinnules folded back to face, so that the successive blades imbricate from the base to the tip of the leaf rankwise on each side of the midrib, the ranks facing next to the stem axis, and the rachis being distal to it. In Cycas the rachis is straight, but the pinnules are

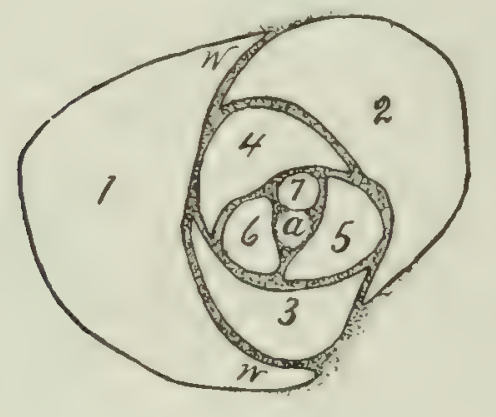

$a$
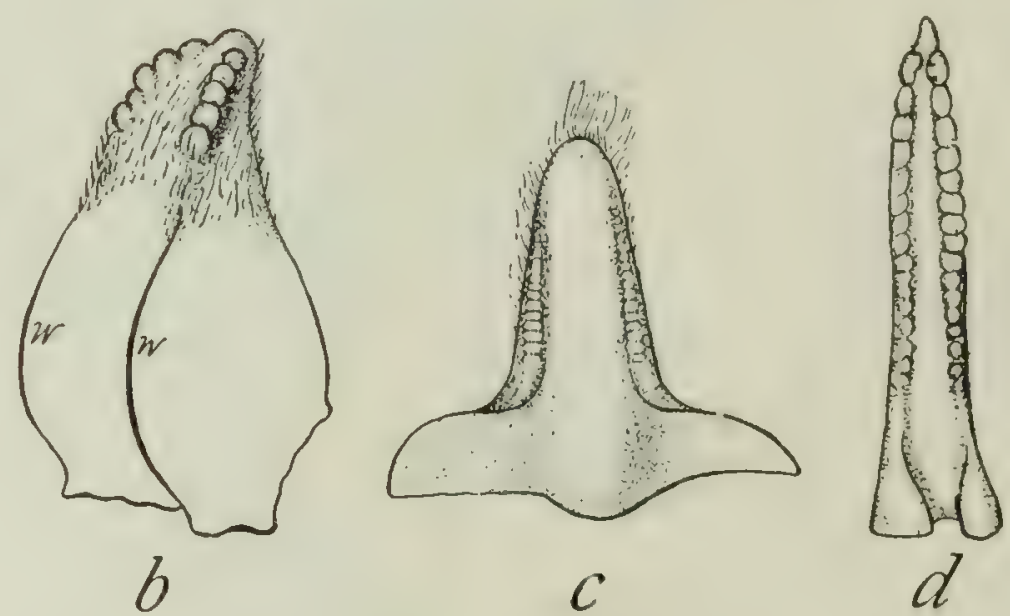

Fig. 121. - Very young fronds of existing Cycads, showing types of pinnule succession. $\times 10$. All from Bower.

a. Cycas Seemanni. Horizontal section through apex of a plant 12 months old. Leaves 1 to 7 are present as numbered: $a$, apex of stem; $w$, wing on basal sheath of frond.

b. Cycas Seemanni. Young frond showing basal wings $(w)$, and incipient pinnules in irregular succession with respect to size.

c. Cycas Jenkinsoniana. Young frond in which the formation of pinnules has begun, those a little below the middle being the most advanced, and the succession hence a mixed one, or partly acropetal (from below up), and partly basipetal (from above down).

d. Macrozamia Miquelii. Developmental stage of young frond, showing an exclusively basipetal order of pinnule succession.

circinately rolled, as in most ferns. Conversely, in perhaps all species of Zamia and in Stangcria, whilst the pinnules are straight the rachis is once-inflexed (see figure 47), as likewise in the megasporophylls of Cycas. This is the exact condition seen also in the microsporophylls of the staminate disk of the Cycadeoidex. Hence, while there is no case in which both axis and pinnules are circinate, vernation may be considered as in general of a filicinean character. The unexpanded leaves as entumerated exhibit four conditions:

(a) Rachis and pinnæe (bearing pinnules) inflexed: Borvenia.

(b) Rachis erect, pinnules circinate: Cycas.

(c) Rachis inflexed (or sub-circinate), pinnules straight: Stangeria and Zamia.

(d) Rachis erect, pinnules erect: Coratozamia, Dion, Encephalartos, Macrozamia. (Also Cycadeoidea and Cycadella amongst the Cycadeoidex.)

'The leaves or fronds, as organized into the palm-like crown borne at the sunnmit of the cycadean trunk, may vary in number from a few to more than a hundred; 
also, as each branch bears its own more or less well developed crown of leaves, freely branching trunks are often objects of great beanty. In size the full-grown leaf varies from ro $\mathrm{cm}$. in length in Zamia pygmaea to more than 3 meters in length in certain species of Cycas and Macrozamia.

The leaf bases and scalc-leaf bases, as seated in the cortex, cover all the surface of the stem as growth proceeds and leave their old bases behind to form the armor. Consequently, as the leaves appear in spiral succession and are closely appressed,

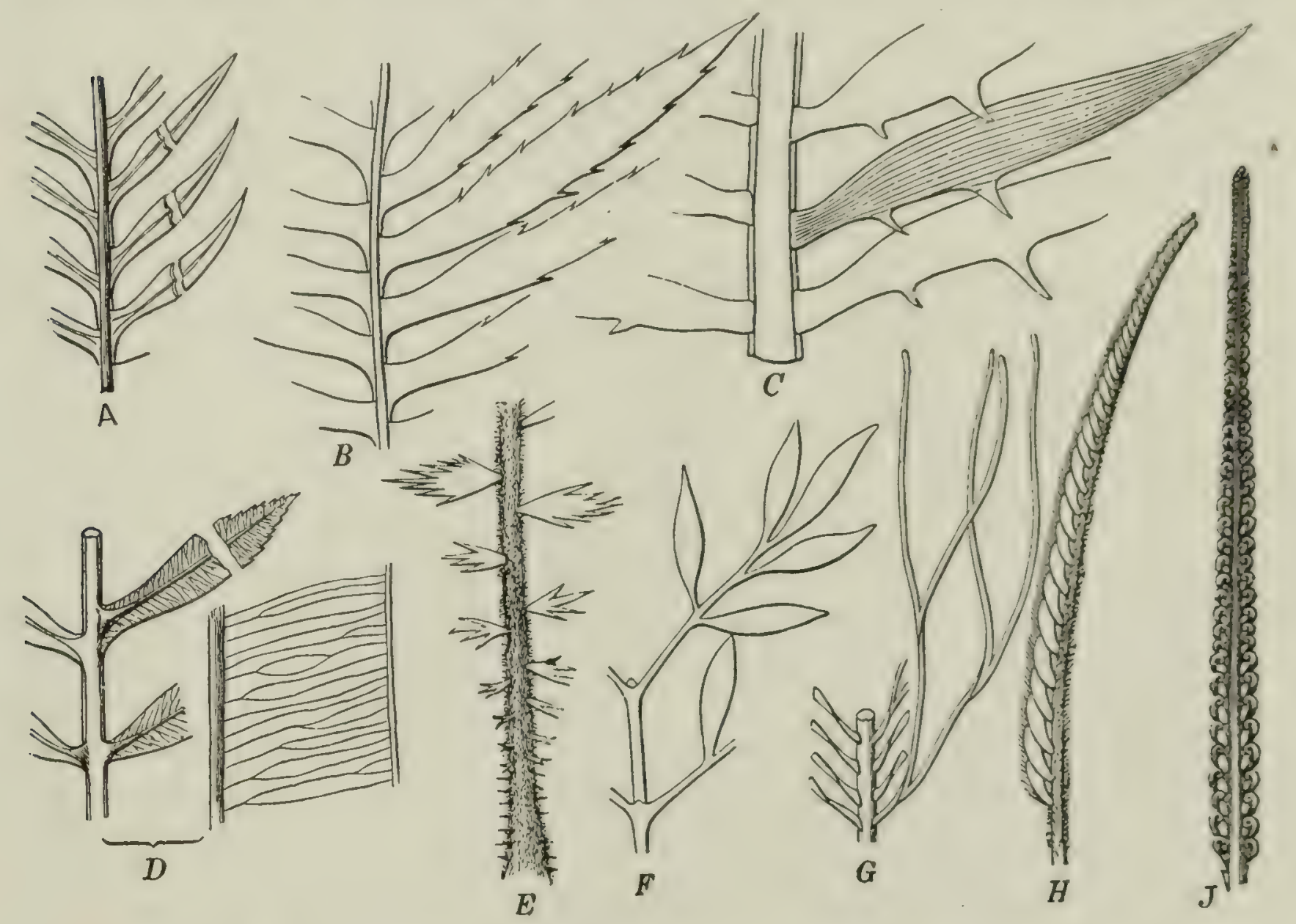

Fig. 122.-Margin, nervation, and other characters of cycadean fronds or leaves.

A, Cycas revoluta; B, Dion spinulosum; C, Encephalartos horridus; D, Stangeria paradoxa: E, Encephalartos villosus (lower rortion of frond bearing numerous prickles); F, Bowenia spectabilis: G. Macrozamia heteromera : $\mathrm{H}$ and I, respectively, prefoliation of Ceratozamia mexicana and Cycas revoluta. Much reduced.-From Engler und Prantl.

the bases assume in transverse section a lozenge-like shape with all the edges more or less curved either convexly or concavely, and the superior and the inferior angles rounded. Moreover, a double-spiral pattern is formed, made up of a high and a low spiral, whence in the tangential section through the armor the dexter canton of each leaf-base cut rests higher than the sinister (or vice versa?). Also the crosssection of each leaf base varies markedly in shape from insertion at the inner border of the armor, where such sections are long and flat, to the periphery, where they are laterally compressed and more rounded, the free petioles of Stangeriu and Bowenia being quite round. (See fig. 32, No. 6, showing the petiolar base of Cycas.)

The fronds are once-pinnate in all the genera but Bowenia, which is bipinnate (see fig. 6) and ancient as indicated by pancity or absence of similar fossil forms. 
The pinnules are commonly inserted in two parallel furrows separated by a broad, heavy, strongly convex midrib. Sometimes the bases are narrow, but there is every variation from narrow to broad based forms, in which the bases fill all the space of the insertion furrow, or even slightly overlap, the posterior basal edge running down beneath the anterior edge of the base of each preceding pinnule, as in Dion and certain species of Cycas. The insertion of pinnules varies from opposite to alternate, often on the same rachis. The rachis may end in a rudimentary point, with the terminal pinnules smaller and smaller, thus producing acuminately tipped fronds (Dion), or the terminal pinnules may be of quite full size and the frond truncate (cf. B, fig. I 23). The number of pinnules varies from a half dozen to as many as I25 on each side of the midrib. Basally the pinnules degenerate into spines, or fail of development, being, as already noted, abortive. In addition, the

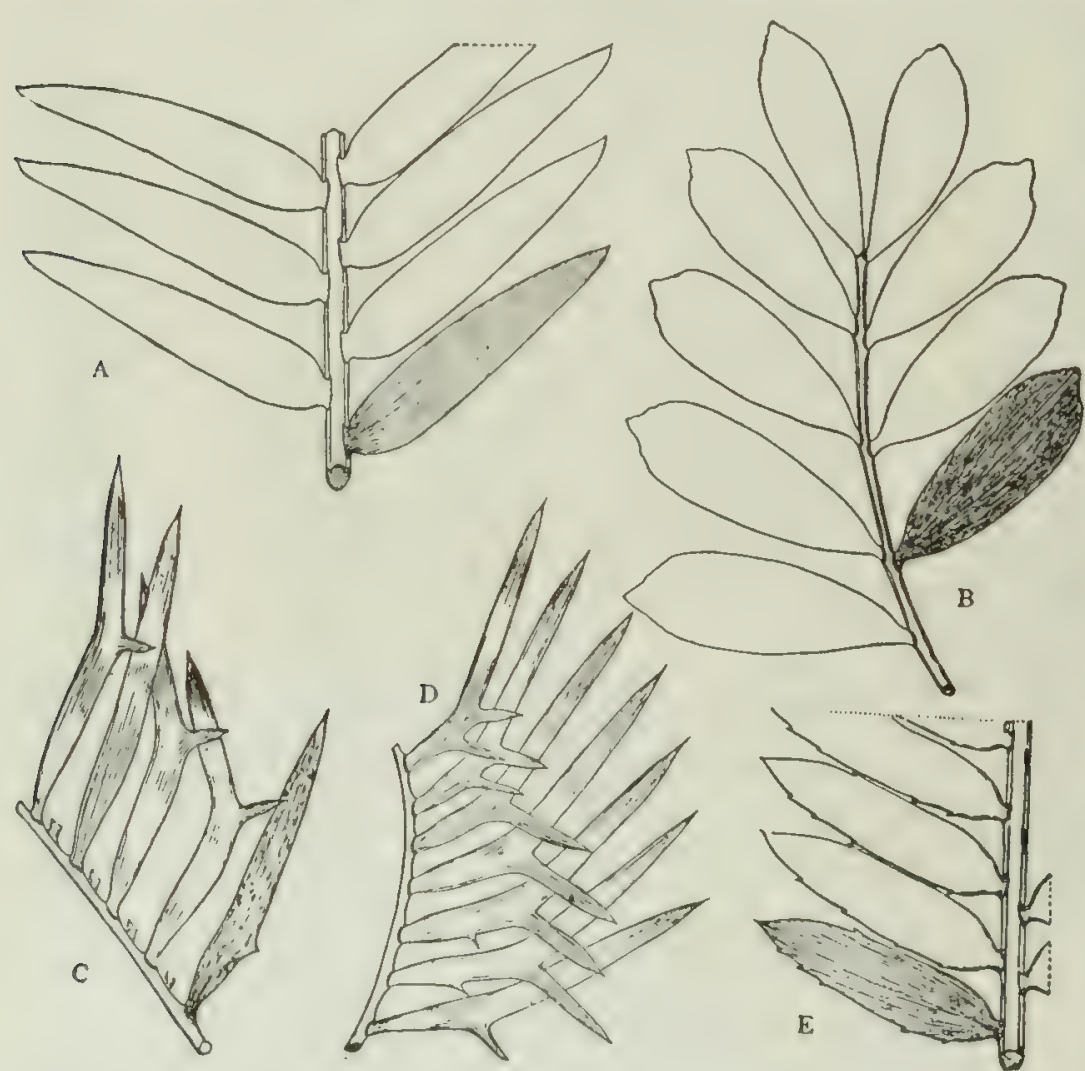

Fig. 123. - Entire and spinose margins of pinnules of existing cycads. $\times \frac{1}{3}$.

A, Encephalartos (?) lanuginosus; B, Zamia "glabra"; C and D,

Encephalartos Lehmanni (side views); E, Zamia (?) vernicosa.

It may be noted that spinose petioles or toothed pinnule margins are rare in fossil cycadean foliage, such characters appearing to distinctly increase with the age of the group, quite in accord with Beecher's theory oí spinose growths (2). petiole and rachis of Zamia pseudoparasitica, also Zamia Wallisii, is numerously set all round its surface with strong, thorny spines.

The pinnules mostly vary in shape from the linear forms as narrow and long as pine needles in certain Zamias to the thick and fleshy ovate forms like those of Zamia furfuracea, reminding one of the leafy blades of Dammara and certain of the Cordaitales. In addition, several very peculiarly shaped pinnules occur. Those of Macrozamia heteromera are grass-like blades twice diclotomizing (see fig. I22, G) and the much larger pinuules of Encephalartos caffer (?) and especially E. Lehmanni (cf. fig. I23, c, D) tend to assume an unequal

$Y$ shape, owing to the development of a lower basal spine into a broad lamina, thus forming unequal dichotomy of the blade. In Encephalartos horridus several such laminiform spines are present ( $c$. fig. I22,C).

Such variations are also to be considered forms of much modified margin, since other marginal thorns are present. Ordinarily the margins are entire and slightly inrolled dorsally. In Dion the margin is sparsely set with strong thorns, and in Zamia psendoparasitica it is sparsely serrate. The marginal characters are of only secondary systematic value. In length the pinnules vary from a few centimeters to half a meter; in texture they are leathery in greatly varying degree; in color they vary from light to a very dark green (Zamia fuscoviridis). 
The bundles are deeply embedded in the parenchyma in all but a few species, and mainly determine the nervature, being often accompanied by or alternating with a strand of hypodermal sclerenchyna. Nervation is of three characteristic kinds:

(I) A mid-nerve without lateral nervules: Cycas.

(2) A mid-nerve with numerous simple or once to twice dichotomizing and occasionally anastomosing lateral nervules: Stangeria.

(3) Numerous equal parallel curving and from one to three times dichotomizing nerves, the remaining genera. (Also Cycadeoidea and Cycadella.)

It is noteworthy that annong the fossil forms belonging to diverse fanilies of the "Cycadophytes," as the great group of cycad-leaved plants lias sometines been called, there is much greater variation in nervature. Dictyozamites (fig. I38) is netted-veined without a mid-nerve, or "dictyopterid, " and Otozamiles has an odontopterid venation.

Résumé of Vegetative Cimaracters of tie Crcadacez.

Trunk Types.

(a) Tuberous............ $\left\{\begin{array}{l}\text { Lumia. } \\ \text { Stangeria. } \\ \text { Bozvenia. } \\ \text { Microcycas. } \\ \text { Macrozamia (in part). }\end{array} \quad\right.$ (b) Columnar............

Armor Types.

(a) Armor not mark- $\left\{\begin{array}{l}\text { Slangeria. } \\ \text { bowlyenia. } \\ \text { Zamia. } \\ \text { Nicrocycas. } \\ \text { Cycas (in part). }\end{array}\right.$

(b) Armor mainly per- $\left\{\begin{array}{l}\text { Dion. } \\ \text { Encephulurlos. } \\ \text { Ceralozamia. } \\ \text { Macrozamia (in part). } \\ \text { Cycas (most species). }\end{array}\right.$

Wood Zone.

(a) Monoxylic........... $\left\{\begin{array}{l}\text { Zamia. } \\ \text { Dion. } \\ \text { Stangeria. } \\ \text { Ceratozamia. } \\ \text { Aicrocjects (?). }\end{array}\right.$

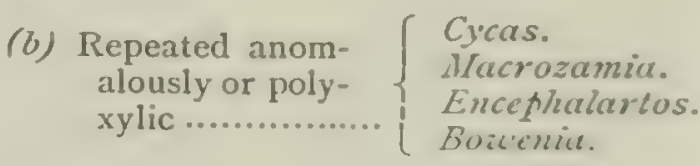

Pith Typpes.

(a) Gum canals only.... $\left\{\begin{array}{l}\text { Cycas. } \\ \text { Zamia. } \\ \text { Dion. } \\ \text { Bowenia (?). } \\ \text { Microcycas (?). } \\ \text { Stangeria. } \\ \text { Ceralozamia. }\end{array}\right.$

(b) Gum canals an,

a system of cau- \{ Encephalar ros. line bundles in Macrozamia.

\section{FRUCTIFICATION.}

The existing cyads areall diœcious. The staminate fronds or microsporophylls are throughout the group reduced to scale-like form and organized into typical bractless cones, which are borne at the summit of the trunk, but are not always terminal to the main stem, since occurring in pairs or small groups as branches. (See figure of Zamia floridana.) The same is true of all the ovulate fronds, except in the genus Cycas, in which the crowns of carpellary leaves are strobiliform, but alternate more or less regularly with the foliar crowns. In other words, the stro- 
bilus of Cycas is of the absulutely simple type, in which a secondary deciduous strobilar axis is not differentiated from the main vegetative axis, the latter standing in the peduncular relation, and continuing anew its growth after fructification. This is the sole surviving example among existing seed plants of this primitive and essentially filicinean arrangement, which must have been widespread if not universal among the Paleozoic phanerogams. Obviously termination of reproductive and then of vegetative growth by lateral branches following the production of carpellary leaves would be the first steps in the direction of true cycad cone evolution.

In outer appearance the cones of both sexes strongly resemble each other, the ovulate strobili of Cycas always excepted. The latter may be noted in figure IO2, while ovulate cones are shown in figures $4,6, I_{34}$, and $\mathrm{I} 35$, and staminate in figures 4, IOI, and II 5. The ovulate axes may greatly exceed the staminate in length and are quite uniformly more robust, but have fewer sporophylls. The size of the cones varies from three to five centimeters in length in Zamia pygmaea to nearly a

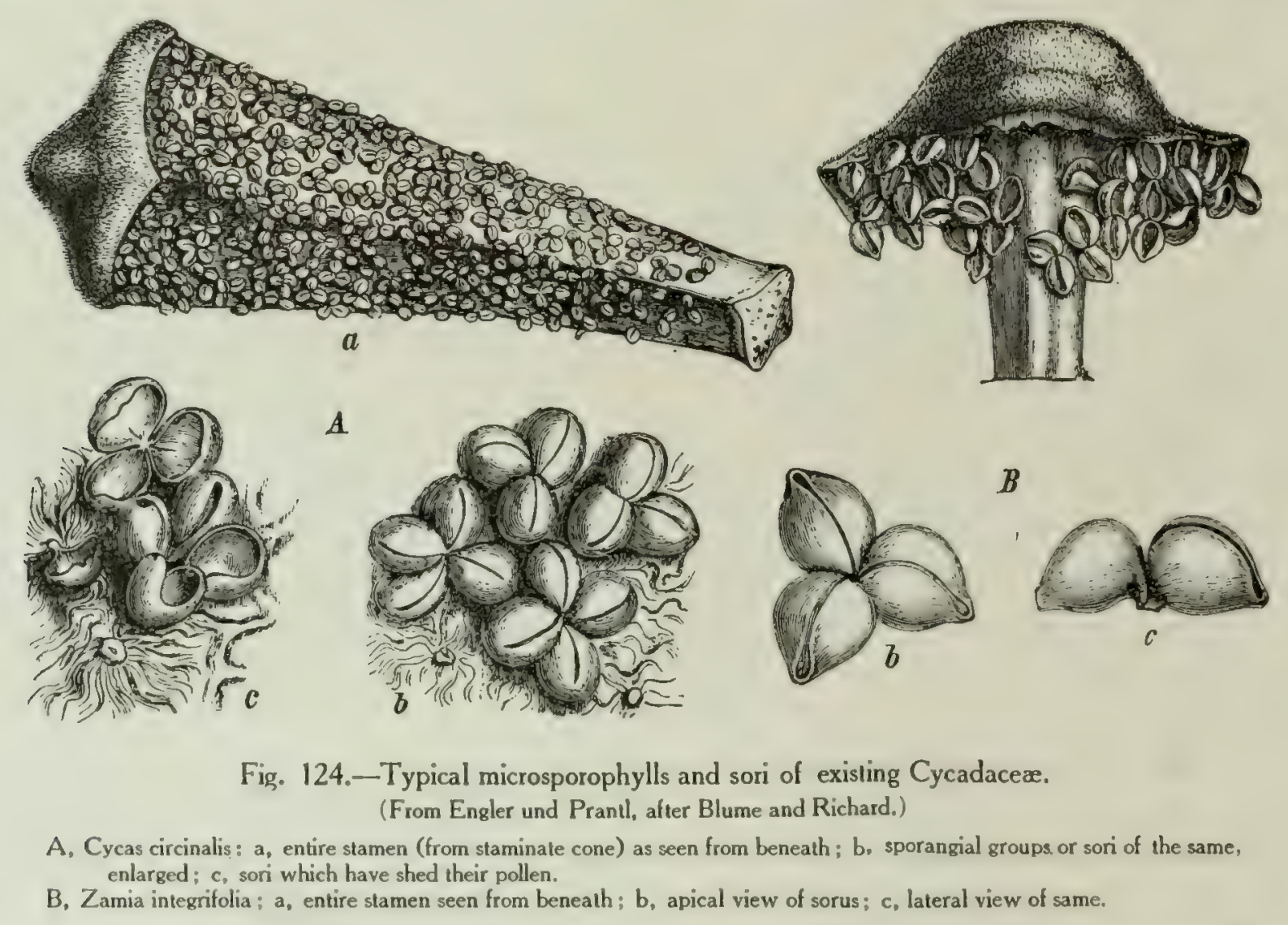

meter in some of the Macrozamias; the number of sporoplylls from less than 30 to more than 6oo. At the base and summit of the cones small sterile scales are present, though evidently only different from the fertile series in non-development and infertility, and hence directly comparable to the numerous infertile scales of the cycadeoidean cone. Also, what must be regarded as a true reversion has been reported by 'Thiselton-Dyer in the case of an immense ovulate cone of Encephalartos bearing at its summit a clear transition from fertile scales to sterile scales, and from these to small but otherwise typical foliaceous fronds. Pinnule-bearing scales have been observed in "Zamia floridana, and are doubtless of not infrequent occurrence in other cycadean species. (See figures $\mathrm{I}_{34}$ and $\mathrm{r} 35$ of these cones.) No instance, however, has thus far been reported of bisporangiate monstrous cones, such as 
are occasionally seen in conifers. The phyllotaxy (12) of the cones is either spiral or alternately whorled. Encephalartos caffer ( 8 and $q$ ) has a $21 / 55$, and $C^{\prime}$ cas spherica (d) a $55 / \mathrm{r} 44$ spiral. Whorled decussate forms are Zamia muricala $(2 / 5$ to $2 / 9)$, Ceratozamia mexicana, of (2/25 to $2 / 23)$, Dion edule, J (2/26 to 2/37). Variations in the number of sporophylls, as well as in their disposition, may, however, occur within the same species and sex.

The microsporophylls (see fig. I24) of wedge to nail-like form, with the lateral edges aligned by mutual appression, mostly terminate in a heavy, blunt, more or less peltate hexagonal end; but they are acuminately extended in the genus Dion, and bear a pair of lateral horns in Ceratozamia. The free terminal surfaces are often

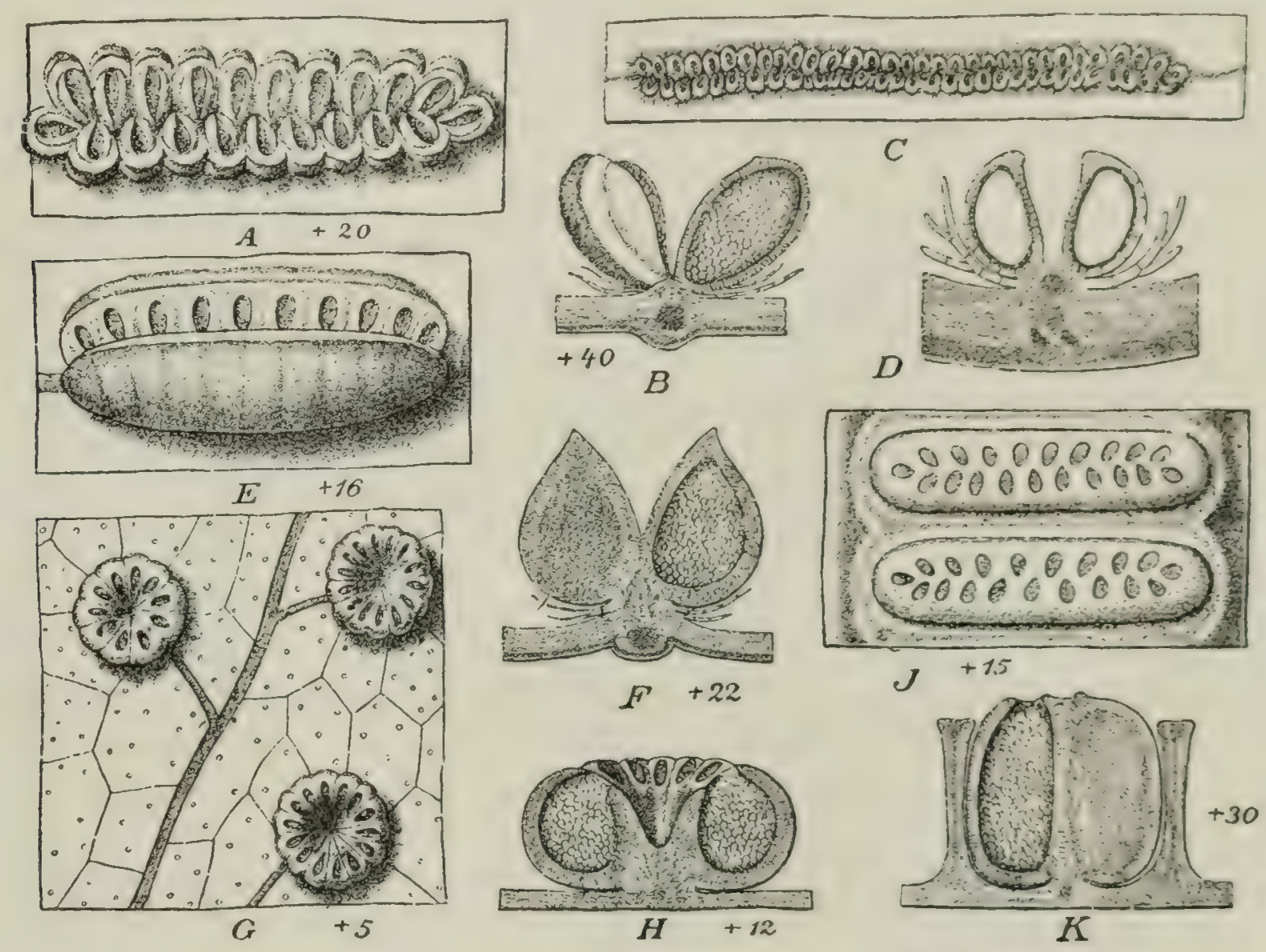

Fig. 125.-Sori and synangia of the five existing genera of Marattiaceæ.

$A$ and $B$, Angiopteris crassipes $W$ all: $A$, sorus: $B$, two sporangia, the one in surface and the other in lateral longitudinal view. $C, D$, sorus of Archangiopteris Henryi Christ et Giesenhagen. Seen from beneath $(C)$ and in transverse section (D). E, F, synangium of Marattia fraxinea in full and transverse longitudinal view (cf. various text-figures of synangia of Cycadeoidea). $\mathrm{G}, \mathrm{H}$, Kaulfussia resculifolia Bl., circular type of synangium as borne on the frond ( $\mathrm{G}$ ), and as seen in median longitudinal section $(H)$; J, K. Danæa elliptica Sm., nearly embedded synangium as seen from beneath (the apical view), and in transverse longitudinal section. (From $\mathrm{G}$. Bitter (5) in Engler und Prantl.)

pubescent, in Dion strikingly so. Only the nether covered surface is sporangial in varying extent, being in Cycas quite continuously so nearly from the axial insertion, but in Zamia distal and divided into two lateral fields, occasionally further restricted to the outer edge of the sporophyll. The number of pendent conifer-like sporangia borne by a single sporophyll varies from fully a thousand in the larger forms to but two or three on each of the lateral sporangial surfaces in some of the small-coned Zamias. Of much significance is the fact that on cioser inspection the sporangia are often found to exhibit grquping in sori similar to those of Angiopteris. 'Three to six sporangia in Cycas and from two to three in the Zamia groups are basally 
attached to a minute elevation, to which the dehiscent slits are radial; whence alignment in sori is more apparent after the discliarge of pollen. In development the sori, moreover, agree with those of Angiopteris, the general structure of the sporangia being likewise Marattiaceous (figs. I 24 and I25). As bearing directly on the existence of a fundamental relationship to the Cycadeoidex, it should be recalled that for quite thirty years, resting mainly on the investigations of Eugen Warming, the derivation of the staminate scales of the cycads from fertile fern fronds of the Marattiaceous type has been one of the best defended and most widely accepted of all working botanical hypotheses; and indeed, with the discovery of the pollen-bearing synangia of the Cycadeoidex so exactly similar in structure to the spore-bearing synangia of Marattia in the first instance, and the later discovery of such seed-bearing "quasi-ferms" as Lagenostoma in the second; this hypothesis, to say the least, has taken on the guise of a demonstrated truth.

The structure of the three-celled pollen is much as in Ginkgo. In germination a small persistent lenticular prothallial cell is cut off. Then a generative cell is cut off in contact with the prothallial cell, the large cell left over being the vegetative or "tube cell," and its nucleus the tube nucleus. In Ginkgo the same alignment is present, except that there is clearly an initial resorbed cell, traces of which have, however, also been observed in the cycads $(69,186)$.

In fertilization the generative cell plays an extraordinary rôle, but recently brought to light by the brilliant researches of Hirase on Ginkgo $(66,67)$ in the primary instance, and rapidly followed by those of Ikeno (69) on Cycas and of Webber (I86) on Zamia. Immediately following the development of this three-celled stage, the large vegetative cell of the pollen grain pushes in the wall of the generative cell and at the same time elongates to form the pollen tube, which then invades and branches more or less freely in the nucellar tissue, also carrying with it the tube nucleus. Meanwhile the generative cell divides into a quiescent stalk and a body cell with an immense nucleus, at whose opposite poles arise the radiately structured cilia formers or blepharoplasts of Webber. Then the tube nucleus makes a retrograde movement from its position in the end of the branches, invading the nucellar tissue and consorting with the basally situated stalk and body cell. Next the nucleus of the latter divides in the equatorial plane and inaugurates the formation, from the body cell contents, of the two spermatozoids, each of which bears a broken ciliferous spiral organized from the adjacent polar body or blepharoplast. The spermatozoids are of large size, visible to the unaided eye, and in effecting fecundation after the rupture of the pollen tube swim actively to the archegonium, the watery medium for this last stage of the journey of the ciliated sperm cells being afforded in part by the tube contents and in part by exudation from the egg cell, rather than from external moisture. The spermatozoids may, however, be observed swimming free in sugar solutions, a highly suggestive fact, since there is absolutely no inferential doubt that such motile male cells took part in fertilization in the Cycadeoidere. It is, moreover, highly probable that owing to the non-cleistogamous character of the flowers of the latter, and the much inclosed ramentum-covered position of the ovulate strobili that the antherozoids were capable of swimming considerable distances through such water and moisture as was present during the season of 
fertilization, much as in the ferns. But contrariwise, a much smaller if not rudimentary pollen tube is supposable.

The megasporophylls of the genus Cycas, as organized into the large terminal strobilus, are once-deflexed, not unlike the staminate fronds of Cycadeoidea. 'They' are of unique and extreme interest as the most primitive of all reproductive structures in any existing spermaplyytes, and unquestionably indicate, inderendently of the absolutely convincing collateral evidence afforded by the Cycadeoidere, that the common history of the sporophylls of all the Cycadacere is that of metamorphosis from fertile leaves of ancestral Marattiaceons ferns by way of cycadofilicinean types like Lyginodendron. The leafy features are quite clear in C. revoluta, in which the basal portion bears three or more pairs of adnate ovules in the pinnular position, and the broad to laminiform terminal portion numerous thickly-liaired pinnules. In the closely related species C. Steenstrupi, from the Atané Cretaceous of Greenland, the pinnules are not so clearly present, the broad tip apparently being thickly
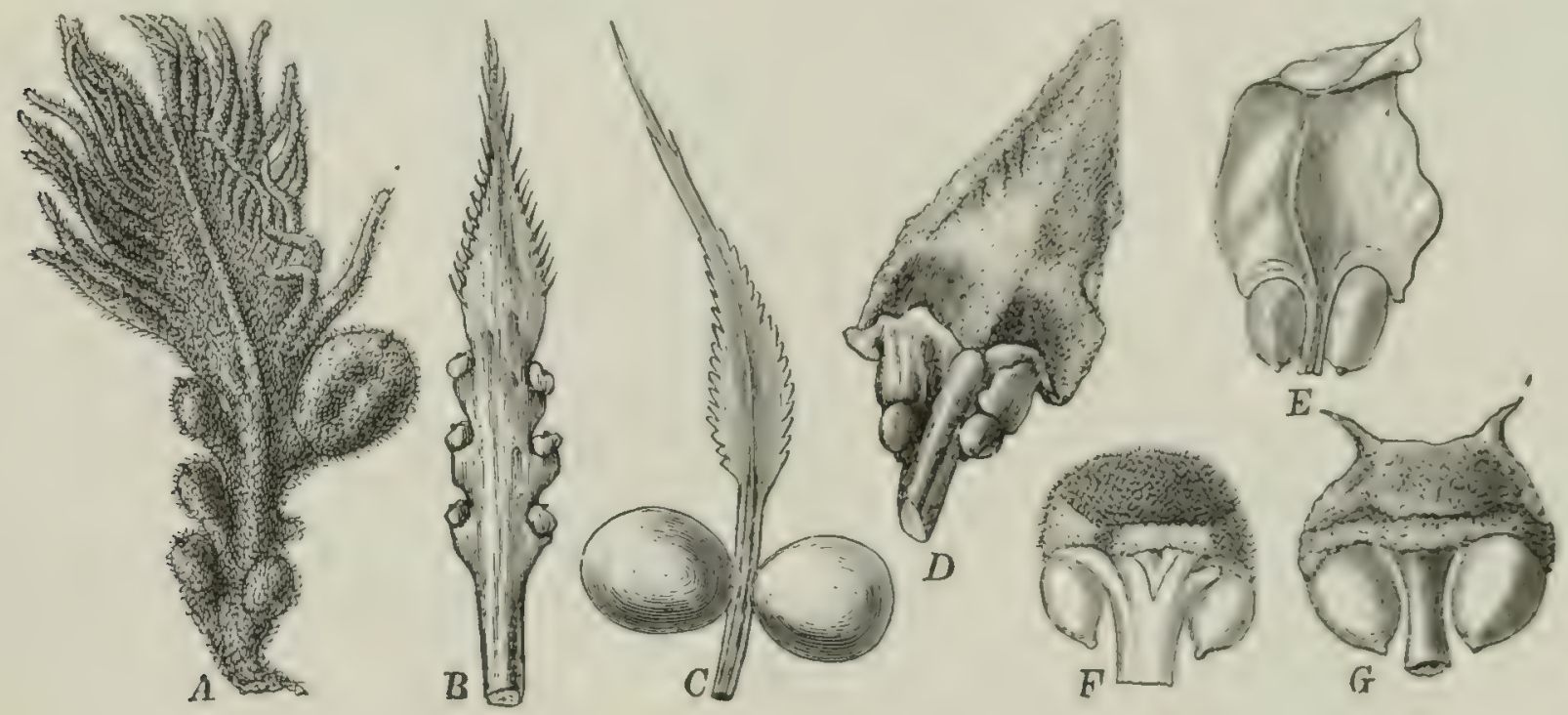

Fig. 126. - Characteristic forms of existing cycadean megasporophylls.

A, Cycas revoluta; B, C. circinalis; C. C. Normanbyana: D, Dion edule; E, Macrozamia Fraseri; F, Zamia integrifolia; G. Ceratozamia mexicana. F and G, natural size; the other forms variously reduced. (From Engler und Prant, after Sachs (A). (C) F. V. Müller, (E) Miquel, (F) Richard.)

set by very long almost ramentum-like hairs. In $C$. circinalis the general form is quite similar to $C$. revoluta and $C$. Steenstmpi, except that the pinnules of the quite laminar extremity of the frond are reduced so as to form simply a serrate edge. From these larger carpophylls there is a gradual reduction to forms like C. Normanbyana, with a broad, elongate tip and a single basal pair of ovules, closely paralleling Dion, which has the least reduced form of carpellary leaf to be seen in the distinctly cone-bearing cycads. In the other genera, much more reduction has occurred, the form being quite scale-like or pedicel-like, with a terminal hexagonally peltate expansion, to which is attached interiorly and laterally a pair of ovules, or abnormally one or three ovules. The outer surface of the scale may be pubescent, and, in Ceratozamia, bears, similarly to the staninate cones, the pair of lateral horns from which this genus takes its name.

The oonles of the cycads are throughout sessile and orthotropous, with a heary tripartite walled integument and slight prolongation of the micropylar tube. As 
borne free on the carpellary leaf, fig. I 27, the ovules of Cycas are slightly flattened laterally, and bilobate, being in size and coloration quite plum-like. In the other genera the inclosed position in the cones produces characteristic appression faces on the relatively smaller ovules, though all are the largest known in seed plants.

The earlier stages of ovule development, up to that shown in figure I27 A, require but brief mention here, since it is seemingly unlikely that they will ever be observed in the fossil condition, though this is by no means conceived wholly impossible. It is, then, only of present importance to note the fact that the earliest observed stage of megasporangial growth consists in a mass of subepidermal sporogenous cells (as in Ophioglossacer, etc.). Next, the sterile envelope of cells rapidly organizes into a large apical nucellar region and a thick integument pierced by a long micropylar passage. At this stage the sporogenous tissue is deeply
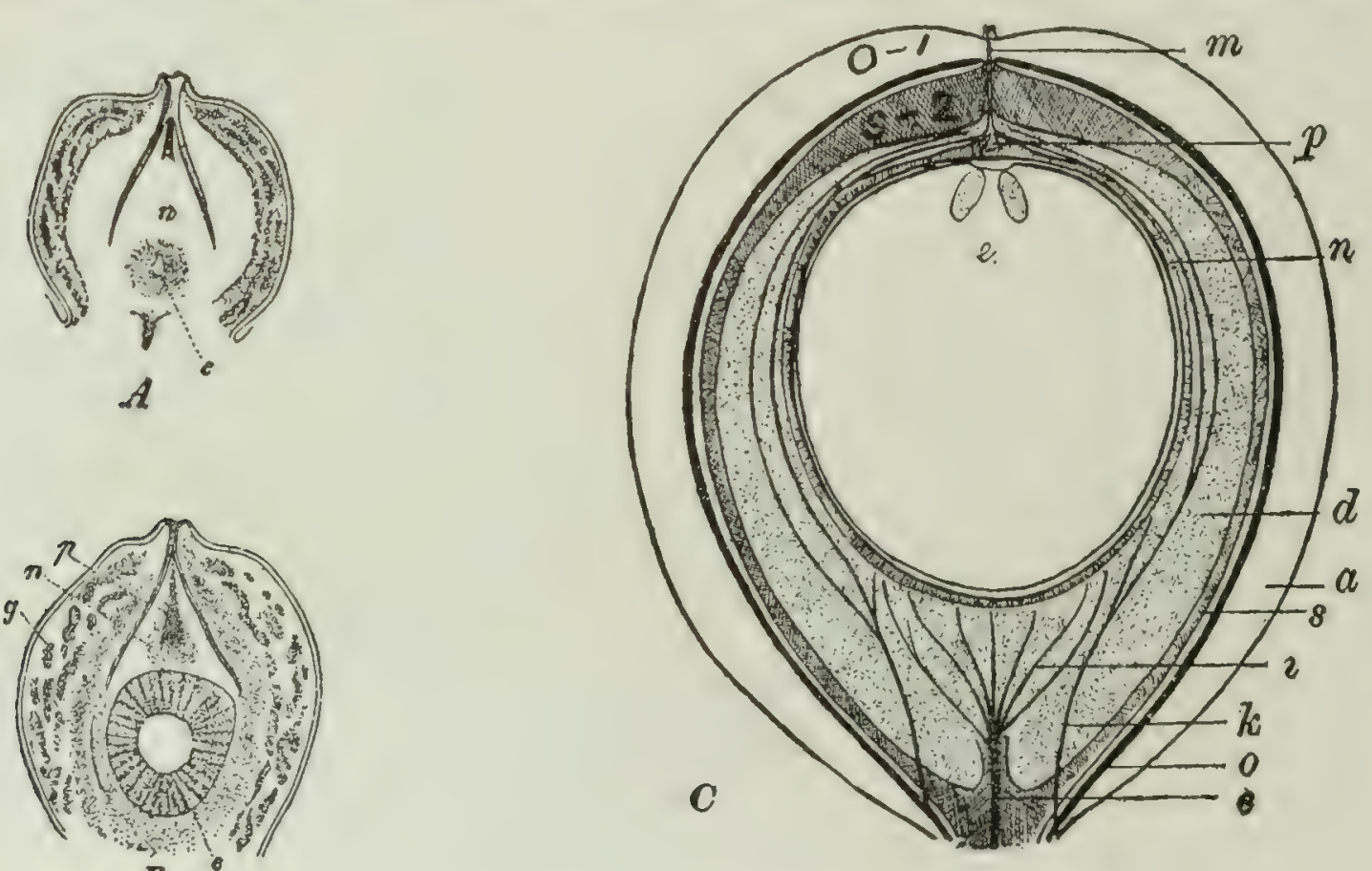

Fig. 127.-Cycas circinalis. Developing and mature ovules.

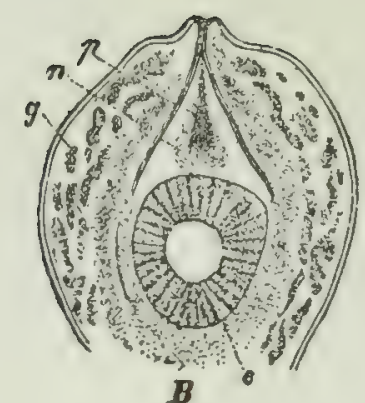

A. Young seed showing an initial stage of the embryo sac. $\times 3$.

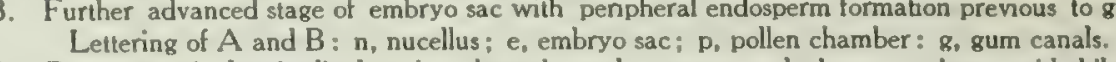

C. Diagrammatic longitudinal section through nearly mature ovule borne on base, with bilateral symmetry in the plane of the carpellary blade. About natural size. $a, s, d$, respectively the outer fleshy, middle stone, and inner fleshy layers of the seed wall $; n$, nucellus; $e$, prothallus or endosperm with archegonia; $m$, micropylar tube; $p$, pollen chamber; $c, i, k, o$, bundle system of the seed walls, of which the central bundle (c) spreading out into the basal system (i) is the primary analogue of the bundle supply of the Cycadeoidean seed; 0 , bundle of outer flesh with system (i) is the primary analogue of the bundle supply of the Cyar
branch $(k)$ in inner flesh. (Compare with figure 128,5 and 6.1

[The preferable interpretation of structure may be that the internal vascular system ( $i$ and $k$ ) belongs wholly to the nucellus, since in the primitive cycadaceous seeds Stephanospermum. Trigonocarpon, etc., the nucellus with a well-developed bundle system is free from the chalaza upwards.] (A and B from Luersson ; C from Marie C. Stopes.)

embedded near the base of the nucellus. Meanwhile the summit of the nucellus assumes a conical form and projects into the micropyle as a cap of firm-walled cells, beneath which is an irregularly conical cavity, the pollen chamber, opening out by a narrow apical passage just beneath the micropyle, and capable of containing a considerable number of pollen grains. Since in Zamia floridana the micropylar tube has a diameter little in excess of a single grain, the pollen is supposed to make its way to the pollen-chamber opening by some form of suction. However this may be, at pollination time the chamber is often packed with pollen grains. While pollen has never been observed inside the integument of any cycadeoidean 
fruit, it doubtless will be, since the pollen chanber has been observed to contain pollen in several cordaitalean species and was found "choke full" in one seed of Lyginodendron. Beneath the pollen chamber lie the archegronia, 2 to ro in number. often 3 to 6, embedded in the large prothallus. The integument of the ripe seed is three-layered, the middle stony stratum being bounded by an outer and inner flesh (I62). It is, however, extremely probable that this integument arises from the fusion of two simpler envelopes, the inner being nucellar, more especially since two such are indicated in the Paleozoic cycadaceous seed Lagenostoma.

1

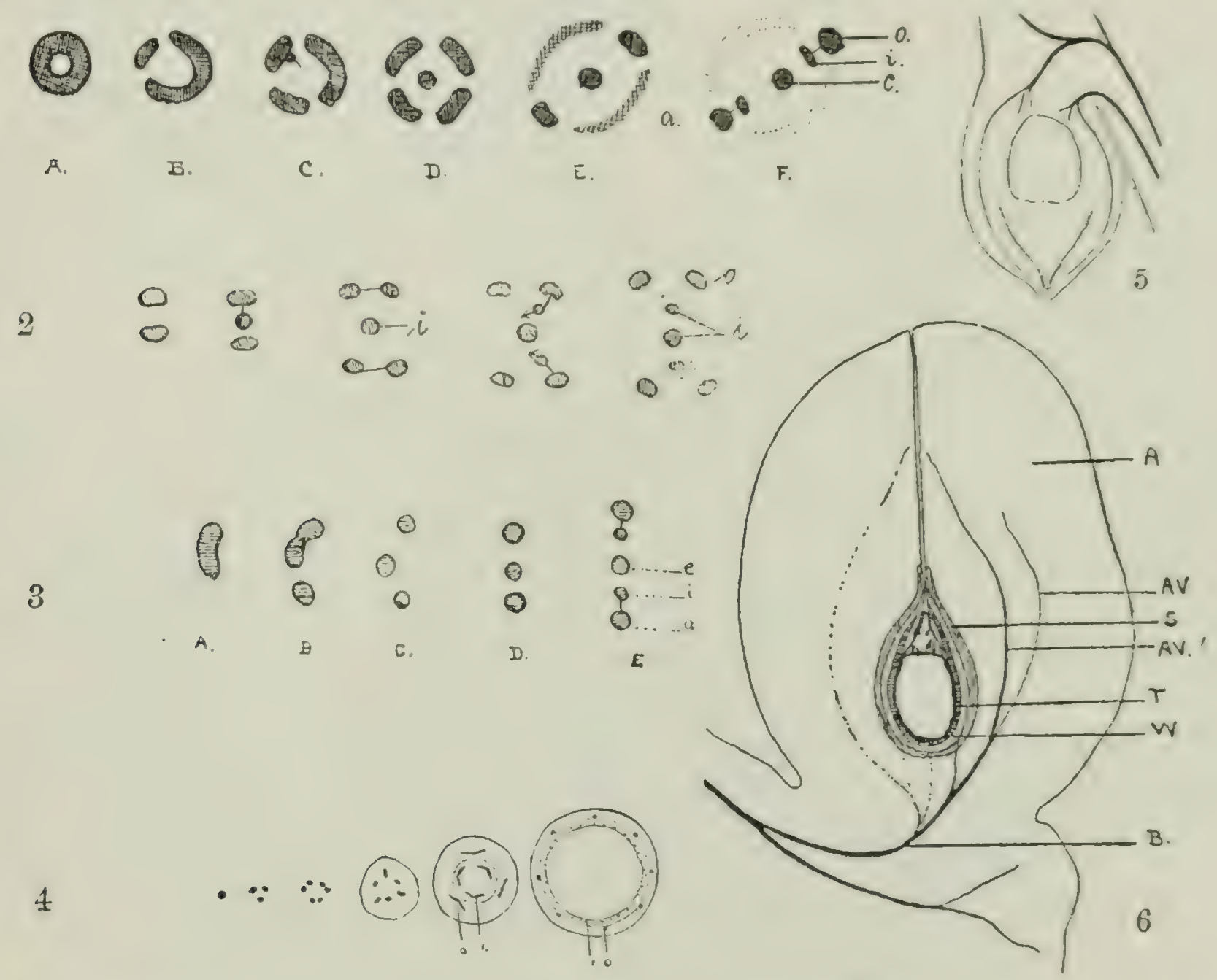

Fig. 128. - Diagrammatic serial transverse sections of bilateral (1 to 3) and radio-symmetnc (4) bundle traces leading from the laminar bundle series of the sporophyll into the seed base, together with longitudinal sections of seeds showing the same (5 and 6 ).

1. Cycas circinalis; 2, C. revoluta; 3. C. Riuminiana; 4, Zamia muricata:5. Bowenia spectabilis; 6. Zamia integrifolia, a (in ! E). disappearing bundle resulting finally in bilateral symmetry: $c$ (in 1 F). central concentric bundle leading into the chalaza: o (in / F), bundle leading to outer flesh, with branch (i) leading to inner flesh (cf, corresponding notation in figure 127); D (in 3), condition at seed base; $E$ (in 3 ), bundle branching in seed base. In figure $6: A$, outer flesh: $A V$, outer main bundle with branch $\mathrm{AV}^{\prime}$ : $\mathrm{S}$, stony median layer of seed: W, inner flesh, presumably the outer envelope of the nucellus: $T$, separation zone: B, the single seed supply bundle. (From Marie C. Stopes.)

Bundle sy'stem of the seed.-The seed and pedicel bundle features but recently elaborated by Miss Stopes (I62) are, needless to say, of the ntmost importance in forming conceptions of relationships with the Cycadeoidere.

(a) In Cycas circinalis six or more mesarch collateral bundles traverse the petiole and rachis of the carpellary leaf in a horizontal plane, the centripetal xylem being preponderant near the carpellary leaf base, and diminishing to half or less than half of the xylem area near the attachment of the lowermost orules. A 
considerable distance below an ovtule, the onter of the horizontally aligned bundles assumes first a horseshoe (selenic) and then a concentric form as it bends outward toward the ovule base, thus presenting at this point a certain similarity to the more compactly organized concentric bundle of the cycadeoidean seed pedicel. On entering the ovule this initial concentric bundle divides into two, three, and finally four or more branches aligned in circular order. 'Then one of these bundles swings into the center to form the main ovule supply, the remaining peripheral bundles again assuming a circular order. As the central bundle swings in from the peripheral position it resumes the typical mesarch concentric structure before splitting up in the inner flesh under the base of the ovule. Of the peripheral series the two bundles which lie in the common plane of the sporophyll and seed form the branches which traverse the outer and inner flesh, while the two in the vertical plane, although at first greatly enlarged, show a lesser differentiation, and do not pass beyond the base of the seed. The manner in which variations of the bilateral symmetry just described occur within the genus Cycas is made fairly evident by the subjoined diagrammatic figures showing the branching in $C$. circinalis, C. revoluta, and C. Riuminiana.

(b) It is a striking fact that in broad contradistinction to the free bilaterally symmetric seeds of Cycas those of all the other existing genera as borne in compacted cones retain a more or less pronounced radial symmetry. That this radio-symmetry may be ancient and not merely a secondary result of sporophyll appression in compacted cones, as might be suspected from its still more pronounced development in the cycadeoidean seed pedicels, is shown by the paleozoic cycadaceous seed Lagenostoma, which is both radio-symmetric and free-borne.

In the radio-symmetric series several types of bundle arrangement are evident, with many intervening gradations and modifications in different genera and species. In Zamia, one of the most reduced forms, a single bundle runs out from the lamina of the sporophyll and divides beneath the seed base into a minor branch passing on to the outer angle of the peltate end of the sporophyll, and a major crescentic collateral or concentric branch forming the entire seed supply, which subsequently divides into circularly aligned bundles, and then into the two circular series supplying the inner and outer flesh by simple branching. (See fig. I28.)

It is perfectly clear that the final reduction stage of a radially arranged bundle supply originating as a single concentric strand, as in Zamia, must be a single bundle supplying a pedicellate seed analogous to that of the cycadeoidean seed. A distinctly inore complex arrangement than that of Zamia is to be seen in one of its least complicated forms in Bowenia spectabilis. Here two bundles branch off to the sporangium, one after the other, the second, however, sending on a continuation into the outer angle of the sporophyll end. Then, either just beneath the seed attachment or in the seed base, the two basal bundles subdivide into eight outer and a greater number of inner flesh bundles.

In Macrozamia and Encephalartos the radio-symmetric arrangement is Bowenia-like, but greatly complicated by branching into the onter angle of the sporophyll and in the seed base, 110 doubt in large part as a plyysiologic result of the enormous increase in the size of the seed. The least differentiation of seed- 

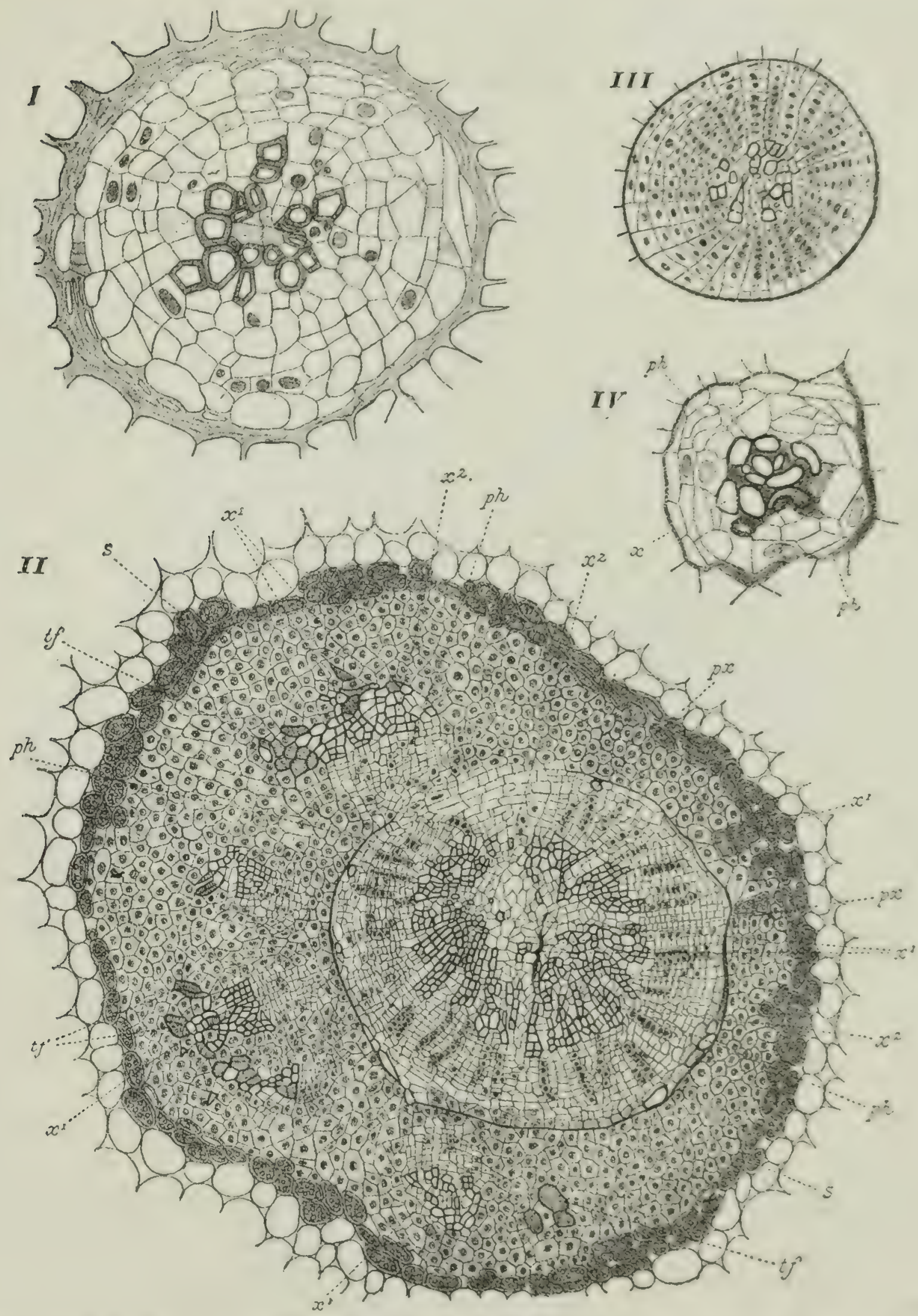

Fig. 129.-Transverse section of concentric megaspore supply bundles of existing cycads, with yet simpler similar bundles from the sporophylls. All form a series passing from a highly complex type of concentric bundle, as in Cycas. to extremely simple forms. These bundles illustrate approximately the range of structural variation in the concentric spore supply bundles in existing forms, and at the same time suggest the manner in which the single concentric bundle of the cycadeoidean seed pedicels must have been derived ty wholly similar simple reductions. (Compare the Stangeria and Bowenia bundles with figure 59.) (Selected figures from Worsdell.)

1. Stangeria paradoxa. $\times 300$. From barren sporophyll. III. Encephalartos horridus, $\times 100$. Bundle entering megasporansium.

II. Cycas revoluta. $\times 65$. Strand about to enter megasporangium. IV. Bowenia spectabilis. $X 450$. From stalk of megasporophyll.

$x, x y l e m$; ph, phloem; $x^{2}$, centrifuzal $x y l e m ; x^{1}$, centripetal $x y l e m ; p x$, protoxylem: if, transfusion tissue; $s_{0}$ bundle sheath. 
envelope bundles, so far as observed, occurs in Stangeria with eight outer and eight inner flesh bundles. In the Paleozoic Lagenostoma, so distinctly cycadean in structure, there are nine bundles in the inner or nucellar, and nine in the outer envelope, so that radio-symmetric types of cycad-like seeds are at least very ancient.

Structure of the megaspore bundle supply.-The character of the bundles entering the megaspore is of fundamental importance to our conceptions of theoretical reduction stages and sporophyll metamorphoses. As investigated by Worsdell the very large bundle entering the megasporophyll of Cycas revoluta is of a highly complex mesarch concentric structure with accessory strands accompanied by much transfusion tissue, the whole being inclosed in a prominent bundle sheath. As appears in fig. I29, II, showing the structure o one of the two main bundles entering the seed base, the minor strands, distributed round more than half the periphery of

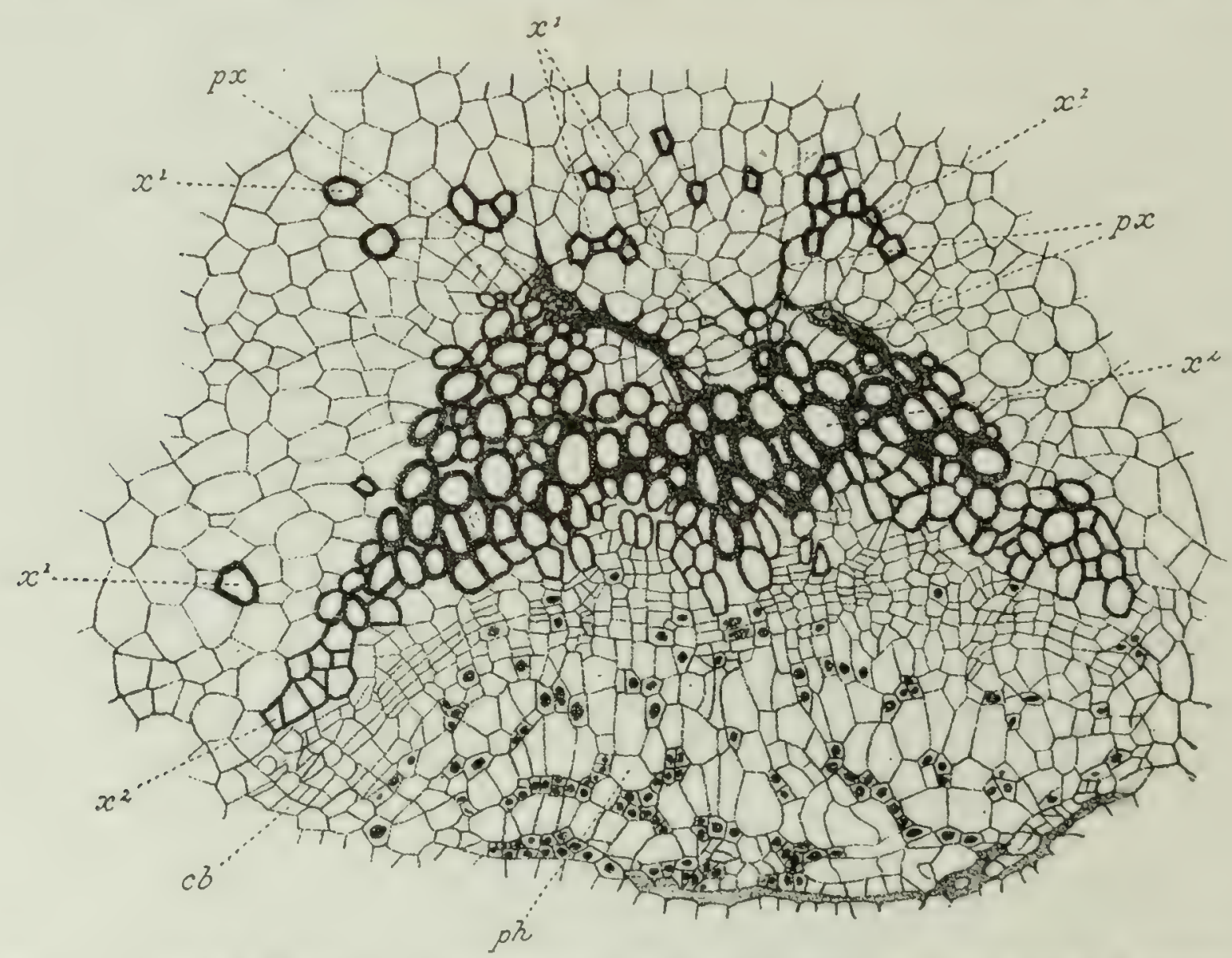

Fig. 130. - Stangeria paradoxa. Transverse section of vascular bundle from upper part of a staminate peduncular bundle ring, showing well-developed centripetal xylem, abutting on the compressed protoxylem. 102.

$x^{1}$, centripetal xylem; px, protoxylem; $x^{2}$ 。 centrifugal xylem; ph, phloem; cb, cambium. (From Scoll.)

the main inner concentric portion, are inverted and embedded in a region of cells with conspicuous nuclei and dense protoplasmic contents: Also, the transfusion tissue so prominently developed on the outer side of the minor strands may occur independently of them, thus suggesting that it could take over their function entirely by separate development around the main bundle as a transfusion tissue zone.

Much simpler types of concentric bundles occur in the much-branched bundle system supplying the seed base in Encephalartos horridus. No bundles, however 
have been described from megasporophylls that so nearly approach the structure of the central concentric bundle of the cycadroidean sced pedicels as does the basal bundle of the somewhat leaf-like sterile sporophylls from the summit of the staminate cone of Slangeria paradoxa (fig. I29, I). 'This resemblance is quite complete in both relative size and distribution of the xylem and phloem, but there is no bundle sheath. Very similar, though still more reduced, bundles of this same type occur in the peduncle of the ovulate cone of Bowenia. Hence the more distinct concentric bundle from the staminate cone of Stangeria may with safety be used in completing the series of bundles mainly derived from the megasporophylls of

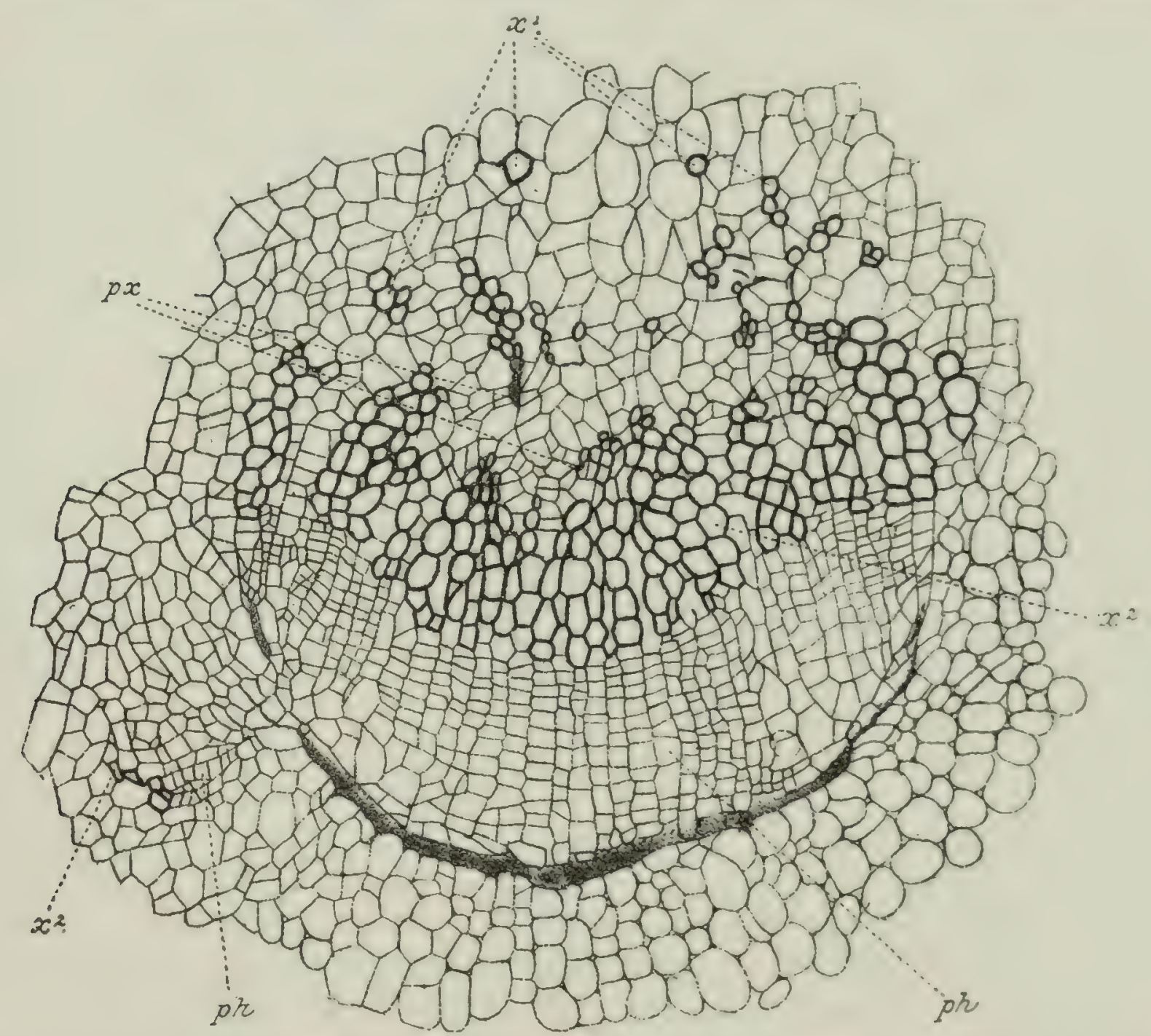

Fig. 131.-Cycas revoluta. Transverse section from stalk of a carpel, showing same structure as in preceding figure, and further illustrating the persistence of ancient structures in reproductive organs of cycads theorelically due to reduction and the checking of further increase in diversity of form. To the left is a small inverted cortical bundle comparable to those outside the main concentric bundle in figure 129, 11. (From Scott.)

the existing cycads, figured above and intended to show the range of structure from the most complex to the most reduced of the concentric bundles.

It is, of course, to the examples of concentric rather than collateral structure we must look for indications of relationship with so prononnced a concentric form as that of the cycadeoidean seed pedicel. Needless to say, however, in considering the possibility of the evolution of a bundle like the latter from a hypothetical type approximating the complexity of Cycas, it is permissible to go beyond the actual changes indicated in the figure without transgressing the linits of erolution within 
a closed group, such as the existing and fossil cycads are here conceived to form. Thus, for instance, stress is laid on the idea of the formation of a hypothetical megaspore supply bundle of sheathed concentric type in which the xylem and phloem assume the simple form seen in fig. I29, I. But we will further suppose this bundle to be related to one that can give rise in the base of the seed to a radio-symmetric and not a bilateral series of collateral strands, with much transfusion tissue. If at this point, as might well be the condition at the base of a small megaspore sustained by a single bundle, a continuous zone of transfusion tissue were to branch off instead of the small inverted collateral bundles as in Cycas, or if such a zone is in itself really the more primitive cycadean condition, as is equally or even more supposable, then we would have a bundle supply of the megaspore much like that of $\mathrm{Cycc}$ deoidea, derived by only slight changes involving the production of not a single new element or course of change not already seen to be strictly cycadean.

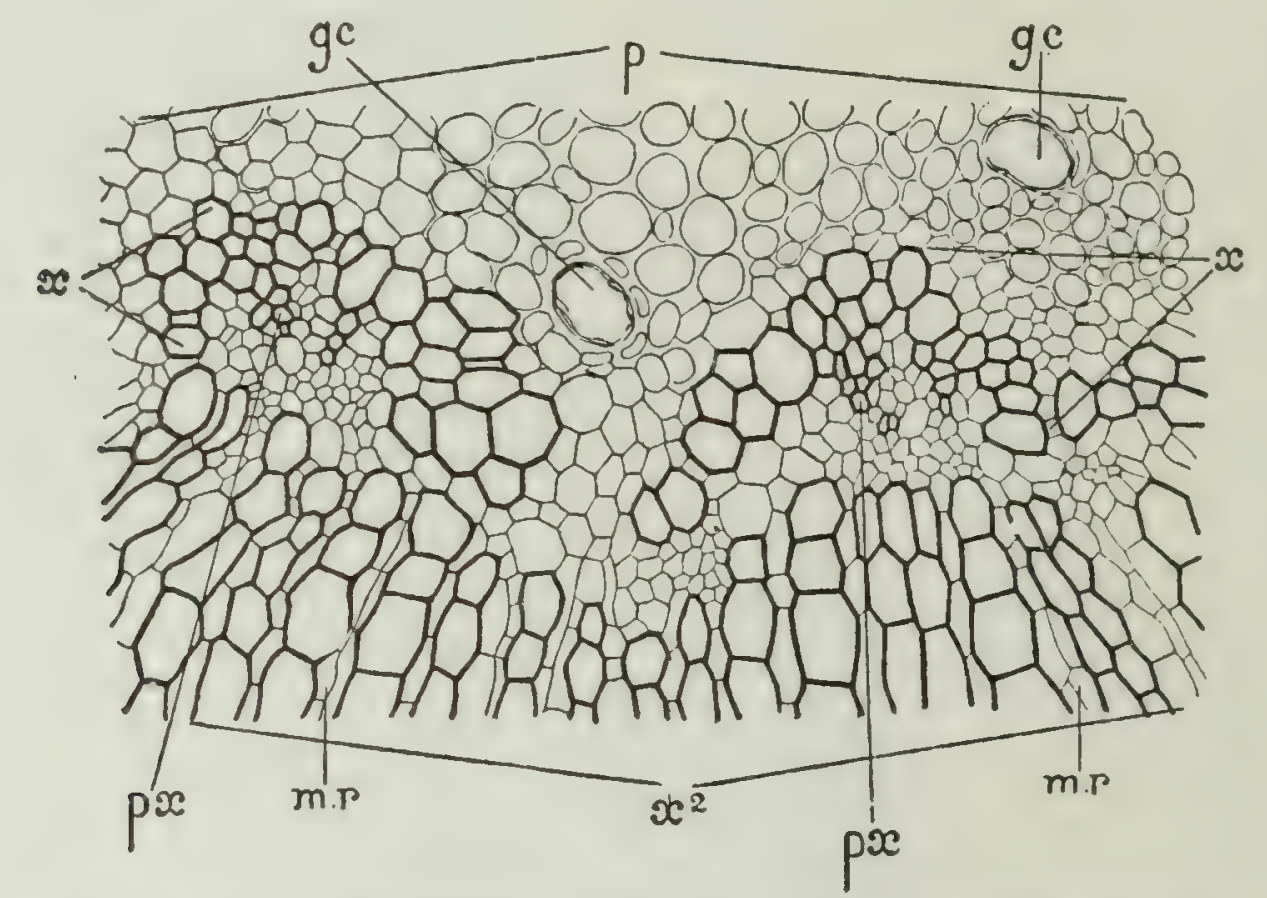

Fig. 132. - Poroxylon Edwardsii. Transverse section of the stem, showing two primary centripetal xylem strands and adjacent tissues, for comparison with the two preceding figures and also with the leaf-base bundles shown in figure 34 . $\times 66$. (From Scott, after Bertrand and Renault.)

$x$. Primary centripetal xylem; $p x$, protoxylem; $x^{2}$, secondary xylem; $m r$, medullary rays; $p$, pith.

Structure and significance of the axis of the cones.-The axis of the fruiting cone is primarily a terminal growth from the main vegetative stem, persistent in the ovulate strobilus of Cycas, fugacious in all the other forms. Plural axes appear to result from dichotomy or polychotomy of the plerome, or else occur as lateral branches from near the apex of the trunk. After dehiscence of the terminal cone renewed plerone activity with sympodial stem growth takes place. The fugacious axes retain a structure comparable in all larger features to that of the cycadeoidean cycads, in which, as described, the peduncle, while a branch of limited growth, is a replica of the parent trunk, the collateral bundles of the woody cylinder of the peduncles and cones having retained little or no centripetal xylem. In the cycads, however, while the course of the sporophyll bundles through the cortex of the cones is a direct and uncomplicated one, anatomical study has revealed the fact that the 
cylindrically-arranged bundles of the peduncle and lower portions of the axis of the cone of some forms are of mesarch collateral structure, comparable to that of the leaf bundles, and indicating, as deternined by Scott(I32), affinity with such ancient types as Lyginodendron and the Poroxylere. (See figs. I3O-I32.)

Count Solms-Laubach was, however, first led to the discovery of the presence of such a fundamentally important ancient relationship by a study of the arrangement of the vascular bundles of the cones. In speaking of the sudden transition from the complicated structure of the vegetative stem to that of the simply and primitively organized peduncle and cone axis, Solms says (I55, P. 213):

"Sehr merkwürdig aber ist die Art und Weise, wie an einem und demselben Spross unter plötzlicher verjüngung des Pleromkörpers der complicirte vegetative Spurverlauf ganz unvermittelt in den einfachen der Blüthe überspringt. Dass dieser letzere eine Reliquie uralter Organisation, dass er den gemeinsamen Vorfahren der Cycadeen und Bennettiteen allgemein eigen gewesen sein wird, dass der vegetative Spurverlauf, wie er jetzt bei ersterer Gruppe vorliegt, aine im Laufe der Zeit erworbene eigenschaft darstellt, die den Gang der Entwicklung in der Richtung vom Einfachen zum Complicirten uns vor Augen führt, scheint mir eine sehr nahe liegende Annahme zu sein."

As in the monostelic vegetative axis, however, only centrifugal wood is present in the woody cylinder of the peduncle of the great majority of the existing cycads. It is in the staminate cone of Stangeria that retention of centripetal wood is most marked. It first appears a little above the peduncle base, is more prominent in its middle region, and finally disappears below the summit of the cone. Other cycads retaining peduncular centripetal wood are Bowenia ( $\delta$ and $q$ ), Ceratozamia ( $\delta$ ), and Zamia in part. It is very interesting that this recondite bundle form should mainly persist in the monotypic genera, which with Zamia constitute a group that for other reasons might be set aside as exhibiting the greatest assemblage of primitive characters of any of the existing cycads, the carpophylls of Cycas excepted. In other words, these genera have proven the least susceptible to change and the most liable to extinction, whence their present isolation. As already noted, mesarch structure is highly developed in the stalk of the Cycas carpophylls, aithough not yet observed in the staminate peduncles. The occasional and inconstant occurrence of concentric bundles which end in the lower cortex of the staminate peduncles of Stangeria and may occur in other genera has, however, been noted by Scott, and is of considerable interest in the present connection. That concentric structure slould be retained in the bundles of a naked peduncular cortex no longer supporting foliar structures, and be, as already seen, also characteristic of the sporophylls and spore-bundle systems, is a correlative fact pointing to an ancient trunk form with concentric rather than collateral cortical traces. For if ever any type of bundle structure may be considered as of phyletic significance rather than the result of homoplastic and physiologic accidence, it must surely be one finding its nearest analogue in related plants known to be ancient and primitive, and at the same time found to exhibit a certain constancy of persistence on the same axis in both the functional and non-functional position. The conciusion is hence reached that the cycadean cone conld only have been segregated from a monostelic trunk with a 
mesarch cylinder and approximately concentric and fern-like rather than collateral cortical traces. The same must perforce be true of the Cycadeoider.

Fruits.-After fertilization the cones do not greatly increase in size, and finally fall apart, except in Cycas, where the carpellary leaves in the course of ripening bend in and out amongst each other and are at last shed, less their bases, like the foliage leaves, a series of which then follows with continued growth of the axis. The mature seeds of the compacted cones do not reach such great size as those borne by the free carpels of Cycas, which in some species are as large as goose eggs. All have heavy woody walls, but as the main structural features of the seed coats have already been treated, and as the extensive subject of related Paleozoic seeds can not be here taken up, it only remains to consicier the embryos and their formation.

After the semi-aquatic zoidogamic fertilization already mentioned, the oosspore as embedded in the large endosperm enlarges, and free nuclei appear in the cytoplasm, as first determined by Treub $(167 b)$. Further details concerning the manner in which the initial nuclear division takes place have been given by Ikeno (69), but are omitted. Free nuclei now become very abundant, and then, following the vacuolation and disorganization of the central region, all of the cytoplasm is massed at the base of the spore and parietally, with a single or in places double parietal layer of equidistantly embedded nuclei, except at the base, where there is some nuclear massing. This is the young proembryo, which, after further nuclear division and the appearance of cell walls, encroaches on the central cavity, but never fills it up with tissue, as in the "protocorm" of Ginkgo. It is this sac-like proembryo of Treub, or preembryonal structure, embedded in the endosperm, immediately preceding suspensor development, which we may in the first instance hope to find differentiated in silicified seeds, though it is not impossible that yet earlier purely nuclear arrangements may also be found indicated. Suspensor development next intervenes. Cells of the basal mass adjacent to the terminal cell develop, by division and elongation, a remarkably long, tortuous, unbranched and massive suspensor, which emerges from the lower archegonial region in a fascicle, with disorganization of adjacent tissue. It is the suspensor tips which bear the cells that initiate the formation of the embryo, the early stages of which have been as yet but little studied. But a single embryo is formed from one archegonium, though according to the number of archegonia present several may be developed to the seed. The embryos are small and deeply embedded in endosperm, and the number of cotyledons is stated to be one in Ceratozamia, two in Cycas and Zamia, and one to three in Macrozamia spiralis.

\section{SUMMARY OF RELATIONSHIPS OF CYCADEOIDEAN TO EXISTING CYCADS.}

In the foregoing sketch of the existing cycads reference has been quite constantly made to details offering distinct structural agreements with or variations from the fossil forms. It is therefore next in order to summarize in a much nore compacted view and more general terms those features of primary physiologic and morphologic significance in determining the plyletic and taxonomic values of the two groups, as well as that position in current classifications which best expresses the known facts. 
COMPARISON OF VEGETATIVE CHARACTERS.

In the pith of the cycaleoidean trunks no such cauline bundles as are present in some existing cycads have been found, but layers of internal periderm are met with in both groups, the relative development and other medullar characters also being the same in both. In the primary woody cylinder of collatera! bundles agreement is complete, although it is not yet determined that the secondary thickening described in Cycadeoidea (pages 78-80) is directly comparable to that of various existing cycad trunks.

In the cortex the same elements are presented in both groups, but the direct course of the cycadeoidean leaf traces agrees only with that of sporophyll traces of the cones of recent cycads, the complex anastomosing leaf-trace system of the latter being of variable development, not always present in young plants, and clearly a condition acquired since the segregation of cones, also since the cycadeoidean and cycadean lines separated.

In the leaf bases the same general characters occur, but instead of the more recent omega bundle pattern there is constantly present in the fossil forms a more fern-like V-shaped grouping, occasionally further modified. The cylindric disposition of the leaf-base bundles in Stangeria and Bowenia is, however, of intermediate type.

Scale leaves have not yet been structurally determined in the American Cycadeoidex, but doubtless occurred sparingly, similarity to existing cycads in this respect probably going further than mere agreement with such Macrozamia species as bear only fully developed foliage leaves. Moreover, Seward distinctly states that a Paris Museum specimen of Williamsonia bears along with more or less detached fronds "typical Williamsonia scale leaves" (I45).

In their ramental growth the cycads have been seen to vary greatly, that of the fossil forms being uniformly profuse and fern-like, that of the existing types panciform and vestigial. It has, however, been shown that this difference has arisen through progressive reduction and can not be regarded as fundamental, since there must have been a time when the development of ramentum was much the same in both cycad groups.

Prefoliation of the fossil forms as observed in various snecies, including two, if not three, genera was direct, as in Macrozamia and various other existing cycads. But the once-deflexed or semi-circinate rachis of the microsporophylls or staminate fronds of Cycadeoidea finds a further analogy in the similarly deflexed foliar rachis of Zamia. Circinate pinnules have not been observed in the fossil condition, but must have occurred. In leafy habit the two groups agree in all fundanental characters, the pinnule form in both varying much within the same limits aild the finer details of structure being nearly the same. In their branching havits both cycadean lines were much alike. Moreover, the scale-leaf buds of Cycas, which readily. develop into growing trunks, form a fundamental analogy to the laterally borne young branches and cones of Cycadcoider and Cycadelia.

The cycadecidean trunk types, while generally of lesser height than those of the existing cycads, present the same gradations from tuberous to branching and 
columnar forms, and also include the much different slender and freely branching Anomozamites. The fossil group as now known hence presents by far the greater diversity of trunk forms.

In brief, there is not a single vegetative character of the Cycadeoideæ which does not find a near analogy in the existing forms, and such minor differences as are present in the latter readily explain themselves when separation in time is considered. Moreover, three pertinent correlative questions arise in this connection, and their probable answers can not be thrust aside if we wish to properly adjudge the significance of all the facts.

Firstly, what would the vegetative parallelism and agreement have been could the Cretaceous ancestry of the existing cycads be compared in microscopic detail with all the coexisting fossil forms; that is, with that more inclusive cycadalean group, of whose members surely all can not yet be known? Probably complexity of leaf traces in the line leading into the modern cycads would have been the only difference that had yet arisen in advance of the more ancient vegetative features of the Cycadeoidere.

Secondly, could such a comparison as that just indicated have been made in early 'Triassic time, when Anomozamites, the oldest cycadeoidean form known with certainty, flourished; what macroscopic or microscopic feature would have been present in the one group and wholly absent from the other? Probably none. Moreover, after comparison of many forms, it must be held as strange indeed if at that time genera did not exist so combining the characters of both the groups as then developed as to have made it difficult to define an intervening border line, if indeed such existed at all, so far as vegetative features are concerned.

Thirdly, could the far-reaching identity and similarity in the vegetative structures of the two cycadean groups be the homoplastic result of physiologic conditions of growth and evolution alone, and merely the result of parallel development from two distinctly and remotely separated fern groups? Probably not. The reasonable hypothesis is that the ancestral line from which the cycadeoidean and existing cycads sprang remained single and homogeneous until the major ontlines of leaf and stem similarity now common to the two groups were establislied. That this original stem type had peculiarities now obscured is of course obvious enough. Probably its greatest departure from the various known Jurassic and Cretaceous trunks lay in the possession of a woody cylinder of mesarch bundles, and a much more prominently concentric type of cortical bundle.

\section{COMPARISON OF REPRODUCTIVE CHARACTERS.}

The lateral bract-inclosed cones of the monopodial stem of the Cycadeoider, as already remarked, are analogons in position and general form to the scale-leaf buds of old trunks of Cycas. Also, according to our view this analogy goes much farther than mere outward form and position. For we regard the bracts of the cycadeoidean strobili as homologous to foliage leaves, scale leaves, and sporophylls, just as in the existing cycads there is a primitive identity in the leaves, scale leaves, and sporophylls of the cones of both sexes. In the earlier growth stages of the 
silicified strobili, as has been seen, the peduncle is large and the bracts prominent long before the sporophylls appear. In such stages, then, there is well-nigh complete similarity to the lateral buds of Cycas. 'There is hence on the one hand the power to develop as a fruiting branch and on the other as a vegretative branch, or if detached a separate trunk. But that lateral buds of the Cycadeoidere, as scarcely: distinguishable from strobili in their earlier stages, also developed as branches may further be assumed. It is, then, fairly evident that the feature seized upon by the cycadeoidean line as a means of progression, or perchance necessity for the production of more numerous seeds-these having already reached a high organizationwas the lateral branch or bud. This was then segregated as a branch of solely reproductive function. On the other hand, the surviving cycads, Cycas excepted, do not now exhibit a truly monopodial habit, although branching is common and the incipient monopodial stages are obviously present. The cones having remained few in number, are produced for the greater part sympodially at or near the summit, although it is entirely possible that more cones, extending farther down the sides of the trunk, were present in past time or in certain extinct genera. It is hence easy to conceive of hypothetical genera falling within the cycadeoidean and existing cycad groups, which would bring the branching features and stem habit of the one group into complete touch with the other; and that there is present, so far as such habitus features go, a fundamental similarity throughout all of the known cycadaceous forms is an inevitable conclusion.

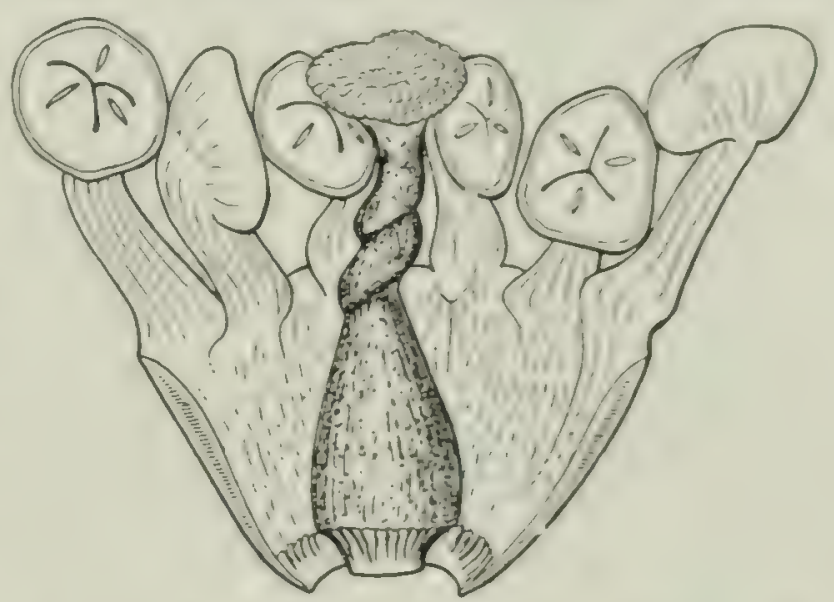

Fig. 133. -Welwitschia mirabilis or Tumboa. Single flower of cone-like inflorescence with enveloping scale and bracts removed to show essential organs, consisting in a staminate disk or androecium inclosing the central abortive megaspore. This flower is hence morphologically but not functionally bisporangiate. It is the only surviving example of true cyclic arrangement in the gymnosperms.

The figure is greally enlarged. (From Engles und Prant. after Strasburger.)

The cycadeoidean microsporophylls are rediced pollen-bearing or staminate fronds of Marattiaceous derivation, antithetically homologous to the megasporophylls of Cycas-such is our conclusion. But while their form is unquestionably normal to primitive cycads in every respect, their arrangement in a disk is mainly characteristic of angiosperm stamens and unique to the cycads, though not entirely so to gymnosperms, since in Tumboa (Welwitschio mirabilis) the most reduced of all gymnospermous sporophylls are likewise organized into staminate disks. As the cycadeoidean disk is epygynous to the spiral of enveloping bracts, in t:urn regarded as reduced fronds, the simplest view of its meaning and origin is that it is derived from a lateral and basal fusion of the members of a closely set whorl or spiral at first placed much like that of the leaves of Sciadopity's. An original $5 / \mathrm{I}_{3}$ arrangement is perchance suggested by the fact that the disk of Cycadeoided ingens and Cycadella is composed of thirteen fronds, and sonie higher form like $2 \mathrm{I} / 55 \mathrm{by}$ C. dacotensis with an eighteen-frond disk. Possibly when fusion took place in the 
latter case several of the members of one or several spirals night have been lost, just as in $C$. Jenneyana there may be several less than thirteen fronds. The antecedent spiral of the disk would probably be the same as that of the bracts at the time the disk first formed. However this may be, the bract spirals liave not yet been determined, and it appears that organization into a disk preceded by spirally arranged bracts with the subsequent prolongation of the main floral axis, either as that of a simple terminal cone (or an inflorescence), is, in later geological tine, mainly an angiospermous juxtaposition, although it may yet prove that its seemingly isolated occurrence in gymmosperms is largely due to an imperfectly known and understood fossil record.

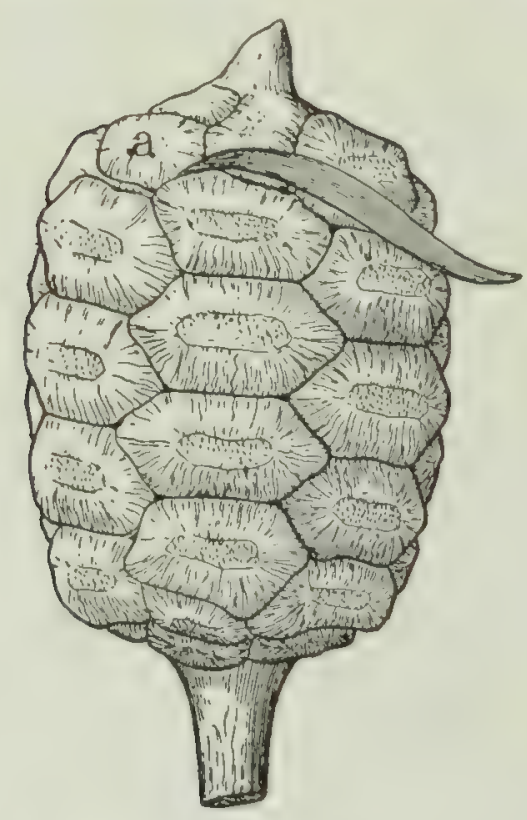

Fig. 134. - Zamia floridana DC. $\times \frac{1}{2}$. Monstrous ovulate cone with sporophyll (at a) bearing a pinnule of the structure and form normal to this species. Miami, Florida, No. vember 15.

In any case the disk is to be regarded as an emplacement attained by the cycadeoidean gymnosperms without the loss of their cycadaceous characters; and while of evident importance in our conceptions of form in hypothetical primitive and ancestral angiosperms, it can not in itself be considered to indicate wide divergence from other gymnosperms. It may be noted in passing that the remarkably interesting isolated campanulate disk Codonotheca (I 39), with a six-segmented sporangiferous inner surface, originally noted as occurring associated with Neuropteris foliage in the Permian of Mazon Creek, Illinois, is a fructification that must be very anciently, if at all, connected with primitive Cycadales, although the Neuropteris seeds (?) since described by Kidston, do indicate certain codonothecan analogies (137). At any rate, the true relation between Rhabdocarpon "seeds" and the Codonotheca microspores (?) is likely to be established soon; and if indeed as here suggested these are respectively the megaspores and microspores of Neuropteris, they may shed new light on the origin of Cordaites and Ginkgo rather than on any of the cycads.

The megasporophylls and interspersed interseminal scales or abortive sporophylls of Cycadeoidea are the most divergent and really difficult feature to reconcile with other cycad structures. If each seed pedicel with the three or more interseminal scales surrounding it were to be regarded as a shoot with a fully reduced axis, the entire cycadeoidean ovulate cone would in a way correspond to the ovulate cone-shaped inflorescence of Tumboa and to pedicellate cordaitean forms; and the amount of reduction undergone by the parts of each one of the minor unisexual flowers, or rather shoots, would be great from any point of view. But there is really little ground for the assumption that such a complexity of structure is present, beyond the quite inconclusive evidence afforded by grouping of the interseminal scales in tufts, as only occasionally to be seen in very young cones. On the whole it appears most reasonable to assign to the ovulate cone the simple uniaxial form it at first sight appears to have. So viewed it seems to have been derived from a cone originally much like that of the existing 
cycads, with a series of spirally arranged megasporophylls all fertile and alike, but borne on an axis with hypogynous microsporopliylls. Subsequently, if this view is correct, with reduction and shortening of the ovulate axis, the original spiral order has been obscured by the assumption of a very perfect radial symmetry in a fertile series of pedicels and the flattening and aborting of adjacent members into interseminal scales.* In either case, however, the theory that the seed pedicel and the interseminal scale are greatly reduced sporophylls

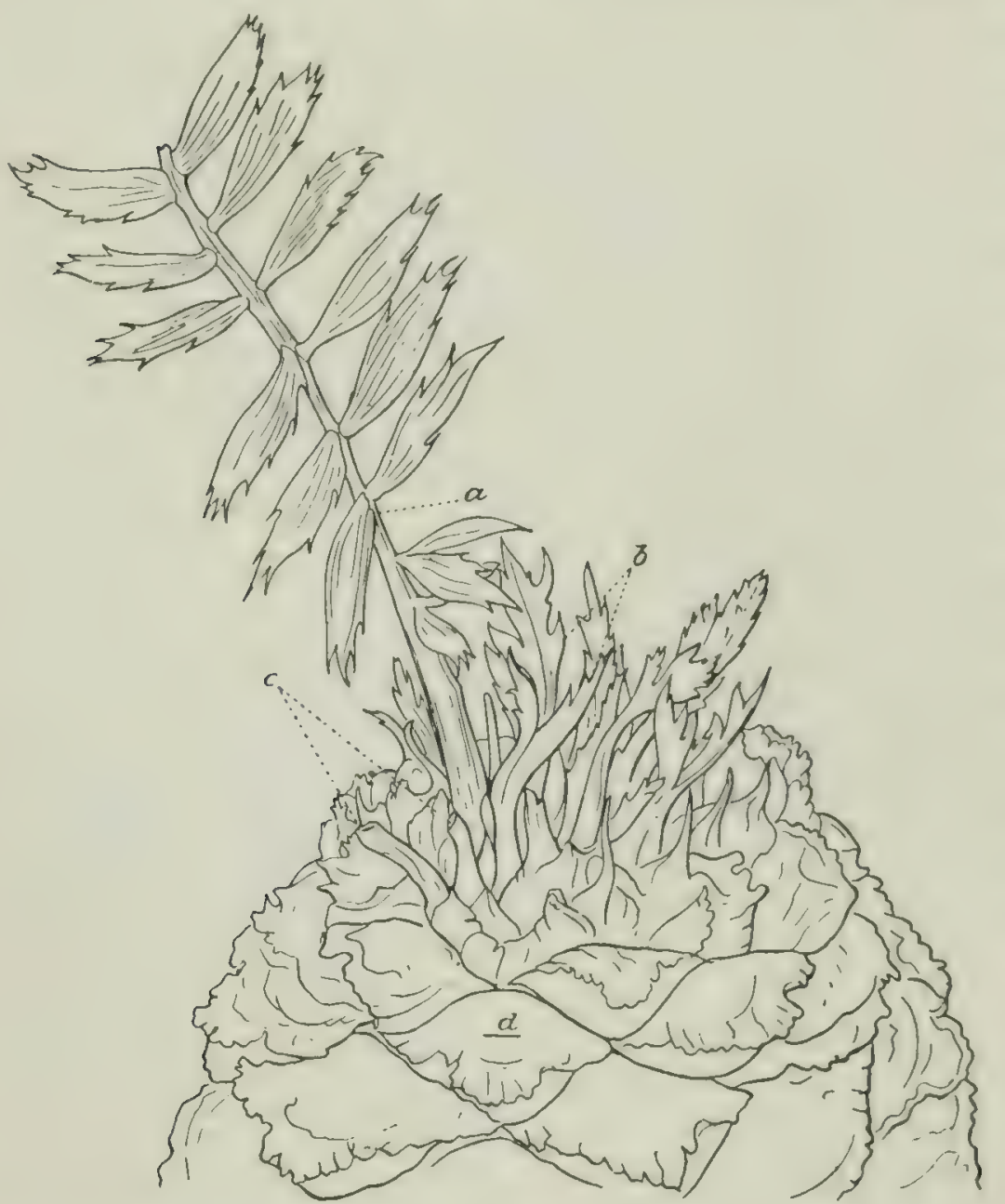

Fig. 135.-Encephalartos villosus Lem. Monstrous cone with more and more leaf-like carpophylls above until finally one of these metamorphosed sporophylls arises as a small but distinct truncated frond bearing well-characterized pinnules of its genus and species.

a, Carpophyll replaced by reduced, though otherwise normal leaf : b, generalized carpophyll of foliaceous habit; c, foliaceous carpophyll of arrested development; $d, a$ normal carpophyll. (Reduced from Thiselton-Dyer -167. ) analogous to and derived from sporophylls like those of the existing cycads is regarded as most tenable. It is not believed that there is any great or insuperable objection to the theory of ours that one of the final reduction stages of a cycadean carpophyll would be a more or less pedicellate form with a single, either endarch or mesarch, concentric bundle supplying an apical and erect radio-symmetric seed as in Cycadeoidea. The ovulate cones of the latter are obviously enough of a far less primitive structure than those of existing cycads.

The fundamental simplicity of such a theory of course rests primarily on the fact that it involves the erolution of no new structures. Where new structures must constantly be invoked and accounted for, evolutionary theories may well pause; but when the result can be reached by a simple process of reduction, and when there are examples of such reduction all along the line, an implied certainty is involved that nature took that course. That the carpellary leaf is primitive and charac-

*The younger the fruit the greater the difficulty of distinguishing between the infertile and fertile series. Moreover, in many cases large areas normally bearing seeds are infertile and closely invested by aborted scales on!y. Therefore, since the distribution of the infertile scales and the sced pedicels is not entirely alternate and the proportion of both varies sc greatly ai the base of the cones, it appears that the determinant change resulting in infertility must arise after the initial stages of growth. Certainly, whether the ovulate axis is primarily a simple axis or consists in reality in a series of secondary shoots, there can be little doubt that the interseminal scales were once fertile organs in ac wise different from whatever was the analogous form of the seed pedicel at that earlier time. 
teristic of medullosan and cycadofilicinean forms we now know with certainty. Kidston has but recently found that in the medullosan form Rhabdocarpon the pedicel of a large seed bore pinnules identical with those of the frond Neuropteris heterophylla. And certainly the amount and character of reduction from the most leaf-like of the Cycas carpophylls to the smallest and most reduced of the Zamia sporophylls is virtually as great as a reduction from a hypothetical zamioid form of megasporophyll with one abortive megaspore to the pedicellate monosporous cycadeoidean type. Indeed, the latter may be the lesser hiatus, for here we have to deal mainly with a radial symmetry and further compacting of form in most obvious

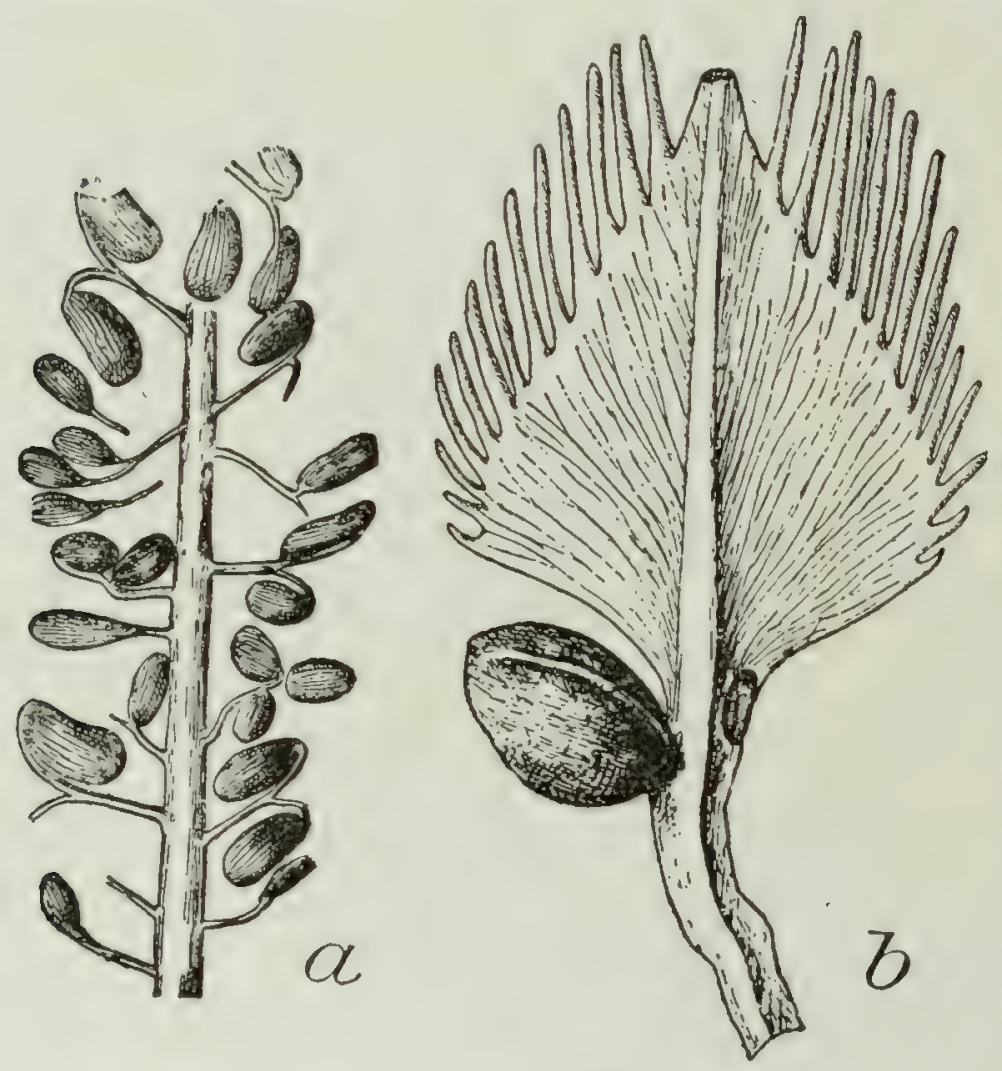

Fig. 136. agreement with physiologic requirements. And do we not see in Zamiostrobus examples of the final reduction stages intervening between the two-spore Zamia stage and the one-spore stage? Have not the sporophylls in this fossil lost all trace of a tip, and are not some of them merely pedicels bearing a single erect and terminal seed? In Ginkgo there is some further corroborative evidence of $\mathrm{such}$ reduction stages, though more obscure. The Ginkgo stalk bears two bilaterally placed ovules, but one of which is ordinarily functional, though both are so occasionally. Now, could it be proven true that the Ginkgo stalk a, Zamiostrobus stenorhachis Nathorst. Ovulate cone with open habit is a bilobate petiole, as Van Tieg-
of growth and 1 to 3 seeds to each sporophyll. From the Rhét of hem thought, and hence with its Sweden. $\quad$ ovules a carpellary leaf, this might

b. Cycadospadix Hennoquei Saporta. Carpellary leaf with seed at- be cited as an example of a gyin-
tached. From the Lower Lias. Both figures from Zeiller, after tached. From the Lower Lias. Both figures from Zeiller, after be cited as an exartion stage only
Saporta et Marion. It is necessary to regard these sporophylls as nospermous reduction equivalent reductions from ancient foliaceous spore-bearing fronds. a little further advanced than in

Zamia. But most botanists now regard the Ginkgo stalk and its pair of ovules as a shoot, whence its sporophyll is virtually reduced to the erect monosporous cordaitalean and cycadeoidean form.

It might be said that the Zamia sporophylls with two oppositely borne ovules are truncate carpels, and that forms bearing a terminal ovule correspond in a way to oddly pinnate leaves. But this must be a minor maiter, since both truncate and oddly ovulate sporophylls appear to occur in the same cone in Zamiostrobus stenorachis of Nathorst. Also, whoever studies the gradual excision of first the distal pinnules and then the complete shortening and reduction of the carpellary leaf in passing from Cycas revoluta to Zamia, and notes the ramose and reduced condition of the terminal bundles in the latter as they pass beyond the large ovule-supply 
bundle, can readily conceive of an aborting of one of the two seeds with the further final reduction of the whole carpophyll to a simple stem bearing a single seed; that is, to a monosporangiate pedicel.

The fact has already been pointed out in detail that even in the existing cycads there are concrete examples of concentric bundles which nay be arranged in a series possessing all the bundle elements and illustrating the theoretical changes involved in the final phases of reduction to the cycadeoidean form of sporophyll. The outlines of this series, being of such fundamental importance to theories of reduction, are here repeated.

(a) The concentric megaspore bundle trace of Cycas revoluta with the most leaf-like cycad sporophyll known is highly complex and gives rise to frequent branches containing much transfusion tissue.

(b) The more reduced megasporophyll of Encephalartos has much simpler megaspore traces than Cycas.

(c) There is present in the stalk of the megasporophyll of Bowenia a reduced concentric bundle strikingly like that of the seed pedicel of Bennettites, with the

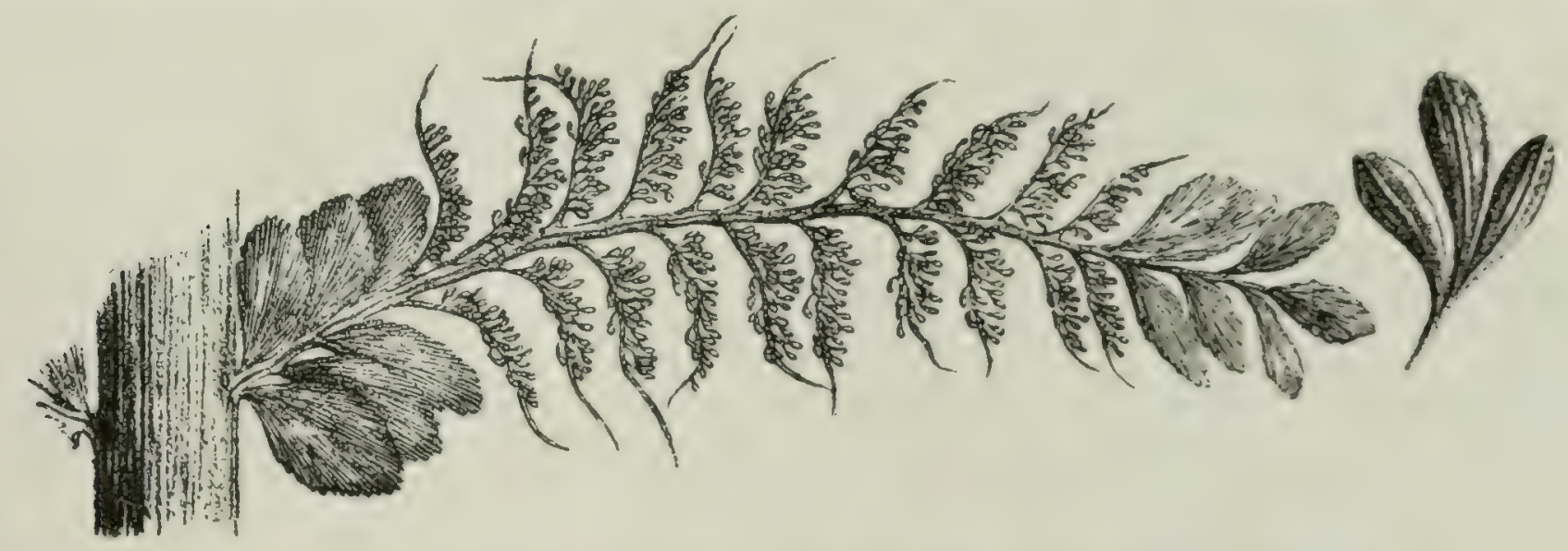

Fig. 137.--Archæopteris. Replacement of leaflets by grouped sporangia in a Devonic fern.

(Frond 3/4 natural size, and sorus enlarged. From Schimper.)

endodermis and cortex excluded, as they should be in such a comparison. If, however, comparison be made with the interseminal scale bundle the agreement with Bowenia is quite complete.

(d) A further example, even more strikingly like the cycadeoidean pedicel bundle, is to be seen in the staminate cones of Stangeria. This concentric type of bundle is therefore of frequent occurrence in cycads. It is, too, especially to be noted in connection with the present bundle series that the single supply bundle of the cycadeoidean megaspore spreads ont to form the chalazal region by increase of its transfusion elements and assumption of a perfectly concentric form. The retained endodermis is primitive, while the outer cortex of the pedicci may be considered as the last trace of the ground tissues of the former peduncle, and perhaps identical with subepidermal bast cells. In the interseminal scales, however, while an endodermis like that of the pedicels is not present, an epidennal sheath appears outside of the cells, forming a less conspicuous cortical zone than that of the pedicels. All of these reductions are in the strictest agreement with the physiologic requirements of arrangement in a compacted ovulate cone so largely made up of much lignified elements as is that of Cycadeoidea. 
Seeds.-The seeds of Cycadeoidea, no larger than a small grain of rye, have many resemblances to and are not, on last analysis, fundamentally different in structure from those of the existing cycads. In the latter there is no distinct demarcation of the outer flesh, middle stone, and inner flesh constituting the seed [and nucellar] wall into an outer and inner integument. Likewise in Cycadeoidea there is no differentiation into separated integuments. Beneath the outer palisaded layer, as covered in the basal region by cortical cells belonging to the pedicel, lies the fibrous, or in C. Morievei fleshy, hypodermal layer, and interior to this the wall of the nucellus. This double to treble layered testa is so much more reduced than is the testa of modern cycad seeds that, in the absence of a knowledge of other explanatory variations in fossil forms that will doubtless soon be found, it is still difficult

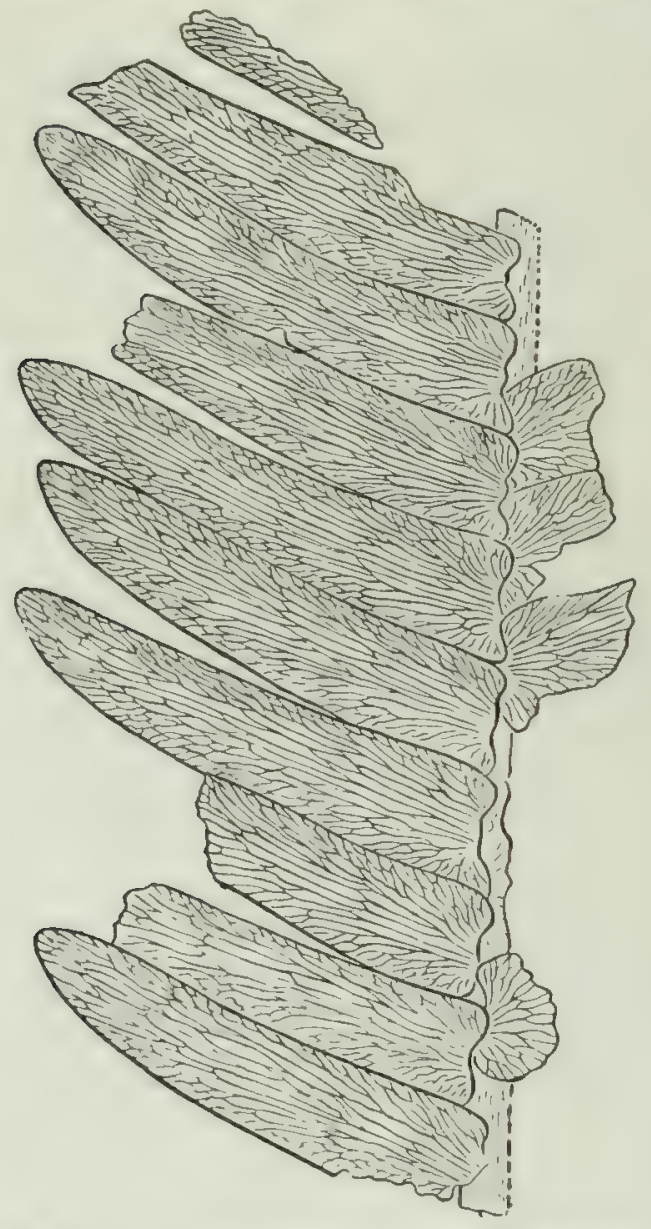

Fig. 138. -Dictyozamites indicus Feistmantel. Natural size. The netted-veined cycad, illustrating marked diversity in venation of cycadean leaves. (After Feistmantel.) to suggest the exact equivalency of the layers. However, in the cycadofilicinean form Lagenostoma Lomaxi, the seed is also in its general structure cycadean, and there is more resemblance to the cycadeoidean testa. The Lagenostoma chalazal region, moreover, as entered by a single concentric bundle, has identically the same radiosymmetric structure as in Bennettites. Likewise (interior to a peculiar cupule) the outer layer of the testa is palisaded. If some such cupule or structure as is seen in Lagenostoma was ever also borne hypogynously in some directly ancestral cycadeoidean seed, its only remnant is the prolongation of the cortical region of the pedicel, as loose, stringy cells forming no true part of the seed walls.

The much-elongate micropylar tube of cycadeoidean forms is a secondary structure correlated with the inclosed position of the seeds between the enlarged tips of the interseminal scales. The dicotyledonous embryo is paralleled by that of the existing Cycas, and it is probable that a much varied polycotyledony was present in the cycadeoidean as in the existing cycads, there being in this respect no fundamental difference. The apparent absence of endosperm is, however, a far more striking variation, in some way connected with the small size of the cycadeoidean seed.

The subject of the embryogeny of Cycadeoidea must, however, for the present be left in abeyance, although there is every good reason to hope it will eventually be worked out with reasonable completeness, so far as concerns all larger features. While it is already evident that a more primitive condition is present than in existing cycads, it is scarcely possible, from the facts given in Chapter VI, that structures or modes of growth not primitively and in large degree cycadean are present. 
TABULAR COMPARISON OF OVULATE AND STAMINATE CONES.

The strobilar homologies between the existing and fossil cycads, as presented and discussed in the foregoing pages, are brought together in the appended tabular comparison.

Ovulate Cone.

\begin{tabular}{|c|c|c|c|c|c|c|c|}
\hline & & Cycadeoidex. & \multicolumn{2}{|c|}{ Cycadex. } & \multicolumn{2}{|l|}{ Zamix. } & Ginkgoacex. \\
\hline Axis. .... & \multicolumn{2}{|c|}{$\begin{array}{l}\text { A short to elongate } \\
\text { branch of the main } \\
\text { stem. }\end{array}$} & \multicolumn{2}{|c|}{$\begin{array}{l}\text { Continuation of main } \\
\text { stem, or can be a lat- } \\
\text { eral branch of limited } \\
\text { growth. A series of } \\
\text { modified fronds is } \\
\text { borne apically or the } \\
\text { trunk in same spiral } \\
\text { order as foliage and } \\
\text { scale leaves. }\end{array}$} & \multicolumn{2}{|c|}{$\begin{array}{l}\text { A rather elongate } \\
\text { branch of the main } \\
\text { stem. }\end{array}$} & A shoot? \\
\hline Bracts.... & \multicolumn{2}{|c|}{$\begin{array}{l}\text { Linear-lanceolate, en- } \\
\text { sheathing, permanent } \\
\text { (order spiral). }\end{array}$} & \multicolumn{2}{|c|}{$\begin{array}{l}\text { The ensheathing scale } \\
\text { leaves (= bracts) are } \\
\text { permanent. }\end{array}$} & \multicolumn{2}{|c|}{$\begin{array}{l}\text { Linear-lanceolate, en- } \\
\text { sheathing, fugacious. }\end{array}$} & [Reduced.] \\
\hline $\begin{array}{c}\text { Interstitial } \\
\text { organs. }\end{array}$ & \multicolumn{2}{|c|}{$\begin{array}{l}\text { Present as abortive } \\
\text { sporophylls, numer- } \\
\text { ous. }\end{array}$} & \multicolumn{2}{|c|}{$\begin{array}{l}\text { Abortive sporophylls at } \\
\text { base and summit of } \\
\text { cone only. }\end{array}$} & \multicolumn{2}{|c|}{$\begin{array}{l}\text { Sterile sporophylls at } \\
\text { summit of cone. }\end{array}$} & Absent. \\
\hline $\begin{array}{l}\text { Sporo- } \\
\text { phylls. }\end{array}$ & \multicolumn{2}{|c|}{$\begin{array}{l}\text { Terminal and subter- } \\
\text { minal to the axis of } \\
\text { cone. } \\
\text { Radio-symmetric...... }\end{array}$} & \multicolumn{2}{|c|}{$\begin{array}{l}\text { Terminal and subter- } \\
\text { minal. }\end{array}$} & \multicolumn{2}{|c|}{$\begin{array}{l}\text { Mostly lateral, upper } \\
\text { ones terminal to axis } \\
\text { of cone. } \\
\text { Radial or subradial in } \\
\text { structure. }\end{array}$} & $\begin{array}{l}\text { Terminal and lat- } \\
\text { eral, as seen in } \\
\text { abnormali t ies. } \\
\text { Radial in struc- } \\
\text { ture. }\end{array}$ \\
\hline Ovules .... & \multicolumn{2}{|c|}{$\begin{array}{l}\text { Terminal to the main } \\
\text { sporophyll. }\end{array}$} & \multicolumn{2}{|c|}{$\begin{array}{l}\text { Terminal to segments } \\
\text { of sporophyll. }\end{array}$} & \multicolumn{2}{|c|}{$\begin{array}{l}\text { Marginal or subdorsal } \\
\text { or terminal to nearly } \\
\text { eliminated segments } \\
\text { of sporophyll. }\end{array}$} & $\begin{array}{l}\text { Terminal to main } \\
\text { sporophyll. }\end{array}$ \\
\hline Cotyledons & \multicolumn{2}{|c|}{$\begin{array}{l}\text { Two, fleshy, exalbu- } \\
\text { minous, little or no } \\
\text { endosperm. }\end{array}$} & \multicolumn{2}{|c|}{$\begin{array}{l}\text { Two hypogaeal, fleshy, } \\
\text { embedded in endo- } \\
\text { sperm. }\end{array}$} & \multicolumn{2}{|c|}{$\begin{array}{l}\text { One to three or more, } \\
\text { hypogreal, embedded } \\
\text { in endosperm. }\end{array}$} & $\begin{array}{l}\text { Two to three hypo- } \\
\text { gaeal, embedded } \\
\text { in endosperm. }\end{array}$ \\
\hline \multicolumn{8}{|c|}{ Staminate Strobilus. } \\
\hline & & \multicolumn{2}{|c|}{ Cycadeoidex. } & \multicolumn{2}{|c|}{ Cycadacea. } & \multicolumn{2}{|r|}{ Ginkgoacex. } \\
\hline Axis. ..... & $\cdots$ & \multicolumn{2}{|c|}{$\begin{array}{l}\text { Terminates as a shortened } \\
\text { ovulate cone to which the } \\
\text { microsporophylls form an } \\
\text { hypogynous disk. }\end{array}$} & $\begin{array}{l}\text { Remains pr } \\
\text { a cone. }\end{array}$ & rimitively elongate, & \multicolumn{2}{|c|}{$\begin{array}{l}\text { Elongate, open form, of } \\
\text { cone inversely com- } \\
\text { parable to ov la te } \\
\text { Zamiostrobus cones. }\end{array}$} \\
\hline Bracts.... & $\cdots$ & \multicolumn{2}{|c|}{$\begin{array}{l}\text { Linear-lanceolate, spiral or- } \\
\text { der, ensheathing. }\end{array}$} & \multicolumn{2}{|c|}{ Ensheathing, fugacious...... } & \multicolumn{2}{|c|}{ None. } \\
\hline $\begin{array}{l}\text { Interstitial } \\
\text { gans. }\end{array}$ & or- & \multicolumn{2}{|c|}{ 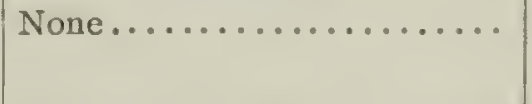 } & \multicolumn{2}{|c|}{$\begin{array}{l}\text { Sterile sporophylls, at base } \\
\text { and summit of cone only. }\end{array}$} & \multicolumn{2}{|c|}{ None. } \\
\hline Sporophylls. & $\cdots \cdots$ & \multicolumn{2}{|c|}{$\begin{array}{l}\text { Fronds of only moderate } \\
\text { reduction. }\end{array}$} & \multicolumn{2}{|c|}{$\begin{array}{l}\text { Fronds reduced to expanded } \\
\text { scale-like form of Zamiac } \\
\text { megasporophylls. }\end{array}$} & \multicolumn{2}{|c|}{ Greatly reduced. } \\
\hline Synangia or & sori. & \multicolumn{2}{|c|}{ Marattioid synangia......... } & \multicolumn{2}{|c|}{$\begin{array}{l}\text { Angiopteroid or paleopteroid } \\
\text { sori. (Cf. figure I } 37 .)\end{array}$} & \multicolumn{2}{|c|}{$\begin{array}{l}\text { Paleopterid or botryop- } \\
\text { terid. }\end{array}$} \\
\hline Pollen. . . . & $\cdots$ & live-celled. ..... & $\ldots \ldots \ldots$ & Three or $\mathrm{f}$ & four (?) celled.... & Thre & e-celled. \\
\hline
\end{tabular}




\section{SYSTEMATIC POSITION OF THE CYCADEOIDEÆ}

A most striking fact has become evident from the discoveries announced in the foregoing cliapters and brought together in a comparative survey of the vegetative and reproductive features of the two great cycadean lines. The hiatus between these is of a two-fold character due to an ancient reproductive advance on the one hand and a later vegetative advance on the other. In the existing cycads complication of the cortical bundle system has arisen, while the reproductive organs are relatively little changed and primitive. Conversely, in the Cycadeoidex, with the retention of a more primitive cortical system, there were in part most surprising reproductive changes leading up to the bisexual flower which mimics that of the angiosperms.

The question next to be answered is whether two groups so related shall be included in one and the same greater gymnosperm class, the Cycadales, or whether the Cycadeoidex shall be excluded from the true Cycadales, as the Bennettitales or Cycadeoidales. Both these classifications have been held to best express the facts ; and it must certainly be a source of profound satisfaction to botanists that what have been regarded as two great groups of gymnosperms have been brought by investigation and fortunate discoveries into the near juxtaposition indicated by such difference of opinion.

The idea that the Cycadeoider represent a separate great group or gymnosperm class, the Bennettitales, has been given force of authority by adoption in Engler und Prantl. This is also the view of Solms-Laubach and Lignier. On the other hand, Scott says in his studies in Fossil Botany, page 474:

"It appears, then, that there are at present known to us three distinct families of Cycadales-on the one hand, the Zamiæ and the Cycadeæ, still existing, and together constituting the order Cycadaceæ; and, on the other, the Bennettitex, wholly extinct, and so different from the other two as to merit ordinal rank."

This is likewise the opinion that has been sustained by Zeiller and Wieland. In reviewing various contributions of the latter, Zeiller (2I7) thus states with precision the views that can only be regarded as fully borne out and confirmed by the more extended studies recorded in the present volume:

“* * * On a affaire là, en somme, à de véritable fleurs, à appareil femelle central entouré, pourrait-on dire, d'un cercle d'étamines composées, fleurs morphologiquement hermaphrodites, et constituées, ainsi que le fait remarquer l'auteur, sur le plan qui caractérise les fleurs des Angiospermes. M. Wieland insiste, d'une part, sur les affinités que tend à dénoter, entre les Bennettitées et les Marattiacées, ce groupement des sacs polliniques en synangium si semblables à ceux des Marattia, d'autre part, sur les analogies qui existent entre ces androphylles de Bennettitées et les carpophylles des Cycas; il présume que les Cycadinées ont dû́ descendre de quelque type ancestral tel qu'une Cycadofilicinée hétérosporée, à microsporanges et à macrosporanges localisés sur des frondes distinctes construites sur le même plan que les frondes stériles, et de laquelle on est passé, des Cryptogames, à des Gymuospermes à appareil mâle semblable à celui des Bennettitées, à appareil femelle semblable à celui des Cycas. L'association identique que réalisent en sens inverses les C.ycas et les Bennettitées, d'appareils en forme de cône pour l'un des sexes avec des appareils en forme 
de feuille à peine modifiee pour l'autre sexe, conduit $M$. Wieland, en tenant compte des affinités de leur appareil végétatif, à les regarder comme des termes symétrique d'un même groupe, et il n'hésite pas, conformément à l'opinion que j'ai soutenue plus d'une fois et qui est également celle de M. Scott, à rattacher les Bennettitées aux Cycadinées, pour constituer parmi celles-ci une famille ou un ordre de même valeur que les Cycadées et les Zamiées de notre flore actuelle."

Such is the conclusion reached as based on the known facts. If, however, one passes on to purely hypothetical considerations, other possibilities present themselves. If after all, we are deceived as to the profundity of structural agreement in the two great cycadean lines, and if some such hypothesis as the following could be shown to approach the truth, it would assuredly be quite logical to erect two cycadophyte classes, the Bennettitales and the Cycadales.

Count Solms has called attention to the similarity between the synangia of Cycadeoidea and Chorionopteris Corda; and Potonié considers the latter to resemble Onoclea externally. Now, suppose Chorionopteris and the Cycadeoidex in turn to have been derived from some very ancient Onocleiform fern stock, and the Cycadacese from some other primitive stock by way of Angiopleris-like tree ferns. In such a case the two different ancestral pteridophyte lines leading respectively into the Cycadacere and Cycadeoidex would have passed independently through essentially the same evolution of heterospory by way of two different cycadofilicinean lines, each nevertheless presenting a great variety of genera and presumably families. Moreover, the generalized forms of these two cycadofilicinean lines, as thus fundamentally and primitively separated, would always present a homoplastic similarity that would perforce be especially striking at the time both assumed the more consolidated type of armored trunk. The paleontologic record thus far known does not, however, disclose even a hint of the existence of any such complexity in the early' history of the present fossil and the existing cycads.

Contrariwise, let us conceive a second hypothetical group made up of Marattiaceous ferns exhibiting, let it be said, to avoid prolixity, double the vegetative and reproductive variation exhibited by the existing Narattiacex; and let it be further conceived that most of the members of this closed group began to assume more compact trunk and foliar structures, and at the same time to develop heterospory, thus producing a great paleozoic "quasi-fern" complex. In such a case all the ecological factors known, bearing in mind the generalized tropical conditions of the Paleozoic, would presumably most favor the series advancing along much the same lines.

Once more, to be specific, let it be conceived that this heterosporous Marattiaceous complex eventually gave rise to a variously branched cycadofilicinean type of trunk with a gradual elimination of separate prothallial stages and a :eproductive advance from a merely heterosporous to a primitive seed and pollen bearing condition; and let it be conceived, too, that these primitive seed plants exhibited a great variety of carpellary leaves and of staminate fronds tending to organize into various bisporangiate ovulate and staninate strobilar forms presenting various phases of monœeism and diœcism; and that eventuilly, from somewhere amongst this complex, was developed, in the later Paleozoic or Permian, the common 
ancestor of the existing and Mesozoic cycads, as a plant with a Lyginodendronlike trunk, bearing micro- and megasporophylls on the main axis monœciously with cycad-like pollen and seeds already developed.

Now, if the Cycadeoidere and Cycader thus arose from such a closed and homogeneous evolutionary series, and then began to separate more and more widely quite as early as the Permian, they must be regarded as fundamentally related. And that they did so arise, and are so related, and that this second hypothesis, in strictest accord with purely morphological data, thus expresses the approximate truth, is our belief, after patient consideration of the botanical and paleontological evidence. In short, the explanatory analogies offered by the reproductive features of the two groups, when considered in connection with vegetative similarity, inhibits derivation from other than a closed group. This being the simpler view, and paleontologic evidence affording nothing in favor of a complex homoplastic derivation, we are forced to the conclusion that the Cycadeoidex, as an ancient apposite of the Cycadex, find their appropriate place amongst the true Cycadales. Were we in ignorance of the quite as ancient Cycas with its huge terminal strobilus of carpellary leaves and its staminate cones, no one would hesitate to assign the Cycadeoidere to the position of a separate great group. To do so, however, is to neglect the simpler hypotheses of descent, the similarity of vegetative characters, and the profoundly significant inverse relationship between the staminate fronds of Cycrdeoidea and the carpellary leaves of Cycas. 


\section{CHAPTER X.}

\section{FERN ANCESTRY AND ANGIOSPERM ANALOGIES.}

\section{THE FERN-CYCAD RELATION SUMMARIZED.}

The evidence indicating the descent of the existing cycads from Marattiaceous tree ferns has been accumulated mainly during the past thirty years. From the botanical side the observations of Warming on the ancient fern-like characters of the sporophytes, and the recent discovery of the spermatozoids of Cycas, quickly following those of Ginkgo, have been of most weight. On the paleontologic side the testimony of anatomical structure and of development has been mainly supported by the discovery of great complexity in cycadaceous forms, with the existence of a great plexus of seed-bearing quasi-ferns and cycadofilices in the Paleozoic typifying theoretical transition forms between ferns and cycads, and most directly by the fact that in the Cycadeoidex the microsporophylls bear the ummistakable stamp of a Marattiaceous origin. In fact, from the earlier belief in the Marattiaceous origin of the cycads, many botanists have come to postulate a pteridophytic origin for all the gymnosperms, and indeed such an origin begins to appear quite probable for most spermaphytes.

Putting aside for the moment, however, the more hypothetical features of present theories of seed-plant evolution, and not overlooking the fact that the complexity of the plants with cycad-like foliage strongly suggests remote and widely separated origins from primitive ferns, a startling result is reached when to the evidence regarded as virtually proving the descent of the Cycadaceæ from ancient Marattiacex is added the category of facts indicating the similar origin of the Cycadeoideæ, as follows :

r. General trunk form, fern-like foliar crown, persistent leaf bases, size, branching, prefoliation, and habits of growth.

2. Large, soft, pulpy medulla as in Cyathea medullaris of New Zealand (which furnishes an article of food similar to sago). filices.

3. Occurrence of mesarch and medullosan bundles so characteristic of cycado-

4. Direct course of cycadeoidean leaf traces through the cortex.

5. Occasional occurrence of incompletely concentric cortical bundles which may be regarded as remnants of earlier concentric bundles.

6. Vestigial hairy ramentum of Dion and other genera, and abundant ramentum of filicinean type in the Cycadeoidex.

7. Alternate production of fertile and foliage leaves on the main axis (Cycas), as in Blechnum, Struthiopteris, and Botryopteris.

8. Prefoliation fern-like.

9. Leaves partially fertile, as in many ferns (Cycas), and presenting bifurcate (Stangeria), odontopterid (Otozamites), and netted-veined (Dictyozamites) types. 
Io. Development of sori as in Marattiaceous forms, and fern-like initial stages of megaspore.

I I. Tendency of sporangia of Cycas to form Angiopteris-like sori.

I2. Marattiaceous structure of the synangia of Cycadeoideæ.

I3. Retention of megaspore membrane in both the Cycadaceæ and Cycadeoideæ.

14. General equivalence of the megaspore to monangial sorus. That is, compared with the vascular cryptogams the ovule is a megaspore, the integument an indusium, and the entire seed therefore a monosporic sorus, with the embryo sac as analogue of a megaspore, the endosperm of the prothallus, and the archegonia of the corpuscula.

I5. Similarity in vegetative and reproductive features to the members of the vast Paleozoic complex of seed-bearing "quasi-ferns."

Plainly the preceding résumé of the principal characters of the two great cycad groups as combined and showing their descent from Marattiaceous ferns of the Paleozoic, is not merely conclusive, but one of the great comerstones upon which the conception of evolution can rest secure. Nevertheless, investigators must doubtless, for a long time to come, very naturally differ greatly in their view of the degree of vegetative and reproductive complexity theoretically reached by the common ancestry of the Cycadacer and Cycadeoider. For not only will the knowledge of the facts bearing on this most interesting problem be greatly augmented, but those facts already known have been gleaned by many investigators; and different students very naturally observe differently, or may study the different classes of evidence falling within their ken in differently accentuated manner. So far as the writer is concerned, however, he has already made it clear in the closing pages of the preceding chapter that he regards the productive and vegetative parallelism of the two great cycadalean orders as fundamentally ontogenetic rather than homoplastic, whence a comparatively modern rather than an ancient separation of the groups appears in his immediate perspective the more plausible.

For the sake of specific clearuess it may be added that we may well conceive of two closely related Marattiacean genera, one with sori of the Angiopteris type, and the other with synangia like Marattia, undergoing a series of parallel changes not completely chronologic, and giving respective and separate origin to the Cycadeoidere and the Cycadacere. In such a case the main point is that this pair of hypothetical ancestral genera must have retained complementary family relationships after the assumption of the primitive cycadaceous form. But of such finer gradations of homoplasy we can have but a vague and nebulous idea, and it must be pleaded that it affords a clearer conception of morphologic and biologic relationships to regard the ancestors of the Cycadeoidex as integrally cycadean, or perchance cycadofilicinean, rather than simply Marattiaceous. In fact, the more distant relationship to Ginkgo and Cordaites would at best leave to the latter conception little of probability.

While with increasing knowledge of the paleontologic record, origins are ever being found more ancient and homoplastic relationships more omnipresent than at first apparent, those who would widely separate the Cycadeoidere from the Cycadacex on the basis of either origin or form may well pause to consider how extremely complex the changes from ferns to existing spermaphytic lines must have been, and how correspondingly small are the chances for long-persistent parallelism. 
In this connection, as well as with regard to the theory of the metamorphosis of fern fronds into cycad sporophylls (and stamens), it is of interest to partly outline the theory of change from the ancestral pteridophytes to spermaphytes.

\section{SPOROPHYTE REDUCTION CORRELATED WITH ELIMINATION GF SEPARATE PROTHALLIAL STAGES AND EVOLUTION OF SEED-BEARING QUASI-FERNS.}

In the ancestral fern lines the nutritive effort of the mature sporophyte, required in the production of myriads of asexual spores, as measured by bulk, was not relatively great. And so long as these asexual spores remained a sufficient or an unchanged reproductive structure, the fertile frond which bore them was fairly: constant in its external form, being only subject to or altered by the more obvious evolutionary factors operating within morphologic limits. Such minor variations are, in a measure, illustrated by the aitered fertile tips of the fronds of Polystichum acrostichoides or the dimorphic Struthiopteris germanica, as compared with Angiopteris evecta, an ancient type which in full fruit presents a striking sight, its foliar laminæ being quite fertile throughout. With the progressive elimination of separate prothallial stages and the incipiency of megaspore differentiation, from whatever cause, determinable or bathmic, the approximate equilibrium finding its expression in a strong resemblance between the fertile and non-fertile segments, or the fertile and non-fertile fronds of the sporophyte, was disturbed. Concomitantly: the resulting megaspore-bearing segment, or frond, became nore and more complex in organization as it approached more and more nearly the carpellary stage, while the microspore-bearing segment retained a simple structure, or became much reduced and staminate.

For the further conception of the evolution of carpels and stamens from asexual sporophytes as based on paleobotanical evidence, it matters not whether differentiation between the megaspore and microspore segments of the fronds of primitive heterosporous filices was resultant or causative. That is to say, we are in the main concerned most with the manner in which this evolution manifested itself morphologically. Presumably, however, differentiation was simply the complementary resultant of the effort or tendency amongst the pteridophytes which hypothetically gave rise to spermaphyte lines, to produce more and more highly differentiated megaspores, these becoming more and more advantageous the parent plant.

In the earliest stages of spore differentiation both megaspores and microspores were borne on the same frond. Later a segmentation must have taken place, resulting possibly in the basal segment of a frond producing megaspores and the apical segment microspores. Secondarily the one segment or the other became barren and greatly altered, or was eliminated. Thirdly, there was a coördinated new grouping of these newly differentiated segments. Fourtlly, fugacious fnetifications and the most varied stages of bisexuality, monœecism, and diocism appeared.

In the case of the living Cycas we may well believe that the sterile apical pinnx of the carpellary leaf once bore microspores. The retention of such aburtive parts long after the evolution of a male cone may be due to mechanical or protective value. The organization of the male cone itself on a different branch, with numerous fronds spirally arranged and reduced to staminate scales, constitutes a 
certain kind of economy. The plant, instead of employing segments of all its crown of leaves, delegates the reproductive effort to a fugacious branch whose leaves have in the course of time been reduced to scales, though here it is to be borne in mind that in certain more or less closely related primitive forms there must have been free branching, all branches being fertile, and perhaps bearing both kinds of spores. Likewise in the Cycadeoidex the reproductive branches and concomitant changes of the sporophyte either originated early or proceeded at an accelerated rate.

Always considering the especial case taken up, namely, the changes in presumed Marattiacean ancestors of the cycadalean and ginkgoalean alliance, the origin of heterospory must be considered as primarily beginning with the spores. Changes in these were reflected in the prothallial structures and, when the primitive stages of megaspory appeared, prothalli tended to dicecism and, what is of more importance in the elimination process, to briefer and briefer stages of separate existence. That is to say, more and more of the vegetative process concerned in reproduction was accomplished in the spore stages, the hitherto asexual plant playing a more and more conspicuous rôle in the nutrition of the reproductive cells. A resultant change in the fertile fronds finding its expression in dimorphism and later trimorphism was also corollary to these spore changes. We may hence consider the life of the separate prothalli, after spore change sets in, as growing shorter and shorter, with a prolonged retention and more active nutrition of the slowly differentiating spores, accompanying prothallial dicecism and finally dimorphism or trimorphism. The separate prothallial stage grew shorter until eliminated. When this finally took place nutritive disturbance was at its height, the ultimate result being marked change of form, and at last retention of the megaspore. The long retention of the megaspore is not seen, therefore, to present any insuperable difficulty. It is a method of reproduction which is the final outcome of spore sterilization and the resulting changes in the sporophylls.*

Accompanying these profound reproductive changes there was a constant reduction of the microsporophyll. The most striking intermediate stage known is that exhibited by the staminate fronds of the Cycadeoidex. In the case of the megasporophyll there is, along with some reduction, a reorganization and evolution of a more highly developed and persistent nutritive system. Correlated with evolution of both mega- and microsporophylls, there may be increasing variance in the time intervening between the maturing of the microspores and fertilization. The long interval between these two stages in many gymnosperms is a striking

* The answer tu the question whether the true ferns of the Paleozoic are of the type strictly ancestral to the seed-bearing forms, rather than devolule, awaits future paleontologic discovery. For bryophyte ancestry of the ferns and polyphyletic origins lie on the remote borders of our present knowledge. However, should our more naive theory of an evolutionary sequence based throughout all its later phases on increasing spore complexity coördinated with sporophyll reduction, which we preferably confine to a monophyletic fern series, prove to fall short of the actual facts, it must yet afford a virtually complete outline of early seed-fern and cycadofilicinean origin. At least, it appears evident that, so far as the cycads are concerned, from the cycadofilices on, reduction of the sporophyte and evolution of the spore was the method nature followed; and that a partly reversed process with more or less evenly coördinated foliage and sporophyte evolution from plants very different from the simpler fern types could have led up to the cycadofilices appears to be the much more unlikely, involved, and difficultly conceivable hypothesis. Conversely, it is an at-first-hand method to predicate the descent of the seed-ferns more directly from an ancestry with well-developed monomorphic foliage, and distinctly filicinean stem organization. 
fact. The retention and ripening of the megaspore is then seen to be no more than analogous to the maturing of pollen, though involving greater time, and eventually more complex nutritive processes.

In conclusion, it remains to suggest some of those floral features of the Cycadeoider, as members of the proangiosperms of Saporta, which suggest at once the existence of fundamental relationships between gymnosperms and angiosperms as well as possible main lines of angiosperm evolution.

\section{ULTRA-RELATIONSHIP OF THE CYCADALEAN GYMNOSPERMS (OR THE CYCADEOID-ANGIOSPERM JUXTAPOSITION).}

Within the past few years evidence has been rapidly accumulating that the gymnosperms have all been remotely derived from the ferns. The most generalized, but withal a much modified, gymnosperm stock combining characters of the conifers and cycadophytes, the Cordaitales, are first recognized in the Devonian, having by this period become highly organized and stately forest types. However, the primitive seed-ferns from which these conspicuous forest types of the Devonian sprang doubtless persisted till a much later period before giving rise to such types as the Mesozoic Cycadeoidex and, as I believe, at much the same time or a little later than these the early angiosperms. It is especially to Nathorst that we owe the discovery of evidence going to show the most surprising variety of types of fructification among cycadophytes, such, for instance, as reproduction by means of antherangia (IO3). This condition, however, goes far toward precluding the descent of all the "cycadophytes" from Marattiaceous types, if it does not even stamp this as an impossibility. It is more and more borne home to us that while we ever and anon gain clearer and clearer insight into the nature of certain features of the greater lines of evidence concerning the descent of the great groups of existing plants, we are, in the absence of the exact facts, singularly helpless when we attempt to frame hypotheses of descent. The fact is also emphasized that the gymnosperm plexus includes not a few score, but hundreds or even thousands of modifications of generic or family value of which we know well scarcely a half dozen of the fundamentally important extinct forms. In the absence of more exact knowledge of such great numbers of diverse forms that gave rise at widely separated periods of time to existing spermaphytes, lines of descent can not readily be picked out. One too soon, becomes involved in extreme difficulties. Attempts at deciphering these lines of descent involve morphologic conceptions which, simple though they be, are not directly thinkable, or even if dimly perceived sufficiently recoguizable, because of the lack of historical perspective. As a result no two investigators ever reached the same conclusion, when nearing the point to which the known evidence actually carries us. But to determine this point is ever the ardent ambition of the paleobiologist. It results that the sanguine worker is constantly asking too much of the evidence, his patient and doubting brother too little. Yet taken merely on the basis of an arithmetical probability, it would be most extraordinary if at the present day the angiosperm line of descent could be laid down, except on the broadest lines. It wonld be most extraordinary, we say, if a 
mere half dozen well-understood great plant types scattered over vast periods of time, and representing but a few of a vast array of unknown evolutionary steps, should be exactly the ones enabling us to say, for instance, that certain lines (cycadofilices) led into the Cycadales and Ginkgoales, and sent off a branch which yielded Cycadeoidean stock first, then the Cordaitales, or vice versa, and that from these latter the angiosperms sprang. And no one fact involves the problem more than the unequal rate of evolution in different organs. This has never before been so well illustrated as now. In Cycas, carpophylls of the simplest types known in seed plants persist and are borne on the stem itself. Yet in this genus the microsporophylls are reduced to scales and borne on a secondary axis, as are both microand megasporophylls in the other genera. Conversely, in the Cycadeoider it is the microsporophylls that remain primitive while the megasporophylls are organized into a strobilus in many respects far more complex than that seen in any living cycad. Moreover, in this case the microsporophylls, though of such primitive type, liave, in assuming the cyclic arrangement so seldom seen in gymnosperms and so often in angiosperms, made possible a wholly new series of reductions. Now, we are certainly permitted to conjecture the former existence of members of a cycadeoidean alliance in which the microsporophylls did not assume a cyclic arrangement and others with perchance freely branching, less compacted trunk types in which there was an early reduction of these spirally arranged microsporophylls to a filamentous staminate form, with, as may often happen, a certain coördination between decrease in bulk and increase in number. It was with this thought in mind that I formerly suggested a certain analogy between the cycadeoidean flower and that of Liriodendron, which I yet regard as very much to the point.

Again, if, as we surely may, we assume the former existence of cycadeoidean bisporangiate types in which, coördinate with freer and freer branching and the production of more numerous bisexual flowers, the ovulate cone bore a more and more reduced number of seeds until only a single terminal one was left, another series of highly suggestive relationships presents itself. Moreover, in this final member of such a series bearing one-seeded flowers, a great variety of possibilities would be bound up in the extent to which the micropylar tube elongated and conditioned the process of fertilization and prothallial growth and change, as likewise in the extent to which reduction and fusion went in the organs present in the cycadeoidean fruit as interseminal scales. But let us take a step farther. The writer has constantly urged that the great variety of stem types suggested by the freely branching Anomozamites minor of Nathorst is a factor of the first importance. Just as the pinnules of a pinnate frond begin to branch and a bipinnate frond arises, so a stem branches and the organs of fructification that were formerly inserted directly come to be borne on secondary and tertiary axes. There is no fundamental difference between the carpel-bearing summit of the trunk of Cycas and the complementary staminate strobilus or the mega- and microsporangiate strobili of the cycads in general. These variations have arisen in the simplest manner by accelerated branching, coupled earlier or later with sporophyll reduction, when the entire phylum was of a much more primitive type than now. This simple view rids us of many difficulties; and it is very clear that the "plexus" to which the 
Cycadeoidere belonged, as in the case of every highly organized plant type, presented members of infinite variety. Alsu, in the case of the sole remote type of which we have now gained a fortuitous knowledge, striking analogies to living angiosperms are suggested, no difference whether, laying histological structure somewhat aside, we fasten our attention upon one set of characters and Liriodendron be called to mind, or upon another with the result that the male and female catkins of Amentacex first suggest themselves, or upon a third set that call to mind some other hint of characters that must have been present in the countless members of a great proangiosperm complex, just as the monocotyl Pandanus thus suggested itself to Saporta. We should not ask too much of isolated evidence, nor yet be content with a scant interpretation of highly suggestive facts. And taking up the general question not from the position of organs so much as their general morphology, what right would we have, in surmising as to the homologies between living plants and hypothetical primitive angiosperms, to look for instance upon the bifurcate stamens of Ginkgo as separated by an unbridgeable hiatus from those of the multibranched stamens of Ricinus? Assuredly none. For the purposes of broader generalization, fern-like fronds upon which were doubtless borne the pollen of Lyginodendron, the staminate fronds of Cycadeoidea of true Marattiacean type, the mega- and microsporophylls of Cycas, the stamens of Cordaites and Ginkgo, and finally of Ricinus and Liriodendron, all belong to a series. Nor is there from a plain point of view an unbridgeable gap between the staminate disk of Cycadeoidea and that of Welwitschia, for the latter could arise similarly to one of the hypothetical one-seeded and bisporangiate forms of the cycadeoidean alliance by one of the simplest of all evolutionary processes, namely, increased number of flowers to the plant and decrease in bulk until there was left of each original frond but a single filament bearing a pair of pollen sacs (as in Ginkgo biloba), and finally: but a single pollen sac, the filaments retaining the original cyclic arrangement of the fronds from which they were derived.

In discussing this question we are forced to the conclusion that it is clearer than ever that there is a universal homology between the mega- and microsporoplyylls of the spermaphyta and the asexual spore-bearing fronds of the ferns, from which it becomes more and more probable that all the spermaphytes of the existing flora have sprung. And for the sake of a clearer conception of the views proposed it has seemed preferable to speak of the stamens or carpophylls of particular plants rather than to attempt some completer form of generalization. The series of plants named is not asserted to be an evolutionary one, except in the most general sense. Other forms in the direct relationship yet remain to be discovered.

It is, then, in Cycadeoidea, and especially in the persistence in such highly organized plants of the Marattiacean synangium, that we get the first 1mmistakable hint of the nature of angiosperm evolution. And the further view would seem to be abundantly justified - that while the staminate disk surrounding the orulate axis of Cycadeoidea indicates primarily an evolution terminating, so far as now possible to trace, in the gymnosperms, the juxtaposition of parts is exceedingly suggestive of the possibility, if not the manner as well, of angiosperm development directly from filicinean forms. 
In more fully describing the microsporophylls of Cycadeoidea, in I90I, I was led, in speaking of the new light shed by the investigation of the American fossil cycads on the nature of the evolutionary course that had culminated in seed reproduction, to call attention to the hypothetical position occupied by Lyginodendron and its allies as follows (I92):

"* * * The most important possibility suggested by the staminate fronds above described is as to the character of fructification in the cycadofilices. If we are permitted to imagine, as we surely are, a plant, vegetatively like Lyginodendron, and either monœcious or diœcious, with microsporophylls like those of the staminate fronds of Cycadcoidea, and megasporophylls like those of $C y$ cas, do we not picture an ancestral form which almost beyond doubt existed and may any day be found? * * * It certainly becomes more than ever probable that the dimorphism of various Paleozoic plants usually referred to the ferns is intimately connected with forms of heterospory and the acquiring of the seed habit by types immediately ancestral to the cycads, if not also to the angiosperms."

This remark has been fully justified. Nearly two years later Oliver and Scott (Io6) reinvestigated the cycad-like seeds described by Williamson under his genus Lagenostoma and proved on the basis of isolated similar parts that seeds of $L$. Lomaxi are really the megaspores of "the Paleozoic quasi-fern" Lyginodendron Oldhamium. And since then evidence has been rapidly accumulating that the majority of the Paleozoic plants with filicinean foliage were either heterosporous, or actually bore pollen and well-developed seeds of cordaitean or cycadean type. In this country the seeds of Aneimites, in England those of Neuropteris, in France those of Pecopteris, have been found in quick succession; while the identity of Trigonocarpon with Medullosa is all but established. Moreover, as these pages go to press, Kidston has determined the pollen-bearing fronds of Lyginodendron Oldhamium to be of the Crossotheca type. It is thus clear that whatever the connections of the advanced condition of floral development of the Cycadeoidex with angiosperm evolution, among the most fundamental organs involved in the origin of seed-bearing plants yet discovered is the staminate frond as first demonstrated in the silicified trunks from the Black Hills. Previously the bearing of pollen or of microspores, incipiently pollinial in nature, by fronds yet retaining a more or less filicinean structure, was only hypothetically involved in various attempts to unravel the manner in which the origin of heterospory had taken place; although the ferns of Marattiaceous type were always first looked to, because of their great abundance in ancient and primitive florx taken together, more especially with the presence of certain vegetative and fruit characters in the existing cycads, testifying more or less directly to an ancient relationship with such tree-fern types as Angiopteris. But undeniably the evidence morphologically and chronologically of most weight in the raising of this hypothesis to the dignity of a definite probability was afforded by the fact that pollen-bearing structures so nearly identical to those of the asexual spore-bearing synangia of Marattia as to be in themselves at most no more than generically separable, and preclude all reasonable possibility of homoplastic development, should actually persist in highly organized seed-bearing plants of the late Jurassic and Lower Cretaceous. 


\section{BIBLIOGRAPHY.}





\section{BIBLIOGRAPHY.}

I. ANdy, S. Pulney. On Branched Palms in Southern India. Trans. Linn. Soc. London, vol. xxve. London, 187o, pp. 66r-662, pl. li.

2. BeEcher, C. E. On the Origin and Significance of Spines. American Journal of Science, fourth series, vol. vi, I898, pp. I-20 : I25-136 : 249268: 329-359.

2 $\alpha$. Bentham, G., and Hooker, J. D. Genera Plantarum. London, vol. I, I862-1867; vol. II, I873-I876; vol. III, I883.

3. Bertrand, C. E., et Renault, B. Remarques sur les faisceaux foliaires des Cycadées actuelles, et sur la signification morphologique des tissus des faisceaux unipolaires diploxyées. Archives Bot. du Nord de la France, 4e Année, vol. 11, 1888, pp. 232-242.

4. Recherches sur les Poroxylons Gymnospermes fossiles des Terrains Houillers supérieurs. Ibid., pp. 243-389.

5. Bitter, G. Marattiaceæ, in Engler und Prantl, Die natürlichen Pflanzenfamilien. Teil $\mathrm{r}, \mathrm{Abt}$. $\mathrm{W}$. Leipzig, Igoo, pp. 422-449. (See Nos. I 126 ; II 26. )

5\%. Bibins, Arthur. Notes on the Paleontology of the Potomac Formation. Johns Hopkins University Circulars, vol. Xv, No. I2I. Baltimore, October, 1895, pp. 17-20, one unnumbered plate.

6. Bower, F. O. On the Comparative Morphology of the Leaf in the Vascular Cryptogams and Gymnosperms. Phil. 'Trans. Roy. Soc. London, for the year 1884 , vol. CLXxv. Pt. II, London, r885, pp. 565-6r5, pl. xxxvii-xl.

7. Studies in the Morphology of Spore-producing Members. I. Equisetineæ and Lycopodineæ. Phil. Trans. Roy. Soc. London, vol. Clxxxv (1894) B, London, I895, pp. 473-572, pl. xlii-lii.

8. - Studies in the Morphology of Spore-producing Members. II. Ophioglossaceæ. (pp. x-86, with 9 plates.) London, I896. (Published by Dulau \& Co., London.)

9. - Studies in the Morphology of Spore-producing Members. III. Marattiacex. Phil. Trans. Roy. Soc. London, for the year 1897 , series B, vol. clxxxix, London, r898, pp. 35-8I, plates vii-xi.

10. - Studies in the Morphology of Spore-producing Members. IV. The Leptosporangiate Ferns. Phil. Trans. Roy. Soc. London (1899), series B, vol. cxcri, London, 1900, pp. 29-r38, pl.ii-vii.
II. - Studies in the Morphclogy of Spore-producing Members. V. General Comparisons and Conclusion. Phil. Trans. Roy. Soc. London (rgo3), series B, vol. cxcvi, London, 1903, pp. 191-257.

12. Braun, A. Die Frage nach der Gymnospermie der Cycadeen, erläutert durch die Stellung dieser Familie im Stufengang des Gewächsreichs. Monatsber. d. k. preuss. Akad. der Wiss. zu Berlin, April, 1875, pp. 24l-267; Mai, 1875, pp. 289-377.

13. Brongriart, A. Prodrome d'une histoire des végétaux fossiles. Paris. 1828 .

14. - Recherches sur l'organisation des tiges des Cycadées. Ann. Sci. Nat., vol. xwy, Paris, 1829, pp. 309-402, pl. xx, xxi.

15. Brown, Robert. (On Cycadites Saxbyanus.) Proc. Linn. Soc. London, vol. 11, 1852, p. 130.

16. Buckland, IV. (Session of June 5, I827.) Proc. Geol. Soc. London, vol. I, No. 8, London, 1827. pp. 8o-8r.

17. - On the Cycadeoideæ, a Family of Fossil Plants found in the Oölite Quarries of the Isle of Portland. Trans. Geol. Soc. London, 2d series, vol. II, London, I828, pp. 395-40I, pl. xvi-xix.

18. - Geology and Mineralogy Considered with Reference to Natural Theology. Bridgewater Treatises, No. 6, 2 vols. London, 1836 (see vol. I. p. 504 ; vol. Ir, p. Ior, pl. lxiii, genus Podocarya).

19. Calvin, Samuel. On the Geological Position of Bennettites dacotensis Macbride, with Remarks on the Stratigraphy of the Region in which the Species was discovered. Proc. Iowa Acad. Sci., vol. I, pt. 1v, Des Moines, I894, pp. 18-22.

20. Campbell, Douglass H. The Structure and Development of the Mosses and Ferns (Archegoniatre). London, I895.

20\%. Candolle, Alpion:s De. Prodromus Systematis Naturalis Regni Vegetabilis. Pars xrr, sect. Ir, Paris, $1864-1868$.

21. Capellini, Giovans. Icthyosaurus campylodon e Tronchi di Cicadee nelle argille scagliose dell" Emilia. Mem. d. R. Accad. delle Sc. dell' Ist. di Bologna. ser. $\mathbb{N}$, vol. $x$, Bologna, Isgo, pp. $+3 \mathrm{I}-450$, pl. i, ii.

22. - e Solms-Laubach, Conte H. I tronchi di Bennettitee dei Musei Italiani. Notizie storiche, geologiche, botaniche. Mem. d. R. Accad. delle Sc. dell' Ist. di Bologna, series $\checkmark$; vol. $\llbracket$, Bologna, I392, pp. I6r-215, pl. i-r. 
23. Carruthers, W. On Cycadeoidea Yatesii, a Fossil Cycadean Stem from the Potton Sands, Bedfordshire. Geol. Mag., vol. IV, I867, pp. 19920I, pl. ix.

24. On Fossil Cycadean Stems from the Secondary Rocks of Britain. Trans. Linn. Soc. London, vol.xxvi, London, 187o, pp.675-708, pl. liv-lxiii.

25. Caruel, Th. Osservazioni sul genere di Cicadacee fossili ed descrizione di una specie nuova. Boll. del R. Comitato geologico d'Italia, vol. I, Firenze, 1870, pp. I8I-I86, I plate.

26. CelakovskÝ L. Zur Gymnospermie der Coniferen. Flora, Lxil Jahrg., Regensburg, I879, pp. 257$264 ; 273-283$.

27. Zur Kritik der Ansichten von der Fruchtschuppe der Abietineen. Abh. d. Königl. Böhm. Gesell. d. Wiss., ser. vi, vol. XI, Prag, r882, Math.naturw. Cl., No. 6.

28. - Gymnospermen: Eine morphologisch-phylogenetische Studie. Abh. d. Königl. Böhm. Gesell. d. Wiss., ser. vili, vol. Iv, Prag, I890, Math.-naturw. Cl., No. I.

29. - Nachtrag zu meiner Schrift über die Gymnospermen. Botanische Jahrbücher, vol. xxıv, Leipzig, I898, pp. 202-231.

30. Chick, Edith. The Seedling of Torreya myristica. The New Phytologist, vol. Ir, London, Nos. 4 and 5, April and May, 1903, pp. 83-9I, pl. vii, viii.

3i. Compter, G. Cycadeenfrüchte aus der Lettenkohle von Apolda. Zeitschrift für Naturwissenschaften, Band Lxxy, Stuttgart, I903, pp. I68-I73, pl. iv.

32. Corda, August J. Pflanzen. In A. E. Reuss: Versteinerungen der bömischen Kreideformation. Stuttgart, I845-46, pp. 8I-96, pl. xlvi-li.

33. — Beiträge zur Flora der Vorwelt. Prag, r 845 , fol.

34. Coulter, J. M., and Chamberlain, Charles J. Morphology of Spermatophytes. New York. Pt. I, Gymnosperms, Igor; Pt. II, Angiosperms, I903.

$34 \alpha$. Coulter, J. M., and Land, W. J. G. Gametophytes and embryo of Torreya taxifolia. Botanical Gazette, vol. xxxix, Chicago, March, 1905, pp. I6I-I78, pl. A, i-iii.

35. Cragin, F. W. Contributions to the Palæontology of the Plains. No. I. Bulletin of the Washburn College Laboratory of Natural History, vol. II, No. Io, Topeka, I889, pp. 65-68.

36. DANA, J. D. Manual of Geology, treating of the principles of the science with special reference to American geological history. 4th ed. New York, 1895 .

37. Dawson, J. W., and Harrington, B. A. Report on the Geological Structure and Mineral Resources of Prince Edward Island. Montreal, 187x, $5^{2}$ pages, 3 plates, $8^{\circ}$ (see p. 45 , pl. iii, fig. 29).
38. - Note on the Fossil Plants from British Columbia, collected by Mr. James Richardson in 1872 . Appendix I to Mr. Richardson's Report on the Coal Fields of Vancouver and Queen Charlotte Islands, Geological Survey of Canada, Report of Progress for $1872-73$, Montreal, r873, pp. $65^{-7 x}$, one unnumbered plate.

39. DE BARY, A. Comparative Anatomy of the Vegetative Organs of the Phanerogams and Ferns. Translated and annotated by F. O. Bower and D. H. Scott." Oxford, I884.

40. Duchartre, P. Note sur l'enracinement de l'albumen d'un Cycas. Bull. Soc. bot.de France, vol. xxxv (2e sér., vol, $x$ ), Paris, 1888, pp. 243-251.

4I. Eaton, Daniel C. Ferns of North America. 2 vols. fol. Boston, I879-80.

42. Eichler, A. W. Zur Kenntniss von Encephalartos Hildebrandtii A. Br. et Bché. Monatsschr. d. Ver. zur Beförd. d. Gartenbaues i. d. K. Preuss. Staaten, Jahrg, xxII, Berlin, I88o, pp. 50-54, pl. i.

43. - Cycadacex, in Engler und Prantl: Die natürlichen Pflanzenfamilien. Teil II, Abt. I. Leipzig, r887, pp. 6-26.

44. Eichwald, Edouard D. Lethaea Rossica. Vols. I-III, 8०. Atlas, fol. Stuttgart, I853-I868.

45. Emmons, E. American Geology. Vol. vi. Albany, r857, pp. I23-r24, fig. $92 \alpha$.

46. Engler, A., and Prantl, K. Die natürlichen Pflanzenfamilien. See Nos. 5, 43, II $2 \alpha, \operatorname{II} 2 b$, II $2 c$

47. Feistmantel, O. Jurassic (Oölitic) Flora of Kach, Fossil Flora of the Gondwana System. Vol. Ir. Calcutta, 1876 , pp. $1-80$, pl. i-xii. Palæontologica Indica, ser. XI, pt. I.

48. - Jurassic (Liassic) Flora of the Rajmahal Group in the Rajmahal Hills, Fossil Flora of Gondwana System. Vol. I. Calcutta, I877, pp. 53-162, pl. xxxvi-xlviii. Palæontologica Indica, ser. II, pt. II.

49. - Palæontologische Beiträge. II. Ueber die Gattung Williamsonia, Carr. in Indien. Palæontographica, Suppl. III, Lieferung III, Heft Ir. Cassel, 1877 .

50. - Jurassic (Liassic) Flora of the Rajmahal Group from Golapili, near Ellore, Scuth Godavari, Fossil Flora of Gondwana System. Vol. 1. Calcutta, 1877, pp. 163-190, pl. i-viii. Palrentologica Indica, ser. II, pt. III.

5I. - Flora of the Jabalpur Group (Upper Gondwanas) in the Son-Narbada Region, Fossil Flora of the Gondwana System. Vol. I1, pt. Ir. Calcutta, 1877, pp. 8I-I05, pl. i-xiv. Palrontologica Indica, ser. xi.

52. - Upper Gondwana Flora of the Outliers on the Madras Coast, Fossil Flora of Gondwana Syster.. Vol. I, pt. Iv. Calcutta, r879, pp, I9I-224. pl. i-xvi. Palxontologica Indica, ser. Ir. 
53. FELIX, J. Untersuchungen über den Versteinerungsprocess und Erhaltungszustand pflanzlicher Membranen. Zeitschr.d. deutsch. geol. Ges., vol. XLxx, Berlin, 1897, pp. I82-192.

54. Fontaine, W. M. The Potomac or Younger Mesozoic Flora. Pt. I, text; pt. II, plates. Monographs of the U. S. Geol. Survey, vol. xv, Washington, x889.

55. Frank, B. Ueber die Gummibildung im Holze und deren physiologische Bedeutung. Berichte d. Deutsch. Bot. Ges,, vol. II, Berlin, I884, pp. 32I-334. Botanisches Centralblatt, vol. $\mathrm{xx}$, I884, pp. I94-196.

56. FUyı, K. On the Different Views hitherto proposed regarding the Morphology of the Flowers of Ginkgo biloba. Bot. Mag. Tokio, vol. x, Tokio, I896, pp. 7, I5-25, IO4-I10, pl. I.

57. Goeber, K. Outlines of Classification and Special Morphology of Plants. A new edition of Sachs Text-Book of Botany. Book II. Authorized English translation by Henry E. F. Garnsey and Isaac Bayley Balfour. Oxford, I887.

58. - Beiträge zur vergleichenden Entwickelungsgeschichte der Sporangien. Botanische Zeitung, xxxvin Jahrg., Leipzig, I880, col. 545-552; 56I575; Jahrg. xxxix, col. 681-694; 697-706; 713720.

59. - Organography of Plants, especially of the Archegoniatæ and Spermaphyta. Authorized English edition by Isaac Bayley Balfour. Part I. Oxford, Igoo.

6o. Göppert, H. R. Ueber die Fossilen Cycadeen überhaupt mit Rücksicht auf die in Schlesien vorkommenden Arten. Uebersicht der Arbeiten und Veränderungen der Schles, Ges. für Vaterl. Cultur. Breslau, 1844 , pp. II $4^{-144 .}$

61. - Ueber die gegenwärtigen Verhältnisse der Palæontologie in Schlesien so wie über Fossile Cycadeen. Ibid. Jubiläums Denkschrift, I844, pp. $25 \mathrm{I}-265$, pl. vII $-\mathrm{X}$.

62. - - und Stenzel, G. Die Medullosex. Eine neue Gruppe der Fossilen Cycadeen. Palxontographica, vol. XxvirI, Cassel, I88I, pp. III-I27, pl. xiv-xvii.

63. Grand 'Eury, Cyrille. Flore Carbonifère du département de la Loire et du centre de la France (étudiée aux trois points de vue, botanique, stratigraphique et géognostique). Mémoires présentés par divers Savants à l'Académie des Sciences de l'Institut de France, vol. XXIv, Paris, I877.

64. GREGG, M. H. Anomalous Thickening in the Roots of Cycas Seemanni, Al. Braun. Annals of Botany, vol. I, London, I887, pp. 63-7o, pl.v.

64c. Hatcher, J. B. Osteology of Haplocanthosaurus, with Description of a New Species, and Kemarks on the Probable Habits of the Sauropoda and the Age and Origin of the Atlantosaurus Beds. Memoirs of the Carnegie Museum, vol. 2, No. I, November, I903, pp. I-75, pi. I-vi.
65. Heer, O. Flora Fossilis Arctica. Vols. 1-vir. Zurich and Winterthur, 1868-1883. (Vol. Ir, Winterthur, 187I.)

66. Hirasḱ, S. On the Spermatozoid of Ginkgo biloba. Bot. Mag. of Tokio, vol. X, p. 325, October 20 , 1896 (in Japanese).

67. E- Etudes sur la fécondation et l'embryogénie du Ginkgo biloba. Jour. Coll. Sci., Imperial Univ., Tokyo, vol. vir, Tokyo, 1895, pp. 307-322, pl. xxxi, xxxii ; (second Mémoire), vol. xu, Tokio. 1898, pp. 103-149, pl. vii-ix.

68. HoOKer, J. D., and JACKSON, 13. D. Index Kewensis Plantarum Phanerogamarum, etc. In two volumes. Oxford, 1895 .

69. IкExo, S. Untersuchungen über die Entwickelung der Geschlechtsorgane und den Vorgang der Befruchtung bei Cycas revoluta. Jahrbücher f. wiss. Botanik, Band xxxr, Heft 16 , Leipzig, I898, pp. 557-600, pl. vi.i-x.

70. Juranyt, L. Ueber den Bau und die Entwickelung des Pollens bei Ceratozamia longifolia Mi . Jahrbücherf. wiss. Bot., vol. vir, Berlin, IS72, pp. 382-40o, pl. xxxi-xxxiv.

7x. KarsteN, H. Organographische Betrachtung der Zamia muricata Willd. Abh. K. Akad. Wiss. zu Berlin, 1856, pp. 193-219, pl. i-iii.

72. Kerner von Marilaun, ANtos. Pflanzenleben. Zweite neubearbeitete Autlage. Leipzig. Is g6.

$72 \alpha$. KNorR. (See Walch, I6ga.)

73. KraUS, Gregor. Über Blütenwärme bei Cycadeen, Palmen und Araceen. Annales du Jardin botanique de Buitenzorg, vol. xin, Leide, ISg6, pp. 2x7-275, pl. xviii--sx.

74. KüuN, R. Untersuclungen über dic Anatomic der Marattiaceen und anderer Gefässkryptogamen. Flora, or Allg. But. Zeit., Jahrg. Lxisi, pp. 457-504, pl. xviii-xx.

75. LANG, William $H$. Studies in the Development and Morphology of Cycadean Sporangia. Annals of Botany, vol. xi, No. 43, London, September, I897, pp. $42 \mathrm{I}-43$ S, pl. xxii.

76. - Studies in the Development and Morphology of Cycadean Sporangia. Pt. Ir. The Ovule of Stangeria paradoxa. Annals of Botany, vol. xw, No. 54, London, June, I900, pp. $2 S i-306$, pl. xvi.

77. Lesquereux, Leo. Contributions to Fossil Flora of the IVestern Territories. Pt. Is. The Tertiary Flora. Report of the United States Geological Survey of the Territories. Vol. VH. Washingtou, $\mathrm{IS}_{7} \mathrm{~S}$. (Zamiostrobus mirabilis described on p. 70, and figured on pl. Ixiii, figs. 1, I $\imath_{0}$ )

78. LIFE, . C. The Tuber-like Roots of Cycas revoluta, Botanical Gazette, vol. xxx1, Chicago, 1901, pp. 265-271. 
79. Lignier, O. De l'emploi de la vésuvine dans l'étude de végétaux fossiles. Bull. Soc. Linnéenne de Normandie, 4e sér., vol. VI, Caen, I892, pp. 9-ro.

80. - A propos de la Forme des Bractées involucrales chez le "Williamsonia Morierei" Sap. et Mar. Association Française pour l'Avancement des Sciences. Compte rendu de la $22 \mathrm{me}$ session, Besançon, 1893. Seconde partie, Notes et Extraits, Paris, I894, pp. $45^{8-460 .}$

8I. - La Nervation des Cycadacées est dichotomique. Ibid., 23mesession. Caen, I894: Seconde partie, Notes et Mémoires, Paris, 1895, pp. 625627 .

82. - Végétaux fossiles de Normandie. Structure et Affinités du Bennettites Morierei Sap. \& Mar. (sp.). Mémoires de la Soc. Linnéenne de Normandie, vol. xvir, pp. 5-78, pl. i-vi, Caen, 1894.

83. - La Nervation Tæniopteridée des Folioles de Cycas et le Tissu de Transfusion. Bulletin de la Soc. Linnéenne de Normandie, 4e sér., vol. vi, Caen, 1892, pp. 65-71.

84. - Végétaux Fossiles de Normandie. III. Etude Anatomique du Cycadeoidea micromyela Mor. Mémoires de la Soc. Linnéenne de Normandie, vol. $\mathrm{xx}, \mathrm{pp} .329-370, \mathrm{pl}$. xii, Caen, I9or.

85. — Le Fruit du Williamsonia gigas Carr. et les Bennettitales. Documents nouveaux et notes critiques. Mémoires de la Soc. Linnéenne de Normandie, vol. XxI, pp. I7-56, Caen, I9o3.

86. — Equisétales et Sphénophyllales. Leur origine filicinéenne commune. Bulletin de la Soc. Linnéenne de Normandie, 5e série, vol. vir, Caen, 1903, pp. 93-137.

$86 \alpha$. Notes complémentaires sur la structure du Bennettites Morierei Sap. et Mar. Bulletin de la Soc. Linnéenne de Normandie, 5e série, vol. vir, Caen, I904, pp. 3-7, with 3 textfigures.

87. Lindley, John, and Hutton, W. Fossil Flora of Great Britain. 3 vols. London, I83I-I837.

$87 \alpha$, LYON, Harold L. The Embryogeny of Ginkgo. Minn. Bot. Studies. 3d ser,, vol. III, Part IIr, Minneapolis, October, I904, pp. 275-290, pl. xxix-xliii.

88. Macbride, 'T. Y. A New Cycad. American Geologist, vol. xII, Minneapolis, October, 1893, pp. 248-250, pl. xi.

89. Mantell, G. A. The Medals of Creation. Two vols. London, I844.

90. Marsh, O.C. The Jurassic Formation on the Atlantic Coast. Amer. Jour. Sci., $4^{\text {th }}$ series, vol. vi, Supplement to No. 32, New Haven, August, 1898, pp. II5-II6.

91. Cycad Horizons in the Rocky Mountain Region. Amer. Jour. Sci., 4th series, vol. vi, New Haven, August, 1898 , p. 197.
92. Mettenius, G. Beiträge zur Anatomie der Cycadeen. Abhandlungen der K. Sächsischen Ges. der Wiss., vol. vir, Math.-phys. Classe, vol. v, Leipzig, I86r, pp. 565-608, pl. i-v.

93. Mrguel, F. A. W. Monographia Cycadearum. Utrecht, 1842 .

94. - Ueber den Bau eines Erwachsenen Stammes von Cycas circinalis. Linnæa, vol. xvin, Halle, I844, pp. I25-144, pl. iv-vi.

95. MiYAKE, K. On the Development of the Sexual Organs and Fertilization in Picea excelsa. Annals of Botany, vol. xvir, No.66, London, March, 1903, pp. 351-372, pl. xvi, xvii.

96. Moril, H. von. Ueber den Bau des Cycadeenstammes und sein Verhältniss zu dem Stamme der Coniferen und Baumfarn. Abhandl. d. math.phys. Cl. d. k. bayerischen Akad. d. Wiss., vol. I, München, I832, pp. 397-442, pl.xviii.

97. Moore, Charles. Notes on the Genus Macrozamia. Jour. \& Proc. Roy. Soc. N. S. IV. for I883, vol. XviI, Sydney, I884, pp. II 5-I22.

98. Morière, J. Note sur deux végétaux fossiles trouvés dans le département du Calvados. Mémoires de la Soc. Linnéenne de Normandie, vol. xv, No. 7 , Caen, r869, pp. I-4, pl, i, ii.

99. MORris, J. See No. IO5.

I0o. Nathorst, A. G. Năgra anmärkningar om Williamsonia, Carruthers. Öfv. K. Vet.-Akad. Förh., No. 9, Stockholm, r88o, pp. 33-52, pl. vii-x.

ıог. - Nya anmärkningar om Williamsonia. Öfv. K. Vet.-Akad. Förh., No. 6, Stockholm, June, I888, pp. 359-365.

102. - Zur Fossilen Flora der Polarländer. Erster Teil. Dritte Lieferung: Zur Oberdevonischen Flora der Bären-Insel. Kongl. Svenska Vet.Akad. Handl., vol. xxxvi, No. 3, Stockholm, r9o2, pp. I-6o, pl. i-xv.

103. - Beiträge zur Kenntniss einiger Mesozoischen Cycadophyten. Kongl. Svenska Vet. Akad. Handl., vol. xxxvi, No. 4, Stockholm, 1902, pp. I-28, pl. i-iii.

104. Nestler, A. Ein Beitrag zur Anatomie der Cycadeenfiedern. Jahrbuicher für wiss. Botanik, vol. xxvir, Berlin, I895, pp. 34I-368, pl. xi-xiv.

I05. Oldham, T., and Morris, J. Fossil Flora of the Rajmahal Series in the Rajmahal Hills. Fossil Flora of the Gondwana System, vol. 1, pt. I, Calcutta, I863, pp. I-52, pl. i-xxxv. Palxontologica Indica, ser. $\mathrm{n}$.

ro6. Oliver, F, W., and Scott, D. H. On Lagenostoma Lomaxi, the Seed of Lyginodendron. Proc. Roy. Soc. London, vol. Lxxi, London, May 7, 1903, pp. 477-48I.

107. Oliver, F. W. The Ovules of the Older Gymnosperms. Annals of Botany, vol. xvir, No. 67. London, June, 1903, pp. 45I-476, pl. xxis. 
ro8. Oliver, F.W. Notes on Trigonocarpus, Brongn. and Polylophospermum, Brongn., two Genera of Palæozuic seeds. New Phytolugist, vol. 11, No. 4, London, April, 1904, pp. 96-104, pl. ii.

rog. - and Scotr, D. H. On the Structure of the Palæozoic Seed, Lagenostoma Lomaxi, with a Statement of the Evidence upon which it is referred to Lyginodendron. Phil. Trans. Roy. Soc. London, Ser. B, vol. cxcvir, London, 1904, pp. 193-247, pl. iv-x.

Ixo. Pearson, H. H. W. Anatomy of the Seedling of Bowenia spectabilis Hook. f. Annals of Botany, vol. xil, London, December, 1898 , pp. 475490, pl. xxvii, xxviii.

III. Penhallow, D. P. Notes on the North American Species of Dadoxylon, with special reference to Type Material in the Collection of the Peter Redpath Museum, McGill College. Trans. Roy. Soc. Canada, second series, rgoo-rgor, Section IV, Ottawa، I900, pp. 5I-97.

II2. Potoní, H. Die Fossile Pflanzen-Gattung Tylodendron. Jahrbuch d. preuss. Geol. Landesanst. u. Bergakademie, Berlin, I887, pp. 31 r33I, pl. xii, xiii, xiii $r$.

II2\%. - Bennettitaceæ. In Engler und Prantl: Die natürlichen Pflanzenfamilien. Nachträge zu Teil II-IV, Leipzig, I897, pp. I4-I7.

r 2 2b. - Fossile Gattungen der Angiopteridex. In Engler und Prantl: Die natürlichen Pflanzenfamilien. I. Teil, 4. Abteilung, Leipzig, rgoo, pp. $439-440$.

II2c. — Fossile Marattiales. Ibid., pp. 444-449.

I13. - Lehrbuch der Pflanzenpalæontologie. Mit besonderer Rücksicht auf die Bedürfnisse des Geologen. Berlin, I897-1899.

II4. Raciborski, M. Cycadeoidea Niedzwiedzkii. Rozprawy Wydzialu matematyczno-przyrodniczego, vol. xxvi, Krakow, I893, pp. 301-310, pl. vii, viii ; German résumé in Bull. Intern. de l'Acad. Sci. de Cracovie. Comptes rendus des séances de l'année I892, Cracovie, I893, pp. 355-359.

II 5. Renault, B., et Grand 'Eury, C. Recherches sur les végétaux silicifiés d'Autun. Étude du Sigillaria spinulosa. Mémoires présentés par divers Savants à l'Académie des Sciences de l'Institut de France, vol. xxII, No. 9, Paris, I876.

I16. - Recherches sur les végétaux silicifiés d'Autun. Etude du genre Myelopteris. Ibid., No, Io, Paris, 1876.

I17. - Cours de Botanique Fossile fait au Muséum d'Histoire naturelle. Paris, Année I (I88I). II (r882), iII (r883), iv (r885).

118. - Recherches sur les Bactériacées rossiles. Annales des Sciences Naturelles, 8e sér., vol. II, Botanique, Paris, 1895, pp. 275-349.

119. - Sur quelques Fougères hétérosporées. Comptes Rendus de l'Acad. d. Sci., vol. cxxxin, No. I7. Paris, 21 octobre 19о1, pp. 648-65I.
120. - et Zerlegr, R. Etude sur le Terrain Houiller de Commentry, Flore Fossile. Liv. II, Text $8^{\circ}$, Atlas fol. Saint-Étienne, I888-1890.

I $2 \mathrm{r}$. - and Betrasd, C. E. See No. 3.

122. Richard, L. Cl. Commentatio botanica de Coniferis et Cycadeis, etc. fol., xv + 282 pp.. 30 plates. Stuttgart, 8826 .

123. RobertSo:, Ag.ses. Notes on the Anatomy of Macrozamia heteromera, Moore. Proc. Cambridge Phil. Soc., vol. xir, Cambridge, 1904, pp. I-15.

124. SAchs, Julius. A Text-book of Botany, Morphological and Physiological. Translated and annotated by Alfred W. Bennett and W. T. Thiselton Dyer. Oxford, 1875 .

125. Saporta, le Comte G. DE. Palæontologie française. 2e sér. Végétaux. Plantes jurassiques. Vol. 1. Cycadées, Paris, 1873-1875; vol. Wv, Paris, I886-189r.

r26. - et MARION, A. F. Sur les Genres Williamsonia Carruth. et Goniolina r'Orb. Comptes Rendus des séances de l'Acad. des Sci. de Paris, vol. Xcr, Paris, r88r, pp. II85-r188.

127. — L'Évolution du Règne végétal. Les Cryptogames. Paris, 188 I. Les Phanérogames. 2 vols. Paris, 1885.

128. Schenk, A. Die Fossilen Pflanzenreste. Breslau, I888. $8^{\circ}$.

129. - Ueber Medullosa Cotta, und Tubicaulis Cotta Abh. d. K. Sächs. Ges. der Wiss., Math.-phy's. Cl., vol. xv, Leipzig, I889, pp. 522-55S, pl. i-iii.

гzo. Schimper, W. PH. Palæophytologie. In Zittel: Handbuch der Palæontologie, München u. Leipzig, I880, Cycadacex, pp. $21 \mathrm{I}-232$, figs. $158-166$.

131. - Traité de Paléontologie Végétale, Paris. Text, $8^{\circ}$, vol. I (1869). II (1870-72), III (1874). Atlas, fol., 1874 .

132. ScotT, D. H. The Anatomical Characters presented by the Peduncle of Cycadacere. Annals of Botany, vol. XI, London, September, 1897, pp. 3994I9, pl. $\mathrm{xx}_{\text {, xxi. }}$

133. - On the Structure and Affinities of Fossil Plants from th" Palrozoic Rocks. III. On Medullosa anglica, a New Representative of the Cycadofilices. Phil. Trans. Roy. Soc. London, vol. cxcr, London, IS99, pp. Si-126, pl. v-xiii.

134. - On the Primary Wood of Certain Araucarioxylons. Annals of Botany, vol. xis, Sio. 52. London, December, rS99, pp. 6r5-6rg.

135. - Studies in Fossil Botany. Lundon, 1900. $\mathrm{S}^{\circ}$. 136. - Germinating Spores in a Fossil Fera-Sporangium. The New thytologist, vol. \$n, No. r. London, January, 1904, pp. 15-23, figs. 60, 6I.

137. - - The Early History of the Seed-bearing Plants, as recorded in the Carboniferous Flora. Mem. and Proc. Manchester Lit. and Phil. Soc., vol. Xlix, Part 11,, No. I2, Manchester, May 15, 1905, pp. I-32, pl. i-iii.

138. - See Oliver and Scott, also Williamson and Scott. 
r39. Sellards, E. H. Codonotheca, a New Type of Spore-bearing Organ from the Coal Measures. Amer. Journ. Sci., $4^{\text {th }}$ ser., vol. Xvi, No. 9I, New Haven, July, I903, pp. 87-95, pl. viii.

I 40. Seward, A. C. Tylodendron Weiss, and Voltzia heterophylla Brongn. Geol. Mag., Decade III, vol. VII, London, I89o, pp. 218-220.

I4I. - On the Genus Myeloxylon (Brongn.). Annals of Botany, vol. vir, No. 25, London, I893, pp. I-20, pl. i, ii.

142. - Some New Facts with regard to Bennettites. Nature, vol. L, London, I894, pp. 594-595.

r43. - Catalogue of the Mesozoic Plants in the Department of Geology, British Museum (Natural History). The Wealden Flora. Pt. II. Gymnospermæ. London I895.

I 44. - On Cycadeoidea gigantea, a new Cycadean Stem from the Purbeck Beds of Portland. Quart. Journ. Geol. Soc. London, vol. LIII, London, February, I897, pp. 22-39, text-figures I-4, pl. $\mathrm{i}-\mathrm{v}$.

145. - On the Leaves of Bennettites. Proc. Cambridge Phil. Soc., vol. Ix, pt. v, March 8, Cambridge, I897, pp. 273-277.

r46. - On Encephalartos Ghellinckii Lem., a rare Cycad. Proc. Cambridge Phil. Soc,, vol. Ix, Cambridge, 1898 , pp. 340-344.

147. - Fossil Plants for Students of Botany and Geology. Vol. I. London, 1898 .

I48. - and Gowan, (Miss) J. The Maidenhair Tree (Ginkgo biloba L.). Annals of Botany, vol. XIV, No. 53, London, March, I90o, pp. Io9-I54, pl. viii-x.

I49. - Catalogue of Mesozoic Plants in the Department of Geology, British Museum (Natural History). Jurassic Flora of Yorkshire. London, rgoo.

I50. - Occurrence of Dictyozamites in England, with Remarks on European and Eastern Mesozoic Floras. Quart. Journ. Geol. Soc., vol. LIX, London, May, I903, pp. 2I7-233, pl, xv.

I51. - Floras of the Past : their Composition and Distribution. Address to the Botanical section, Report of the seventy-third meeting of the British Association for the Advancement of Science, Southport, I903; London, I904, pp. 824-849.

152. - Catalogue of the Mesozoic Plants in the Department of Geology, British Museum (Natural History). The Jurassic Flora. II. Liassic and Oölitic Floras of England (excluding the inferior Oölite Plants of the Yorkshire Coast). London, I904.

I53. Strove, R. F. (Miss). On the structure of the Stem of Angiopteris evecta. Annals of Botany, vol. xIv, No. 55, London, September, I90o, pp. 497$525, \mathrm{pl}$. xxviii, xxix.

I54. Sмiтн, J. Observations on a remarkable Cycadaceous Plant from Port Natal. Hooker's Journal of Botany and Kew Garden Miscellany, vol. vi, London, 1854, pp. 88-9o.
I55. Solms-Laubach, H. Graf zu. Die Sprossfolge der Stangeria und übrigen Cycadeen. Bot. Zeitung, xlviii Jahrg., Leipzig, I89o, pp. I78-187: I94-199; 210-215; 226-230, pl. ii.

156. - Ueber die Fructification von Bennettites Gibsonianus Carr. Botanische Zeitung, vol. XLvIrr, Leipzig, I89o, col. 789-798; 805-8I6; 82I-833; $843-847, \mathrm{pl}$. ix, $x$. Translated in Annals of Botany, vol. v, London, November, I8gr, pp. 4I9-454, pl. xxv, xxvi.

157. - Fossil Botany. Being an Introduction to Palæophytology from the standpoint of the Botanist. The authorized English translation by E. F. Garnsey, revised by Isaac Bayley Balfour. Oxford, I89I.

i58. Solms-Laubach, Conte E., and Capellini, G. See No. 22.

I59. Solms-Laubach, H. Graf zu. Ueber Medullosa Leuckarti. Botanische Zeitung, Jahrg. lv, Heft $\mathrm{x}$, Leipzig, I897, pl. 175-202, pl.v, vi.

I6o. Stark, J. On the Shedding of Branches and Leaves in Coniferx. Trans. Roy. Soc. Edinburgh, vol. xxvir, Edinburgh, I876, pp. 651-66o, pl. xliv.

i6I. Stopes, Marie C. On the Leaf Structure of Cordaites. The New Phytologist, vol. II, Nos. 4 and 5, London, April and May, 1903, pp. 9r98, pl. ix.

I62. - Beiträge zur Kenntniss der Fortpflanzungsorgane der Cycadeen. Flora oder Allg. Bot. Zeitung, vol. XcIII, Regensburg, I904, pp. 435482.

i63. Strasburger, Dr. Eduard. Ueber Scolecopteris elegans Zenk., einen fossilen Farn aus der Gruppe der Marattiaceen. Jenaische Zeitschrift für Naturw., N. F., vol. vin, Jena, I874, pp. 8I-95, pl. ii, iii.

I64. Stur, D. Die Carbon-Flora der Schatzlarer Schichten. Abhandlung der Kais, Königl. Geologischen Reichsanstalt, vol. xI, Abth. i, WVien, 1885 .

I65. Thiвout, E. Ire Thèse. Recherche sur l'Appareil Mâle des Gymnospermes. Lille, I896, pp. I-235, pls. i-xvi.

166. Thiselton-Dyer, Sir W. T. On a New Species of Cycas from Southern India. Trans. Linn. Soc., 2 d ser., Bot., vol. II, London, I883, pp. 85-86, pl. xvii.

I67. - Morphological Notes. III. The Carpophyll of Encephalartos. Annals of Botany, vol.xv, No. 59, London, September, r9or, pp. 54S-550.

$I 67 \alpha$. Thompson, R. B. The Megaspore Membrane of the Gymnosperms. University of Toronto Studies. Biological Series No. 4. The University Library, Toronto, 1905,64 pp., 5 plates. $8^{\circ}$.

I67〕. Trevb, M. Recherches sur les Cycadées. Annales du Jardin Botanique de Buitenzorg, vol. II, Leide. I885, pp. 32-53, pl. i-vii. 
167c. TReUb, M. Recherches sur les Cycadées. Embryogénie du Cycas circinalis. Ibid., vol. Iv, Leide, I884, pp. I-II, pl. i-iii.

I68. Tyson, Philip. Report, State Agricultural Chemist to the House of Delegates of Maryland. Annapolis, 1860 .

I69. Van Tieghem, PH. Recherches sur la symétrie de structure des Plantes Vasculaires. Ann. Sci. Nat, Botanique, 5e ser., vol. xirr, pp. 5-3I4, pl. iii-viii. (Cycadées, pp. 204-2II.)

i6ga. Walch, Ernst Immanuel. Die Naturgeschichte der Versteinerungen zur Erläuterung der Knorrischen Samlung von Merkwürdigkeiten der Natur. Nürnberg, Erster Theil, I773; Zweyter Theil, Erster Abschnitt, I768, Zweyter Abschnitt, I769; Dritter Theil, I77I; Vierter Theil, I773. When preceded by a fascicle of 36 pp. by Knorr (Nürnberg, I755), and accompanied by a separate atlas, known as Knorr and Walch.

I70. Uard, Lester F. Fossil Cycadean Trunks of North America, with a Revision of the Genus Cycadeoidea Buckland. Proc. Biol. Soc. Washington, vol. Ix, Washington, Apr. 9, I894, pp. 75-87.

I7I. - The Cretaceous Rim of the Black Hills. Journal of Geology, vol. II, Chicago, AprilMay, I894, pp. 250-266.

r72. - Recent Discoveries of Cycadean Trunks in the Potomac Formation of Maryland. Bull. Torr. Bot. Club, vol. xxi, No. 7, New York, July 20, I894, pp. 29I-299.

173. - Some Analogies in the Lower Cretaceous of Europe and America. Sixteenth Annual Report of the U. S. Geological Survey, Pt. I, Washington, I896, pp. 463-542, pl. xcvii-cvii.

174. Descriptions of the Species of Cycadeoidea, or Fossil Cycadean Trunks, thus far discovered in the Iron Ore Belt, Potomac Formation, of Maryland. Proc. Biol. Soc. Washington, vol.xI. Washington, March I3, I897, pp. I-I7.

I75. - Descriptions of the Species of Cycadeoidea, or Fossil Cycadean Trunks, thus far determined from the Lower Cretaceous Rim of the Black Hills. Proc. U. S. Nat. Museum, vol. Xxi, Washington, 1898, pp. 195-229.

I76. - The Cretaceous Formation of the Black Hills as indicated by the Fossil Plants (with the collaboration of Walter P. Jenney, IVm. M. Fontaine, and F. H. Knowlton). Nineteenth Ann. Rep. U. S. Geol.' Survey, Pt. II, Washington, I899, pp. 52I-958, pl. 1vii-clxxii.

177. - Description of a New Genus and Twenty New Species of Fossil Cycadean Trunks from the Jurassic of Wyoming. Proc. IVashington Acad. Sci., vol. I, Washington, Feb. 14, 1900, pp. 253-300.
178. - Status of the Mesozoic Floras of the United States. First Paper: The Older Mesozoic. 'Twenticth Annual Report of the U. S. Geol. Survey, Pt. II, Washington, 1900, pp. 2II748, pl. xxi-clxxix.

179. - Elaboration of the Fossil Cycads in the Yale Museum. Am. Jour. Sci., th ser. New Haven, Nov., r9o0, pp. 327-345, pl. ii-iv.

180. - A Famous Fossil Cycad. Am. Jour. Sci.

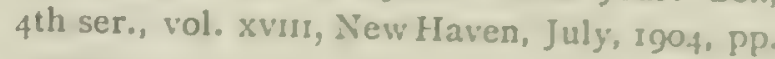
40-52.

180a. - Status of the Mesozoic Floras of the United States, Second Paper. Monographs of the $U$. S. Geological Survey, vol, xLvm. Part I, Text: Part II, Plates. Washington, 1905.

I8I. Warming, E. Bidrag til Cycrdeernes Naturhistorie. Contributions à l'histoire naturelle des $\mathrm{Cy}^{\prime} \mathrm{ca}$ dées, 1879 .

182. - A Handbook of Systematic Botany, with a revision of the Fungi by Dr. E. Knoblauch. Translated and edited by M. C. Potter, I.ondon, 1895 .

183. Webber, Herbert J. Peculiar Structures occurring in the Pollen :Tube of Zamia. Botanical Gazette, vol. xxı1, Chicago, June, 1897, pp.453$459, \mathrm{pl} . \mathrm{xl}$

184. - The Development of the Antherozoids of Zamia. Botanical Gazette, vol. xxw, Chicago, July, I897, pp. I6-22.

185. - Notes on the Fecundation of Zamia and the Pollen Tube Apparatus of Ginkgo. Botanical Gazette, vol. XxIv, Chicago, October, IS97, pp. 225-235, pl. $x$.

186. - Spermatogenesis and Fecundation of Zamia, U.S. Dept. of Agric., Bureau of Plant Industry: Bull. No. 2, Washington, December 2S, Igor.

r86 $\alpha$. White, David. The Seeds of Aneimites. Smithsonian Miscellazeous Collections, Quarterly. Issue, vol. xLvu, Part III, Washington. Dec. Io, I904, pp. 322-33I, pl. xlvii-:-lviii.

I86b. - Fossil Plant; of the Group Cycadofilices. Smithsonian Miscellaneous Collections, vol. xLvi, Part III, Washington, March 2, 1905. pp. 377-390, pl. liii-ls.

I87. Wieland, G. R. A Study of Some American Fossil Cycads. Pt. I. The Male Flower of Cycadeoidea. Am. Journ. Sci., fth ser., vo!. VII. New Haven, March, IS99, pp. 2I9-226, pl. ii-it:

I88. - A Study of Some American Fossil Crcads. Pt. II. The Leaf Structure of Cycadeoiden. Ibid., April, ISg9, pp. 305-30S, pl. vii.

rSg. - A Study" of American Fossil Cycads. Pt. III. The Female Fructification of Cycadeoidea. Ibid., May, IS99, pp. 3\$3-39r, pl. viii-x.

190. - Cycadean Monccism. Ibid., vol. vu, New Haven, August, IS99, p. sóq. 
Igr. Wieland, G. R. The Yale Collection of Fossil Cycads. Yale Scientific Monthly, vol. vi, No. 6 , New Haven, March, I900, pp. 21 I-22I, pl. i.

192. - A Study of Some American Fossil Cycads. Pt. IV. On the Microsporangiate Fructification of Cycadeoidea. Am. Journ. Sci., 4th ser., vol. XI, New Haven, June, rgor, pp. 423-436.

193. - Notes on Living Cycads. I. On the Zamias of Florida. Am. Journ. Sci., $4^{\text {th }}$ ser., vol. XIII, New Haven, May, 1902, pp. 33I-338.

194. - On the foliage of the Jurassic Cycads of the genus Cycadella. Monographs of the U.S. Geological Survey, vol. xLVIII, pp. I98-203, pl. lxii, lxiii.

195. - Jurassic Cycads from the Black Hills. Ibid., pp. 203-207.

196. - Notes on the Stratigraphy and Paleontology of the Black Hills Rim. Ibid., pp. 317-325, pl. Ixxiii [figure I5].

197. - Cycads. Encyclopedia Americana, vol. v, New York, 1903.

198. - Polar Climate in Time the Major Factor in the Evolution of Plants and Animals. Am. Journ. Sci., $4^{\text {th }}$ ser., vol. xvi, New Haven, December, 1903, pp. 40I-430.

199. - The Proembryo of the Bennettitex. Am. Journ. Sci., $4^{\text {th }}$ ser., vol. Xvili, New Haven, December, I904, pp. 445-447, pl. xx.

200. Wrlliamson, W. C. On the Distribution of Fossil Remains on the Yorkshire Coast, from the Lower Lias to the Bath Oölite inclusive. Trans. Geol. Soc. London, 2d ser., vol. v, London, I837, pp. 223-242.

201. On the Scaly heads or collars from Runswick Bay, supposed to belong to Zamia gigas. Proc. Yorkshire Phil. Soc., Part I, vol. I, London, r 849 , pp. 45-5r.

202. - Contributions towards the History of Zamia gigas Lindl. \& Hutton. Trans. Linn. Soc. London, vol. xxvı, London, I870, pp. 663-674, pl. lii, liii.

203. - On the Organisation of the Fossil Plants of the Coal Measures. Pt. XIV. The True Fructification of Calamites. Phil. Trans. Roy.Soc. London, vol. cLxxix, London, I888, pp. 4757, pl. viii-xi.

204. - and ScotT, D. H. Further Observations on the Organization of the Fossil Plants of the Coal Measures. Pt. III. Lyginodendron and Heterangium. Phil. Trans. Roy. Soc. London, vol. CLxxxvi (1895) B, London, I895, pp. 703779. pl. xviii-xxix.

204a. Williston, M. W. The Hallopus, Baptanodon, and Atlantosaurus Beds of Marsh. Journal of Geology, vol. xin, No. 4, Chicago, May-June, 1905, pp. 339-350.
205. Worsdell, W. C. The Anatomy of the Stem of Macrozamia compared with that of other Genera of Cycadeæ. Annals of Botany, vol. $x$, No. 40, London, December, 1896, pp. 60I-620, pl. xxvii, xxviii.

206. - On Transfusion Tissue. Its origin and function in the leaves of Gymnospermous plants. Trans. Linn. Soc. London, 2d ser., Bot., vol. v, Pt. VIII, London, December, 1897, pp. 3or319, pl. xxiii-xxvi.

207. - The Vascular Structure of the Sporophylls of Cycadacex. Annals of Botany, vol. XII, No. 46, London, June, 1898, pp. 203-24I, pl. xvii, xvini.

208. The Comparative Anatomy of certain Genera of the Cycadacex. Jour. Linn. Soc. London, Botany, vol. xxxir, London, July I, I898, pp. 437-457, pl. $x x$.

209. - Observations on the Vascular System of the Female Flowers of Coniferæ. Annals of Botany, vol. XIII, No. 52, London, December, 1899 , pp. 527-548, pl. xxvii.

2I0. - The Structure of the Female Flower in Coniferæ. An Historical Study. Annals of Botany, vol. xiv, No. 53, London, March, Igoo, pp. $39-82$.

2II. The Anatomical Structure of Bowenia spectabilis Hook. Annals of Botany, vol. xiv, No. 53, London, March, I900, pp. I59-16o.

212. - The Vascular Structure of the Ovule of Cephalotaxus. Annals of Botany, vol. xrv, No. 54, London, June, I9oo, pp. 3I7-318.

213. - The Affinities of the Mesozoic Fossil, Bennettites Gibsonianus, Carr. Annals of Botany, vol. XIV, No. 56, London, December, I900, pp. 7 I 7-72I.

214. Zeiller, R., et Renault, B. See No. i2O.

2I5. ZEILler, R. Paléontologie végétale. (Ouvrages publiés en I892.) Annuaire géolog. univ., vol. IX, Année 1892, Paris, I893-94, pp. III-116, 935-975.

216. - Éléments de Paléobotanique. Paris, I9oo.

217. - Revue des Travaux de Paléontologie Végétale, publiés dans le cours des années 1897-1900. Revue Générale de Botanique, vol. xrv, 1902 , pp. 427-435 ; 487-496; 539-543; vol. xv, I903, pp. $39^{-48} ; 83^{-89}$; I25-I 39; I 86-I $92 ; 235^{-240}$; $328-336$; $393-400 ; 470-480$.

218. Zeiller, R., et Fliche, P. Découverte de Strobiles de Sequoia et de Pin dans le Portlandien des ervirons de Boulogne-sur-Mer. Comptes rendus des séances de l'Acad. Sci., vol. cxxxvir, 14 décembre 1903, pp. I020-1022.

219. ZIGNu, A. Flora fossilis formationis Oölithicx. vol. 11 . Padova, I873-I885. 


\section{DESCRIPTION OF ILLUSTRATIONS.}





\section{DESCRIPTION OF PLATES.*}

Frontispiece-Longitudinal and transverse sections of bisporangiate strobili and ovulate cones of Cycadeoidea in natural size and (approximate) color.

Photographs I and 4, C. dacotensis; photograph 2, C. dacotensis (?); photograph 3 , C. Wielandi. No. I is from a longitudinal section of a bisporangiate strobilus belonging to the collection of the State University of Iowa. No. 2 is from the longitudinal section through an ovulate strobilus numbered 353 in the Yale Museum Cycad Section List. No. 3 is the transverse section 393 of two adjacent ovulate cones, and No. 4 the transverse section $48 \mathrm{I}$ of a bisporangiate strobilus.

\section{Plate I. Cycadeoidea ingens (type). $\times 0.25$.}

The type specimen, No. 100 of the Yale collection. From locality at southern end of the Cycad Valley in the eastern "Rim" of the Black Hills, shown in-photngraph 2, plate XLIX. This magnificent cycadean trunk is preserved as a huge block of light-gray silica, somewhat elliptical in transverse section, and weighing 304 kilograms ( 671 pounds). At the summit, as marked by the horizontal arrow on the left of the photograph, the bisporangiate flower bud illustrated in the succeeding plates II and III appears as seer in its original natural position before removal for sectioning. To the right other lines (six in number) indicate the position of the peduncles, $p, p$, of still other floral axes, synangia being present in one instance, $s$. Of floral axes as marked by basal portions of peduncles there were originally fully thirty in all, mostly borne by upper two-thirds of trunk and belonging to a single or at most several seasons of flower-producing activity, just preceding the first event in fossilization of parent trunk. Only a few of the axes yet bear basal portions of the fertile staminate fronds as at $s$; most are simply terminal portions of peduncles surrounded by basal parts of bracts, thus indicating that the strobili of $C$. ingens mostly protruded farther beyond the armor of immense leaf bases than in the case of the much more lightly armored C. dacotensis, and also making probable such an expansion of the flower bud at the time of pollen maturity as is indicated in the restoration shown in figure facing Chapter VI.

At the summit of the trunk between the projecting strobilus on the left and the peduncle ends marked by the lines $p p$ on the right, there is a crown of wonderfully preserved young fronds deeply embedded in ramentum. Several are partly emergent, while others are smaller and completely immersed in the silky ramental mass. Photographs I-3. plate XIX, show the transverse sections of several of these prefoliate fronds.

Plate II. Cycadeoidea ingens (type). Summit of trunk. $\times 0.3$.

$S$ (above).-The bisporangiate strobilus denoted by arrow in plate $I$ and shown in longitudinal and transverse section in plates III and IV. The slightly worn outer surfaces of the middle portions of the incurved rachides of the yet folded flower or strobilus appear as a more or less regular series of sectors forming a circle, the cevier of which lies one centimeter above the apex of the inclosed interior cavity marking in lart the central ovulate cone as explained in the legend of the following plate.

$\mathrm{S}^{\prime}$ (below).-A second strobilus, in which a few of the lowermost synangia-bearing pinnules were found to be yet present, most having been broken away during erosion.

$p$, $p$, the peduncles of the other strobili, doubtless similar to those shown at $\mathrm{S} \mathrm{S}^{\prime}$.

$l$, position of the helicoid of preserved young and partially emergent fronds illustrated on plate $\mathrm{xIx}$.

* The section numbers throughout the plate legeuds, as in the text, are those of Yale University Museum Cycad Section List, whether so specified or not. These numbers are the ones given by the author, and all the fossil cycad sections on which this volume is based were made by him, save the single Liguier section, photograph 3, plate XXVII. Most of tixe photographs and photomicrographs, as well as rarious text-figures aud the original tracings, are also by the author. The ink s ork on mcst figures, and the brush drawings, are by the scientific illustrator, Mr. G. S. Barkeutiu, of Albauy, N. Y. 


\section{Plate III. Cycadeoidea ingens (type). $\times 3$.}

Photograph of longitudinal section through the bisporangiate flower bud.

This is the fruit marked by an arrow near the summit of the trunk shown in plate I. The upper line is the saw cut of the transverse section shown in photograph I, plate III, the lower that shown in photograph 2, plate III. The photograph is from a polished surfacenot from a thin section-and fairly reproduces the shades of light and grayish quartz colorations to be seen in the fossil itself. The subjoined figure, traced directly from the photograph, locates the main features of this wonderfully well-preserved bisporangiate strobilus-historically the first to clearly indicate the true nature of fructification in the Cycadeoidex.

A. one of the series of synangia borne by a middle pinnule of one of the once-decurved staminate fronds.

B. ascending portion of the rachis of one of the staminate fronds.

C. a large central cavity due to the non-preservation of most of the central ovulate cone, the unquestionable contour of which is shown in dotted ouline with interior palisaded lines to indicate the young seed zone, a portion of which is at several points conserved. (The cavity is lined by a quartz druse.)

D. synangia.

E, bract hairs.

F. a subcylindrical area of broken-down tissue.

G, small basal synangia.

$\mathrm{H}$, base or receptacular region of ovulate cone.

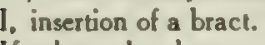

$\dot{K}$, the peduncle.
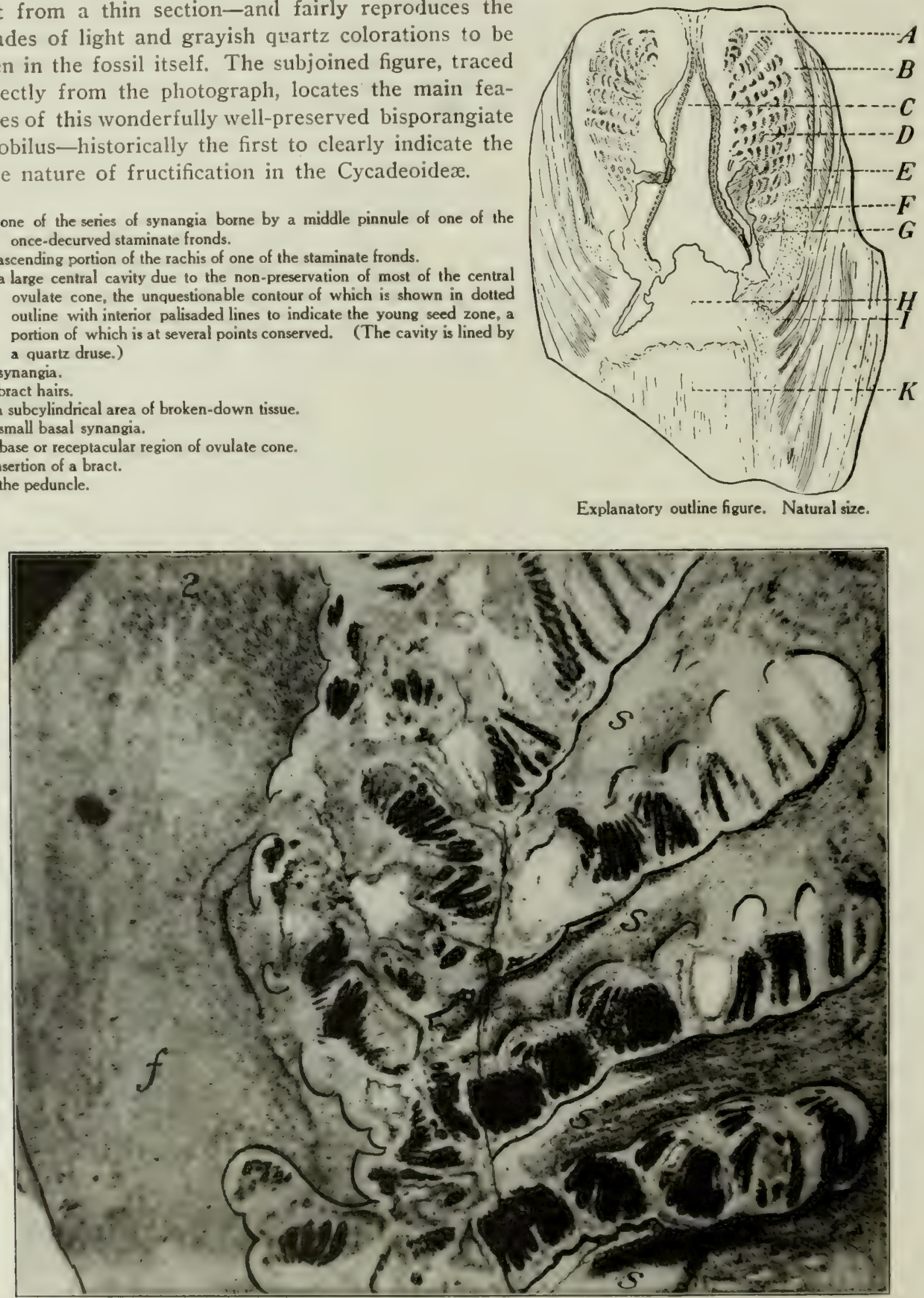

Enlarged view of thin section from summit of strobilus parallel to surface view shown in plate. Photographed in transmitted light. 
In the second supplementary figure to plate in, a section parallel to that photographed in the plate as an opaque object is reproduced from a photograph by transmitted light. The pinnules, $s, s, s$, bear the closely packed synangia, indicated by the masses of pollen slling the sporangia, the synangial walls not being delimited by color differentiation, although present. The broad vertically and longitudinally cut decurved tip of the rachis, the ascending limb of which bears the pinntiles, $s, s$, is denoted by $f$.

\section{Pláte IV. Cycadeoidea ingens (type).}

Photographs of polished transverse sections of the bisporangiate flower but shown in the precerling plate III. Enlarged to a little more than twice natural size.

Photograph 1.-Section from the uppermost of the two saw curts to be noted in the photograph of the accompanying longitudinal section, plate ir. In the present section all the main features except the central cone are very distinct. The synangia are especially prominent because of the preservation of the pollen. filling completely all the sporangial loculi in milkwhite masses, which stand out clearly and distinctly in the gray and translucent to transparent matrix-the synangial walls not being sharply marked, though present. The synangial pollen contents thus show the I3-rayed asteriate arrangement of the synangia, corresponding to thirteen fronds composing the flower. Of the central cone only some small areas of the peripheral portion showing the young seed zone are present, the outline of the cone being approximately indicated by a cavity lined by a druse of quartz crystals. All the rachides of the thirteen staminate fronds are clearly indicated, as well as the lines showing their sides, which are so closely appressed as to form a capsular bud. The decurved ends of the fronds are mostly present, but not so clearly defined at the level of this section. The accompanying outline (shown in natural size) affords a key to the structures present, the lettering being the same as in the key figure to the legend for longitudinal section shown in plate III.

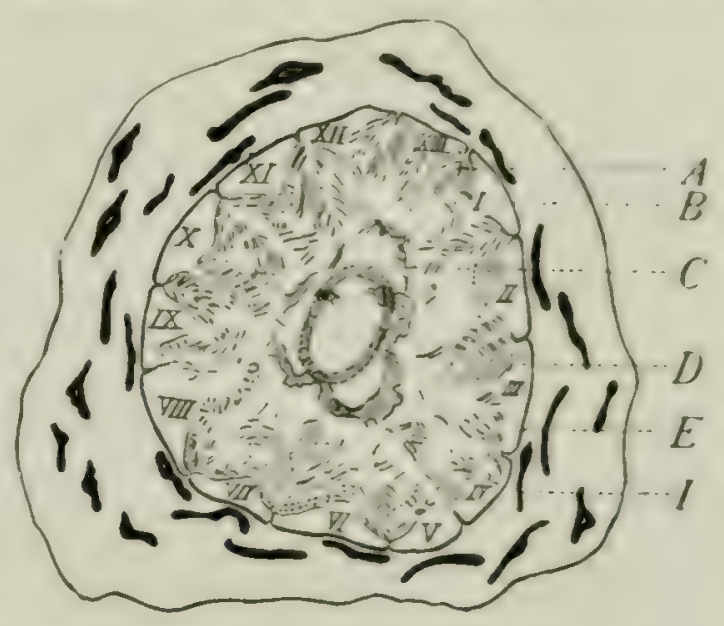

Explanatory Figure.-A, group of synangia belonging to pinnules borne by the first and thirteenth rachides: B, rachis numbered I: C, outline of the but partially preserved central ovulate cone, the fermes position of which is in the fossil mainly taken up by a cavity lined by a druse of quartz crystals: D, synangia of staminate frond (III): $E$, ventral (lower) surface of rachis lying against mass of bract hairs; I, one of the hair-covered bracts: I-XIII, the staminate fronds. Natural size.

Photograph 2.-Section from the lowermost of the two saw cuts. to be seen in the photograph of the longitudinal section, plate in. This section is cut approximately through the receptacle of the central ovulate cone and the bases of the staminate fronds, which are scen to be fused into a single clearly outlined continuous disk. As in the other sections all the space between the bracts is densely packed with rather long and silky bract hairs. The bracts are at this height not nearly so flat in transverse section as at the higher level. photograph $\mathrm{x}$. Their spiral succession is clcarly discernible. The features of the bract hairs are illustrated in connection with the description of the young crown of leaves accompanying the present flower bud.

\section{Plate IVA. Cycadcoidea ingens.}

Plan of the bisporangiate strobilus or flower, consisting of a central ovulate wne, an hypogynous staminate disk, and a series of spirally-inserted enveloping bracts, all shown diagrammatically a little under the natural size, and as if pressed out flat. (Compare with illustrations of Chapter VII and the restoration of an expanded flower facing Chapter VI, noting that in the latter a form with fourteen fronds has been indicated. Nlthough the actual number thirteen would be preferable as the observed number, variations of from one to three fronds in the total number composing the disk are to be expected.) 


\section{PLATE V. Cycadeoidca. Typical trunk forms, showing stages of growth and fructification.}

Photograph I.-Cycadeoidea Marshiana. Height, $45 \mathrm{~cm}$; weight, I47 kg. Collected by Wieland at Minnekahta, S. Dak. The largest of a group of three branches associated in situ, but no longer organically connected. These trunks rested on a bluish clay stratum overlaid by a sandstone horizon. As found, they were completely cmbedded, the smaller of the trunks almost entirely in sandstone and the largest one here figured mainly in sandstone matrix, but forming for itself a slight depression or bed in the underlying clay ("Liegenden"). These several silicified trunks no doubt belonged to a group that was closely connected in life, and at the time of its fossilization subjected to pressure by an inrush of matrix sand forcing the separate branches somewhat asunder as they lay on a clayey lake bed, or, possibly, estuarine river deposit. ( $C f$. account of discovery of these trunks given in Chapter II, page 40.) Notwithstanding the great size of the branch figured, it had never produced more than a very few if any fructifications, as quite plainly indicated by the yet strongly marked regularity of the leaf-base spirals, but slightly thrust aside by the emergence of the various small and young lateral fructifications when the chain of events that led to fossilization began. This branch was, in short, just then leaving what is explained in Chapter VI as the pulcherrima stage of growth or condition of symmetrical leaf-base spirals preceding rearrangement due to the emergence of large numbers of lateral fructifications, and probably marking the closing stage in the life of many of the Cycadeoidex.

Photograph 2.-Cycadcoidea dacotensis (T. 54). Height, $43.5 \mathrm{~cm}$.; weight, $96.6 \mathrm{~kg}$. Stage of growth, in which the spiral order of the leaf bases has been obscured over all the lateral surface of the trunk by the emergence of large and numerous strobili. While this is unquestionably an example of culminant fructification, the strobili are not all in exactly the same stage of development. Some of those present are in the bisporangiate condition, and pollen fills the loculi in the synangia borne by the yet folded or prefoliate staminate disks. In other cases the disks (so far as originally present) have been shed and the ovulate strobili, though not yet matured, are of larger size, fully $5 \mathrm{~cm}$. in diameter. One of these $(O . S$.$) is indicated, all the bract tips and apical portion of the seed stem and inter-$ seminal scale region having split away so as to expose the summit of the large receptacle, as plainly appears in the photograph.

Photograph 3.-Cycadeoidea Marshiana. X o.I7. A Minnekahta, South Dakota, specimen in a stage of fruit growth somewhat intermediate to the two preceding. (Originally received as three fragments, subsequently found to join as an entire trunk.)

Photograph 4.-Cycadeoidca rhombica. A characteristic species of simple-stemmed tru'ık in the pulcherrima stage. $X 0.33$. From the Piedmont-Black Hawk region of South Dakota. Only a few small and as yet young and indistinct fructifications are present. Had the trunk been fossilized a few years sooner no fruits would have been evident and the spiral succession of the leaf bases would in consequence have been an uninterruptedly symmetric one.

Photograph 5.-Cycadcoidea turrita (T. $76+375)$. A medium-sized columnar speimen remarkable for the regularity of its. leaf-base spirals, which arc undistorted, save for the emergence of the single ovulate strobilus $(O . S$.$) shown in median longitudinal section,$ photograph I, plate Xxv.

PLATE VI. Group of low-growing Cycadeoidean trunks, both simple-stemmed and branched, from the Lower Cretaceous (or Uppermost Jurassic?) strata of the Black Hills Rim.

Illustrating various habits of growth, stages of fructification, and types of prescrvation, shown by specimens in the Yale collection figured by Wicland in the Yale Scientific Monthly for March, I900. The photographs are about one-ninth natural size. (Catalogue numbers in parenthesis.) 
Photograph r.-Cycadeoidea Wiclandi (T. I3I). Bcars (like 77, photograph 6) numerous ovulate cones and scars from which such have been shed. (C/. plate Xxir.)

Photograph 2.-Cycadeoidea McBridei (T. 8). Basal vicw of a trunk bearing ovulate iruits much like those of Bennettites Gibsonianus, B. Morierei, and C. Wielandi. Thnugl: not quite so large, the characteristic leaf-base spirals in form and habit much resemble those of Cycadeoidea megalophylla, to which the present is deemed a closely related species.

Photograph 3.-C. nano (type) (T. 84). Supposed to be a pygmic species. There are wne or two very minute or young lateral fruits or buds tc be noted on the specimen, which, however, affords a clear example of the pulcherrima stage of growth. The leaf-base spirals are correspondingly symmetrical.

Photograph 4.-C. Stilivelli (T. i05). The type, A trunk bearing a few lateral fructifications or buds, and notable alike for a near approach to the existing cycads in the regularity of its leaf-base spirals, the even shearing of the armor by periderm, and the very slight development of ramentum.

Photograph 5--C. formosa (T. 89). The type specimen, inverted to better show the leaf-base spirals of the basal region, the base itself being shown in photograph 2 , plate xIv. Like the preceding specimen this trunk is notable for the symmetry and even shearing of its leaf-base spirals, strongly recalling the regularity of these features in the existing Australian Macrozamias, especially such as are without scale leaves. The rather broad spaces between the leaf-base cnds are, however, densely nacked with func, hairy, scale-like ramentum, and a few young fruits appear. Their growth and maturity would have marker the close of the pulcherrima stage so beatifully illustrated by this specimen.

Photograph 6.-C. Wiclandi (T. 77). Type of the species. A fincly preserved stem which bears laterally between its leaf bases about 50 ovulate cones and scars left by the dehiscence or perhaps crushing away of cones during the process of crosion from matrix. The stage of seed (or gamete) growth has not yet been determined, further sections being required. A cone from this specimen is shown in longitudinal section, plate xxm, plotograph 2, and in transverse section, plate xxvi, photograph 2. This cone was the first from an American cycadeoidean plant to be cut and studied structurally. The secd interiors are not conserved in any of the cones thus far cut from the present trunk.

Photographs 7 and 9.-C. Marshiana (T. 161 and 164). Top and hottom views of the first of the symmetrically branched specimens added to the Yale collection. The remainder of the wonderfully handsome specimen No. I6I, photograph 7 , has never been obtained. All the quite similar specimen 164 was secured by the writer as related in Chapter II. "The trunk as thus completed is shown on plates vir and vin following.

Photograph 8.-C. dacotensis (T. 54). A globular form of trunk bearing several incipient branches. (See photograph 2, plate v.)

Photograph 9.-See legend of photograph 7.

Photograph ro.-C. mimmekahtensis (T.212). A slightly more columnar trunk than the preceding, bearing two large lateral branches, but one of which appears in the present view. This trunk las advanced beyond its pulcherrima stage, and is nearing a culminant period of fructification. Its fruits have not been studied in detail, but are clearly young. it being of special interest that those borne on the branches and in larger number on the: main trunk over all its surface are all about equally advanced in growth.

Photograph II.-C. colossalis (T. I0). From a clump of huge branches. A robust trunk or huge branch bearing several partly emergent and a large crown of non-emergent young fronds, as well as smaller lateral branches and fruits. Traces of the origimal symmetry of the leaf-base spirals are still evident. The fruits appear to be young and small, though not yet studied in detail.

Photograph 12.-Cycadeoidea dacotensis (T.214). A cycad trunk (cvidently from a large branching trunk or clump as in the preceding instance) in culminant fructification. More than 40 strobili are present, 16 of which have been studied in detail, as related in Chapter VIII. For figures of sections from these strobili see plates xxxr-xiss. 


\section{PlATE VII. Cycadeoidea Marshiana. $\times 0.2$. Weight $205 \cdot 3 \mathrm{~kg}$.}

Lateral and superior view of trunk 164. The lettering corresponds in both photographs, and the upper arrow in the lower photograph shows the lirection of the lateral view. The main original central stem of the group is that with the largest summit $(e)$ at the left hand of lower photograph. Basal view in plate vir, with the several hranches lettered as here. (For the interesting history of this specimen see Chapter II.)

The fructifications of the present specimen are numerous, but very small, and the leafbase spirals correspondingly regular. When fossilized this beatiful branching cycad was about to pass from the pulcherrima stage into active and probably culminant fructification. (The arrow marked VIII shows the direction of the lateral view given in the upper photograph of plate vir.)

\section{PLATE VIII. Cycadeoidea Marshiana. X 0.2 . Weight $205.3 \mathrm{~kg}$.}

Lateral and basal view of trunk 164 , etc., shown in superior view in the preceding plate vir. Upper photograph the lateral, lower photograph the basal view. No portions of the roots remain, and the woody cylinder of the main or parent stem is plainly outlined at $x$ in the center of the lower photograph. By comparison with the similarly lettered plate VII the approximate order in which the scven lateral branches grew out in nearly prone position on the surface of the ground may be readily verified as that given in the brief description in Chapter II.

\section{PLATE IX. Stages of Fruit Production in Branching Species of Cycadeoidea,} illustrated by trunks with exceptionally distinct surface features.

Photograph I.-Cycadeoidca Marshiana. $\times 0.25$. View of lateral superior surface of three branches attached to a portion of the parent stem. Shows all that was secured of a plant which must have branched in quite identically the same manner as that shown in plates viI and viII. The bract scars marking numerous quite equally developed but very small and yet young lateral fructifications are plainly visible in the photograph, where upwards of forty small axes may be counted on the branch to the right alone. The regularity of the leaf-base spirals is still striking, the present specimen being one of the very handsomest examples of the pulcherrima stage ever recovered. Whether these branching Marshianas were typically bisexual, monœcicus, or partially diocious has not yet been fully determined, as explained in Chapter VIII.

Photograph 2.-Cycadeoidea superba (type). $\times 0.25$. These two adjacent lateral branches constitute the incomplete type specimens originally described. They are only closely appressed and not directly connected with each other, but the xylem cylinder of each branches off from that of the same central parcnt stem. In the succeeding plates $\mathrm{x}$ and $\mathrm{xI}$ the entire plant is shown as mounted after the collection of the parent stem and other missing parts by the writer. Trunks $c$ and $d$ are similarly lettered in plates $\mathrm{x}$ and $\mathrm{XI}$. The present lateral view shows the wonderfully distinct surface characters and a comparatively small number of strobili of considerable size, doubtless the first borne by these branches. It was determined that some of these strobili were ovulate, and certainly some are bisporangiate, though all may have been so, the disk having been later shed and the bracts again closing in over the ovulate cones. (For a discussion of these possibilities sec Chapter VIII.)

\section{Plate X. Cycadcoidea superba. $\times 0.25$. Weight $235 \mathrm{~kg}$.}

Oblique view of type, complete. In the preceding plate $\mathrm{Ix}$ are shown the two branches constituting the portion of this plant originally secured and described. The missing parts found subsequently by the author, as related in Chapter II, consist in the central stem, a large lateral branch, and many fragments, in all more than half the bulk of the entire plant.

As here seen the parent stem projects above the lateral branches and ends in a shallow somewhat oblongate "crow's nest." The terminal buds of the branches are well conserved, but rounded and smooth, owing to the large quantity of apical ramentum. (Each of the branches is lettered to correspond with plates $\mathbf{I X}$ and $\mathrm{XI}_{0}$ ) 
Plate XI. Cycadeoidea superba. $\times .02$.

Photograph I.-An cxactly lateral view of the completed type specimen, showing central parent stem ending in a "crow's nest," with a branch on each side. This view is from the direction indicated by the upper arrow of the lower photograph, and is correspondingly lettered. (Note the basal boss $b$, which appears in both the present views.)

Photograph 2.-Basal view of type specimen complete, showing the woody cylinder of the central stem and the connection of the three larger, lower, and earliest formed branches $(a),(c),(e)$. Branches lettered to correspond with photograph $I$ and plates $I x$ and $x$, which show lateral views in the direction indicated by the correspondingly numbered arrows. (See the lateral view of the two branches $(c),(d)$ in plate $\mathrm{Ix}$, and the oblique superior view of the entire plant in plate $\mathrm{x}$.)

\section{Plate XII. Cycadeoidea Marshiana.}

A branching Cycadeoidean trunk from the Black Hills as mounted in the Yale Iruseum (No. 300). About one-fifth natural size. This trunk has five branches, the smallest of which has been partially restored. The three larger branches $(a),(b)$, and $(c)$ are of nearly. equal size, and formed Zamia-like, early in the life of the plant, so that there is no distinct central parent trunk as in the case of the branching cycads represented on plates III-XI, although ( $a$ ) appears to be the largest and oldest. A superior view correspondingly lettered is shown in the succeeding plate XIIr.

(The present is the largest fossil cycad ever recovered, the weight as collected being 383 kilograms. One of the smaller and most beautifully preserved branches (d) was received at the Yale Museum as a separate specimen nearly two years earlier than the remainder of the trunk. When it was found that there was a missing branch a search made by the writer through the collection first obtained revealed it. The chances against such a fortunate accident were very great. Even such durable objects as silicifed cycads, capable of resisting the weathering action of ten thousand winters, should if possible be collected by knowing and sympathetic hands. As related on page 40 the original presence at the Minnekahta locality of a branching cycad larger than No. 300 is clearly indicated.)

\section{Plate XIII. Cycadeoidea Marshiana. Superior View of T. 300.}

Compare with oblique view on plate XII. That this plant early took a tri-ramial form is here evident. The very earliest branch of all to form must have been the largest and most central, or that with the "crow's nest" summit, marked (a). From this older stem plainly springs the smaller of the two minor branches, while the attachment of the other has not been determined. The lettering of the branches corresponds with that of the superior view shown on plate XIr. Branches $(a)$, $(b)$, and $(c)$ originally constituted przcisely such a clump as that formed by Encephalartos villosus (cf. text-figure 17), (a) being the original trunk of the group, and $(d)$ and $(e)$ secondary branches.

PLATE XIV. Two types of Woody Cylinder in Cycadeoidean Plants.

Photograph I.-Cycadeoidea Jenneyana. (T. 178.) $\times$ 0.5. Polished basal end of a cylindrical stem segment from near the base of a trunk mostly denuded of its armor. A primary ring of twenty-one bundles incloses the relatively small medulla, which increases but little in width in a distance of $35 \mathrm{~cm}$. The medullary rays are as narrow as those of conifers, and extensive augmentation of the xylem zone has taken place. The nearly solid wood, with a seasonal growth-ring appearance similar to conifers and dicotyls, increased at the expense of the cortical region, which is scarcely a centimeter wide. Whether the growth rings have originated from scrial cambiums as in other polyxylic cyenas or, as less likely, from a persistent primary cambium, is not wholly clear, as explained in the text. Chapter IV. At the extreme outer edge of the specimen itself a few basal portions of leaf bases of normal cycadean form may be noted.

Photograph 2.-Cycadeoidea formosa. Basal view of T. S9. $X 0.45$. Lateral view of same, plate vi, figure 5. A trunk with a very large medulla inclosed by a single but heavy woody cylinder of collateral bundles and a very narrow cortical region $(c)$. $x$, xylem; $p$, phloem. 
Plate XV.* Wood Structure of Cycadeoidea Wielandi. T. 393.

Photograph I.-S. 255. $\times$ 5. Longitudinal tangential section through wood, showing a portion of the cylindrical trellis of collateral bundles and the meshes in which the leaf traces arise; the xylem elements of the latter being superior, the phloem inferior.

Photograph 2.-S. 26I. X 5. Transverse section through two adjacent "werges" or collateral bundles of the woody cylinder, showing the opening or medullary mesh between and a horse-shoe bundle entering the cortex. The latter may arise in a mesh farther down beneath the plane of the section.

Photomicrograph 3.-S. 255. X I40. Enlarged view of a portion of figure I, showing more or less distinctly that the xylem of the woody cylinder is mainly composed of scalariform tracheids. Medullary rays one, seldom two, cells thick and one to fifteen cells high, with intervening wood one to five cells thick.

Photomicrograph 4.-S. 255. X 125 (?). A portion of same section as the preceding, which cuts the xylem nearer the medulla, where the ray cells are relatively larger and the tracheids smaller than further out towards the cambial line.

PIATE XVI. Structure of Woody Cylinder and Peduncle Trace in C. Wielandi. T. 393. (Cf. text-figures 39,40 , etc.)

Photomicrograph I.-S. 260. $\times$ I50. Transverse section through xylem of one of the collateral bundles of the woody cylinder and an adjacent mesh, showing in part the origin of the xylem of a leaf trace. From position marked $x$ in photograph 5 .

Photomicrograph 2.-S. 260. X about 200. Transverse section through phloem of collateral bundle of woody cylinder.

Photomicrograph 3.-S. 26I. X I50. Transverse section througin xylem of a cylindrical bundle of the cortex, known to pass on and enter the peduncle of an ovulate cone. The indistinctly preserved zone $(c)$ crossing near the upper edge of the photograph is the cambial region and beyond are a few of the cells of the phloem rays.

Photomicrograph 4.-S. 26I. X I50. Transverse section traversing the distal xylem, the cambium, and the proximal two-thirds of the phloem of the same peduncle trace shown in the preceding photomicrograph. Note the similarity of the xylem and the phloem structure of the peduncle to that of the woody cylinder of the trunk. The main differences consist in the large proportion of phloem in the peduncle trace, and the smaller size of its xylem and phloem elements. Further out the heavy-walled elements of the peduncular phloem diminish greatly in number.

Photograph 5.-S. 247. $\times$ 3.33. Transverse section of trunk extending from the medulla through the woody cylinder, the cortex, and the basal armor. $c$, Cambium of wood cylinder; $r$, ramentum seated on outer cortex. At $x$ is indicated the location of the xylem area shown by photomicrograph I. Crescentic bundle emerging from between the two woody wedges is a leaf trace, and the brokenly concentric bundle traversing the middle region of the cortex a peduncle trace similar to that shown by the photomicrographs 3 and 4 .

Photograph 6.-S. 243. $\times$ 3.33. A peduncle trace cut transversely in its passage through the outermost cortex, together with the leaf trace beneath to which it is axillary. This bundle enters an ovulate cone from which various sections were cut. Note the distinct cambial line and the width of the phloem, about four times that of the xylem. (For detailed structure see photomicrographs 3 and 4.)

PlATE XVII. Transverse Thin Section through Armor of Colorado, Freezeout Hills (Wyoming), and Black Hills Cycadeoidean Trunks. Twice natural size.

Photograph I.-Cycadeoidea nigra. Peduncle and four of the five very large surrounding bracts appearing at the level of this section.

Photograph 2.-Cycadeoidea nigra. Two adjacent leaf bases with axillary peduncles. The two lowermost and oppositely-borne bracts of the upper peduncle are visible, but the

*The reader should note that these and the succeediug heliotypes showing structure will readily admit the use of a strong reading glass or hand leus. 
lower peduncle is cut beneath all its bracts. The present and the preceding sections thus afford a series of three peduncle sections, the lowermost of which passes near the cortex and beneath all the bracts, the middle one througil the two laterally-borne basal bracts, and the uppermost through five bracts. (Cf. outline text-figure $3 I_{\circ}$ )

Photograph 3.-Cycadella sp. A series of leaf bases that would be difficult to orient were the leaf-base bundle patterns not preserved. Old peduncle traces may perchance be present outside the area of this thin section.

Photograph 4.-Cycadeoidea Wielandi. T. 393. S. 395. Thin section cutting leaf and peduncle bases as well as a very young fruit or latent bract-bearing bud near the base of the armor, and then passing obliquely to the trunk into the cortex above, where a peduncle bundle trace is cut. (Cf. outline text-figure 23.)

\section{Plate XVIII. Cycadella ramentosa. S. 445.}

Transverse section of a very young frond, cutting through non-emergent rachis and iolded pinnules, all deeply immersed in a luxuriant growth of ramentum and borne laterally on the trunk. Enlarged 35 times. The fluted character of the rachis may be due in part to some form of shrinkage or desiccation. The Podozamites-like attachment of the pinnules very near to the midline is indicated.

\section{PLATE XIX. Cycadeoidean Foliage.}

Leaf structure and prefoliation of cycadeoidean trunks, as seen in photographs of transverse thin sections of prefoliate to partly emergent crowns of leaves, and in isolated young leaves borne laterally amongst older leaf bases and photographed in their natural position on the trunk, in both naturally and artificially polished sections.

Photographs 1-3.-Young leaves from the crown of Cycadeoidea ingens type, from position indicated in plate II. Enlarged about three times. In photographs I and 2 the summit of the rachis may be noted, but in 3 one sees only the pinnules, which rise at least $5 \mathrm{~cm}$. above the end of the rachis in this instance and perhaps several centimeters more. (The pinnule ends were eroded away.) Photographs $I$ and 2 are from the adjacent thin sections 167 and 168 , and 3 is from thin section 169 .

Photograph 4.-Cycadeoidea sp. Portion of transverse section cut about three centimeters beneath the summit of an isolated bud bearing a prefoliate crown of young leaves deeply embedded in ramentum. Note the heavy $\mathbf{V}$-form of the bundle pattern of the two rachides on the left side of the photograph, a feature more distinctly appearing in drawing of this section, text-figure 52 .

Photograph 5.-Cycadeoidea Marshiana. Portion of a transverse section cut similarly to the preceding and showing the profuse growth of ramentum about the apex of the trunk. In this section the young leaves are not preserved, although structure may be present a centimeter or two lower down. The orientation of the ramentum in regular lozenge-shaped areas disposed in helicoid order, indicating the incipient leaves of the terminal bud, is a striking feature, the more so since the present section is cut $5 \mathrm{~cm}$. beneath the summit of the enveloping bud ramentum.

Photographs 6-8.-Cycadeoidea Jenneyana (T. 208). Transverse sections of prefoliate young leaves borne laterally on trunk. Enlarged about three times. Nos. 6 and 8 are photographed from sections of partially emergent leaves polished by hand without removal from the trunk, whilst the slightly oblique section shown by photograph 7 was naturally polished on the original specimen by sand-laden winds. ( $f$. text-figures 44,49 , and $5 \mathrm{I}$.)

\section{PLATE XX. Vascular Bundles of Cycadeoider and Cycadacer.}

Photographs of transverse sections of vascular bundles from the leaf bases of fossil cycads, together with supplementary figures from existing forms. The latter are from Mettenius (92).

Photomicrographs I-4.-Cycadeoidea dacotensis. $X$ 86. All from T. 214. I, S. 506, $2-4$, S. 484. Transverse sections from middle region of leaf bases. No. I is the lowermost of these sections; compare its large body of centrifugal xylem witin that of the quite similarly proportioned lowermost bundle from the leaf base of Dion edule, figure I. For further explanation see text-figure 34 . 


\author{
Figures 1-5. Dion edule. $\times 40$.
}

I. From near seat of leaf base. The annular and spiral tracheids lie on the inner side of the bundle, separated from the scalariform elements of the xylem (Holztheil) by thinwalled tissue. Scalariform cells (centrifugal xylem) ranged radially in rows separated by medullary rays, as in photograph $\mathbf{I}$.

2 (above I). Spiral cells (or protoxylem) surrounded by thin-walled tissue which separates the centrifugal and centripetal xylem.

3 (above 2). The centrifugal xylem is markedly diminished; the centripetal xylem correspondingly increased.

4. Xylem in three groups, the two lower centripetal.

5 (above the preceding). Only three cells of the centrifugal xylem remain.

$$
\text { Figure 14.-Cycas revoluta. } \times 40 \text {. }
$$

Transverse section of a root bundle, showing a further example of the mesarch bundle characteristic of the Cycadales. Development of sclerenchyma in the phloem is much as in the fossil leaf-base bundles shown in photomicrographs above.

\title{
Plate XXI. Cycadeoidea Wielandi (T. 393). $\times 0.33$.
}

Two views of a remarkably preserved specimen bearing numerous ovulate cones from which various sections have been cut. The lines at upper $c$ of photograph I indicate the seed-bearing summits of four of the cones preserved entire, while at lower $c$ another such a summit is cut away; and at $s$ two more such are cut, a portion of the summit of cone to the left remaining with the seeds plainly showing on the horizontal saw cut.

At $b$, photograph 2, owing to the breaking away of the armor near the cortex, the bases of numerous peduncles may be seen; five are marked. Although not thus thickly set with fruits all over its lateral surface, the present trunk bears several such closely set groups of cones; whilst no considerable area at any point from the vase to near the summit is sterile. The seeds of the strobilus at $s$ contain a preserved pre-embryonal stage like those cut from yet another strobilus of this trunk and illustrated on plate $\mathrm{xxx}$. The strobili borne by the trunk illustrated on the succeeding plate XXII, while of the same outer appearance as the present, are slightly more advanced in growth, a few of the seeds containing young dicotyledonous embryos.

\section{Plate XXII. Cycadeoidea Wielandi. Entire Trunk and One of Its Numerous Cones in Longitudinal Section.}

Photograph I.-T. I3I. $\times 0.5$. A finely preserved trunk bearing many ovulate cones with seeds approaching maturity, and a lesser number of either young or abortive cones. $f^{\prime}$, receptacle of a shed or non-preserved cone with surrounding bracts yet present; $f^{\prime \prime}$, two cones broken away during erosion, with a portion of the basal infertile pedicel series yet remaining; $f^{\prime \prime \prime}$, four cones eroded down to the surface of the armor, in this instance about or a little beneath the level of the lowermost seeds; $y$, three of the dozen or more very young cones, in some cases known to be simply ovulate and to be regarded as having aborted or else as belonging to a later and sparser series of fructifications than the seed-bearing cones present, the latter unquestionably representing the culminant fruit-producing period in the life of this cycad; $s$ (over lower arrow), the ovulate strobilus shown in figure 2 in its natural position, this photograph having been made before the cone was cut out by a cylindrical drill.

Photograph 2.-S. 4I6. $\times$ 5. Longitudinal section of the small ovulate strobilus cut from its natural position on the trunk as denoted by the arrow $s$, in photograph 1 . $c$ (upper arrow), seed with dicotyledonous embryo preserved, cotyledons being similarly present in the lowermost seed on the left-hand side of the strobilus; $s$, traces of hypogynous staminate disk; $b$, bracts; 1 , leaf bases; $d$, layer of developing periderm (?) marking the line at which the fruit might have later dehisced. 


\section{PLATE XXIII. Surface Features of Cycadeoidean Ovulate Strobili or Cones.}

Photograph I.-Cycadeoidea sp. Suriace of sted-bearing region of rather young ovulate cone enlarged 20 times. ( $C f$. photograph 5, showing larger area of surface.)

Photograph 2.-Cycadeoidea dacotensis (T. 6I). X 10. Surface of young cone showing stigma-like tips of micropylar tubes, each surrounded by from five to six ends of interseminal scales in interlocking rosette pattern.

Photograph 3.-Cycadeoidea sp. $\times$ 4. Surface view of a young strobilus quite similar to that seen in photograph 5 .

Photograph 4.-Cycadeoidea Wielandi Ward. $\times 4$. Surface view from near summit of nearly full-sized cone borne by T. 77 and photographed in natural position on the trunk.

Photograph 5.-Same as photograph 1. $\times 5$. [Number of specimen should be 750.]

Photograph 6.-C. Wielandi. $\times 4$. Longitudinal thin section through a cone relatively larger, but otherwise of quite similar structure to that shown in surface view in figure 4 . This supplementary figure indicates the more usual type of cone preservation in which the nail-head-like ends of the interseminal scales are mostly broken away, thus otliterating the true surface sculpturing and leaving behind only the projecting blunter ends of the more or less distinctly ranked seeds.

Photograph 7.-Williamsonia Leckenbyi Nath. Enlarged view of portion of surface, showing the tips of the micropylar tubes projecting between the ends of the interseminal scales in identically the same manner as in the Black Hills specimens, and as in cone impressions of Anomozamites from the Trias (103).

\section{PlATE XXIV. Ovulate Strobili of Cycadeoidea.}

Photographs of longitudinal sections through various cycadeoidean ovulate strobili. [That more than a single species is indicated by these severai strobili and the trunks from which they are derived is open to question.]

Photograph I.-Cycadeoidea Wielandi (T. 13I). S. 4I6. $\times 2.5$. (Strobilus and receptacle only.)

Photograph 2.-C. turrita (T. 364). S. 113. $\times$ 2. Strobilus and receptacle with shoulder of old tissue $(s)$, probably marking the insertion of an earlier matured and shed staminate disk. Such a shoulder with a more or less distinct annular band of periderm (?) beneath, extending round the peduncle, hypogynously to the ovulate cone, is present in all these sections, the presumption being that most of these axes, if not ail, bore and matured hypogynous staminate disks previous to fossilization. (Cf. enlarged view of basal area $(s)$, plate XXI, photomicrograph 2; also photograph 7 , plate xLIII, showing a younger cone with synangia and disk remnants still present.)

Photograph 3.-C. Wielandi (T. 393). S. 39r. X 2. Radial longitudinaí section of trunk, cutting lengthwise through an ovulate bract-surrounded strobilus borne oil a heavy peduncle, between two old leaf bases. Note that the present and two following cones are all from the same trunk. (Cf. restoration, figure 56.)

Photograph 4.-C. Wielandi (T. 393). S. 392. Natural size. Radial longitudinal section of trunk, cutting through a strobilus and its peduncle, also through the cortex (c), xylem $(x)$, and medulla $(m)$, interiorly. This section shows with liagrammatic clearness the direct course of the cortical bundle traces from the xylem cylinder of the trunk into the leaf and peduncle bases. ( $C f$. outline drawing of same, text-figure $\left.\xi \xi_{0}\right)$

Photograph 5.-C. Wielandi (T. 393). S. $218 . \times 2$. Similar to preceding, but with apex of cone entire.

Photograph 6.-Cycadeoidea Paynei (T. 272). S. 386. $\times 2$. A strobilus similar to the preceding, but with relatively much larger bracts, slender in the basal and robust in the apical region. strobilus.

Photograph 7.-Cycadeoidea McBridei. Basal region of a markedly symmetrical 


\section{PLATE XXV. Cycadeoidean Ovulate Strobili in Longitudinal and Transverse Section.}

Photograph I.-Cycadeoidea turrita (T. $76+375$ ). S. $349 . \times 5$. Longitudinal section through ovulate strobilus with rather short (young) seed pedicels. This strobilus is of especial interest as the only fruit whatsoever borne on a large segment of a cylindrical trunk with otherwise unbroken regularity of leaf-base spirals. Photograph 5, plate v, shows the original trunk and position (O. S.) of the present strobilus.

Photograph 2.-Cycadeoidea turrita. (T. 48I). S. 179. $\times 5$. Longitudinal section through base of strobilus and receptacle, showing characteristic splitting off of woody mass of seed pedicels and interseminal scales from the pithy receptacle or "cushion" beneath.

Photograph 3.-C. turrita. (T. I5). S. 74. $\times 4$. Longitudinal section through strobilus. $s$, a short-pedicelled seed; $i$, a mass of interseminal scales or of aboried pedicels borne over a considerable portion of the inner area of the receptacle, to the exclusion of fertile pedicels; $p$, receptacle; $b$, bract; $d$, dehiscent line (?), similar to that seen in photograph 2 , plate Xxir.

Photograph 4.-C. Wielandi (T. 393). S. 103. X 4. Transverse section cutting portion of strobilus with seeds evenly ranked as in No. 6 , which is cut at right angles to the present section from the same cone, whence two peripheral rows of seeds appear. The cone from which this section was cut is shown as seated on the parent trunk in its natural position at $s$, photograph I, plate XxI. Transverse saw cut made in making the section likewise further indicates the exact position in the cone.

Photograph 5.-C. Wielandi (T. 393). S. 394. X 3. Similar to the preceding, but cutting through the lowermost seeds, whence but a single peripheral row of seeds appears. For enlarged view of two adjacent seeds containing proembryos $(p)$, see plate $\mathrm{xxx}$.

Photograph 6.-C. Wielandi (T. 393). S. 108. $\times$ 12. Longitudinal section through adjacent seeds.

\section{Plate XXVI. Cycadeoidea. Seed Pedicel System of Ovulate Cone.}

Photograph I.-Cycadeoidea Wiclandi (T. 393). S. 393. $\times$ 4. Transverse thin section through two adjacent ovulate strobili; cut beneath the lowermost seeds and displaying the series of enveloping bracts and several of the surrounding leaf-bases. ( $C f$. photographs 4 and 5 of the preceding plate, showing two sections cut at a higher level.)

Photomicrograph 2.-Cycadeoidea Wielandi (T. 77). S. 7. $\times 32$. A small area of a section similar to the preceding, but from another cone, showing the transversely cut series of seeds pedicels and surrounding interseminal scales. The ground tissue is not preserved in either the central bundle of the pedicels or interseminal scales; whence the relations between the pedicel and scale system appear with diagrammatic clearness. Inspection of the figure at once discloses the fact that the wide envelope of cortical tissue forms the ontermost structure of the pedicels, and that the catenulate rows of small transversely cut woody cells are double between appressed sterile scales and single next to the fertile pedicels, and hence epidermal to the scales. ( $C f$. text-figures 59 and $6 I_{0}$ )

\section{PlAte XXVII. Cycadeoidea. Structure of the seed pedicels, and interseminal scales.}

Photomicrographs 1-3.-C. Wiclandi (T. 393). S. 103. (Cf. view of entire section, plate $\mathrm{xxv}$, figure 4.)

I. Pedicels and interseminal scales with all structure preserved, cut transversely a centimeter or less beneath the seed bases. Compare with the lower figure of plate xxir, where the bundle parenchyma has failed of preservation in both pedicels and scales. $X 35$.

2. Transverse section of a single interseminal scale, with cortex of three adjacent seed pedicels. $\times$ 225. But a single vascular bundle appears at the center of the scale and no instance of a second bundle has been noted in any of the sections, although four or more bundles are present in the basal scales of the cone Bcnnettites Morierei, as recently observed by Lignier ( $86 a)$. 
3. Transverse section of the central concentric bundle of a fertile pedicel, with larger cells of enveloping cortex shown in part. $\times 225$

4. C. Wielandi (T. 77). S. 2. X about 35. Insertion of pedicels and scales on receptacle in longitudinal section.

5. Pedicel from another cone cut transversely in the basal region. Included in this plate for comparison with photograph I, where the seed pedicels are cut but a short distance beneath their summits. Note the great increase in the number of cortical cells and decrease in their size towards the insertion of the pedicels. $\times 30$.

PlATE XXVIII. Sections from ovulate cones of the Cycadeoidex. Seed structures (with figure 7, further illustrating insertion of seed peclicels and interseminal scales).

Photomicrograph 1.-C. Wiclandi ('T. 393). S. 108. X 50. Longitudinal section through a seed. After passing through the seed base very nearly in the median vertical plane this section cuts just beneath a much flattened portion of the integument and then finally passes outside the integument. The conserved tissue in the central and basal third of the seed is plainly a depressed portion of the nucellar wall. The slightly convex flattened or even concave lateral surfaces of the various forms of asymmetric seeds to be noted in the accompanying transverse section, photograph 6 , illustrate how, as in the present instance, a large lateral area of the nucellus or of the integument may appear in a longitudinal section. The chief structures present are indicated as follows: $s$, seed pedicel, about two-thirds of the diameter being made up of the ensheathing cortical husk, which thins out to a single cell in thickness half way up the side of the seed and may disappear entirely; $v$, the single central concentric bundle of the radio-symmetric pedicel passing into the chalazal region; $p$, short, nearly cubical palisaded cells a single cell in thickness, forming the true outer layer of the seed as set in the basal cup-like extension of the cortical husk; $h f$, fibrous hypoderm. may be heavier-celled below; $a l$, abscission line between hypoderm and chalazal region; $c$ chalaza, mainly composed of scalariform tracheids (the present photograph is much too little magnified to disclose the scalariform markings, which are very distinct throughout all the chalazal region); $n$, nucellus, with lower third of the nucellar wall tissue preserved and in appearance much like the wall-tissue of the sporangial loculi. At the upper left-hand corner of the photograph there is a darker area which examination of the original section shows to be a rather indistinctly preserved portion of the palisade layer, with the nucellar wall underlying.

The foregoing structures find their closest known and almost identical parallel in the several times larger Paleozoic seed Lagenostoma Lomaxi. Whether or not there is a series of diminutive or vestigial vascular bundles disposed about the circumference of the megaspore as in Lagenostoma has not been determined; though far more reduction than in that form is evident.

From a petrographic point of view the present section, be it further noted, is of much interest because of the fact that its several tissue systems, from thick-walled and woody fibers to the most delicate cellular tissues, are alike traversed by numerous remarkably clear and distinct phenocrysts with but slight disturbance of the cell walls. These phenocrysts hence formed after the strobilus was silicified; there being here afforded a clear instance of a solid or semi-solid behaving as a solution, under conditions producing in some instances pheno- and in others spharocry'sts.

Photomicrograph 2.-Cycadeoidea dacotensis (?). $\times 20$. A younger seed than the preceding, with two of the characteristic surrounding infertile scales, between which projects the entire length of the micropylar tube. Partially collapsed nucellus distinct.

Photomicrograph 3.-Bennettites Morierei Saporta et Marion. Iongitudinal section through three consecutive seeds cut by Professor Lignier from the original type. $X$ Io. From the Oxfordian Jurassic of Vaches Noire, Villers-sur-Mer, Calvados, France. Fior comparison with the seed tips to be seen in photographs 2 and 4 . The most clearly marked 
difference exhibited by the Calvados seeds consists in the thickening of the integument in the apical region, as shared in by both the palisade and underlying fleshy hypodermal layer. These are clearly outlined in the figure as an outer light-colored and an inner dark-colored zone enveloping the nucellus.

Photomicrograph 4.-C. excelsa (T. 48I). S. 183. X 20. Somewhat oblique section through summit of seeds and enveloping interseminal scales. These seeds are rather younger than thuse of the Calvados specimen shown in the preceding section. In the original section itself the thick-walled cells composing the expanded tips of the interseminal scales are seen to be remarkably well preserved, and to exhibit scalariform markings very similar to those of the bracts surrounding the strobili.

Photograph 5.-C. colossalis (T. 354). S. 128. $\times$ ro. Transverse section through a very young ovulate cone in which the seed pedicels have not yet elongated. The pedicels of this species (as well as the very similar C dacotensis, minnekahtensis, etc.), do not, however, attain at any time as great length as in the other species illustrated on this plate. (An hypogynous and dehiscent disk may have been present.)

Photograph 6.-Cycadeoidea turrita. $\times 4$. Transverse section of ovulate strobilus traversing lowermost seeds.

Photomicrograpin 7.-Cycadeoidea Wiclandi (T. 77). S. 102. $\times$ 16. A transverse section that was cut obliquely through the summit of the parenchymatous receptacle of an ovulate cone to show the insertion of the seed pedicels and surrounding interseminal scales. The central bundle of the pedicels is seated highest on the large and pithy cells beneath, the small-celled cortical region next lowest, and the interseminal scales lowest of all, whence the latter project brush-like beyond the end of the cortical zone in longitudinal sections, as may be seen in photographs $I$ and 2 of the succeeding plate xxix. This explains how in all the upper portion of the present photograph the section passes beneath the basal tissue of the pedicels, although the latter are clearly outlined by the system of enveloping interseminal scales. The relations described were found difficult to photograph, although clearly defined in the original section 102 .

\section{PLATE XXIX. Peculiarities of Cycadeoidean Fruit Silicification, as shown by Photomicrographs.}

I. Basal region of seed pedicels and interseminal scales finely conserved, with the result that differentiation of separate organs is not distinct as in the succeeding photomicrograph of similar but less perfectly conserved organs. T. 77. S. 2.

2. Basal region of seed pedicels and interseminal scales preservell with vague outlining of individual cells, but otherwise clear demarcation of organs. At the top of the photomicrograph the several pedicels are lettered in succession $(a, b, c, d, c)$, and the number of the intervening scales is also indicated by accents ('). As in the preceding instance the woody mass of stems and scales has split away from the pithy tissue of the receptacle. The transverse section through another cone, photograph 7, plate xxvm, supplements these illustrations.

3. Interseminal scales and pedicels from near seed zone. Only partially preserved and traversed by numerous pheno- or sphærocrysts. T. $77 . \times 16$.

4. A type of "parenchymatous-cushion," or receptacle preservation, frequently noted. Individual cells of the parenchyma sometimes present, but mostly indistinct, with numerous sphærocrysts, varying from minute forms to about the size of a parenchyma cell, the whole being traversed by numerous gum ducts or elongated secretory sacs. T. 66 (C. turrita). S. $29 . \times$ I6.

5 and 6. The usual type of seed preservation, with the tissues of the integument more or less distinct and the interior cavity filled with clear silica, often containing large phenoor sphxrocrysts. Note that in No. 6 the decrease of the cortical region of the pedicel at the seed base is very clearly shown in the case of the middle seed. Photomicrograph 5 from T. 77 (S. $7 . \times 20)$. Photograph 6 from 'T. I5 (S. 89. $\times 20)$. 


\section{PlATE XXX. Cycadeoidea Wielandi. Transverse Section through Young} Seeds, showing a pre-cmbryonal stage. T. 393. S. 394. X 35 .

See photograph of portion of this section, which cuts transversely through the entire strobilus given in reduced scale, plate $\mathrm{xxv}$, No. 5. At $p$ are the seeds here shown. The section traverses two exterior bracts and the mass of seed pedicels and interseminal scales, inclosing two peripheral seeds in a pre-embryonic stage of growth that may represent the

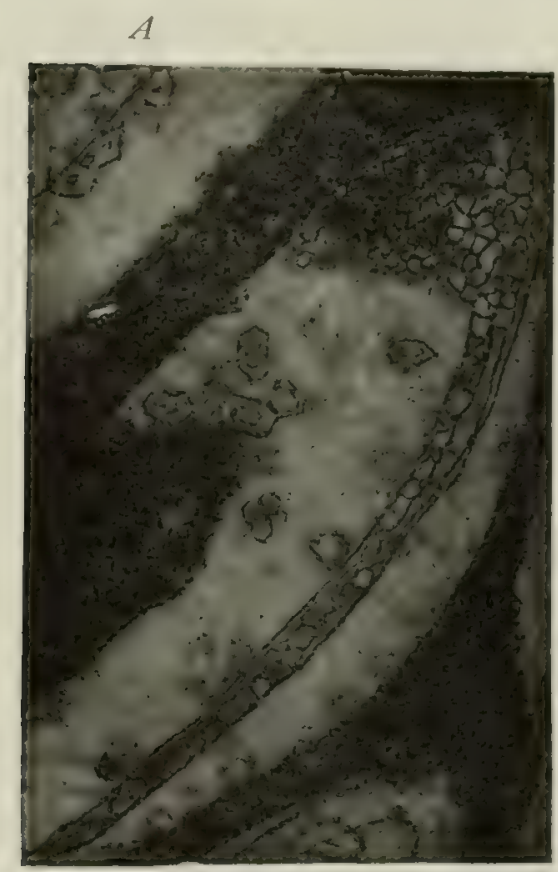

C

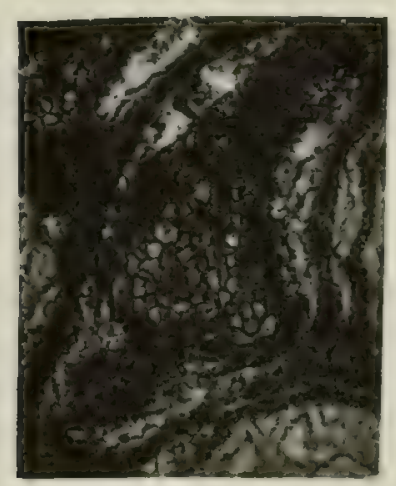

A, from S. 218. $\times$ 17. Longitudical to oblique section cutting tip o seed; B, from same section as the preceding, showing lower threefourths of seed (upper portion was not preserved); C and D, approx imately median oblique sections. $X 17$. The comparison of the various sections illustrated suggests that the large-celled tissue was not so compact throughout all the interior of the seed cavity as at the level of the two transversely cut seed sections shown in the plate But no such large cavity appears as in the proembryo of $\mathrm{Cycas.}$ proembryo rather than prothallial tissue. The structures present must nearly if not entirely fill the seed cavity, as indicated by the subjoined figures of seeds from sections of several other strobili of T. 393, in a similar stage of growth.

[With the cutting of further sections there will in the course of time accumulate $a$ series of fully preserved examples in longitudinal as well as transverse section-in some cases no doubt showing both younger and later stages of growth. Should it be required, a single seed may be studied in serial section by photographing either a tangential, or basal, or an apical polished surface as an opaque object and then repeatedly polishing and photographing at equidistant levels. These may of course be at any desired distance apart, and the results obtained therefore of absolute completeness. No other process than this, which would destroy the original specimen and leave in its place a series of photographs, would be available for these objects. To simply let the sections made in the crdinary way accumulate must in the end prove the more wasteful method, since a single one of these small seeds will seldom be traversed by more than two well-placed successively paralle! sections. Time for this work has not yet been available.]

\section{Plate XXXI. Various Strobilar and Foliar Structures of Cycadeoider.}

Photomicrograph r.-Cycadeoidea Wielandi (T. I31). S. $34 . \times$ Io. Transverse section through peduncle cut near insertion on cortex and showing a portion of the woody cylinder giving origin to large crescentic bract traces. The strong development of the bundles suggests that the bracts are reduced forms that once fuifilled some higher function than that of mere enveloping organs.

Photomicrograph 2.-C. turrita ('T. 364). S. I13. X 25. Longitudinal section through base of ovulate strobilus $(0)$, showing loose annulus or cnllar of wilted tissue $(s)$, and a bract base $(b) ; v$ is the peduncle bundle, and it is seen to give off a branch to the left, which, after passing out through the ground tissue with scalariform markings like that of 
all the outer receptacle and the bracts, ends abruptly where a layer of periderm (?) marks the abscission of the annulus $(s)$. The entire cone is shown in longitudinal section on plate XxIV, photograph 2, both basal sides of the section presenting at $s$ identically the same structure and features of preservation. It is hence quite evident that some time previous to fossilization the present axis bore an hypogynous disk which had performed its function and wilted away, leaving behind a small basal portion, subsequently excised by a layer of periderm and left hanging loosely round the stem of the ovulate cone as an annulus held in place by the surrounding bracts. The appearance of the scalariform ground tissue beneath the annulus, as well as that of all the periphery of the upper end of the peduncle, the receptacle, and the bract bases, were the coloration more favorable and the enlargement half again as great, would be much the same as in the similar and homologous ground tissue on the under side of the bracts shown in photograph 3. [These features appear in the present illustrations, if studied under a hand lens.]

Photomicrograph 3.-Cycadeoidea Paynei (T. 272). S. 387. X 30. Vertical longitudinal section through bract from point opposite the apex of the seed-bearing cone, which is shown entire in the longitudinal section, plate xxiv, photograph 6 . The upper side of the photograph is that next the cone. Ground tissue with scalariform marking throughout. (Cf. diagrammatic text-figure 60 в.)

Photomicrograph 4.-C. dacotensis (T. 214). S. IIO, $X$ 200. Portion of a section cutting a synangium longitudinally so as to traverse opposite walls of a sporangial loculus with pollen grains clinging to them. In one of these pollen grains cell structures are certainly indicated. In this view five cells are seen and they appear to be all that were present. In the section itself the walls are distinct, and in the photograph only the superior end of the grain was retouched, so as to complete its outline a little more clearly. Whatever may be said of the uncertainty of spore markings in general it is believed that these are not accidental and that they indicate a five-celled pollinial stage. (See page 160.)

Photomicrograph 5.-C. dacotensis (T. 214). S. 103. $X$ about 80 . Transverse section through the outer layer of palisaded cells enveloping a synangium homologously to the outer palisaded layer of the megaspore.

Photograph 6.-C. ingens (type) (T. 100). S. I70. $\times 4$. Transverse section through a young frond, cutting folded pinnules and rachis. Belongs to the series shown on plate xix.

Photomicrograph 7.-The same as photograph 6, enlarged to show summits of ramental scales splitting or fraying up into one-celled fibers enveloping the young leaves.

\section{Plate XXXII. Cycadeoidea dacotensis (?). T. 505. S. $353 . \times 4$.}

Longitudinal section through ovulate strobilus. The summit of this beautiful fructification rises to the same level as the leaf bases of the surrounding armor. The form of the receptacle is abruptly conical instead of rounded as in B. Gibsonianus, B. Morierci, etc., or elongate-conical, as in fruits like that shown on the following plate. For a pen drawing of the present and other strobili borne on T. 505 see text-figures 28 and 66 . The former is a tracing from the polished cylindrical trunk fragment, bearing additional fruits to the present, which was seated a short distance outside the area polished. Still more important to a clear idea of the features of the present cone is photograph 5, plate XLIIr, showing the naturally eroded nearly median section left by the splitting away of nearly all the seed pedicels aid scales from all of the side of the conical receptacle.

\section{PrATE XXXIII. Cycadeoidea Marshiana. Trunk and Serial Sections from Ovulate Strobilus.}

Photograph I.-S. 404. Natural sizc. Radial longitudinal section of cycadeoidean trunk No. 229, cutting the ovulate strobilus pointed out by the arrow in photograph 2 , in an approximately median vertical plane. The arrow in photograph $I$ indicates the superior side of the fruit, and the lines $a-d$ the respective serial transverse sections shown in photographs $I a-I d$. ( $I c$ and $I d$ are in reverse position.) ( $C f$. figure 67.)

Photographs Ia-Id.-All natural size except Ia, which is enlarged twice. Serial transverse sections cut at successively lower levels from strobilus shown in photograph 1 , in 
the planes $a$ to $d$, respectively. Owing to the elongation of the receptacle the verticallyinserted seed pedicels are cut through their entir. length in transverse section Ia. (Ia, S. $400 ; 1 b$, S. $401 ; 1 c$, S. $402 ; 1 d$, S. 403.)

Photograph 2.-Cycadeoidea Marshiana (T. 229). X about 0.1\%. From Minnekahta, in the Southern Black Hills. The arrow indicates the strobilus shown in section by photographs I, I $a-I d$, as borne on the trunk in its natural position previous to removal and sectioning. [T. 229 was doubtfully assigned by Ward to C. Minnekahtensis.]

Photograph 3.-Longitudinal section of seeds from a section parallel to S. 400. It is loubtful if these seeds were fertilized. A small clear space in the more or less collapsed nucellus of the seed to the right is not believed to be an archegonium.

NoTE-Cf. small ovulate cone, photograph 4, plate XLIV, also borne by T. 229 Such compared with forms like the present always suggest the possibility of rlehiscent staminate disks and a monœcious habit, with the pollen-bearing axes morphologically but not functionally bisporangiate. That most cones have earlier borne a rehiscent disk and are simply young is, however, the view taken in the study of the very similar trunk 2I4.

\section{PlATE XXXIV. Bisporangiate Strobilus of Cycadeoidea dacotensis in} (I) a longitudinal and (2) corresponding transverse section.

Photograph I.-Cycadeoidea dacotensis Macbride. Four times natural size. Longitudinal section through the summit of an unexpanded bisporangiate strobilus cut by the writer from a splendid example of a branching trunk and cotype in the collection of the State University of Iowa, Iowa City, Iowa. The original specimen was collected by Prof. Thomas Macbride at Minnekahta, in the Southern Black Hills, in I893, at the same time as the type of the species. The present and accompanying serial transverse sections cut from this same strobilus belong to the museum of the State University of Iowa. In all these sections preservation is unusually perfect. The synangia are yet closed and the indehiscent sporangial loculi frequently filled with preserved pollen grains nearly or wholly mature. As will be noted in the photograph, the pinnules of the once-pinnate decurved fronds are thickly set with synangia, and so regularly inturned as to be cut throughout quite their entire length, one after another, with a diagrammatic regularity. The section itself is exquisitely iron-stained and an object of rare beauty.

Photograph 2.-Cycadeoidea dacotensis (T. 2I4). S. 48I. X 5. Transverse section of bisporangiate strobilus and enveloping bracts cut relatively at or a centimeter beneath the level of the base of upper photograph and but a short distance below the level of disk division into separate fronds. It may be noted especially that the megasporophyll zone of the central ovulate cone is not so far advanced in growth as in the State University of Iowa specimen.

PlATE XXXV. Cycadeoidea dacotensis. Transverse Secticus through Bisporangiate Strobili. (Illustrations from same strobili as those of plate xxxiv.)

Photograph I.-Transverse section from the same strobilus as the upper photograph of plate xxxiv. Cut near level of summit of central cone and above the division of disk into discrete fronds, of which nine arise on the semi-circumference. $\times 2.66$.

Photograph Ia.-Transverse section parallel to and about 2 centimeters beneath the preceding section, cutting the enveloping bracts, the undivided disk, the decurver frond tips with a few synangia, and the central cone. $\times 2.66$. (A section of the disk, with two appressed frond tips, the lower of which bears a single synangium, has floated to the left. slightly out of the natural position.)

Photographs 2-2c. -T. 214. Serial sections 48I-484, respectively. All X I.33. C:1t transversely from fruit $I$, as drilled from the parent truak in the form of a cylindrical core.

2. Section cutting a leaf base, the bracts series, the disk and decurved frond tips, and the central strobilus. S. 48r. For enlarged view of disk and cone see lower photograph. plate Xxxiv. 
2a. Parallel to and quite three centimeters beneath preceding section. Cuts peduncle and surrounding bracts only. S. 482.

2b. Parallel to and several centimeters beneath the preceding section. Passes through central region of the large peduncle, of flattened barrel-shape, and beneath the insertion of most of the bracts. S. 483 .

2c. Parallel to and several centimeters beneath preceding section. Cuts peduncle and leaf bases beneath all the bracts, and but a short distance above insertion on cortex. S. 484 .

The photographs of the present plate, although from two different strobili, virtually constitute a complete series of transverse sections. Taken as the complement of the longitudinal sections shown in the upper photograph, plate xxxiv, and photograph 4, plate xxxix, they afford a complete pictorial vicw of the macroscopic features of the bisporangiate strobilus. Compare with the outline figures 74 and 75, pp. I49-I5I.

\section{PLATE XXXVI. Cycadeoidea dacotensis. Serial sections through} a bisporangiate strobilus.

All the photographs of this plate are twice natural size.

Photograph I.-Longitudinal section so cut that in the once-decurved frond to the right of the ovulate cone none of the synangia-bearing pinnules appear. Instead, the entire space between the ascending and descending limbs of the rachis is closely packed with synangia. To the left of the cone a few of the synangia are seen to be borne on pinnules attached to the microsporophyll rachis.

Photograph 2.-Longitudinal section parallel to the preceding at a distance of several millimeters, and so cut that the pinnules of the microsporophylls on both sides of the central cone are successively cut throughout their entire length. (Planes of the serial transverse sections $2 a-2 d$ indicated by the respective lines $a-d$. Likewise planes S. 110 and S. 302 indicate the position of the two sections at right angles to the preceding, but cut from another of the cones borne by T. 2I4, and shown in enlarged view in the photomicrographs 2 and 3 of the following plate.)

Photographs $2 a, 2 b, 2 c$, and $2 d$.- Serial transverse sections cut in the respective planes indicated by $a, b, c$, and $d$, in photograph 2. It is especially to be observed that in photograph $2 a$ the disk is divided into discrete fronds, while in photograph $2 b$, owing to slight obliquity, separate fronds are to be seen on the left, but not on the right. The latter section hence indicates that the exact height at which the disk divides into fronds is on a level with the summit of the ovulate cone. Compare with outline figures 72 and $73, \mathrm{pp}$. I45-I47.

\section{I'LATE XXXVII. Cycadeoidea dacotensis. Longitudinal Sections of Bisporan-} giate Strobilus. (I, T. 2I4. Structural details.)

Photograph I.-S. 83. $\times 8$. Longitudinal section through upper portion of ovtlate cone and the decurved limb of an appressed microsporophyll.

Photograph 2.-S. 302. $\times$ 8. Tangential section of strobilus passing through region of closely packed synangia near ascending limb of a rachis in a position approximately vertical to line marked S. 302, in photograph 2, plate xxxvi. The pinnules (s) of the oncepinnate microsporophylls, as folded in lengthwise, are cut transversely in pairs and the synangia are seen to be attached pendently well to the side of the heavy median nether keel.

Photograph 3.-S. IIo. $\times 8$. Section passing radially outward and upward through the folded once-pinnate microsporophylls at such an angle as to cut a pinnule ( $p^{1}$ horizontally throughout its entire length. The approximate position of the section is vertical to the line S. Iro, photograph 2, plate Xxxvi. Taken in conjunction with the preceding tangential section the present section pretty clearly shows the form of the pinnule and the distribution and attachment of the synangia in two lateral pendent rows. $f^{1}$ and $f^{2}$, two adjacent fronds; $p^{1}$, pinnule borne by frond $I ; p^{2}$, pinnule borne by frond 2 and cut off obliquely; $p^{3}$, another obliquely cut pinnule either borne by frond 2 or an adjacent frond.

In the present section the pinnule $\left(p^{1}\right)$, as attached to the rachis of the frond $\left(f^{1}\right)$ of the disk, bears on its left side the row of five synangia seen to the left of the photograph, 
and on its right side another row of synangia, nether to the plane of this section. The pinnules $p^{2}$ and $p^{8}$ are borne by the frond rachis $\left(^{(2)}\right.$ of the disk, and pinnule $p^{2}$ bears the two vertical rows of synangia in the middle of the photograph so characteristically disposed in interlocking Vs; whilst the pinnule $p^{3}$ bears on its left side the row of ten synangia seen to the right of the photograph in part.

Photograph 4.-S. 104. $\times 8$. Radial longitudinal section of strobilus, passing through pinnules lengthwise (in a plane at right angles to section i10). The section passes through the distal half of three successive pinnules all the way to the tips, the area shown being near the summit of the central ovulate cone.

Photograph 5.-S. 107. $\times$ 9. Radial longitudinal or slightly tangential section of strobilus from nearly same position as section 83 , photograph $r$. Note large synangium cut longitudinally.

Photograph 6.-Enlarged view of a section passing through a portion of a synangium in the lateral longitudinal plane, and through a portion of another synangium in the transverse direction. In both these synangia the sporangial loculi are filled full with pollen grains, and much pollen is present in the loculi of all the sections illustrated on the present plate.

\section{PLATE XXXVIII. Young Fructifications and Other Structures of Cycadeoidex. I, 2, 4, Cycadeoidea; 3, Cycadella.}

Photograph I.-Cycadeoidea dacotensis (T. 2I4). S. 56I. Natural size. Fruiting axis xrv. For position on trunk see text-figure I4. Transverse section of an axis of fructification cut from trunk, together with surrounding leaf bases, in the form of a cylindrical core. The section passes $4.5 \mathrm{~cm}$. beneath surface of armor. (Cf. photograph 2.) See page I8I.

Photograph 2.-S. 560. Natural size. Transverse section through same axis as the preceding. Cut $2.5 \mathrm{~cm}$. above S. $56 \mathrm{r}(2 \mathrm{~cm}$. beneath the surface of the armor), and disclosing the presence of a small apical ovulate cone. The large size of the peduncle and the numerous bracts, with the small size of the seed zone and broken-down condition of most of the cone tissues, suggest the failure of the cone to develop following maturity and dehiscence of a staminate disk. But while this particular axis may not have been functionally bisporangiate others amongst the sixteen axes studied from T. 214 appear to have been truly bisexual.

Photomicrograph 3.-Cycadella ramentosa. Transverse section through ramentum of leaf bases. Heavy type of ramental scale two or three cells thick. $X$ IIo.

Photomicrograph 4.-Cycadeoidea dacotensis. Transverse section through ramentum of bracts (the Cyathea type one cell thick) and the bract itself. $\times 20$.

PLATE XXXIX. Cycadeoidea dacotensis. Sections of young axes of fructification cut from T. $2 \mathrm{r}_{4}$ in form of cylindrical cores. All natural size.

Photograph 1.-S. 512 (axis vi). (For position of this and other axes cut from T. 2I4 see text-figure I4, and the two other figures, 89 and 94.) Radial longitudinal section of trunk cutting through the medulla $(m)$, xylem $(x)$, cortex $(c)$, and armor, so as to pass through the entire length of a young fructification and its cortical bundle trace in the median vertical plane. Only the barrel-shaped peduncle densely set with hairy bracts has as yet developed. This young axis is one of six quite regularly disposed circularly about the crown of non-emergent young leaves at the summit of the trunk. All six projcated as conical masses of ramentum rising three or four centimeters above the armor, and are evidently in much the same incipient stage of growth or arrested development, as the casc may be. The arrow to the right indicates the relation of the section to the axis of the trunk. (The terminal ramentum is present in the section to a distance of about three cent:meters further than shown in the photograph.) (See figure 95.)

Photograph: 2.-S. 520 (axis viII). Transverse section of a cylindrical core passing from the cortex into the armor in an obliquely tangential plane to the trunk. The present 
is a highly instructive section; it first cuts a cortical peduncle trace above, and then passes through a peduncle insertion and various adjacent leaf bases below. (See figure 96.)

Photograph 3.-S. 490 (axis II). Median vertical longitudinal section through an ovulate strobilus and all of its peduncle, a small portion of the outer cortex being visible to the left in the photograph. An hypogynous annulus of wilted tissue, doubtless the basal remnant of a dehiscent disk, appears at base of the ovulate cone. (See figure 99.)

Photograph 4.-S. 5I5 (axis vII). Median vertical longitudinal section through a bisporangiate strobilus passing from its summit through the entire length of the peduncle to its insertion on the cortex. The sporophylls appear to have been partially macerated or otherwise broken down before silicification, although the numerous more or less displaced synangia have reached a full size and are well preserved. The central ovulate cone is partially preserved and in normal position. The complete agreement in length and development of the peduncle of the present and the ovulate forms is especially to be noted.

s. $n$., synangia; $o$, base of ovulate cone; $s$, insertion of the partially conserved pollenbearing disk; $l$, axillary leaf-base insertion on cortex. (See restoration, figure 7I.)

[Position of axes VI, VIII and II on trunk appears in figure 94; of VII in figure 14.]

\section{PLATE, XL. Cycadeoidea dacotensis. Serial Thin Sections through Ovulate Strobilus.}

The fifth axis of fructification drilled from T. 214 in the form of a cylindrical core. $X$ I.25. (For position on trunk see text-figure 14, p. 47.)

Photograph I.-S. 499. Section cut in an exactly radial longitudinal plane of the trunk and passing through the entire length of an ovulate axis and the surrounding armor, as seated on the cortex. In the photograph the summit of the cone is slightly restored, but in the specimen itself very little of the apex is eroded away, so that a slightly more tangential section would have appeared complete. That the section fortunitely is, as cut, a very exactly radial and median longitudinal one is testified to by the fact that bracts are cut throughout all of their length preserved on both sides of the peduncle. All the photographs of the present plate are reproduced $I^{I} / 4$ the natural size, this slight enlargement being deemed a minor matter so far as concerns the ovulate cones, those in the same stage of growth varying greatly in size, and in some trunks-notably in the in-every-way-comparable T. 54-reaching nearly twice the diameter of the present example. The planes 501-503, 505, 506,508 , and 509 are those of the respective transverse sections shown in the photograpls 2-8. (See text-figure 100.)

Photographs 2-8.-Serial transverse sections 50I-503, 505, 506, 508, and 509, from the same cylindrical core as S. 499 (photograph I), but from the opposite half. (It would have been better to have made the transverse series from the same half as the longitudinal section.) The respective planes of the several sections are vertical to the lines numbered in correspondence with the sections in photograph I. The several arrows indicate direction vertical to the trunk.

The handsomest feature revealed is the basal fluting of the cone due to bract appression ( $c f$. photograph 3 ), and the most interesting, the hypogynous annulus of wilted tissue $(s, s$, photograph 4.) The woody cylinder of the karrel-shaped peduncle, in the present instance but little flattened except near the peduncle insertion on the cortex, is distinct, as is likewise the cortical peduncle trace. ( $C f$. photographs 5 and 6 , also 7 and 8.)

\section{Plate XLI. Cycadeoidea dacotensis. Serial Sections through a Young} Strobilus.

The fourth axis drilled from T. $2 \mathrm{I}_{4}$ in the form of a cylindrical core. An incipient fructification similar and similarly borne to that shown in longitudinal section in photograph I, plate $\mathrm{xxxix.} \mathrm{For} \mathrm{position} \mathrm{on} \mathrm{trunk} \mathrm{see} \mathrm{figure} \mathrm{94,} \mathrm{IV,} \mathrm{and} \mathrm{photograph} \mathrm{12,} \mathrm{plate} \mathrm{v1.}$

Photograph I.-S. 369 (T. 214). Natural size. Radial longitudinal section of trunk passing from the medulla $(m)$ through the xylem $(x)$, costex $(c)$, and armor, thus cutting an entire lateral axis in its median vertical plane. The entire bundle course from the xylem 
(x) through the cortex (c) into the peduncle and axillary leaf base is traversed by this section. Especially to be noted is the downwardly directed elbow of the most nearly axillary leaf to the right, apparently produced by the growth and emergence of the peduncle. The accompanying serial transverse sections are from the same half of the cylindrical core as the longitudinal section, and their planes were originally indicated on the section by the graphite lines and Roman numerals I to VII, an inconvenient notation for use in plate legends; whence the transverse sections photographed are in addition indicated in their respective positions by the section number at the right of the photograph.

Photographs 2-7.-Twice natural size. Transverse sections 371, 373, 377, 379, 380, and $38 \mathrm{r}$, from the same half of the same fruit as the accompanying S. 369, photograph I. The arrows indicate direction vertical to the trunk. Section 38r traverses the conical mass of bracts and bract hairs several centimeters above the outer armor, or trunk surface. The most interesting section is No. 380 (photograph 3 ), passing through the apex of the peduncle and disclosing no distinct fronds or central cone. Several sections were cut through the summit, but No. 380 is the best. There is a slight but not definite suggestion of division into segments. Section 371 (photograph 7) is of interest as passing tangentially through the woody cylinder of the trunk or trellis of collateral bundles, in the meshes of which large crescentic bundles are seen to arise, with the xylem above and phloem beneath. The leaf bases surrounding the present fruit are still young and the immense size of the areas of radially arranged centrifugal xylem-the only bundle element preserved-is noteworthy. A vegetative rather than a fruiting branch might at first have much the appearance of the present axis, although bracts or scale leaves appear throughout the Cycadeoidex to be mostly characteristic of axes of fructification.

Plate XLII. Cycadeoidea dacotensis. Serial 'Thin Sections through a Young Ovulate Strobilus. Tenth axis studied from T. II4. [Cf. figure 89, x.]

Photograph I.-S. 540. $\times 2$. Longitudinal section through a small cylindrical corc, cutting an ovulate strobilus and a portion of its peduncle in the median vertical plane. The present longitudinal section was made after the three transverse sections $a, b$, and $c$ were cut, by cementing the four resulting segments of the fruit together again in their natural position, recorded by a plaster mold as described in Chapter III. The present is believed to be the first instance of the cutting of complete complementary longitudinal sections from silicified plants. As in other such strobili from T. 214, remnants of an hypogynous and dehiscent disk are unmistakably present.

Photograph $\mathrm{I}$ b.-S. 538. $\times 2$. Transverse to preceding in vertical plane $b$. Intcrestingly enough, several isolated synangia appear between the cone and the appressed ramentum. One such may be seen plainly in the present view just below the arrow as it crosses the space between the cone and ramentum to the right.

Photograph Ic.-Central portion of S. 537 (transverse to 540 in plane c). X 5 .

PlATE XLIII. Ovulate and Bisporangiate Strobili of Cycadeoidea in various Stages of Growth and Development.

Photograph 1.-C. Colei (?). S. 284. X 3.2. A very young ovulate cone cut in slightly oblique direction, showing a seed pedicel zone bounded by ramentum on one side and a shoulder $(D)$ on the other side. Whether an aborted disk is indicated or a nonfertile disk, or a dehiscent matured staminate disk, is not determined. Needless to sa.y, in such an instance as the present, such facts can as little be determined from a single section as from serial sections from a single fruit. All the facts can be learned only from longitudinal and transverse sections cut from a considerable number of axes borme by the same trunk; even then the results from trunks in different stages of growth must be further compared.

Photographs 2 and 3.-Sections II4 and I36. X 3.2. ( $\digamma_{0}$ Paynci?) Transverse sections through basal portion of a disk-bearing axis (2) and its peduncle (3). It is especially 
to be noted in photograph 2 that the fluting of the sterile base of the central cone as surrounded by disk remnants is distinct, whereas in the fruit shown in photograph I the seed zone is well developed for so young and small a fruit quite to the base of the cone. As before, safe deductions as to the conditions indicated may only be made from such appearances and stages of growth when it is known how constantly they appear in series of fruits from the same and different trunks.

Photograph 4.-Cycadeoidea dacotensis (T. 549). S. 29I. X 3.2. Transverse section through an ovulate strobilus, with the receptacle, seed-pedicel zone, ramentum, and bracts all clearly indicated, but without clear differentiation of individual cells, the several tissue zones being traversed by pheno- or sphrrocrysts. This strobilus is one of a group of five in a quite similar stage of growth.

Photograph 5.-Cycadeoidea dacotensis (?) (T. 505). An ovulate cone with half of the seed pedicel region $(S)$ split away from the conical-shaped receptacle $(R)$ during the process of erosion from the rocky matrix in which the trunk was embedded. A photograph of a longitudinal thin section of this cone nearly parallel to the eroded surface here seen is the subject of plate xxxI, and text-figure 28 is a diagrammatic representation of the cylindrical transverse section of the armor of the cylindrical trunk fragment from which the cone was cut. In this latter view the present cone does not appear, having been removed for sectioning previous to the polishing of the remainder of the trunk in the form of $a$ columnar segment. [The true species of this fruit remains in some doubt.]

Photograph 6.-Cycadeoidea Wellsii (?) (T. 400). S. 348. × 3.2. Transverse section of a cone with a space $(s)$ between it and the enveloping bracts, apparently left by the shedding of a disk. At $c$ in the cone a cavity has been left by the flowing out into the space $s$ of part of the pithy receptacular tissue when in a macerated condition previous to silicification or else a viscid or gelatinous condition after silicification.

Photograph 7.-Cycadeoidea Paynei (T. 434). S. 467. X 3.2. Longitudinal section through a bisporangiate strobilus. $R$, receptacle; $D$, staminate disk borne hypogynously to the large but young apical cone $(S) ; d$, abscission line of disk; $f$, mass of wilted and more or less broken-down pinnules of the microsporophylls with intermingled synangia; $b$, enveloping bracts.

The present strobilus is of great importance because cut from a well-conserved half of a trunk, and because it is clearly an example of staminate inflorescence in the Bennettites Gibsonianus, B. Morierei, C. Paynei, C. Wielandi, and C. turrita group of cycadeoidean species.

\section{Plate XLIV. Cycadeoidea. Young Strobili.}

Photograph I.-S. 410. X 2. A small isolated ovulate cone cut in both longitudinal and transverse section. A disk insertion is plainly present at the base of the cone, although the disk, as seen in the transverse section $s s$ below (from the plane of the saw cut $s s$ of the longitudinal section), appears to have loosened. Its apical portions are not preserved.

Photograph 2.-S. 4II. X 2. Serially mounted supplementary transverse sections from the same cone as the preceding, with their respective planes indicated by the lines $a-e$ in photograph I. Section $b$ shows distinct basal fluting of the central cone.

Photograph 3.-Cycadeoidea dacotensis. S. 47. T. 719. X 2. Young and fluted ovulate cone surrounded by numerous closely packed bracts, with finely silicified leaf base.

Photograph 4.-Cycadeoidea minnekahtensis (?). S. 399. T. 229. X 5. Longitudinal section through summit of very small ovulate cone. ( $C f$. the illustrations showing a larger cone from T. 229, plate XxxII; also the appended note.)

Photograph 5.-Cycadeoidea minnekahtensis. S. 351. × 2. Serics of bracts with nonpreservation of strobilus.

Photograph 6.-Cycadeoidea superba (type). S. 412. X 2. Transverse section through an axis borne prominently near the summit of one of the branches. Only the outline of the central strobilus is clearly indicated, but faint outlines suggest a bisporangiate condition. 


\section{PLATE XLV. Bisporangiate Strobili of Cycadeoidex. (I) Preserved as an impression on a flat slab; (2-4) silicified entire.}

Photograph I.-Cycadocephalus Sezvardi Nathorst (103). I, Natural size. Supplementary figures $\mathrm{I} a$-I $c$ show the respective areas, $a, b$, and $c$, enlarged twice.

This cycadeoidean strobilus occurs preserved as impressions on flat slabs in plantbearing bed $a$ of the Trias of Bjuf, Southern Sweden; and in accord with Williamson's original conception of the disk of Zamites gigas (202) it has been supposed to represent a disk composed of inwardly-deflexed carpellary fronds. But while not primarily impossible that such disks should occur, it is more likely that in the present instance fructification is bisporangiate. If so the bodies at $c$ (figure Ic) are not megasporangia but synangia, and there must be present beneath them an apical ovilate cone much like the silicified cone seen in longitudinal section in photograph 4 . In either case figure I shows a very instructive example of the preservation of strobilar forms like the foregoing silicified strobili as impressions on flat slabs. Each of these two modes of preservation aids in the interpretation of the other. For the meaning of the structures at $b$ and $c$, see photograph 3 below.

Photographs 2 and 3.-Cycadeoidea dacotensis. External view of an upper and a lower portion respectively of an ovulate strobilus divested of its enveloping bracts. In 2 the rachis of the staminate fronds of the disk are also split or eroded away in all the upper region, disclosing the synangia at $c$ and the insertion of the pinnules of the sporophylls at $p . p$. Moreover, the long, deep furrows mark the inner edge of each microsporophyll rachis, and the branches sent from these the inner edges of the alternately inserted pinnules, thus clearly indicating the once-pinnate character of the microsporophylls or staminate fronds into which the staminate disk divides. Note especially that the pairs of pinnule insertions, $n, p$, are not those of the same, but two adjacent rachides. While this surface is not precisely the same as at points $a$ and $b$, figure $\mathrm{r}$, there is relative similarity, and it seems pretty clear that in both instances the attachment of the pinnules of a once-pinnate frond laterally to the rachis is indicated:

Photograph 3.-Showing the basal region of the strobilus. The fronds of the disk are not split away and the surface features are precisely comparable to those of Cycadocephalus (figure I).

Photograph 4.-Cycadeoidca dacotensis. T. 214. S. 360. $\times 5$. View of central ovulate cone enlarged four times. It will be observed that a thin zone of clear silica lies outside the tips of the small micropylar tubes and the interseminal scales.

As already noted in the text, this would make possible the development by polishing such a cone so as to display its surface features in great perfection. The obliquely set pedicels and scales of the lower right-hand portion of the cone are in part cut nearly transversely. On the left the very young seeds are especially well indicated and a number are cut in so exactly the median longitudinal plane that the entire lengths of the micropylar tubes appear.

\section{Plate XLVI. Williamsonia gigas Carruthers.}

Various imprints and casts of strobili from the Yorkshire coast, now partly in the Paris Museum. From Saporta, Plantes Jurassiques, vol. IV, plates xviri and ccxivi (I25). The interpretation of these fossils as given in the following legends differs from that of Saporta. All figures $\times 0.8$.

Figure 1.-Cast reproduction of specimen shown in figure 4, exhibiting the true outline of the basal portion of an ovulate strobilus with its surrounding bracts. Receptacle globular; only the closely set basal and sterile sporophylls and scales being indicated. Such a strobilus might or might not have earlier borne an hypogynous staminate disk. The size as well as the general form and appearance of the bracts, the receptacle, and the sterile basal region all find their near counterpart in the silicified strobili borne by several of the Black Hills trunks, notably the fine specimens of Cycadroidea dacotensis. The Yorkshire fruit on which the reproduction is based must in fact be closely related to the silicified $C$. dacotensis specimens generically if not even specifically. One of the main differences in general appearance is due to the completer preservation of the latter, including the profuse 
bract hairs. ( $C f$. the fruit marked $O . S$. in natural position on the trunk shown on plate $v$, photograph 2. Also see counterpart, figure Io, plate xLvir.)

Figure 2,-Similar to the preceding, but showing the receptacle at its basal and most constricted point.

Figures 3 and 7.-These orbicular leafy bodies have usually been considered as apical, and explaining the manner in which the so-called "pyriform axis" of Williamson terminated. The form of this axis being also accounted for by the position of the parts of the unexpanded bisporangiate strobilus, these orbicular growths may perchance represent: $(a)$ A terminal leafy growth of the ovulate strobilus as supposed by Saporta and Lignier; $(b)$ a funnel-form calyx of either a bi- or simply macrosporangiate strobilus; or, $(c)$ as is quite likely, as an Alphlebia-like leaf of some accompanying plant. See legend, 5 and 6.

Figure 4.-A cast similar to that shown in figure 2, but with the bracts completer and suggesting the general size and outline of the ovulate cone. Globular receptacle not conserved. ( $C f$. figure I.)-Specimen 2402, collection of Paris Museum.

4a.-Surface details from sterile region at base of preceding cone.

Figures 5 and 6.-Respectively the prepared cast and original natural mold of a strobilus with a conical instead of globular shaped receptacle, which in the cast appears to terminate as a pyriform axis. A possible explanation of the salver-shaped summit is that it is not a true organic continuation of the conical ovulate receptacle, bearing sterile scales below with the ovulate region mostly split away, but a cast of the central funnel-form depression at the summit of an unexpanded bisporangiate strobilus, the lateral groovings simply being the imprints of decurved rachides of the microsporophylls. Compare with various textfigures in Chapter VII, showing the summits of unexpanded bisporangiate strobili. Some central cones may have terminated in a spreading silky or scaly mass.

Figure 7.- See legend of figure 3 .

PLATE XLVII. Ovulate Strobili of Cycadeoidea. From Jurassic of England and France, as figured by Saporta, Plantes Jurassiques, vol. IV, atlas (I25).

Figures I-4.-Bennettites Morierci Saporta et Marion. Partially bract-covered ovulate strobilus with microscopic structure preserved in iron carbonate. From the Middle Oxfordian Jurassic of Vaches Noire (between Villers sur Mer and Auberville), Calvados, - Vormandy. The type specimen is the only one known and is now in the collections of the University of Caen. It has been made the subject of elaborate memoirs by Lignier $(82,85)$.

I. Strobilus, natural size.

Ia. Enlarged view of surface, showing the interlocking system of pericarp rosettes formed by the nail-head-like termini of the interseminal scales surrounding the micropylar tubes. The strobilus is generically related to some of the Black Hills forms.

2, 3, and 4. Structural details of cone near summit of seed stems as revealed by the splitting away of the outer portion of the cone. (2) Adjacent seeds borne apically on their pedicels. (3) Ends of sterile sporophylls or interseminal scales and adjacent seeds. (4) 'The same as 3, but near the lowermost seeds. Enlarged about four times.

Figures 5-8.-Williamsonia Bucklandi Saporta. From Lower Oölite of Charmouth, Dorsetshire, England. Collection of the Museum of Oxford. Figures 5, 5a, 6, 6a, and 8 originally from Buckland (I8).

5. An entire fruit divested of its enveloping bracts and showing the rosette-marked epicarp made up of the interlocking hexagonal series of five to six sterile scales surromnling each seed. $\times 0.8$.

5 a. Surface view of same enlarged.

6. Seed slightly reduced. $\times 0.8$.

$6 a$. Seed enlarged four times.

7. Portion of surface of ovulate strobilus shown in figure 5, enlarged to show details of the pericarp rosettes of interseminal scales and relation to surrounding stigmatic openings.

8. Same as preceding, further enlarged. Compare these figures with the photographs of similar features of the Black Hills specimens, plate xxm, and with text figure 57. 
Figures 9, 9a, and 10.-Williamsonia gigas. Natural molds or casts of ovulate fruits from the cliffs of Hawkser and Runswick, coast of Yorkshire, near Scarborough, together with an artificial cast.

9. Mold of basal portion of an ovulate strobilus with inprint of sterile organs. A Whitby specimen sent to Brongniart in 1847 .

9a. An artificial cast made from the preceding natural mold. The cast very clearly displays the true nature of the original strobilus. Compare the receptacle with that of the exactly similar silicified strobilus from the Black Hills shown on plate XLII, photograph 5 .

I0. Involucre of bracts from cast of interior face of ovulate cone, with part of sterile basal region and globular to conical hollow indicating the form of the receptacle. (See figures $x$ and 4 of the preceding plate.)

PLA'TE XLVIII. Views from the Southern End of the Cycad Valley, Meade County, South Dakota, showing Piedmont-Black Hawk locality in upper cycad horizon of the Eastern Black Hills Rim.

Photograph I.-Cycad Hill (I,I89 meters), at the southern end of the Cycad Valley, $2^{\mathrm{T} / 2}$ miles north of Black Hawk. N. lat. $44^{\circ} \mathrm{II}^{\prime} 30^{\prime \prime}$; W. long. 103 ${ }^{\circ}$ 19'. Looking south with Fort Benton plains and Pierre hills or Upper Cretaceous Nos. 3 and 4, respectively, in the far distance. Dakota sandstone (Upper Cretaceous No. I) outcrops at the group of Pinus ponderosa in the left foreground. Wealden sandstones (Jurassic or Lower Cretaceous) form the main foreground and the anticlinal hill to the right yielding varions cycadcoidean trunks, as C. ingens, Jcnneyana, rhombica, Stilwelli. Over all of the foreground various more or less complete trunks were secured, and at the edge of the thick copse of large pines near the top of the hill $(x)$ Wieland found many fragments of C. Jenneyana, including a fine summit of a large trunk, this being one of the only two summits of trunks of this species ever recovered. Over the brow of the hill to the right, and beyond a deep gorge cut well back into the anticlinal, portions of very large and fine columnar trunks were obtained. Much Araucarioxylon wood accompanies the Cycadean trunks. Cycads were first observed at or near this hill in 1877 , and a portion of a trunk taken away in that year is included in the Yale collections.

Photograph 2.-Cycad Hill, looking south, as indicated by the arrow, into heat of ravine mentioned in legend of photograph $I$. Both in the foreground and amongst the small, thickly set pines to the left of the hill various fragmentary specimens could be obtained formerly, although few or none now remain. Erosion over most or all of the anticlinal surface in this view has passed beneath original level of the silicified cycadean trunks, except to the right of the area seen in the picture, where the cycad horizon passes beneath a talus lining the front of ridge forming the western border of the Cycad Valley.

Photograph 3.-Looking north. High southeastern border of Cycad Valley, 200 meters east of where $C$. ingens type was obtained, and about 300 meters northeast of top of Cycad Hill. All the foreground is a fossil cycad landscape or uncoved cycad stratum, and specimens would appear in the photograph just as they originally occurred, had they not been removed. In the distance the northern edge of Cycad Valley appears, as well as the faint outline of the Black Hills, interior to the "Rim."

PLATE, XLIX. Views of the Cycad Valley, Eastern Black Hills Rim, South Dakota. Continued from Plate XLVIII.

Photograph I.-Northern slope of the Cycad Hill, looking northeasterly across the outlet of the Cycad Valley, and over its southern and eastern border $(R)$. The man in the right foreground is at the exact spot where C. ingens type (plate 1) was obtained

Photograph 2.-The Cycad Valley, looking north from the slope in the extreme right of the preceding photograph, $(R)$ being the same hill. The star in the middle distance denotes the Bear Butte (altitude $1,3 \% 0$ meters), exactly 20 miles north-northwest. The present photograph clearly displays the main features of the Cycad Valley anticlinal. The valley itself has its greatest length of about 2 miles from north to south and is about I 
mile wide. It is from 100 to 125 meters deep, but its existence is not indicated on the contour map of the U. S. Geological Survey. The base of the valley is mostly marine Jurassic (Baptanodon beds), but in places, as at $T$, the Trias is exposed.

Photograph 3.-Summit of high bluff at northern end of the Cycad Valley, with large cycadean trunk (T. 208, figure 44) raised from its in situ original position. This location is of especial interest because the large trunk here found can have been displaced but little or not at all during erosion. ( $C f$. I78, p. 564.) The horizon is identically the same as that of the Cycad Hill specimens 2 miles south.

\section{PLATE L. Upper and Lower Cycad-yielding Strata of Eastern Black Hills Rim, near Piedmont, South Dakota, in the Piedmont Black Hawk region.}

Photograph r.-Upper horizon. Straticulate sandstones forming Goblin Arch at the northern border of the Cycad Valley, about I25 meters west of the cycad locality shown in preceding photograph, plate XLIX. The top of the arch marks the lower limit of the cycadbearing stratum, which consists at this point in deeply iron-stained to light flesh-colored sandstone, and is succeeded by a heavy capping of quartzitic sand rock belonging to the Dakota Cretaceous of Meek and Hayden. In the latter stratum but little silicified wood occurs, while in the stratum beneath immense silicified Araucarioxylon logs are associated with the cycads. A few hundred feet from the Goblin Arch the smaller end only of a long section of an Araucarioxylon trunk I meter in diameter projects from its natural bed of deeply iron-stained sandstone. This is essentially the same horizon as that which yields the cycads of the old locality at the southern end of the Cycad Valley, where, however, there is rather less iron staining. The evident continuation of the beds at the summit of the Cycad Hill around to the northern end of the valley led the writer to the repeated and persistent search which resulted in the discovery of the splendid trunk No. 208 (cf. figure 44) at the point shown in the preceding photograph. It is also of interest to note that the writer has secured cycad trunks in situ from both straticulate sand rock of nearly similar character and much iron-stained sandstone superimposed, at Minnekahta, in the Southern Black Hills, 60 miles southwest of the Cycad Valley. The relations are evidently alike in both these localities.

Photograph 2.-Lower cycad-bearing horizon of the Black Hills Rim, as seen II/2 miles east of Piedmont at the quarry made by the writer to secure the type specimen of the huge Dinosaurian Barosaurus lentus Marsh. This lower horizon consists mainly in dark or chocolate-colored to lighter and arenaceous clays, extending around the entire Black Hills Rim, except for a few miles on the southeast. In it the trunks of the genus Cycadella occur rarely, associated with more frequent silicified wood and the skeletons of Dinosauria and turtles ( $c f$. page 8 ). Various sandstone, with occasional clay strata, aggregating from 30 to 60 meters thick, intervene between the lower and upper Black Hills cycad horizons. 


\section{TEXT FIGURES.}

FIG. I. Cycadeoidea Marylandica (type).....

2. Cycadeoidean strobili and associated fronds from the Jurassic of India. .

3. Ryûgeji Temple garden, [facing]...

4. Tuberous and low-growing columnar cycadean trunk types ...........

5. Angiopteris Teysmanniana, habitus of

6. Bowenia spectabilis, plant and fruit..

7. Cycadeoidea Goucheriana (type) ...

8. Cycas revoluta.-"Shishi," or lion's

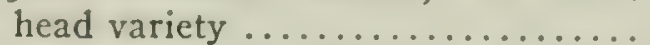

9. Cycas revoluta.-"Shishi," or lion's head form ....................

I0. Cycas revoluta.-"Hoso" or "treeformed palm," and "Shishi" form.

II. Zamia vernicosa (?), branching plant

12. Anomozamites minor, restoration....

I3. Cycas revoluta, plantation in Ceylon..

I4. Cycadeoidea dacotensis (Trunk 214)

I5. Armor development of existing cycad-

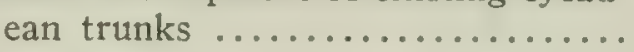

16. Cycad and fern ramental types......

17. Encephalartos villosis ............

18. Cycadella ramentosa, ramentum ....

19. Cycadeoidea ingens, leaf base.......

20. Cycadeoidea turrita, armor section...

21. Cycadella utopiensis, armor section..

22. Cycadeoidea turrita, armor section..

23. Cycadeoidea Wielandi, armor section.

24. Cycadeoidea sp., armor section......

25. Cycadeoidea sp., armor section.......

26. Cycadeoidea sp., armor section......

27. Cycadeoidea ingens, armor section...

28. Cycadeoidea dacotensis (?), armor section ....................

29. Cycadeoidea sp., armor section.....

30. Cycadeoidea dacotensis, leaf bases ..

3I. Cycadeoidea nigra, armor...........

32. Bundle patterns and petiole bases of existing cycads ................

33. Leaf-base bundle patterns of various cycadeoidean species ...........

34. Cycadeoidea dacotensis, vascular bun-

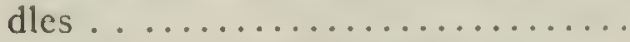

35. Cycadella sp., trunk section........

36. Cycadeoidea Wielandi, trunk section. .

37. Cycadeoidea Wielandi, trunk section..

38. Cycadeoidea Wielandi, trunk section. .

39 A-C. Cycadeoidea Wiclandi, peduncle. 73,73

40. Cycadeoidea Wiclandi, woody cylinder

4I. Cycadeoidea Wielandi, woody cylinder

4IA. Cycadeoidea Wielandi, woody cylinder

42. Cycadeoidea Wielandi, woody cylinder

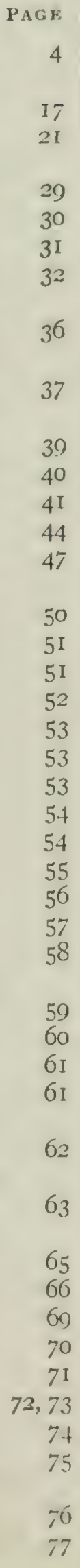

FIG. 43. Cordaites Newberryi, woody cylinder

44. Cycadeoidea ingens, Trunk 208 [facing]

45. Cycadeoidea ingens (type), leaves...

46. Prefoliation of existing cycads, type I

47. Prefoliation of existing cycads, type II

48. Prefoliation of existing cycads, type III

49. Cycadeoidea ingens (type), leaves ... 88,8

50. Bowenia spectabilis, pinnule ........

51. Cycadeoidea ingens, prefoliate frond.. 93

52. Cycadeoidea sp............... 99

53. Zamia Vroomi ................. 103

54. Cycadeoidea ingens (restoration of

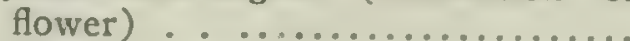

55. Cycadeoidea sp., ovulate fruit surface

56. Cycadeoidea, ovulate strobilus .......

57. Cycadeoidea, surface of ovulate cones

58. Cycadeoidea Wielandi, cones .......

59. Cycadeoidea Wielandi, trunk and cone

60. Cycadeoidea Paynei (?), bracts......

61. Cycadeoidea Wielandi, seed stems and interseminal scales .............

62. Cycadeoidia turrita, seed surface...

63. Seeds of Cycadeoidex ..............

64. Cycadeoidea turrita, ovulate cone in longitudinal section ............

65. Cycadeoidea Jenneyana (?), ovulate cone in longitudinal section........

66. Cycadeoidea dacotensis (?), ovulate cone in longitudinal section.......

67. Cycadeoidea Marshiana, ovulate cone in longitudinal section ...........

67A. Cycadeoidea Marshiana, serial sections through ovulate axis.........

68. Cycadeoidea superba, ovulate cone...

69. Cycadeoidea, restoration of ovulate cone.......................

70. Cycadeoidea dacotensis, restored flower

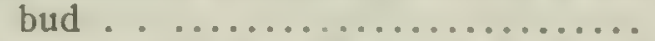

7I. Cycadeoidea dacotensis, longitudinal section of bisporangiate strobilus..

72. Cycadeoidea dacotensis, longitudinal section of bisporangiate strobilus..

73. Cycadeoidea dacotensis, transverse sections of bisporangiate strobilus, I46, I47

74. Cycadeoidea dacotensis, transverse sections of bisporangiate strobilus....

75. Cycadeoidea dacotensis serial transverse sections of bisporangiate axis . . ..................... I50, I5I

76. Williamsonia gigas, cast of bisporangiate strobilus . ...............

77. Willicmsonia gigas, imprint of staminate disk ................. 153

78. Zamia gigas, "carpellary disk"..... 154
$A G E$

78

83

84

85

86

(1)

9

106

109

I IO

I II

II 2

II 3

II6

II9

I2I

122

129

I 3 I

I 32

I 33

134

I 35

I36

I 38

I4

I 45

149 
Fig. 79. Cycadeoidea, bisporangiate strobilus.

8o. Cycadeoidea dacotensis, structural details of bisporangiate strobilus....

8I. Cycadcoidea dacotensis, synangia .... 82. Cycadcoidca dacotcnsis, synangium...

83. Pollen grains of existing and fossil cycads (including Stephanosper-

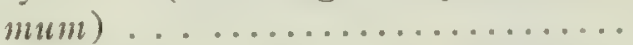

8. Cycadeoidea dacotensis, markings on pollen grains .................

85. Cycadeoidea dacotensis, transverse section of bisporangiate strobilus....

86. Cycadeoidea dacotensis, synangia....

87. Cycadeoidea dacotensis, flower......

88. Cycadcoidea, flower bud in longitudinal section . .................

80. Cycadeoidea dacotensis, Trunk 2I4..

9o. Young fructifications of Cycadenidea

91. Cycadeoidea pulcherrima, strobilus...

92. Young fructifications of Cycadeoidea

93. Transverse sections of young bisporangiate strobili of Cycadeoider...

94. Cycadeoidea dacotensis (Trunk 2I4) [facing] . ....................

05. Cycadeoidea dacotensis (T. 214), radial and transverse sections of axis IV. 178,179

96. Cycadeoidea dacotensis (T.2I4), axis

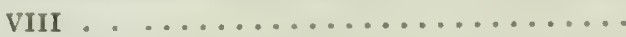

97. Cycadeoidea dacotensis (T. 214), axis $\mathrm{X}$ in radial and transverse section. .

98. Cycadeoidea dacotensis (T. 214), transverse sections of axis XIV....

99. Cycadeoidea dacotensis ( T. $2 \mathrm{I} 4$ ), longitudinal section of axis II........

IOO. Cycadcoidea dacotensis (T. 2I4), serial sections of axis $v \ldots \ldots .83,184,185$

roI. Dion cdule, staminate plant........ I 88

102. Cycas Normanbyana and Cycas media,

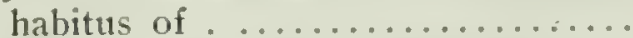

103. Zamia san Houtteii, habitus of.....

104. Zamia Roczlii, habitus of..........

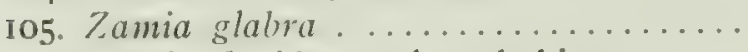

106. Zamia floridana, plant habitus......

107. Zamia floridana, staminate cones.....

108. Extremes of variation in size and form of trunks of existing cycads......
PAGE

I 55

156

157

158

I59

160

I6I

162

I64

165

I 68

170

I 7 I

173

175

176

I80

I8I

182
Ceratozamia Mexicana (?) - " in6

I

III. Macrozamia Fraseri, trunk ....... I9?

I12. Cycas revoluta, young trunks...... 200

I13. Zamia floridana, conical transverse

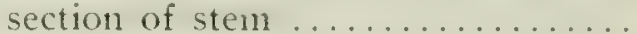

I I. Cycas Rumphii, plant bearing partially

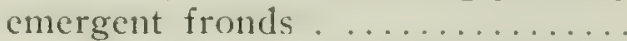

II5. Cycas neo-caledonica, staminate plant

II6. Cycas siamensis (?) .............

I17. Cycas media, a small plant.........

II8. Encephalartos Ghellinckii .........

I 19. Dion cdule, entire plant..........

120. Stangeria paradoxa and oak seedlings

I 21 . Very young cycad fronds..........

122. Margin, nervation, and other characters of cycad fronds.............

123. Pinnule forms in Encephalartos and

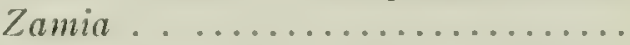

24. Microsporophylls of Cycadacez

125. Sori and synangia of existing Maratti-

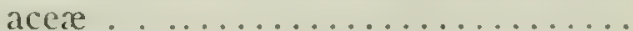

126. Megasporophylls of the Cycadacer... 127. Cycas circinalis, developing and mature ovules ................

28. Bilateral and radiosymmetric megaspore bundle traces of various $\mathrm{Cy}$ -

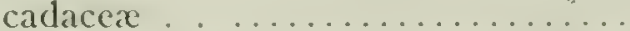

I29. Concentric megaspore supply and other bundles of existing cycads..

I30. Stangeria paradoxa, transverse section of a staminate peduncular bundle.

I3I. Cycas revoluta, transverse section of bundle from stalk of a carpel.....

I32. Poroxylon Edwardsii, transverse sec-

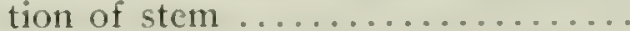

133. Welcuitschia mirabilis or Tumboa,

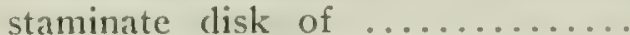

134. Zamia floridana, monstrous ovulate cone..............................

I35. Encephalartos villosus, monstrous ovulate cone ....................

136. Zamiostrobus stcnorhachis and C.ycadospadix Hennoquei......... 23.

137. Archapteris .............. 2.33

I38. Dictyosamites indicus .......... 2.34 
IN DEX. 



\section{N D EX.}

Alsophila excelsa, height of, compared with cycads, 36

Amentacea, 245

American Museum of Natural History, cycad collection secured for, 8

Aneimites, discovery of seeds of, 246

Angiopteris, 216, 237, 240, 246

Angiopteris crassipes, sorus of, *2I5

Angiopteris evecta, 24 I

Size of stem, 35

Sporangium of, I59

Angiopteris Teysmanniana, *30

Angiosperms, possible ancestry of, 38, I43, 245

Anomozamites, 44, 228

Anomozamites minor, 38, *4I, 244

Arancaria brasiliana, pitted tracheids of, 75

Araucarioxylon, occurrence in form of logs in talus of Black Hills rim, 33, 34, 100

Archangiopteris Henryi, sorus of, $*_{21} 5$

Armor of-

Cycadacece, 193, 205, 206

Cycadeoidea, 5 I- 66

Artificial staining of silicified plant tissues, 9I, I32

Atlantosaurus Beds of Marsh, 23, 24, 94, 95, 100

Balantium antarcticum, stature comparison, 36

Barosaurus, occurrence in lower cycad horizon of the Black Hills, 100

Bennettitales, 236, 237

Bennettitea, I 39, 236

Bennettites Gibsonianus, 15, 16, 33, 67, 108, 127, I37, I39, I40, I4I, I43, [233]

Described by William Carruthers, I 5

Discovery of ovulate strobili of, I07, 139

Embryos of, I6, I07, I24

Hypogynous disk of, II4

Leaf-base bundle structure, 64

Of bisporangiate character, $\mathrm{I}_{3}$

Ramentum, 52

Stomata of bracts, II5

Bennettites Morierei, 13, 107, I08, 109, I37

Embryo, I2I, I24

Integumentary structures of, I23, I24

Interseminal scales, II8, 120

Of bisporangiate character, I63

Sections of type in Yale Museum, I23

Seeds, $*_{I 22}, 234$

Big Horn Mountains, "Rim" of, 8, I0

Bisexuality, evolution of, in cycad ancestry, 24I

Bisporangiate strobili:

Homologies of, 235

Of Cycadeoidea, I39-167

Of Tumboa, *229

Significance of, 236, 244
Black Hawk, South Dakota, 8, 9, 25

Pollen-bearing cycad trunks from, 143

Black Hills, I4I, I42, 143, 246

Branching cycads of, 31,38

Discovery of cycads in, 7

Exploration in cycad-bearing horizons of, 39 Occurrence of cycad types from "Rim" of, 9 Profusion of young fruits borne by cycad trunks from, 169

Silicified crowns of cycad leaves from, 82, 102

Black Hills Rim, 94, 102

Lower and upper cy"cad-bearing horizons of, 23,24

Blechnum, 239

Blepharoplasts, 216

Borassus flabellifer, branching of, 36

Botrychium, I58, 210

Botryopteris, 239

Borvenia, 3I, 102, I57, 189, 199, 201, 223, 225, 227,233

Leaf-base bundle pattern, 62,63

Borvenia spectabilis, *31, 92, 101

Fronds of, $*_{2 I I}$

Leaf-base bundle pattern, *62

Megasporophyll bundle of, 22I, 233

Pinnule bundle structure, $* 93$

Seed bundle system of, *219, 220

Branching of cycads, 36-44, I9I, I94, 244, 245

British Museum, Black Hills cycad trunk in, 10

Brontosaurus, Ioo

Bucklandia, I4, I6

Calcium oxalate crystals in cycad stem tisstes, 198, 204

California, cycad from Colusa County, 10

Carpels, evolution from asexual sporophytes, $24 \mathrm{I}$ (See Cycas, carpellary leaves of.)

Carpellary disk of Williamsonia, $154,{ }_{5} 6$

Ceratozamia, $189,197,203,207,210,225,226$ Microsporophylls of, 215

Old peduncle bundles in pith of, 196

Petiolar thorns of, 209

Ceratozamia longifolia, pollen of, *159

Ceratozamia mexicanta, *196

Fronds of, *2I I

Megasporophyll of, *217

Pliyllotaxy of cone, 215

Chorionopteris, synangia of, 237

Cocos uncifcra, branching of, 36

Codonotheca, 230

Cordaitales, 76, 126, 195, 212

Cordaites, 90, 92, 166, 230, 240

Pollen of, I60, I6r, 162

IVoocy cylinder of, 79

NotE.-An asterisk preceding the page number deno'es a figure in the text. 
Cordaites-Continued.

Stamens of, 245

Silicified strobili of, 176

Cordaites Brandlingi, 198

Cordaites Newberryi, 75, 76, *78

Cone-axis, structural significance of, 224-226

Cortex of -

Cycadacea $, 66,201-205,206$

Cycadeoidea, 66-74

Corypha umbraculifera, culminant fructification of, $126,128,185$

Cyathea, ramentum of, 52,53

Cyathea excelsa, ramentum of, *51, 53 medullaris, 195, 239

Cycad collections in-

American Museum of Natural History, 7, 9

Johns Hopkins University, 4, 5, 6

State University of Iowa, 7, 39

State University of Wyoming, Io

United States National Museum, 7, 9, 39

Woman's College of Baltimore, 6

Yale University Museum, 8, Io

Cycad Valley, 94

Cycadacea, 102,236

Archegonia of, 2 I9

Bundle system of seed, 219-22I

Cone-axis, structure and significance of, 224226

Cortical bundle distribution (see Trunk structure)

Distribution of existing genera of, 189

Embryos of, 226, 234

Fern-like characters of, 239-240

Fertilization, rôle of generative cell in, 216

Foliage of, 209-2I3

Fructification of, 21,3-226

Fruits of, 226

General description of, $189-226$

Leaf development of, 209-210

Megaspore bundle supply, 222, 224

Megasporophylls of, 217

Microsporophylls of, 215

Monoxylic trunk forms, I96 Description of, 197-199

Northern limits of, 192

Occidental genera of, 189

Oriental genera of, 189

Ovules of, 217-219

Ovulate cones of, 2I4, 2I5

Pollen of, $2 \mathrm{If}$

Polyxylic trunk forms, 196 Description of, 199

Prefoliation of, $84,85,86,210$

Ramentum, 54

Rarity of defmitely known fossil forms of, 190

Résumé of vegetative characters of, 2I 3

Root of, 207-208

Seed-bundle system in, 219-221

Seed integument of, $2 \times 9$

Simple-stemmed forms, 31

Size of limited by stem structure. 35

Sori of, $* 214,215,216$
Cycadacea-Continued.

Staminate cone, homologies of, 235

Summary of relationships with Cycadeoidea, 226-235

(a) Vegetative characters, 227-228

(b) Reproductive characters, $228-235$

(c) Strobilar homologies, 235

Thorny frond growths of, 212

Trunk structure of, 195-208

Armor, 204

Cortex, 66, 20I-204

Medulla, 195-196

Periderm, 205-206

Vascular zone, 196-200

Cycadalcs, 54, 76, 230, 236, 237, 238, 244

Cycadea, $142,236,237,238$

Causes of stature of, 35

Lateral buds of, 30

Ovulate cone, homologies of, 235

Crecadclla, 22, 28, 3I, 77, I00, I0I, I66, 210, 227

Profuse ramentum of, 51

Size of trunks, 3I

Species of, IO, II

Cycadella ramentosa, 82, 104

Foliage of, 100-102

Pinnule structure, IOI

Rachis, IOI

Ramentum, $*_{52}$

Cycadclla sp., transverse section of trunk, *66

Cycadclla (Cycadcoidea) utopiensis, 8, 9

Leaf bases of, $*_{53}, * 63$

Cycadclla wyomingensis, strobilus of, $167,[229]$

Young bisporangiate strobilus of, $*_{175^{-1} 76}$

Cycadeoid-angiosperm juxtaposition, 243-246

Cycadeoidales, 236

Cycadeoidca, 8, *99, I00, IOI, *I09, *I55, * ${ }_{1} 65,245$

Abundance of cones in certain Black Hills species of, 108

American localities of, 6-10

Armor of, 5 I-56

Expanded strobili of, *Io6, 155, 156, * 164

General character of foliage, 102-104

Generic value of, 30,78

Localities of the Black Hills types of, 9

Maryland types of, 6

Medulla, 77,78

Medullar cavities, 77

Megasporophyll homologies of, 230-23.3

Microsporangiate fructification of, I42, 246

Nuclei of medullar cells, 78

Phloem, 76

Ramentum, 5I-54

Seed resemblances of, 234

Cycadcoidea sp.

Distortion of leaf base spirals in, *60

Leaf bases, $*_{55}, *_{5} 6, *_{57}$

Section $389, *$ I 7 O, I I I

Section through crown of young fronds, *99

Sections 410 and 4 II, I60, * 170

Surface of fruit, * ${ }^{*}$ og

Young iructifications of, $168-174,176-186$

Cycadcoidea Colci, 7, 163

Young fruit of, $17+$ 
Cycadeoidea colossalis, 7, 100

Foliage of, 98, 99

Frond succession in, 104

Ramentum of, 52

Cycadeoidea dacotcnsis, *47, 99, *III, $130, *{ }_{132}$, I $34, * 168,186$

Bisexuality of, 184

Bisporangiate strobilus described, I42, I43.

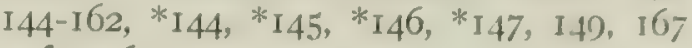

Bracts of, 146

Discovery of type of, 7

Fruiting habit and fecundation in, 184

Growth-stages of, I 86

Leaf-base bundle pattern, $* 61, * 63$

Leaf-base bundle structure, $64, * 65$

Leaf-base spirals of, $* 59$

Ovulate cone of, I33, I $47-149, * 156$

Peduncle, I46, * $I_{5} \mathrm{~J}, *{ }_{5} \mathrm{I}$

Peduncle growth in, I78

Pollen of, * $*_{59}$, * ${ }_{160-162}$

Preservation of cones of, 108

Ramentum, 53, 54

Restoration of energent bisporangiate strobilus, * ${ }_{3} 38$

Staminate disk of, $*_{149-162,} *_{150}, *_{55}$ I, * I5 $_{5}$. I67, 220

Synangia of, $*_{157}, *_{15} 8, I_{5} 9, *_{162}$

Young ovulate axes of (T. 214), I76-186, $*_{I 78}, *_{179}, *_{180}, *_{181}, *_{182}, *_{183}, *_{1} 84$. * 185

Cycadeoidea etrusca, 5, 12

Bisporangiate strobilus of, I39-I4I, I67

Pollen of, I39, * ${ }_{5} 59$

Height of, 33

Scant ramentum of, 54

Cycadeoidea excelsa, stature of, 33, 44

Cycadeoidea gigantea, 16

Habitus of, 33, 36

Leaf-base bundle distribution, 59, 62

Leaf-base bundles of, 64

Nuclei (?) of medullar cells, 78

Stature of, I6, 36,44

Ramentum of, $*_{5}$, 53

Cycadcoidea Goucheriana, *32

Cycadeoidea heliochorea, bisporangiate flowerbud of, * $161, * 162$

Cycadeoidea ingens, 81-97, 82, *83,*88,*89,*93, 98 , I00, 102, 104, I 39, I55, 163

Comparative trunk size and form, 28,36

Discovery of staminate flower-bucl, I 4 I, I 42

Flower-bud of, I62, I63, I67, 229

Foliage of, 84-97

Frond truncation in, 90

Full-grown pinnules and fronds of, 90

Leaf-base bundle grouping in, *59, 63

Leaf bases of, $*_{53}, * 58$

Method for plotting pinnule outline and venation, 97

Petiole preservation in, 9I

Pinnules, 87, 90, 92

Prefoliation, 86, *88, *93

Restoration of strobilus of, * 106

Trunk No. 208, *facing 81, 94-97
Cycadeoidea ingens-Continued.

Woody cylinder of, $78-80$

Cycadcoidea intermedia, I39

C'ycadeoidea Jenneyana, 95, 190

Flower-bud of, 14.3, 162, 163, 167, 230

Leaf-base bundle pattern, 6

Leaf bases, 58

Ovulate cone of, I3I, 132

Tallest cycadeoidean species, 33. 34. 35. 36. H

Trunk form of, 28, 34

Woody cylinder of, $78-80$

Cycadcoidea Maraniana, I39

Cycadeoidea Marshiana, *133, *I34

Bracts of, II 5

Branching of, $38-42$

Fancied resemblances of, 37

Growth-stages of, 186

Large basal branches of, 40

Large section through summit of trunk, 102

Large size of branching forms, 38

Ovulate cone of, $135,1 \leqslant 5$

Ramentum, 53

$C_{y}$ cadcoidea marylandica, *4

Specimens of, in Yale collection, 6

Cycadeoidca Massciana, 12, 22

Cycadeoidea $\mathrm{McBridei},{ }^{*} 6_{3}$

Bisexuality of, I30, I3I

Cy'cadeoidea megalophylla, 33

Cycadcoidea micromyela, I3. 28

Leaf-base bundles, 6I, 64

Pittings of xylem cells, 75

Type possibly a branch, 3 I

Cycadcoidea microphylla, 33

Cycadcoidea minnekahtensis, 38, 23, 135

Collection of type, 7

Ramentum, 53

Cycadeoidea Inontiana, 12, 18

Creadcoidea nigra, T, 12, 22

Height of, 33

Leaf-base bundle pattern, $60, * 61,62 * 63,64$

Peduncle and bracts of. ${ }^{*} 6 \mathrm{I}$

Ramentum, 52

Cycadeoidea Paynci. 7. I 30

Bisexuality of, I30, I3I

Bisporangiate flower-bud of. 16,3-164. 16-

Bracts, II5,*II6

Young fruits of, I7t

Cycadeoidea pulcherrima. 7.*I7I

Founded on a growth-stage, I\$6

Cycadeoidea Raumeriana, stature of, 3.3

Cycadeoidea Reichenbacliana, 12. 33

Cy'cadeoidea rhombica, 28, 33

Cycadeoidea Stantoni, culmination of fructilication in, 185

Cycadeoidea Stilucelli, $* 63$

Scant ramentum of, it

Stature of, 33

Cycadeoidea superba, I6-

Collection of type, 43

Leaf-bise bundle pattern of, $* \sigma_{3}$

Ovulate strobilus of. ${ }^{*}$ [ 35

Resemblance to Cycas reioluba, fiz

Restoration of ovulate strobilus, * ${ }^{3} 36$ 
Cycadeoidea supcrba-Continued.

Young fructifications of, I7I-I74, *I75

Cycadeoidea turrita:

Bisexuality of, I30, I3I

Ovulate cone of, I29, I30

Leaf bases of, $*_{53}, *_{54}, *_{6}$

Cycadeoidea Uhleri (type), 6, 12, 22

Columnar form of, 32, 33

Cycadeoidea Wielandi, 29, 107, 108, *III, *II2, I29, I30, 149

Bracts, II5

Cone-bearing habitus of, 126,127

Cortex of, $68-74$

Cotyledons of, 124

General features of cones, I09, *III

Hypogynous disks of, II 4, II 5

Integumentary structures of, I23, I24

Interseminal scales, I I6-* I I9

Leaf bases of, *54

Longitudinal sections of cones, II2

Megaspore membrane, I22, I23

Nucellus, I22

Ovulate cone of, I08-126

Peduncle and its bundle supply, *II3, II

Seed pedicels, II8, *II9, I20

Seeds, I20-126, * I2I, * 122

Transverse section of cones of, IIO, $*$ II 2

Trunk structure illustrated, *69-*77

Cycadeoider, 102, 123, I94, 210, 216

Adventitious leaves in, 94, 100, I04

Bisexuality in certain species of, I30, I3I

Bisporangiate axes of, $138-167$

Branches, late development of, 39

Branching forms of, 36,37

Colloquial names of silicified trunks of, 6

Columnar forms, 33

Cone-bearing habitus in species of, I26-130

Cortex of, 66-74, 227

Culminant fructification in, $126-128,185,186$

Embryos and pre-embryonal structures in, I $24-\mathrm{I} 26,234$

Extent of foliage preservation in, 99

Fern-like characters of, 239-240

Hypogynous disks of, II 4

Hypothetical forms of, 244

Leaf bases, 55-66, 227

Limits of stature in, $30,34,35$

List of bisporangiate forms of, 167

Prefoliation of, 227

Probable root type of, 35

Proposed by Robert Brown, I4

Ramental growth, 5I, 54, 227

Relationships of, $187-246$

Reproductive structures, I05-I86

Résumé of bisporangiate characters, I65-167

Résumé of chief outer trunk characters, 44

Résumé of ovulate cone features, 137

Scale leaves in, 227

Short columnar forms, 33

Size limited by stem structure, 35

Staminate disk a sporophyll emplacement, 230

Staminate fronds of, 200

Stature of trunks from Maryland, 3I
Cycadeoidece-Continued.

Stature of trunks from Black Hills, 3I

Strobilar homologies of, 235

Strobili equivalent to lateral branches, 30

Summary of relationships with Cycadacer, 226-235

(a) Vegetative characters, 227-228

(b) Reproductive characters, 228-235

(c) Strobilar homologies, 235

Synangia of, 216

Systematic position of, $236-238$

Young fructifications of, $169-186$

Vegetative features, 49-104

Cycadites, 15,28

pecten, I7

Saxbyanus, I5

Cycadocephalus Sezvardi, bisporangiate strobilus of, 167

Cycadofilices, 66, 76, 123,236, 239, 242, 244

"Cycadophytes," 213, 243

Cycadospadix Hennoquei, carpellary leaf of, *232

Cycads, hypothetical ancestry of, 237

Cycas, 14, 26, 30, 76, 79, 189, 197, 199, 201, 210, 212, $223,224,225,226,227,234$

Armor retention in, 50, 206

Antiquity of, I9I

Branching of, 37,38

Carpellary leaves of, I4, 66, *190, 213, 2I4. $*_{21} 7,232,236,238,239,24 \mathrm{I}, 244,245,246$

Cone axis of, 224

Excrescent growth on roots of, 207

Fertilization in, 216

Microsporophylls of, 215,245

Nervation of, 213

Scale-leaf buds of, 56, 103, 228, 229

Sori of, 2I5, 240

Spermatozoids of, 216, 239

Cycas celebica, 65

Leaf-base bundle pattern of, $* 62$

Cycas circinalis:

Trunk of, 195

Microsporophylls of, $*_{214}$

Ovules of, $*_{217}, *_{218}$

Seed-bundle system of, *219, 220

Cycas Jenkinsoniana; 209,

Young leaves of, *2I0

Cycas media, $*_{190,} 206$

Concentric cortical traces in, 202

Cycas neo-caledonica, 204

Cycas Normanbyana, *190, 204

Height of, 34, 36

Megasporophyll of, $*_{21}$ I

Cycas revoluta, ${ }^{*} 39, * 44,127,190, * 200$

Carpel bundle of, $*_{223}$

Cortical bundles of, 202

Fronds of, *2II

Great trunks of, in garden of Ryîgeji temple, *fronts page 20,34

"Hoso" form of Japanese gardeners, 38 , *39

Megaspore bundle supply, *221, 222, 232, 233

Megasporophyll of, $*_{21}, 232$

Sced-bundle system of, $* 219,220$

"Shishi" type of Japanese gardeners, *36-38, 43 
Cycas revoluta-Continued. Tracheids of, 198

Cycas Riuminiana, ${ }_{50}$ Seed-bundle system of, $*_{219}, 220$

Cycas Rumphii, *203

Cycas Seemanni, 209

Young leaves of, $*_{210}$

Cycas siamensis (?), *205

Cycas Steenstrupi, I9I, 2I7

Dakota sandstone, 95

Dammara, 212

Dance, locular septation in synangia of, 159

Danaa elliptica, synangium of, $* 215$

Distribution-

Of existing cycads, I89-I9I, I92

Of fossil cycads, 5-20, 8r, I67, I9I, I92

Dictyozamites, nervation of, 213, 239

Dictyozamites indicus, frond of, $* 234$

Dion, 33, 86, 87, 90, 189, 201, 212, 239

Microsporophylls of, 215

Monoxylic vascular zone of, 197

Old peduncle bundles in pith of, 196

Pinnule growth in, 209

Prefoliation of, 210

Dion edule, *84, *1 88

Cortical bundles of, 202

Megasporophyll of, *2I7

Phyllotaxy of cones, 215

Ramentum, *5I, 53

Root of, 207, *208

Dion spinulosum, fronds of, *2I I

Diplodocus, 100

Embryos of-

Bennettites Gibsonianus, 107, I24

Cycadacea, 226

Cycadeoidea Wielandi, 124

Encephalartos, 92, 93, 124, 189, 197, 199, 205, 206, 209, 210

Carpellary leaf reversion in cone of, 2I4

Leaf-base bundles, 60,62

Megaspore bundle of, $*_{221}, 232,233$

Ramentum, 54

Seed-bundle system of, 220

Encephalartos Altensteinnii, * 197

Branching of, 38

Encephalartos caffer, 212

Phyllotaxy of cones, 215

Encephalartos cycadifolius, *62, 93

Ghellinckii, $*_{207}$

Gorceixianus, 190

Hildebrandtii, *29

Encephalartos horridus, fronds of, *2I I

Megaspore bundle supply of, 222

Encephalartos (?) lanuginosus, pinnules of, *212

Encephalartos Lehmanni, pinnules of, *212

Encephalartos villosus, $*_{29}$, *5 I

Fronds of, $*_{21}$ I

Monstrous cone of, $*_{23}$ I

Encephalartos "Vroomi," *62

England, cycads of, I4

Eolirion, 8I

European cycad localities of minor note, I6

European cycads, discovery of principal types, $12-16,18,19,107$
Fertilization, 216

Fossil cycad localities (see European cycads, Wyoming, Black Hills, etc.)

Fossil cycadean trunks:

Occurrence in time in Old World, 18-20

Occurrence in time in North America, II

Old World types, list of, 18-20

Popular names of, 6

Rarity oi, 5

France, cycad types from, I3

Freezout Hills, Carbon County, Wyoming, 23. 100, 102

Galicia, cycad from, I3

Ginkgo, 125, I37, 230, 240

Fertilization in, 216

Megasporophyll homologies of, 232

Protocorm of, 226

Spermatozoids of, 216,239

Stamens of, 245

Ginkgo biloba, I37

Embryos of, 124

Pollen of, I6r

Protocorm of, 125, 126

Ginkgoacea, strobilar homologies of, 235

Ginkgoales, 244

Gnctales, 123

Gondwana system, cycads from, I6

Growth accommodation in cycad stem, 200, 203

Hawkser and Runswick, discovery of cycads in cliffs of, 15

India, cycads of, 16

Interseminal scales, 23 I

Description of, I16-118

Figured, *I16, *I19

Inyan Kara Mountain, Wyoming, cycads found near, 8

"Iron Ore Belt" (see Maryland)

Isle of Portland cycads, 6 , I6

Isle of Wight, cycads from, 16, 107

Italy, cycads of, I2

Johns Hopkins University, fossil cycads in, 4. 5

Kaulfussia cesculifolia, synangium of, *215

Lagenostoma, 216, 219, 220, 246

Megaspore membrane of, 123

Seed-bundle system of, 222

Seed of, $124,234,246$

Lagenostoma Lomaxi, 246

Leaf bases of Cycadeoidea, 56-66

Bundle grouping, 59, 60

Bundle structure of, $64-66$

Variation in spirals, $56,57,58,59,60$

Liriodendron, 129, 143, 244, 245

Lyginodendron, 217, 219, 225, 237, 21 .

Lyginodendron Oldhamium, 65

Discovery of mega- and microspores of, 246

Macrozamia, 79, 86, 87, 91, 96, 189, 197, 198, 205 , $207,210,226,227$

Polyxylic vascular zone of, *199, 200.

Ramentum, 54

Seed-bundle system of, 220

Macrozamia cylindracea, So

Macrozamia Fraseri, *199

Inverted bundles of vascular zone, 200

Irregular periderm excision in, 206 
Macrozamia Fraseri-Continued.

Megasporophyll of, *217

Macrozamia hetcromera, fronds of, *2II

Macrozamia Miqueli, young leaves of, *210

Macrozania spiralis, *86

Occurrence, 189

Pinnule growth in, 86, 209

Marattia, I4I, I 42, I58, I 59, I66, 216, 236, 240, 246

Locular septation in synangia of, I 59

IIaratia fraxinca, synangium of, *2I5

Marattiacec, $142,237,239$

Sori of, $* 215$

Maryland Academy of Natural Sciences, types originally in collections of, 6

Maryland, cycads from Potomac Group of, 5-6, 22. 32

Medulla of:

Cycadacec, I95-196

Cycadeoidece, 77-78

Cordaitales, 195

Cy'athea medullaris, 195, 239

Mcdullosa, 246

Megaspore membrane, I22, I23

Microcycas, 189,197

Mineralization of plant tissues, 21-22

In Black Hills, 23

In Potomac of Maryland, 23

Control of, by local conditions, 23

Rare occurrence of requisite conditions for, 26

Minnekalita, South Dakota, 9, 24, I33

Cycad discoveries at, $7,8,4 \mathrm{I}$

Pollen-bearing cycad fruits from, I43

Series of branching cycads from, 38, 39

Morosaurus, IOO

Morrison Formation, Ioo

Ncuropteris, discovery of seeds of, 230, 246

Ncuropteris heterophylla, 232

Nilssonia, occurrence in Black Hills, Ioo

Nostoc, in cycad roots, 207

Old World cycadean types, list of, I8-20

Onoclea, 237

Oölite quarries of Isle of Portland, I4

Oöspore of gymnosperms, I25

Ophioglossacea, 218

Osmunda, ${ }_{58}$

Wilting of fertile fronds, I 29

Otozamites, $6_{3}, 6_{4}$

Nervation of, 213

Ovulate cones of Cycadacec

Composed of frond derivatives, 229)-23.3

Homologies of, 235

Reversion forms of, 214, *230, *23I

Ovulate cones of Cycadeoidec, 213-215

Cycadcoidca dacotonsis, $133-1.34,147-149$

Jenneyana, I.3I-I32

Marshiana, 135-136

Wiclandi, 108-126

P'alcosamia, Io

Pandanus, 245

Pecopteris, seeds of, 246

Periderm, formation and action of, in Cycadaccc, 205-206

Petrotome, for section cutting, 74
Piedmont, South Dakota, 94

Piedmont-Black Hawk cycad arca, 94

Podocarya, 8I

Podozanites, 9I

Pollen grains of -

Cycadacea, 216

Cycadeoidea, * I59-162

Polystichum acrostichoides, $24 \mathrm{I}$

Poroxylca, 225

Poroxylon Edruardsii, stem section of, *224

Pre-embryonal stages of Cycadeoidea, 124-126

Prefoliation of:

Cycadacea $* 84, * 85, * 86,209-210$

Cycadclla ramentosa, 99, 100

Cycadeoidea ingens, 86, *93

Cycadcoidea colossalis, 99

Pritchardia Martii, $* 205$

Proangiosperms, 243, 245

Prothalli:

Diocism of, 242

Elimination of, $24 \mathrm{I}-243$

Pterophyllum [should be Ptilophyllum]. 25

Ptilophyllum acutifolium, I6, *17, [63]

Ptilophyllum cutchense, $17,63,79$

Persistent (?) cambial cylinder of, 79

Quasi-ferns, 237, 239, 240

Evolution of, 24I

Rajmahal series, silicified stems from, I6

Ramentum, 5I-54, 239

Profuse growth of, 102

Red Valley, 94

Rhabdocarpon, 230, 232

Ricinus, 245

Roots of-

Cycadacce, 207-208

Cycadeoidea [not silicilicl], 208

Ryûgeji temple garden, $3+$

Scale-leaf buds of-

Cycadeoidec, 103

Cycas, 103

Sciadopitys, 229

Section cutting, 45-48, 74

Carborundum used in securing cores for, 46

Chiseling out cores for, 45

Cylindrical cores for, $45,46,47$

Double sectioning, 46, 47, 74, I8I

Meyerische Steinkitte used in, 46

Petrotome used in, 74

Use of plate-glass mounting, 48

Use of bort-charged drills for core cutting, 48

Tubular drills devised to secure cores for, 45

Section numbers, system of, 53

Secds, 234

Of Cycadacece, 217-222, 226

Of Cycadcoidea, I20-126

Secd pedicels, II8-120

Homology of, 230-233

Silicification of plant tissues ( $s e c$ Mincralization of )

South Dakota (sce Black Hawk; Black Hills; Black Hills Rim; Minnckahta)

Spermatozoids, 216

Sporophytes, foliar homology of, $30,242,245$ 
Stamens:

Eimplacement of, 230,244

Evolution from asexual sporophytes, 24r, 245

Staminate disk:

Gencral description of, 149-160

In Cycadocephalus, I67

In Weluitschia, 229

List of forms, 167

Significance in angiosperm evolution, 246

Staminate frond, I5I-I55 et scq.

Homology of, 229

Stangeria, 31, 82, 189, 197, 201, 203, 209, 220, 225. 227,233

Leaf-base bundle pattern, 62,63

Nervation of, 213, 239

Xylem of, 198

Stangeria paradoxa, $*_{29}, 142,223$

Fronds of, $*_{2 \text { II }}$

Megaspore bundle of, *22I

Peduncular bundle of, *222

Seedling of, *209

Sporangial wall of, I59

Thickets of, in Natal, 189

State University of Iowa:

Cycad collection of, ?

Cycad material from, I 44

Stephanospermum, pollen of, $*_{159}$

Seed of, 218

Struthiopteris, 239

germanica, 24 I

Sundance, Wyoming, strobilus from, I 43

Swiss lake-dwellers, use of Sambucus drills by, $4^{8}$

Tree ferns:

Branching of, 36

Similarity to Cycads in size of, 35

Trigonocarpon, 218,246

Trunk forms, 26, 29, 57

Obliquely compressed, 27

Vertically shortened, 27

Transversely elliptical, 28, 29

Trunk numbers, 53

Trunk structure, 227, 228

Of Cycadacce, 195-208, 2I3

Of Cycadeoidea, 5I-80

Tumboa, *229, 230

Types (sce Cycad collections)

Unexplored or little-known regions, I8

Wealden sandstones, cycads from, 14

IV clavitschia mirabilis, 229

Staminate disk of, 245

Williamsonia, 13, I6, 8I, 82, 9I, 102, I29, I37, I42, I56, I66, I74, 227

Williamsonia Blanfordi, * 17

Villiamsonia gigas, $16, I_{7}, 38,8{ }_{1}, *_{152}, *_{153}$. * $154, \quad$ I 74

Bisporanginte strobilus of, I67

Fruit-bearing branch of, 38

Habitus, 33

Restoration of, 18

Williamsonia Leckenbyi, I7

Moricrei, 107 pecten, 17, II 7

Wyoming, cycad localities of central, io Of Inyan Kara Mountain, 8
Xylem zone of Cycadeoidea, 74-77

Yale Museum:

Cycal collections in, 8 , 10

Matching of isolated cycad trunk fragments in, 39

Yorkshire coast, cycad specimens from, in Paris Muscum, I3, 82

Young fruits, $147-149,169-186$

Yuccites, 8I

Zamia, 189, 191-195, 199, 207, 220, 225, 226, 227, 232

Fertilization in, 216

Microsporophylls of, 215

Monoxylic vascular zone of, int

Old peduncle bundles in pith of, 196

Prefoliation of, 87, 209, 210

Sporophyll homologies of, 2.32

Trunk habitus of, 3 I, ${ }^{*}$ I9I

Zamia floridana, I0I, I54, 162, 191, *193. *194. *195

Branching of, 194

Cones of, *194

Cortical bundles of, *20I

Foliar reversion in cone $n f, 214$

General features of, 192-195

Leaf-base bundle pattern of, * $0_{2}$

Sicropylar tube diameter, 218

Prefoliation, *85

Range of, 192

Spiral cells of xylem, 75

Tap-root of, 197, 207, 208

Xylem of, 198

Zamia furfuracca, 93, 191, 212

Zamia gigas, $8 \mathrm{I}, 82, *_{54}$

Described by Williamson, I5

Zamia Lindeni, *85

Zamia "glabra," *192

Pinnules of, *2I2

Zamia integrifolia, I9I

Megasporophyll of, *2I 7

Microsporophylls of, *2I4

Seed-bundle system of, *219

Zamia muricata, 20I

Pliyllotaxy of cones, 215

Secd-bundle system of, *219

Zamia Pöprigiana, 190 pscudoparasitica, 190, 212

pumila, range of, 192

pygmara, 191, 21I

Cones of, 214

Zamia Roezlii, *191

Leaf base of, $* 62$

\%amia ían Houttci, * 190

\%amia "iernicosa," *40

Pinmules of, *212

Zamia "Vroomi," *103

\%amia $/ \mathrm{V}$ allisii. True petiolar spines of, 212

Zamic, 34, H. 63, 230, 237

Ovulate cone homologies of, 2.35

Trunk structure, 34

Low stature of, 35

Zamiostrobus stchorachis, *2,32

Zamites, frc 7 ds of, $8_{2}$

Zamites giglls, 8I

Zurich, limestone cores cut by lake-rlwellers in museum at, 48 


\section{ADDENDA ET CORRIGENDA.}

Page 4, line 8, read Maryland Academy of [Sciences].

Page Ir, second clause of first complete sentence at top of page is misleading. Statement should be: an old peduncle is present in the axil of nearly every leaf base over large areas of the trunk surface. Cf. clusing of page 185 .

Page 19. Wealden cycads: Bennettites [Saxbyanus].

Page 25. In third paragraph, Pterophyllum is to be read Ptilophyllum.

Page 25. It should be added to the third paragraph, that like the matuve leaves, the roots of fossil cycad trunks uniformly fail of silicification.

Page I04. Closing sentence is obscure. The leaf and scale leaf succession of the fossil cycad trunks is far from sufficiently studied; although it is surmised that most species bore foliage leaves only, whereas in the existing cycads many species bear fully as numerous scale as foliage leaves, while but a very few species bear foliage leaves only. A study of the rate of trunk elongation as conditioned by the several types of scale and foliage leaf succession in existing cycads must aid in determining the approximate rate of growth and age of the fossil trunks.

Page 107. To fourth sentence. The first cycad trunk sections made are probably those presented by W'itham to Buckland, and studied by Robert Brown. Diagrammatic figures of these sections are given by Buckland (I 8 , vol. II, plates $6 \mathrm{I}$ and 62 ).

Page I76, in last paragraph, eighth line, read Plate VI [No. I2].

Page 177 , in last paragraph, first line, read Plate VI [No. I 2].

Page 240 , line 25 , eighth word [reproduction].

Text figures I4, 89, and 94 show three views of Yale cycad trunk 2 I $_{4}$ (Cycadeoidea dacotensis, cotype), after the removal of a study series of floral axes. A view of the trunk as collected is given on Plate VI, No. I2. Photographs of various sections from the axes numbered in the several figures are located as follows:

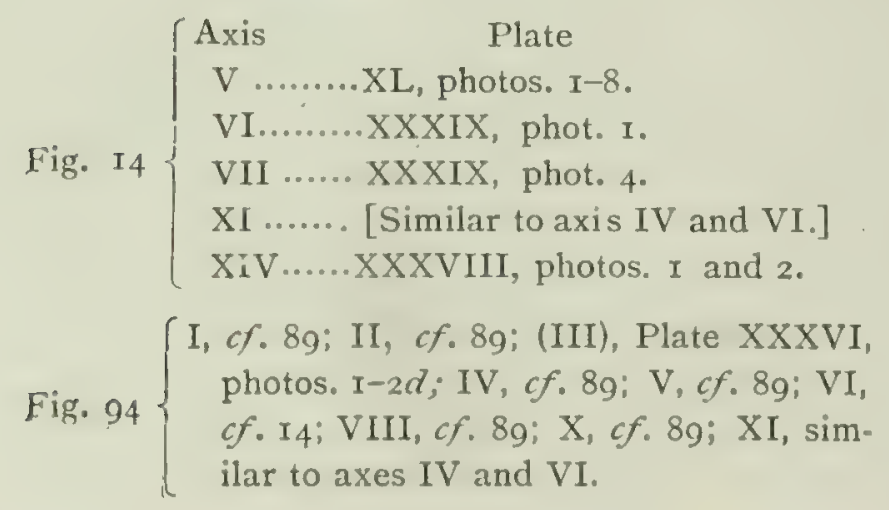

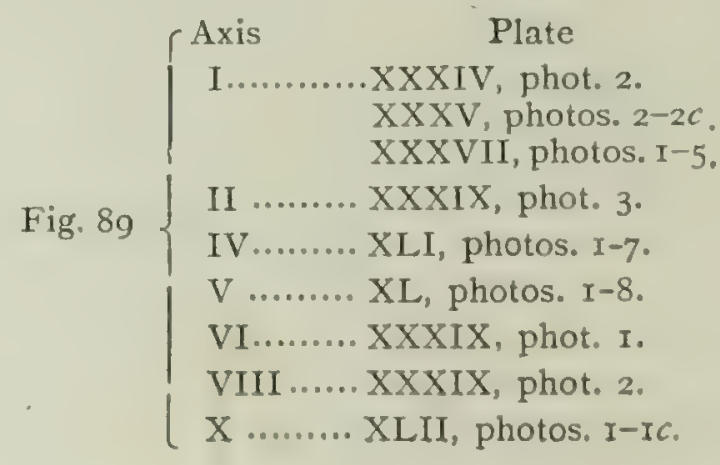




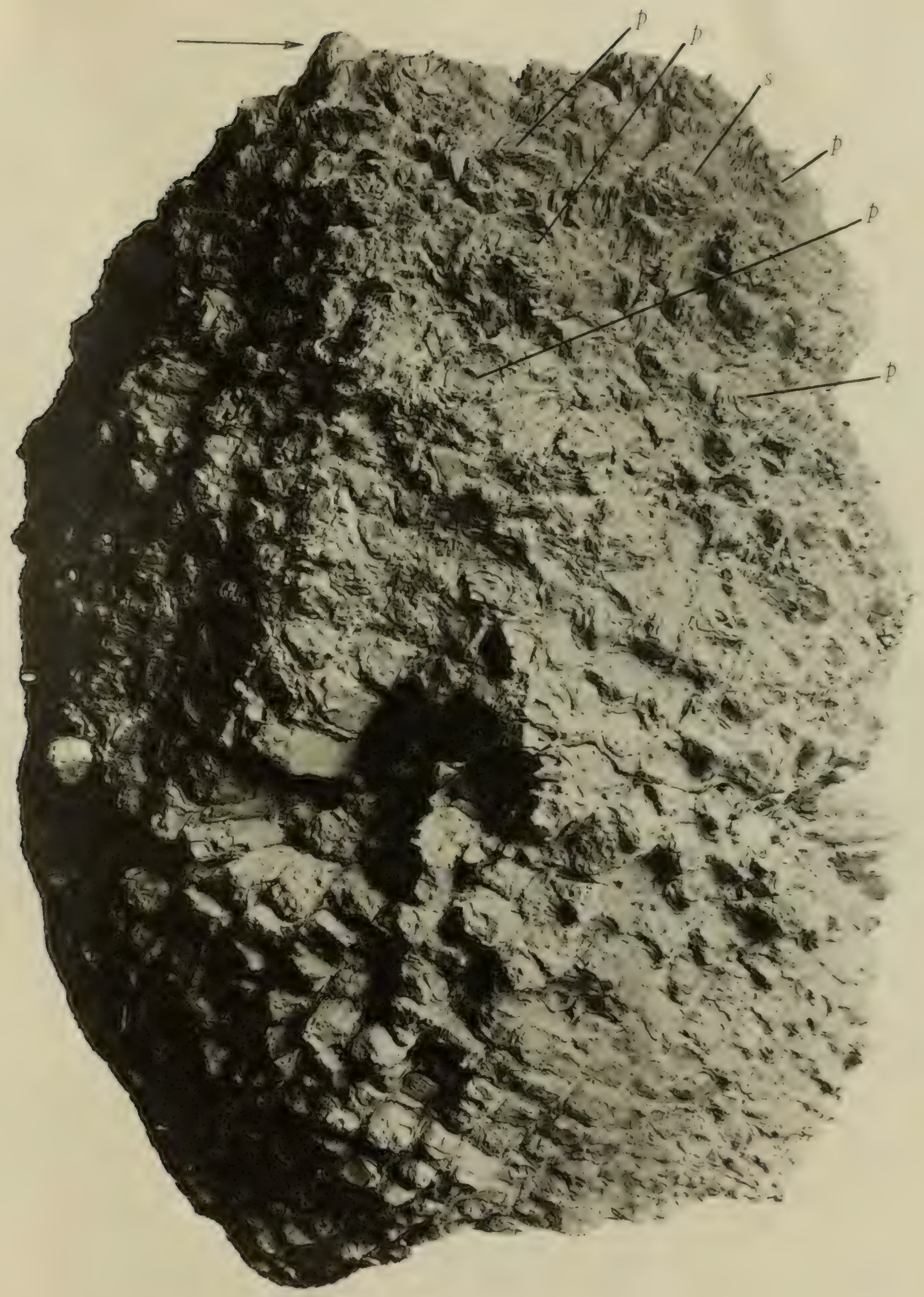





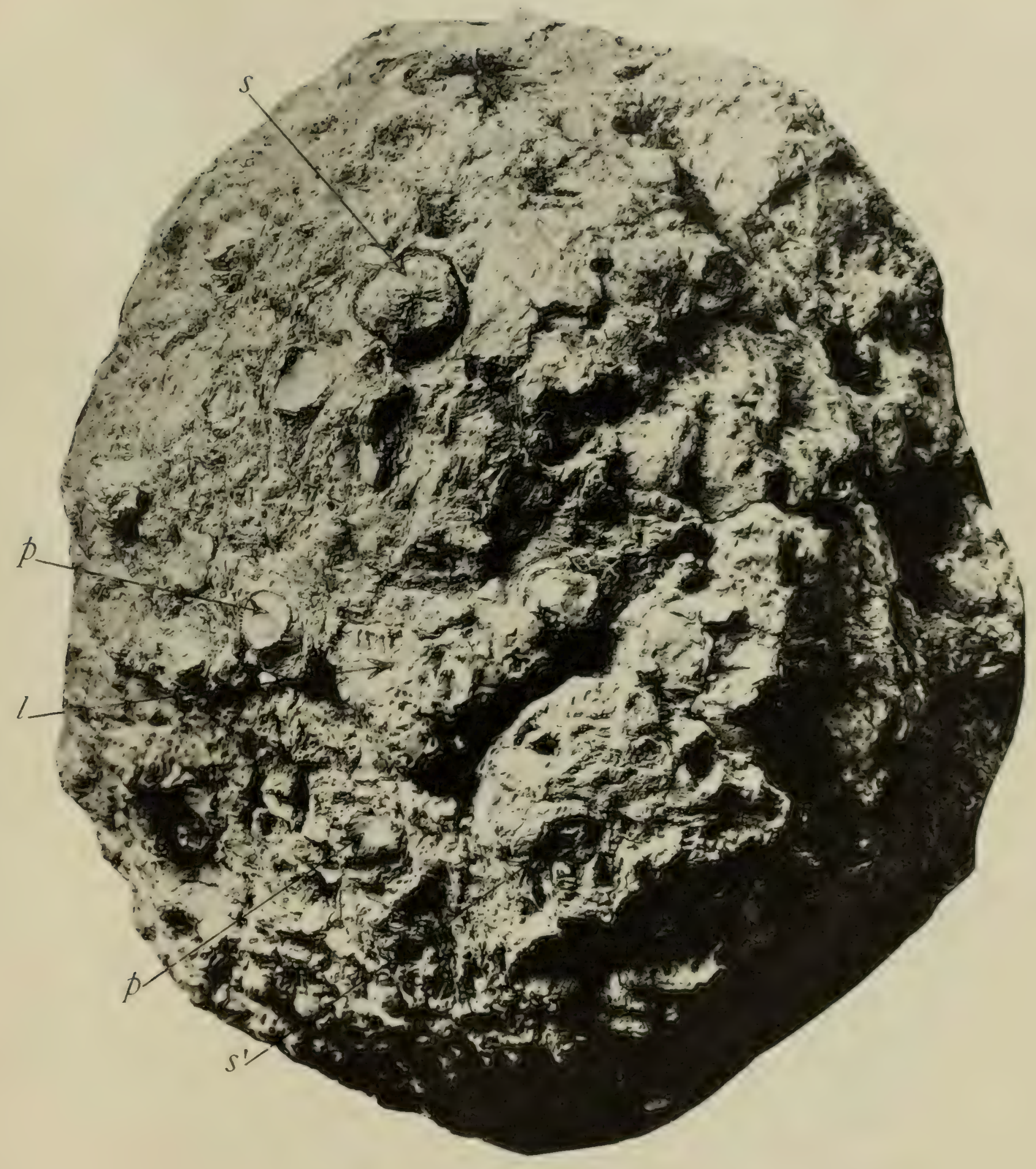





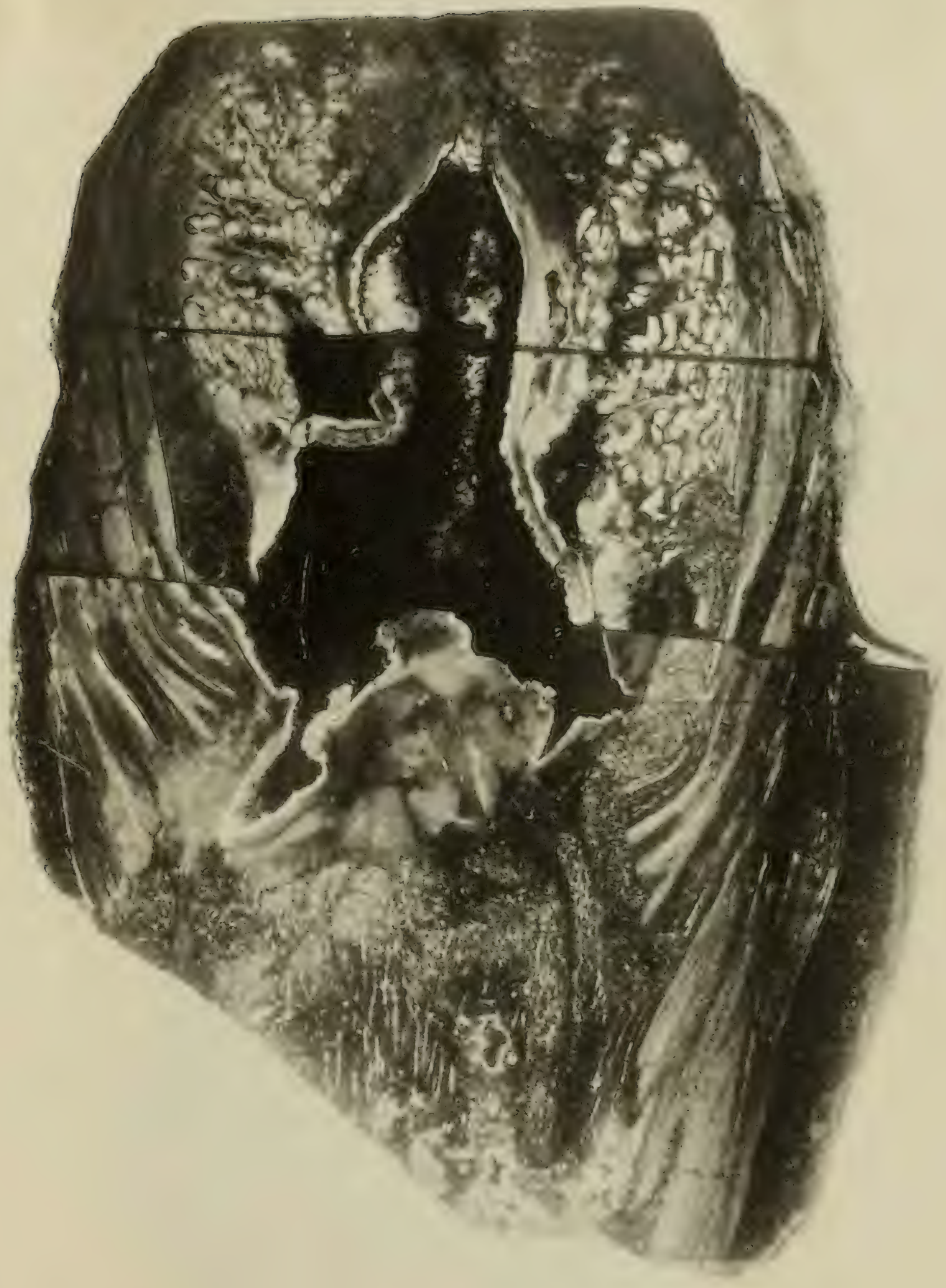

CYCADEOIDEA INGENS (TYPS 


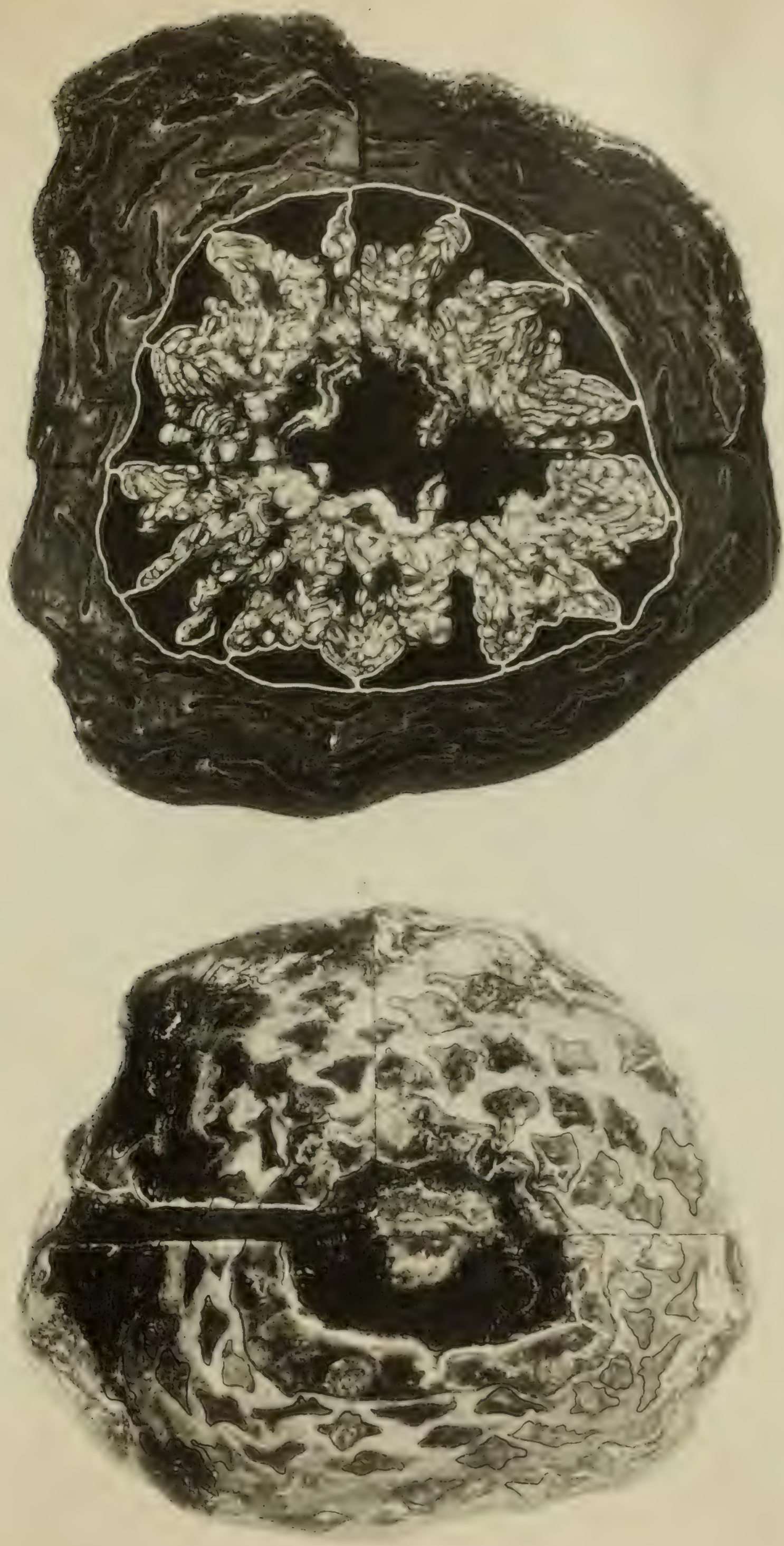



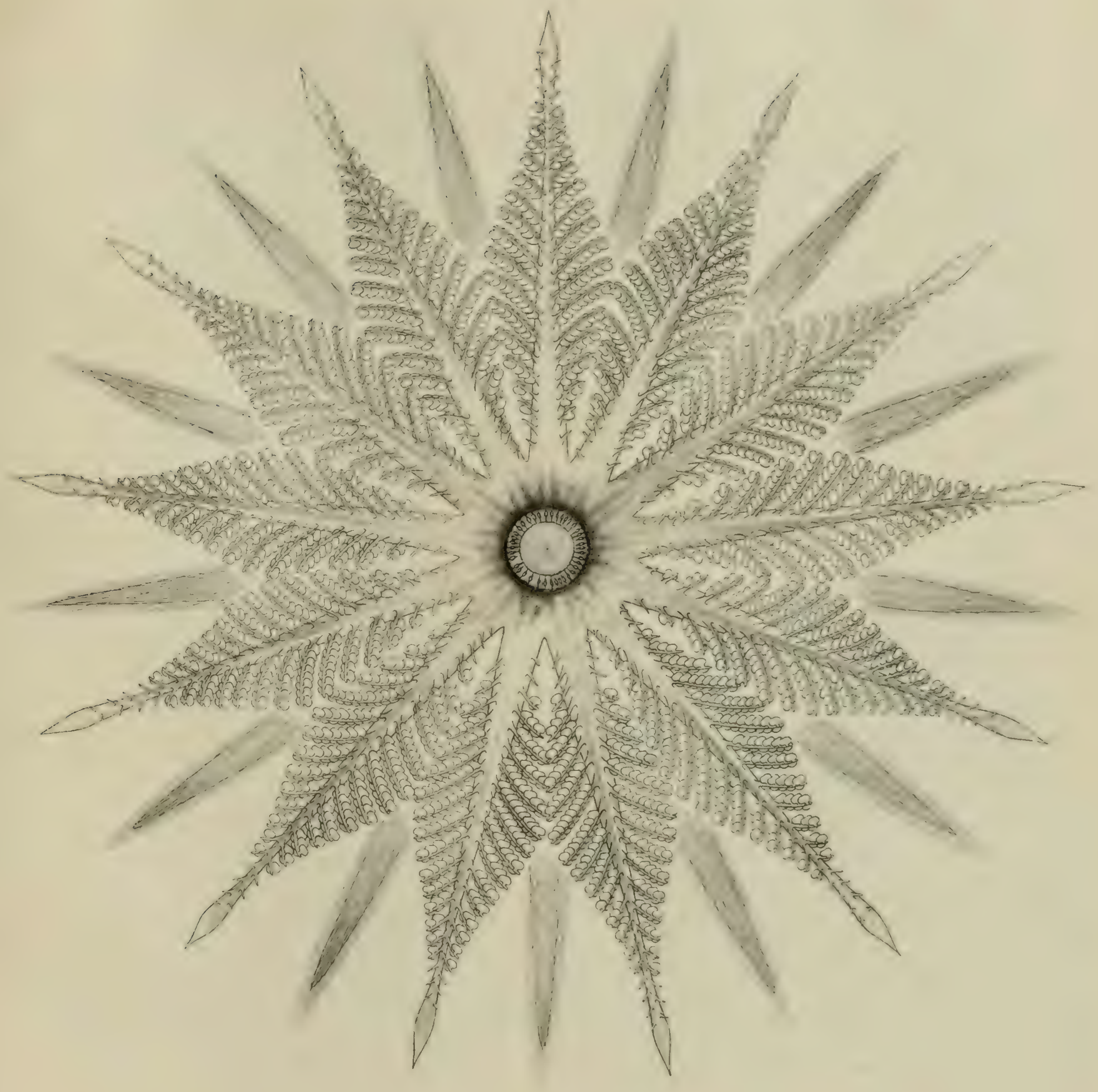

CYCADEOIDEA INGENS.

PLAN OF THE BISPORANGIATE STROBILUS OR FLONER CONSISTING OF A CENTRAL OVULATE CONE,

AN HYPOGYNOUS STAMINATE D!SK, AND A SERIES OF SPIRALLY INSERTED ENVELOPING BRACTS. 


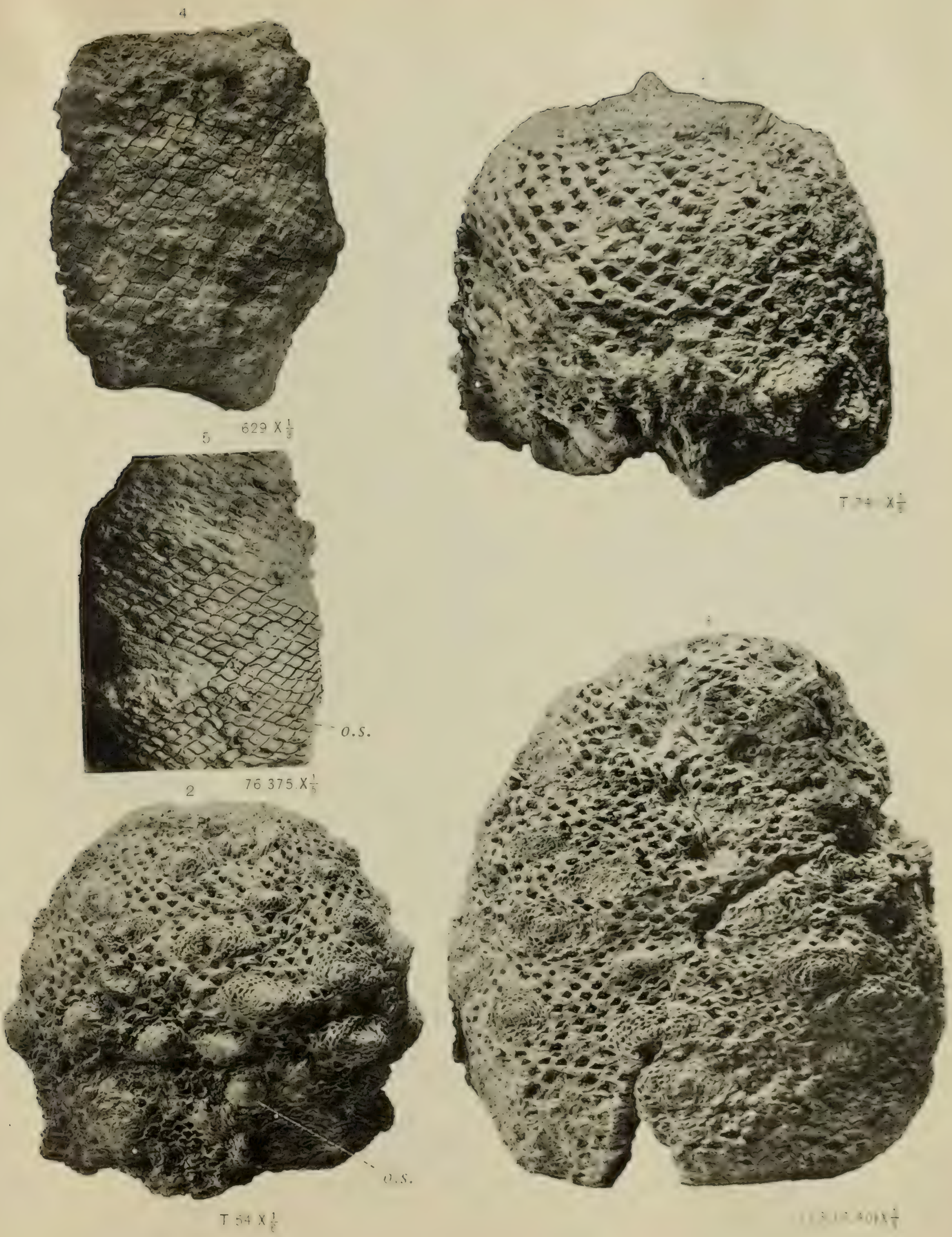



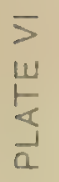
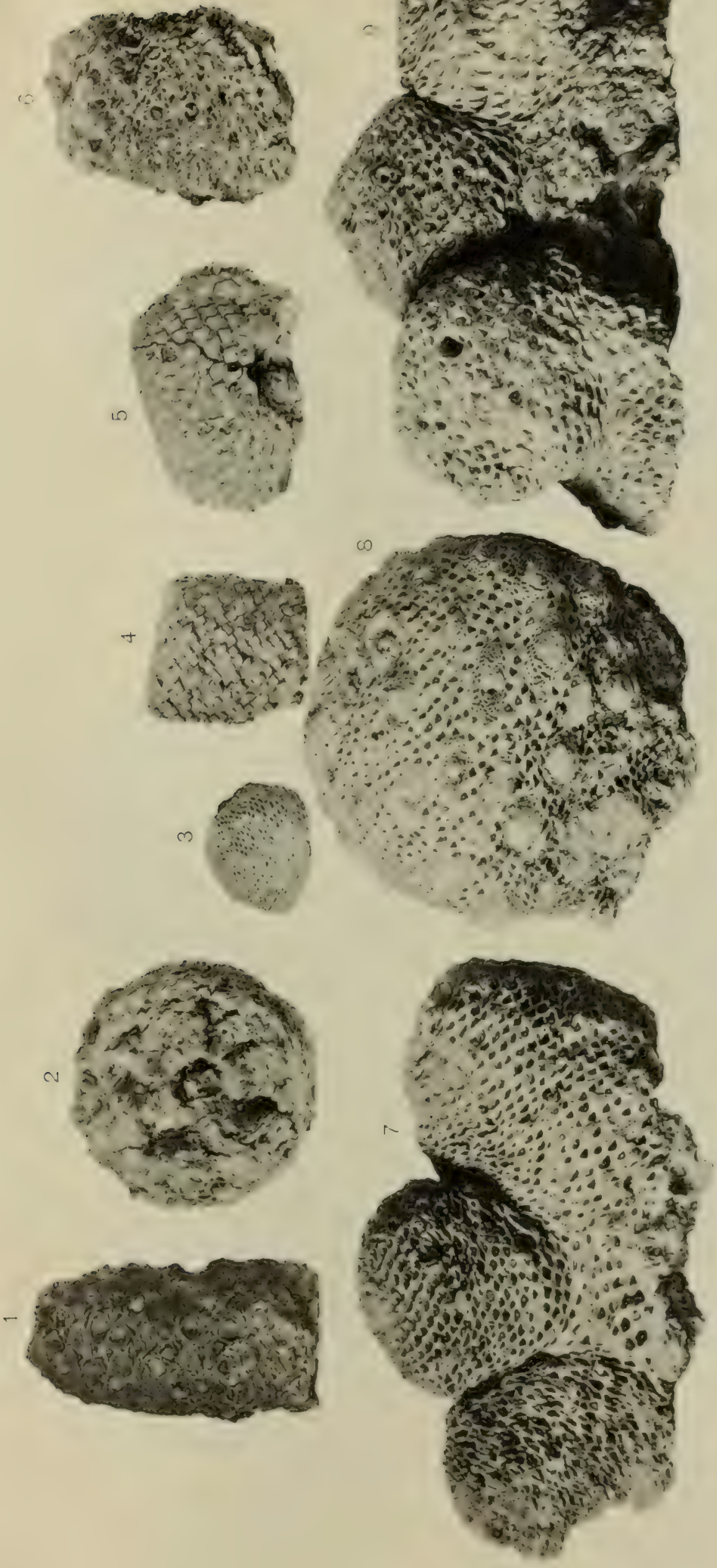
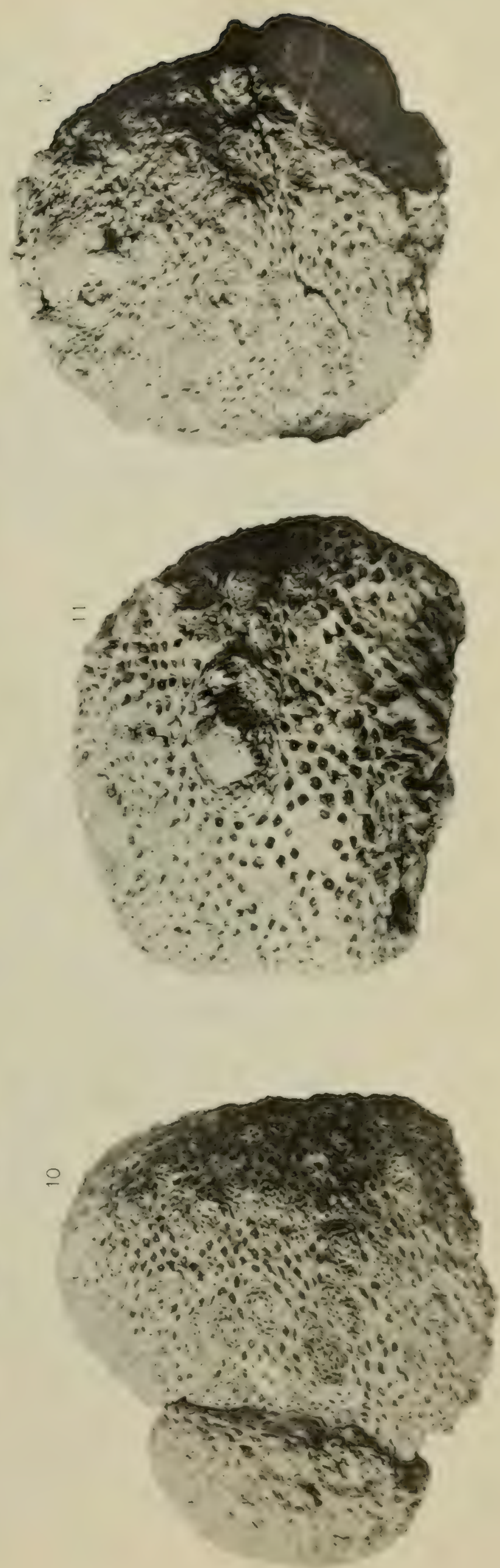



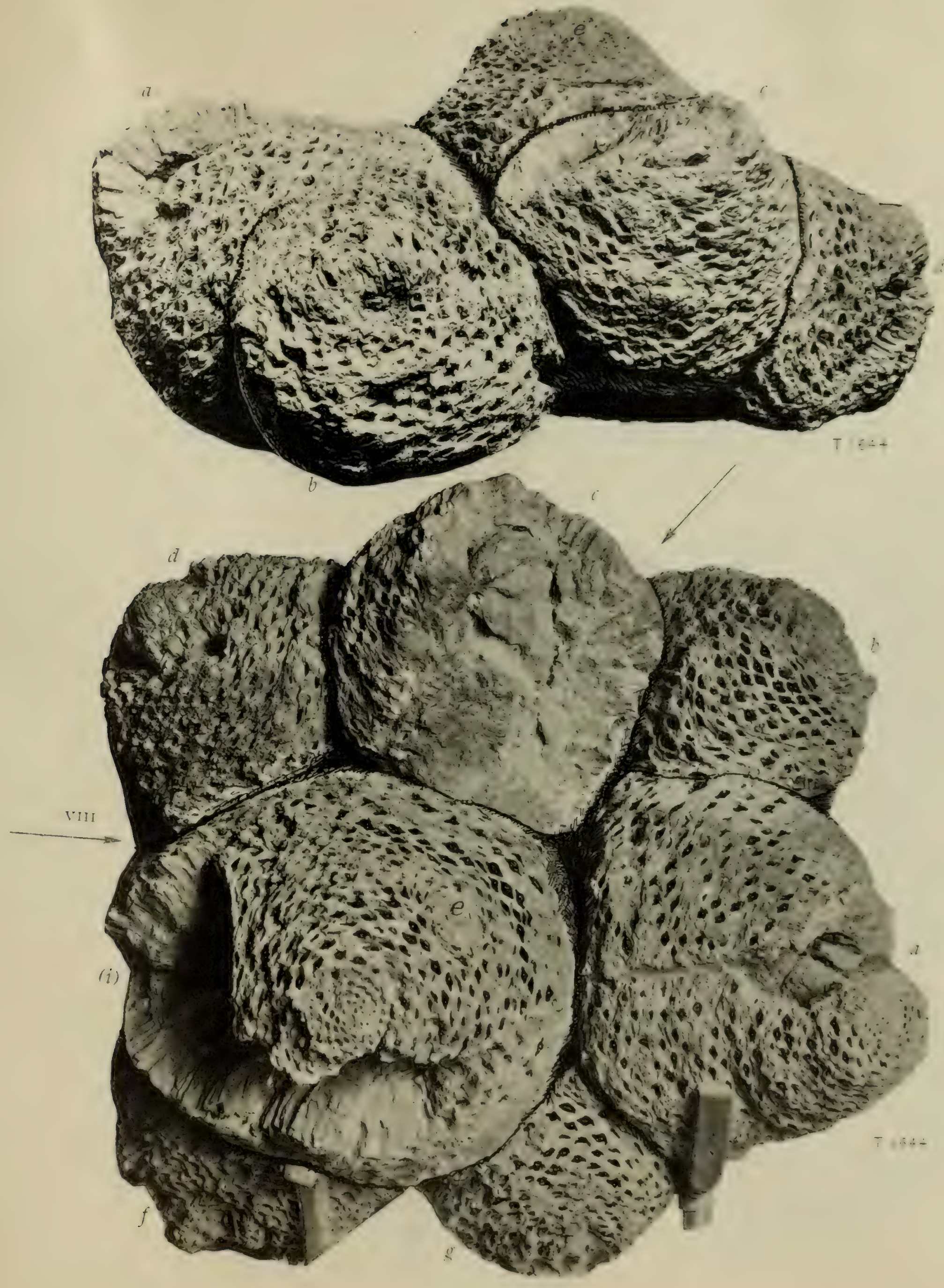





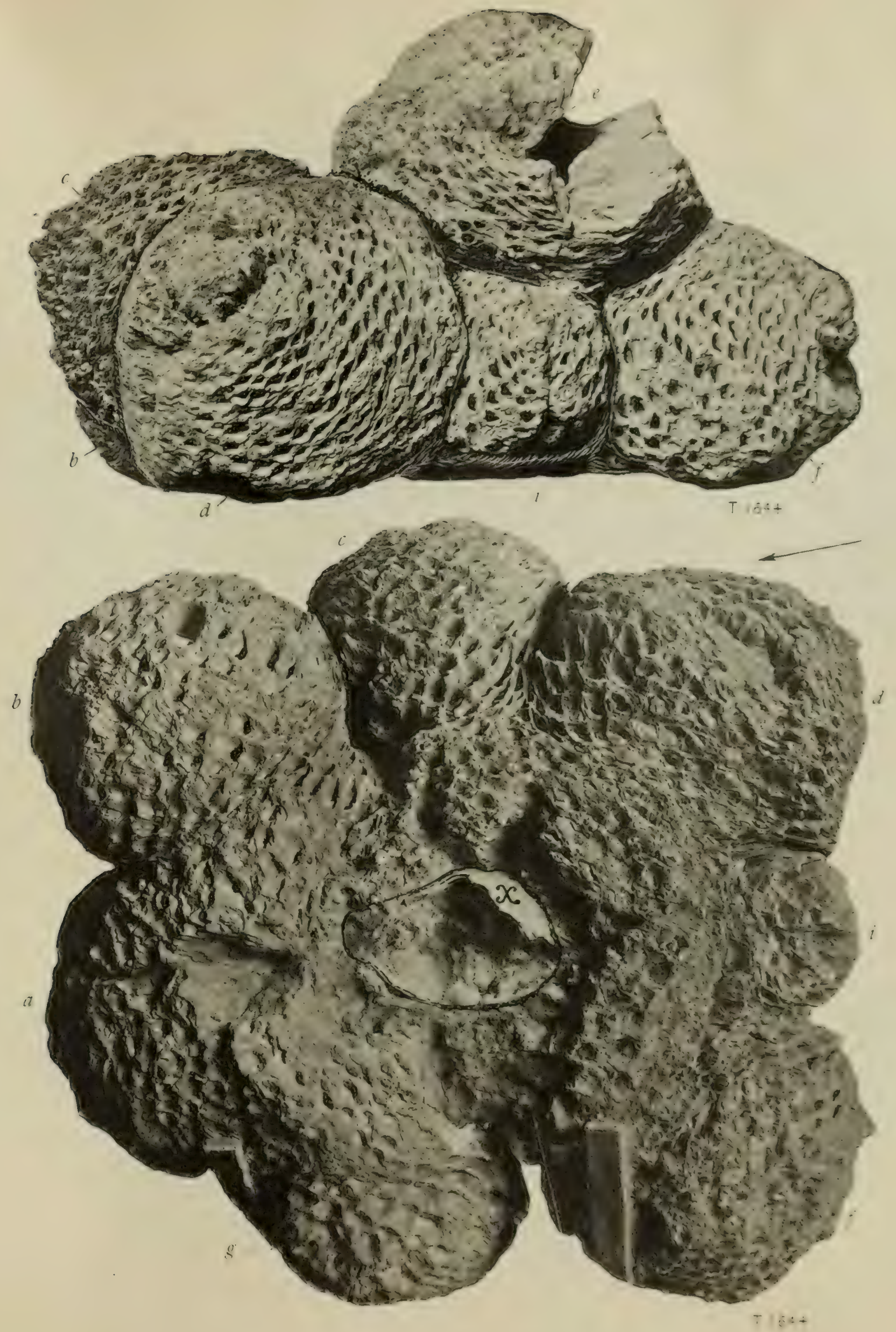

CYCADEOIDEA MARSHIANA. :LAT :-RAL AND BASAL I EWS.) 



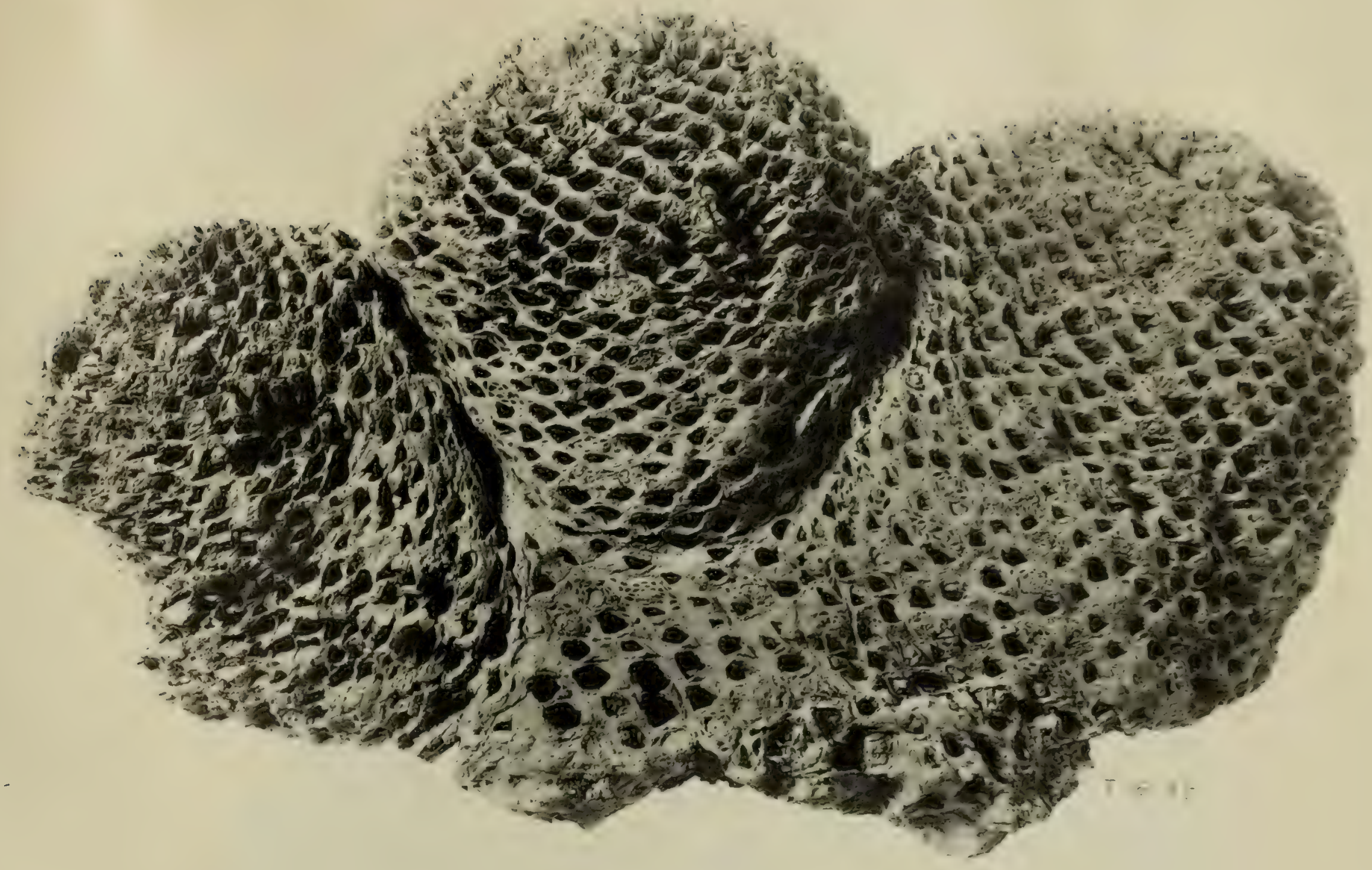

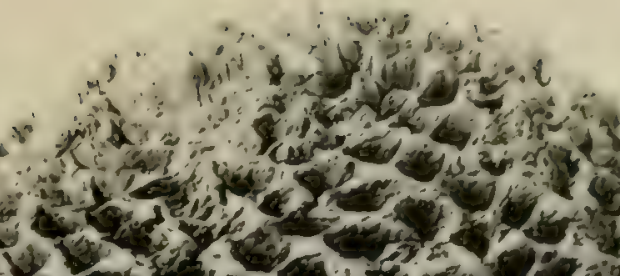

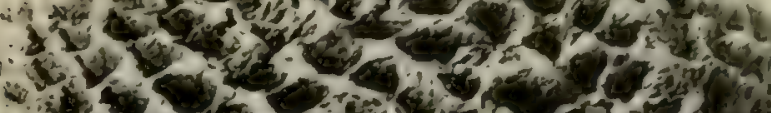

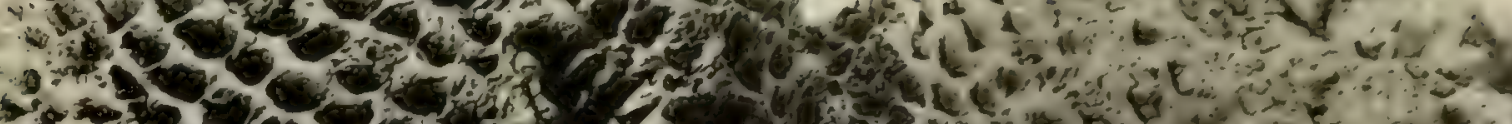

$-2-6012$

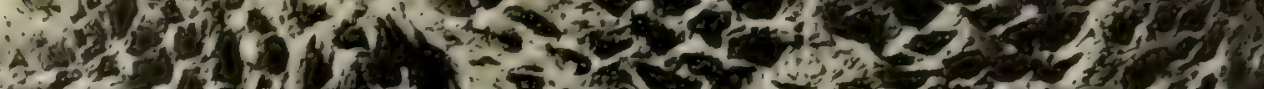

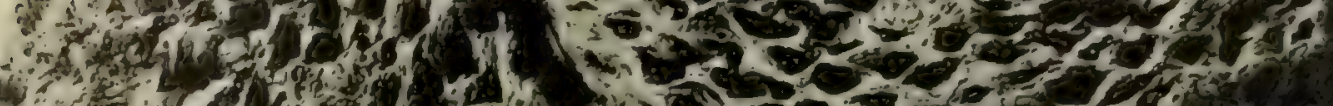

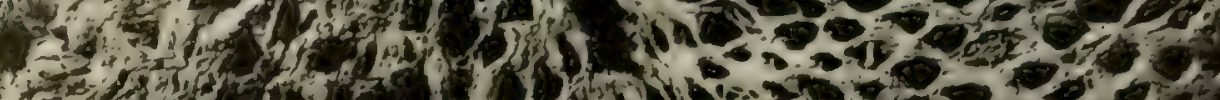
+

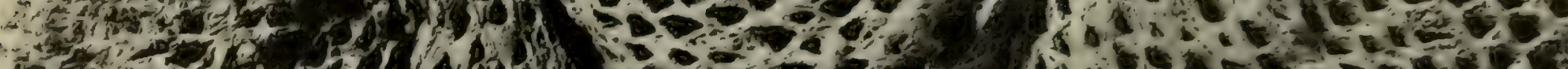

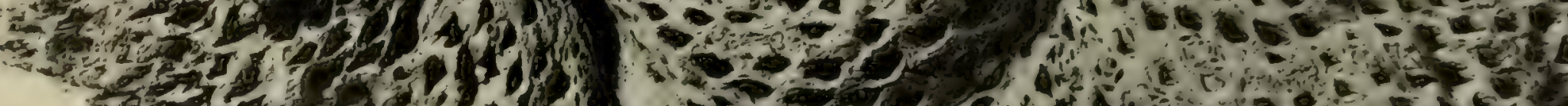

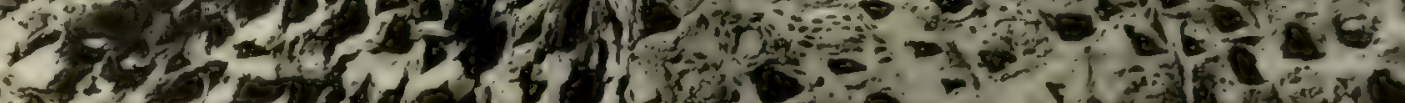

3.

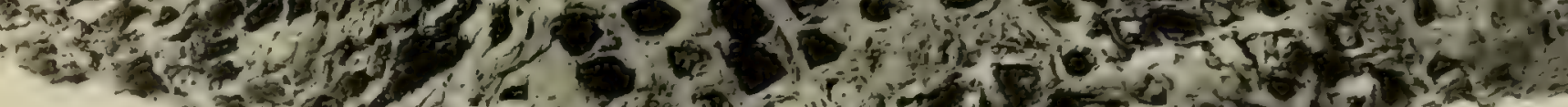

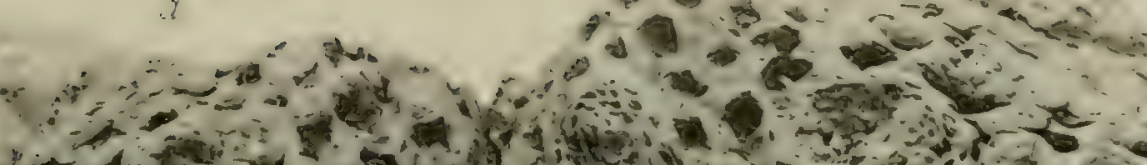

4.

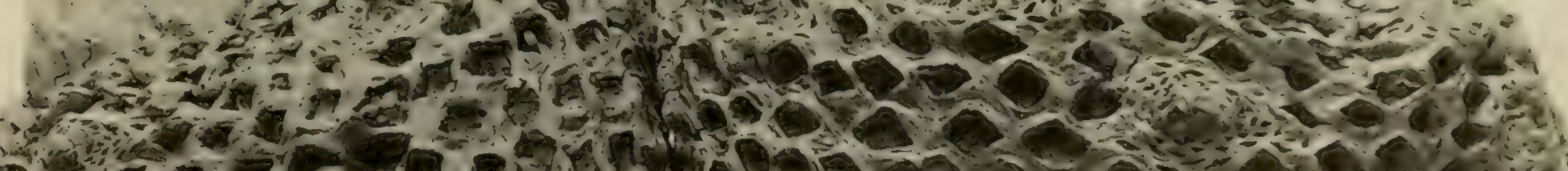

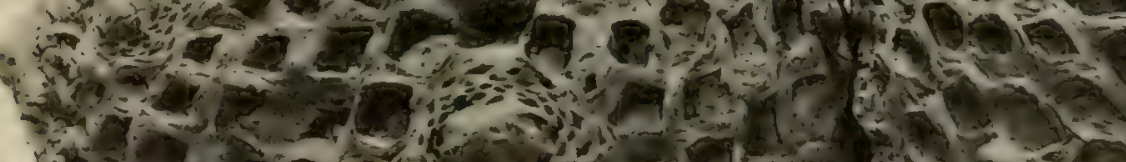
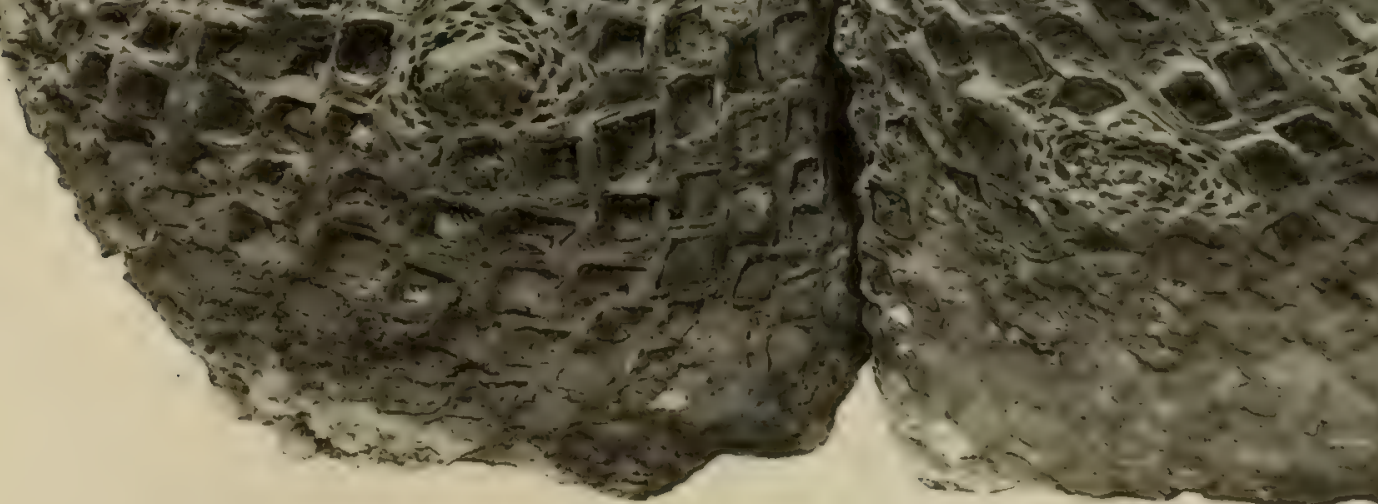



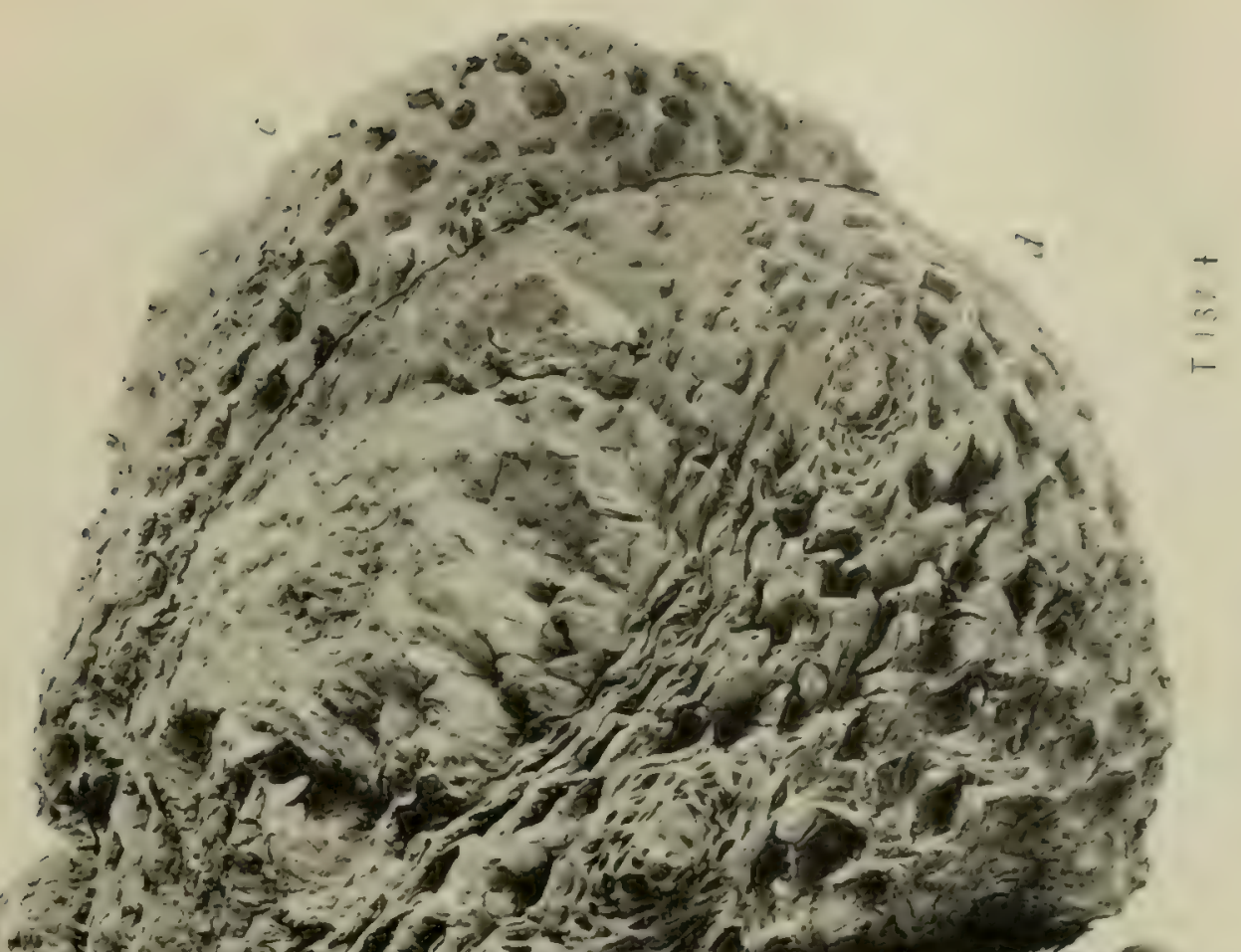

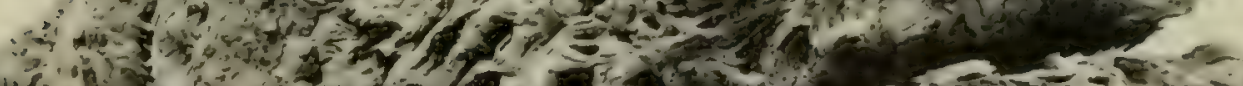

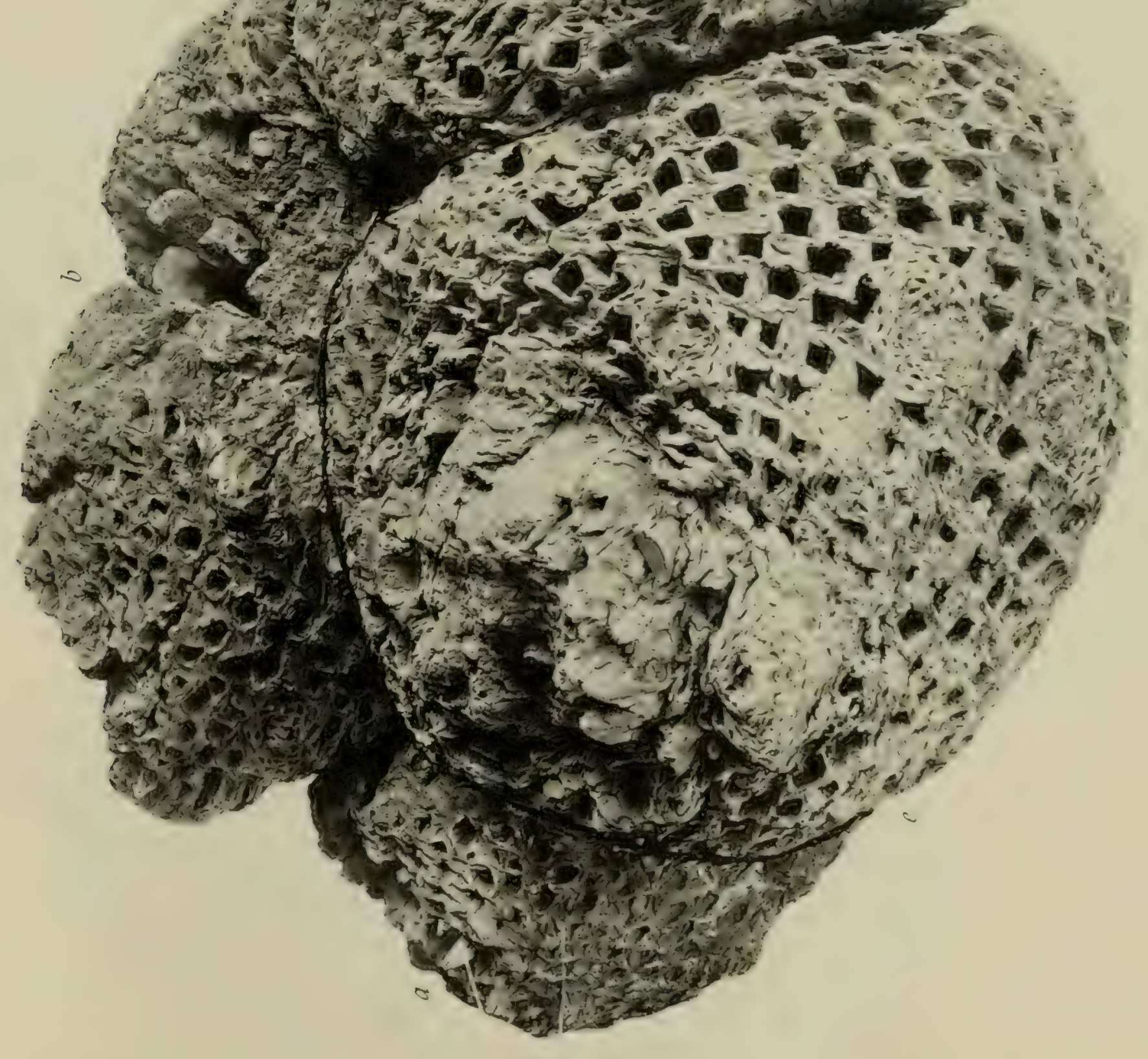





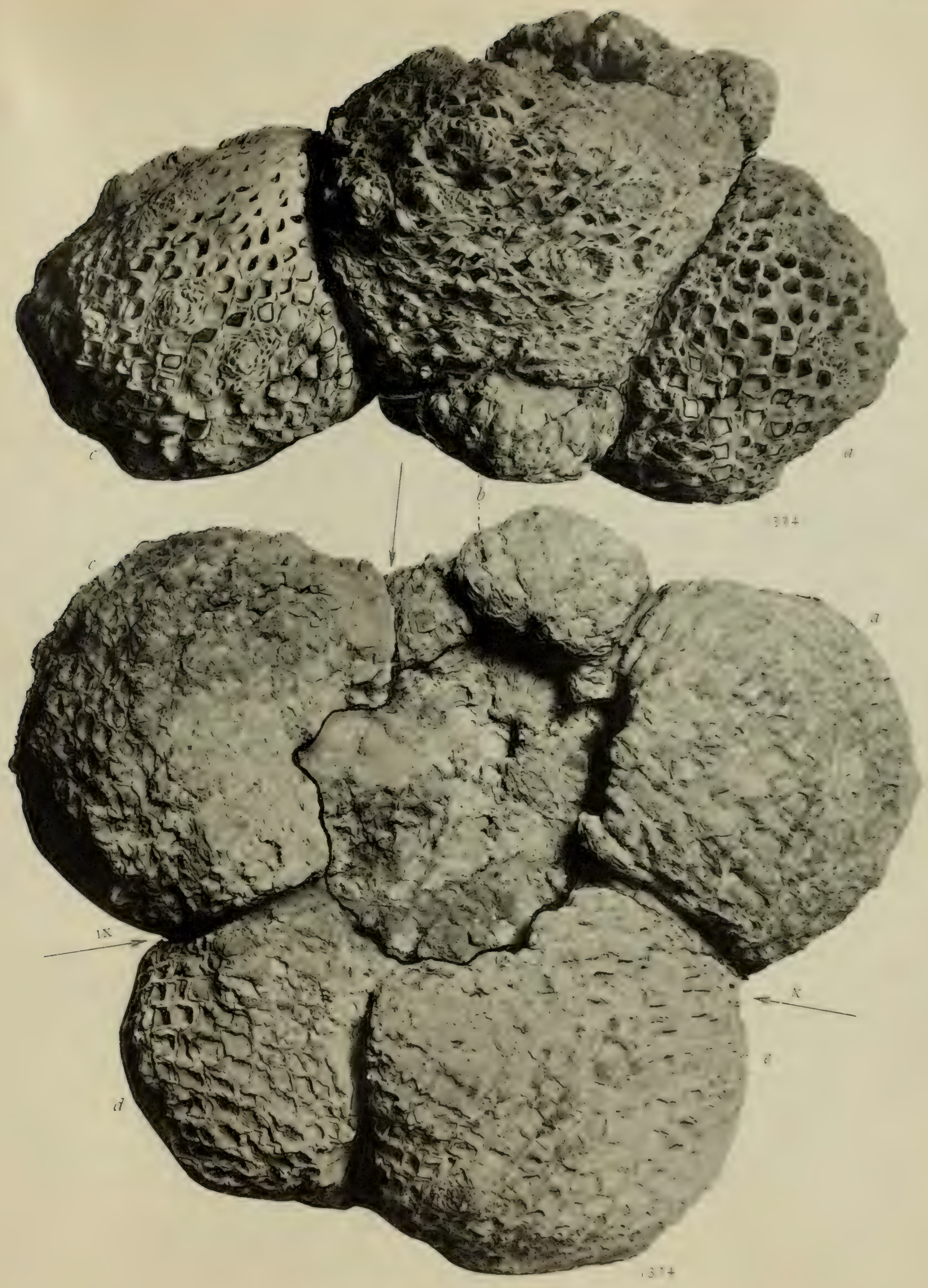





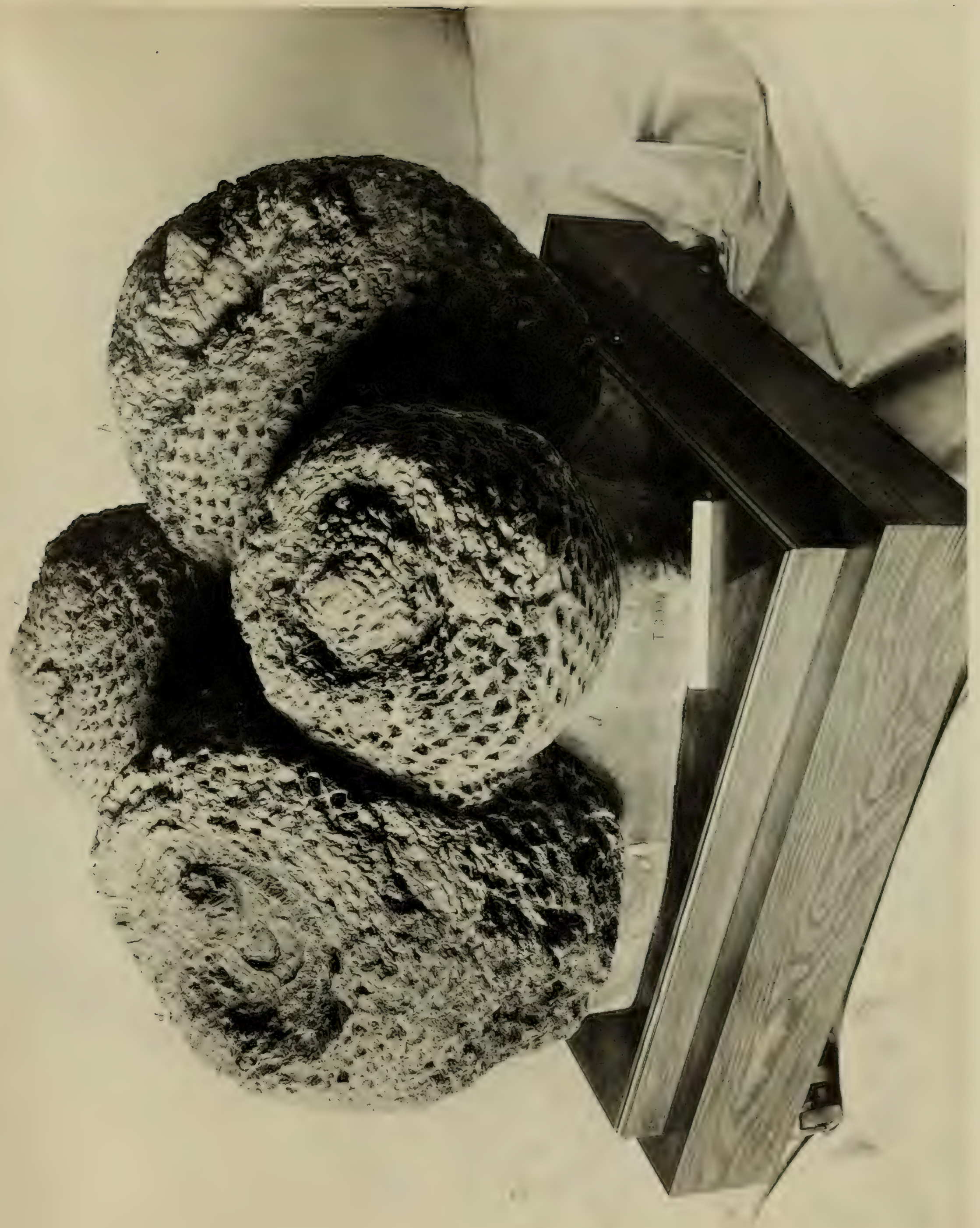





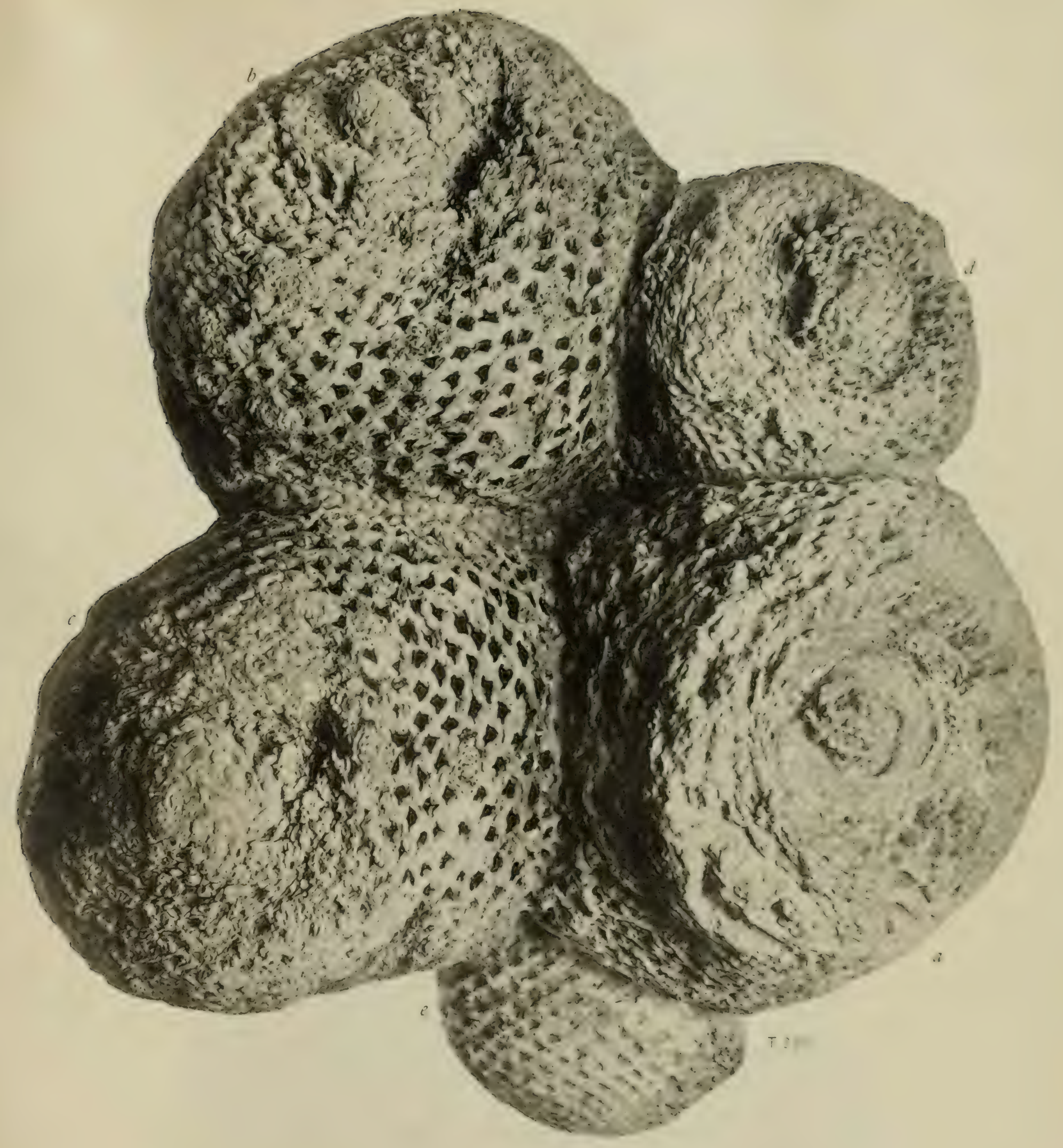




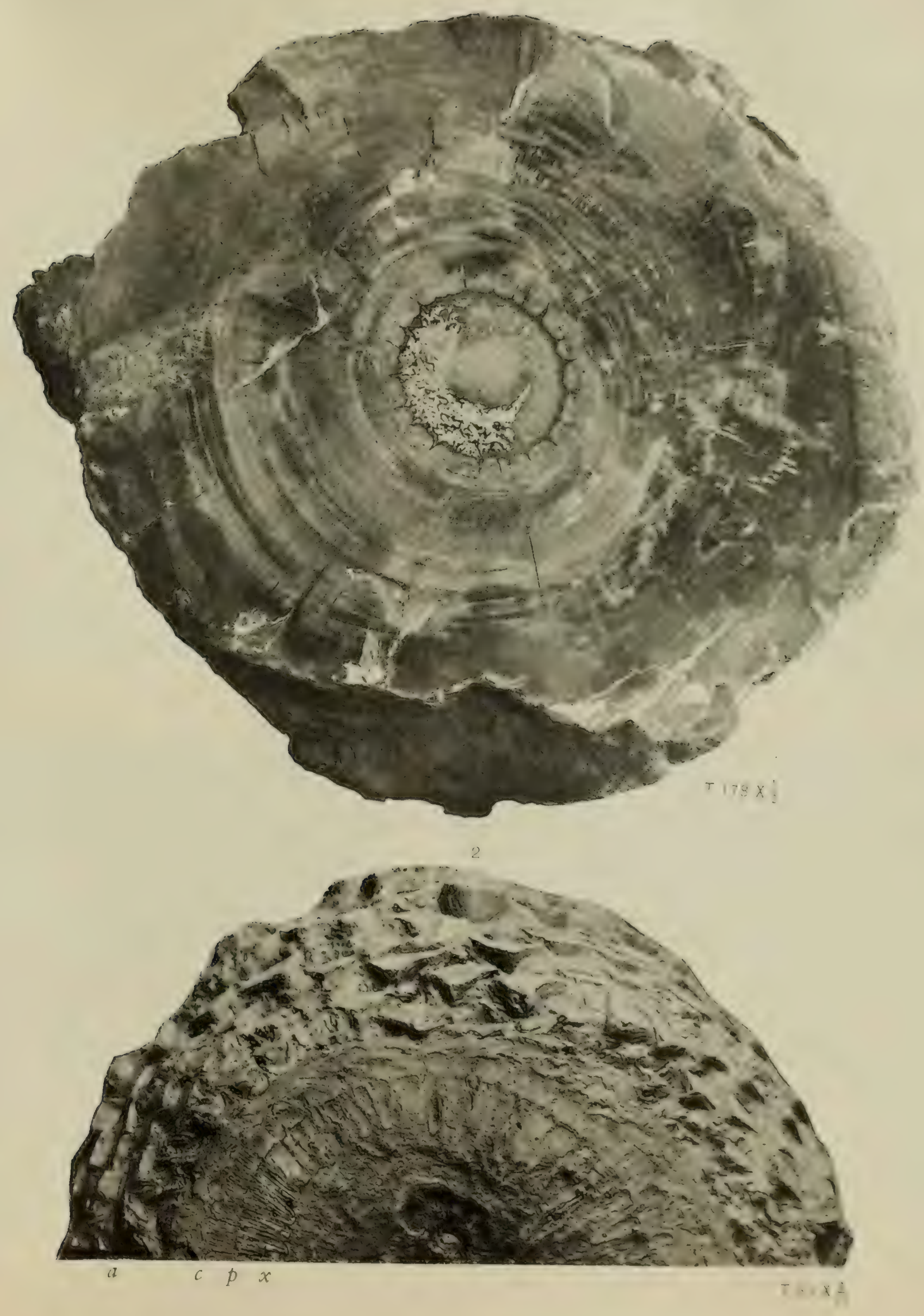

1. CYCADEOIDEA JENNEYANA. 


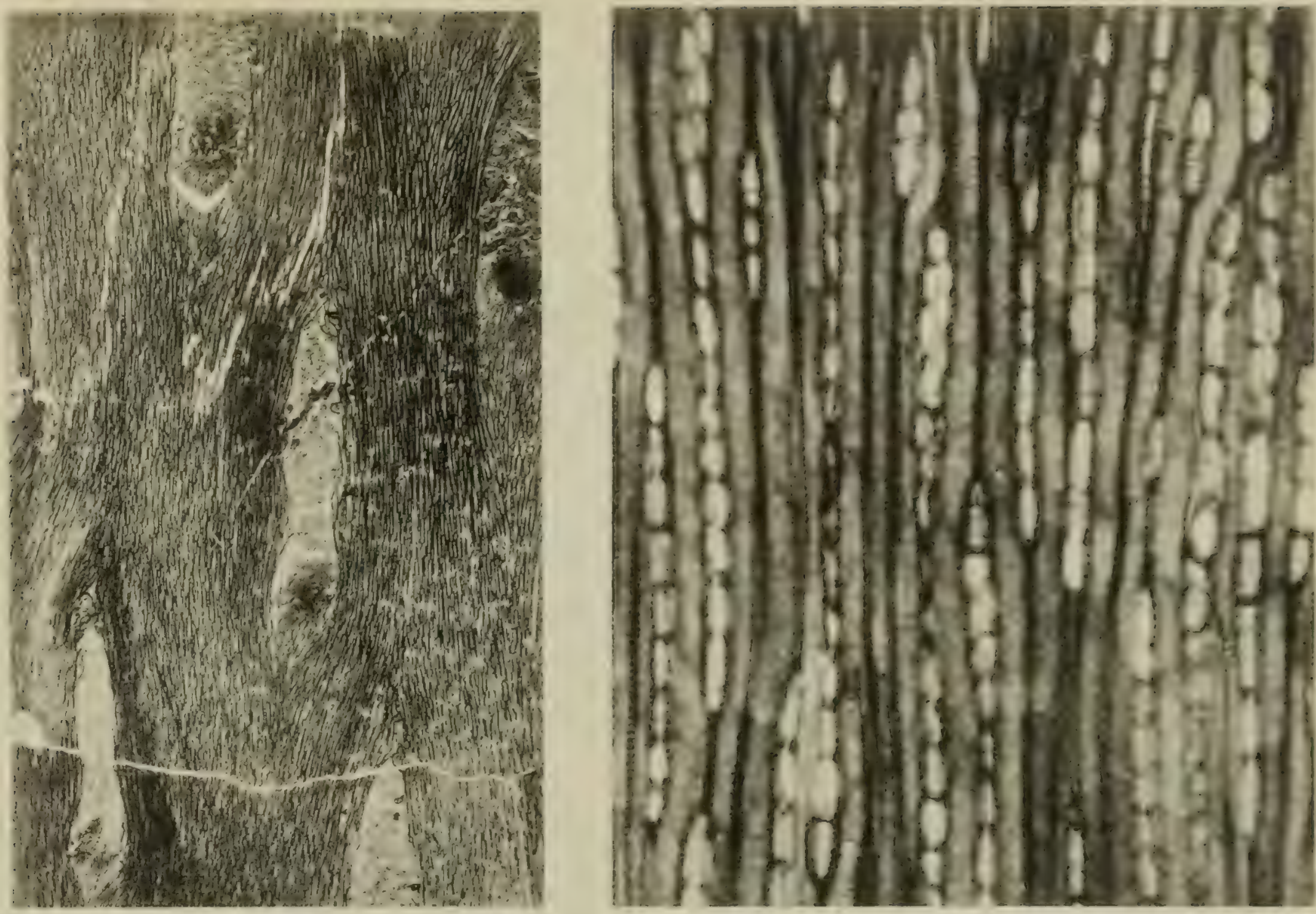

S. $225 . \times 5$
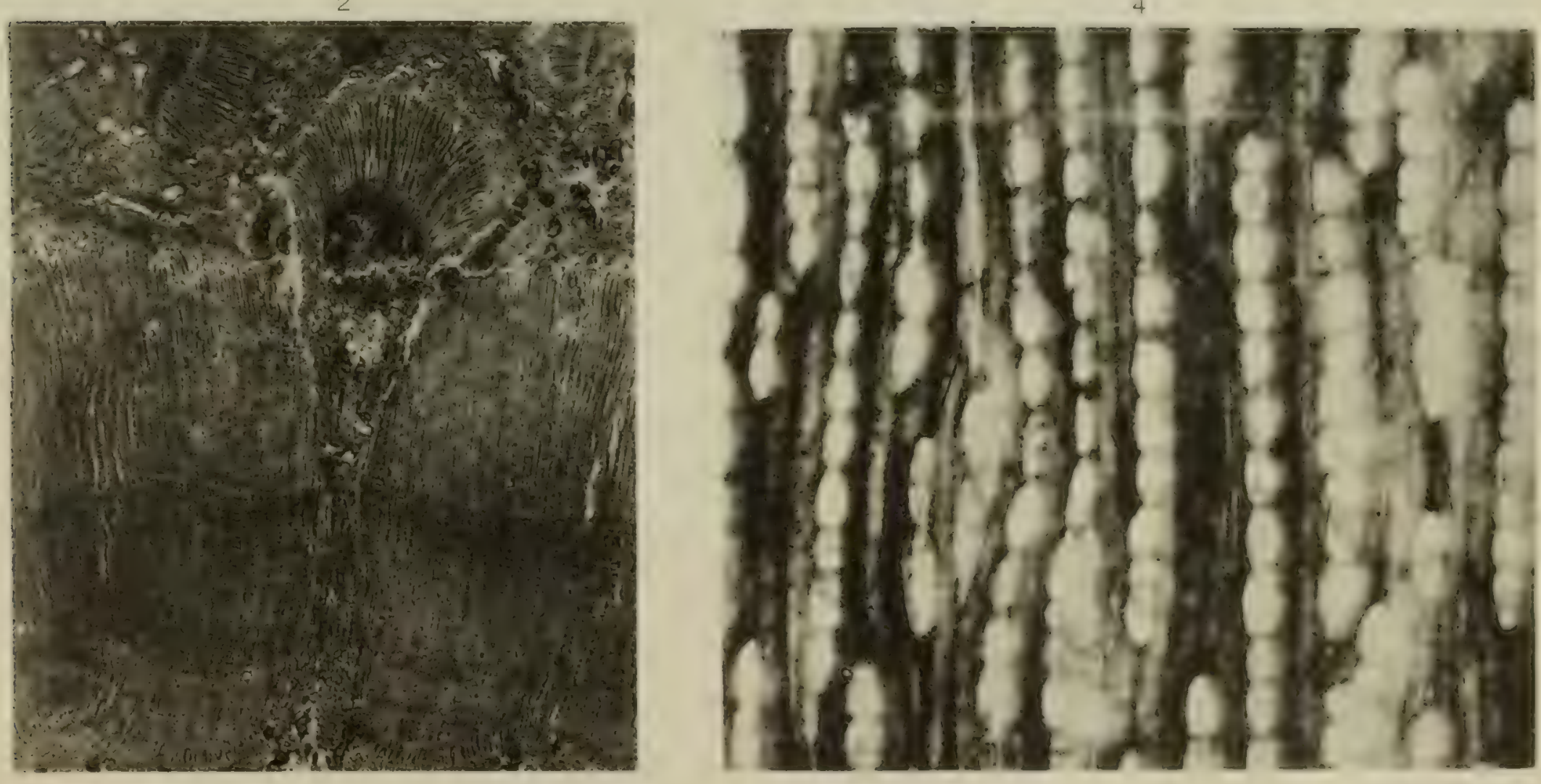

$5.261 \times 5$

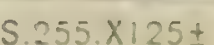




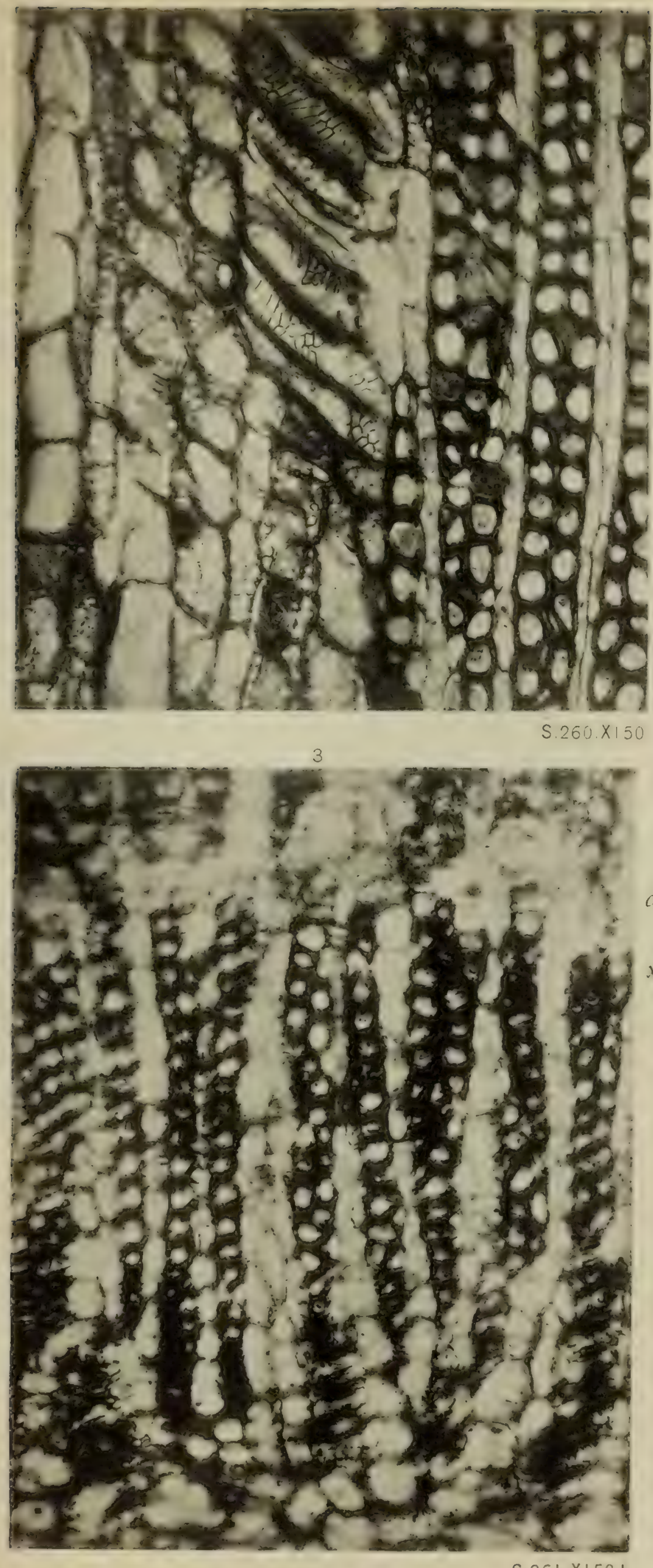
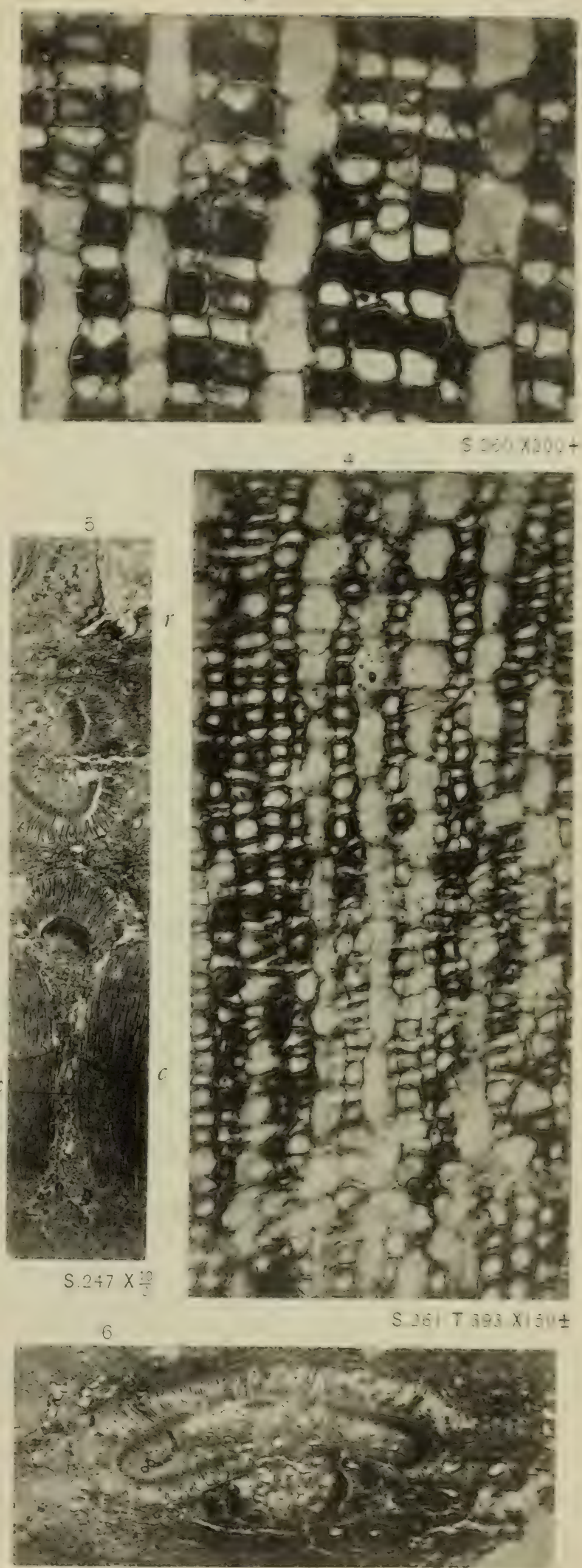



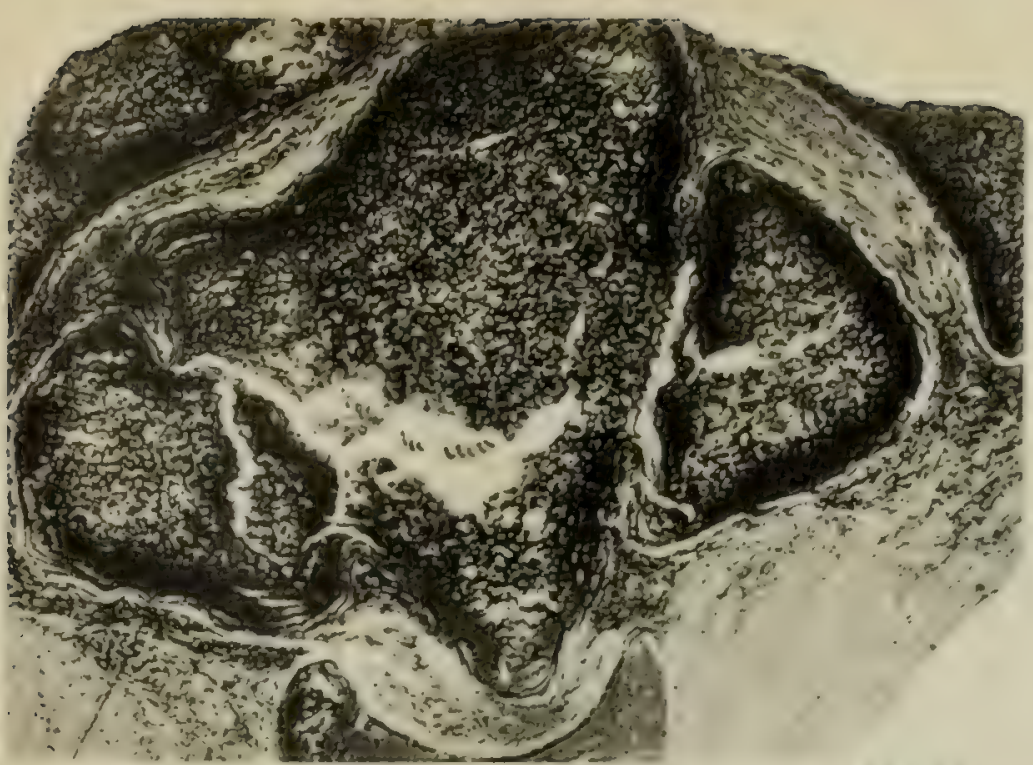

S. $456 \times 5$

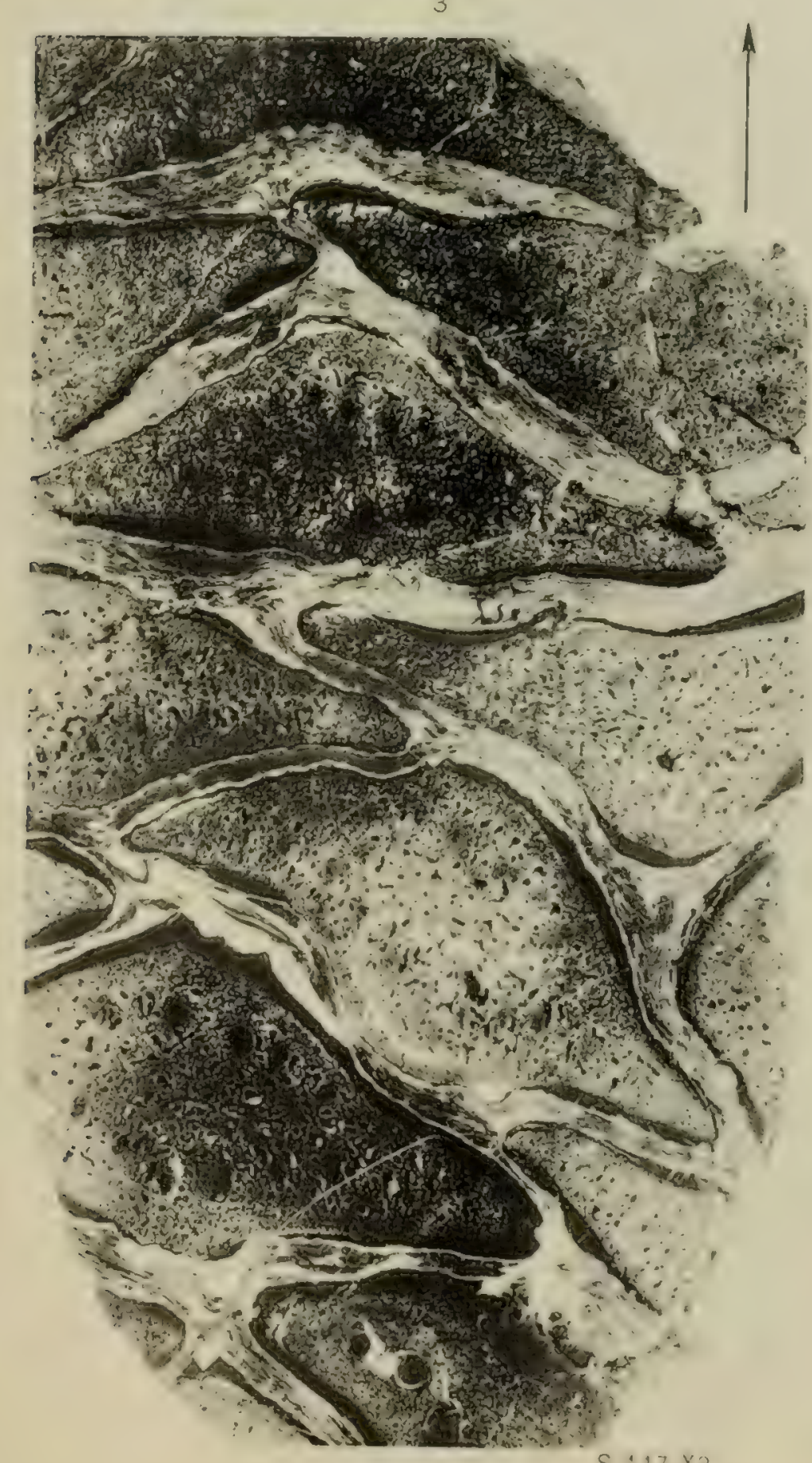

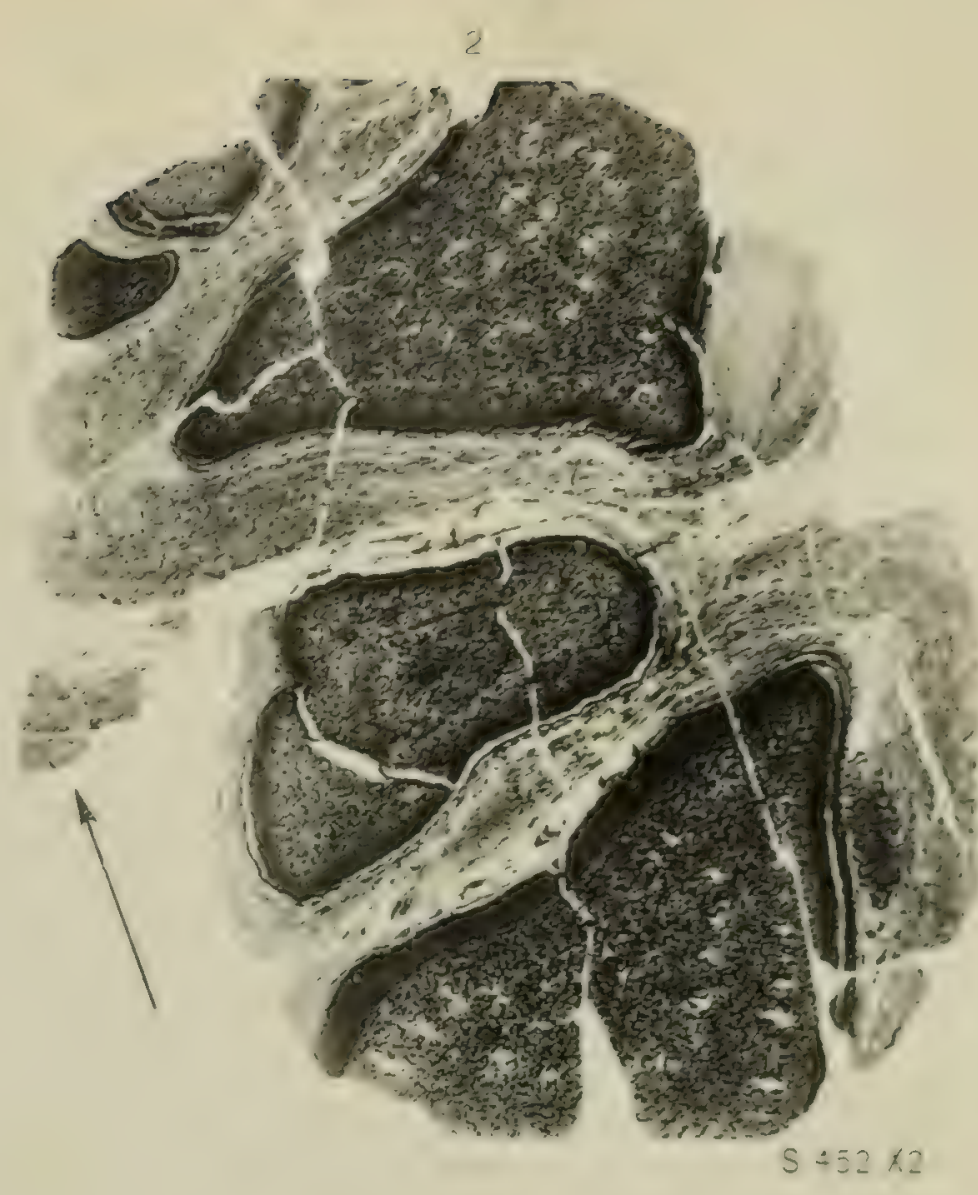

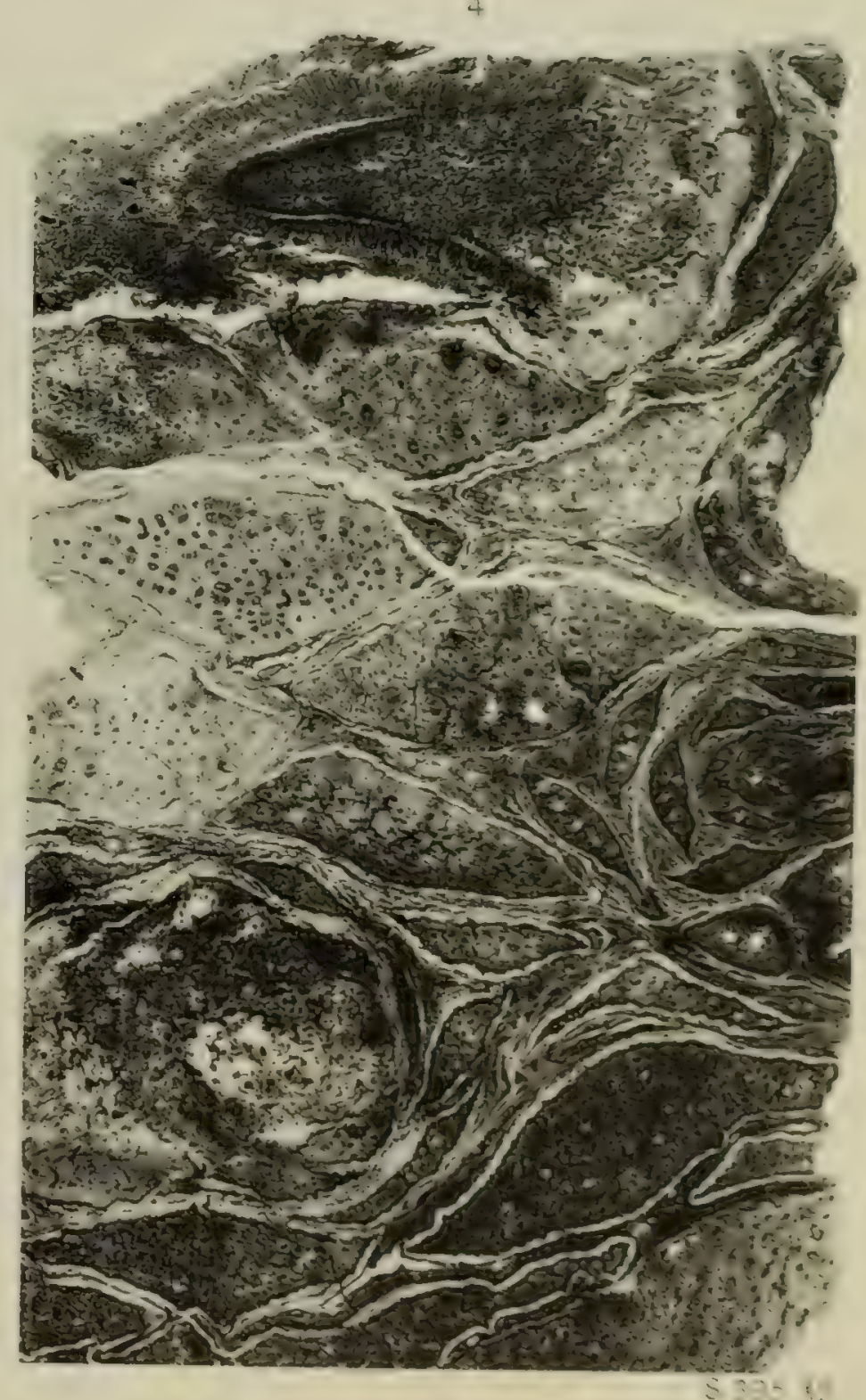




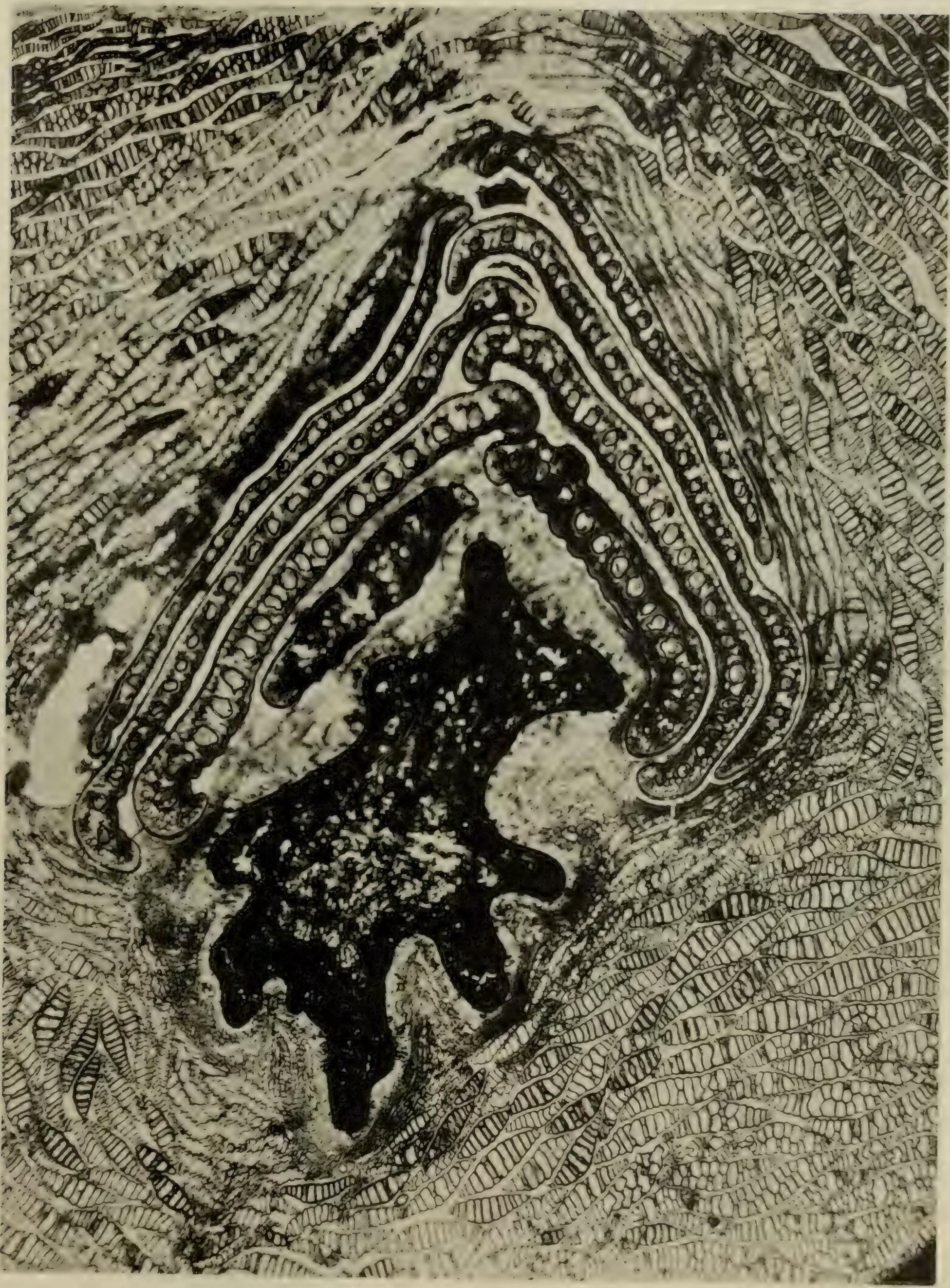





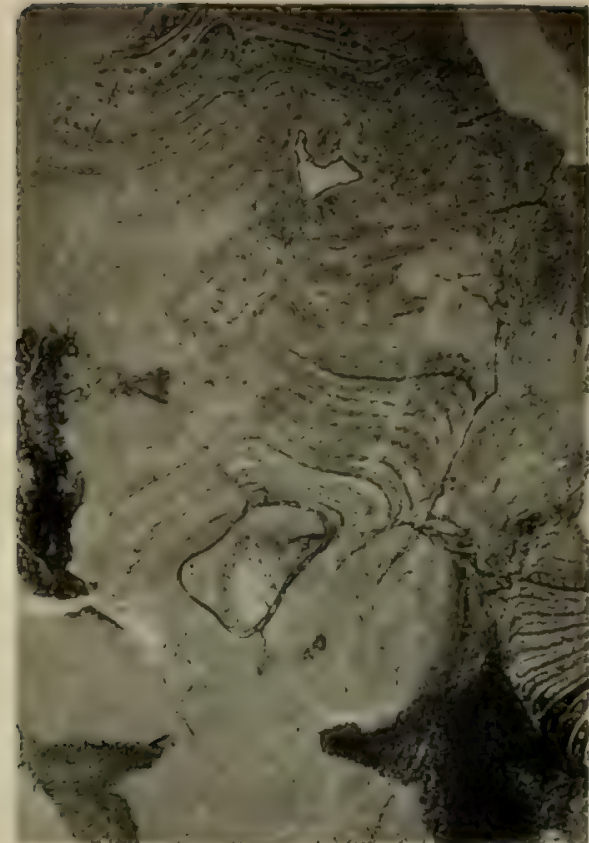

$\mathrm{S} 167 . T .100 . \times 3$

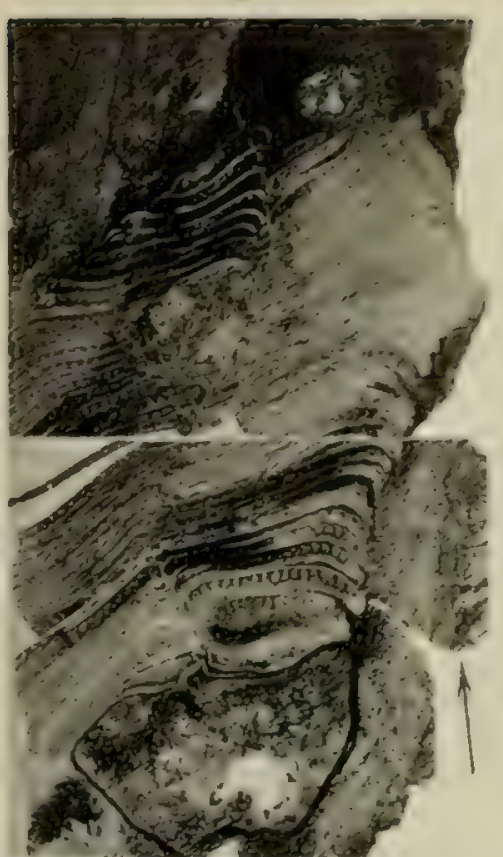

S. $168 . T .100 . X_{3}$
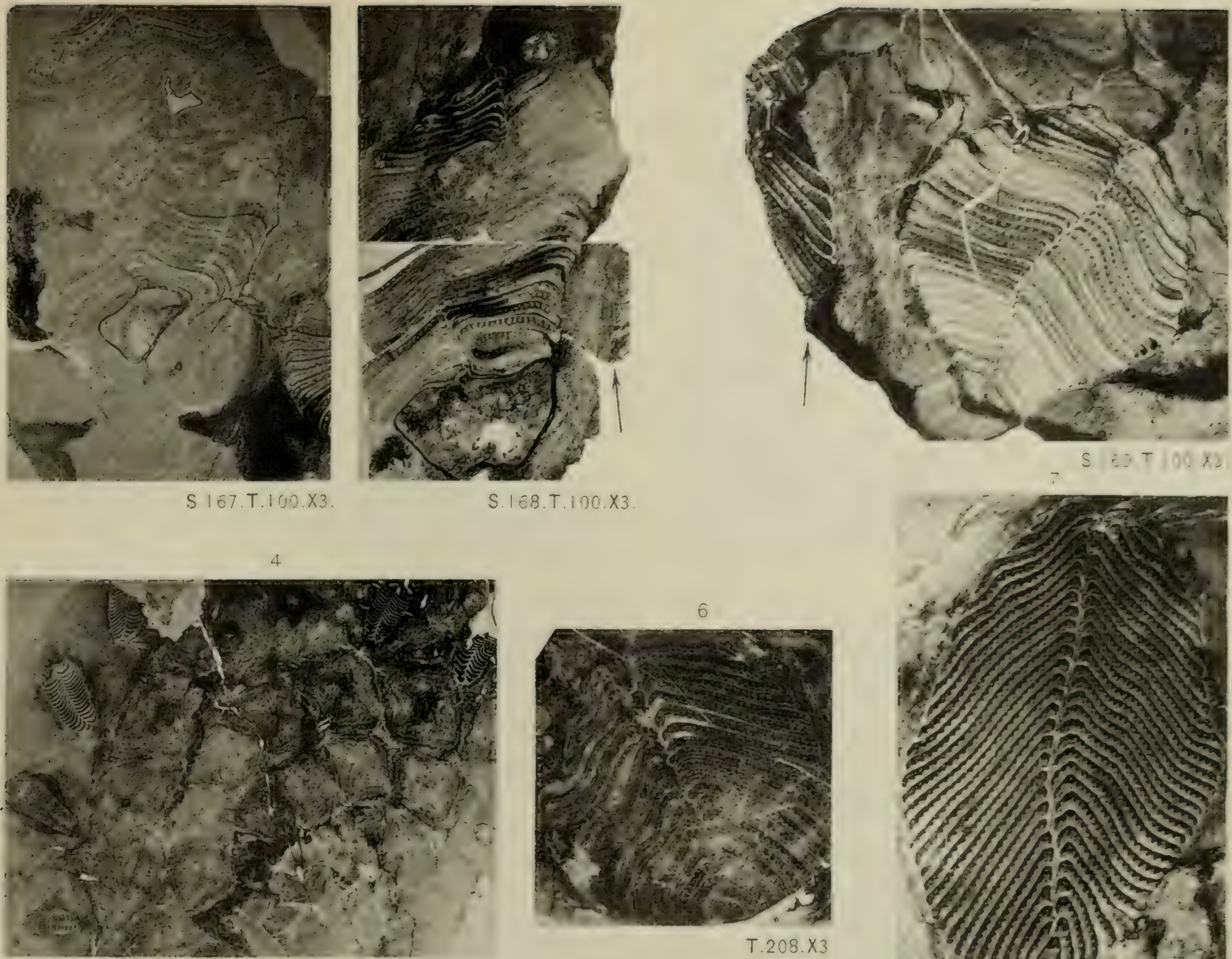

$5.407 \times \frac{3}{2}$

T.208.X3
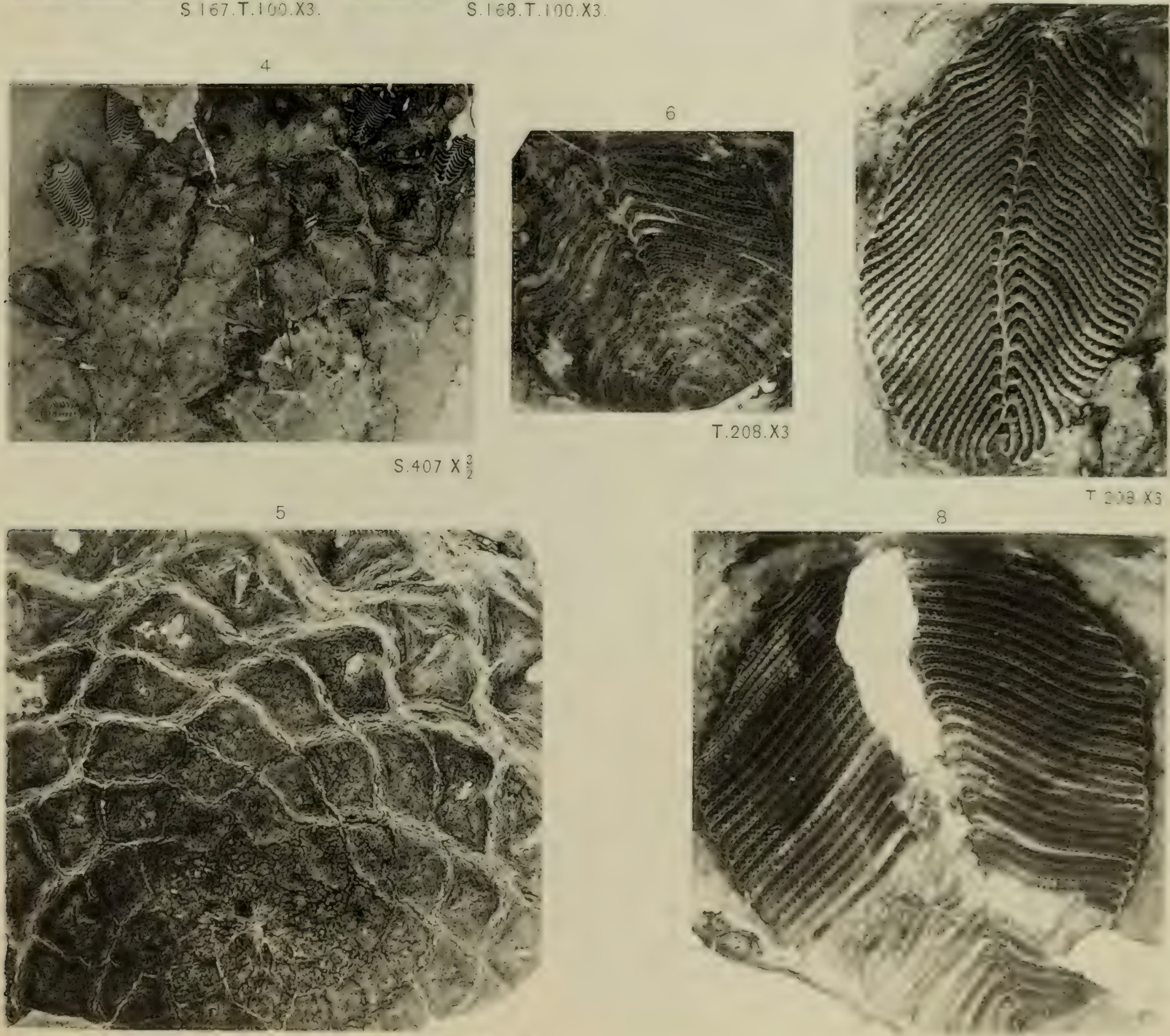

S. $398 . \times \frac{3}{2}$ 



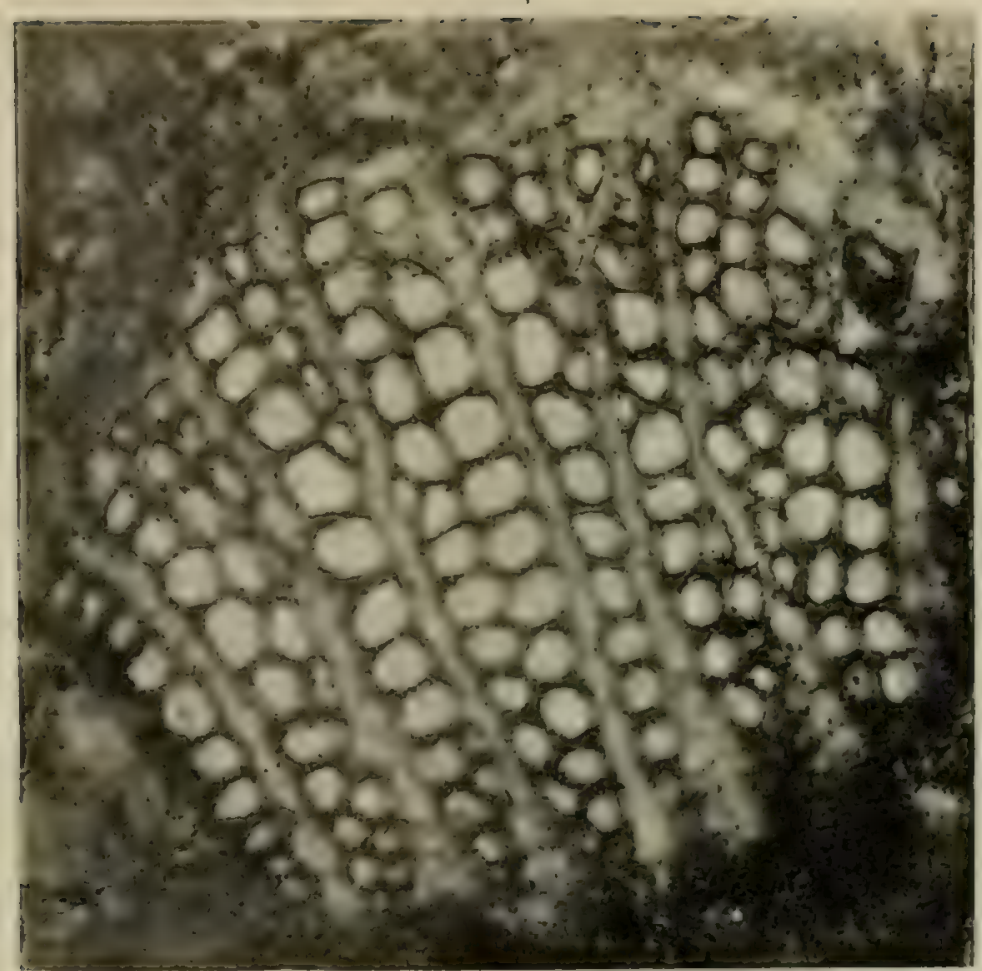

S.506.T. $214 . \times 86$

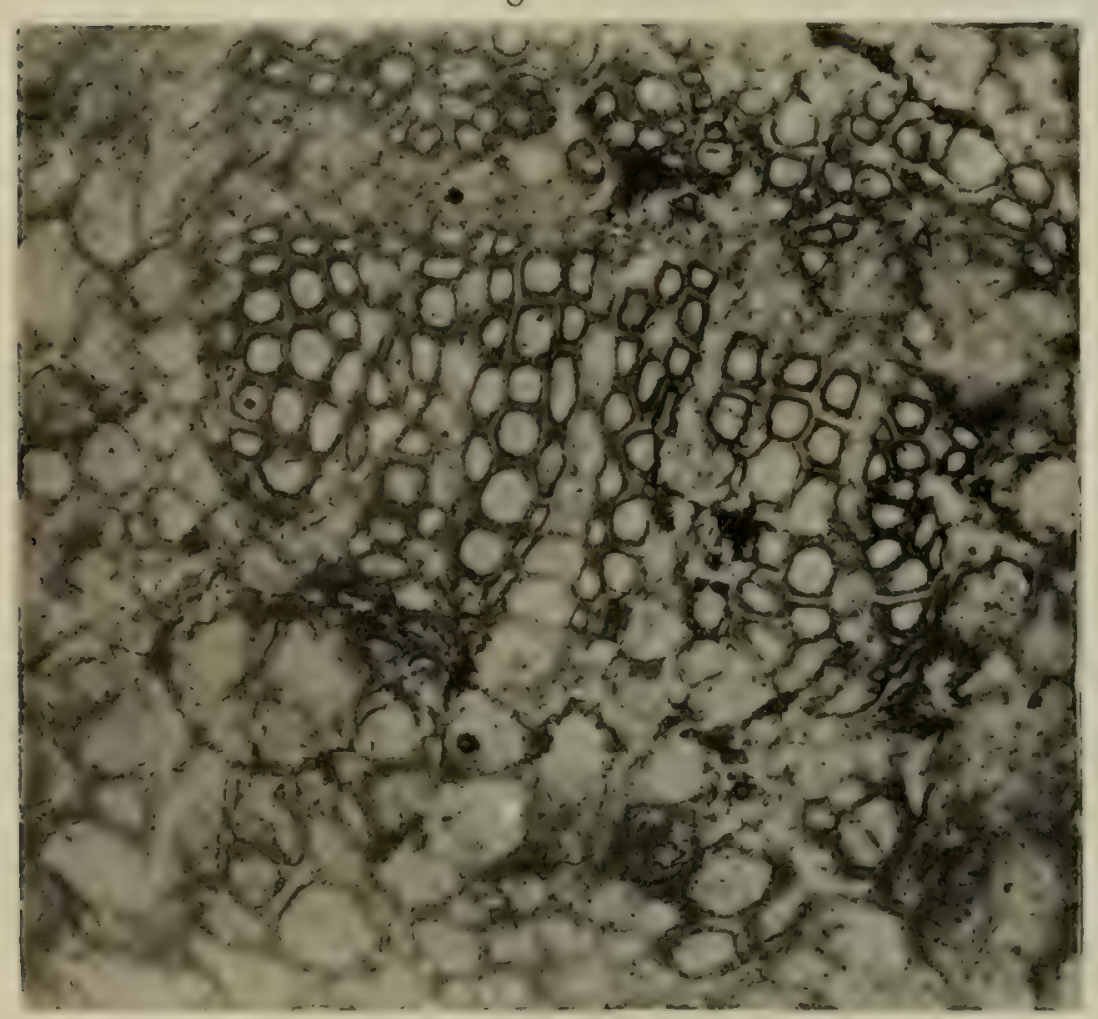

S. $483 . T .214 . \times 86$
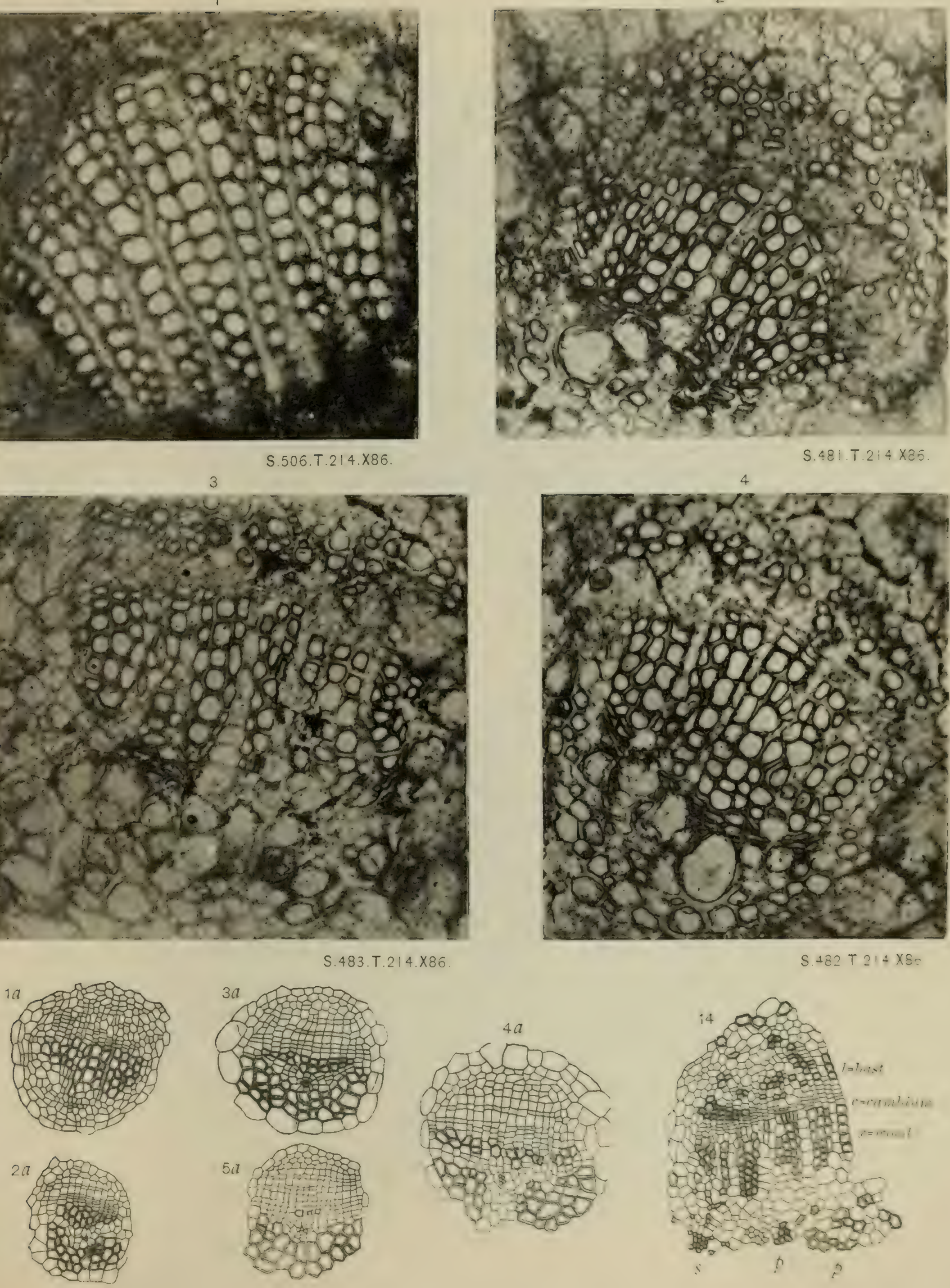

S. $481 . T .214 \times 85$

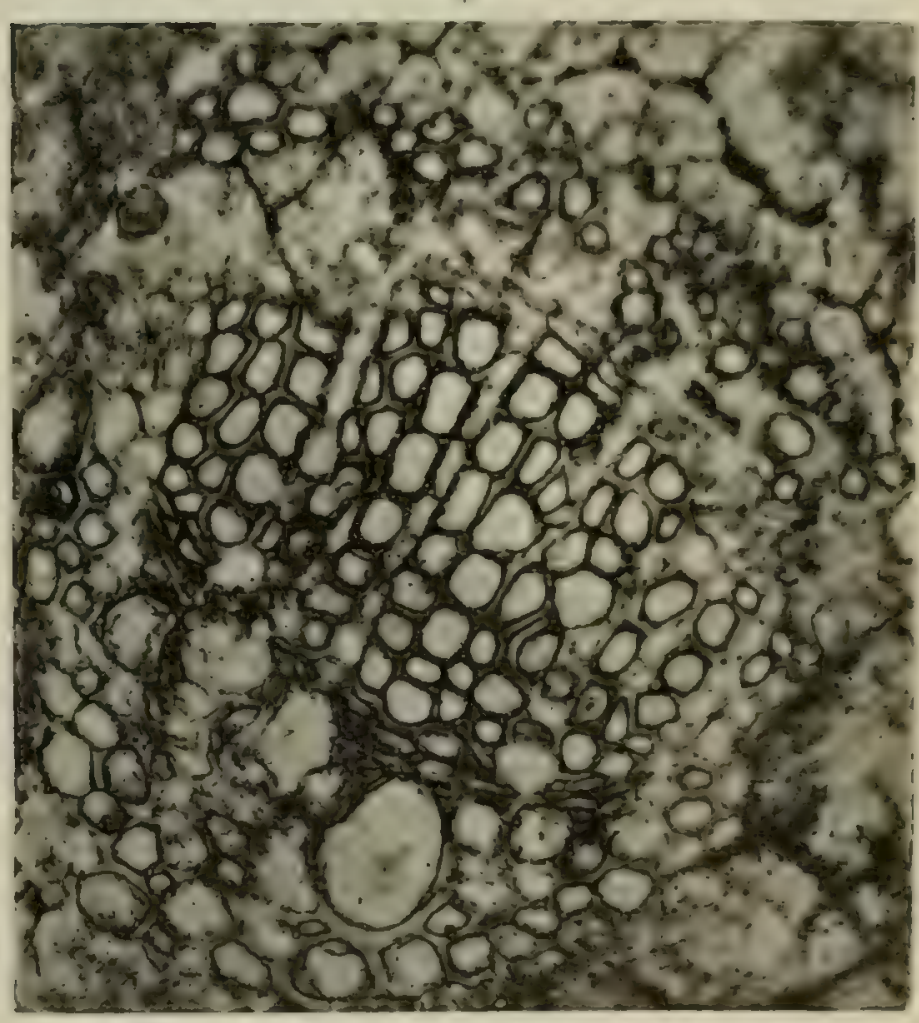

S. $182+21 \div \times 8=$

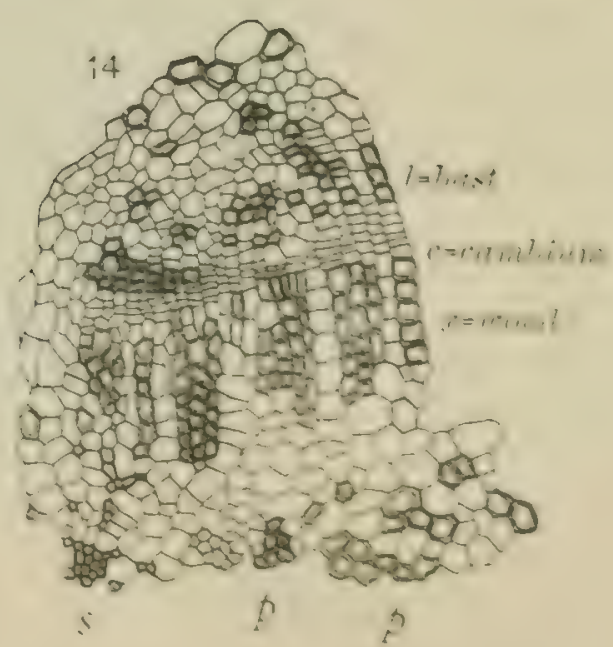




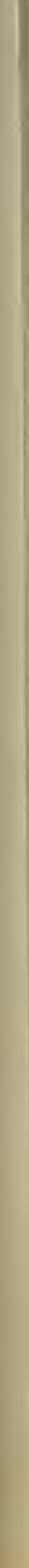




$$
\frac{\bar{x}}{\frac{\underline{x}}{2}}
$$
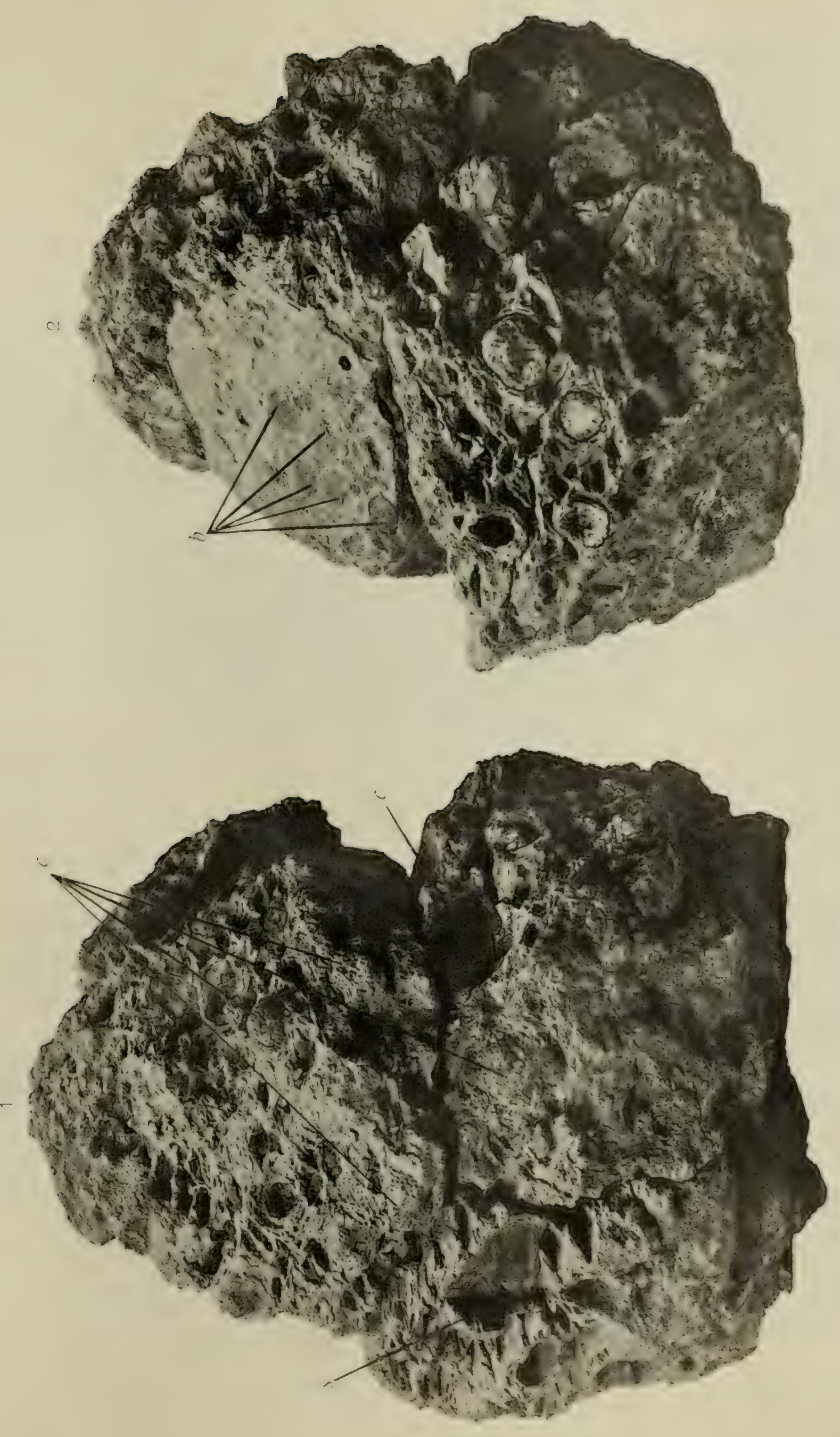

产
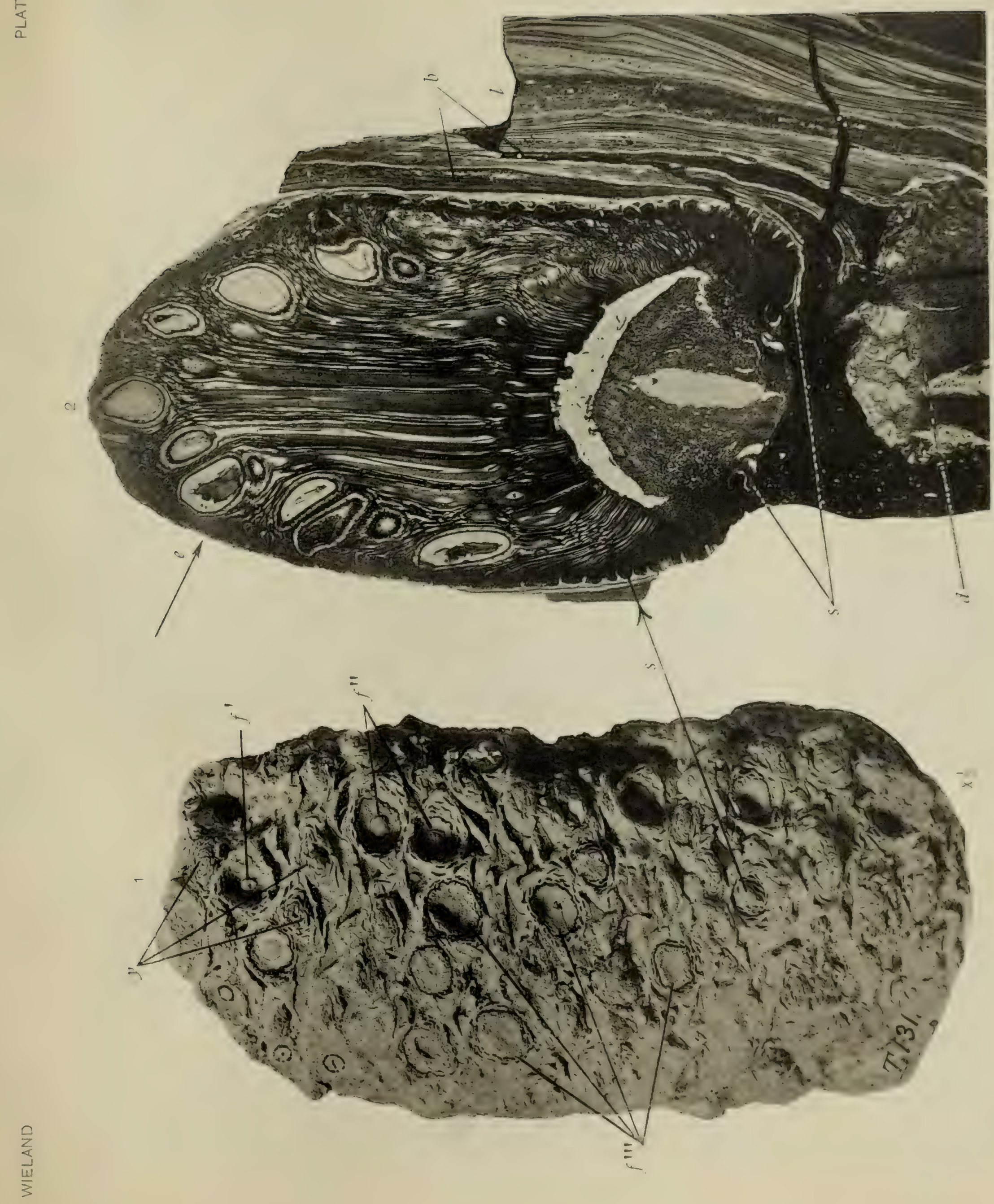


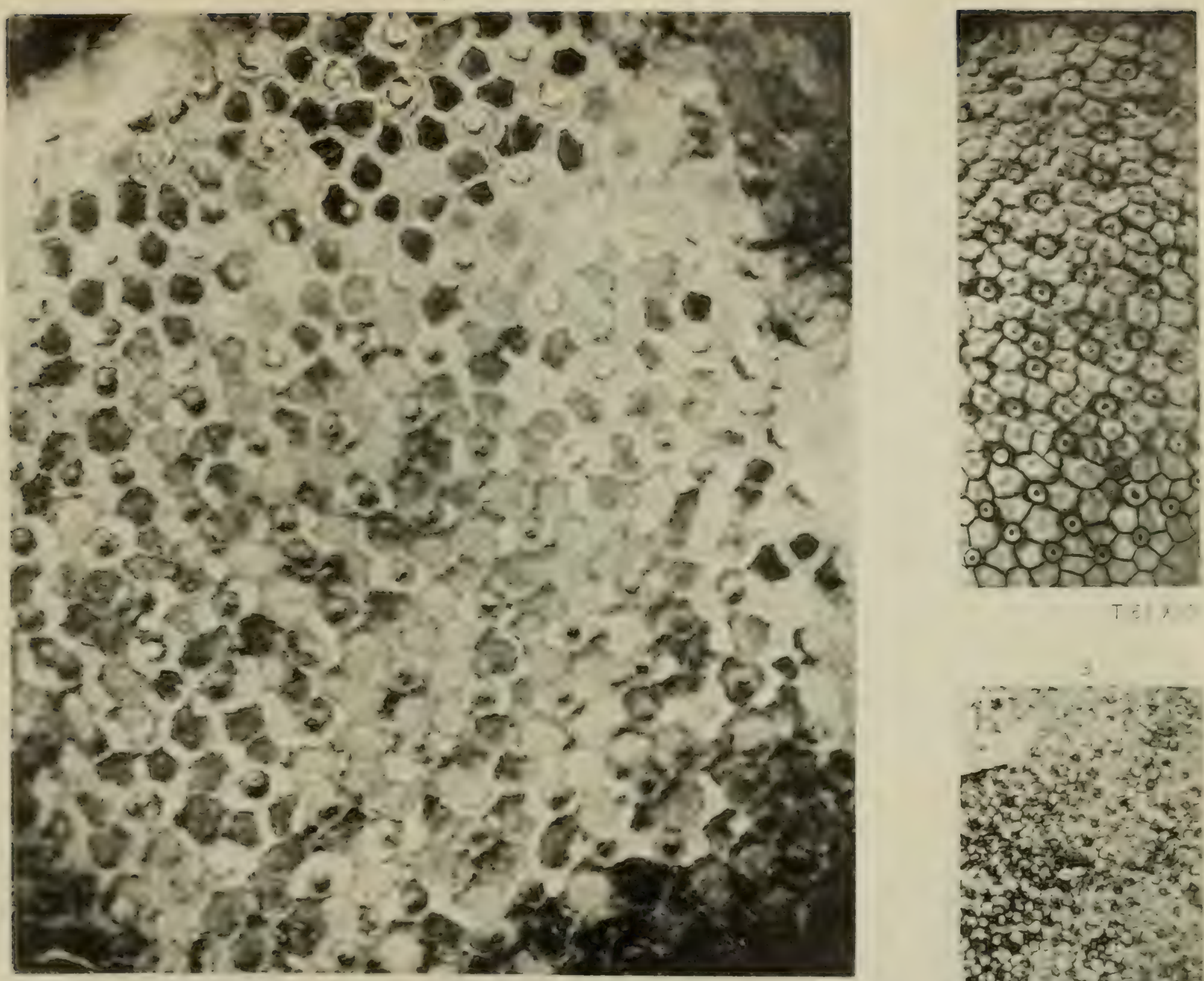

T.761.X20
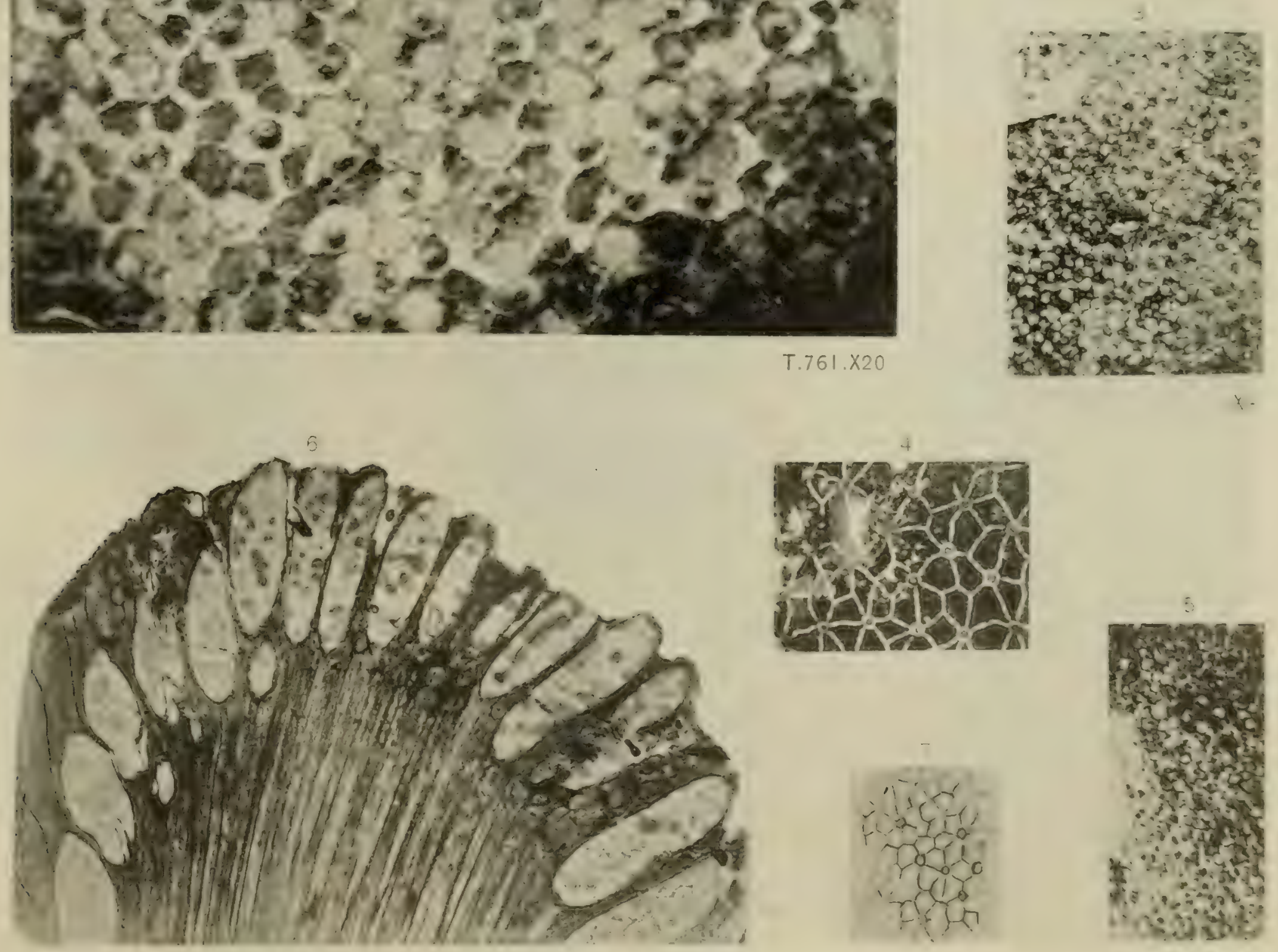

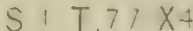

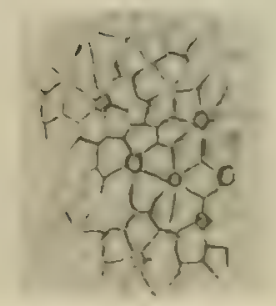



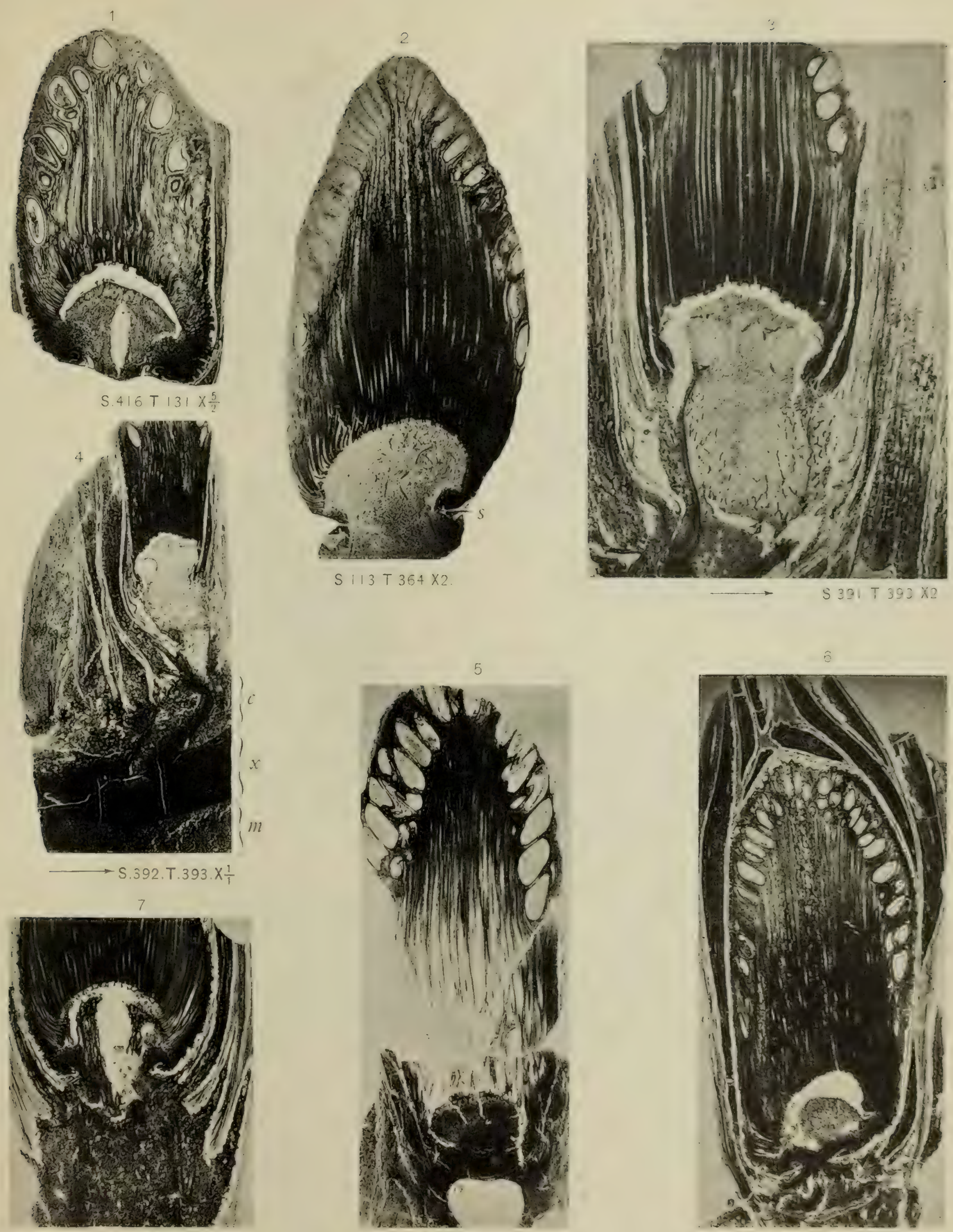

S. $289 . T 8 \times 2$
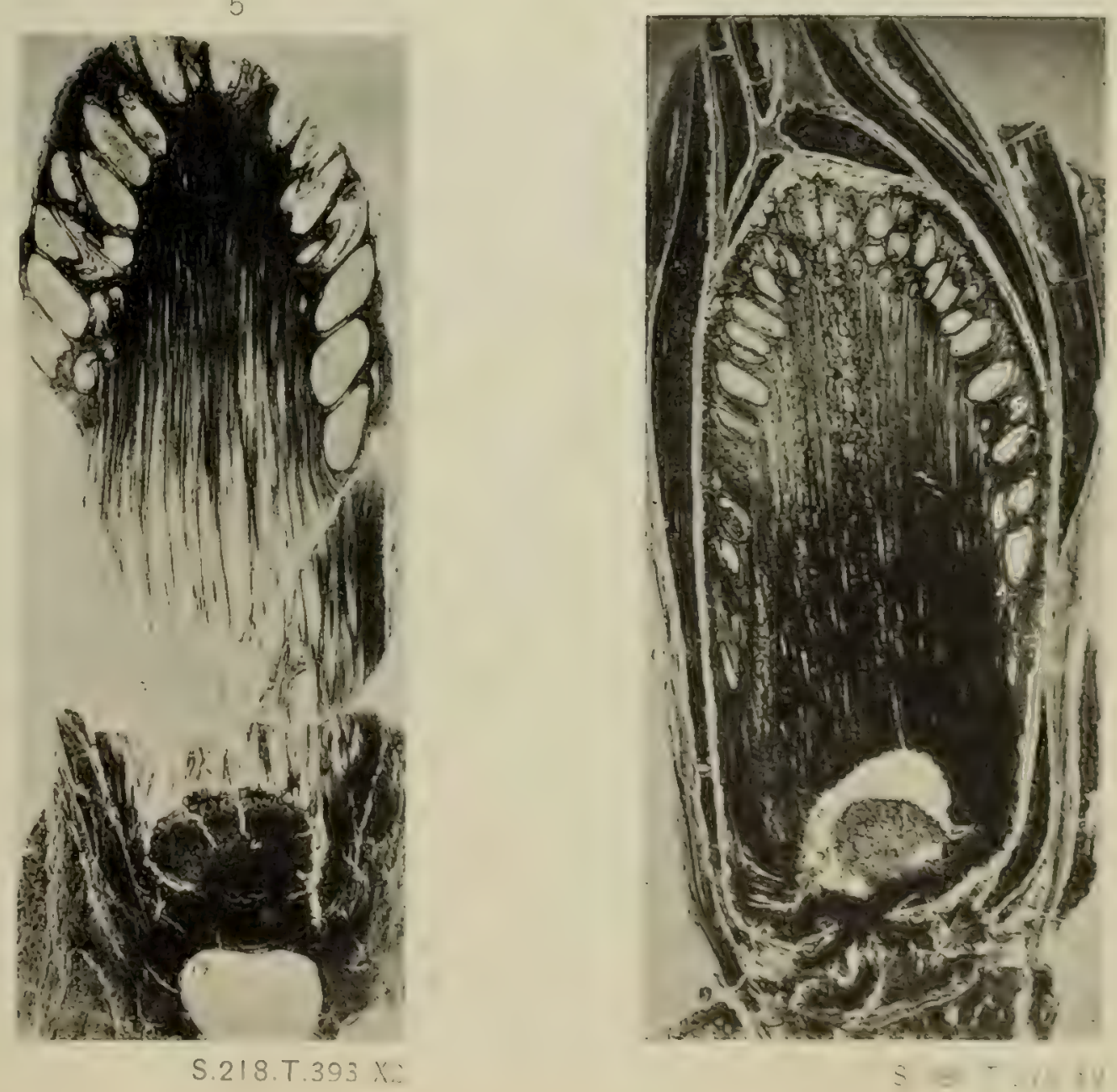


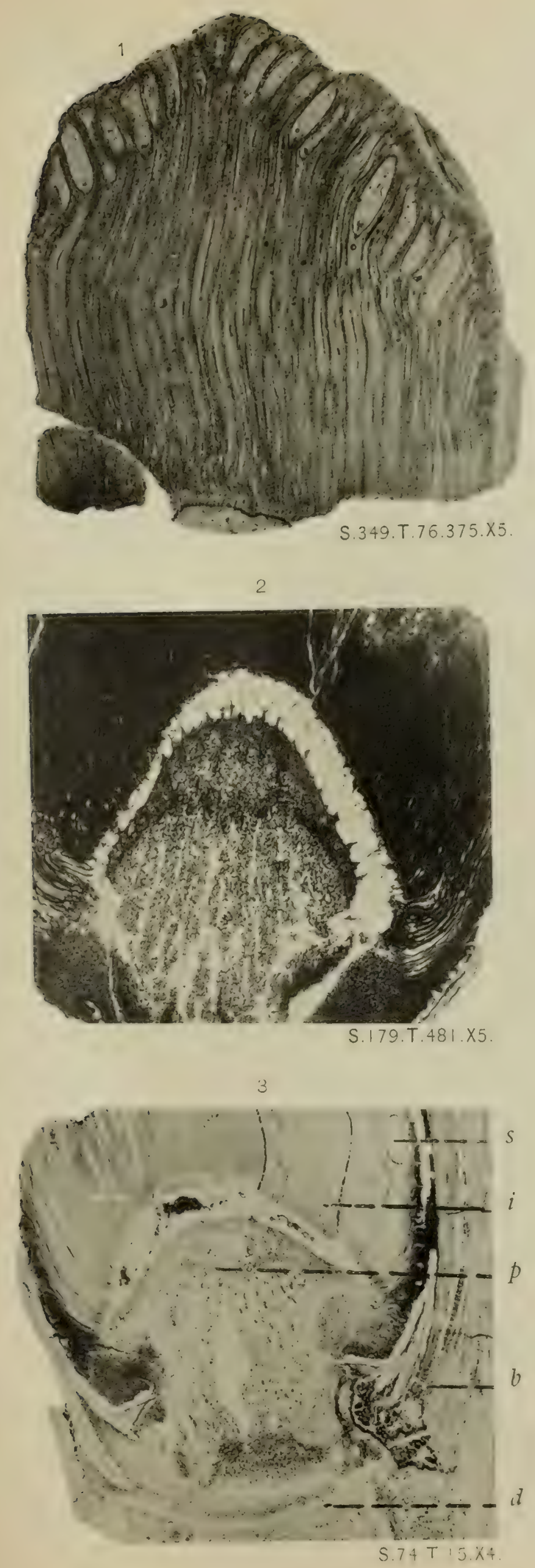
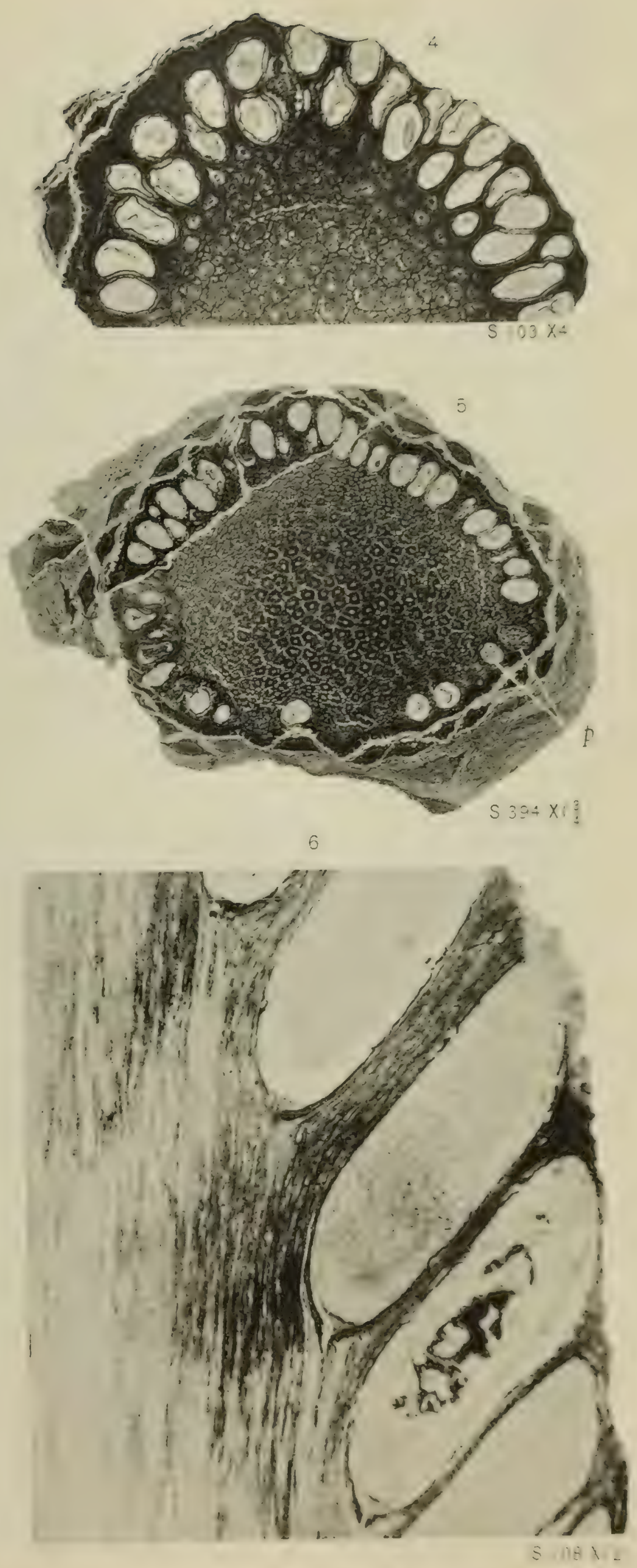


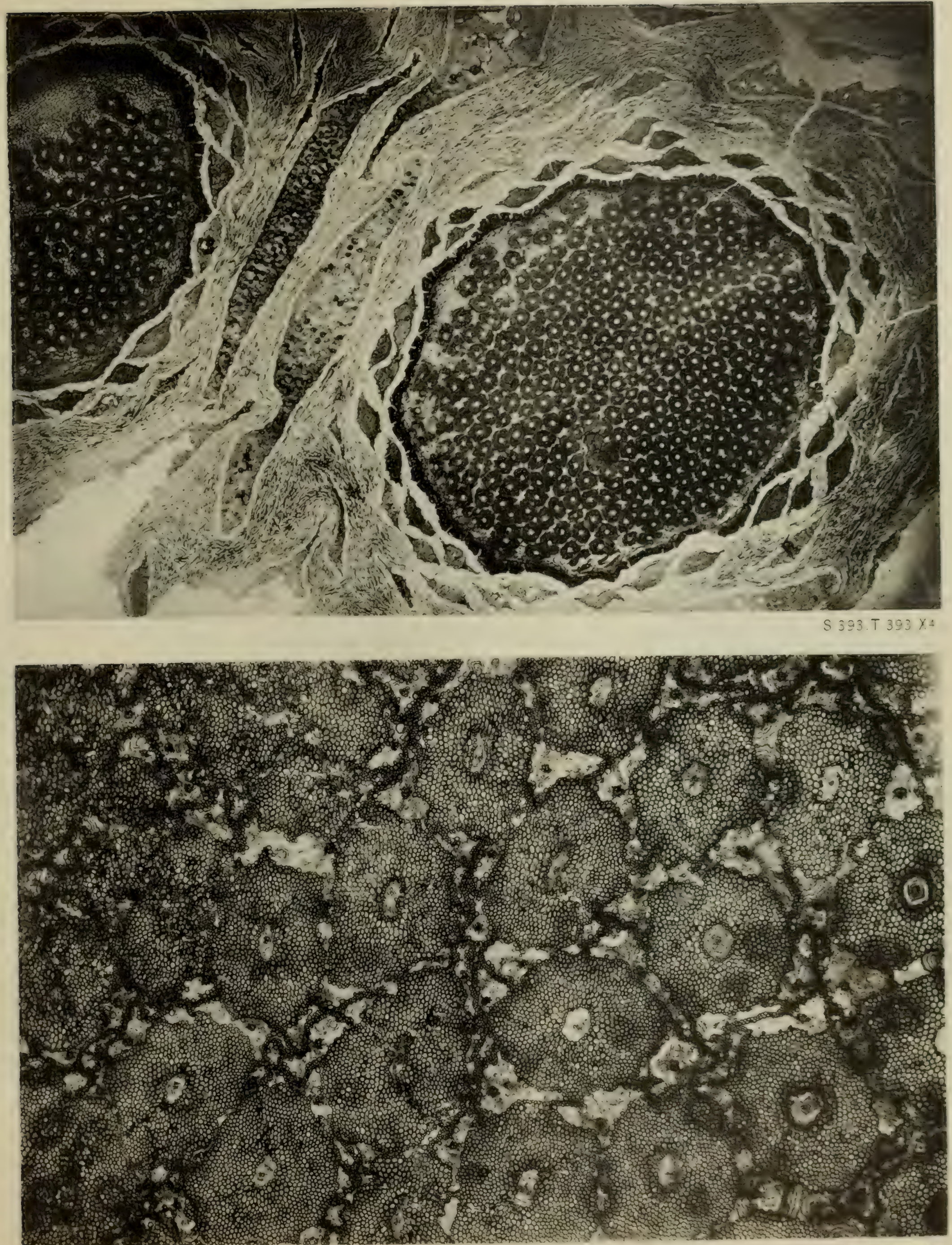



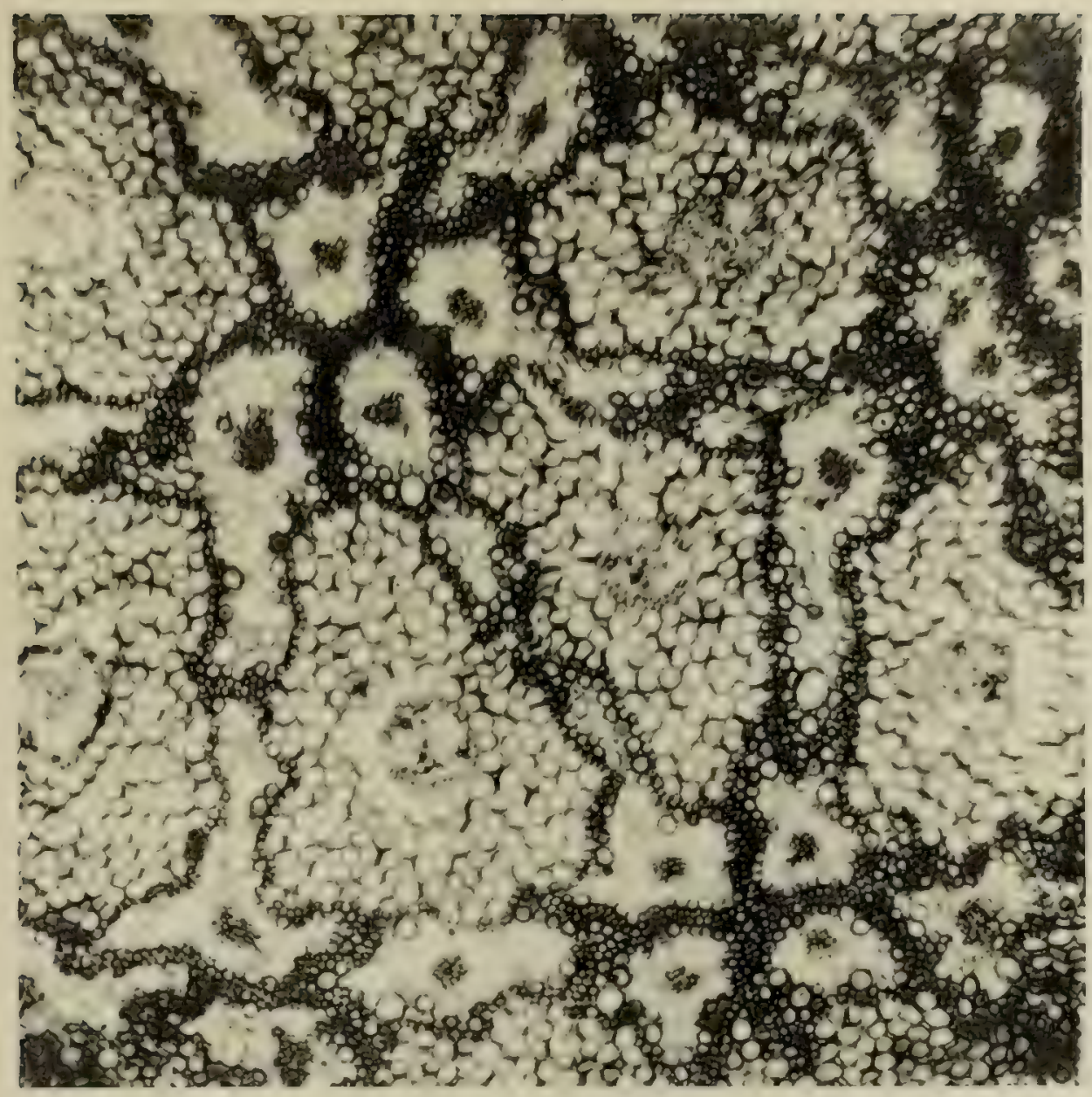

S $103 \mathrm{~T} 393 \times 35$

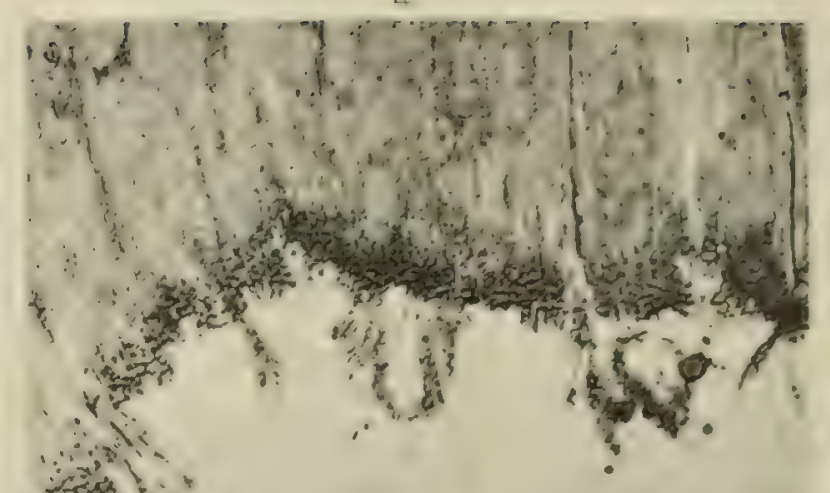

is

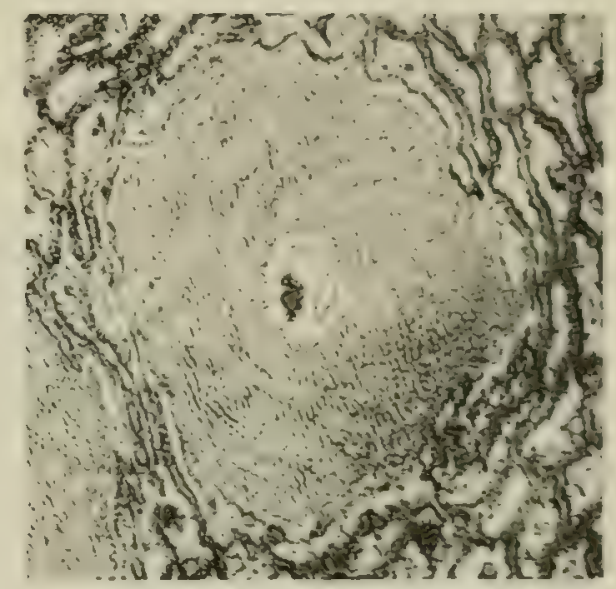

$S \& 5 T X \div$
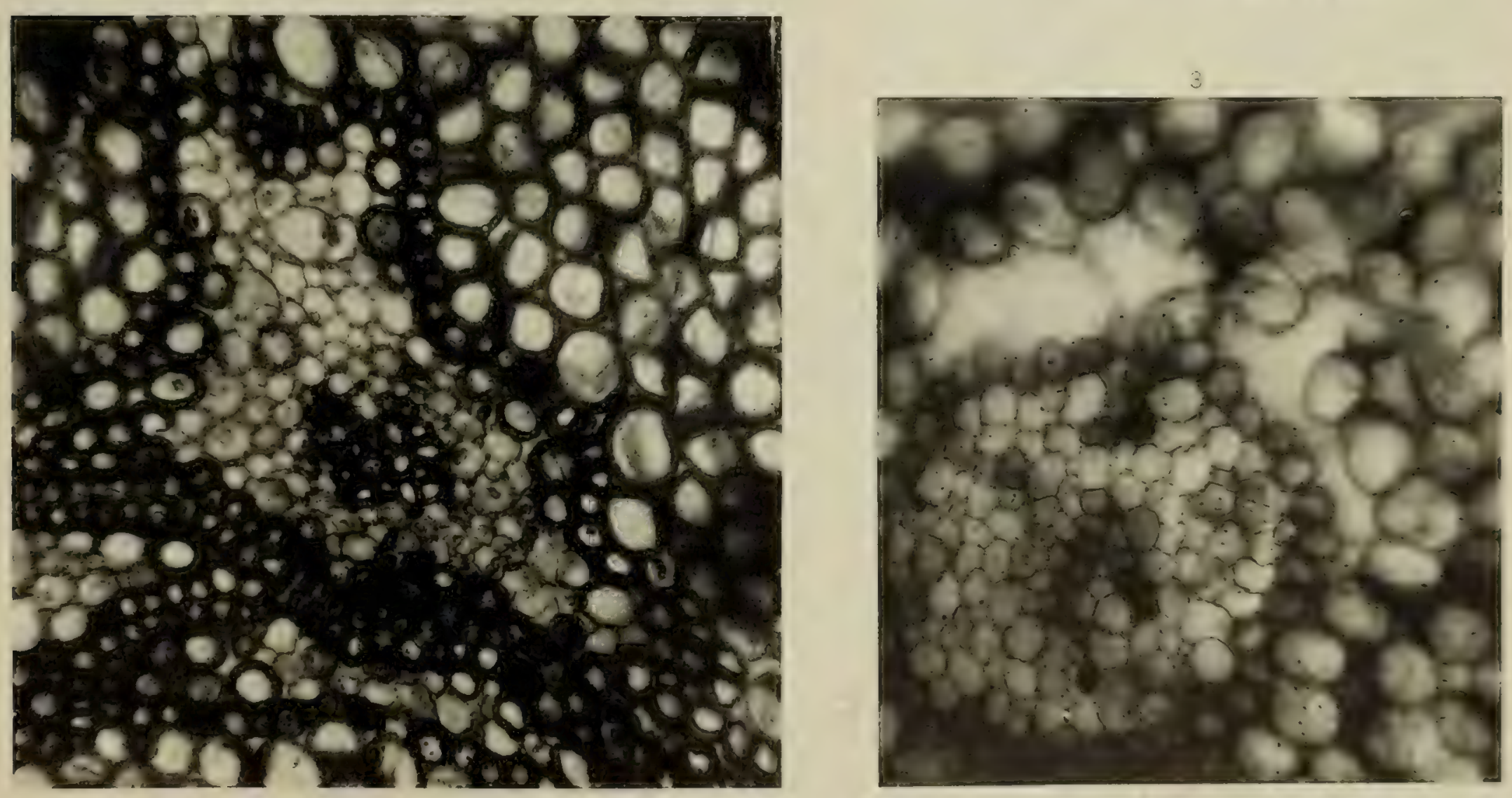


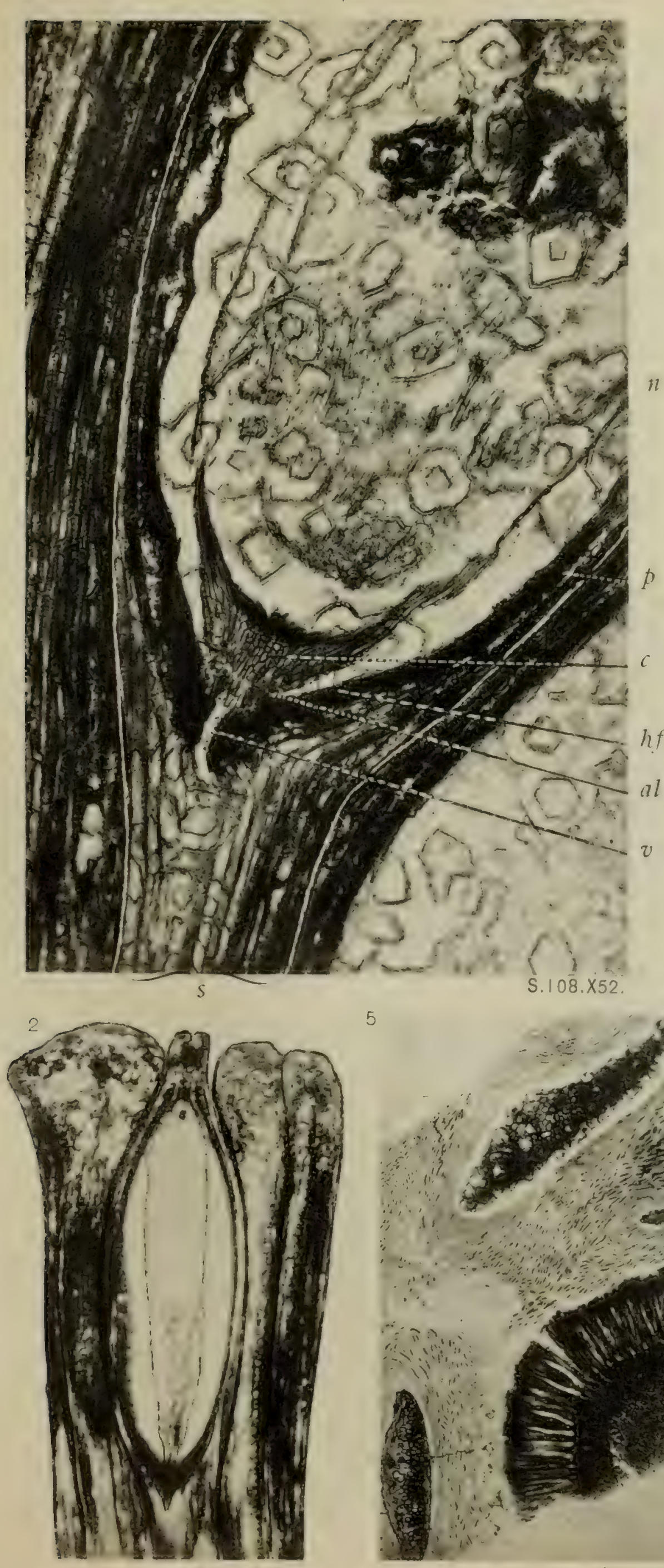

S.393.X20.

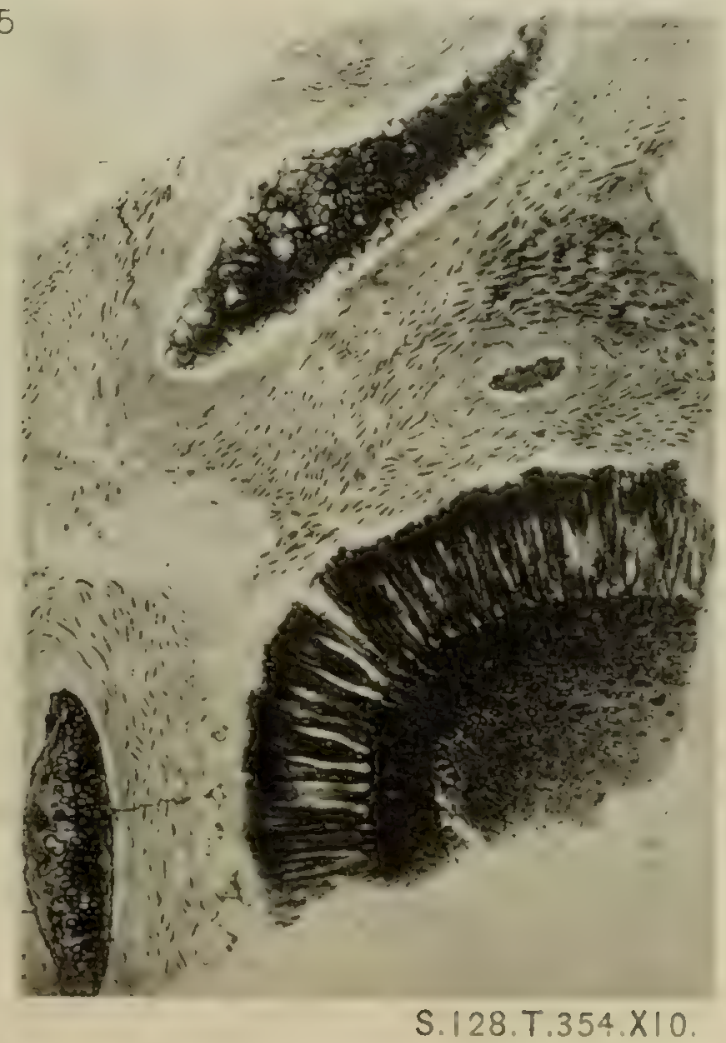





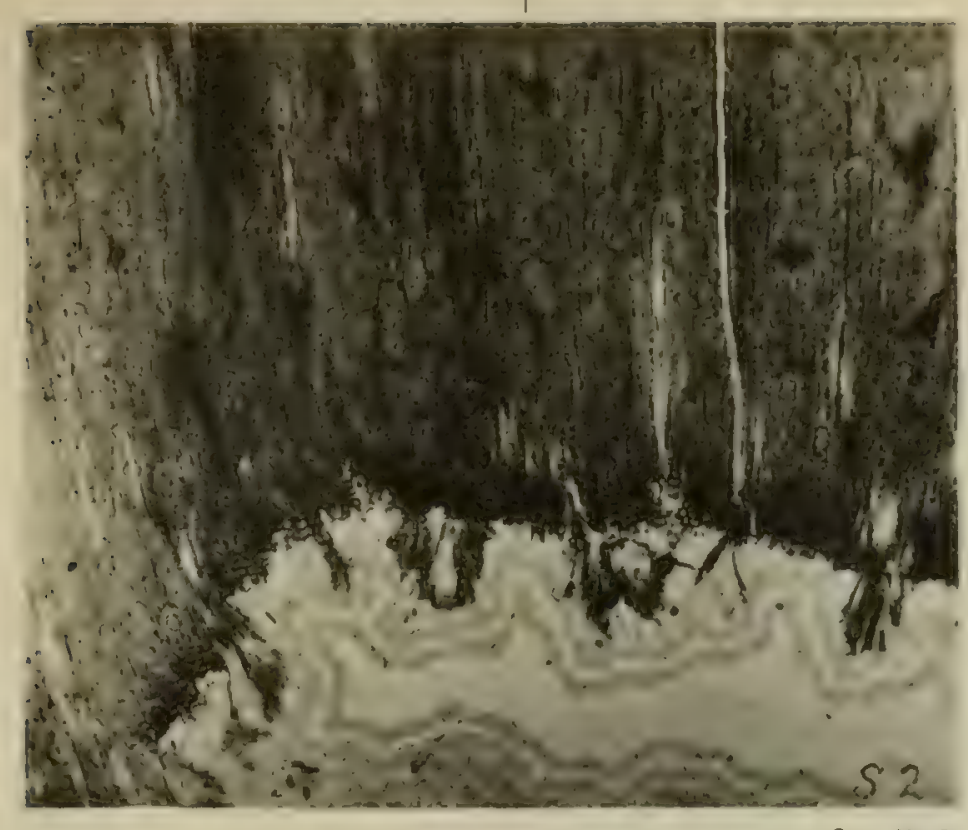

S.2.X18.
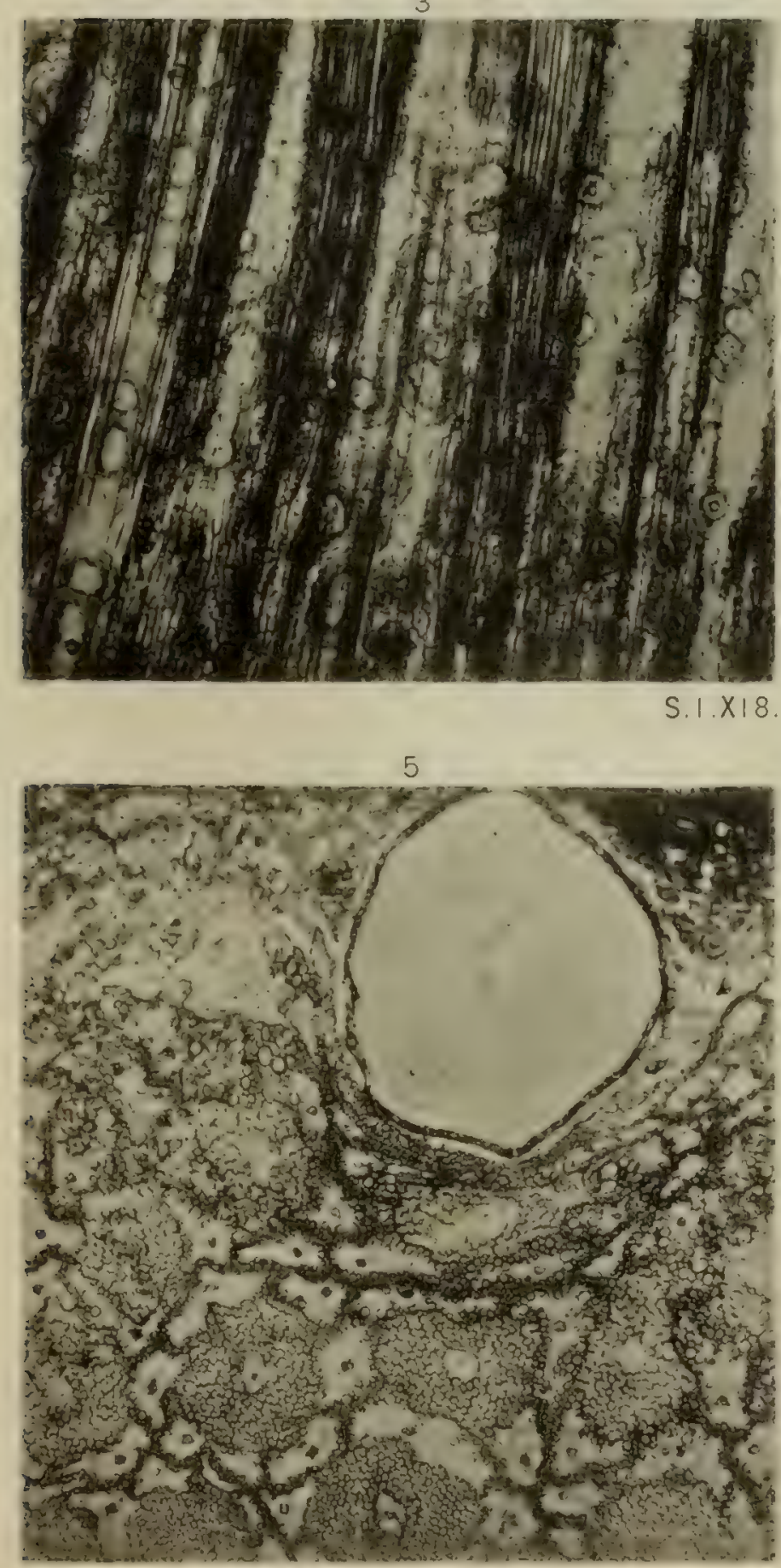

$5.7 . \times 23$

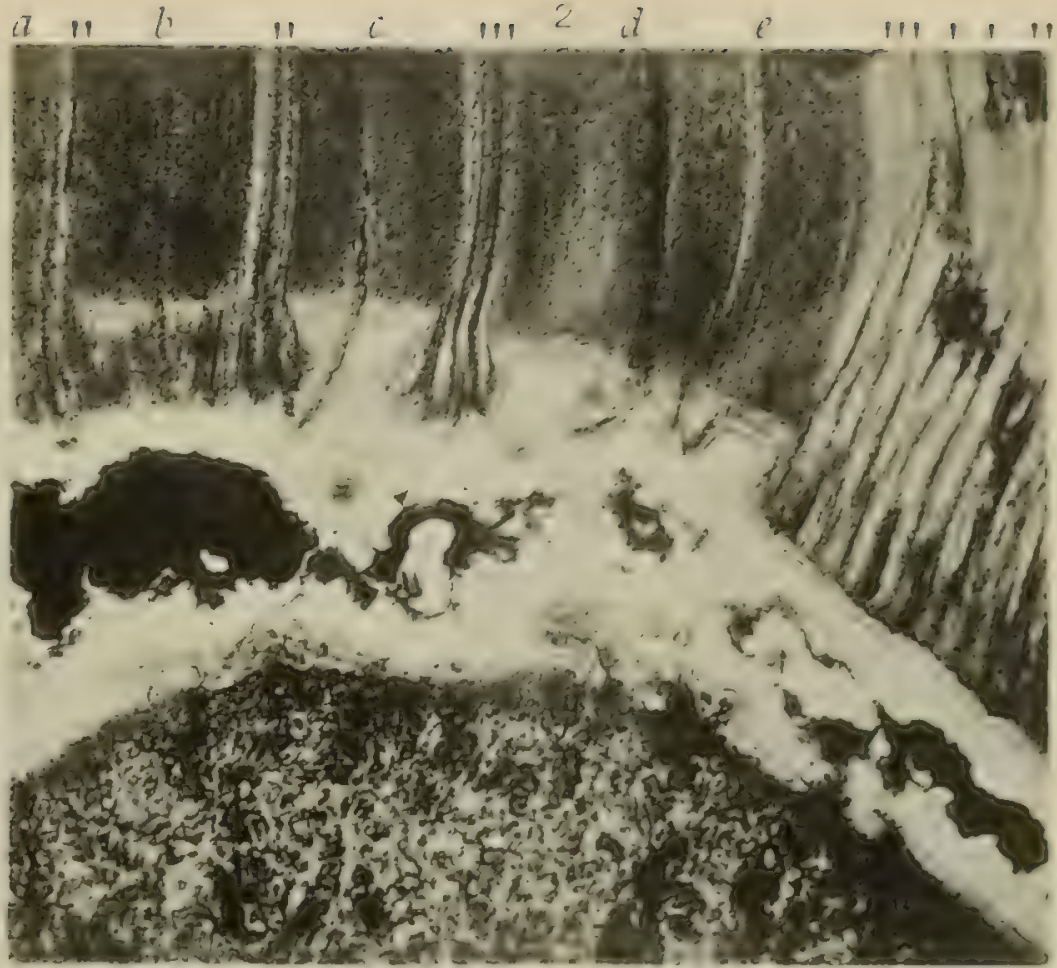

S. $74.0177 \times 3$

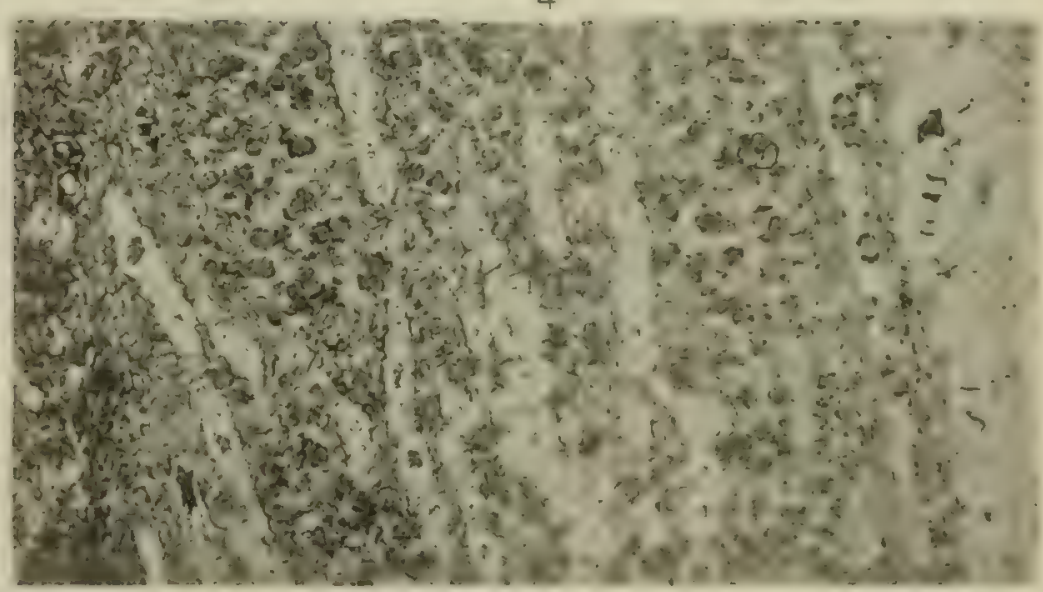

$5.29 . x: 8$

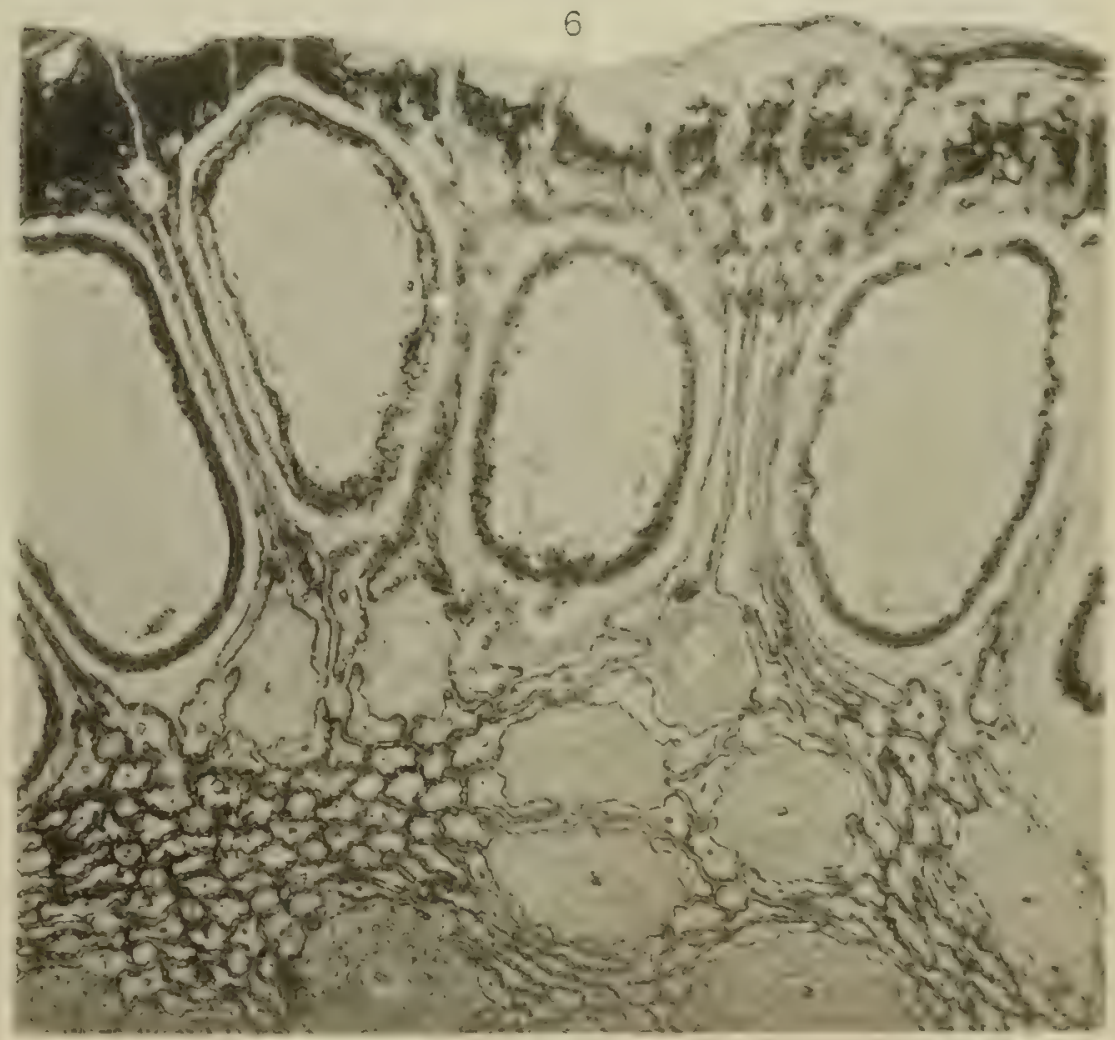

$58 \cong \times 23$ 
. 


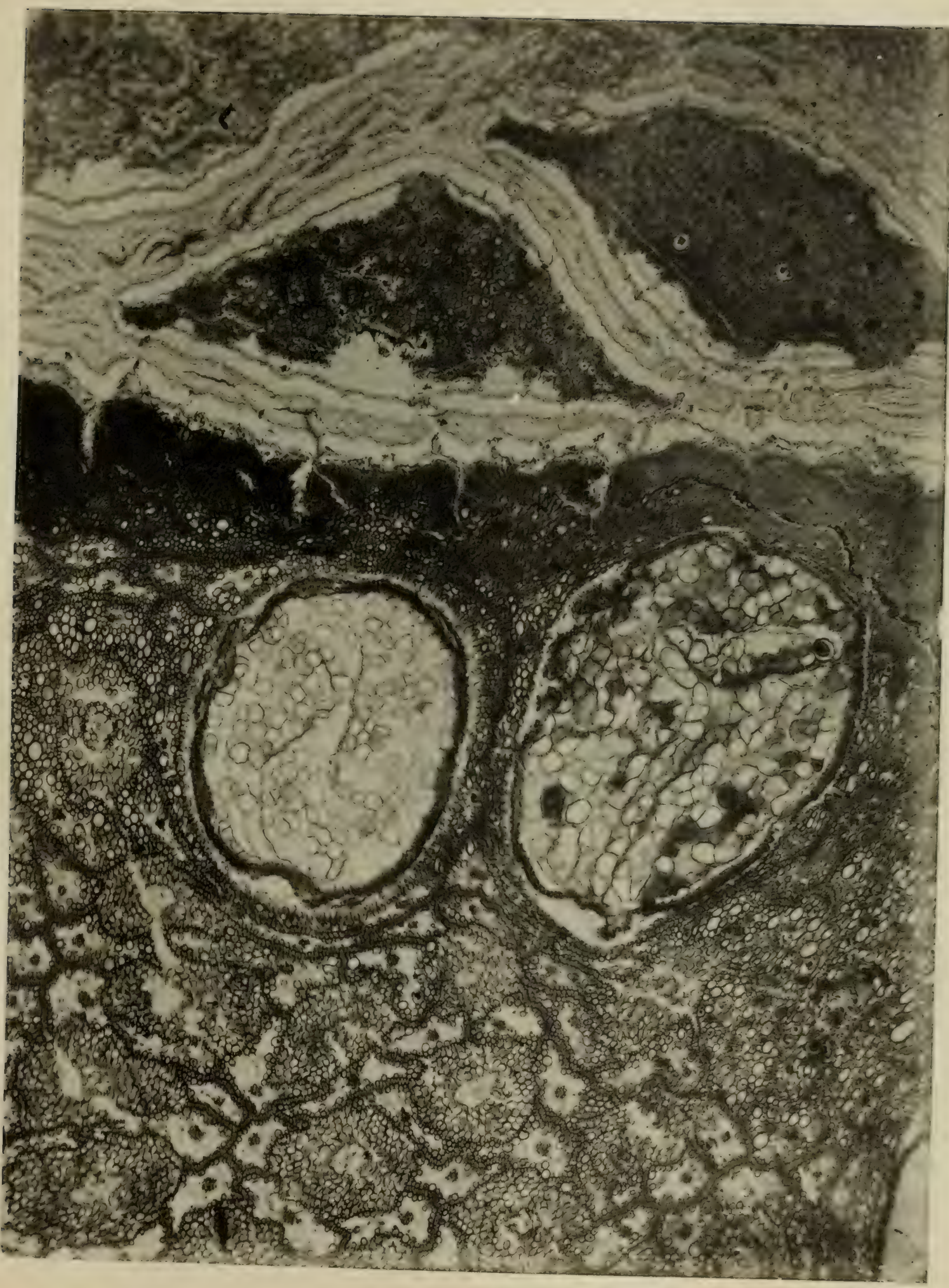





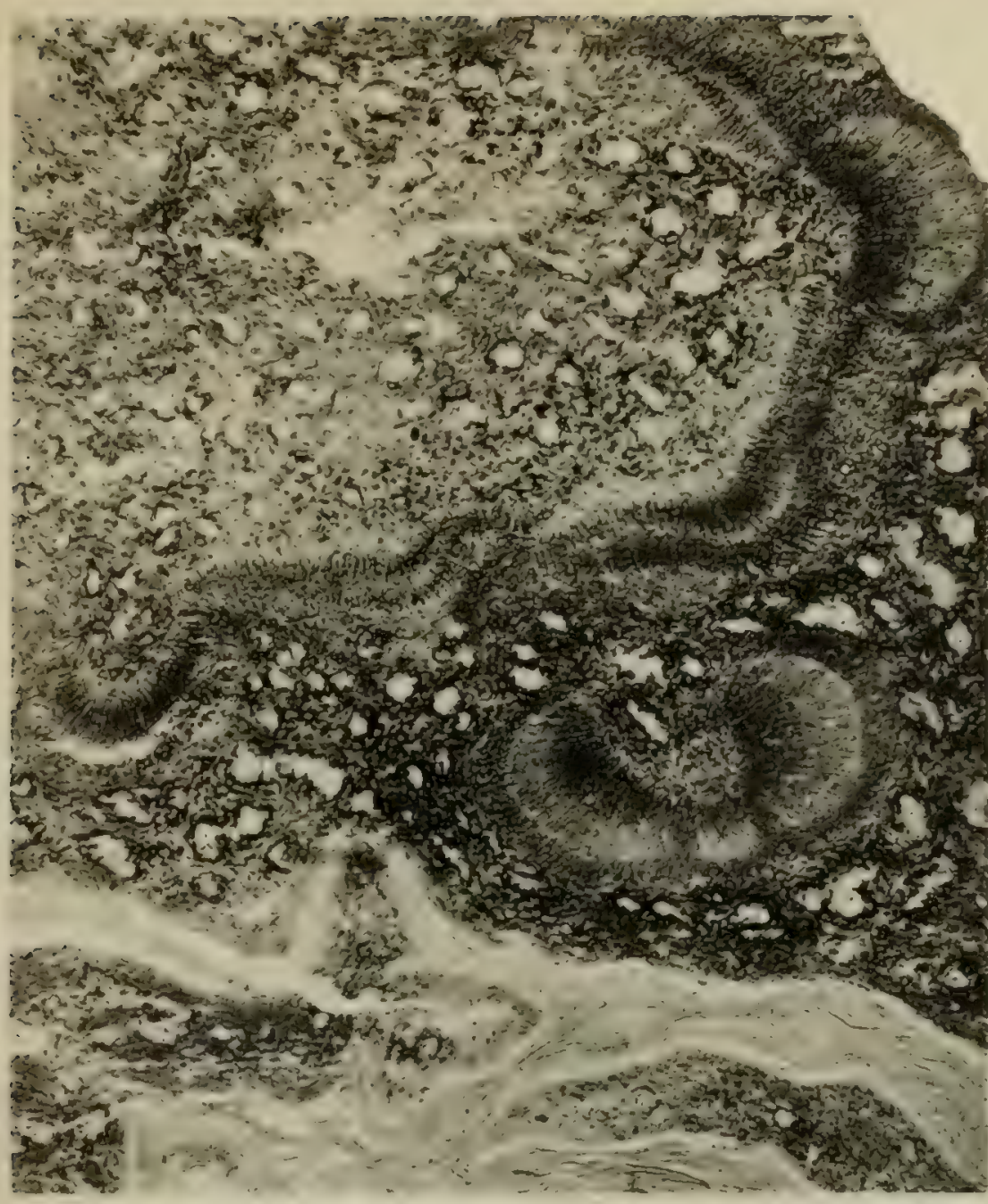

S.34.X10
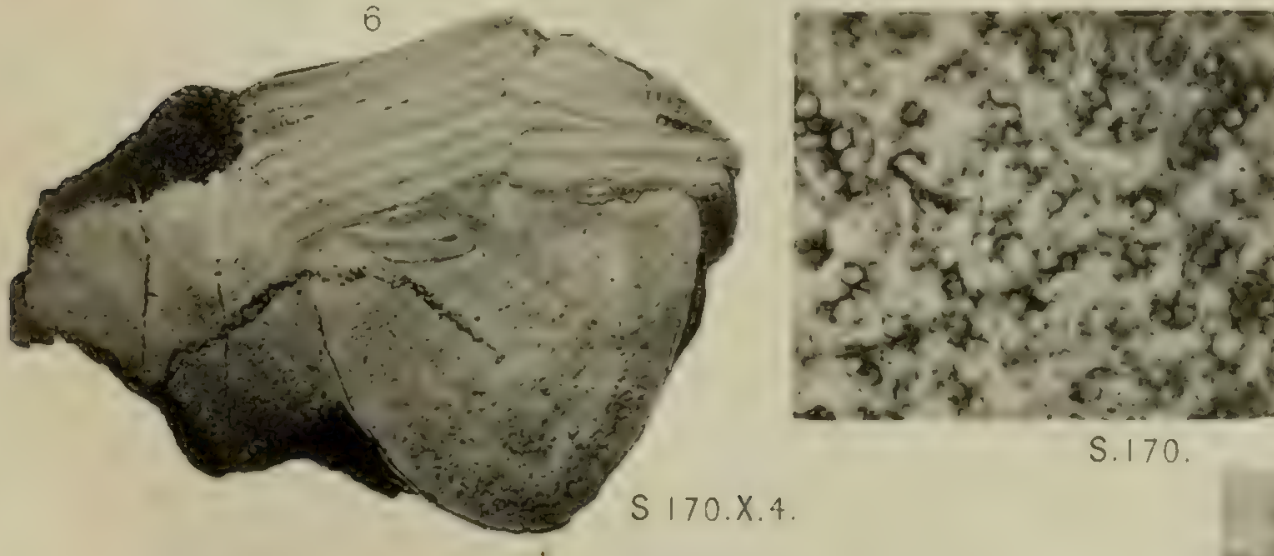

$S .170$
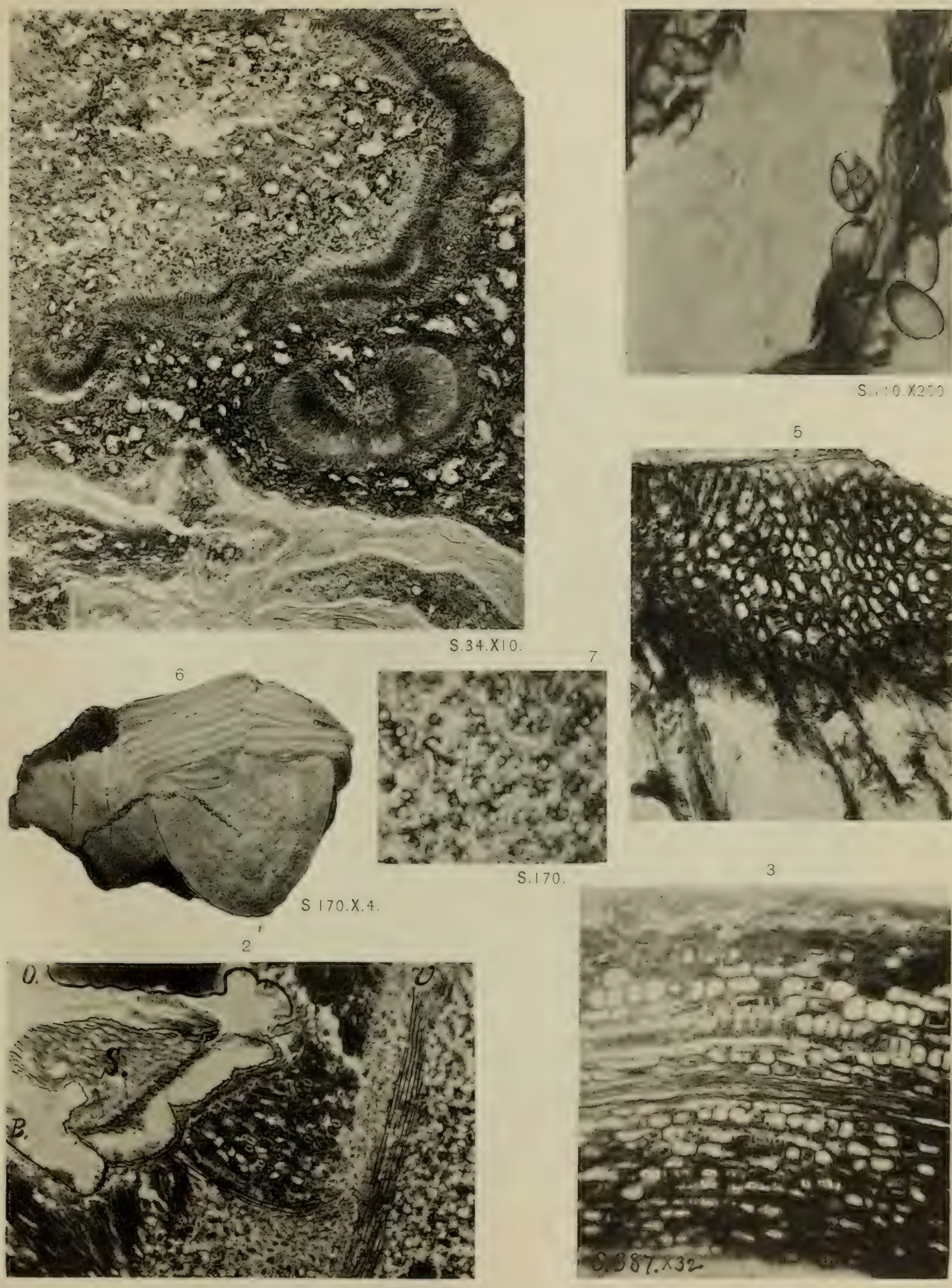

5

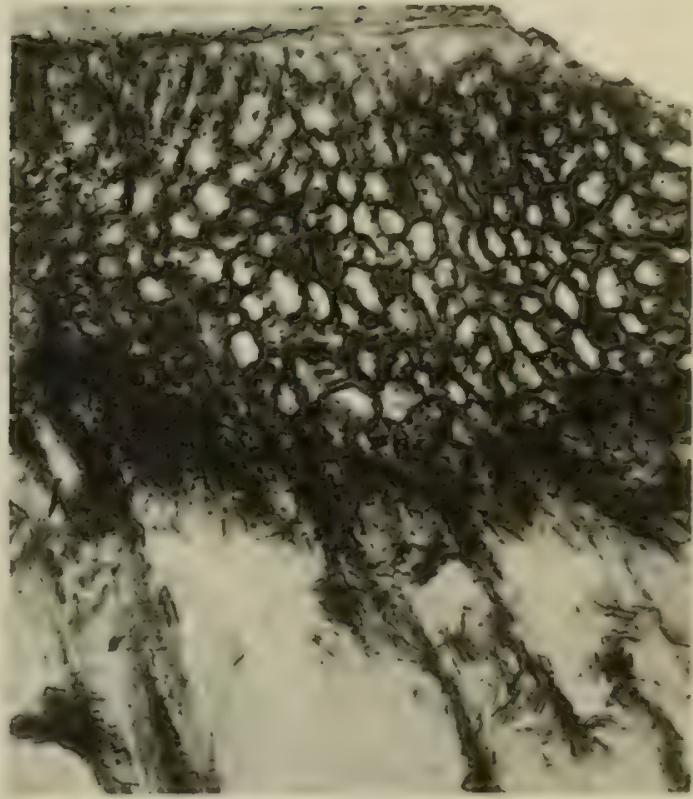

$5.38 ! \times 32$ 



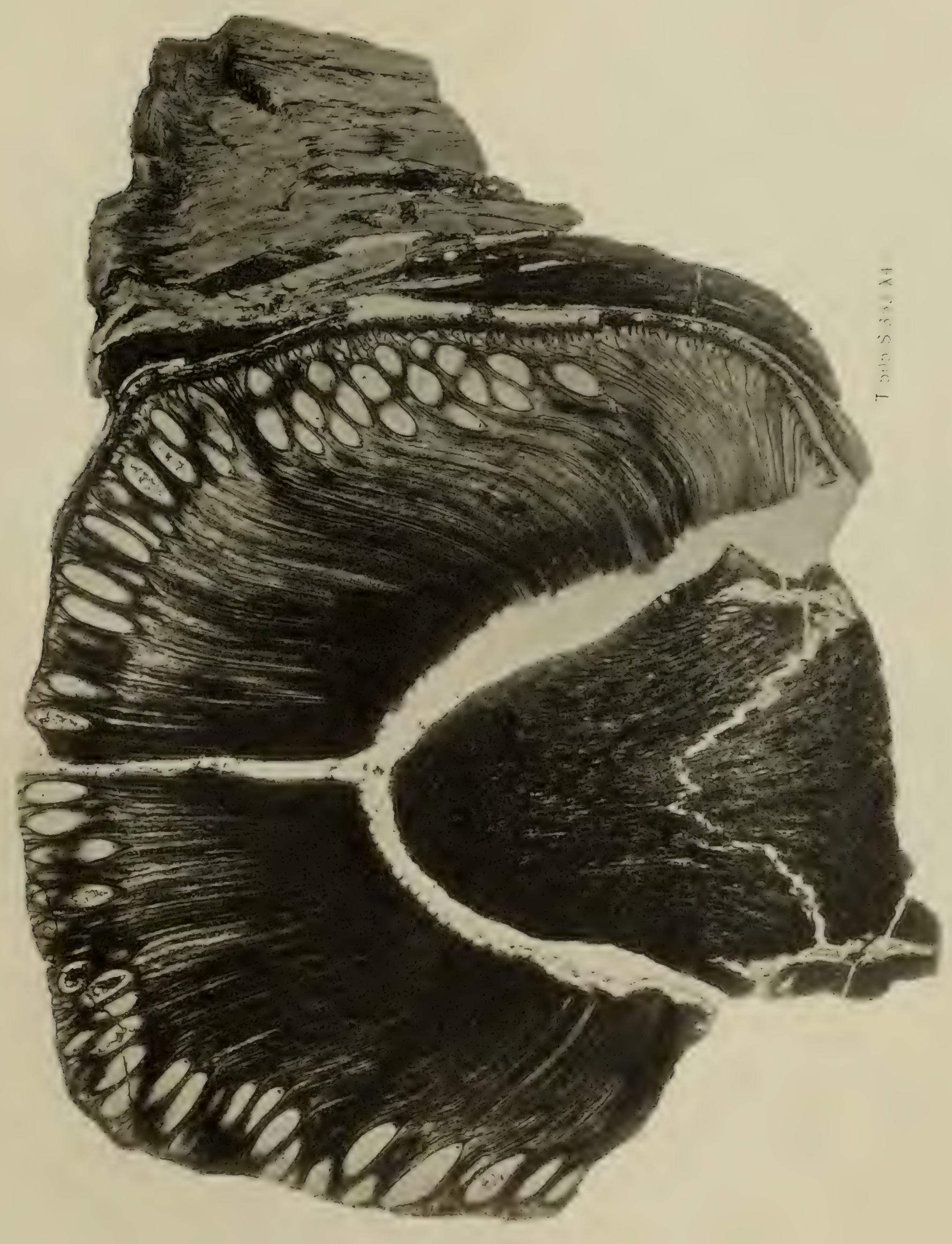

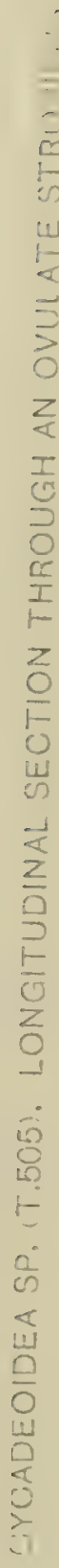




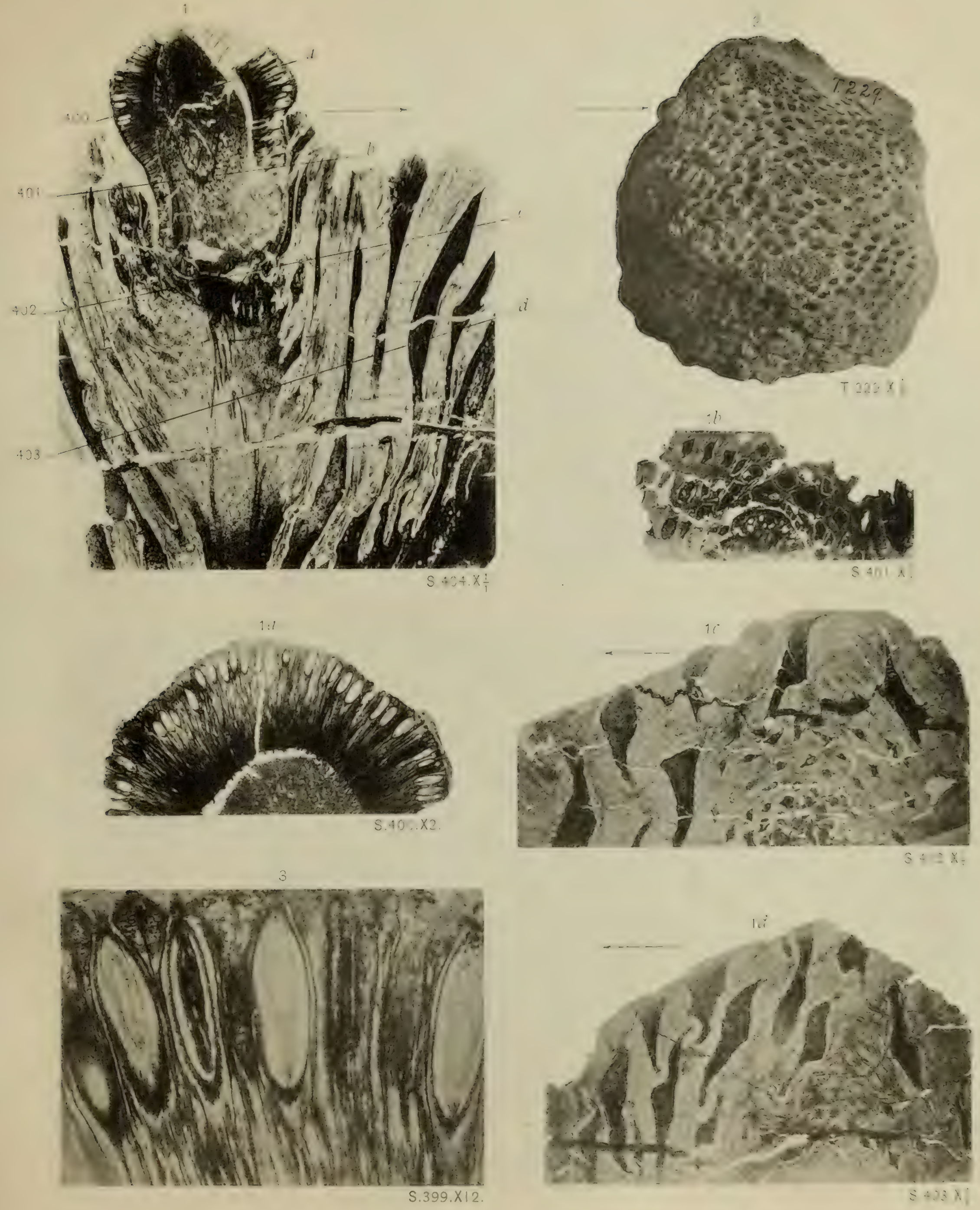



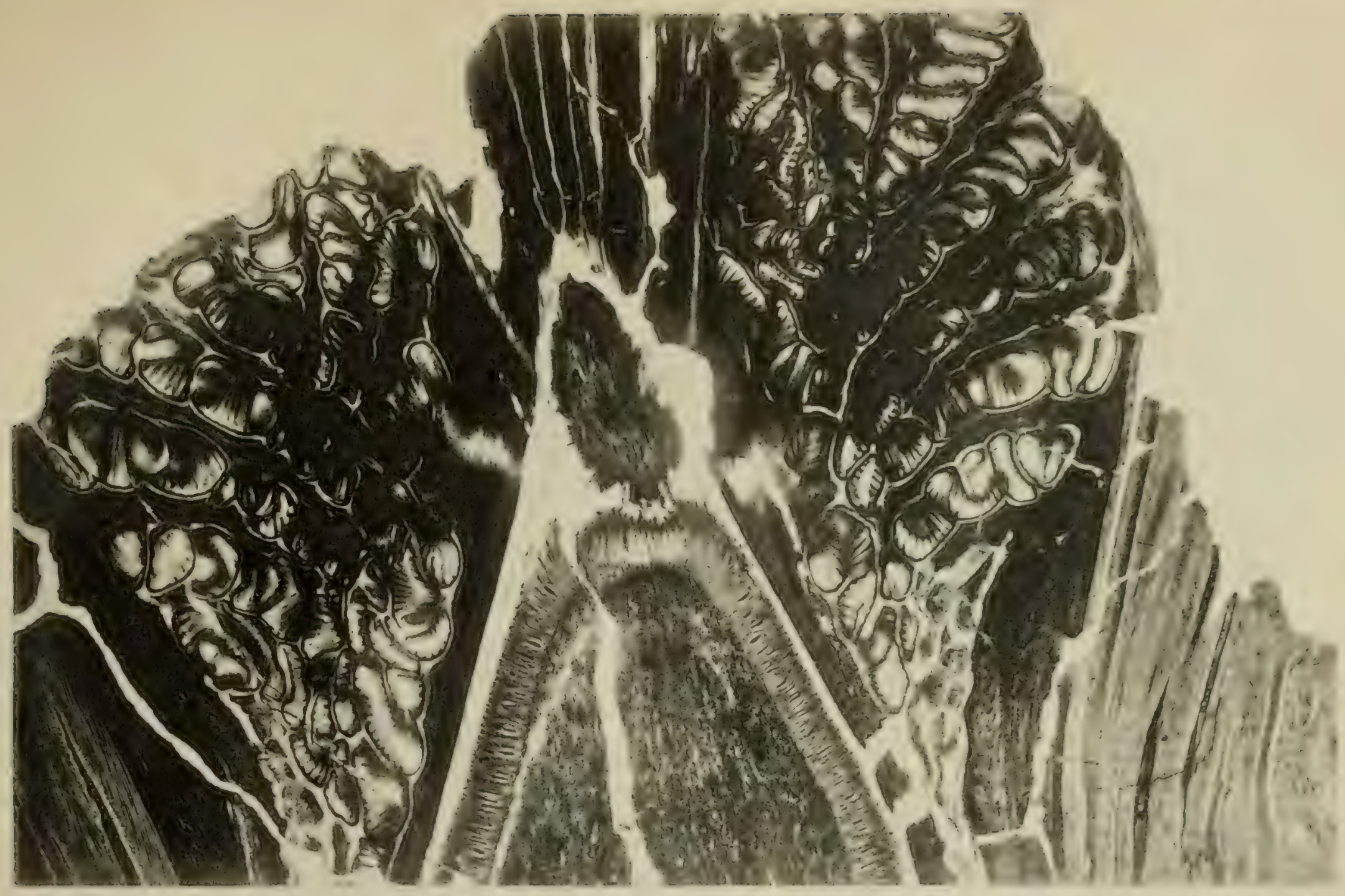

$x:$

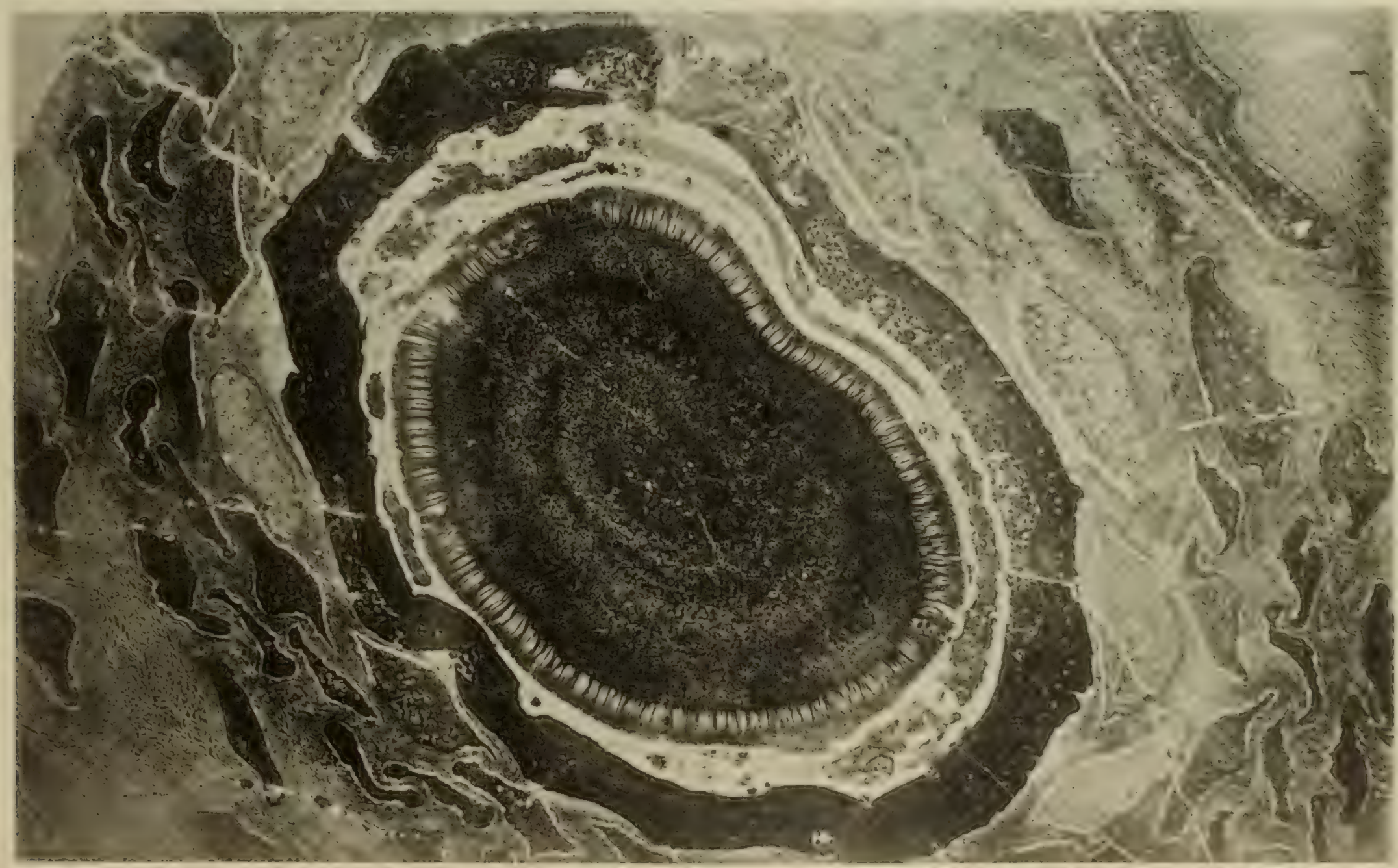




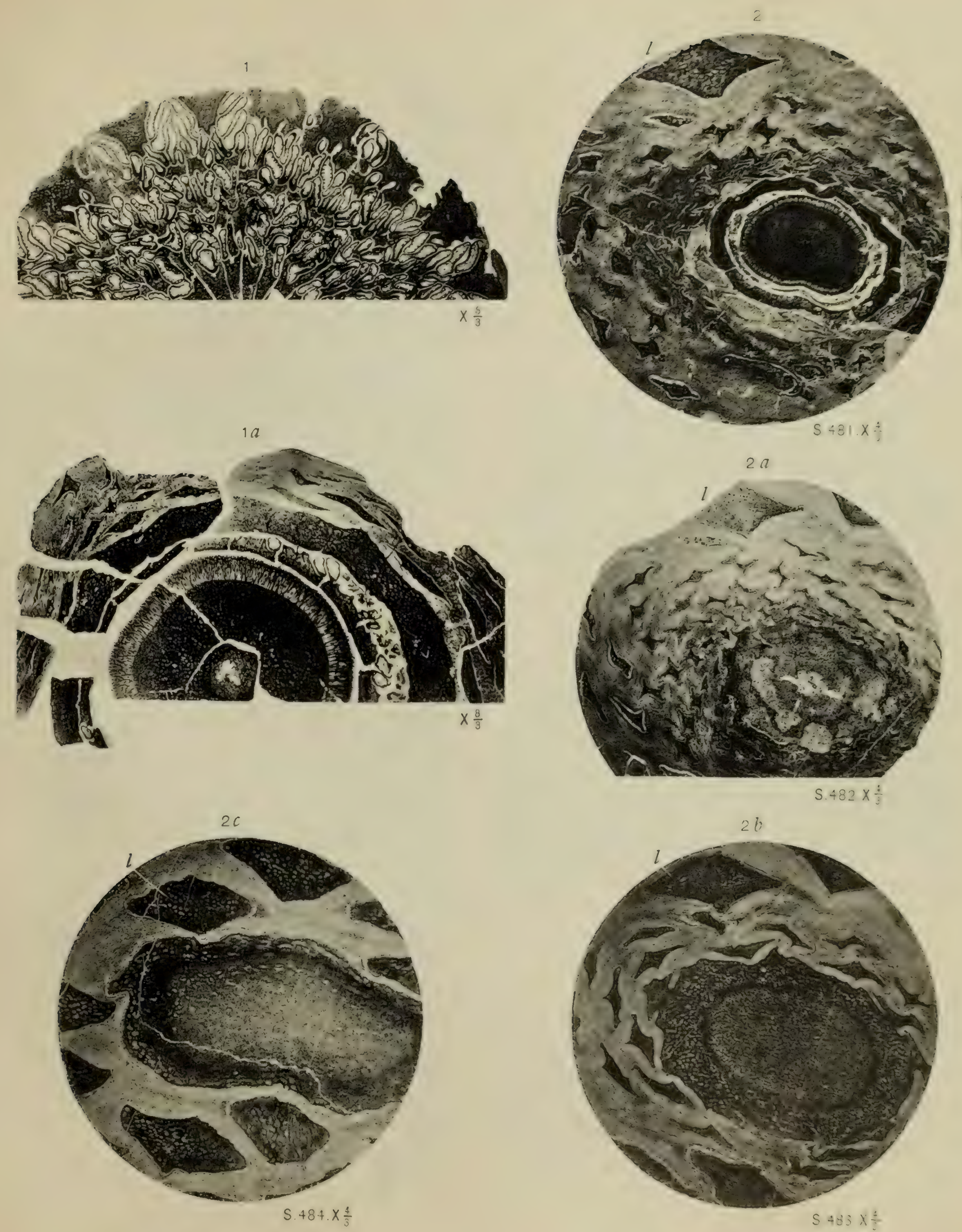



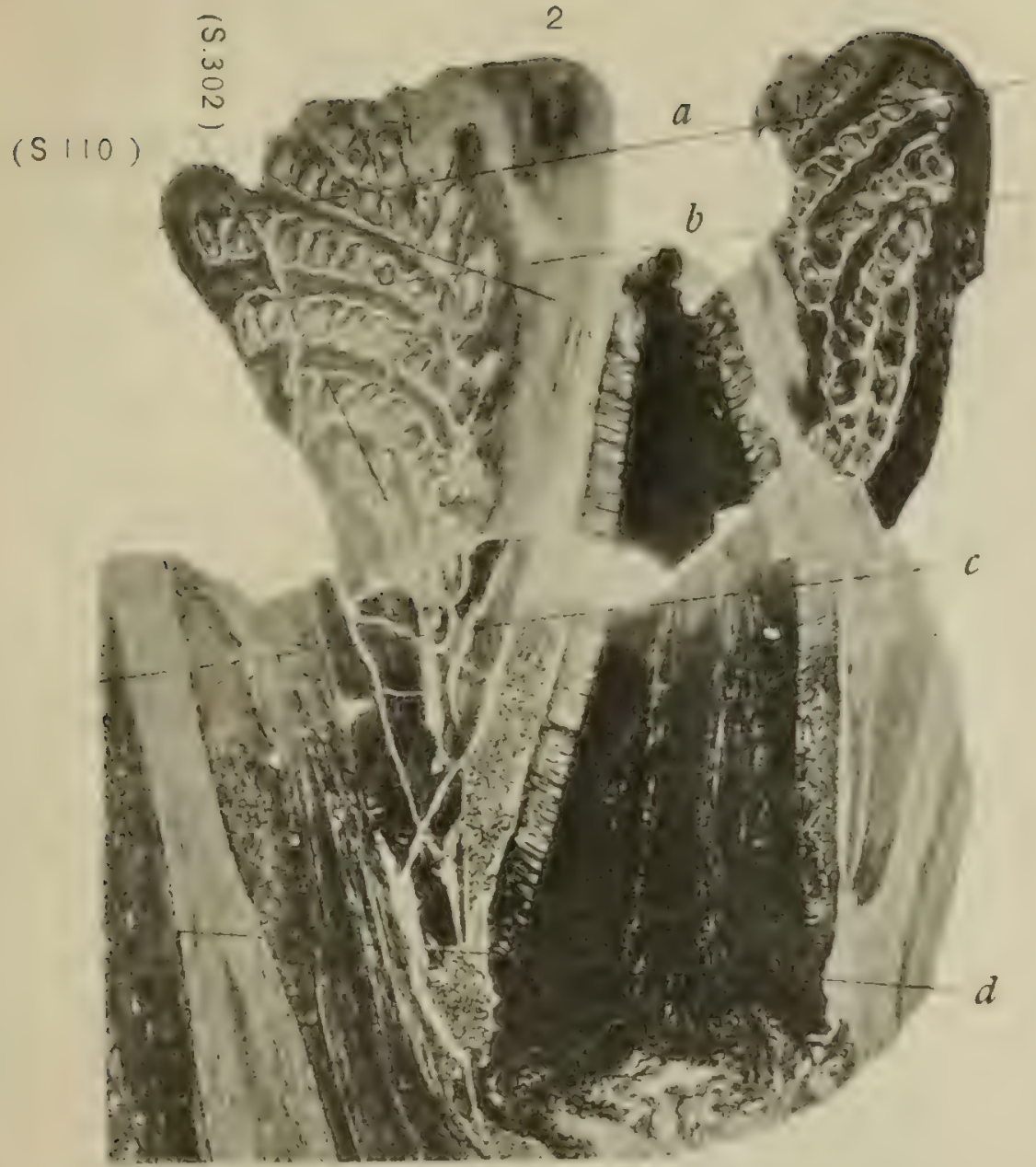

S. $360 . \times 2$

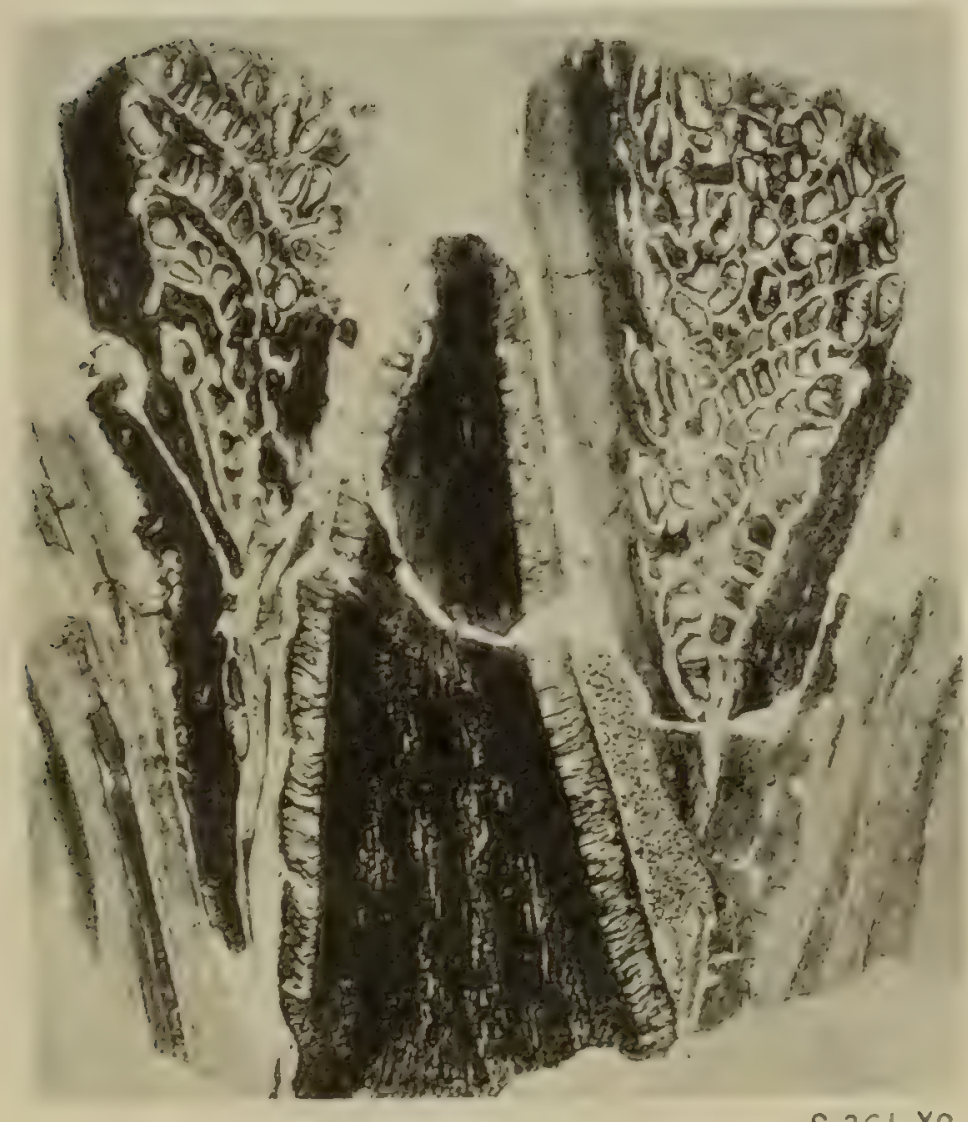

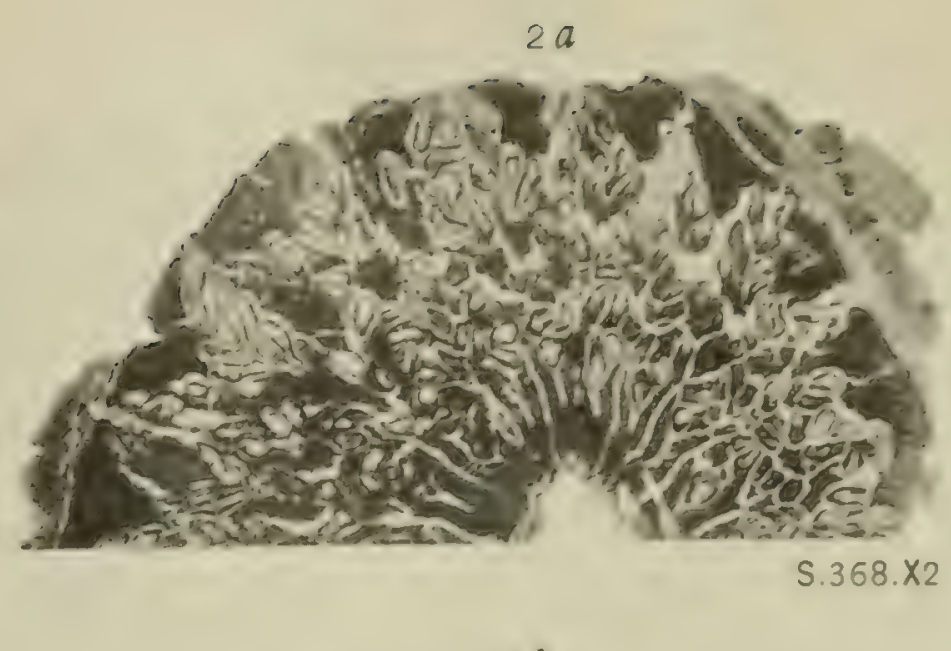
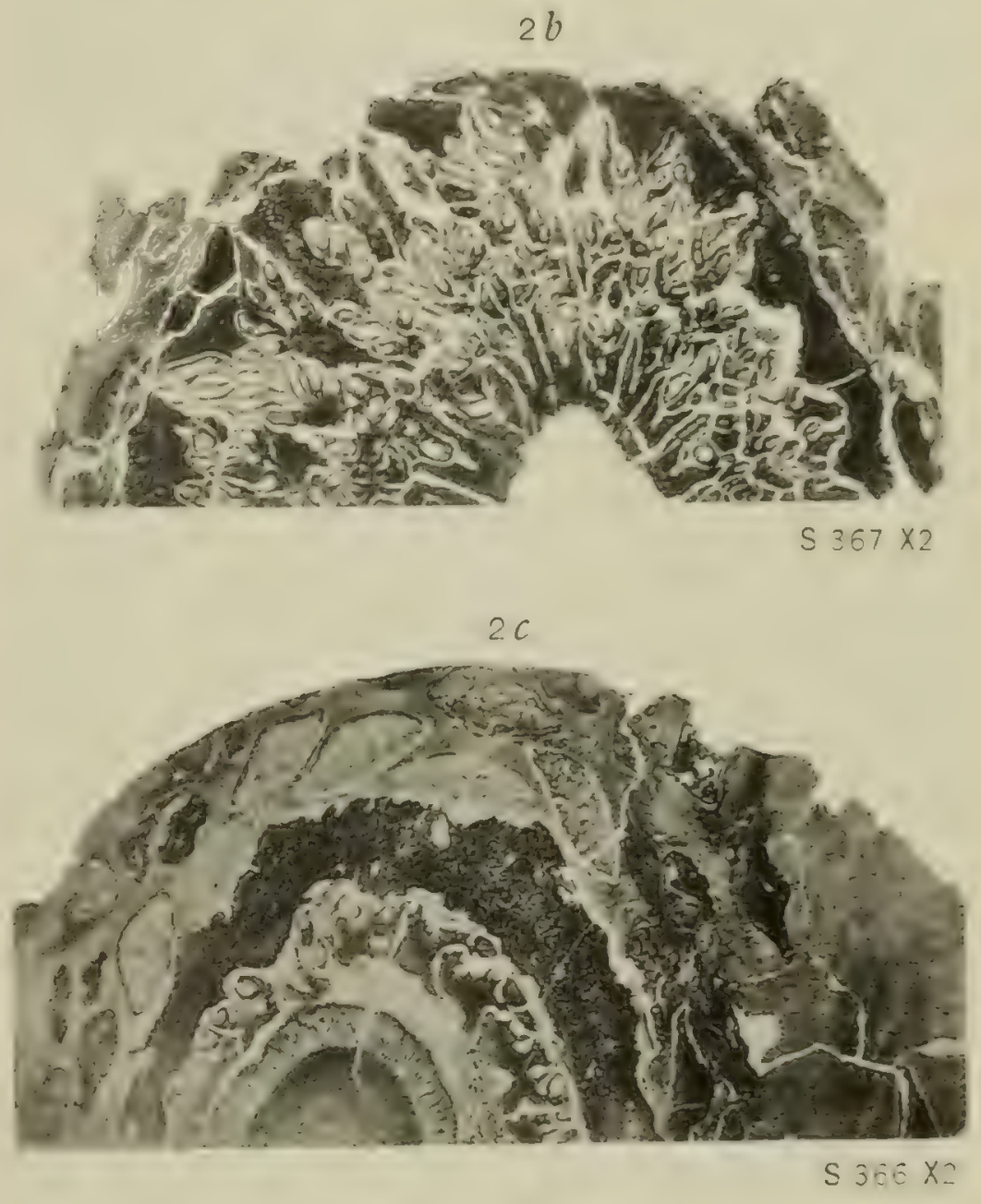

$2 d$

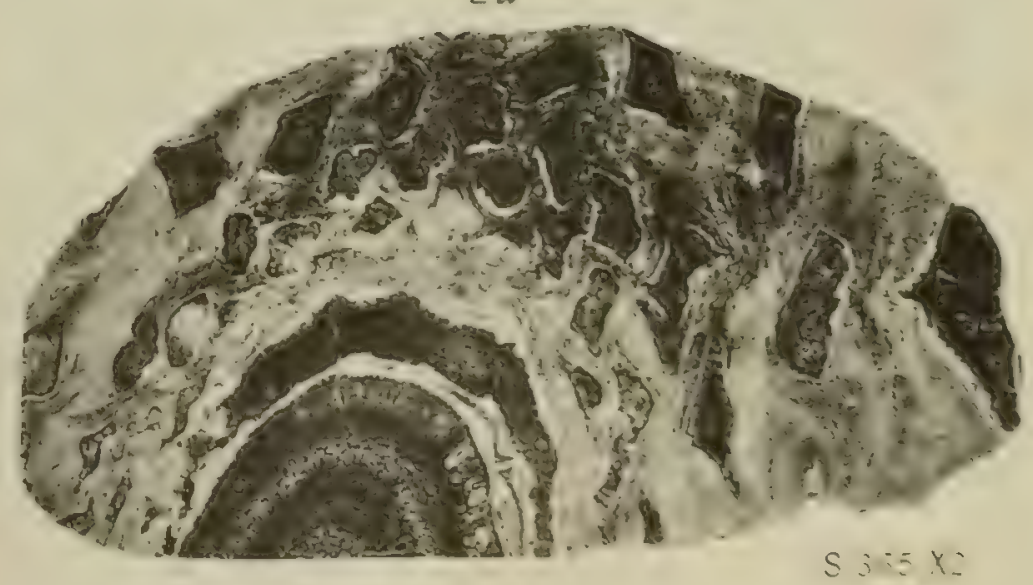




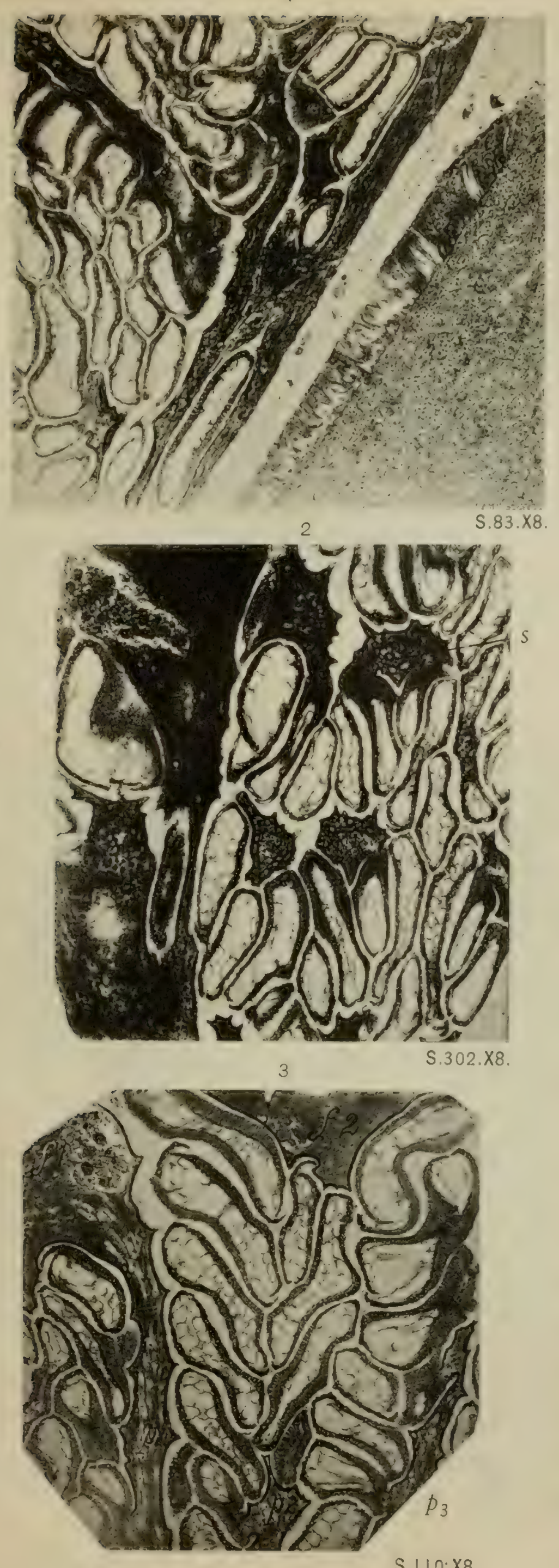
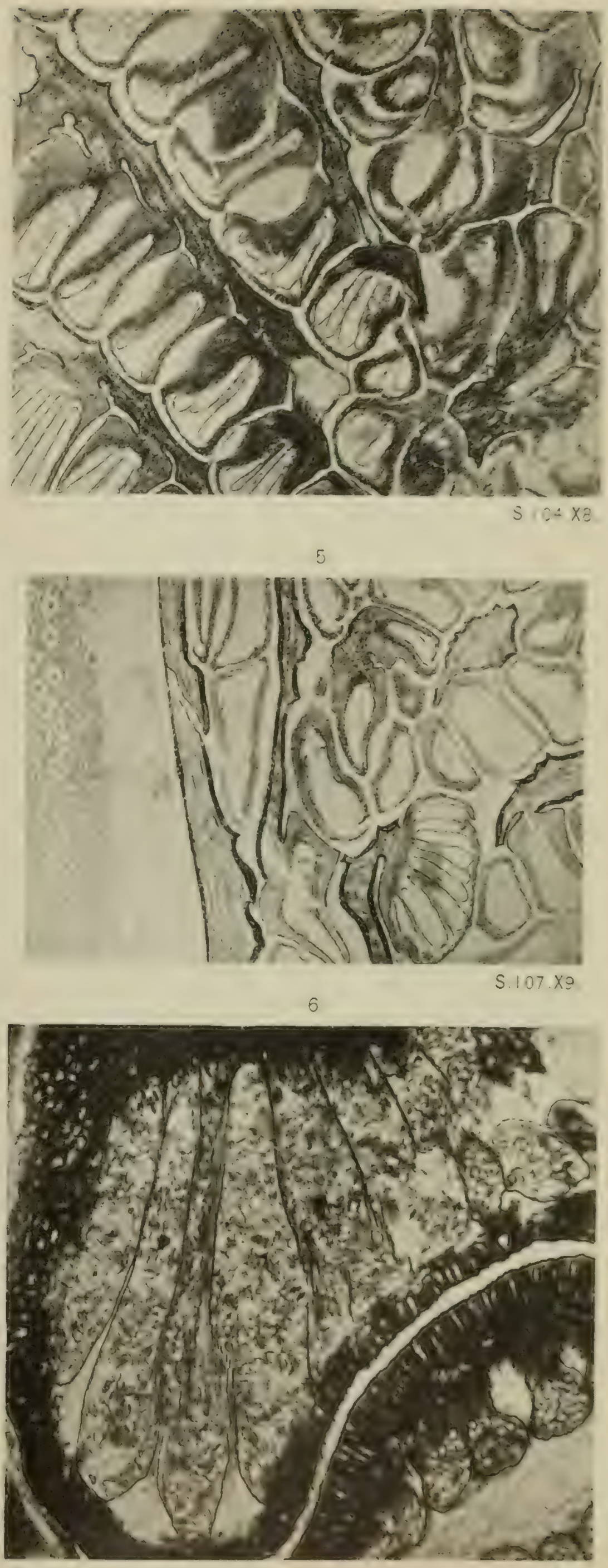


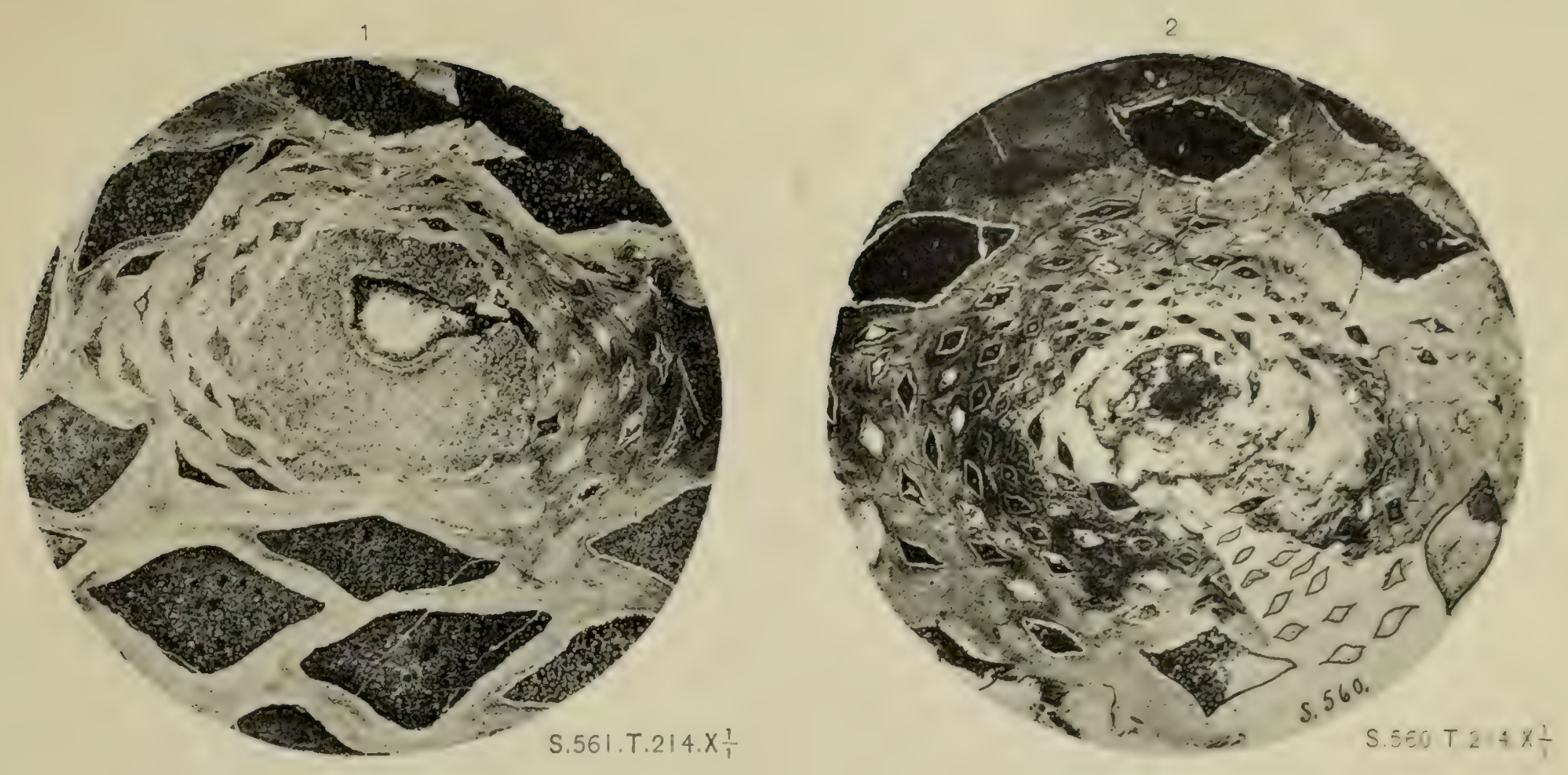

3
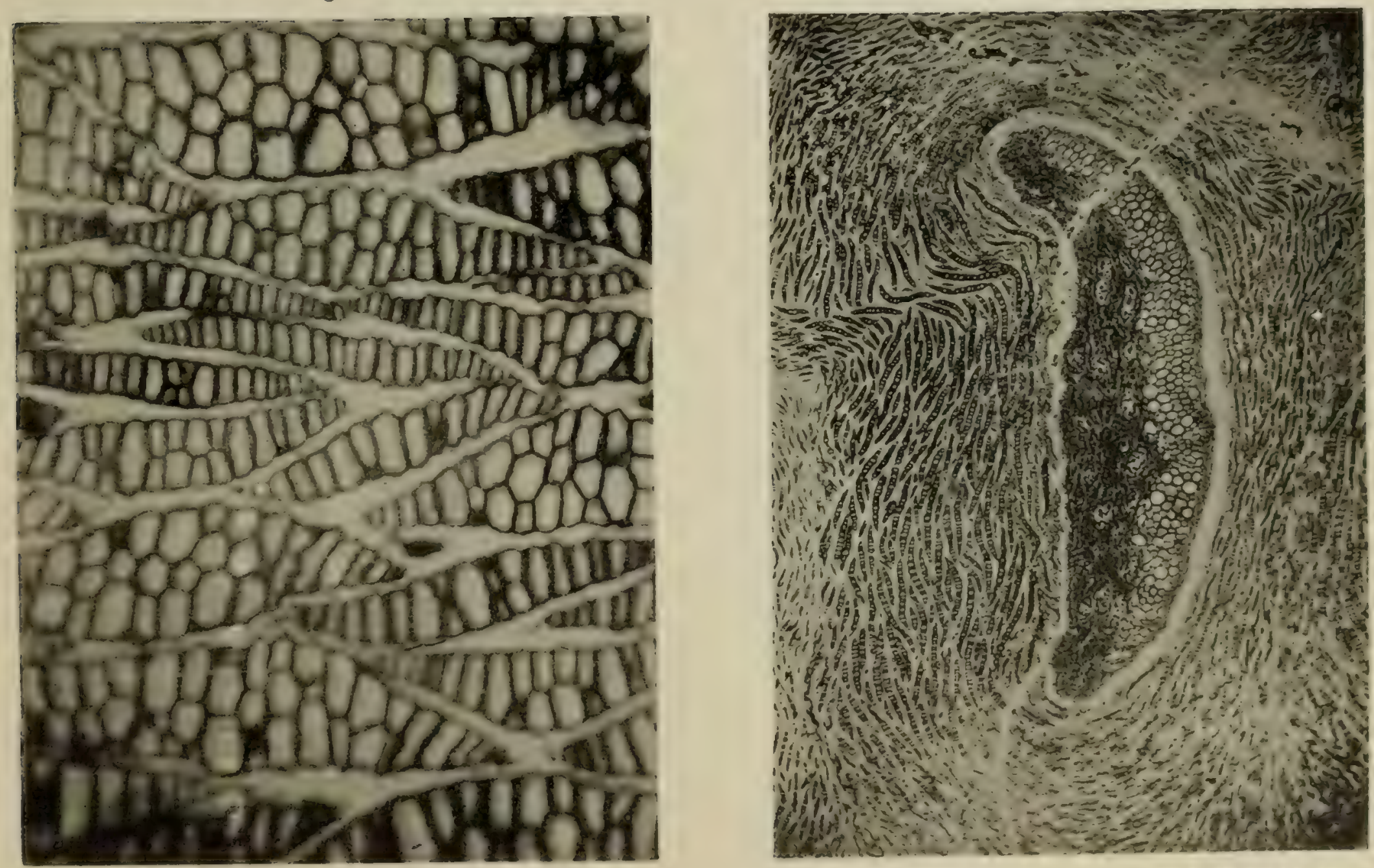

S. $445 . \times 110$.

STE T $200 \times 20$ 


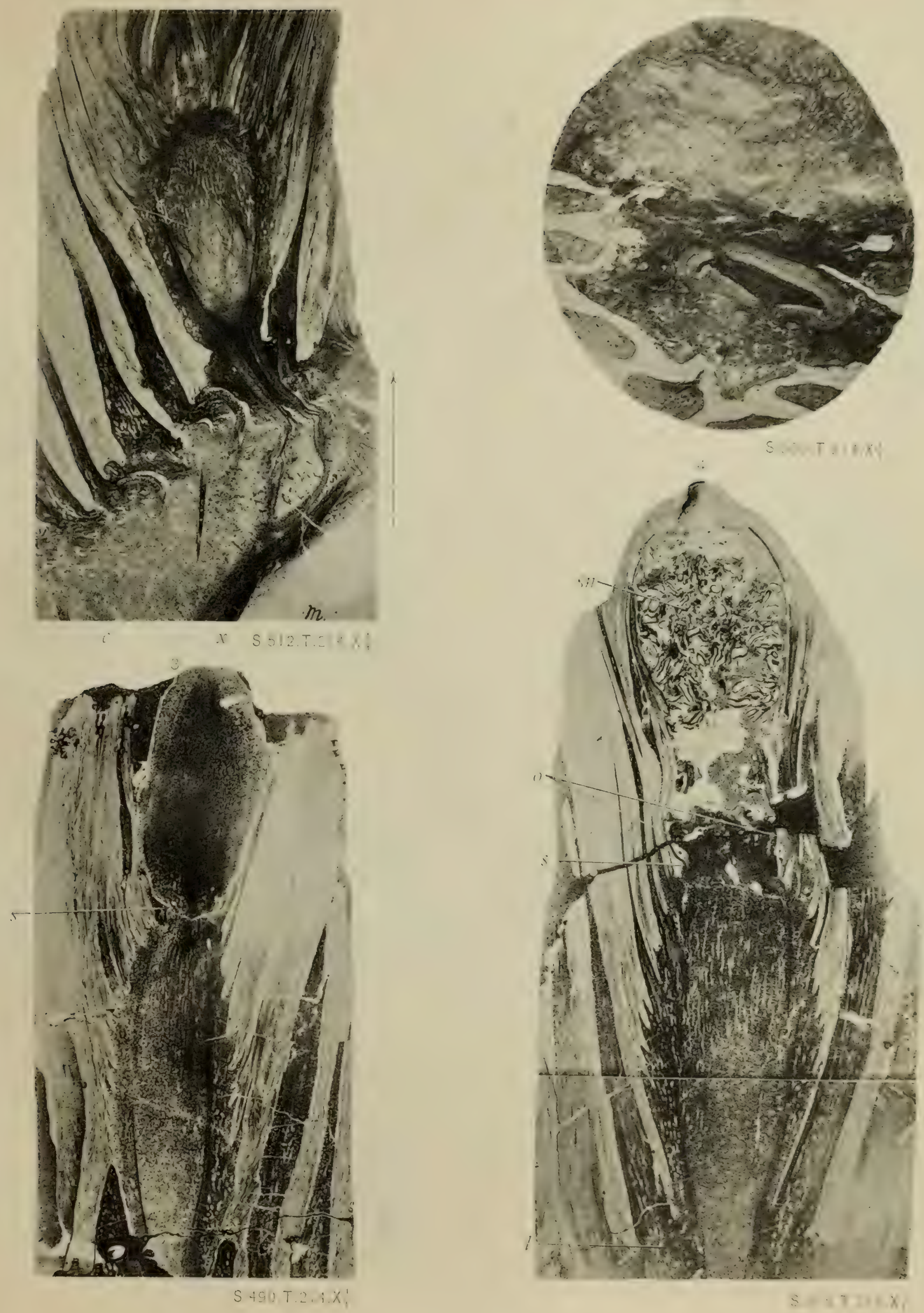


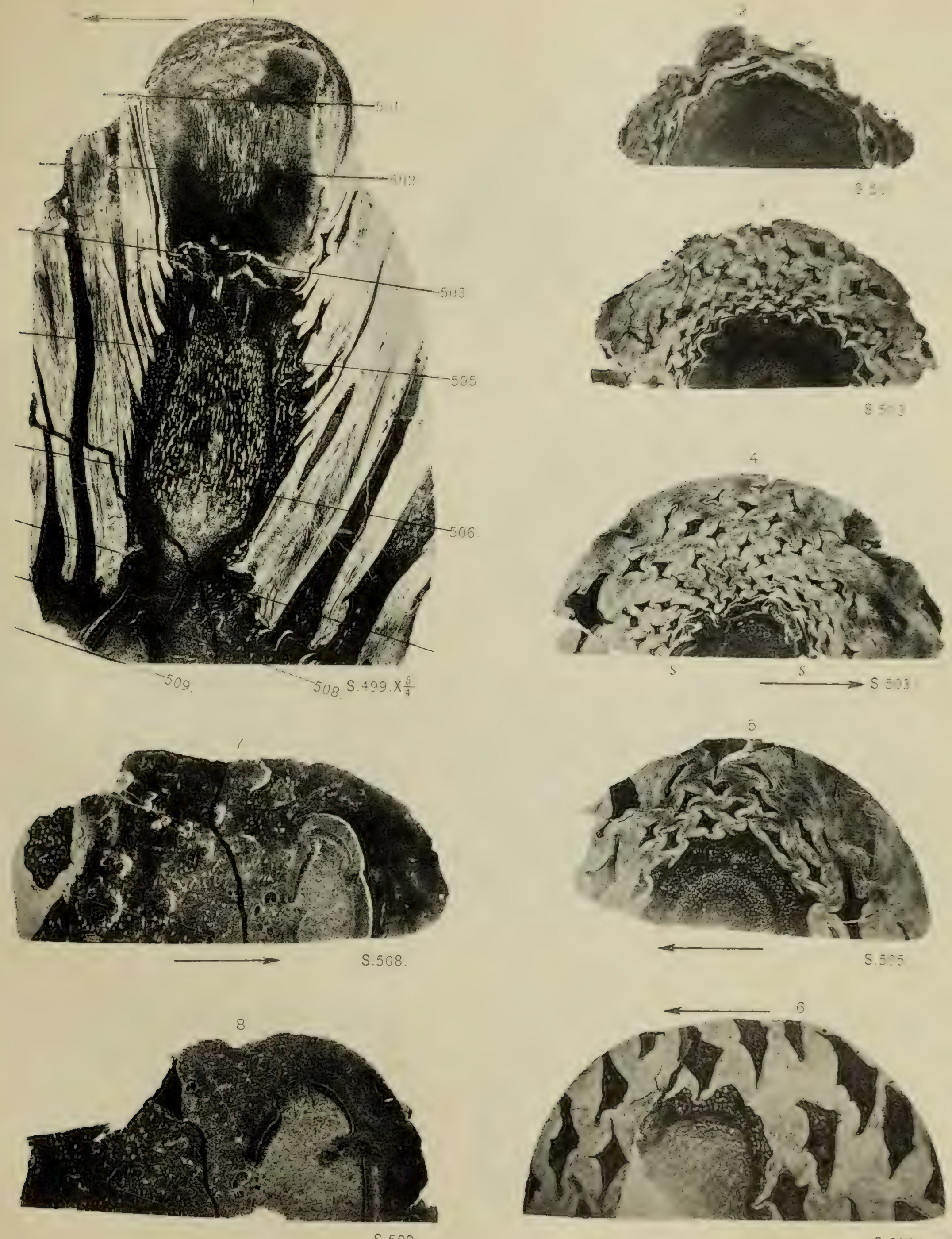

S.509.

5.506 


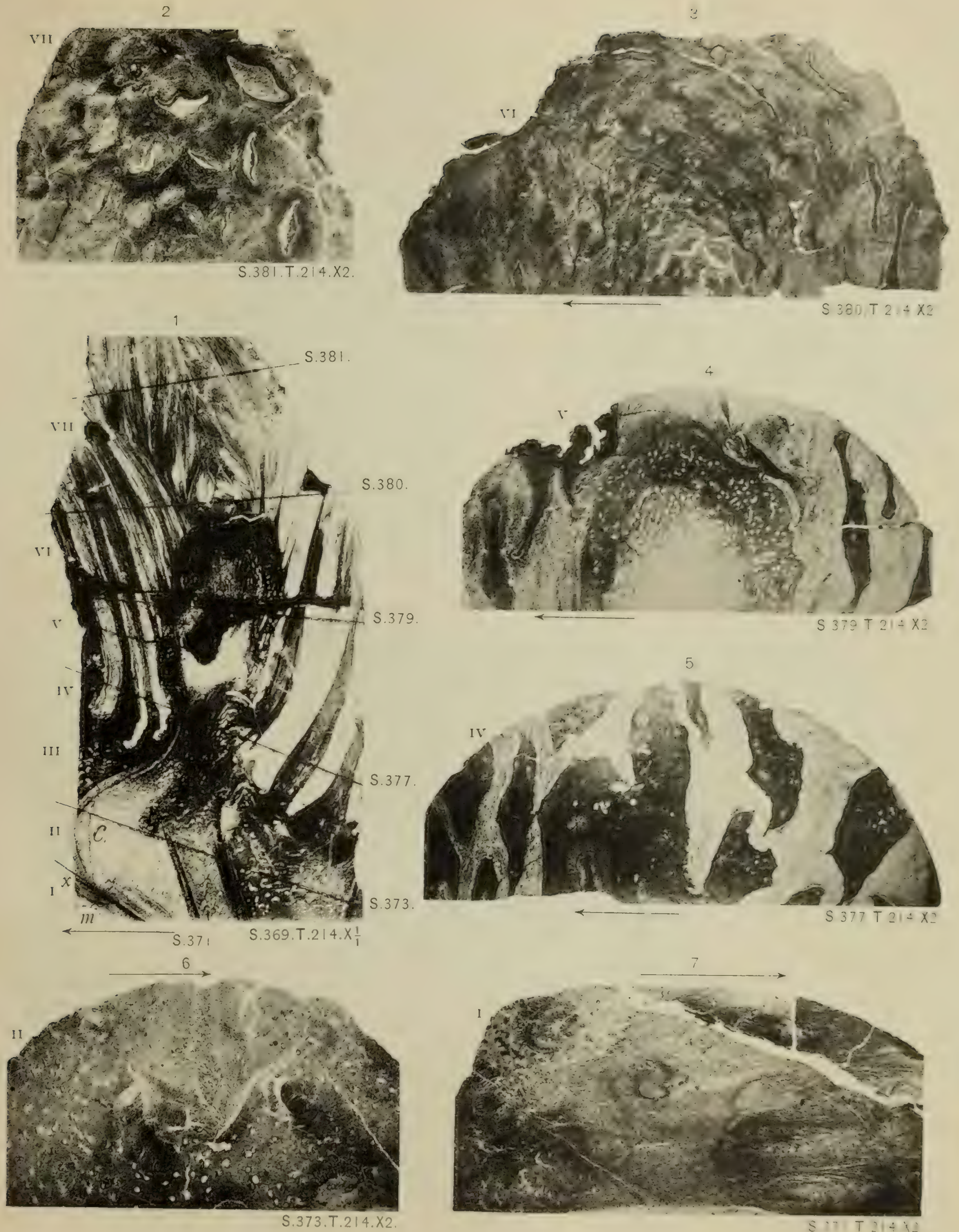


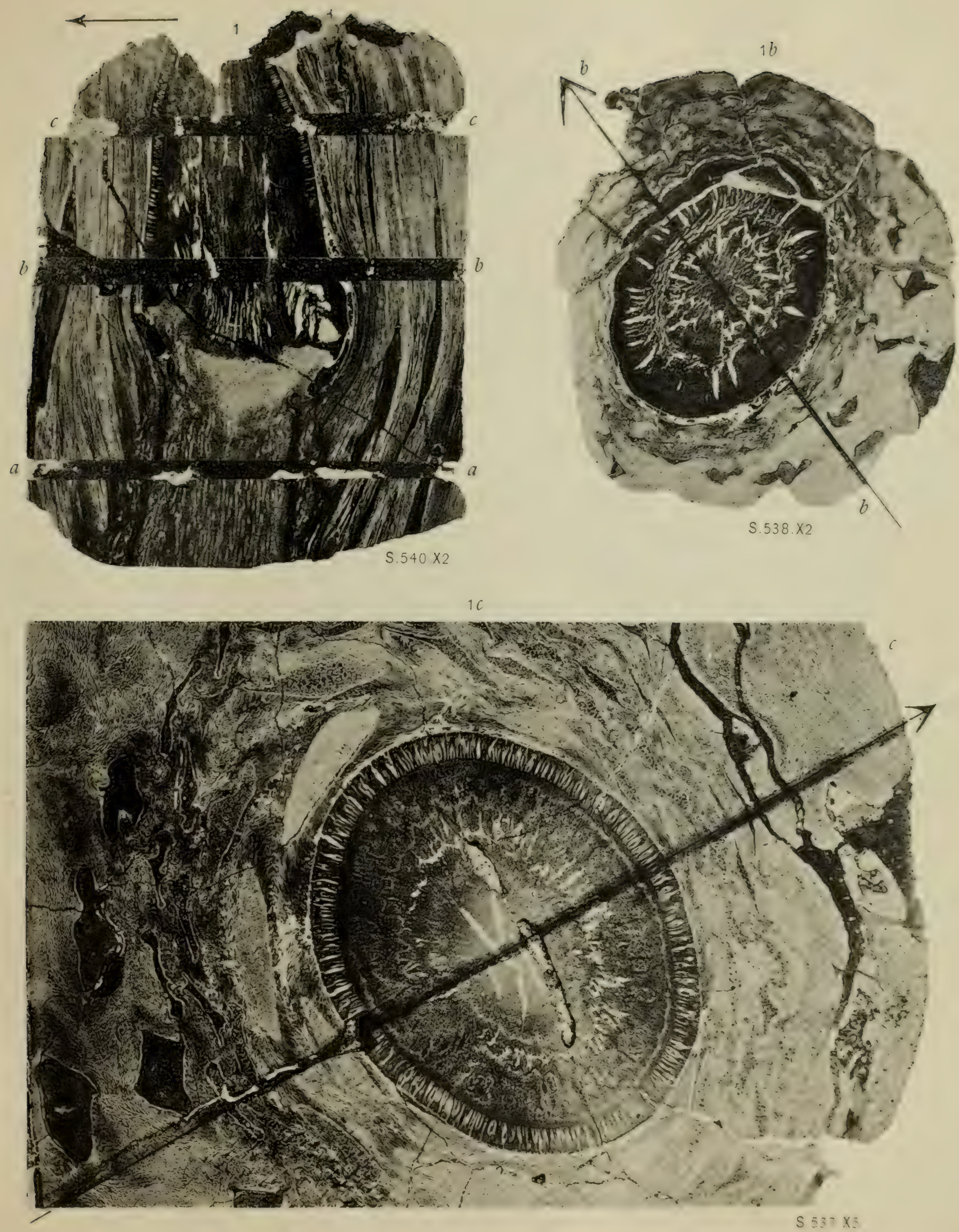

CYCADEOIDEA DACOTENSIS. T:214 


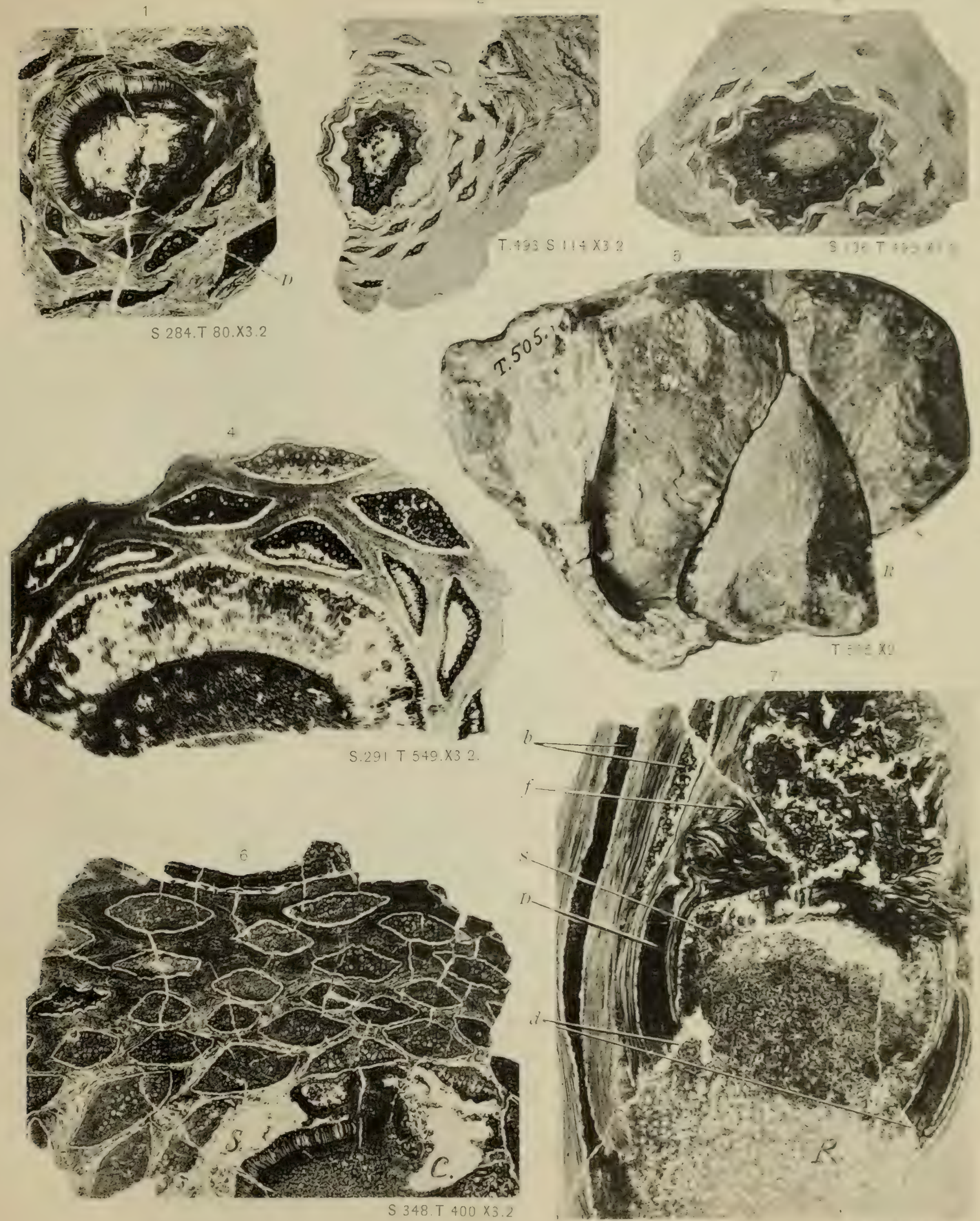


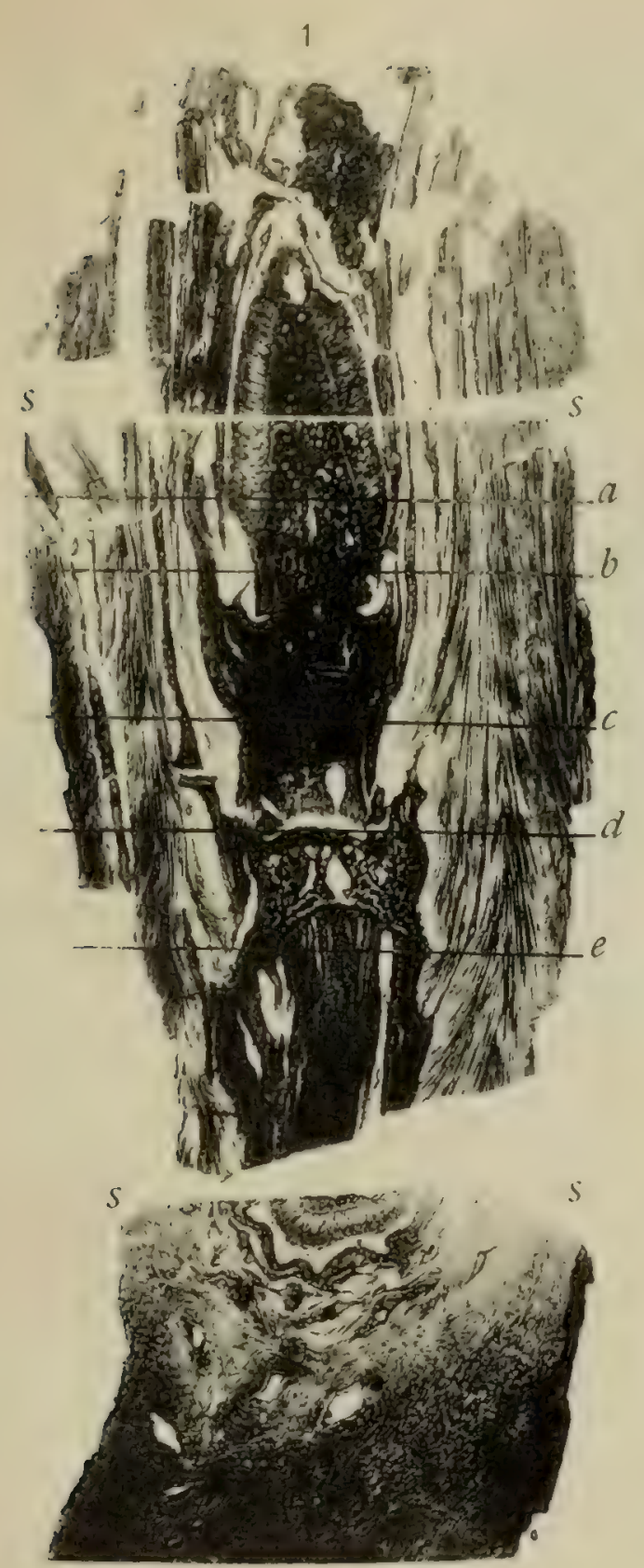

S. $410 . \times 2$
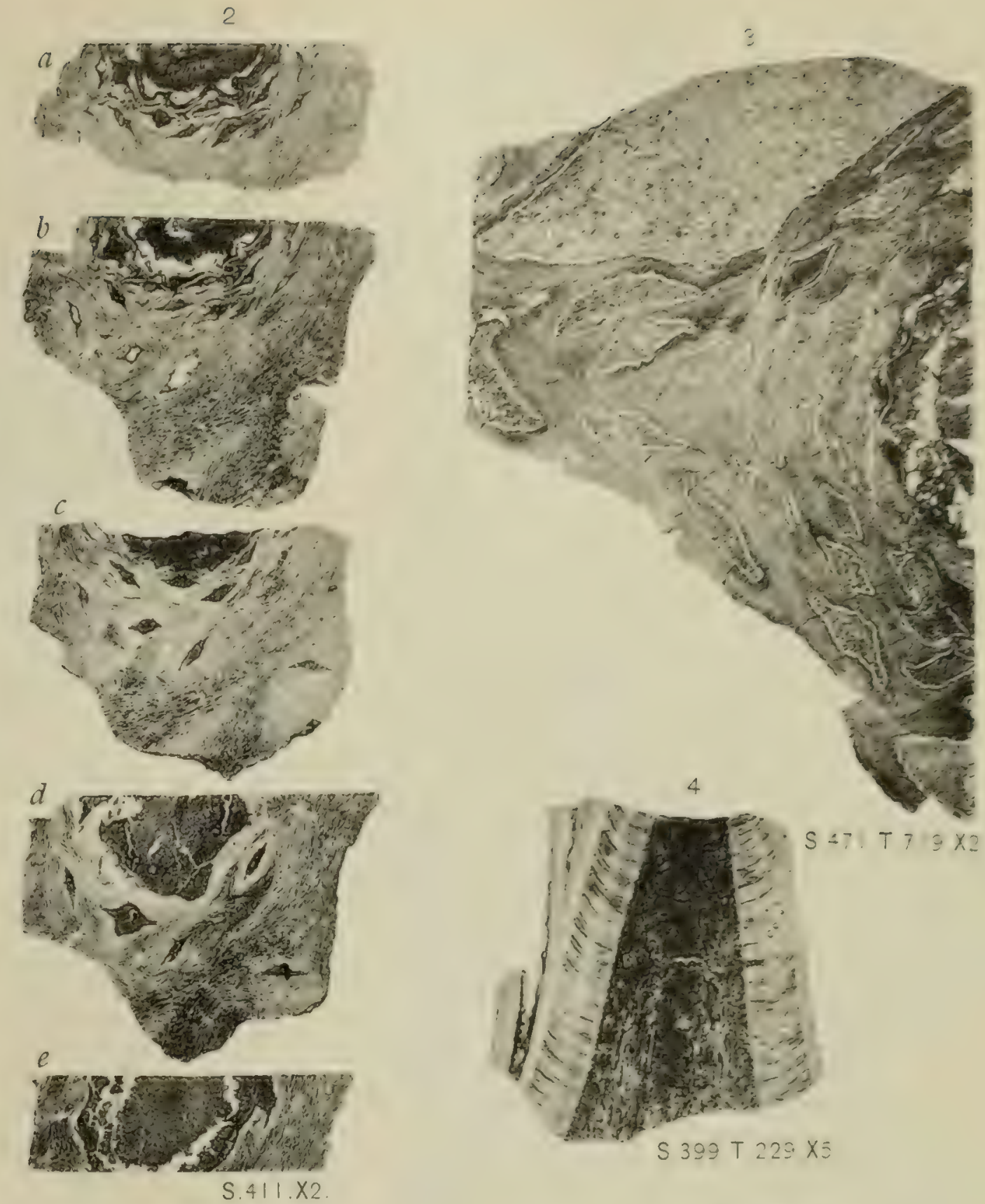

5
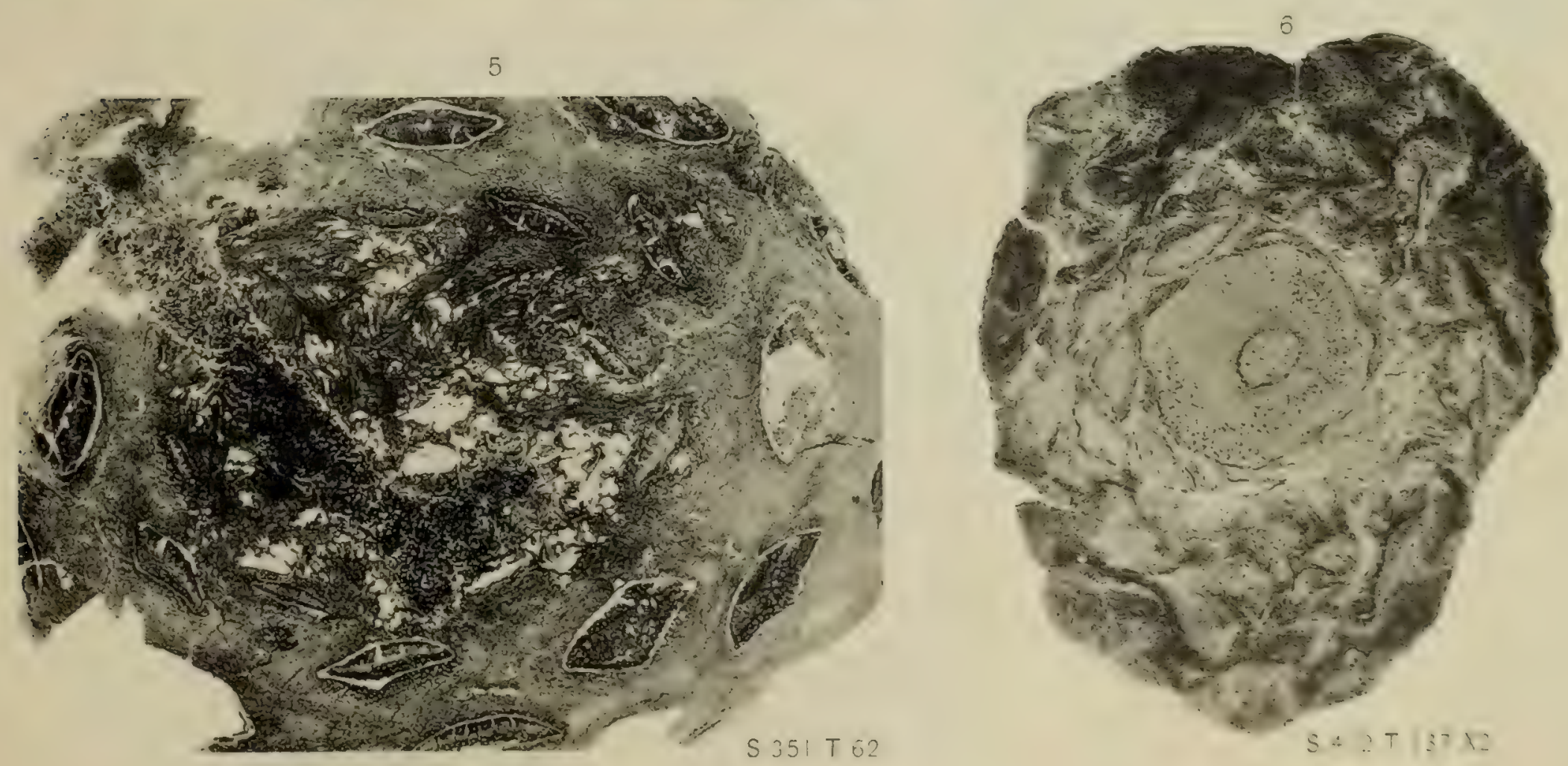


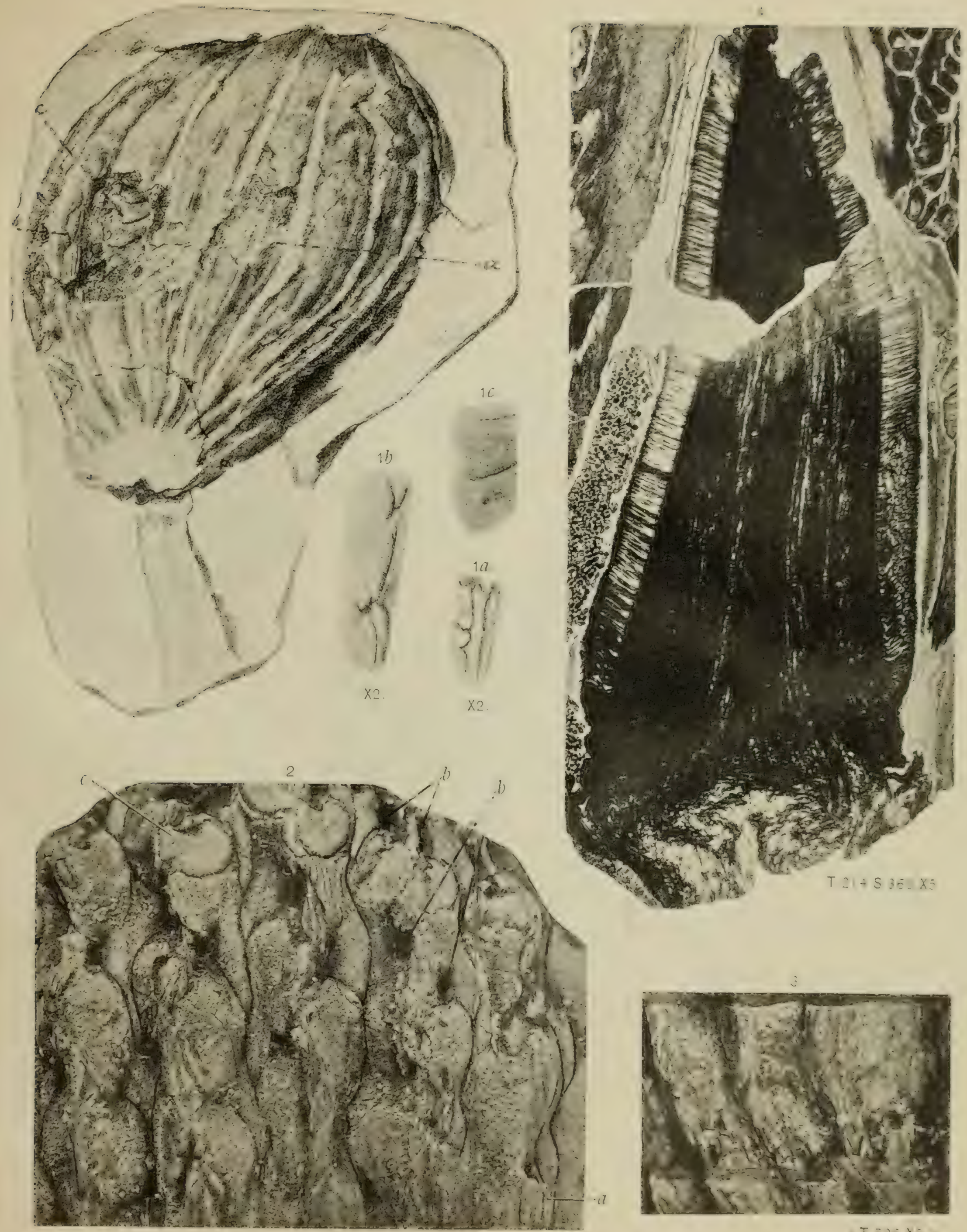

$(T 720 x=1$

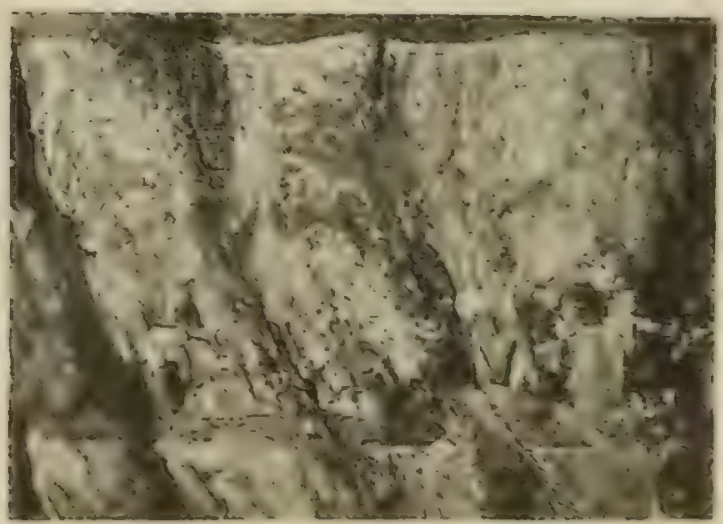

$T-2 B x=$ 


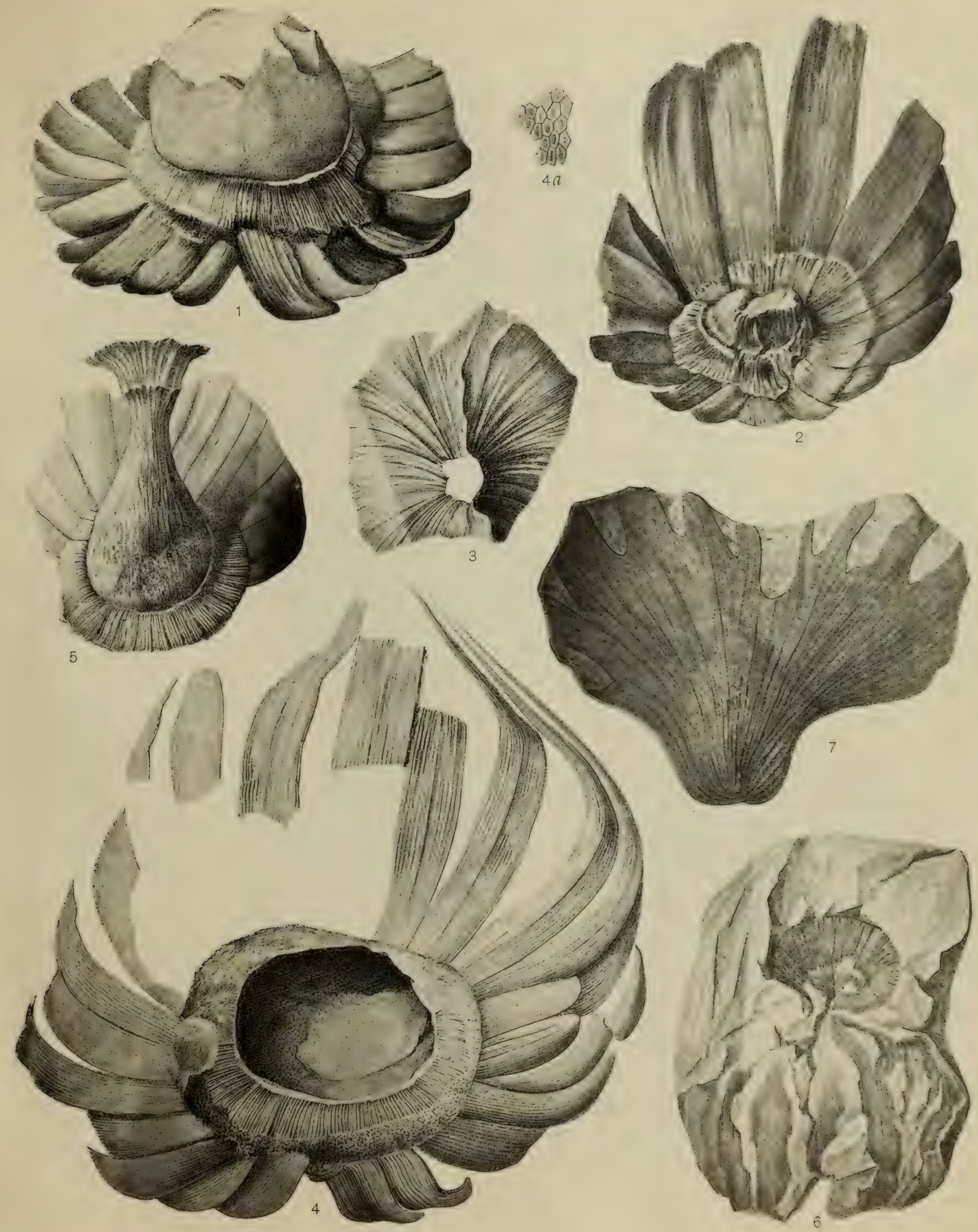


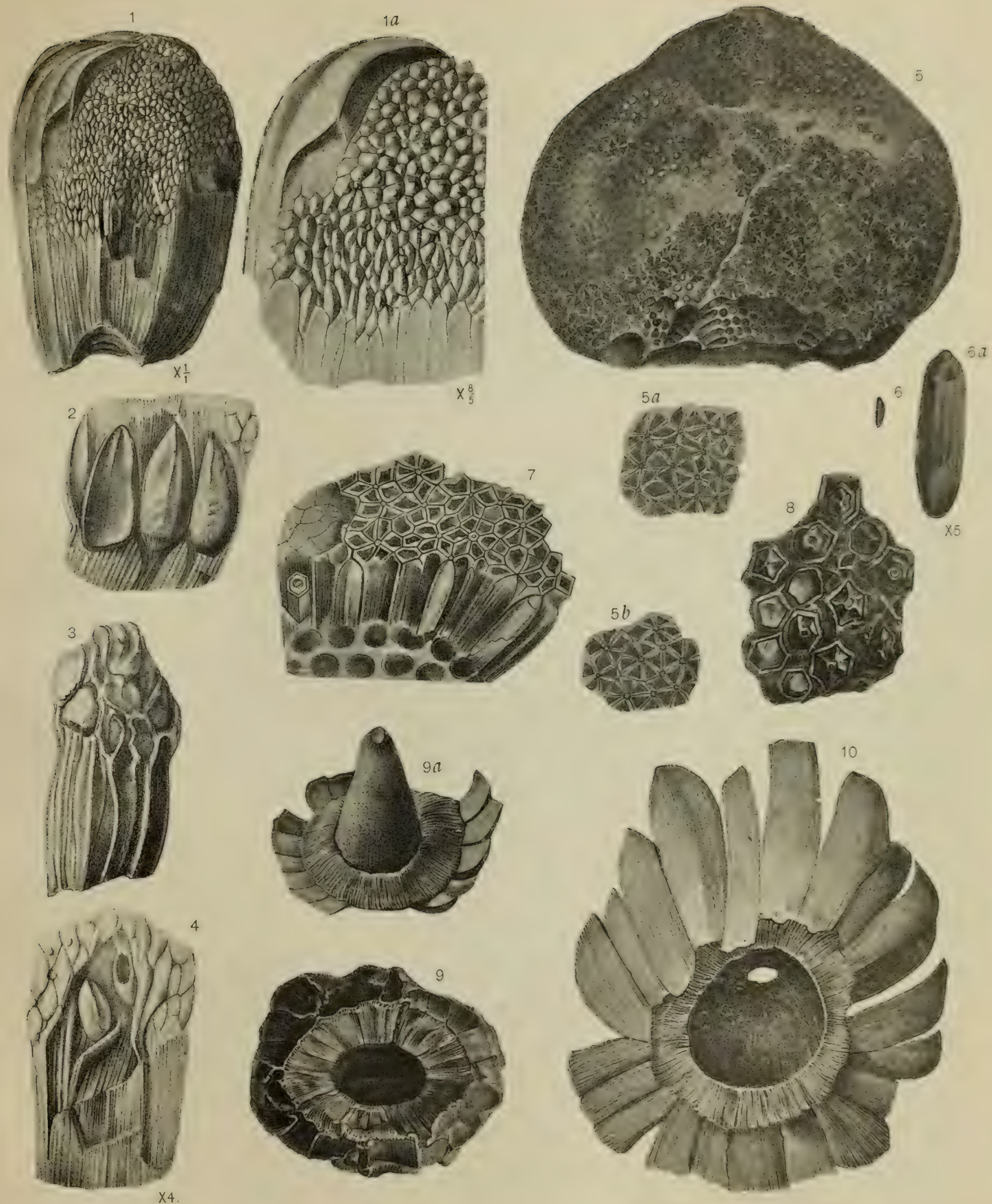


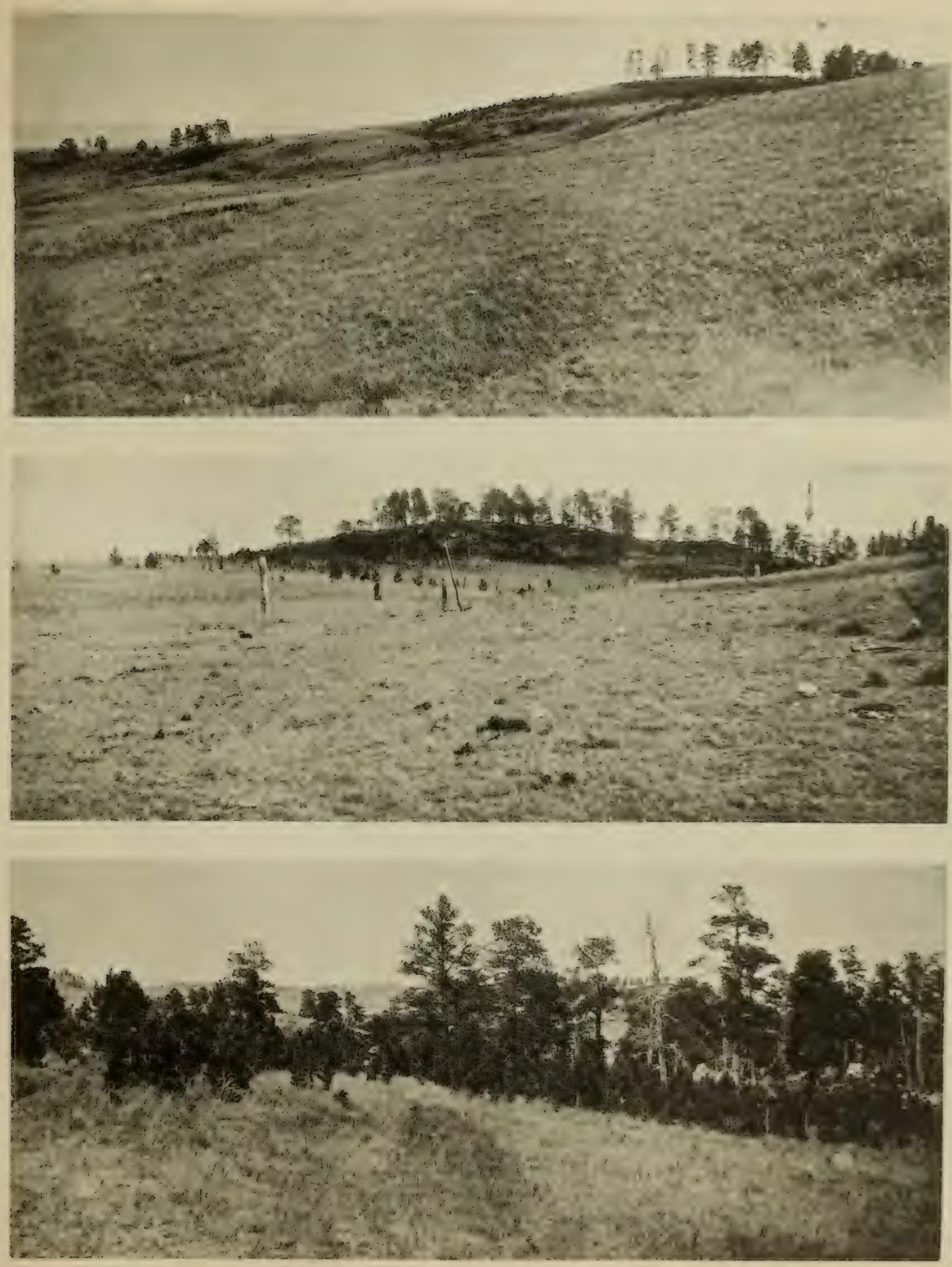


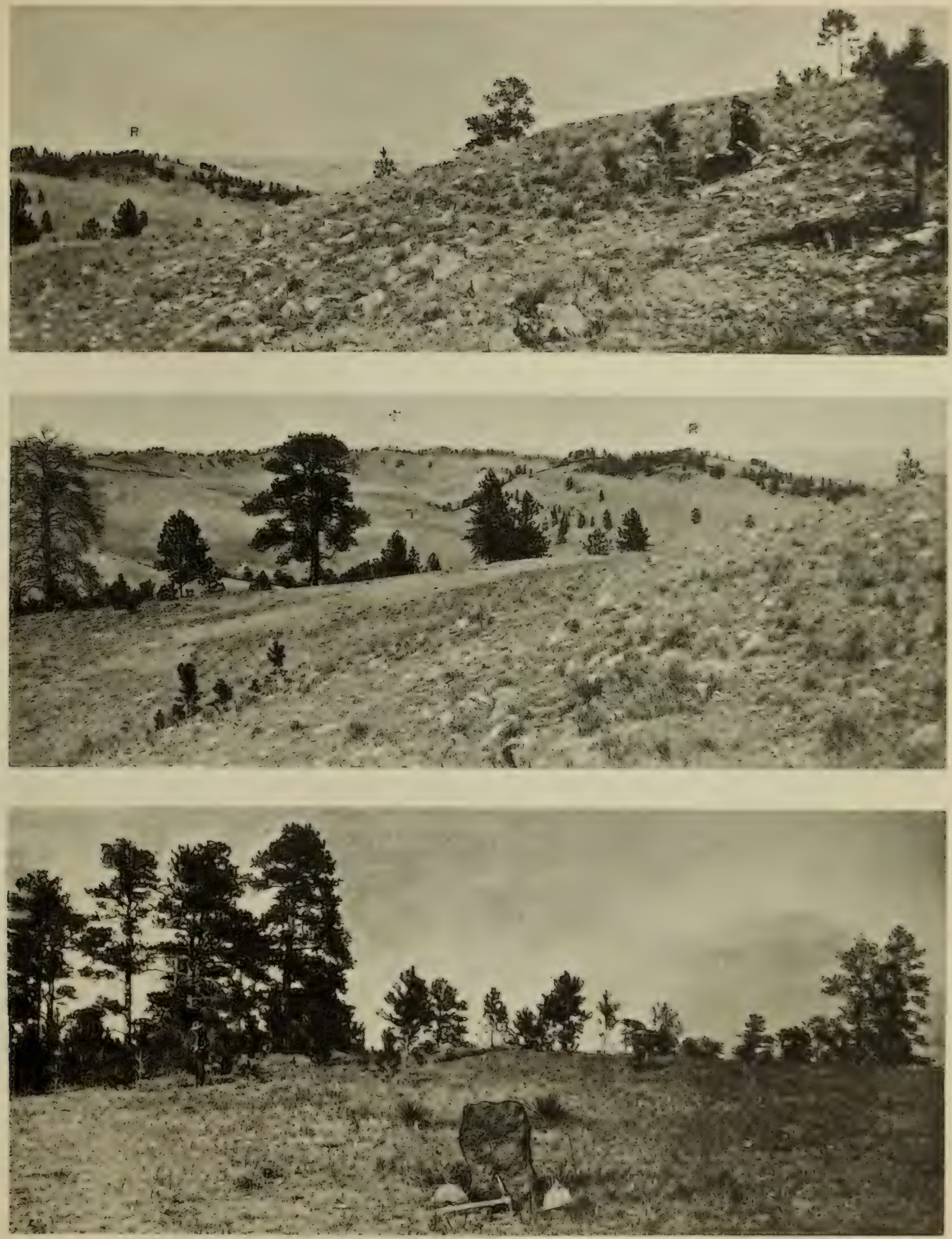


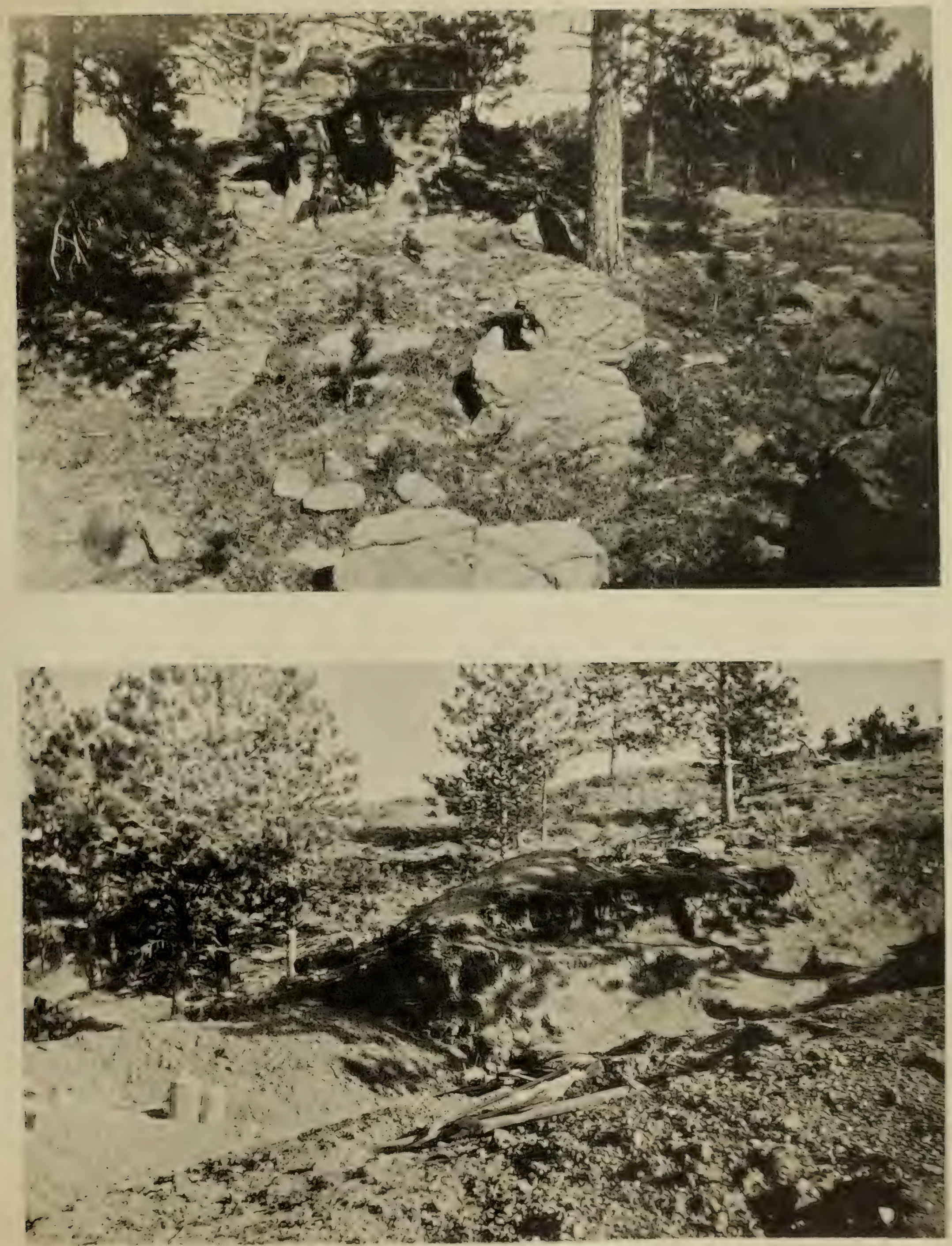





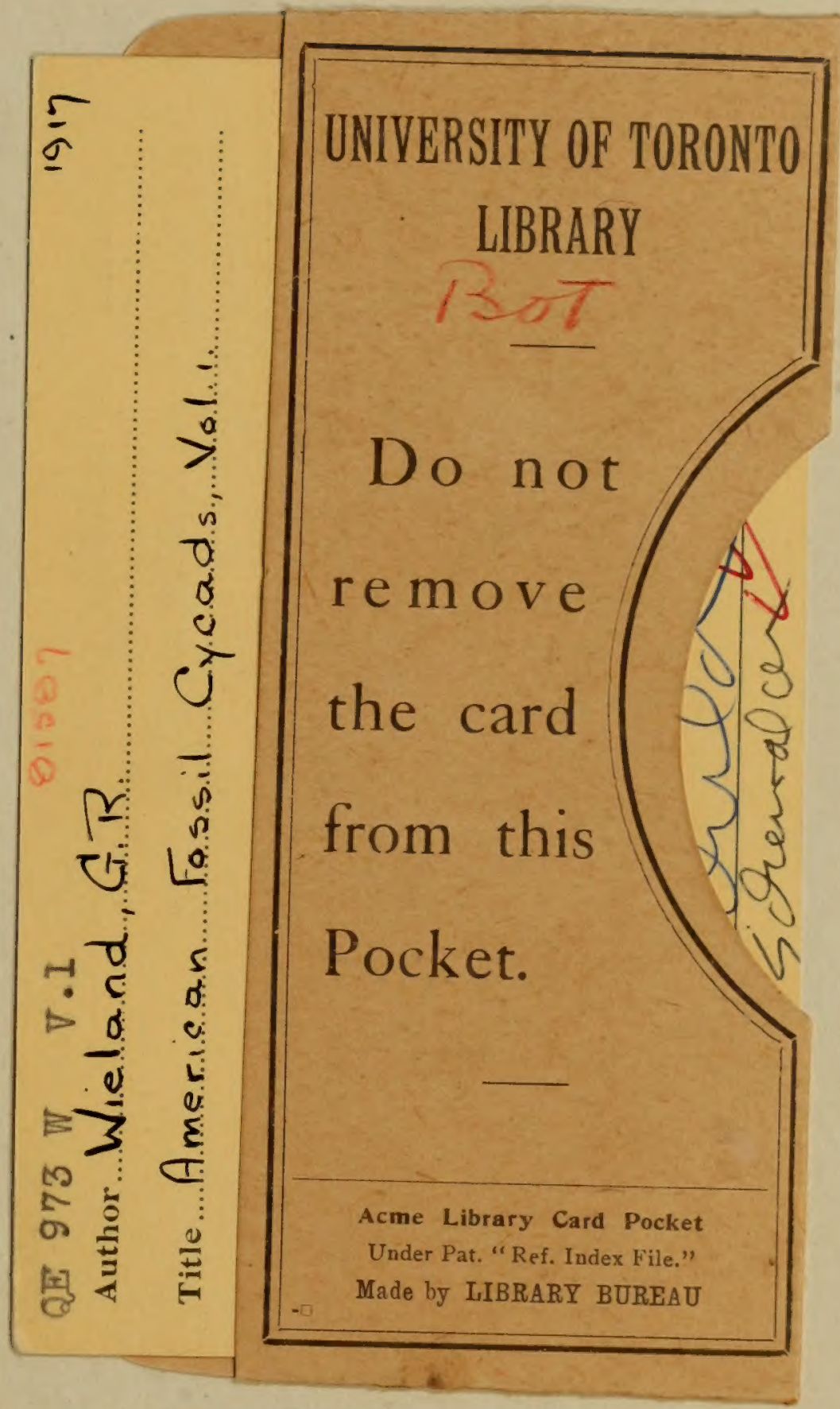




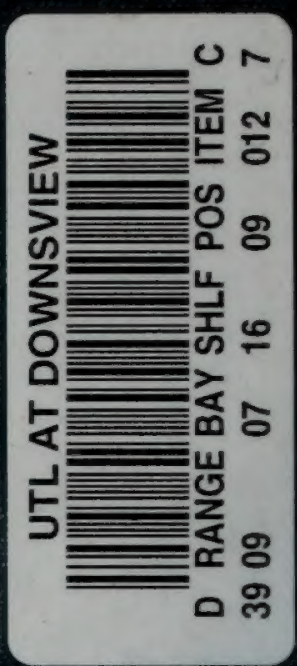

